ESCUELA TÉCNICA SUPERIOR DE EDIFICACIÓN

TESIS DOCTORAL

\title{
EVALUACIÓN DEL COMPORTAMIENTO MECÁNICO DE ESTRUCTURAS DE HORMIGÓN ARMADO UTILIZADAS COMO ELEMENTOS TERMOACTIVOS
}

\author{
Inmaculada Martínez Pérez \\ Arquitecto Técnico e Ingeniero de Edificación
}

2014 



\section{DEPARTAMENTO DE CONSTRUCCIONES}

ARQUITECTÓNICAS Y SU CONTROL

ESCUELA TÉCNICA SUPERIOR DE EDIFICACIÓN

\section{EVALUACIÓN DEL COMPORTAMIENTO MECÁNICO DE ESTRUCTURAS DE HORMIGÓN ARMADO UTILIZADAS COMO ELEMENTOS TERMOACTIVOS}

Autor: Inmaculada Martínez Pérez

Director: Dr. Alfonso Cobo Escamilla 





\section{Agradecimientos}

Quisiera dar las gracias a mi director Alfonso Cobo Escamilla, y a su grupo de investigación, por darme la oportunidad de trabajar en este proyecto, por su ayuda y su disponibilidad; y a Santiago Villa Ortega, por compartir conmigo todo el proceso de trabajo realizado en el Laboratorio de Materiales de Construcción de la E.T.S.E.M.

Agradecer a Ricardo Tendero Caballero y a Luis de Pereda Fernandez sus aportaciones durante estos años, que me han ayudado a crecer a nivel docente, profesional, y personal.

Especialmente agradezco a mi marido, a mis padres y a mis tres hijos su paciencia, apoyo y comprensión. 



\section{Resumen}

El objetivo de este trabajo es conocer las posibles modificaciones que puede producir en el comportamiento de las estructuras de hormigón armado (EHA) el hecho de que sean utilizadas como estructuras termoactivas, ya sea como intercambiadores en contacto con el terreno, o como sistema de distribución de calor utilizando la inercia térmica de los elementos de hormigón del edificio, basándose en el uso de energías renovables.

Las EHA termoactivas se caracterizan por la incorporación en su interior de tubos de polietileno por los que circulan fluidos a temperaturas medias, que pueden incidir en el comportamiento mecánico de los elementos estructurales debido a dos efectos fundamentales: el incremento de temperatura que se produce en el interior de la EHA y la perturbación provocada por la incorporación de los tubos de polietileno.

Con este fin, se ha realizado una campaña experimental de probetas de hormigón, estudiando los dos efectos por separado, por un lado se ha evaluado el comportamiento de probetas de hormigón tipo $\mathrm{H}-25$ y tipo $\mathrm{H}-30$ sometidas a cuatro temperaturas diferentes: $20^{\circ} \mathrm{C}, 40^{\circ} \mathrm{C}, 70^{\circ} \mathrm{C}$ y $100^{\circ} \mathrm{C}$, ensayando la resistencia a compresión y la resistencia a anclaje/adherencia mediante ensayo "pull-out"; y, por otro lado, se ha evaluado el comportamiento de probetas de hormigón tipo $\mathrm{H}$ 25 y tipo H-30, elaboradas con dos tipos de molde (cilíndrico y cúbico), en las que se ha colocado tubos de polietileno en su interior en distintas posiciones, ensayando su resistencia a compresión.

Los resultados de los ensayos han puesto de manifiesto que aunque se produce una disminución en la resistencia a compresión, y a arrancamiento, del hormigón, al ser sometido a aumentos de temperatura, esta disminución de la propiedades mecánicas es inferior al $20 \%$ al no superar esta tecnología los $70^{\circ} \mathrm{C}$; y respecto a la variación de la resistencia a compresión de probetas cilíndricas y cúbicas, debidas a la incorporación de los tubos de polietileno, se observa que si la posición de los mismos es paralela a la dirección de la carga tampoco se ven comprometidas las propiedad mecánicas del hormigón en valores superiores al $20 \%$.

Palabras clave: estructuras termoactivas, inercia térmica, intercambio geotérmico, hormigón. 



\section{Abstract}

The aim of this project is to study the effects of using concrete structures as thermo-active constructions, either as energy foundations or other kind of thermoactive ground structures, or as a thermally activated building structure utilizing its own thermal mass conductivity and storage capacity to heat and cool buildings, based on renewable or "free" energy sources.

The pipes, filled with a heat carrier fluid, that are embedded into the building's concrete elements may bring on two different adverse effects on concrete structures. In one hand, the consequence of thermal variations and, on the other hand, because of the fact that the pipes are inside of the concrete mortar and in direct contact with the reinforcing steel bars.

For this reason, different types of specimens and testing procedures have been proposed to discuss the effects of temperature $\left(20^{\circ}, 40^{\circ} \mathrm{C}, 70^{\circ} \mathrm{C}\right.$ y $\left.100^{\circ} \mathrm{C}\right)$ on the performance of two different hardened concrete: $\mathrm{H}-25$ and $\mathrm{H}-30$, and the effects of having the pipes embedded in different positions inside of specimens made of two types of concrete, $\mathrm{H}-25$ and $\mathrm{H}-30$, and with two kind of cast, cylindrical and cubical.

The experimental program includes the use of compressive strength test and also pull-out test, in order to investigate the interfacial adhesion quality and interfacial properties between steel bar and concrete.

The results of the mechanical test showed that the increase of temperature in hardened concrete specimens lower than $70^{\circ} \mathrm{C}$, and the introduction of embedded pipes placed in parallel to the load, in cylindrical or cubic specimens, does not jeopardize the mechanical properties of concrete with strength decreases higher than $20 \%$.

Keywords: Thermo-active Building Systems (TABS), Thermo-active foundations, thermal building mass, geothermal heat exchangers, concrete. 



\section{Índice General}

Agradecimientos ..

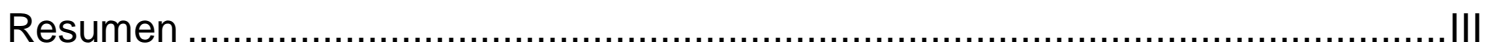

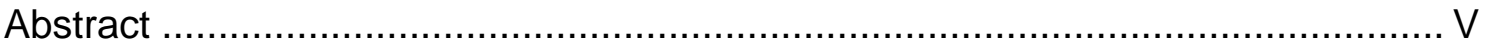

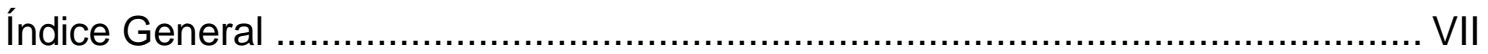

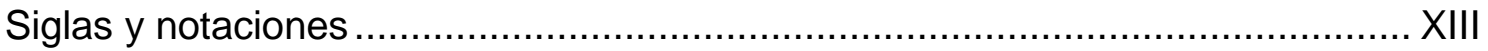

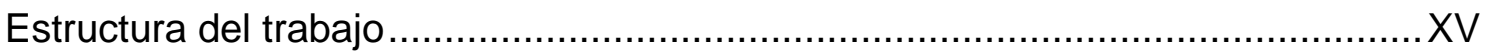

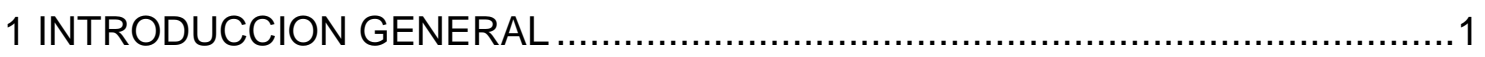

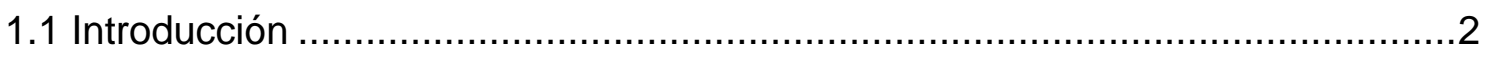

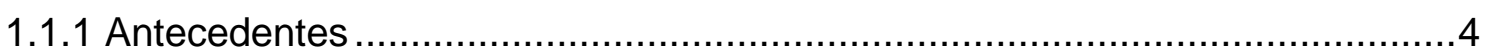

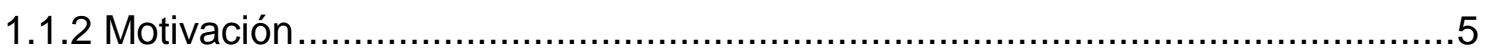

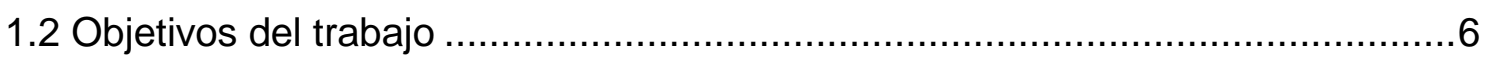

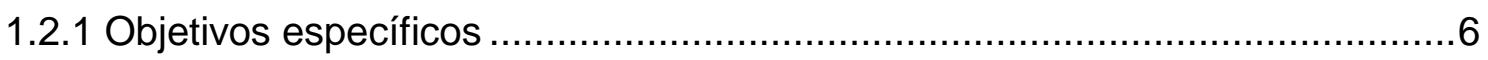

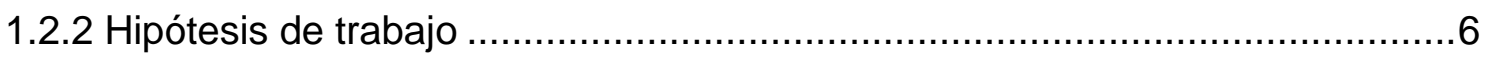

2 ESTADO DEL CONOCIMIENTO …..............................................................

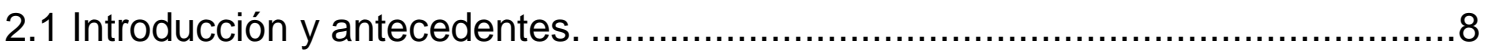

2.1.1 Normativa y legislación relacionada con el interés en la utilización de

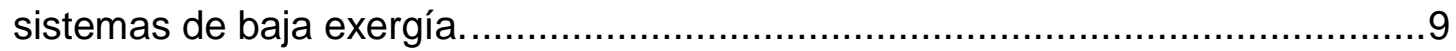

2.2 Las estructuras de hormigón armado utilizadas como elementos

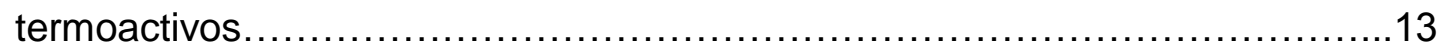

2.2.1 Tipos de estructuras de hormigón armado utilizadas como elementos

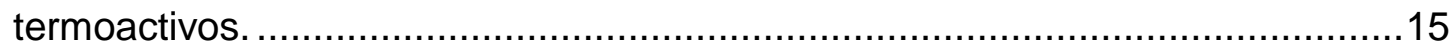

2.2.1.1 Cimentaciones termoactivas. ............................................................. 15

2.2.1.1.1 Energía geotérmica de muy baja entalpía.........................................20

2.2.1.1.2 Aprovechamiento de recursos desperdiciados...................................25 
2.2.1.1.3 Tipos de cimentaciones termoactivas.

2.2.1.2 Estructuras termoactivas en el edificio. Thermo active building systems (TABS). 34

2.2.1.2.1 Confort térmico 40

2.2.1.2.2 Sistemas pasivos de calefacción y refrigeración .44

2.2.1.2.3 Sistemas hidrónicos 46

2.2.1.3 Funcionamiento conjunto, en el edificio, de cimentaciones termoactivas y TABS

2.2.1.3.1 Bomba de calor geotérmica .50

2.2.2 Impacto en el comportamiento mecánico de las estructuras termoactivas...53

2.2.2.1 Efecto de las estructuras termoactivas sobre el terreno .53

2.2.2.2 Efecto de las estructuras termoactivas sobre la cimentación .57

2.2.2.3 Efecto de las estructuras termoactivas sobre la estructura del edificio .59

2.3 Características físicas del hormigón endurecido 61

2.3.1 Factores que afectan a la resistencia del hormigón 62

2.3.1.1 Características y proporciones de los materiales que componen el hormigón .66

2.3.1.2 Condiciones de curado del hormigón ..............................................70

2.3.1.3 Parámetros relacionados con los ensayos .............................................. 73

2.3.2 Factores que afectan al módulo de elasticidad del hormigón........................74

2.3.3 Factores que afectan a la adherencia hormigón-acero ...........................78

2.4 Cómo afecta la temperatura al hormigón endurecido .................................83

2.4.1 Factores que afectan a la resistencia a compresión del hormigón.................89

2.4.2 Factores que afectan a la adherencia hormigón-acero .............................94

2.5 Antecedentes que influyen en la metodología de los ensayos .....................97

2.5.1 Caracterización de los ensayos en probetas de hormigón endurecido .........97

2.5.1.1 Caracterización de la resistencia a compresión del hormigón.....................98

2.5.1.2 Caracterización de la adherencia hormigón-acero .100 
3 TRABAJO EXPERIMENTAL REALIZADO 105

3.1 Introducción 106

3.2 Materiales utilizados y proceso de elaboración 107

3.3 Estudio del efecto del incremento de temperatura 115

3.3.1 Probetas cilíndricas para estudiar la resistencia a compresión 115

3.3.2 Probetas cúbicas para ensayar a arrancamiento. "pull-out" 118

3.4 Estudio del efecto de la incorporación de tubos de polietileno PE 122

3.4.1 Probetas cilíndricas para estudiar la resistencia a compresión 122

3.4.2 Probetas cúbicas para estudiar la resistencia a compresión 125

4 RESULTADOS OBTENIDOS 129

4.1 Introducción 130

4.2 Diagramas tipo de los ensayos 130

4.2.1 Diagrama tipo tensión-deformación compresión 131

4.2.2 Diagrama tipo fuerza-desplazamiento arrancamiento. "pull-out" 133

4.3 Estudio del efecto del incremento de temperatura 135

4.3.1 Resultados de los ensayos a compresión 136

4.3.2 Resultados de los ensayos a arrancamiento. "pull-out" 138

4.4 Estudio del efecto de la incorporación de tubos de polietileno PE .141

4.4.1 Resultados de los ensayos a compresión probeta cilíndrica 142

4.4.2 Resultados de los ensayos a compresión probeta cúbica 145

5 ANÁLISIS Y DISCUSIÓN DE LOS RESULTADOS 150

5.1 Introducción 150

5.2 Estudio del efecto del incremento de temperatura 151

5.2.1 Estudio de los resultados de rotura a compresión (temperatura) 152

5.2.1.1. Estudio comparativo de los resultados de tensión/deformación 152

5.2.1.2. Estudio comparativo de los resultados omax, عmax, عu, Emax y Eu ...154

5.2.1.3. Estudio comparativo de evolución de resultados omax, عmax, Emax.158 
5.2.1.4. Análisis porcentual de las pérdidas de resistencia .159

5.2.2 Estudio comparativo de los resultados de rotura a arrancamiento (temperatura) ......................................................................................... 161

5.2.2.1. Estudio comparativo de los resultados de fuerza /desplazamiento ......161

5.2.2.2. Estudio comparativo de los resultados $7 R$, סmax, סu, Emax y Eu ......163

5.2.2.3. Estudio comparativo de evolución de los resultados סmax, סu, y Emax .168

5.2.2.4. Análisis porcentual de las pérdidas de resistencia 169

5.3 Estudio del efecto de la incorporación de tubos de polietileno 171

5.3.1 Estudio de los resultados de rotura a compresión de probetas cilíndricas (polietileno) 172

5.3.1.1. Estudio comparativo de los resultados de tensión/deformación .173

5.3.1.2. Estudio comparativo de los resultados omax, $\varepsilon \max , \varepsilon u$, Emax y Eu ...174

5.3.1.3. Estudio comparativo de la evolución de los resultados omax, عmax y Emax 180

5.3.1.4. Análisis porcentual de las pérdidas de resistencia 181

5.3.1.5. Análisis gráfico comparativo de la evolución de la energía última. 182

5.3.2 Estudio de los resultados de rotura a compresión de probetas cúbicas (polietileno) 183

5.3.2.1. Estudio comparativo de los resultados de tensión/deformación .184

5.3.2.2. Estudio comparativo de los resultados omax, عmax, $\varepsilon u$, Emax y Eu ...185

5.3.2.3. Estudio comparativo de la evolución de los resultados omax, emax y

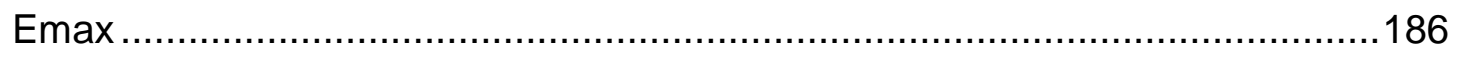

5.3.2.4. Análisis porcentual de las pérdidas de resistencia .............................191

5.3.2.5. Análisis gráfico comparativo de la evolución de la energía última........192

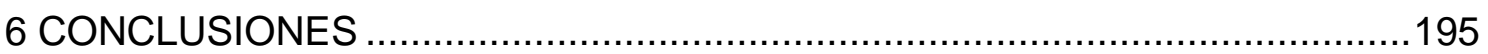

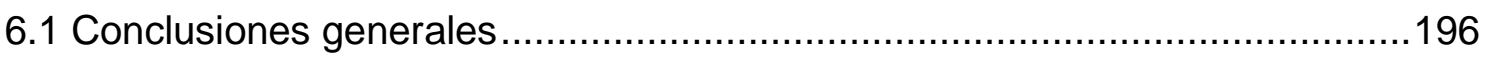

6.2 Conclusiones estudio efecto temperatura ............................................. 197 
7 LÍNEAS FUTURAS DE INVESTIGACIÓN 199

7.1 Introducción 200

7.2 Futuras líneas de investigación sobre efecto temperatura y tubo polietileno .200

7.2.1 Probetas cilíndricas para analizar su resistencia a compresión en función de la temperatura 200

7.2.2 Probetas cúbicas con arnjmadura corrugada para analizar su resistencia a arrancamiento en función de la temperatura y de la disposición del tubo de polietileno 201

7.2.3 Probetas cilíndricas para analizar su resistencia a compresión en función de la temperatura y de la disposición del tubo de polietileno 202

7.2.4 Vigas armadas para ensayar a a flexión y arrancamiento en función de la temperatura y de la disposición del tubo de polietileno estudiado por separado. 202

7.2.5 Vigas armadas para ensayar a a flexión y arrancamiento en función de la temperatura y de la disposición del tubo de polietileno estudiado en conjunto. 202

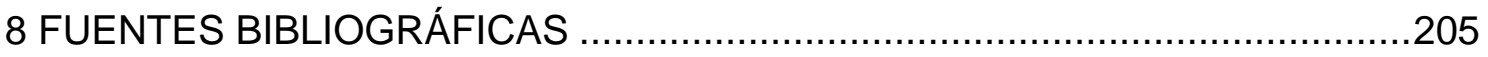

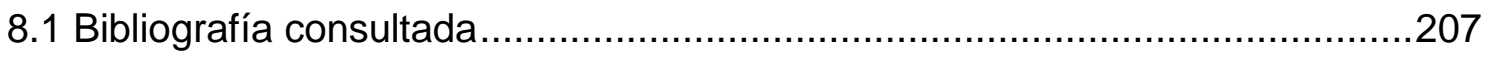

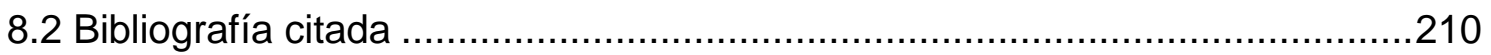

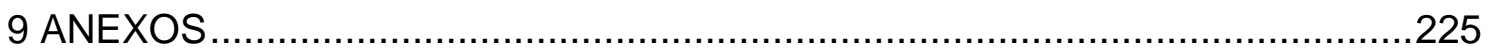

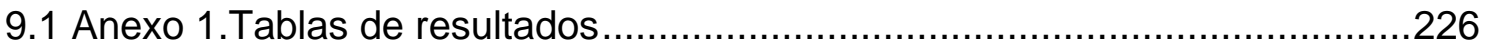

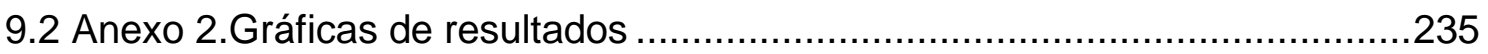

9.2.1 Anexo 2.1. Gráficas de resultados individuales .....................................236

9.2.2 Anexo 2.2 Gráficas de resultados comparadas ....................................263

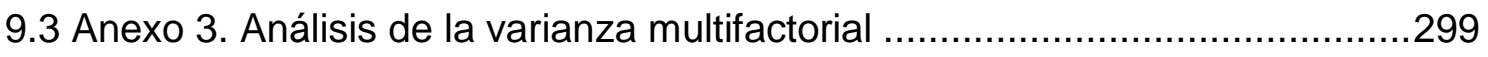

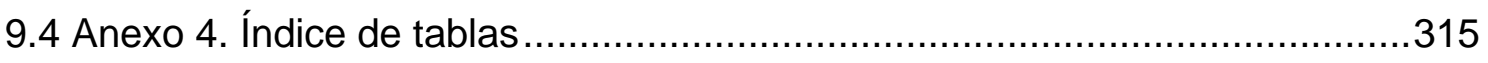

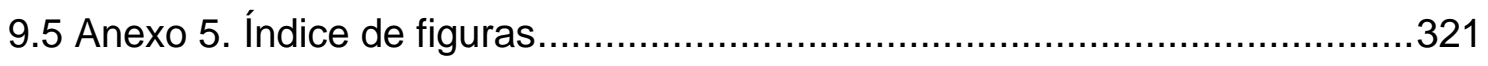

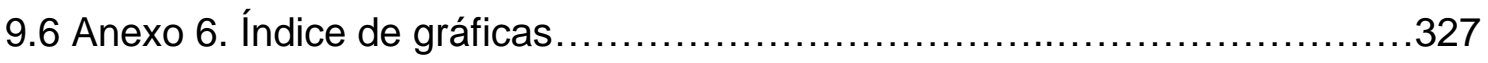





\section{Siglas y notaciones}

EHA Estructuras de hormigón armado

COP Coeficiente de rendimiento de la bomba de calor

CTE Código técnico de la edificación

$F$ Fuerza $(\mathrm{KN})$

$\delta$ Desplazamientos obtenidos en el ensayo en carrera $(\mathrm{mm})$

$A_{c}$ Sección de hormigón $\left(\mathrm{mm}^{2}\right)$

$\sigma_{c}$ Tensión de resistencia a compresión del hormigón $\left(\mathrm{N} / \mathrm{mm}^{2}\right)$

$\sigma_{\max }$ Tensión máxima del hormigón $\left(\mathrm{N} / \mathrm{mm}^{2}\right)$

$\varepsilon_{c}$ Deformación del hormigón

$\varepsilon_{\max }$ Deformación máxima del hormigón

$\varepsilon_{u}$ Deformación última del hormigón

$E_{\max }$ Energía máxima generada durante el ensayo $\left(\mathrm{N} / \mathrm{mm}^{2}\right)$

Eu Energía última generada durante el ensayo $\left(\mathrm{N} / \mathrm{mm}^{2}\right)$

fc Resistencia a compresión, en Mpa ( $\mathrm{N} / \mathrm{mm} 2)$

$干_{R}$ Fuerza de rotura ensayo de arrancamiento "pull-out" (KN)

$\delta_{\max }$ Desplazamiento máximo ensayo arrancamiento "pull-out" $(\mathrm{mm})$

$\delta_{u}$ Desplazamiento último ensayo arrancamiento "pull-out" $(\mathrm{mm})$

$\varnothing$ Diámetro de armadura utilizada

$E_{\max }$ Energía máxima generada en el ensayo a arrancamiento $(\mathrm{KN} / \mathrm{mm})$

Eu Energía última generada en el ensayo a arrancamiento $(\mathrm{KN} / \mathrm{mm})$

kg Kilógramos

kW Kilowatios

kWh Kilowatios hora

I Litros

mm Milímetros

oC Grados centígrados

$\%$ Porcentaje

TABS Thermo active building system

RITE Reglamento de instalaciones térmicas de edificación 



\section{Estructura del trabajo}

El presente trabajo se divide en nueve capítulos, ordenados de la siguiente manera:

\section{Introducción general}

Presenta los argumentos que motivan la elección del tema de estudio general, las estructuras de hormigón utilizadas como elementos termoactivos, y la importancia relativa al campo de trabajo del objeto de estudio, el comportamiento mecánico del hormigón de dichas estructuras, indicando cuáles son los objetivos a conseguir de su análisis.

\section{Estado de la cuestión}

Describe el contexto académico previo al trabajo, y que ha sido relevante para su desarrollo, además de presentar las bases empíricas sobre las que se sustenta el trabajo.

\section{Trabajo experimental realizado}

Describe el proceso metodológico empleado para alcanzar los objetivos del trabajo.

\section{Resultados obtenidos}

Se define el contexto general y concreto del trabajo desde un punto de vista legislativo, económico, constructivo y energético.

\section{Análisis y discusión de los resultados}

Analiza los resultados obtenidos en los ensayos realizados, comparándolos entre si y poniéndolos en contexto.

\section{Conclusiones}

Resume las conclusiones obtenidas durante la investigación.

\section{Futuras líneas de investigación}

\section{Fuentes bibliográficas}

Enumera la bibliografía utilizada y recoge los anexos a los que hace referencia el trabajo.

\section{Anexos}


La figura 1.1 muestra la estructura general de esta tesis, que se irá repitiendo al principio de cada capítulo para facilitar la lectura del documento.

\section{INTRODUCCIÓN}

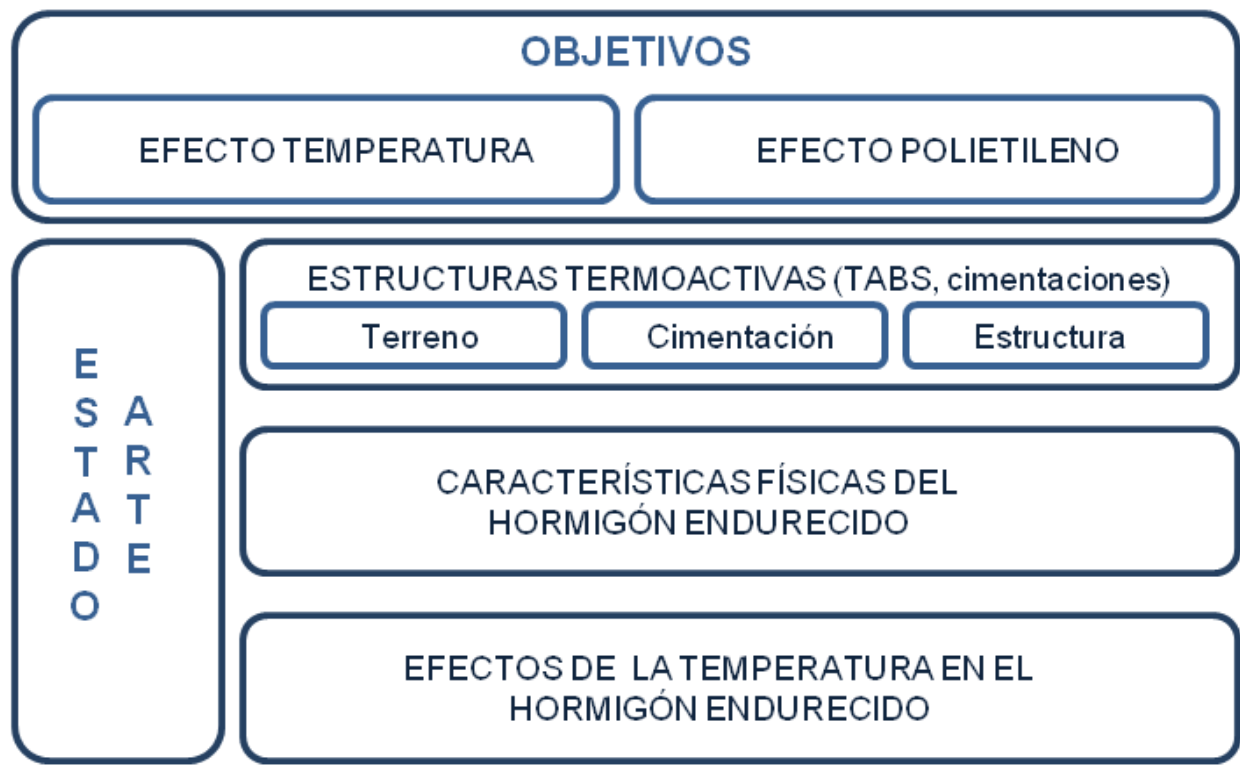

\section{ANTECEDENTES}

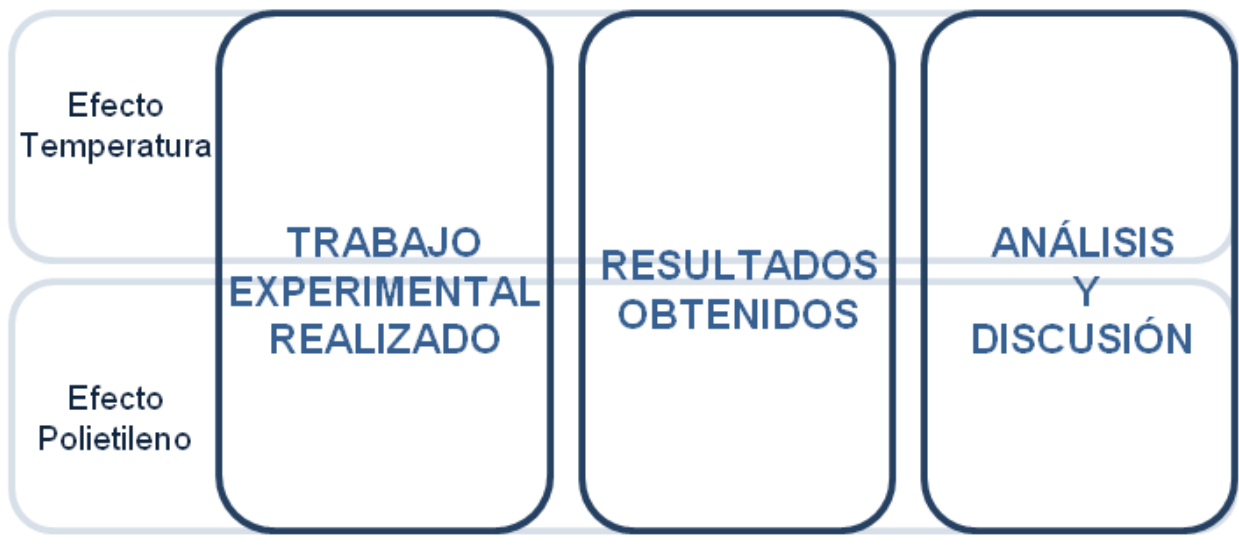

\section{CONCLUSIONESY FUTURAS LÍNEAS DE INVESTIGACIÓN}

Figura 1.1 Estructura general de la tesis. Elaboración propia. 


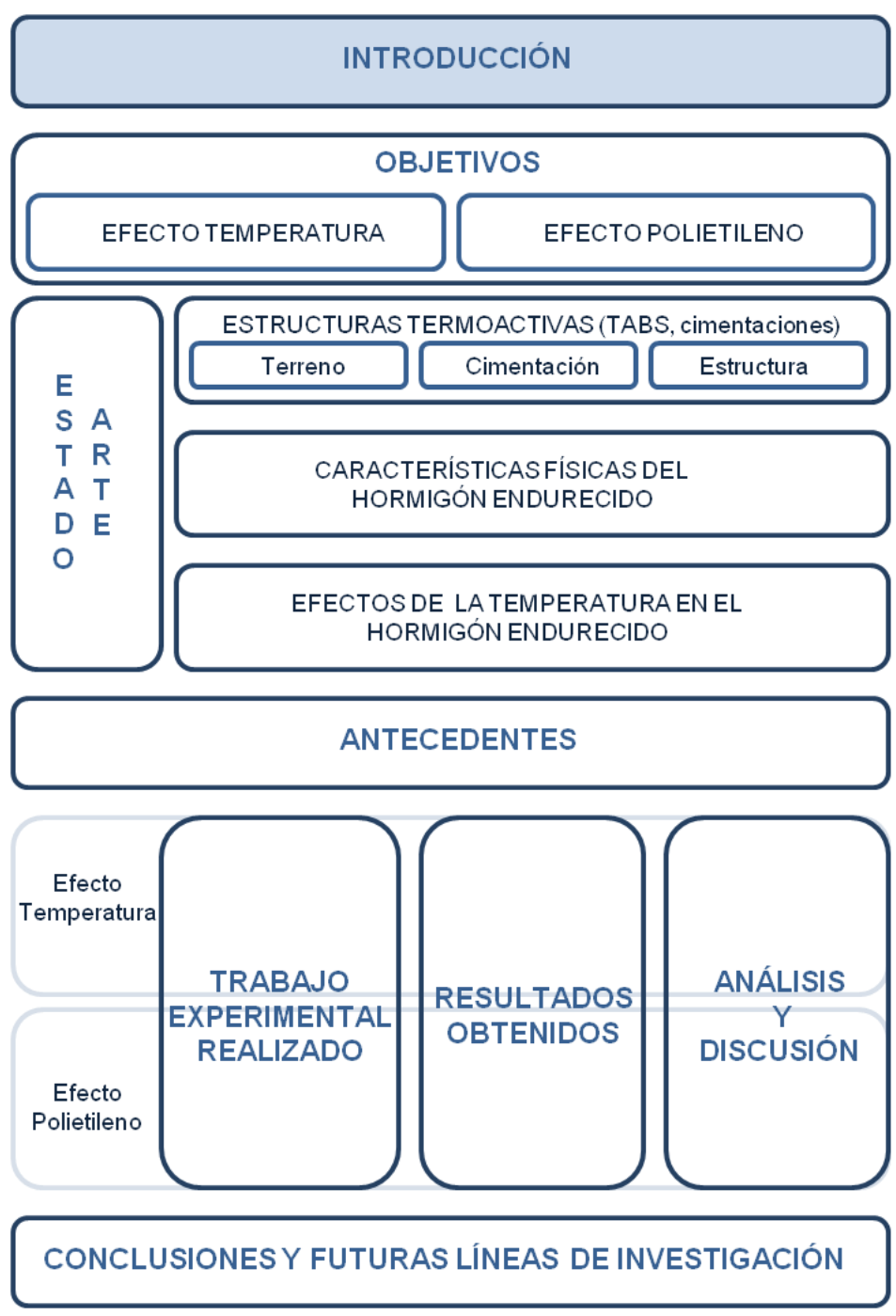

CAPÍTULO 1

INTRODUCCIÓN

GENERAL 


\section{$1.1 \quad$ Introducción}

Hoy en día, el calentamiento global (Naciones Unidas) [97], es uno de los problemas que más preocupan en el mundo. El panel intergubernamental de cambio climático augura un incremento en la temperatura terrestre que, posiblemente, alcance los $6^{\circ} \mathrm{C}$ en 2050. (Edenhofer, O., et al.) [47]. Por lo tanto, urge que se encuentren sistemas de uso de la energía más eficientes, para reducir significativamente tanto el consumo de energía primaria como las emisiones de efecto invernadero.

El sector de la edificación representa aproximadamente el $40 \%$ del consumo total de energía en el mundo, y el $20 \%$ de las emisiones de CO2, (Directiva 2010/31/UE) [45], es por lo tanto imprescindible, que los edificios sostenibles utilicen las energías renovables y los recursos desperdiciados con el fin de convertirse en edificios de consumo casi nulo.

Tal y como se recoge en la introducción del Capítulo 2, estado del conocimiento, la Unión Europea ha creado su propia iniciativa para prevenir el cambio climático, el objetivo 20/20/20, (Directiva 2010/31/UE) [45], con la intención de alcanzar una reducción del $20 \%$ de la emisión de gases invernadero, el aumento en un $20 \%$ de la eficiencia energética, y el uso del $20 \%$ del total de energía procedente de fuentes renovables. 
España se ha sumado a la iniciativa europea 20/20/20 llevando a cabo diversas acciones de regulación de los aspectos constructivos y tecnológicos con la publicación y revisiones del Código Técnico de la Edificación (CTE) y del Reglamento de Instalaciones Térmicas de los Edificios (RITE), además de implantar ayudas económicas a la rehabilitación energética e imponer la obligatoriedad de realizar certificados en viviendas nuevas y existentes para conocer su rendimiento energético.

Existen diferentes niveles de calidad de energía necesaria para los distintos servicios energéticos a cubrir en el edificio, desde las necesidades de electricidad para los aparatos electrónicos, pasando por los requisitos de alrededor de 55ㄷ $\mathrm{C}$ de temperatura para el agua caliente sanitaria, o para aplicaciones de cocina o de sauna, hasta las necesidades de confort térmico de los espacios habitables, cercanos a $\operatorname{los} 20^{\circ} \mathrm{C}$.

Las tecnologías de baja exergía basan su funcionamiento en el uso de bajas temperaturas de calefacción y altas temperaturas de refrigeración de modo que el uso de energía en los edificios mejore su eficiencia al permitir el uso de energía renovables y recursos desperdiciados, como puede ser la energía geotérmica o la captación térmica de aguas residuales.

Una de las mayores dificultades que conlleva el uso de energía renovables, reside en que la mayoría de las fuentes energéticas renovables (especialmente la energía solar y la energía eólica) son intermitentes, como también es en muchos casos, el consumo de energía en edificios, ya que depende del uso del edificio y del comportamiento y características del usuario.

Por consiguiente, los sistemas de almacenamiento de energía térmica se consideran como una de las más prometedoras tecnologías para el edificio, ya que corrigen el factor tiempo entre la demanda y los momentos de producción de energía más favorables a nivel económico y medioambiental.

Esta tecnología, además de adaptarse a la producción intermitente de determinadas fuentes renovables, almacena el exceso de energía durante periodos de mayor producción y permite utilizarla en los periodos de carestía.

El mejor ejemplo conocido de sistema de almacenamiento de energía térmica es el uso de la inercia térmica del edificio que se viene utilizando desde la 
antigüedad. (Zhuang, Z., et al.) [141]. Hoy en día, existen numerosos sistemas de almacenamiento térmico comercializados, pero muchos de ellos, como el uso de materiales de cambio de fase, que trabajan con calor latente de vaporización y por tanto tiene una mayor capacidad de almacenamiento energético por unidad de masa y una gran inercia térmica, están todavía en desarrollo y en vías de perfeccionamiento de su curva de aprendizaje.

Los sistemas que utilizan la masa inercial del edificio como sistema de almacenamiento térmico y los que aprovechan la energía geotérmica, utilizando el terreno como sistema de acumulación y transmisión al edificio a través de de intercambiadores térmicos, son dos buenos ejemplos de sistemas de acumulación térmica que utilizan medias y bajas temperaturas y que además permiten el uso de energía renovables y recursos despreciados de bajas y medias temperaturas.

Ambos sistemas basan su funcionamiento en la acumulación de calor realizada por el agua, ya que a media y baja temperatura, el agua es uno de los mejores elementos de almacenaje dada su elevada capacidad calorífica y alto calor específico, su estabilidad química y su disponibilidad y bajo precio.

\subsubsection{Antecedentes}

La activación térmica de las estructuras de hormigón está ampliamente desarrollada desde los años 70 en países de nuestro entorno. (Olesen B.W. et al., [104]. Se activan térmicamente no sólo las cimentaciones de edificación y las infraestructuras subterráneas, basándose en la geotermia de muy baja entalpía, sino los elementos estructurales de los edificios, muros, forjados, losas, etc..

El análisis económico realizado en los sistemas de climatización por geotermia de muy baja entalpía instalados en países como Austria, Suiza y Alemania, indican que utilizar estos sistemas de calefacción y refrigeración usando como intercambiadores las estructuras en contacto con el terreno (Laloui L., et al.) [77] (ya sean de hormigón o no), genera ahorros de dos terceras partes de los costes de calefacción convencional, y además, representan una eficaz contribución a la protección medioambiental al ser una energía renovable, sobre todo cuando se establece un sistema estacional que equilibre térmicamente el terreno. (Laloui, L., et al.) [78] 
En nuestro país, las EHA termoactivas son todavía una novedad, pero las tendencias actuales de eficiencia energética, que apuntan a la utilización de sistemas de climatización a través de fuentes de energía renovables y a técnicas de acondicionamiento pasivo de edificios apoyándose en la inercia térmica de su masa, convierten a las estructuras termoactivas en un sistema a implantar con mayor asiduidad en el futuro próximo del sector de la construcción de nuestro país.

Además, existen ejemplos suficientes ya ejecutados, que están funcionando a pleno rendimiento y cuyo control y monitorización arroja datos claros sobre la conveniencia de su utilización desde el punto de vista social, económico y medioambiental.

\subsubsection{Motivación}

Aunque no se han encontrado investigaciones realizadas que estén enfocadas a la influencia directa en el hormigón del factor temperatura, aun siendo esta moderada, ni tampoco referentes a la introducción de los tubos de polietileno en los elementos estructurales, existe una literatura experimental tan amplia sobre los distintos factores que afectan a las EHA y cada una de sus propiedades, que los países que han liderado el desarrollo de estos sistemas, parecen no haberse visto en la necesidad de profundizar en dicha influencia por considerar despreciables sus efectos.

No obstante, y aunque los años en los que se llevan desarrollando este tipo de estructuras en otros países han servido como garantía, (Koschenz M.,) [71], en nuestro país, la novedad del sistema obliga a que nos preguntemos cuales son exactamente los efectos que puede generar en las EHA de nuestras infraestructuras subterráneas, cimentaciones y edificios, el hecho de que estén sometidas a temperaturas de entre $0^{\circ}$ y $55^{\circ} \mathrm{C}$ y lleven incorporados tubos de polietileno atados a las armaduras de refuerzo de los elementos estructurales, que podrían provocar problemas de adherencia hormigón-acero. 


\subsection{Objetivos del trabajo}

Este trabajo pretende, como objetivo general, cuantificar los efectos producidos en los elementos estructurales de hormigón armado cuando se activan térmicamente, con la intención de poder establecer con el apoyo de datos experimentales la importancia de dichos efectos y la conveniencia de su activación térmica.

\subsubsection{Objetivos específicos}

En primer lugar se pretende identificar el efecto provocado en el hormigón por la temperatura que alcanza y que le transmite el fluido caloportador que circula por los tubos de polietileno embebidos en el mismo.

$Y$ en segundo lugar se quiere determinar cómo afecta en el elemento estructural de hormigón el hecho de tener incorporados tubos de polietileno embebidos en su masa y en contacto con sus armaduras de refuerzo.

\subsubsection{Hipótesis de trabajo}

Se va a realizar el estudio de los dos efectos por separado:

Para evaluar el efecto de la temperatura, se van a preparar una serie de probetas con dos tipos de hormigones, $\mathrm{H}-25$ y $\mathrm{H}-30$, sometidas a cuatro temperaturas diferentes: $20^{\circ} \mathrm{C}, 40^{\circ} \mathrm{C}, 70^{\circ} \mathrm{C}$ y $100^{\circ} \mathrm{C}$. Se realizarán la mitad de ellas con molde cilíndrico para realizar ensayos de resistencia a compresión y la otra mitad con molde de probeta cúbica a la que se incorporará una armadura de acero corrugado de $10 \mathrm{~mm}$ de diámetro para determinar su adherencia mediante ensayo de arrancamiento "pull-out".

Por otro lado para evaluar el efecto de la incorporación de los tubos, se prepararán una serie de probetas con dos tipos de hormigones, $\mathrm{H}-25$ y tipo $\mathrm{H}-30$, elaboradas con dos tipos de molde (cilíndrico y cúbico), en las que se van a colocar los tubos de polietileno en su interior en distintas posiciones, para realizar ensayos de su resistencia a compresión. 


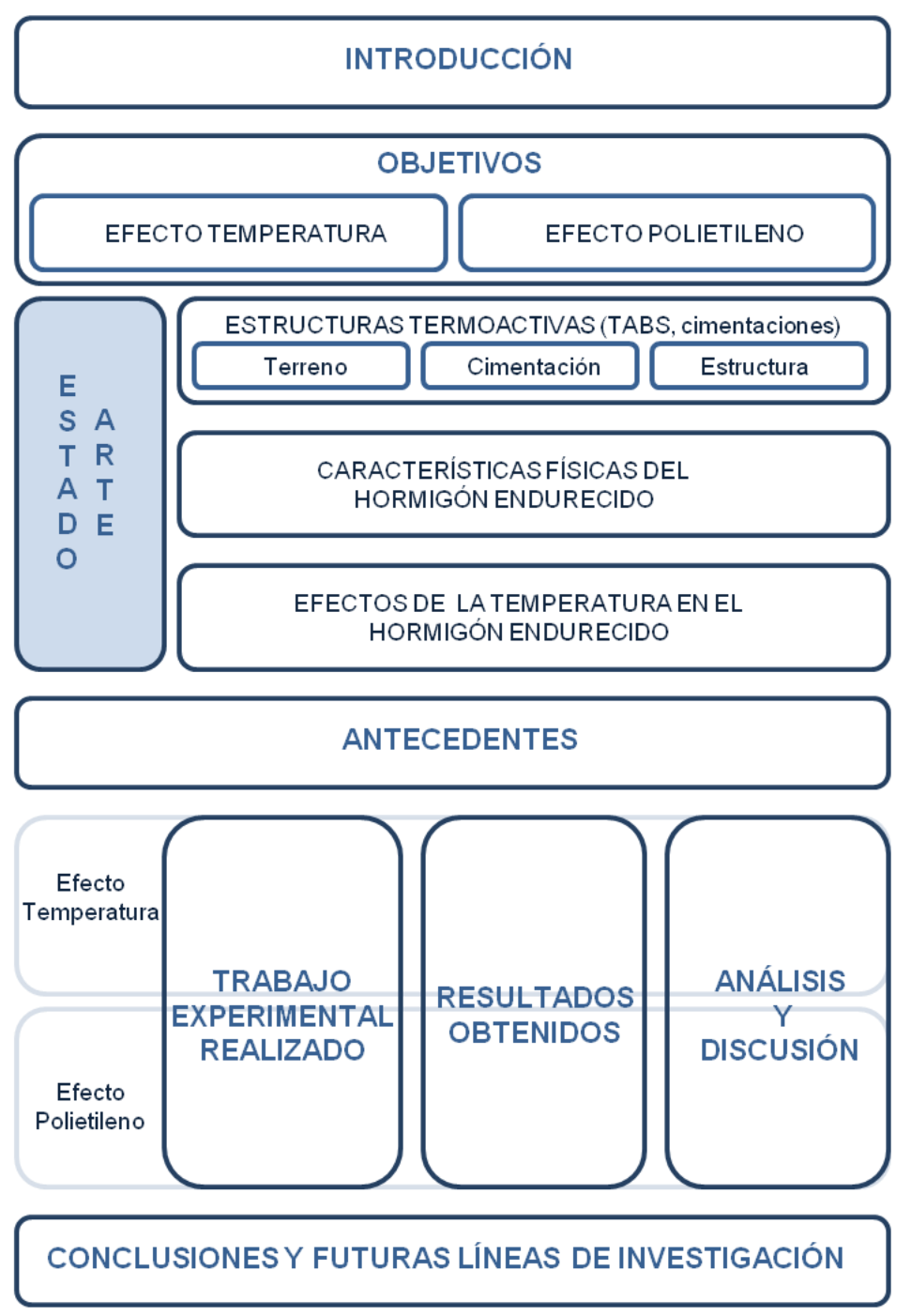

CAPÍTULO 2

ESTADO DEL

CONOCIMIENTO 


\subsection{Introducción y antecedentes.}

Las estructuras termoactivas utilizan la inercia térmica, o capacidad de almacenamiento térmico, de los elementos estructurales para captar o desprender calor con el fin de ser utilizados en los sistemas de climatización: calefacción y refrigeración de los edificios.

Existen dos tipos de estructuras que pueden activarse térmicamente: las que están en contacto con el terreno, cuya finalidad reside en el intercambio geotérmico de muy baja entalpía y, por otro lado, las estructuras del interior del edificio, utilizadas para refrigerar o calefactar directamente las estancias aprovechando la masa térmica de sus elementos estructurales.

Estos sistemas pueden obtener tanto el agua utilizada como fluido caloportador, como el gradiente térmico alcanzado por ésta de distintas fuentes consideradas como renovables o gratuitas.

Tanto las cimentaciones termoactivas, que actúan como intercambiadores geotérmicos con el terreno, como las TABS, cuya superficie total puede ser utilizada para calefactar o refrigerar, trabajan con temperaturas moderadas, hecho que facilita coeficientes de rendimiento muy elevados en las bombas de calor y alta eficiencia para garantizar un confort térmico adecuado en el edificio. 


\subsubsection{Normativa y legislación relacionada con el interés en la utilización de sistemas de baja exergía.}

En este apartado se presentan las leyes y normas más representativas, que conciernen al interés por la utilización de los sistemas de baja energía, y que afectan tanto a aspectos constructivos, energéticos, como climáticos.

El objetivo final de esta normativa es la reducción del efecto del cambio climático a través de la disminución de la emisión de gases de efecto invernadero, principalmente de dióxido de carbono, $\mathrm{CO} 2$.

Con sistemas basados en la producción, acumulación, y uso de bajas temperaturas para calefacción, y altas temperaturas para refrigeración, se dirige el sector de la edificación hacia el cumplimiento de los objetivos 20/20/20 de la Unión Europea, ya que se limita de forma importante la producción de energía primaria, se potencia el uso de energía renovables, como es la energía geotérmica de muy baja entalpía, y se garantiza la disminución de la generación de CO2 derivada del consumo de energía final en los edificios, dado que alrededor del $70 \%$ del consumo de energía final de edificios residenciales proviene de fuentes energéticas productoras de dióxido de carbono.

\section{Normativa global}

A nivel global, la Convención Marco de las Naciones Unidas sobre el Cambio Climático, adoptada en 1992 por 195 países, fue la primera gran apuesta para estabilizar las concentraciones de gases de efecto invernadero en la atmósfera a un nivel que impida cambios peligrosos en el sistema climático. Los países firmantes se comprometían a reducir las emisiones de gases invernadero en un 5\% respecto a 1990 para 2012, que se prorrogó a 2020.

En el Protocolo de Kioto, adoptado en 1997, 37 países industrializados y la Unión Europea, se comprometen a reducir la emisión de gases de efecto invernadero en un 5\% entre 2008 y 2012, tomando como referencia los niveles de 1990

Debido a la falta de resultados del Protocolo de Kioto, en 2012 se decidió prorrogarlo por un segundo período de tiempo, que comenzó en 2013 y se prolongará hasta 2020 durante la denominada Puerta Climática de Doha, aunque 
esta ampliación no ha sido respaldada por varios de los países con mayor producción de CO2, como Estados Unidos, Rusia, Japón o Canadá.

\section{Normativa europea}

La Unión Europea ha creado su propia iniciativa para prevenir el cambio climático, el objetivo 20/20/20, con la intención de alcanzar una reducción del $20 \%$ de la emisión de gases invernadero, el aumento en un $20 \%$ de la eficiencia energética, y el uso del $20 \%$ del total de energía procedente de fuentes renovables.

A través de la Directiva 2010/31/UE del Parlamento Europeo y del Consejo de 19 de mayo de 2010 relativa a la eficiencia energética de edificios, se pretende fomentar la eficiencia energética en edificios de la Unión Europea, teniendo en cuenta las condiciones climáticas y particularidades locales.

Esta directiva obliga a los países miembros a: tomar medidas, garantizando que todos los edificios de obra nueva a partir del 31 de diciembre de 2020 sean de consumo de energía casi nulo y a partir del 31 de diciembre de 2018 para los edificios de la Administración; aplicar medidas en eficiencia energética en edificios de nueva planta y existentes, si la reforma supera el $25 \%$ del valor del inmueble o afecta a más del $25 \%$ de la envolvente del edificio; elaborar una lista de medidas e instrumentos vigentes y de propuestas de medidas e instrumentos que promuevan los objetivos de la Directiva, antes del 30 de junio de 2011; y realizar el Certificado de Eficiencia Energética siempre que se construya, venda o alquile edificios o unidades de éstos.

Posteriormente, con la Directiva 2012/27/UE del Parlamento Europeo y el Consejo de 25 de octubre de 2012, relativa a la eficiencia energética, se hace hincapié en la necesidad de reducir el consumo energético en un $20 \%$ para 2020 , objetivo que afirma que no se está cumpliendo.

Con la obligación de los países miembros de: renovar, a partir de 2014, el 3\% de la superficie aclimatada de la administración cada año según criterios de la Directiva 2010/31/UE y publicar el ahorro de energía obtenido; garantizar que los productos energéticos que adquiera la Administración sean de alto rendimiento; fomentar las auditorías energéticas; instalar contadores inteligentes en los hogares que informen del consumo a los usuarios; y promover el uso eficiente de la energía 
a los usuarios finales, con incentivos fiscales, suministro de información, proyectos, ejemplares, etc.

\section{Normativa nacional}

España se ha sumado a la iniciativa europea 20/20/20 por imperativo legal, transponiendo las directrices energéticas de Bruselas. Ha llevado a cabo diversas acciones, entre ellas la implantación de ayudas económicas a la rehabilitación energética o la obligatoriedad de realizar certificados en viviendas nuevas y existentes para conocer su rendimiento energético.

Los aspectos constructivos están regulados por el Código Técnico de la Edificación, CTE, desde 2006. Establece los requisitos básicos de seguridad, habitabilidad y consumo de las viviendas. Las legislaciones autonómicas y locales regulan los aspectos más concretos que el CTE delega sobre ellas, como las dimensiones y superficies mínimas de la vivienda.

Las condiciones que las instalaciones de un edificio deben cumplir para conseguir el confort térmico de sus usuarios se establecen en el Reglamento de Instalaciones Térmicas de los Edificios (RITE), publicado en 2007, y de aplicación en construcciones de obra nueva y rehabilitaciones. 


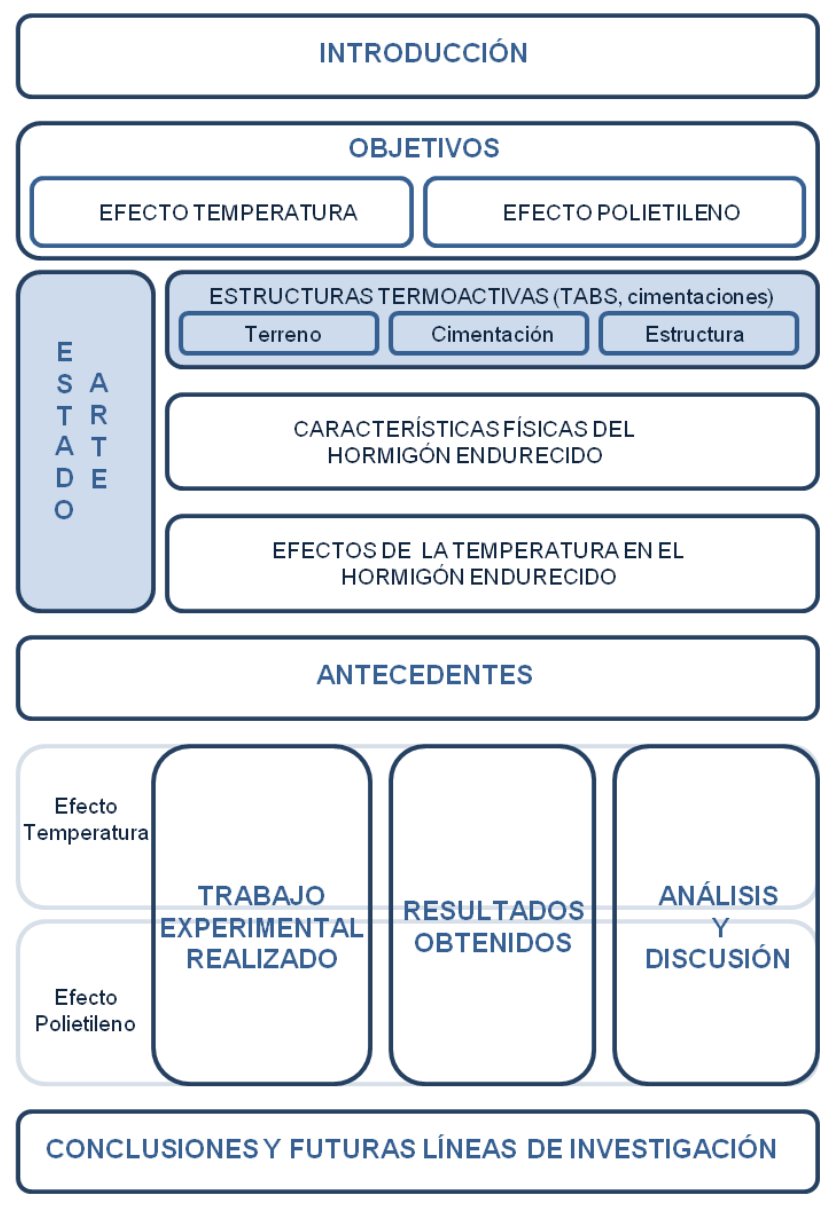

\subsection{Las estructuras de hormigón armado utilizadas como elementos termoactivos.}

La mayoría de la energía utilizada en el sector de la edificación es requerida para mantener una temperatura constante, en las estancias habitables, de alrededor de $20^{\circ} \mathrm{C}$.

El desarrollo y aplicaciones de tecnologías de baja exergía para edificios, permite eliminar, o al menos reducir, la dependencia de la producción eléctrica con materia prima fósil, a la vez que permite proporcionar adecuadas condiciones de confort en el interior del edificio.

Ejemplos de fuentes de baja energía son la energía solar, la energía geotérmica, y el aprovechamiento de recursos energéticos desperdiciados, como 
el calor de las aguas residuales que puede ser utilizado para cubrir las demandas energéticas de los edificios con sistemas de recuperación de calor.

Los sistemas de recuperación de calor utilizados con sistemas de alta eficiencia energética, como son las bombas de calor, y en conexión con sistemas de superficie radiante para calefacción y refrigeración, funcionando a bajos niveles de temperatura, son beneficiosos y altamente efectivos.

Entre esas tecnologías de baja exergía, la masa inercial de las estructuras de los edificios es ampliamente utilizada en edificios en toda Europa, permitiendo el uso de fuentes de baja energía para calefacción y refrigeración.

Además, los elementos estructurales de hormigón armado de las cimentaciones son utilizados para proporcionar energía térmica al edificio, utilizando una de esas fuentes de baja energía, la energía geotérmica de baja entalpía, por medio de la introducción de tubos por los que circulan fluidos en la estructura, ya sean pilotes, pantallas, o losas de cimentación, convirtiéndolos en cimentaciones termoactivas que actúan como intercambiadores térmicos con el terreno.

De modo que la masa térmica del subsuelo permite al edificio almacenar grandes cantidades de energía térmica sobrante en agua caliente, transfiriéndola al terreno, y a la vez, con la ayuda de la bomba de calor geotérmica, permite calentar el edificio en invierno. (Laloui et al.) [76].

Como se ha mencionado anteriormente, este sistema es altamente efectivo en conexión con sistemas de superficie radiante de calefacción y refrigeración, como son las estructuras termoactivas de edificios, comúnmente denominadas en inglés thermo-active building systems (TABS). Estos sistemas incrementan enórmemente la eficiencia de bombas de calor geotérmicas, intercambiadores de calor geotérmicos, y otros sistemas que utilizan fuentes de energía renovables de baja temperatura. (Kalz D., et al.), [66].

Las estructuras termoactivas en los edificios, utilizadas como mecanismos de control de la temperatura al albergar tubos de polietileno con fluido caloportador, que recorren el interior de la masa inercial de los mismos, utilizan la capacidad de acumulación térmica de los forjados y losas para calefactar y refrigerar el edificio y 
proporcionar un adecuado nivel de confort. (Olesen B.W.,et al.), [103], (Basecq V., et al.), [9].

\subsubsection{Tipos de estructuras de hormigón armado utilizadas como elementos termoactivos.}

Como se ha mencionado anteriormente, existen dos tipos de estructuras que pueden activarse térmicamente: las que están en contacto con el terreno, losas, muros, pilotes, que actúan como intercambiadores de calor geotérmico utilizando el subsuelo como medio de extracción y almacenamiento de energía, y, por otro lado, las estructuras del interior del edificio, losas, forjados, muros, vigas, que están en contacto con el medio habitado y son utilizadas intercambiando energía, absorbiendo calor del aire y de los usuarios para refrigerar, o cediendo calor al aire y a los usuarios para calefactar.

\subsubsection{Cimentaciones termoactivas.}

Algunos sistemas de infraestructuras subterráneas, construidas con hormigón de elevada conductividad térmica, pueden ser termoactivadas para su uso como intercambiador, incorporando circuitos de transferencia de energía que llevan en su interior un fluido caloportador, y así intercambiar directamente energía con el terreno.

Se puede utilizar también como EHA termoactiva la superficie de un aparcamiento bajo rasante en contacto con el terreno, los muros de los sótanos de los edificios, las galerías subterráneas o las cimentaciones, losas, muros pantalla perimetrales, pilotes, de forma que trabajen como intercambiador y extraigan energía del terreno para climatizar el edificio que tienen encima.

En comparación con los sistemas convencionales de intercambiadores geotérmicos profundos, las cimentaciones termoactivas resultan más económicas que las sondas geotérmicas, dado que se aprovecha la estructura existente evitando realizar nuevas perforaciones en el terreno, además, la conductividad térmica de las estructuras de hormigón es dos veces mayor que la del mortero utilizado en las sondas geotérmicas. (Yavari N., et al.) [137] 
Aunque la utilización de la cimentación termoactiva se encuentra en fase incipiente en España, está ampliamente desarrollada y consolidada en países de nuestro entorno tales como Suiza, Austria y Alemania, (Pahud, D., et al.) [109], donde se ha llevado a cabo múltiples investigaciones y aplicaciones prácticas de diferentes sistemas innovadores, con objeto de climatizar edificios, basadas en elementos estructurales.

\section{BRANDL}

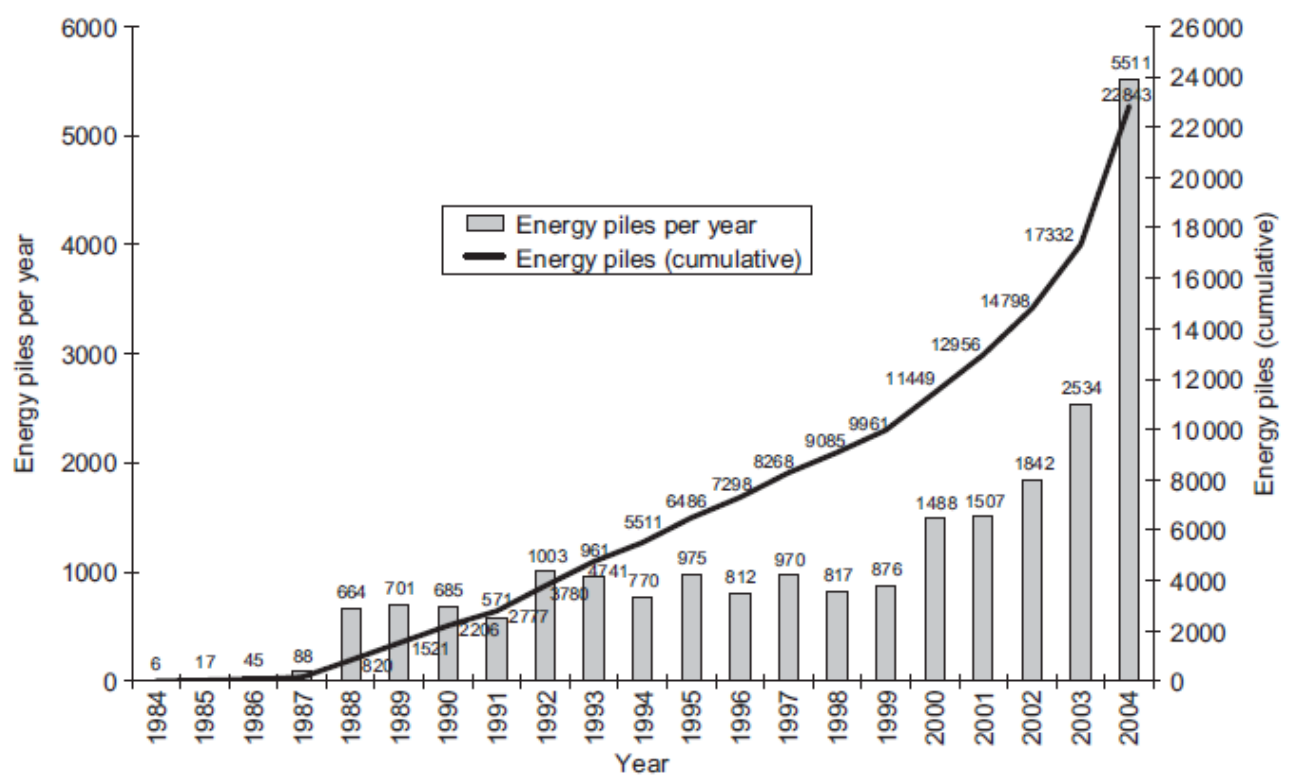

Figura 2.2- 1. Número de pilotes termoactivos instalados en Austria hasta el año 2004. (Brandl, H.,) [16]

Si el sistema de obtención y aprovechamiento de energía se utiliza tanto para la calefacción como para el aire acondicionado del edificio, los costes de inversión y los costes operativos se reducen notablemente, ya que la refrigeración de origen terrestre casi no supone gasto alguno. El potencial energético se eleva debido a que la calefacción con bomba térmica enfría el suelo.

En las estructuras utilizadas como cimentación termoactiva, y en concreto en los pilotes, suele predominar una temperatura media de $13^{\circ} \mathrm{C}$. El fluido caloportador que circula por el pilote utilizado como intercambiador geotérmico se ajusta normalmente a entre $11^{\circ} \mathrm{C}$ a $19^{\circ} \mathrm{C}$ por encima de la temperatura del sustrato en su funcionamiento en verano, para satisfacer las necesidades de refrigeración, 
y entre $6^{\circ} \mathrm{C}$ a $8^{\circ} \mathrm{C}$ por debajo de la temperatura constante del suelo en el modo de invierno, para satisfacer las necesidades de calefacción.

La carga térmica del fluido en invierno, es transmitida, por la bomba de calor geotérmica, al interior del edificio proporcionando temperaturas medias de $25^{\circ} \mathrm{C}$ a $3^{\circ} \mathrm{C}$, que son suficientes para la calefacción por suelo radiante o sistema de radiación en techo, paredes, o en otros elementos estructurales. Por cada KWh de potencia calorífica se requiere sólo de 0,22 a 0,3 KWh de electricidad para el funcionamiento de la bomba de calor. (Amatya B.L., et al.) [5]. La eficiencia del sistema puede llegar a alcanzar coeficientes de rendimiento de la bomba de calor de 5,1, reduciendo por consiguiente los costes del ciclo de vida, aunque el coeficiente de rendimiento de la misma dependerá de la diferencia de temperatura exacta existente entre el fluido del sistema geotérmico y las necesidades de demanda del edificio.

El primer requisito para asegurar el éxito de un proyecto de cimentación termoactiva pasa por incluir e integrar esta tecnología desde la propia concepción y planificación general de la obra, puesto que su ámbito de aplicación supera las meras técnicas de generación de frío y calor.

Para diseñar de forma adecuada un sistema de intercambio termoactivo con el terreno, se precisa conocer en detalle las condiciones generales de la mecánica del suelo, la hidrología, las cimentaciones y las estructuras que vamos a utilizar, el régimen de uso del edificio, y la distribución pormenorizada en el tiempo de la demanda de energía.

El modo de garantizar el mejor aprovechamiento posible de la energía geotérmica, y de su potencial, pasa por realizar una simulación tridimensional de las condiciones dinámicas, y valorarla adecuadamente, no sólo mediante el cálculo sino a la luz de la experiencia en cada caso.

En el caso de los pilotes y de las pantallas, al ir empotrados en terrenos poco resistentes (arcillas, limos, arenas y gravas), a nivel de la capa freática, entre $10 \mathrm{~m}$ y $40 \mathrm{~m}$ de profundidad, la permeabilidad del terreno y la velocidad del flujo del agua freática tienen una gran influencia en la capacidad del suelo para ceder, disipar, o almacenar calor. (De Isabel, J.A.) [33] 

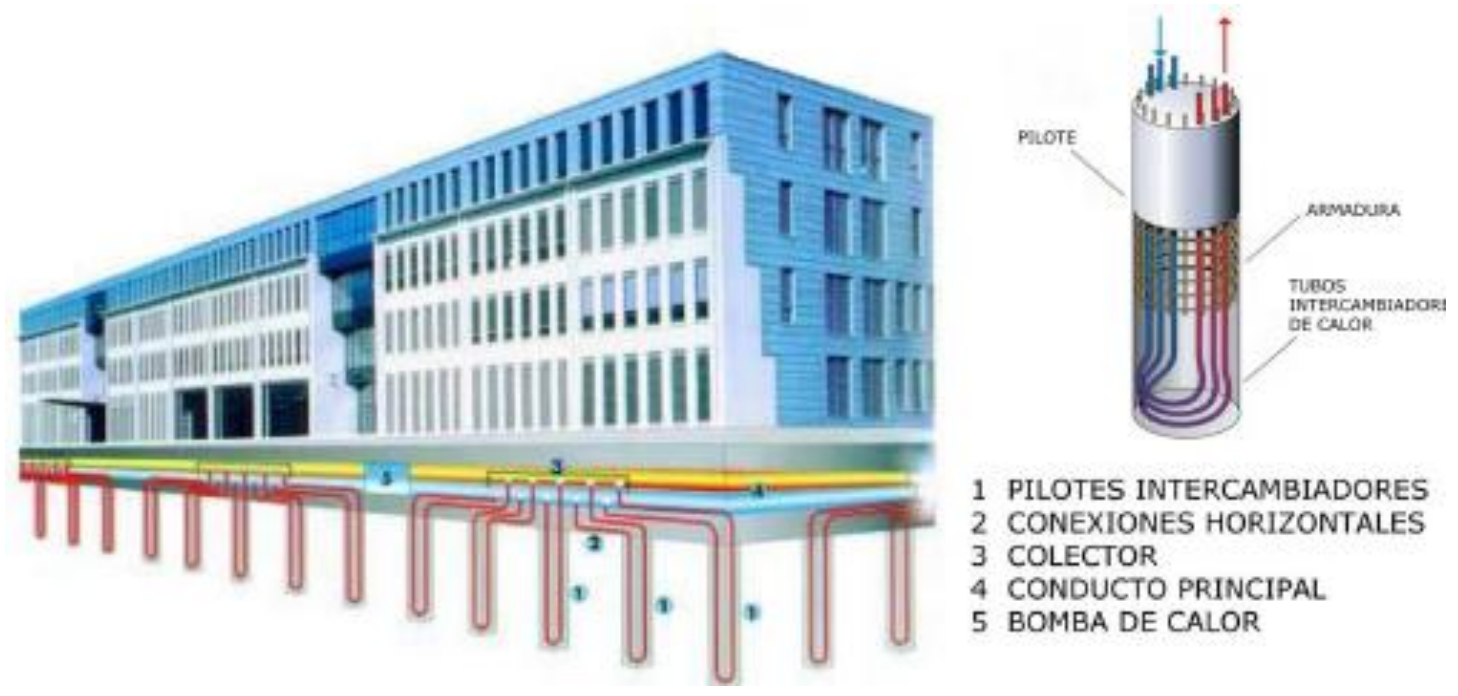

1 PILOTES INTERCAMBIADORES

2 CONEXIONES HORIZONTALES

3 COLECTOR

4 CONDUCTO PRINCIPAL

5 BOMBA DE CALOR

Figura 2.2- 2. Cimentación termoactiva por medio de pilotes de hormigón armado. Fuente: Geothermal energy and heatstorage. Pahud, D. y SIA D 0190.

Por eso, las bases de un buen proyecto de cimentación termoactiva se sustentan en un correcto dimensionamiento del sistema, justificándose a través de estudios edafológicos, geotécnicos, geológicos, e hidrogeológicos, en los que se cuantifica la conductividad eléctrica del terreno, para así poder conocer la potencia por unidad de longitud de pilote extraíble del terreno.

Además, es muy importante dimensionar, con antelación y con precisión, el número, la separación, y la profundidad de los sondeos, en función de las necesidades energéticas y de las instalaciones y tipos de máquinas que se emplearán en la climatización de los edificios, una vez realizado el comentado estudio del sistema de cimentación, del subsuelo, y del edificio, para simular un balance energético completo del edificio y de la cimentación termoactiva.

El sistema de cimentación estará definido con el número y dimensiones de elementos de la cimentación, su distribución geométrica, su colocación, y la distancia entre los elementos, la longitud total y el diámetro disponible, el número de sondas a instalar, y el diámetro y espesor de las sondas seleccionadas. (Kwag, B.C., et al.) [75]

Del subsuelo deben conocerse las condiciones locales geológicas e hidrogeológicas, la caracterización litológica del terreno, la conductividad térmica de los estratos geológicos, la difusividad, la velocidad del caudal de agua en los 
distintos niveles freáticos, la conductividad hidráulica, la capacidad específica de almacenamiento térmico, y el diagrama de temperatura del terreno.

Y con respecto al edificio se deben estudiar las demandas energéticas, el esquema básico energético, si es un sistema mono o bivalente, los niveles de temperatura en el sistema de distribución energético, y los niveles de temperatura del fluido caloportador: mínima temperatura permitida en los pilotes para evitar la congelación, y máxima temperatura permitida que coincidirá con la temperatura de retorno de la enfriadora o bomba de calor en modo refrigeración. (De Isabel, J.A.) [32]

Cobra gran importancia las características del fluido caloportador utilizado, su viscosidad, conductividad térmica y el tipo de flujo. Con el objeto de poder realizar una simulación lo más real posible, y para determinar la energía de extracción disponible en todo el sistema de cimentación activa, será necesario considerar las pérdidas de presión que se van a encontrar en el sistema hidráulico, considerando el conexionado de todos los pilotes activos.

La función principal del fluido caloportador es impedir la formación de hielo en el evaporador cuando está funcionando en modo calefacción. Además, debe proteger contra la corrosión los materiales del circuito cerrado y no debe contaminar el agua subterránea.

Los fluidos más utilizados son: el agua, el etilenglicol, el propilenglicol, el etanol, el metanol, y otros como los cloruros sódico, de calcio, de magnesio y potásico, y los carbonatos sódico y potásico.

El agua es el medio más económico, pero es el que peor cumple la función de anticongelación. El menos corrosivo y menos contaminante es el propilenglicol, pero también es el menos económico.

Con respecto a la ejecución de estos sistemas, conviene recordar que, por motivos de responsabilidad, las instalaciones termoactivas deben ponerse siempre en manos de empresas experimentadas. Son múltiples las fuentes de posibles errores que pueden conducir a un funcionamiento defectuoso de la instalación.

Para supervisar permanentemente el montaje se deben realizar las pruebas de estanqueidad oportunas. 
Si se desea evitar inconvenientes, es aconsejable planificar con exactitud la agenda de ejecución con las otras empresas que participan en la obra.

\subsection{Energía geotérmica de muy baja entalpía.}

Dentro de los distintos tipos de energía geotérmica existentes, clasificados por la entalpía, la energía geotérmica de muy baja entalpía, menos de $30^{\circ} \mathrm{C}$, es la que podemos aprovechar para la climatización de viviendas, edificios, oficinas, etc., y para producción de agua caliente sanitaria, empleando intercambiadores de calor subterráneos y bombas de calor conectadas al terreno, llamadas también bombas de calor geotérmicas, que, a cambio de pequeños consumos de energía eléctrica necesaria para el funcionamiento del sistema, permiten captar ese escaso y difuso calor, concentrarlo y aprovecharlo, proporcionando ahorros de energía térmica en hogares y edificios comerciales y públicos, ahorros que, comparados con sistemas convencionales de gas-oil, gas o electricidad para calefacción, pueden representar entre un $30 \%$ y un $70 \%$.

En realidad no hace falta hablar de un yacimiento de energía geotérmica de muy baja temperatura (o de entalpía) ya que cualquier punto de la corteza terrestre puede ser empleado como fuente de energía al estar la temperatura normalmente por debajo de los $25^{\circ} \mathrm{C}$. Incluso en los países nórdicos, donde la energía geotérmica para climatización está muy extendida, la temperatura del subsuelo llega próxima a los $0{ }^{\circ} \mathrm{C}$ alcanzándose excelentes rendimientos de las bombas de calor geotérmicas cuando la temperatura exterior está por debajo de $0 \stackrel{\circ}{\circ}$.

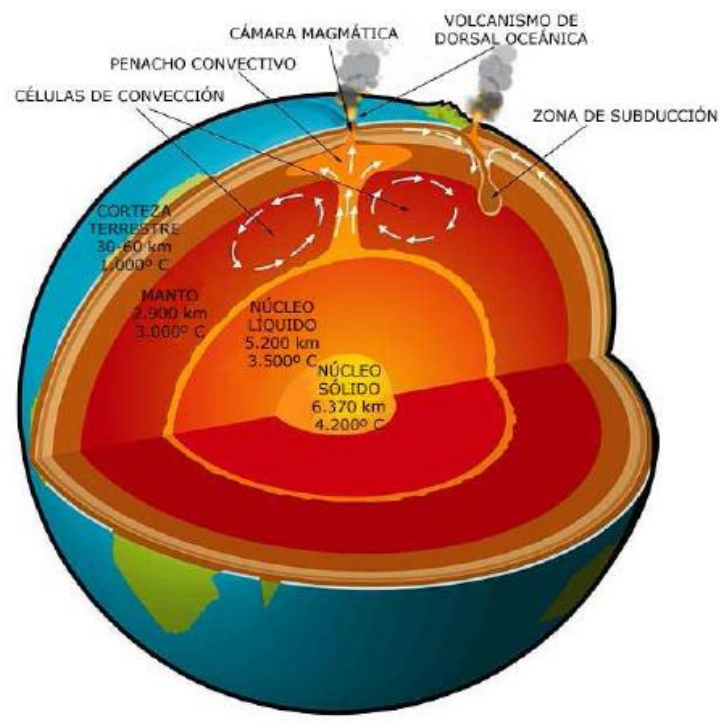

Figura 2.2- 3. Energía geotérmica.

Fuente: Geothermie-Perspectives de I'ADEMEet duBRGM. 
La distribución de la temperatura, en el suelo en los países del norte de Europa, encuentra el equilibrio térmico a $10^{\circ} \mathrm{C}$ y una profundidad de 15 metros.

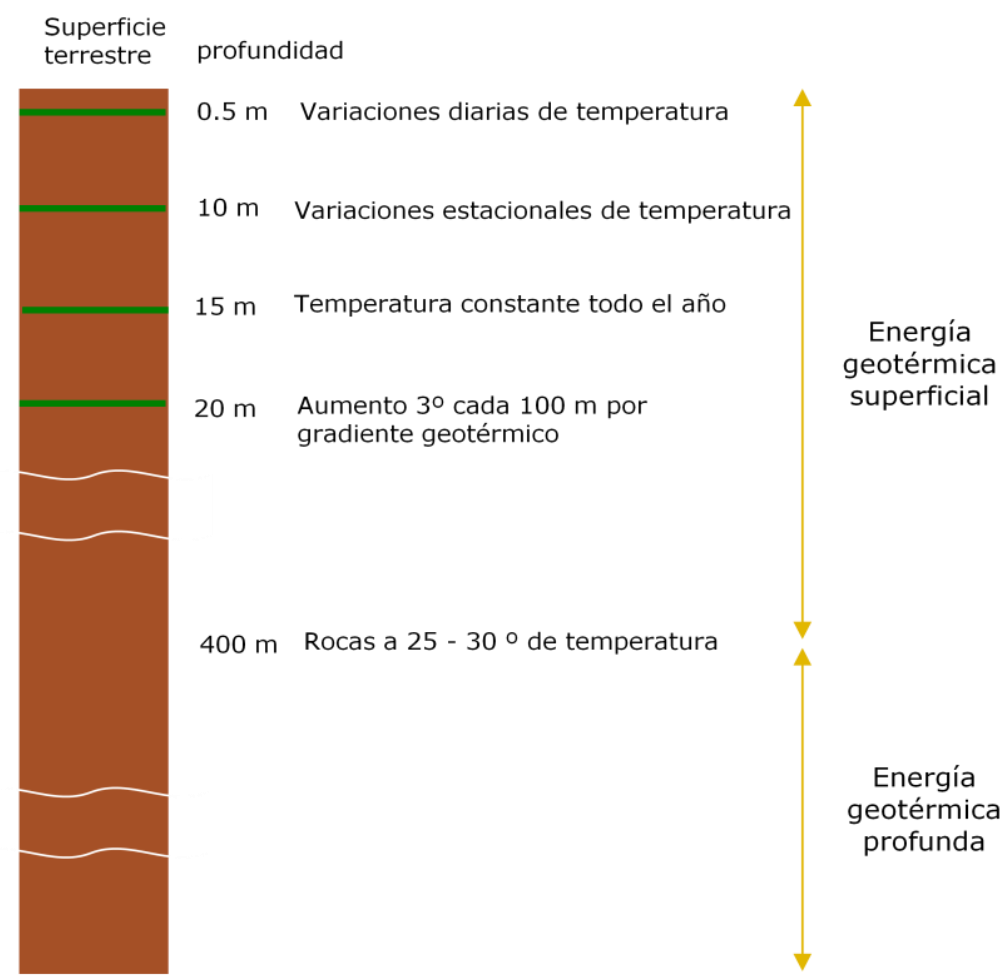

Figura 2.2- 4. Distintos tipos de energía geotérmica. Variaciones en función de la profundidad y de la temperatura. Elaboración propia.

Si hacemos un estudio de la temperatura que tiene el subsuelo a medida que profundizamos en diferentes épocas del año, obtendremos un gráfico como el que se aprecia en la figura 2.2- 5 en el que observamos cuatro curvas:

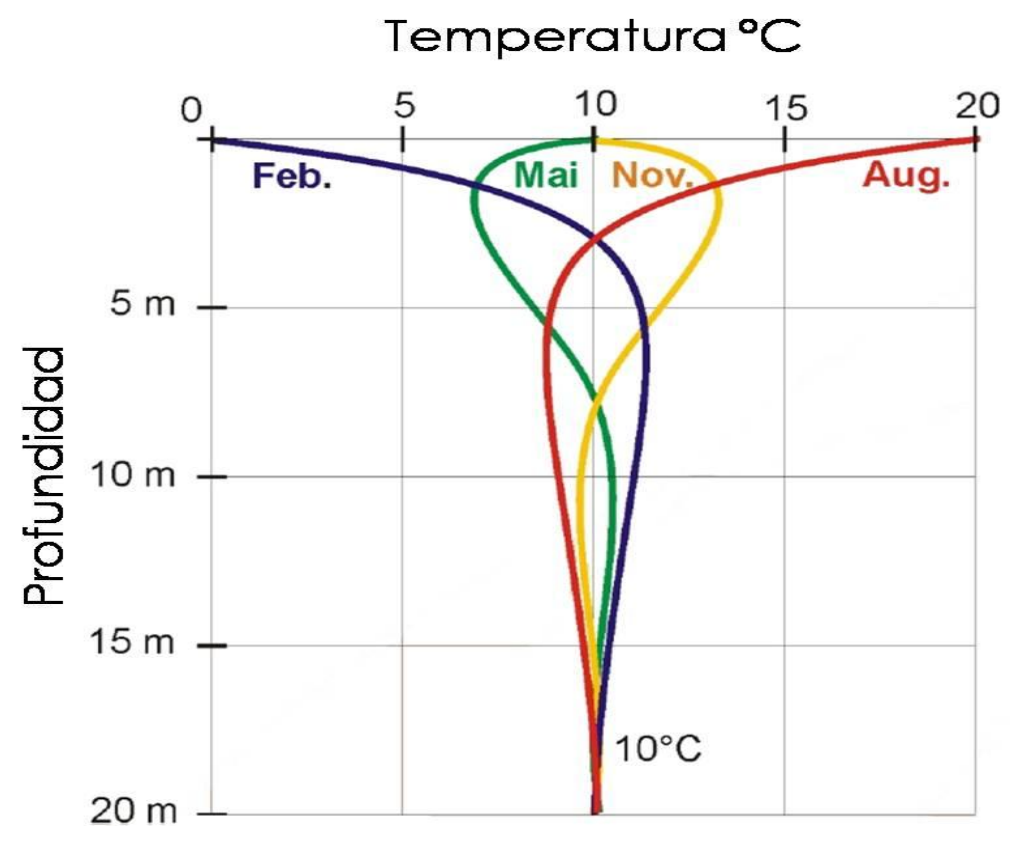

Figura 2.2- 5: Temperatura del subsuelo en función de la profundidad. (De Isabel, J.A.) [34] 
Azul: En invierno, a medida que profundizamos, la temperatura va aumentando hasta alcanzar un valor fijo de $10^{\circ} \mathrm{C}$.

Roja: En verano ocurre lo contrario; a medida que profundizamos la temperatura desciende hasta los $10^{\circ} \mathrm{C}$.

Verde y amarilla: En primavera y otoño las variaciones son menores, llegándose a alcanzar, en profundidad, el mismo valor de $10 \stackrel{\circ}{ } \mathrm{C}$.

Este hecho es sumamente importante porque quiere decir que, a partir de una determinada profundidad la temperatura del subsuelo es constante e independiente de la estación anual en la que nos encontremos, y, por supuesto, independiente de la hora del día o de la noche. Disponemos por ello, a unos pocos metros de nosotros, de una fuente de energía constante a lo largo de todo el año y accesible en todos los lugares.

La temperatura media que tiene el subsuelo en un determinado punto es aproximadamente igual a la temperatura media anual de la zona. En España se estima que la temperatura media del subsuelo puede estar en torno a los $15^{\circ} \mathrm{C}$.

El origen de esta energía proviene de dos fuentes de calor que mantienen dicha temperatura constante:

La energía procedente del sol, que aporta $1,74 \times 1017 \mathrm{~J} / \mathrm{m} 2 \mathrm{~s}$, y la energía terrestre (desintegración isotópica, calor inicial, movimientos diferenciales), que aporta 4,2 x $1012 \mathrm{~J} / \mathrm{m} 2 \mathrm{~s}$.

A medida que se profundice mayor importancia adquiere la energía procedente del interior de la tierra. Sin embargo, en las primeras decenas de metros el sol es una auténtica fuente de energía, que no solo calienta la superficie de la corteza terrestre, sino que calienta toda la atmósfera y por consiguiente las nubes y, en definitiva, el agua de lluvia que se convierte de esta manera en un aporte extra de energía al subsuelo.

Un sistema geotérmico está integrado, generalmente, por tres subsistemas principales: 
- Un intercambiador de calor subterráneo, que extrae el calor del subsuelo o evacua el calor del edificio.

Pueden ser sistemas cerrados o abiertos. Dentro de los cerrados, los intercambiadores pueden ser horizontales o verticales, por medio de sondas geotérmicas o utilizando los elementos estructurales de la cimentación de los edificios, entre otros sistemas existentes con ciertas peculiaridades, como los pozos canadienses y la utilización de aguas residuales urbanas.

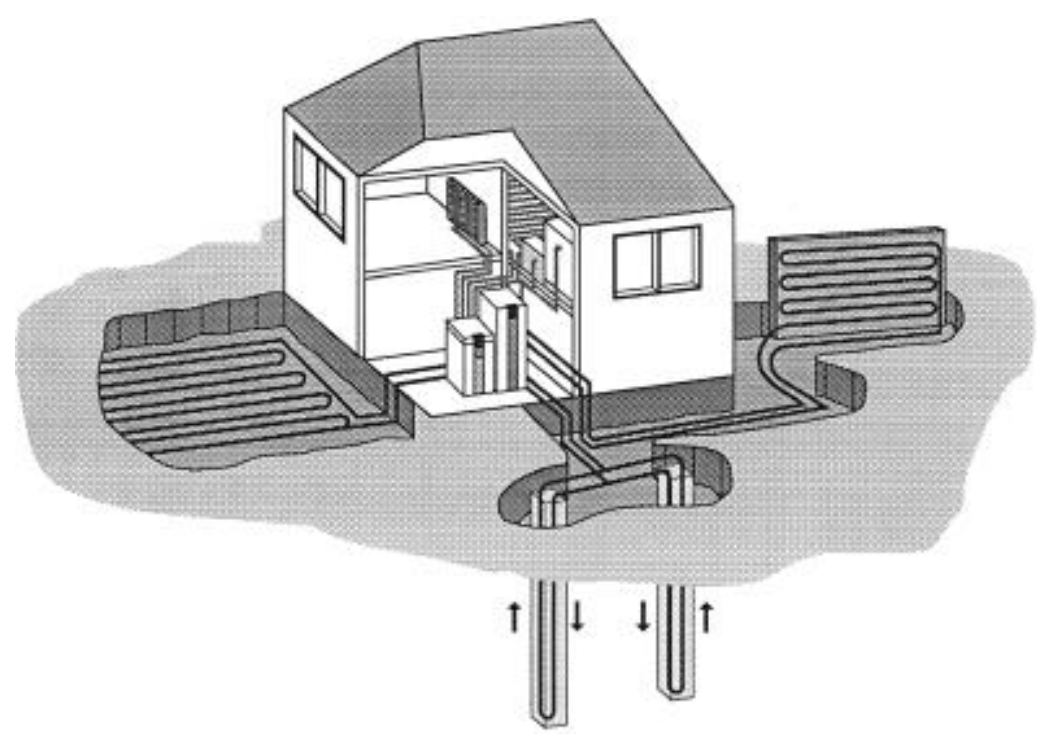

Figura 2.2- 6. Esquema de climatización de una vivienda unifamiliar por medio de cimentación termoactiva, complementario a otros sistemas activos de captación de calor. (Brandl, H.,) [16]

En nuestro caso nos centraremos en los elementos estructurales que pueden ser utilizados como intercambiador de calor geotérmico.

- Una bomba de calor, que transfiere el calor entre el intercambiador de calor subterráneo y el sistema de distribución de un edificio, y que dispone de un circuito cerrado estanco por el que circula un fluido frigorífico que cambia de estado (líquido o gaseoso) en función de los cuatro órganos que atraviesa: evaporador, compresor, condensador y la válvula de expansión. 


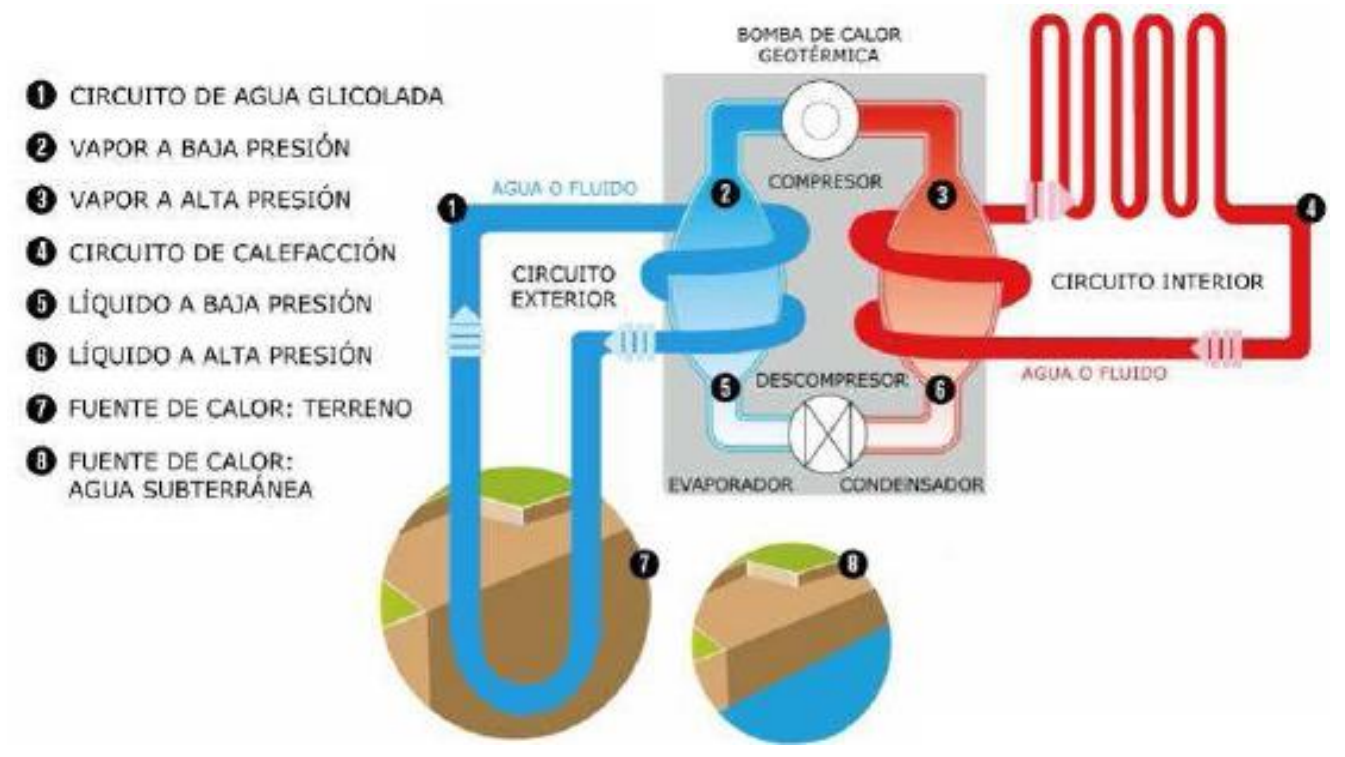

Figura 2.2- 7. Componentes básicos de una bomba de calor por compresión en modo calentamiento. (Geoener 2009).

En modo refrigeración, mediante una válvula de expansión de doble sentido y una válvula de cuatro vías a la salida del compresor, se invierte el sentido de funcionamiento del sistema, y el calor excedente del edificio es evacuado al subsuelo fresco, utilizándolo como acumulador de calor, pudiendo establecerse así un sistema geotérmico de aprovechamiento de energía por almacenamiento estacional, evitando que se agote el recurso y garantizando además que se reduzcan notablemente los costes de inversión y los costes operativos, ya que si utilizamos este sistema para la refrigeración natural "free cooling" con intercambio directo con el subsuelo, se permite conseguir elevados COP (coeficiente de rendimiento).

- Sistema de distribución que encauza el calor o el frío a las diferentes estancias de un edificio.

Aunque existen diversos sistemas de distribución dentro del edificio de la energía captada para su climatización, como fan-coils, radiadores, splits, etc., los sistemas de radiación en suelo o en techo son los más apropiados al necesitar una menor temperatura de impulsión; además, 
al combinar estos sistemas de radiación con la ventilación por desplazamiento, se consiguen disminuir notablemente las cargas radiantes.

Por lo tanto, el intercambio geotérmico permite la utilización inercial del terreno y de la masa construida de los edificios y las infraestructuras, para la acumulación de grandes cantidades de energía térmica con potencias bajas y bandas moderadas de temperatura, siendo un medio para acumular la energía térmica generada, y a menudo considerada residual, por sistemas industriales e infraestructuras urbanas, y propiciar su reutilización con costes muy bajos y ciclo de vida muy largo. Además, la acumulación de energía térmica en el terreno se puede también aplicar a sistemas integrados y distribuidos de captación solar térmica y solar fotovoltaica.

De ese modo, en un sistema de captación de energía geotérmica, las estructuras de hormigón termoactivas pueden formar parte de dos de los subsistemas existentes; en el caso de los intercambiadores de calor subterráneos se puede utilizar las cimentaciones termoactivas y todo tipo de estructuras subterráneas de hormigón armado de edificación o de obra civil, como infraestructuras urbanas subterráneas, túneles y redes subterráneas de transporte, aparcamientos subterráneos, etc. (De Pereda, L., et al.) [38], como circuito cerrado, pero enterrado y en exterior del edificio a climatizar.

Por otro lado, las estructuras de hormigón termoactivas pueden formar parte del sistema de climatización que distribuye el calor o el frío a las distintas estancias de un edificio como circuito cerrado, pero en el interior del edificio que se pretende climatizar.

\subsection{Aprovechamiento de recursos desperdiciados.}

Las fuentes de calor naturales y las residuales desperdiciadas generan en el entorno de los edificios enormes cantidades de energía térmica que puede ser incorporada al sistema como recursos primarios. Para ello, basta con tener instrumentos para captar, almacenar, y reutilizar este calor a temperatura moderada y baja intensidad, que con frecuencia se desperdicia. 
Los recursos que proceden de la recuperación de calor en el agua residual, los gases y el aire, los de los sistemas urbanos que expulsan calor, los de las fuentes renovables solares, y los del intercambio nocturno con el aire exterior, se almacenan en el terreno y se transfieren estacionalmente a los ocupantes y usuarios de los edificios a través de sus estructuras, con el uso de forjados termoactivos, que están en contacto con los usuarios en todo el espacio habitable.

La naturaleza del intercambio de energía con el terreno es la de la baja presión, la baja velocidad, la baja intensidad, y la temperatura moderada, y esto es lo que permite incorporar al sistema la energía procedente de muchas de las fuentes renovables del medio natural, y energías residuales de los sistemas desperdiciados, que tienen esta misma naturaleza moderada.

Para evitar el desajuste estacional entre demanda y suministro, el almacenamiento subterráneo de energía térmica a través de cimentaciones termoactivas es una técnica muy efectiva. Hay innumerables sistemas en funcionamiento en Europa en aplicaciones de baja temperatura, entre $5^{\circ} \mathrm{C}$ y $25^{\circ} \mathrm{C}$, para el almacenamiento de calor o el enfriamiento del terreno para la refrigeración estival.

Estos sistemas permiten aprovechar geotérmicamente el terreno, pero también permiten aprovechar la energía térmica existente en los fluidos que circulan bajo este.

Un ejemplo es la recuperación de calor en invierno, e inyección de calor en verano, utilizando elementos prefabricados como canalización de aguas residuales de nuestras ciudades, con el fin de intercambiar térmicamente energía con el fluido.

Cuando el agua fluye por los colectores tiene un doble efecto, por un lado el de la temperatura del agua, que a modo de ejemplo conviene indicar que en Madrid suele estar entre $15^{\circ} \mathrm{C}$ y $20^{\circ} \mathrm{C}$, y la del efecto recuperador de intercambio con el terreno, porque esa tubería está enterrada y el suelo está a temperaturas estables.

Este recurso se utiliza en algunas ciudades, por ejemplo, de Suiza, donde se realiza un estudio de todo el potencial de aprovechamiento de aguas residuales y se implanta en el plan general de la ciudad, para que los edificios que están en la 
zona aprovechen como un recurso renovable y gratuito el intercambio térmico con aguas residuales. En nuestro país el potencial de uso de este sistema es enorme, no sólo para calefactar sino para refrigerar los edificios intercambiando energía con las aguas residuales.

En segundo lugar, tratando el aprovechamiento geotérmico, la capacidad del terreno para acumular energía en pequeños volúmenes, y confinados de manera natural, lo convierte en un importante y poderoso recurso para la gestión de todo tipo de energías del entorno, y éste es uno de los principales mecanismos de reducción de la demanda en los edificios eficientes.

El terreno es un recurso de almacenamiento a disposición de todos y en todas las ubicaciones. Especialmente adecuado a los múltiples recursos energéticos de moderada intensidad que deben ser recuperados y consumidos localmente, en modo distribuido, pues no requieren el transporte ni la centralización.
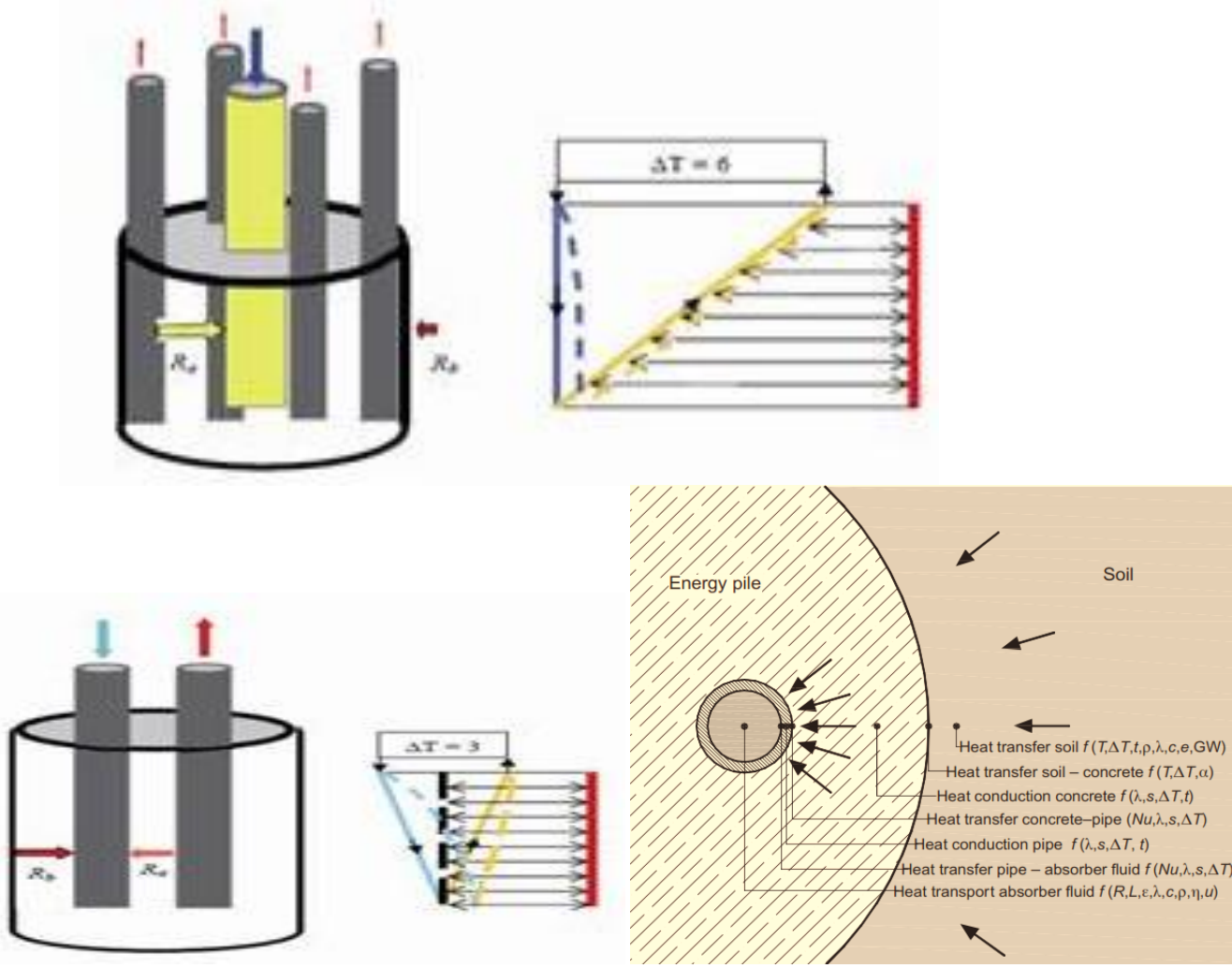

Figura 2.2- 8. La Conducción, como mecanismo de transferencia de calor entre el terreno y las cimentaciones termoactivas. Fuente: Eneres. 
El rendimiento del almacenamiento de frio y calor a baja temperatura es alto. Para inducir al terreno a temperaturas entre $5^{\circ} \mathrm{C}$ y $30^{\circ} \mathrm{C}$ es, durante un periodo interestacional, del $70 \%$ al $90 \%$. Si se almacena calor a más alta temperatura, el rendimiento del almacenamiento baja a medida que la temperatura sube, pues la capacidad de agitación molecular de un terreno natural medio resuelve el almacenaje de energía en rangos equilibrados de tipo medio.

La transferencia por convección y radiación es muy baja dentro del terreno. Realmente, el mecanismo de transferencia de calor entre el terreno y las cimentaciones termoactivas es esencialmente conductivo, si bien las características del terreno pueden hacer variar su grado de transferencia por conducción.

La temperatura de almacenamiento con cimentaciones termoactivas tiene como rangos, la baja temperatura, de $5^{\circ} \mathrm{C}$ a $30^{\circ} \mathrm{C}$, y la media temperatura, de $30^{\circ} \mathrm{C}$ a $50^{\circ} \mathrm{C}$. 


\subsection{Tipos de cimentaciones termoactivas.}

Aunque cabe la posibilidad de utilizar zapatas y losas termoactivas como medio de aprovechamiento energético, los elementos más habituales utilizados son los pilotes y los muros pantalla.
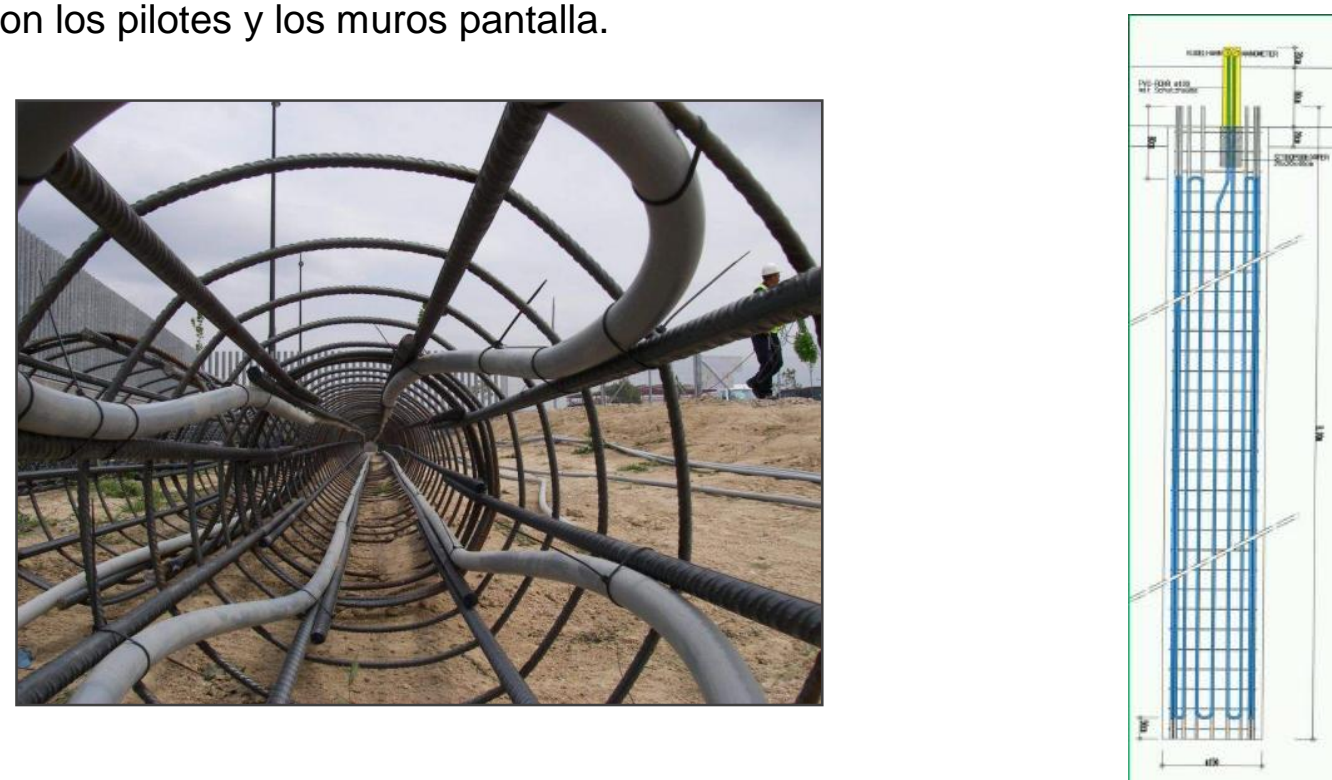

Figura 2.2- 9. Pilote termoactivo. Fuente: Eneres.

En caso de utilizarse pilotes, éstos pueden ser prefabricados o ejecutados "in situ". Los prefabricados suelen tener un diámetro entre 30 y 60 centímetros y una profundidad estimada de entre 10 y 30 metros, mientras que los ejecutados "in situ", pueden variar su diámetro entre 60, 150 y 200 centímetros y su profundidad estimada máxima suele ser de 60 metros. Además, desde el punto de vista de su montaje los pilotes prefabricados se pueden hincar a través de vibración, presión, o perforación. (De Isabel, J.A.) [34]

En muchos casos se utilizan pilotes intercambiadores de energía prefabricados especialmente cuando se trata de pilotes de fricción y/o para edificaciones menores. La prefabricación de pilotes termoactivos de hormigón es muy común en zonas de Europa donde se hace mejora de la capacidad portante del terreno con hinca de pilotes prefabricados.

Este tipo de pilotes se emplea generalmente por sus ventajas económicas y de rapidez de ejecución. El sistema de absorción, compuesto por tubos apropiados de PEX, se integra en los pilotes en nuestros talleres para elementos prefabricados.

Después de hincar los pilotes ya sólo se precisa retirar el suplemento de icopor para conectar el pilote a la línea de interconexión. Estos pilotes 
transmisores de energía miden en sección transversal de 30/30 cm a 40/40 cm y alcanzan hasta 14 metros de longitud.

Los pilotes prefabricados pueden llegar a alcanzar hasta 28 metros de longitud gracias a un nuevo sistema de unión, de montaje rápido e idóneo para las obras de construcción.
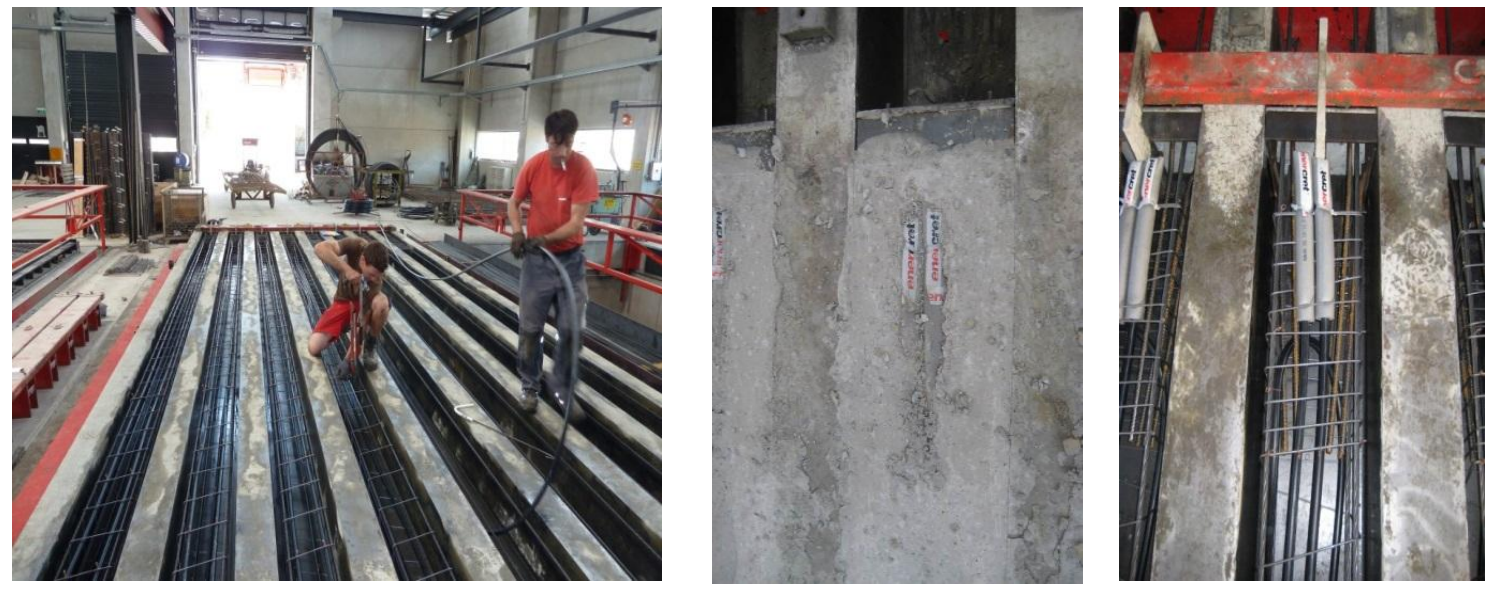

Figura 2.2- 10. Fabricación de pilotes termoactivos. Fuente: Nagelebau/Eneres.

La potencia de extracción específica de los pilotes activos se encuentra por lo general dentro de la horquilla de calores de $40 \mathrm{~W} / \mathrm{m}$ a $80 \mathrm{~W} / \mathrm{m}$. Un sobredimensionamiento en la longitud de los pilotes termoactivos no implica un sobrecoste excesivo, y permite conseguir un pequeño incremento de temperatura en el fluido caloportador, mejorando el COP de la bomba de calor y reduciendo el riesgo de congelación. ( Magraner, T., et al.) [85]

Siguiendo el principio básico de funcionamiento de las bombas de calor geotérmicas, para optimizar su coeficiente de rendimiento o COP, hay que garantizar que entre el evaporador y el condensador de la bomba se mantenga la menor diferencia de temperatura posible. Esto influirá en el cálculo del número necesario de pilotes, que estarán del lado del evaporador y, por otro lado, influirá en el sistema de distribución de la energía en el edificio con la menor temperatura posible de impulsión, es decir, sistemas basados en el principio de radiación. 


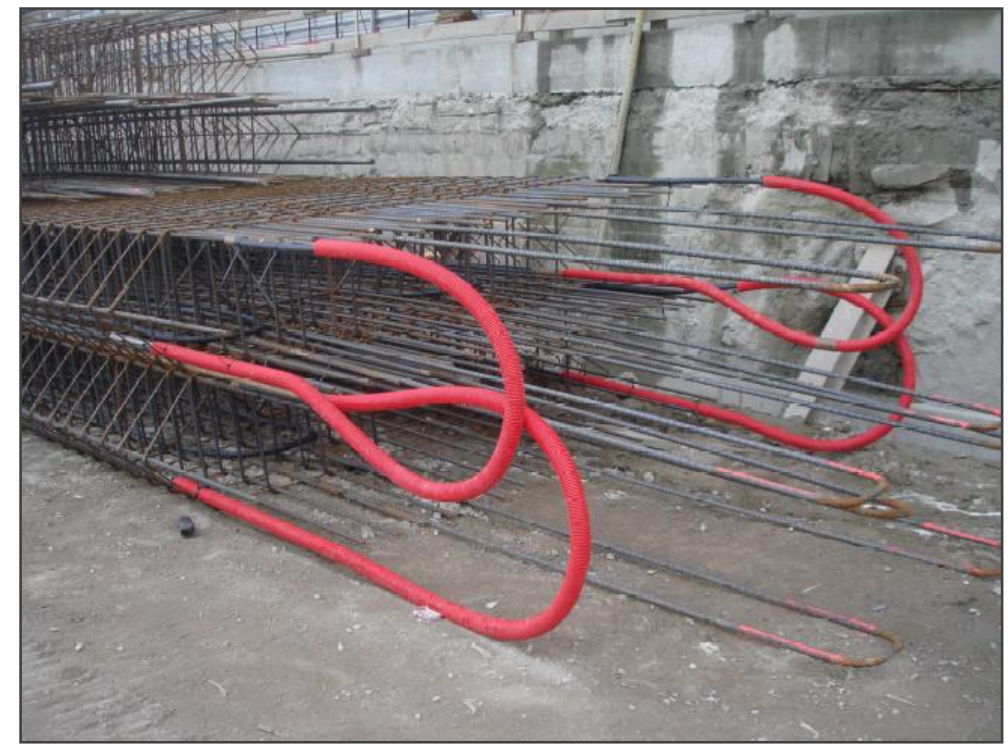

Figura 2.2- 11. Armadura de muro pantalla perimetral termoactivo con tubería de polietileno. Fuente: Enercret.

Una vez realizado este predimensionamiento y proyectado el trabajo globalmente, se pasa a la fase de Ejecución, en la que se llevarán a cabo las tareas de cimentación termoactiva como tal. Es preciso que se realice de la mejor manera posible, siempre atendiendo a los requerimientos de las normas especificas existentes. En la actualidad estos sistemas se rigen en Europa por las normas Alemana VDI 4640 y Suiza SIA D 0190, sobre estructuras subterráneas termoactivas, y por la norma Suiza SIA 384/6, que profundiza en el cálculo de las sondas geotérmicas.

Dentro de la fase de ejecución se engloban las tareas propias del proceso de cimentación, ya sea mediante pilotes prefabricados, "in-situ", o de inyección y, obviamente, las de introducción de sondas geotérmicas en el pilote, es decir, su activación energética. Las fases a seguir comienzan por la perforación, la introducción del registro de sondas, el hormigonado, la preparación de las conexiones, el conexionado de los pilotes, y, por último, la finalización del pilote.

Las sondas por las que circula el fluido caloportador, que, como se ha mencionado, puede ser agua con aditivos antcongelantes, y al estar colocadas en los pilotes, o bajo la solera, o en los muros exteriores del edifico que están en contacto con el terreno, formando circuitos de tuberías que se conectan al distribuidor mediante conductos horizontales e interconexión, constituyendo un circuito hidráulico, conectado con los colectores y distribuidores y con la bomba de calor geotérmica situada en la sala técnica del edificio. 


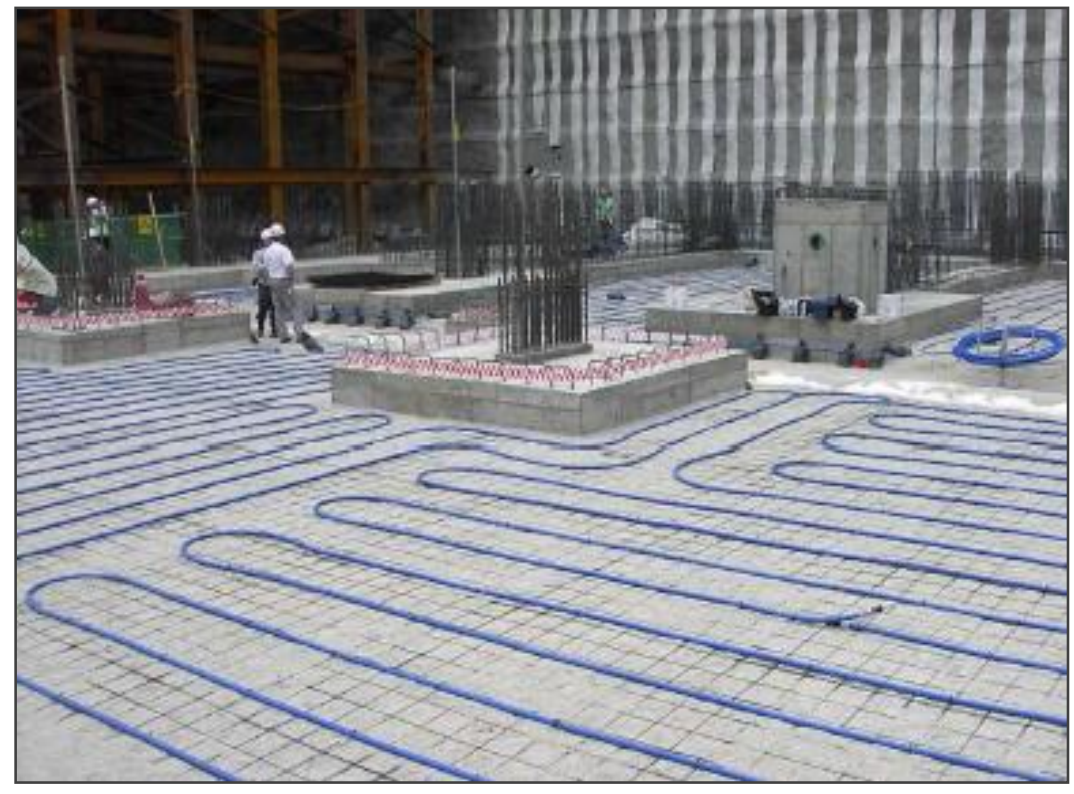

Figura 2.2- 12.

Colocación tubos

polietileno en losa de

cimentación termoactiva.

Fuente:Uponor

Por lo general, estos trabajos se realizan por fases, ya que los muros de la planta baja deben estar listos para el montaje de los conductos de unión. El espacio destinado al distribuidor general debe encontrarse por encima del nivel freático y, de ser posible, ubicado cerca de la sala técnica. El distribuidor consiste en un colector de flujo y reflujo, al que se conectan los circuitos de tuberías.

Durante la ejecución de todos los trabajos los circuitos de tuberías se someten a una presión de 7-8 bar para que sea posible controlar constantemente su estanqueidad. Antes y después de aplicar el hormigón se controlan las presiones y se registran en protocolo.

Cuando se ejecutan pilotes termoactivos, se debe dejar un hueco de unos 50 cms en la cabeza de los pilotes para facilitar el conexionado de sondas entre ellos. En los pilotes "in situ" se instala un manómetro y una válvula de cierre.

La dimensión y la longitud de los sistemas de tubería y conexionado proceden del cálculo hidráulico. El material sintético recomendado es el HDPE 100, polietileno de alta densidad, de $20 \mathrm{~mm}$ o de $25 \mathrm{~mm}$ de diámetro, con espesor de pared de 2,0 $\mathrm{mm}$ o 2,3 $\mathrm{mm}$ respectivamente. El fabricante establece un protocolo de calidad con una garantía mínima de 100 años de vida útil en su comportamiento, siempre que todos los elementos de conexión y soldaduras empleadas se realicen con materiales y técnicas específicas para el trabajo con PE. (Escuer. J., et al.) [50] 
No se recomienda la utilización de tubos de PE estancos al oxígeno, ya que ocasionan dificultades serias en las conexiones, siendo favorable la utilización de inhibidores en el fluido caloportador para evitar la formación de lodos y posibles corrosiones de la estructura metálica.

A continuación se procede a la interconexión de los circuitos de la cimentación termoactiva, que acabarán recogiéndose mediante un colector central que canalice la energía hasta la sala técnica. Dicho colector debe colocarse en un compartimento accesible, en la propia sala técnica o en el muro exterior de la misma, por encima del nivel freático.

Los volúmenes de circulación en los distintos circuitos deben poderse equilibrar mediante válvulas de ajuste de precisión. Partiendo del distribuidor se debe tener acceso a las tuberías de impulsión y retorno que conducen a la unidad central de energía geotérmica.

Otro aspecto fundamental para el éxito de un proceso de cimentación termoactiva proviene del correcto hormigonado de los pilotes, que garantice un relleno total libre de oquedades que perjudiquen el intercambio energético y, por ende, el rendimiento global de la instalación.

También es esencial llevar un estricto control del todo el proceso, realizando las pertinentes pruebas de estanqueidad especificadas en la normativa, para así conseguir los registros proyectados. Además, este control es un aspecto clave en la globalidad del proyecto, puesto que una vez conectados los circuitos a la bomba de calor no es posible realizar modificación alguna.

Desde el punto de vista de la seguridad de la instalación completa será necesario controlar y comprobar rigurosamente que las temperaturas de impulsión y retorno se encuentran dentro de un rango de parámetros adecuados para su funcionamiento.

El proyecto de monitorización, con las técnicas de medida, regulación y control, permite establecer las tendencias que el proyecto inicial había establecido en cuanto a los distintos modos de operación (calefacción, refrigeración pasiva, refrigeración activa, o modo dual), así como determinar el comportamiento del subsuelo en cuanto a su capacidad de almacenamiento y regeneración en las distintas temporadas de uso. 


\subsubsection{Estructuras termoactivas en el edificio. Thermo active building systems TABS.}

Cuando las estructuras de los edifcios se utilizan como dispositivo para la climatización, actuando como intercambiadores de energía en la captación de calor, el intercambio, y el almacenamiento, se las denomina en ingles Thermo active building systems (TABS).

Las TABS basan su funcionamiento en el uso de bajas temperaturas de calefacción y altas temperaturas de refrigeración, y han ido ganando una gran cuota de mercado en toda Europa desde que a finales de 1990 se utilizaron por pirmera vez en Suiza. (Olesen, B.W.) [105]. Su eficiecia se debe al uso del agua, que tiene gran capacidad calorífica, como medio de transporte de energía, en lugar de utilizar los sistemas tradicionales basados en el aire.

Este tipo de sistemas realiza la transferencia de calor por radiación y por convección. En general tal y como recoge Olesen, B.W. [105] en sus trabajos, la transferencia de calor es por medio de mecanismos de radiación en un 50\%, beneficiando la mejora del confort térmico de los usuarios.

Además, el hecho de integrar estos sistemas en el interior de la estrucutra de hormigón de los edificios permite utilizar la masa térmica inercial del edificio de forma efectiva, y potenciar el ahorro en el consumo energético de energía primaria.

Investigaciones relativas a los sistemas de radiación para calefacción y refrigeración en edificios llevadas a cabo por Fonseca, N., et al., [54], y Xu, X., et al. [135] confirman la eficiencia de esta tecnología que permite el intercambio de calor entre el aire interior y la masa inercial térmicamente activada, incluso con pequeñas diferencias de temperatura. Raftery, P., et al., [114], y Lehmann B., et al., [79]

En un estudio realizado por Olesen, B.W. [105], se llevó a cabo una monitorización de los parámetros de temperatura den varios edificios, concluyendo que los edificios pueden mantener fácilmente la temperatura interior por debajo de $26^{\circ} \mathrm{C}$ durante casi la totalidad de la jornada laboral sin superar en ningún momento los $27^{\circ} \mathrm{C}$, incluso con temperaturas exteriores superiores a $30^{\circ} \mathrm{C}$.

El diseño y dimensionamiento de los forjados termoactivos se realiza de acuerdo a la normativa europea EN ISO 7730 [49] y Standard EN 15377-1 [125], a 
la normativa y guías Suizas SIA 2024 y SN 546 382/1, y a las UNE-EN 1264 sobre climatización por superficies radiantes.

Se integran en el mismo proceso de diseño los sistemas control por medio de sensores para monitorizar la instalación durante su funcionamiento (Lehmann, B., et al. 2008) [81] y (Lehmann, B., et al. 2011) [82], pudiendo analizarse por medio de la obtención de datos el potencial de ahorro energético, como se realiza en los estudios de M. Gwerder, et al., [84], por medio del sistema de control PWM.

Actualmente existe una norma Alemana (DIN EN 15377-1/2/3: 2006) que regula el diseño de las losas y forjados termoactivos que utilizan fluidos caloportadores en su interior y se utilizan tanto para refrigeración como para calefacción.

Al ser un sistema basado en calefacción a baja temperatura y en refrigeración a alta temperatura, es compatible con fuentes de energía renovables de baja temperatura como la energía solar térmica, la energía geotérmica y el frío solar, ya que al funcionar como un suelo o techo radiante necesita una menor temperatura de impulsión. Si se combinan estos sistemas de radiación con la ventilación por desplazamiento se consiguen disminuir notablemente las cargas radiantes. (Causone, F., et al.), [25] y (Artmann, N., et al.) [7]

Además, por el sistema de funcionamiento, esta tecnología se adapta perfectamente a los requisitos mencionados de los sistemas geotérmicos, aunque requieren que la temperatura de confort se especifique en un rango de temperaturas y por zonas ya que no se puede controlar de modo individual ni para un temperatura específica. (Meierhans, R.A. 1993) [91] y Meierhans, R.A. 1996) [90]

Los forjados termoactivos, o también denominados "con núcleo de hormigón atemperado", suponen un nuevo avance que se complementa igualmente de forma idónea con los sistemas de cimentación activa. Permiten conseguir una temperatura homogénea en todas las superficies, consiguiendo el denominado "efecto catedral". Esta tecnología se puede aprovechar como sistema base del control de las cargas térmicas, utilizando de forma óptima la capacidad de acumulación de calor del hormigón para neutralizar las cargas térmicas puntuales, que incluso pueden transmitirse al exterior en momentos de alta ocupación. (De Pereda, L.) [37] 


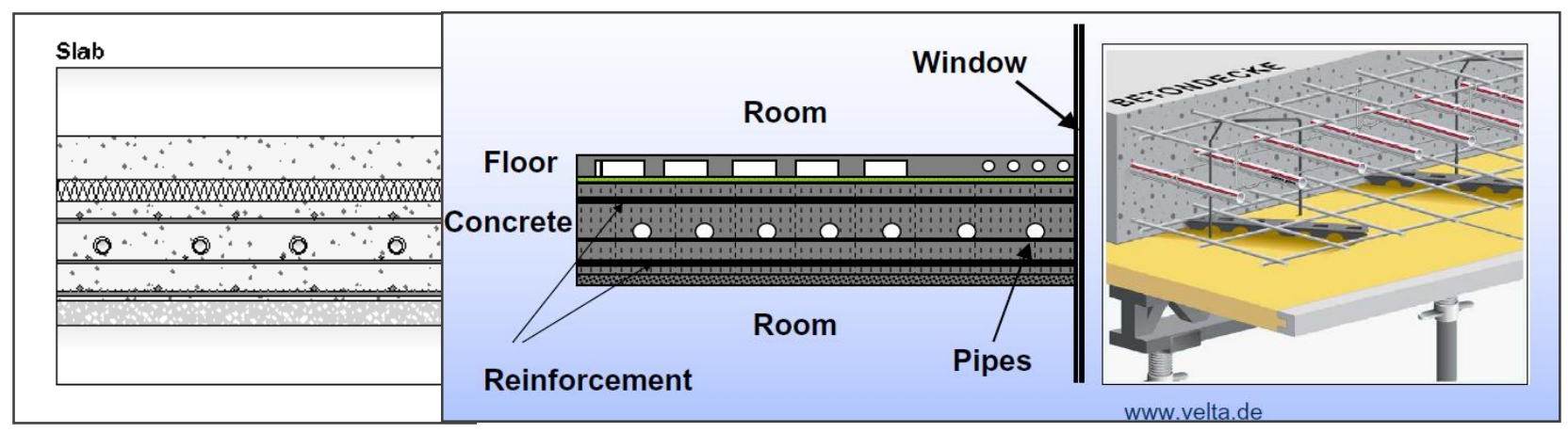

Figura 2.2- 13. Ejemplos de posicionamiento de tuberías de polietileno en forjados (Olesen, B.W.) [105] y (Kolarik,J.) [70]

En su proceso de ejecución, los intercambiadores tubulares de calor se integran directamente en la masa de hormigón, Se trata de tubos multicapa de polietileno, PE, y aluminio, que se usan como intercambiadores. Los tubos tienen un diámetro de $15 \mathrm{~mm}$ a $20 \mathrm{~mm}$, y se colocan a intervalos entre 10 y 30 centímetros, dentro de las losas, a una altura intermedia, más o menos a la altura de la zona neutra de la losa estructural.
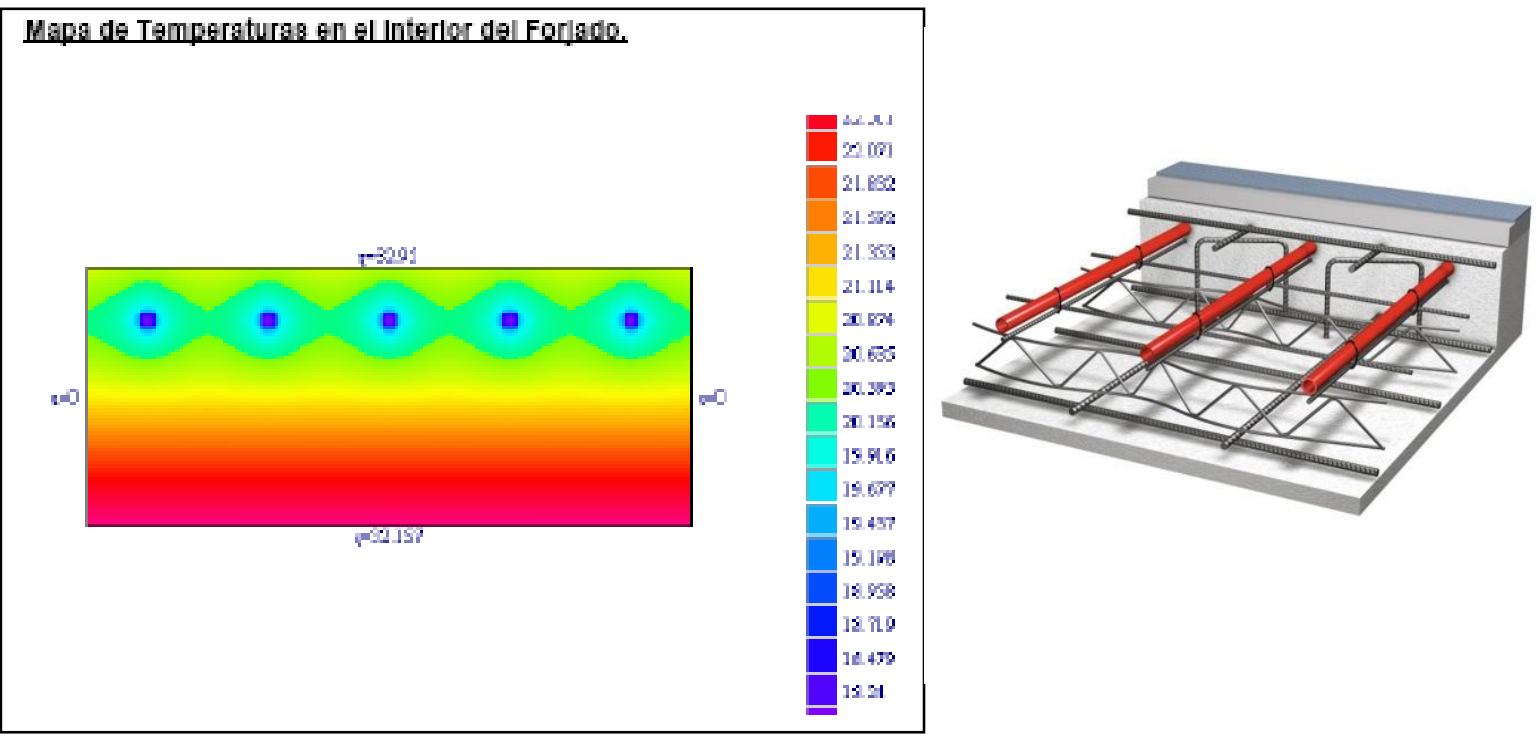

Figura 2.2- 14. Posicionamiento de los tubos de PE dentro de la losa. Fuente:

Eneres.

En los primeros edificios en los que se incorporó este sistema en Suiza las tuberias para la circulación del fluido caloportador eran metálicas, con los consiguientes problemas generados por su soldadura y su curvatura, además de los problemas de condensación durante las operaciones de refrigeración. 
Posteriormente se ha recurrido al uso de tubos PE-Xa herméticos a la difusión del oxígeno. Por ellos circula el fluido caloportador que conduce la energía a los distintos recintos. (Muñoz, D., et al.) [96]

Como la mayoría del intercambio se realiza a través del techo, sobre $2 / 3$, y no a través del suelo, 1/3, los tubos también se pueden desplazar cerca de las superficies del techo, que son más efectivas en la transferencia térmica.

En función de la posición de los intercambiadores, y de la posición en que están dentro de las losas, se puede realizar distintas variantes de intercambio térmico en distintos momentos. Es muy importante que los acabados y revestimientos de los techos y suelos estén resueltos con materiales y soluciones que no comprometan la transferencia térmica.

Al contrario de lo que sucede con los sistemas de climatización por suelo radiante, en el caso de los sistemas termoactivos, la instalación de los circuitos de intercambio tubulares se integra en el proceso de ejecución de la estructura, armado, encofrado, y vertido del hormigón. Esto requiere de una cuidadosa planificación e integración en el diseño estructural, para evitar afecciones estructurales de áreas, particularmente, con mucha tensión en el entorno de pilares y patios.

Antes de ser embebidos en las losas y forjados, los tubos se revisan para detectar pérdidas mediante inspección visual y puesta a presión. Los tubos deben ser colocados cuidadosamente para evitar daños y posteriores reparaciones. La experiencia demuestra que los retrasos en el proceso de construcción se pueden evitar mediante medidas apropiadas y con la presencia de suministradores expertos en estos sistemas.

En el caso de los forjados termoactivos la tubería de polietileno reticulado se coloca entre las armaduras de las losas de hormigón armado. Habitualmente se suministra pre montada, según diseño, sobre unas mallas metálicas que se integran entre las armaduras estructurales. Por estos circuitos circula el agua que es el medio de transferencia de calor que transporta la energía al interior del edificio. Con esta tecnología se aprovecha la capacidad de almacenaje de calor del hormigón, que es ideal para amortiguar las cargas de calor y frío. 


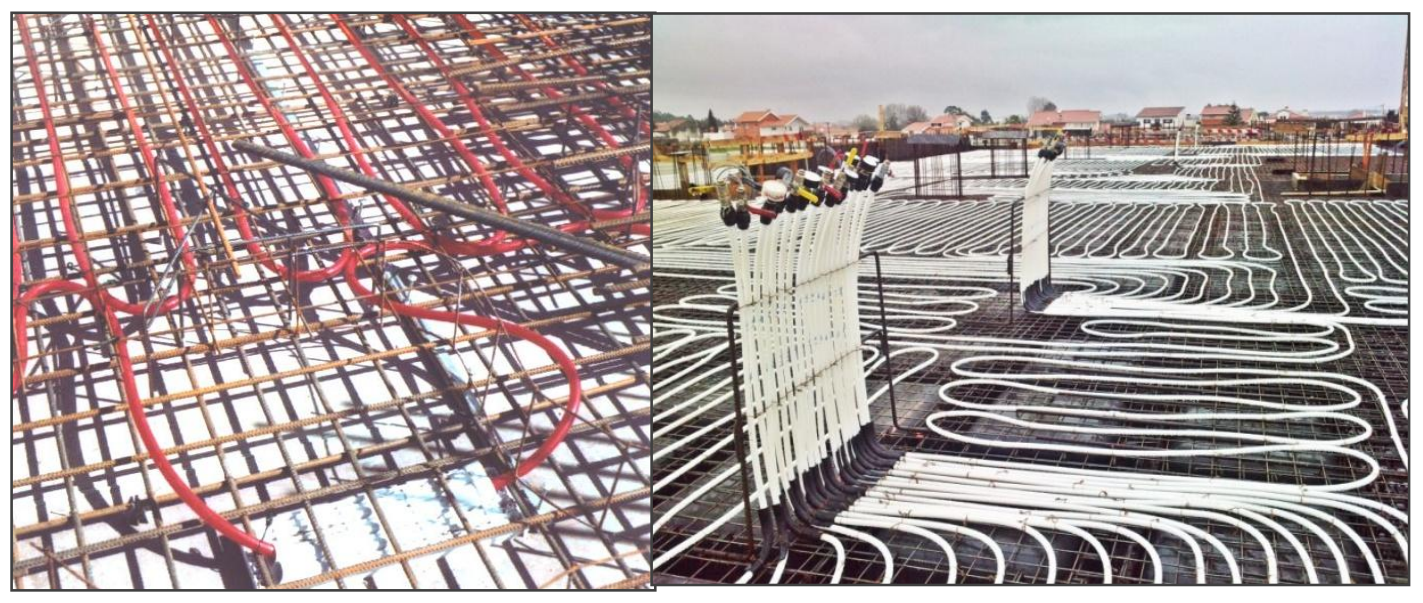

Figura 2.2- 15. Ejecución forjados termoactivos. Fuente: Uponor.

Cuando el forjado termoactivo se utiliza en modo refrigeración se precisa un conocimiento más preciso de la demanda energética del edificio, y un control más exhaustivo de la temperaturas, ya que las necesidades de refrigeración del edificio varían más a lo largo del día que las necesidades de calefacción, sufriendo más picos de demanda imprevistos (Rijksen, D.O., et al.) [116]. Además, el control de la humedad puede limitar la capacidad de refrigeración del sistema por motivo de condensación. (Minarova, M.) [92]

Los principales beneficios de este sistema, además de no requerir un gran sistema de ventilación, y permitir la utilización de energías renovables, por operar en rangos de temperatura moderados, derivan de que evita la necesidad de utilizar falsos techos: reduce las instalaciones de refrigeración, ya que el uso de la inercia térmica de la masa del hormigón, aminora las cargas térmicas puntuales, consigue un ambiente de confort en las estancias debido al reparto uniforme de la temperatura, permite el enfriamiento pasivo o "free-cooling" durante la noche, sin necesidad de utilizar la bomba de calor y, en caso de edificios con demandas energéticas de climatización de entre 40 y $50 \mathrm{~W} / \mathrm{m}^{2}$, no requiere instalaciones adicionales de climatización. (Lehmann B., et al.) [80] 
Se ha hallado estudios destinados a realizar un control y monitorización de las distintas temperaturas que se alcanzan en las estancias climatizadas con estos sistemas como el RC-model (Varming, N., et al.) [130], o mediciones realizadas en la propia estructura de hormigón armado del forjado, a distintas cotas, y de las temperaturas de ida y retorno del fuido caloportador, por medio del programa de medición FEM. (Weber, T., et al.) [133].

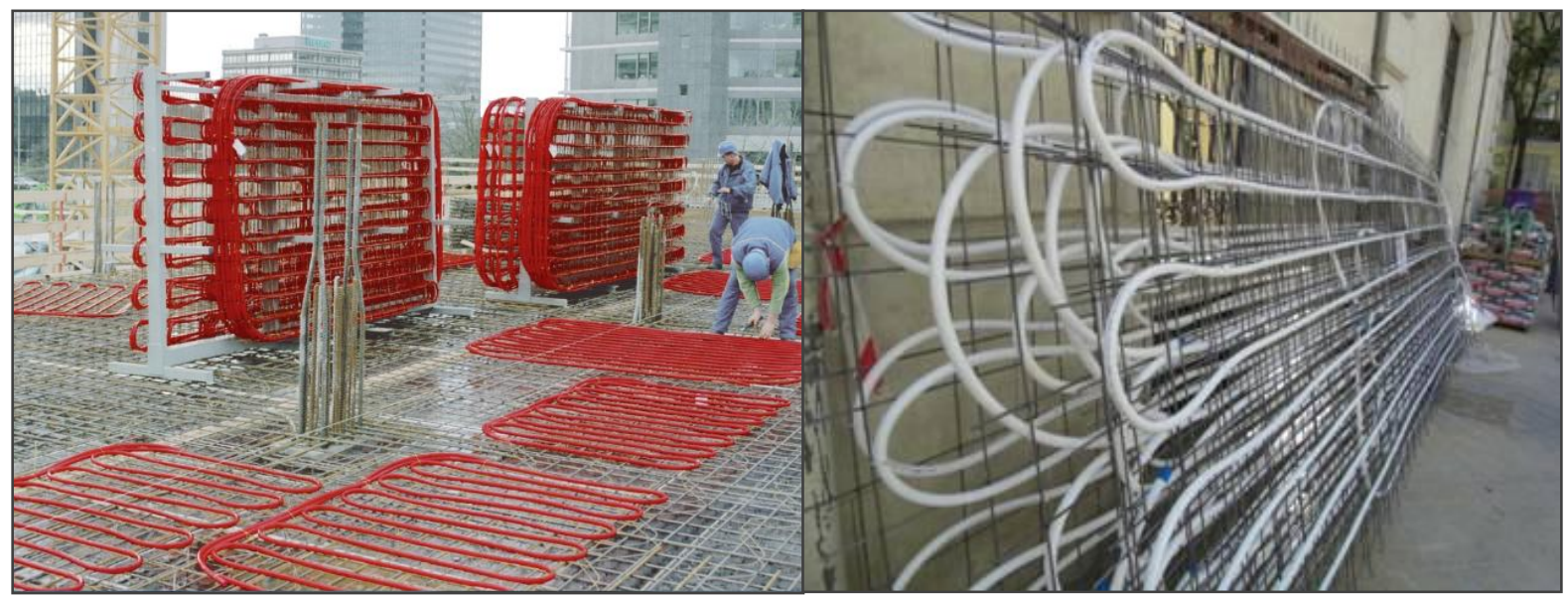

Figura 2.2- 16. Ejecución muros termoactivos. Fuente: Rehau.

La construcción de losas termoactivas es posible no sólo en procesos de nueva edificación sino también en procesos de rehabilitación, potenciando la capacidad inercial de los forjados al dotarlos de circuitos de intercambio y sistemas de colectores y control, y hormigonarlos con morteros conductores, de forma que quedan solidariamente integradosa la estructura original en $5 \mathrm{~cm}$ ó $7 \mathrm{~cm}$ de masa.

Del mismo modo que la prefabricación resuelve de manera práctica la ejecución de cimentaciones termoactivas, podemos encontrar componentes estructurales termoactivos preindustrializados, prelosas termoactivas dotadas en su cara inferior con circuitos de intercambio embebidos, y conectores en el exterior para resolver la conexión entre losas. Estos componentes reducen significativamente los costes y los plazos de ejecución, garantizan unas condiciones óptimas de control de calidad y unos acabados perfectos.

La completa pre industrialización de este elemento constructivo garantiza unos niveles de control de calidad imposibles de implementar en obra para la manipulación del tubo de intercambio, la ejecución de los circuitos, el hormigonado, y los acabados. El sobrecoste de un elemento de este tipo se 
compensa con la reducción de plazos y costes globales que supone y por sus altas prestaciones.

\subsection{Confort térmico.}

El transporte o flujo de energía en forma de calor se denomina generalmente transferencia de calor y tiene lugar siempre que haya una diferencia de temperatura en el medio, o entre dos medios en contacto, terminando cuando el sistema alcanza el equilibrio térmico. El calor puede ser transferido de tres modos: por conducción, por convección, o por radiación, pero en todo caso requieren la existencia de diferencias de temperatura.

La convección es el mecanismo por el que se produce una transmisión de calor debido a los movimientos de la masa de un fluido, ya sea gas o líquido. Al transmitirse la energía entre moléculas en contacto la transferencia es por conducción, pero debida al movimiento de la materia.

Cuando el desplazamiento se produce por causas artificiales, como en el caso de la ventilación mecánica, se trata de convección forzada. Si es consecuencia de causas naturales, como el aire que se enfría al tocar una pared y se mueve hacia el suelo, se denomina convección natural.

La conducción es el método de transferencia de energía entre cuerpos puestos en contacto. La energía se transmite de las moléculas con mayor temperatura a aquellas contiguas con menor energía y con menor temperatura. Este proceso tiene lugar entre sólidos, líquidos, y gases.

La transferencia por conducción de un material de construcción se calcula según la conductividad térmica, $\lambda$, que es la cantidad de energía que atraviesa una superficie de 1 metro cuadrado y 1 metro de espesor cuando la diferencia de temperatura entre las caras es de 1 grado centígrado. A mayor conductividad térmica menor es la resistencia a la transferencia de calor de un material.

La resistencia térmica, $R$, indica la oposición de un material a permitir que el calor fluya en su interior. La transmitancia térmica, $U$, la facilidad de un sistema constructivo formado por capas homogéneas de material para transmitir calor; se calcula mediante la inversa de la resistencia térmica: 
La radiación es la transferencia de calor debido a su temperatura de un cuerpo a otro con el que no está en contacto. La mayor fuente de energía que tenemos en nuestro planeta es el sol, transmitiendo energía, por medio de ondas electromagnéticas, a la superficie de la Tierra, con una variación enorme a lo largo del día.

Las propiedades de los distintos materiales, como son: la capacidad calorifica, entendida como la medida de la cantidad de calor que se necesita para cambiar la tempertura de la materia, y la difusividad y efusividad térmica, son factores fundamentales a tener en cuenta cuando estamos considerando la masa termica de los edificios.

La difusividad térmica representa la rapidez con la que cambia la temperatura de un material expuesto a una fuente de calor, y la difusividad térmica representa la relación entre un cambio brusco de temperatura en una posición determinada y el cambio del flujo de calor en la dirección del mismo. De modo que, un material que tiene una alta conductividad térmica y una capacidad calorífica volumétrica baja tendrá una alta difusividad térmica.

Cuando nos referimos a las cimentaciones termoactivas conviene recordar que el mecanismo de tranferencia de calor entre el subsuelo y las cimentaciones termoactivas es esencialmente conductivo, en mayor o menor medida, en función de las caractrísticas del terreno.

Por el contrario, los sistemas de estrucutras termoactivas del interior del edificio funcionan fundamentalmente por absorción de la radiación, y por convecición producida por las diferencias de temperatura del aire, ofreciendo un gran confort al usuario ya que no se producen las corrientes de aire frecuentes en las instalaciones convencionales de climatización, permitiendo temperaturas muy uniformes, gracias a su capacidad de acumulación y libertad a la hora de configurar los espacios.

El techo y el suelo son las mejores superficies para instalar sistemas termoactivos. En la configuración de refrigeración o absorción de energía las superficies termoactivas absorben las ganancias de calor del espacio. Estas ganancias incluyen las del cuerpo humano, equipos, iluminación, ganancias solares, ganancias a través de la envolvente, y de la ventilación. 
En este proceso, el aire caliente asciende y se produce convección. Adicionalmente el calor radiante de los objetos calientes como cuerpos humanos u ordenadores, se transfiere electromagnéticamente a los paramentos activos debido a su menor temperatura.

El agua del sistema hidrónico captura finalmente ese calor en las superficies termoactivas y lo extrae del espacio y del edificio. En todos los casos, si la temperatura superficial del elemento termoactivo está por debajo de la del aire, el cuerpo, y otros objetos de la habitación, la superficie termoactiva estará absorbiendo y extrayendo aire del espacio. Es importante visualizar que el flujo de calor es siempre desde los objetos con altos niveles de energía térmica hacia aquellos objetos que tienen niveles más bajos de energía.

La humedad de un espacio juega también un importante papel en el confort humano. (De Pereda, L.). En los sistemas de climatización termoactivos se debe considerar la humedad. Desacoplar las cargas térmicas de la humedad y de las necesidades de ventilación supone una reducción muy considerable de las cargas de ventilación que permite reducir equipos, conductos, compuertas, rejillas, etc. En muchos casos esta drástica reducción del sistema de aire, incluido el control de la humedad y la ventilación, supone una liberación de espacio y una reducción de costes de implantación y mantenimiento que, a menudo, compensan el coste de los sistemas termoactivos.

El aire se renueva por razones de salubridad con un régimen que varía según las necesidades vinculadas al uso y la ocupación del edificio. Para asegurar el mínimo gasto de energía en la ventilación el aire de renovación puede ser pretratado, enfriado, o calentado, mediante un intercambiador tierra-aire. La toma de aire y la expulsión están dotadas de un recuperador de calor para reducir las pérdidas de energía en la ventilación, y sin la necesidad de un sistema adicional para calentar o enfriar el aire en invierno o verano.

En paralelo al sistema de ventilación mecánica, los edificios deben tener ventanas practicables. (De Pereda, L.). Dependiendo del clima y de la época del año, y de las dinámicas locales de la humedad ambiental, es posible que no sea necesaria la ventilación mecánica en buena parte del año.

En todo proyecto de edificación debe elegirse el sistema completo más interesante en función del uso que se le vaya a dar al edificio, de las fuentes de 
energía apropiadas, de los elementos de distribución concordantes a esas fuentes de energía y, por lo tanto, de los elementos terminales que sean capaces de sacar el máximo rendimiento o mínimo consumo energético de las fuentes de energía que vayan a alimentar a esos elementos terminales.

Las energías de baja o media temperatura requieren sistemas de distribución de la energía térmica dentro del edificio que requieran una baja temperatura de impulsión, por eso el sistema más adecuado es la radiación.

Por otro lado, si atendemos a párametros razonables para el confort y el bienestar térmico, el $50 \%$ del del intercambio térmico producido entre el cuerpo y el entorno se produce por medio de radiación,

Para calcular el rendimiento y el confort térmico se utiliza la temperatura operativa, como promedio de varias temperaturas radiantes del aire y del medio, y otros aspectos como: la humedad relativa, la velocidad del aire, la acitvidad metabólica, y el grado de vestimenta.

La humedad juega también un importante papel en el confort humano, y aunque los dispositivos termoactivos se integran en sistemas que tienen por objeto asegurar el confort higrotérmico en el edificio, no contribuyen a mantener la calidad del aire interior, ni al control de la humedad.

Esto requiere desagregar los sistemas de aire de la climatización de edificio, de modo que se combaten las cargas sensibles con los elementos de radiación termoactivos, y se combate parte de la carga latente, la renovación del aire, y el grado de humedad con aquellos equipos de acondicionamiento de aire que funcionan por convección.

Esta separación, supone una reducción muy considerable de las cargas de ventilación que permite reducir equipos, conductos, compuertas, rejillas, etc. Y por otro lado, como por razones de salubridad, es necesario renovar el aire del edificio en función de su uso y de su intensidad de ocupación, para asegurar el mínimo gasto de energía en la ventilación, el aire de renovación puede ser pretratado.

Y esta es otra de las funciones de esta tecnología, ya que mediante un intercambiador tierra-aire, se puede pretratar el aire de renovación, enfriandolo o calentandolo, evitando necesitar un sistema adicional para calentar o enfriar el aire en invierno o verano. 
No obstante, en paralelo al sistema de ventilación mecánica, siempre es recomendable que los edificios cuenten con ventanas practicables, ya que, dependiendo del clima, de la época del año y de la humedad ambiental, es posible que no sea necesaria la ventilación mecánica en buena parte del año.

\subsection{Sistemas pasivos de calefacción y refrigeración: inercia térmica y enfriamiento gratuito.}

Las estrategias para conseguir edificios con un menor consumo energético requieren una reducción de las demandas pasivas (eliminando puentes térmicos, aprovechando el aporte solar, y mejorando el aislamiento), y de las demandas activas (con instalaciones más eficientes, y mayor concienciación energética por parte del usuario), y, a la vez, potenciar el uso de energías renovables y recursos desperdiciados de baja temperatura.

Dentro de las estrategias a seguir para reducir la demanda pasiva hay que tener en cuenta la conservación de la energía, que requiere la eliminación de puentes térmicos e infiltraciones y el aumento del aislamiento térmico; la acumulación de energía, mediante la inercia térmica de los materiales y acumuladores, ayudados en ocasiones por la ventilación natural y cuando sea necesario por la ventilación mecánica; la distribución de la energía, evitando el sobrecalentamiento y enfriamiento entre las distintas estancias de una misma vivienda; y el aprovechamiento solar, a través de su captación, o protección en su caso, para evitar sobrecalentamiento y controlar la iluminación natural.

Por lo tanto, una cuidadosa combinación de estrategias que incorporen un buen aislamiento y control solar, capacidad de almacenamiento térmico en el edificio, y estanqueidad en la envolvente, vinculada a la renovación de aire y a la recuperación de energía, garantizará el diseño de edificios en los que se obtiene un elevado confort interior evitando costosas inversiones en equipamiento.

El motivo por el que estos sistemas garantizan una importantísima eficiencia en la capacidad de gestión térmica del edificio se basa en que son recursos inerciales de almacenamiento de calor con capacidad de transferencia muy variable, en periodos cortos, diarios, o largos, y estacionales. 
Además, la utilización de recursos de refrigeración pasiva en verano, abandonando el enfriamiento activo, al que se recurre cada vez más influenciado por los diseños de la envolvente de los edificios, solo es posible si los edificios son concebidos para que el diseño estructural, las necesidades de los ocupantes, y el equipamiento técnico formen parte de un sistema integrado de gestión de la energía.

El creciente aumento en el uso de aparatos eléctricos en las oficinas, las extensas superficies de vidrio en las fachadas, y el perfeccionamiento del aislamiento térmico de los edificios permiten prever en el futuro un empleo cada vez mayor del aire acondicionado. Y con este aumento será también cada vez más importante el acoplamiento al suelo de la masa del edificio.

Y si el sistema de obtención y aprovechamiento de energía se utiliza tanto para la calefacción como para el aire acondicionado del edificio los costes de inversión y los costes operativos se reducen notablemente, ya que la refrigeración de origen terrestre casi no supone gasto alguno. El potencial energético se eleva debido a que la calefacción con bomba térmica enfría el suelo.

Conceptos como el free cooling pueden llevar a cabo en algunos periodos intermedios, primavera y otoño, en los que las temperaturas del terreno pasan por una fase muy próxima a las temperaturas de servicio del agua en los forjados del edificio.

\subsection{Sistemas hidrónicos.}

En los sistemas de climatización por aire el flujo convectivo, en torno a los usuarios y a los equipos, puede hacer impredecible e ineficiente la transferencia de aire y de calor. Esto es así incluso en el más pequeño de los espacios climatizados por aire. En cambio, las superficies termoactivas permiten lograr un medio térmico mucho más equilibrado.

Los sistemas estructurales termoactivos están considerandos, junto a otros sitemas de radiación, como elementos de calefacción y de refrigeración hidrónicos.

Hay una distinción conceptual muy importante entre estos dos modelos de climatización. En un sistema basado en el aire el objetivo es climatizar el volumen de aire que está dentro del espacio para desplazar las temperaturas superficiales 
del espacio y para intercambiar calor con el cuerpo por medio del flujo convectivo. En un sistema termoactivo, hidrónico, basado en la circulación de agua, el reto es intercambiar energía a través de las superficies que delimitan el espacio. Las superficies termoactivas no enfrían el espacio, más bien impiden que se vaya calentando. Si un edificio no se sobrecalienta no necesita ser refrigerado. Es un cambio de concepto en las teorías de climatización.

La eficiencia termodinámica del agua y el aire, como mecanismos para la captura y canalización de la energía, trasciende los factores fisiológicos porque, al ser el agua 832 veces más densa que el aire, los sistemas hidrónicos requieren una fracción del volumen que ocupan los sistemas térmicos basados en el aire. Gracias a la densidad del agua la energía consumida en bombear agua en un sistema hidrónico es menos que la consumida por los ventiladores que mueven la misma cantidad de energía a través de sistemas de aire forzado.

No sólo se recupera espacio, se gana en flexibilidad y se minimizan los problemas de coordinación y uso del espacio por parte de los sistemas y redes de instalaciones. En muchas ocasiones estos ahorros de espacio resultan: en aumentar la superficie útil de los edificios, reducir el volumen al integrar los sistemas de clima en las losas, y reducir el peso y cantidad de materiales y las cargas estructurales. (De Pereda. L)

\subsubsection{Funcionamiento conjunto, en el edificio, de cimentaciones termoactivas y estructuras termoactivas.}

La interacción entre las cimentaciones termoactivas y las estructuras termoactivas o TABS, para la climatización, tiene lugar dentro de la estructura del edificio como un proceso distribuido de generación y uso eficiente de energía térmica, que en su mayor parte se produce en el propio edificio.

El intercambio de calor estacional entre el edificio y el terreno o entre el terreno y el edificio, funciona transfiriendo calor de un ámbito al otro mediante el intercambio entre circuitos por los que circula el agua que porta el calor. El diseño de los sistemas termoactivos se orienta hacia el equilibrio en el intercambio, de modo que se reduzcan las pérdidas en la transferencia de la energía captada y 
almacenada, y que la energía se transfiera entre el terreno y el edificio con el menor consumo de energía primaria posible.

El factor que de entrada las hace eficientes es que se perfeccionan al activar el potencial térmico de elementos estructurales inerciales que ya existen, y que pueden además realizar una importante función termodinámica.

El sistema consiste en dotar, por un lado, a los elementos estructurales en contacto con el terreno, muros, pantallas, o pilotes, de circuitos cerrados por los que circula un fluido que cede o absorbe calor a un terreno respectivamente más frío o caliente, y lo transporta hasta un intercambiador donde este calor absorbido y transportado se transfiere al agua que circula por otros circuitos que, embebidos en las estructuras que están en contacto con espacios habitados, forjados, losas, muros o vigas, transfieren el calor a un espacio más frío o absorbe calor de un espacio más caliente.

El funcionamiento este sistema consta de tres fases fundamentales: una fase de carga en la que las estructuras, a menudo losas o forjados del edificio, están cargadas de energía para la calefacción o refrigeración a través del fluido que circula por ellos, de modo que, controlado activamente la variación de la temperatura del agua, su caudal, y el tiempo de intercambio, la losa adquiere la capacidad de refrigerar o calefactar.

Gracias a la inercia del sistema, el reto es almacenar suficiente energía en las losas para satisfacer la demanda del día siguiente. De hecho, como puede haber fluctuación en la demanda prevista para el día siguiente, el sistema debe operar mediante la gestión de las reservas de energía en las losas, para evitar los desfases térmicos y los posibles sobre calentamientos y sobre enfriamientos de los distintos espacios.

La segunda fase es la de almacenamiento, que permite salvar el desfase temporal entre la disponibilidad de energía y la demanda de energía. El exceso de calor diurno, procedente de la exposición solar o del calor de los usuarios y de los equipos, denominados habitualmente cargas internas, se transforman inmediatamente en recursos almacenados en los forjados y hace que la temperatura de la masa del edificio se eleve. Al hacerlo también se eleva la temperatura operativa de la habitación, aunque moderada por la masa inercial. A modo de ejemplo, el calentamiento o enfriamiento en $2^{\circ} \mathrm{C}$ de una losa de $14 \mathrm{~cm}$ de 
hormigón, supone el almacenamiento de 190Wh/m2 de calor o frío y, por ejemplo, una capacidad de intercambio de $25 \mathrm{w} / \mathrm{m} 2$, disponible durante 8 horas. (De Pereda, L.)

La tercera y última fase es la de descarga, que se realiza de un modo pasivo gracias a la inercia del sistema y parcialmente de un modo activo en la interacción radiante entre las losas y los usuarios, de modo que el $60 \%$ del calor almacenado en la masa de hormigón se transfiere por radiación en la habitación y el 40\% por convección.

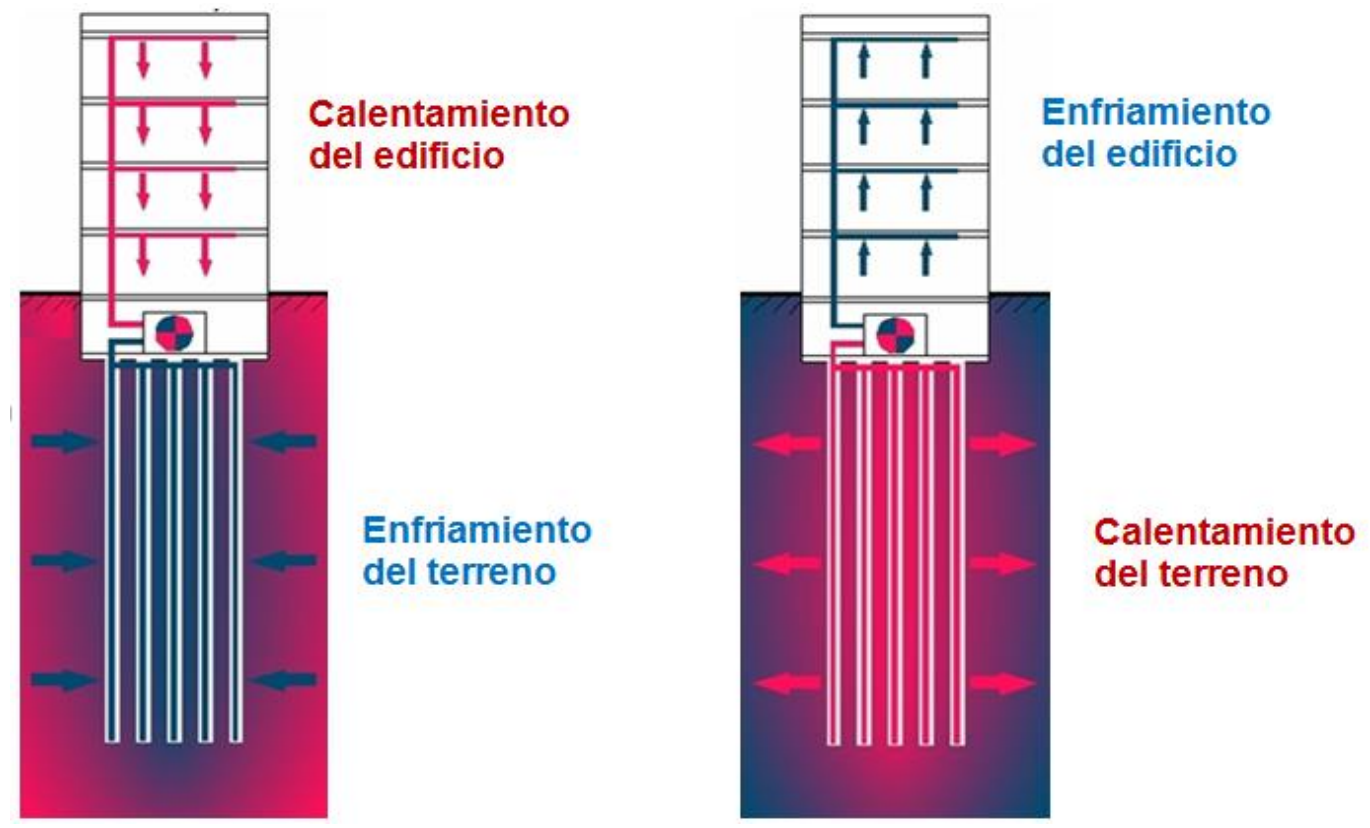

Figura 2.2- 17. Intercambio térmico entre el interior del edificio y el terreno a través de estructuras termoactivas. Fuente: Eneres. 
Simulation: Apolonio Morales

energy piles: 6 drillings á $100 \mathrm{~m}+23$ piles á $10 \mathrm{~m}$ period under review: 5 th year of operation

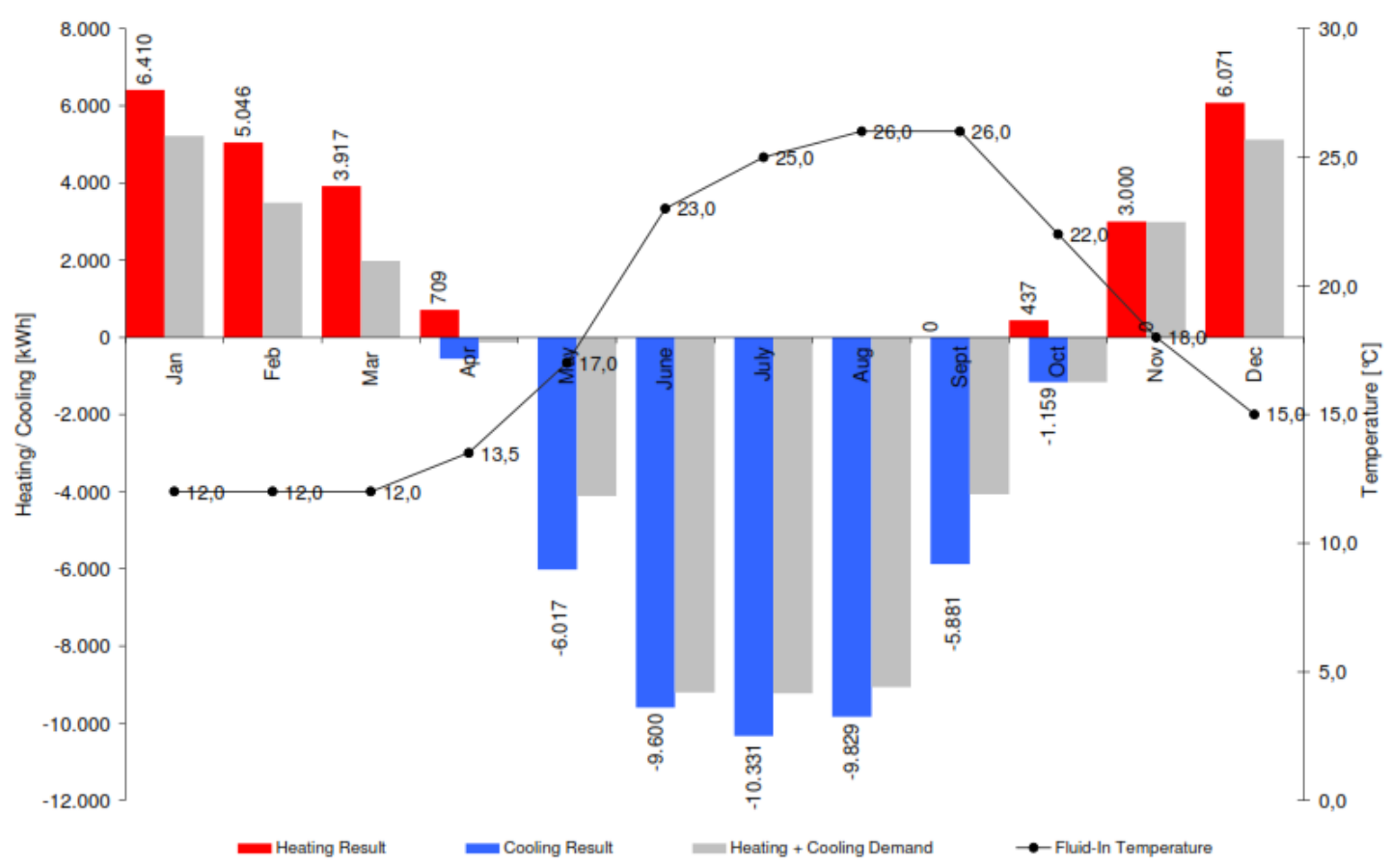

Figura 2.2- 18. Curva de adecuación instantánea de la demanda energética a la generación producida por el intercambio geotérmico. Fuente: Eneres.

Los sistemas termoactivos se integran de manera equilibrada para obtener todo el rendimiento posible, funcionando en rangos de temperatura armonizados entre el espacio a climatizar $\left(20^{\circ} \mathrm{C}\right.$ a $\left.25^{\circ} \mathrm{C}\right)$, los sistemas de climatización termoactivos $\left(18^{\circ} \mathrm{C}\right.$ a $30^{\circ} \mathrm{C}$, y el terreno en el intercambio geotérmico $\left(10^{\circ} \mathrm{C}\right.$ a $\left.30^{\circ} \mathrm{C}\right)$.

Realmente, para igualar la temperatura del sistema de intercambio geotérmico a la temperatura del fluido en la estructura del edificio se requiere muy poca energía primaria, y el uso de la bomba de calor geotérmica reversible y válida para calefacción y refrigeración consigue unos coeficientes de rendimiento muy elevados, manteniendo un equilibrio perfecto durante todo el año y durante todo el ciclo de vida del edificio. 

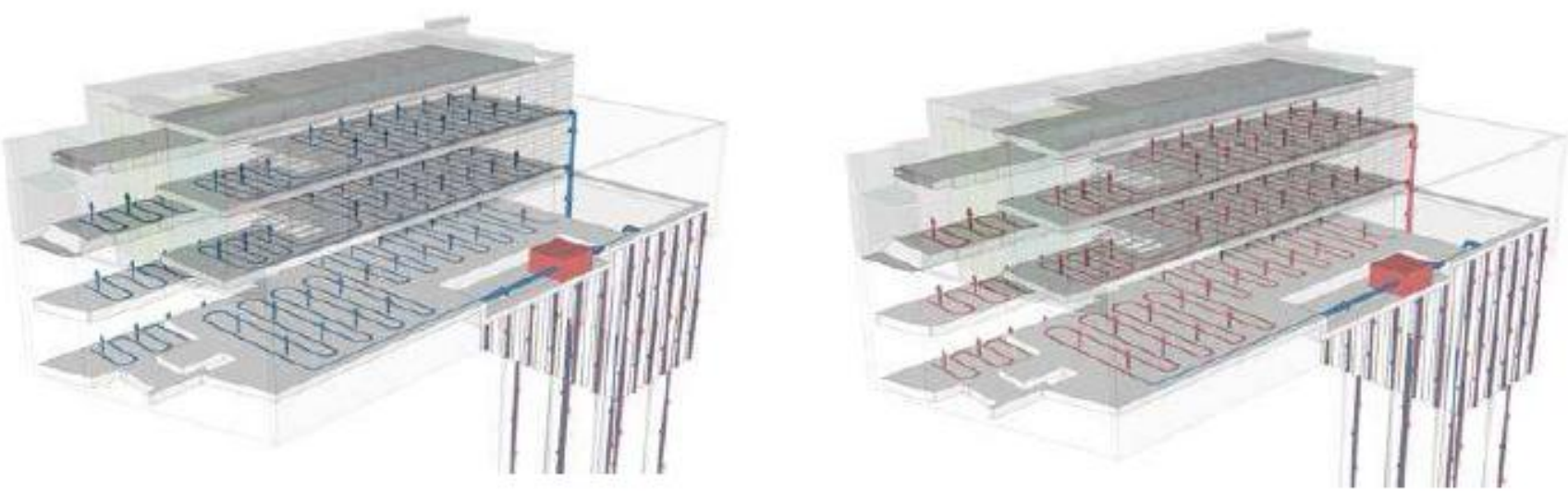

Figura 2.2- 19. Estructura termoactiva y cimentación termoactiva. Edificio $\mathrm{C} /$ Apolonio Morales. Arquitectos Luis de Pereda y Manuel Mallo. (ENERES)

\subsection{Bomba de calor geotérmica.}

Por su principio de funcionamiento, la bomba de calor geotérmica es simplemente una bomba de calor que transfiere calor desde el edificio al terreno y viceversa. Ello posibilita una menor demanda de energía primaria por parte del compresor, que puede ser eléctrico o de gas, debido a que, en muchos momentos, el suelo posee condiciones de temperatura más favorables que el aire.

Otras de sus ventajas residen en su capacidad de ahorro, de entre el $40 \%$ y el $60 \%$ de la energía primaria que se utiliza en climatización, en eficicencia, por su facilidad de integración, escasa necesidad de mantenimiento y de producción de ruido, y por su capacidad de integrarse con otras fuentes de energía renovable, a las que puede complementar y ayudar en su desarrollo, como los paneles solares térmicos. 


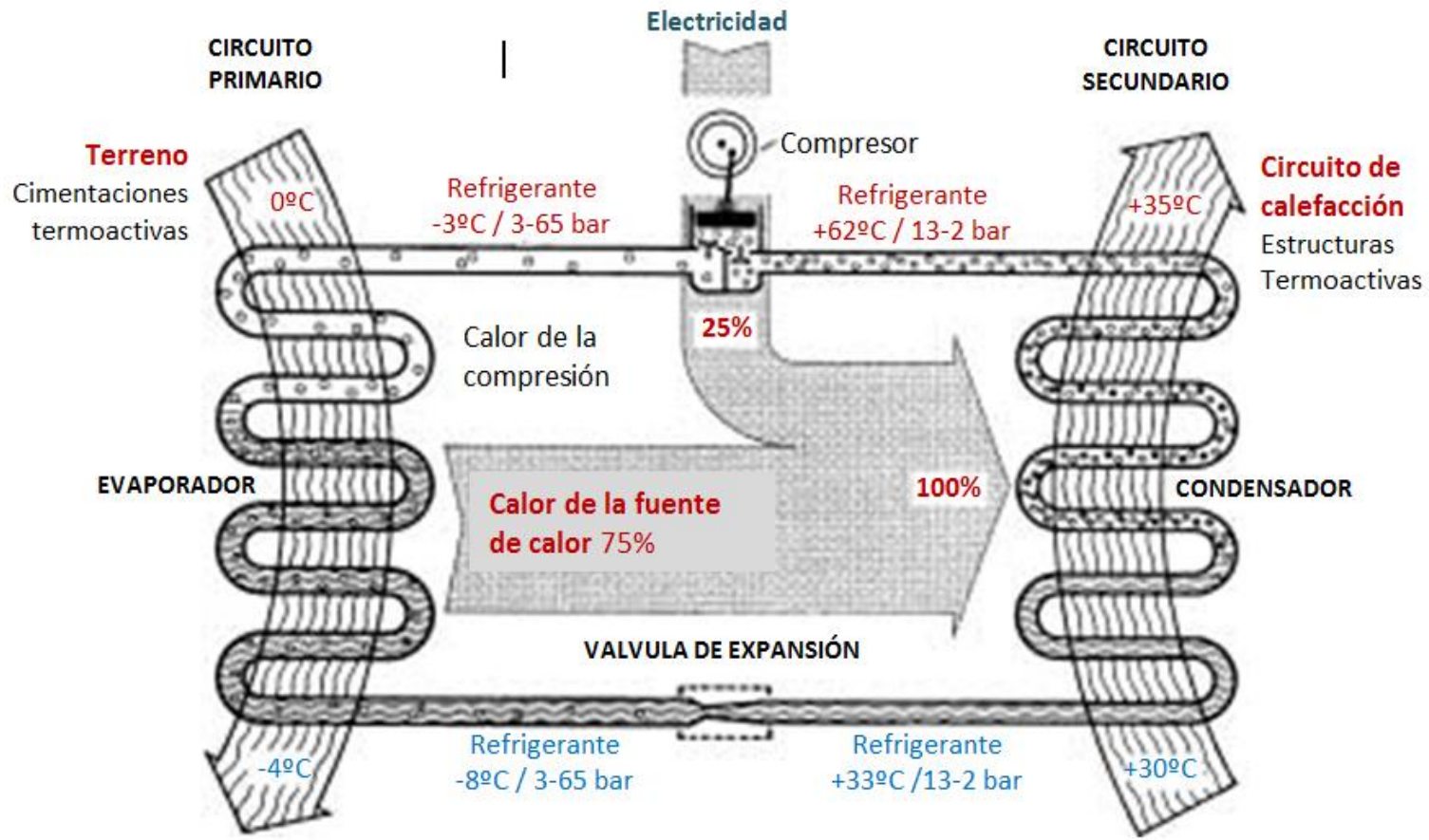

Figura 2.2- 20. Esquema de funcionamiento de la bomba de calor geotérmica.

$$
\text { (Brandl, H.,) [16] }
$$

La eficiencia de la bomba de calor geotérmica está extremadamente influenciada por la diferencia de temperatura entre el circuito primario y el secundario. Esa diferencia variará el COP de la máquina, que por razones económicas debe ser mayor o igual a 4.

Para poder garantizar ese coeficiente de rendimiento de la bomba de calor, la temperatura en el ciruito secundario (interior del edificio) no debe exceder de 35$45^{\circ} \mathrm{C}$, y la temperatura de extracción en el circuito primario (intercambiador geotérmico) no debe ser inferior a $5^{\circ} \mathrm{C}$. Por esta razón, este tipo de tecnología está limitada al uso de sistemas de calefacción y refrigeración a temperaturas moderadas.

Cuando la bomba térmica consume $1 \mathrm{~kW}$ de corriente, se ganan de tres a cuatro kW de energía calorífica para la calefacción. Si, además, la energía eléctrica proviene de una planta hidroeléctrica el impacto ambiental es prácticamente nulo. 
।

Energía externa (electricidad)

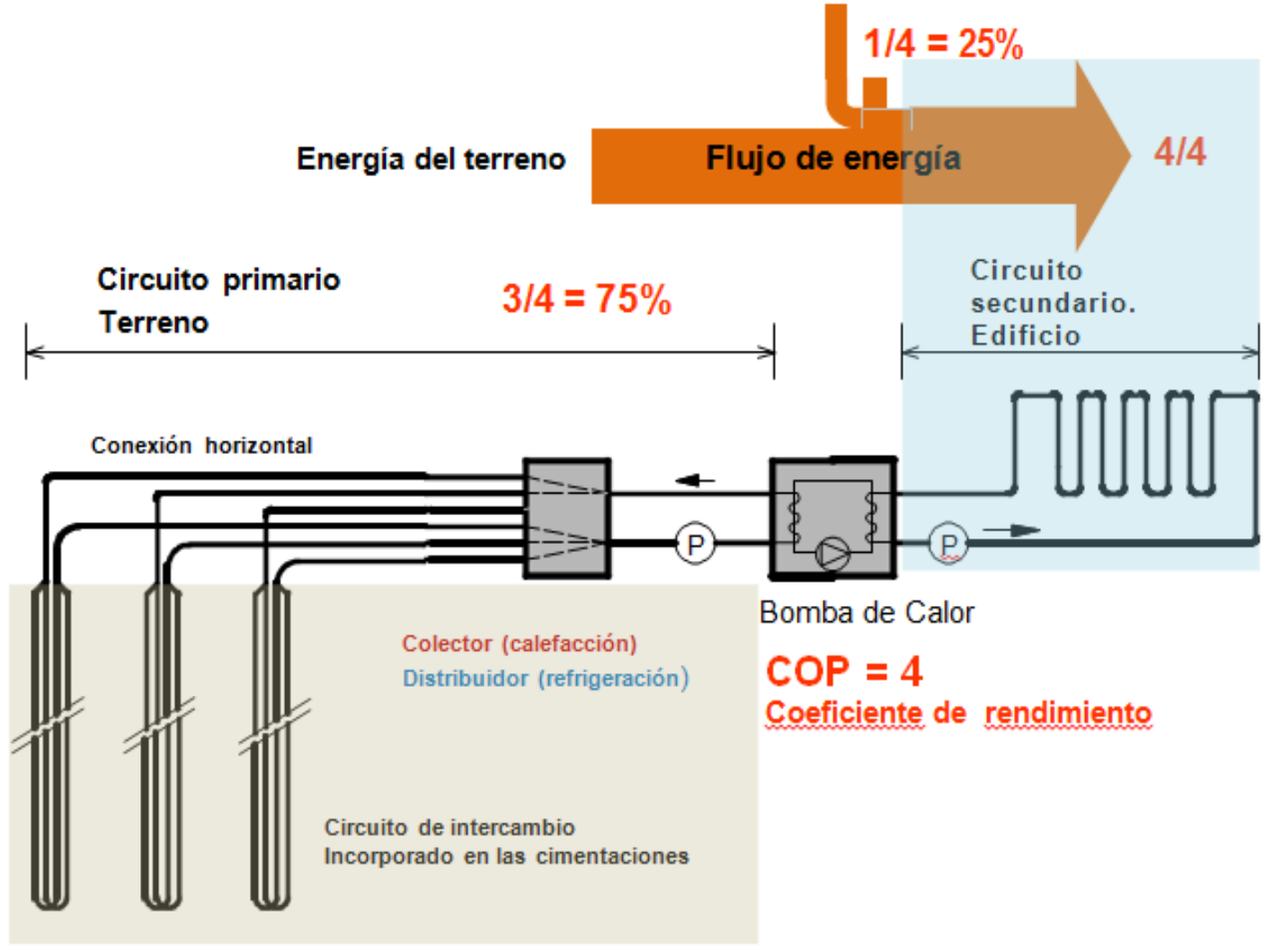

Figura 2.2- 21. Esquema de sistema geotérmico de intercambio con cimentaciones termoactivas y estructuras termoactivas con bomba de calor geotérmica.

(Brandl, H.,) [16] 


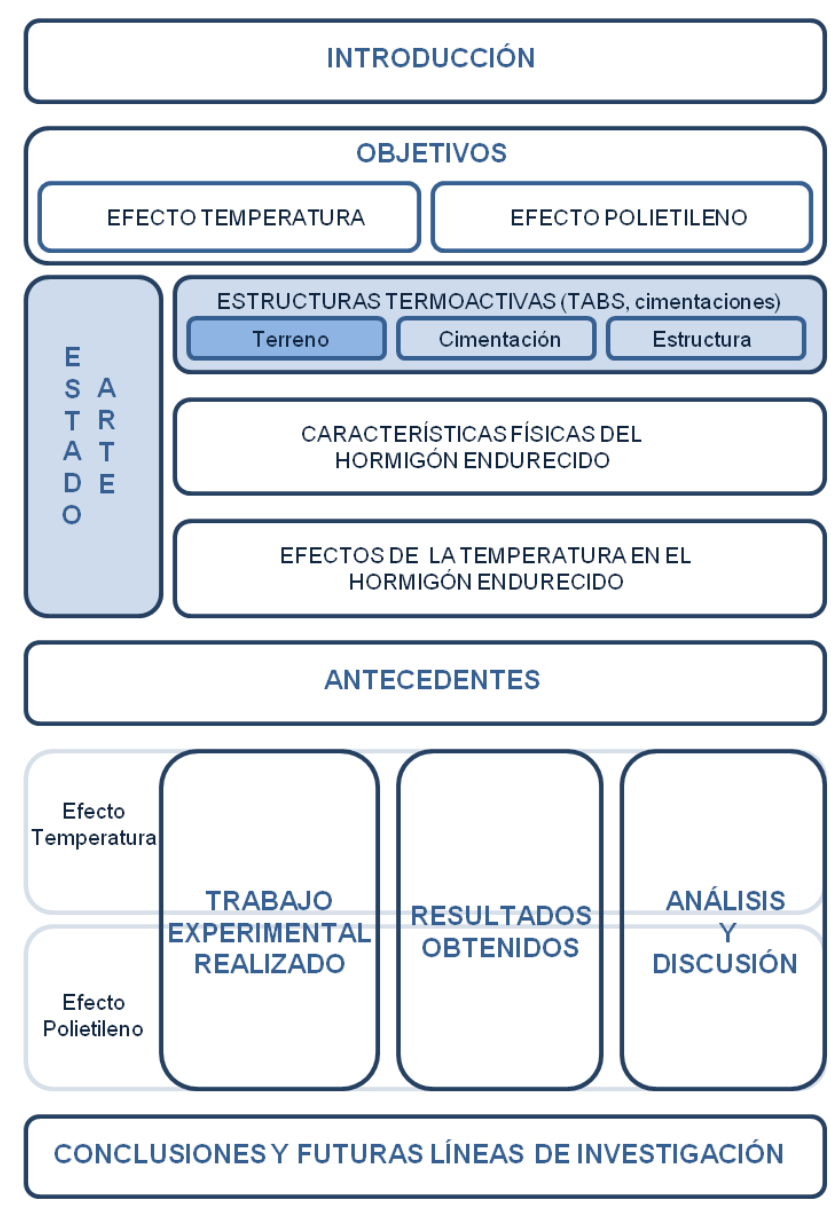

\subsubsection{Impacto de las estructuras termoactivas sobre el comportamiento mecánico de las mismas.}

A pesar de los indudables y numerosos beneficios de las estructuras termoactivas, es necesario analizar el impacto de las estructuras termoactivadas sobre el comportamiento mecánicos de las mismas.

Este análisis se pude realizar a tres niveles: el efecto sobre el terreno, el efecto sobre la cimentacion, y el efecto sobre las losas que constituyen los forjados.

2.2.2.1 Efecto de las estructuras de hormigón armado, utilizadas como elementos termoactivos, sobre el terreno.

El subsuelo puede ser utilizado para almacenar temporalmente calor, o, enfriado, para absorberlo. Éste posee una alta capacidad calorífica y, también, unas buenas propiedades de aislamiento térmico lo que ofrece la 
posibilidad de almacenar grandes cantidades de calor y frio durante un largo periodo de tiempo, por ejemplo, un periodo interestacional completo.

El Almacenamiento subterráneo de energía crea un gran espectro de posibilidades de ahorro energético y aplicación de recursos energéticos renovables, como el almacenamiento de calor procedente de la energía solar en verano para su uso posterior en invierno para calefacción, o el enfriamiento del terreno aprovechando el desfase térmico en el aire exterior entre invierno y verano, o el salto térmico que supone el enfriamiento del aire entre el día y la noche.

Mediante los sistemas de cimentaciones termoactivas se realiza un almacenamiento estacional de frio y de calor. El intercambio de energía térmica puede producirse con el subsuelo o bien con algún acuífero próximo a la superficie. Por el contrario la existencia de flujos de agua o de accidentes geológicos puede transformar al sistema de intercambio en un disipador de energía, algo que en muchas circunstancias pude tener interés.

El objetivo de todo proyecto de cimentación termoactiva y a su vez de toda instalación geotérmica, es la viabilidad del mismo a largo plazo, sin llegar nunca a producir el agotamiento del terreno. De este modo se puede utilizar la cimentación, en invierno, para cubrir una cierta demanda térmica extrayendo calor del terreno y, en verano, con la inversión del ciclo de la bomba de calor geotérmica, refrigerar el edificio, recargando energéticamente el terreno, convirtiendo el subsuelo en un sumidero térmico.

La regeneración es un aspecto muy importante a considerar, ya que se necesita conocer el comportamiento del subsuelo a largo plazo y su influencia en las exigencias que precisa la instalación. En algunos casos se produce una recarga de manera natural gracias al caudal y flujo de las aguas subterráneas, aunque de manera general no se produce la regeneración natural suficiente para garantizar un buen funcionamiento a largo plazo.

Para recargar el terreno se utiliza el principio de obtención de energía geotérmica por almacenamiento estacional. La figura 2.2- 22 es un resumen anual que refleja el principio de la obtención de energía geotérmica por almacenamiento estacional. En las épocas de calor se extrae del suelo frío para la climatización y el 
calor se transmite al suelo. Es decir, se utiliza como acumulador de calor. Cuando hace frío, esa energía acumulada se utiliza para calentar el edificio.

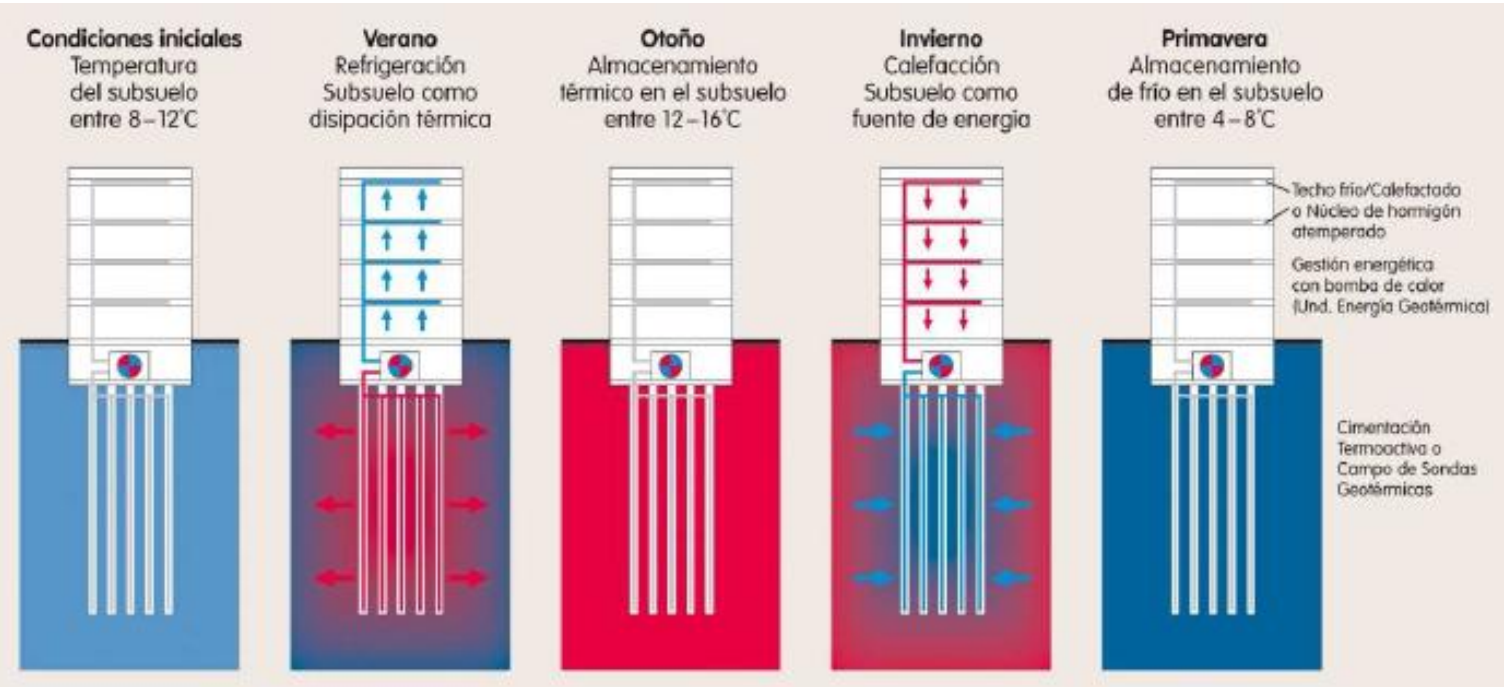

Figura 2.2- 22. Régimen anual de temperatura de una cimentación termoactiva.

(De Isabel, J.A.) [34]

También, debido a las influencias que en el subsuelo pueden ocasionar los pilotes activos en el proceso de extracción calorífica, se puede producir un enfriamiento excesivo del subsuelo que afectaría no solamente al sistema energético, sino que también podría ocasionar daños serios en el sistema de cimentación de la edificación.

Para evitarlo, se recurre a realizar ensayos de respuesta térmica del terreno (TRT), en uno o varios sondeos, antes de perforar el resto. Se inyecta calor de forma contínua al subsuelo, normalmente entre 50 y 60 horas, y se aplican herramientas informáticas de simulación para predecir su comportamiento térmico con el transcurso de los años de utilización del campo de sondas geotérmicas, obteniendo dos de los parámetros decisivos en el dimensionamiento de la cimentación: la conductividad térmica del terreno en $\mathrm{W} / \mathrm{m}^{\circ} \mathrm{K}$ y la temperatura de comienzo en ${ }^{\circ} \mathrm{KW} / \mathrm{m}$.

Se ha realizado estudios para determinar el impacto de las variaciones térmicas sobre el terreno (Abuel-Naga et al.,[3]; Burghignoli et al. [20]; Cekerevac et al., [28] y Hong et al., [61]). 
El impacto de las cargas térmicas sobre la respuesta mecánica del subsuelo también ha sido estudiada, realizándose ensayos gran escala sobre pilotes de cimentación (Brandl [16]; Laloui et al., [76]; Bourne-Webb et al., [15]; Amatya et al., [5]; McCartney et al., [88]) y sobre pantallas de cimentación (Brandl, [16]).

El comportamiento del terreno, antes la inducción térmica que realizan los intercambiadores de la cimentación, es el de un auténtico acumulador inercial en el que el calor queda confinado en un volumen finito, que en términos generales no excede un radio de 6 metros desde el eje del elemento intercambiador, de modo que el intercambio de calor con el edificio crea ciclos de carga y descarga del terreno, que coinciden con la demanda estacional de calor y frío para la climatización.

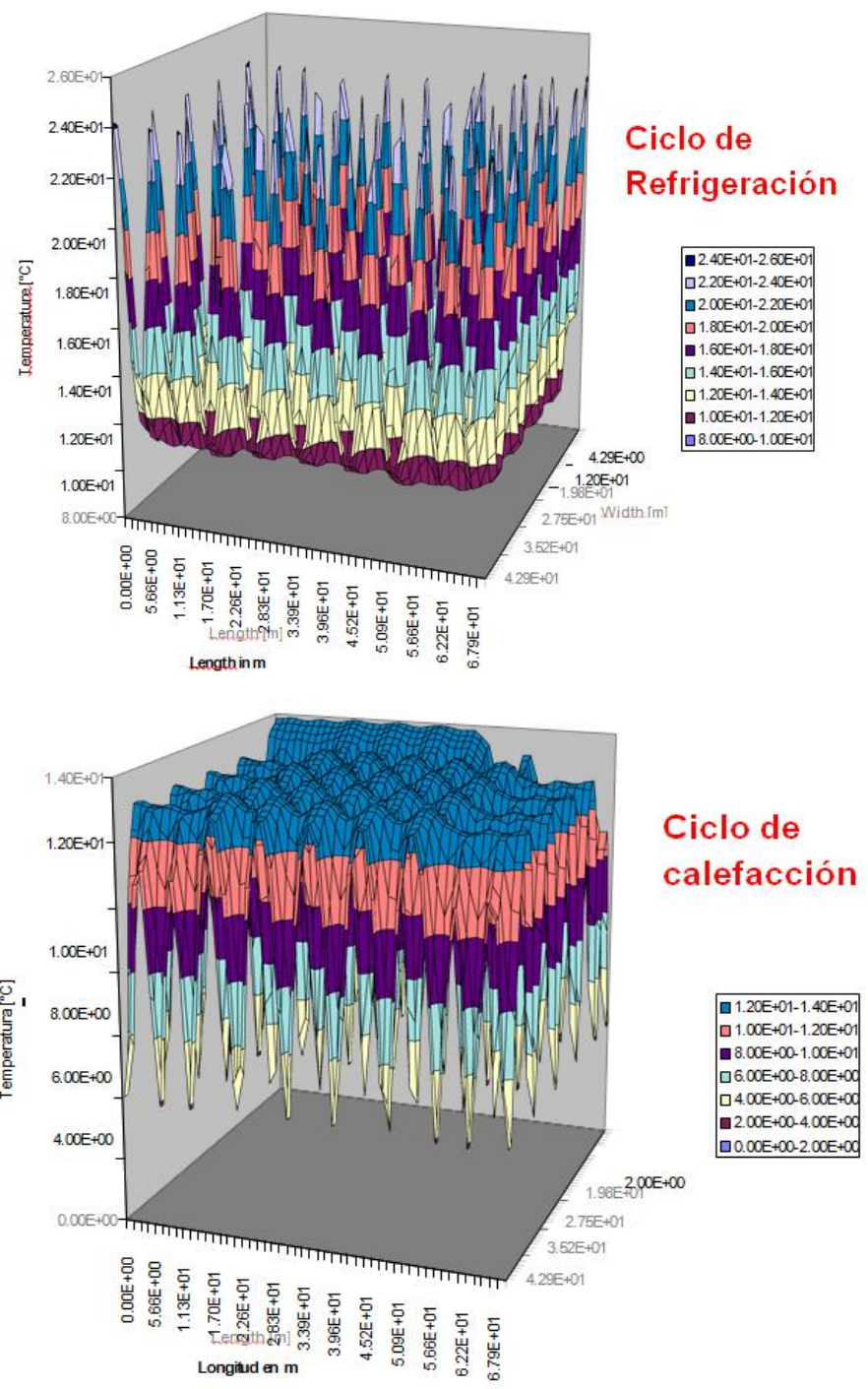

Figura 2.2- 23.

Gráfica tridimensional del campo de temperaturas generadas por un grupo de pilotes termoactivos sobre el terreno en el intercambio térmico con un edificio. Fuente: Eneres/Enercret 


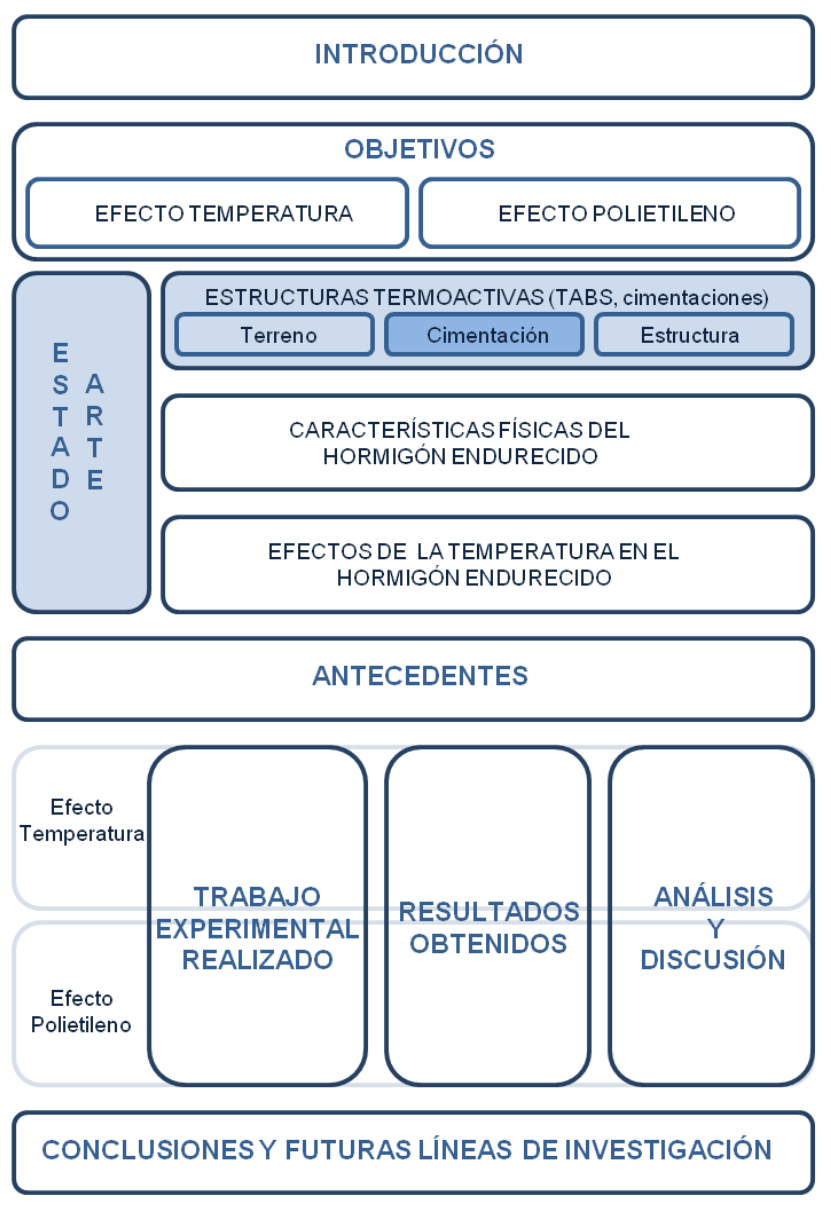

\subsubsection{Efecto de las estructuras de hormigón armado, utilizadas como elementos termoactivos, sobre la cimentación.}

Respecto al efecto que tiene sobre los elementos estructurales de la cimentación el hecho de estar termoactivada y funcionar como un intercambiador geotérmico, se ha estudiado con bastante profundidad en los ensayos a gran escala sobre pilotes y pantallas de cimentación, que tratan de averiguar cuál es la influencia en la interacción del terreno con el elemento estructural del hormigón, provocada por la carga térmica de forma independiente y también por la carga termomecánica, cuando estos elementos están trabajando estructuralmente.

También se ha realizado ensayos a pequeña escala sobre pilotes termoactivados (McCartney et al., [87]; Kalantidou et al. [64]; Stewart et al., [126] y Wang et al.,[131]). 
Y además se ha realizado modelos numéricos que simulan el comportamiento de estas estructuras (Alonso et al., [4]; Gens et al., [57]; Olivella et al., [106]).

En los ensayos realizados para valorar el efecto de la carga térmica sobre los pilotes se estudia cuál es el alargamiento térmico lineal, concluyéndose en los estudios de Amatya et al., [5] que a medida que aumenta la temperatura se produce un mayor alargamiento en la cabeza del pilote que en su punta.

También se analiza la tensión térmica inducida producida por dicha carga térmica, concluyéndose en investigaciones realizadas por Bourne-Webb et al., [15] que los aumentos de tensión térmica inducida son superiores en la punta del pilote que en la cabeza, es decir, en las zonas de menor alargamiento.

Por otro lado, al analizar la resistencia a fricción resultante de la carga térmica, (Brandl, [16]) y Laloui et al., [77], observan que al aumentar la temperatura, aumenta el volumen del pilote, lo que genera una resistencia por fricción negativa en punta y en cabeza.

Estudios de Suryatriyastuti M.E., et al. [127] aportan información sobre el comportamiento de los pilotes termoactivos sometidos a ciclos térmicos y de carga simultáneos. 


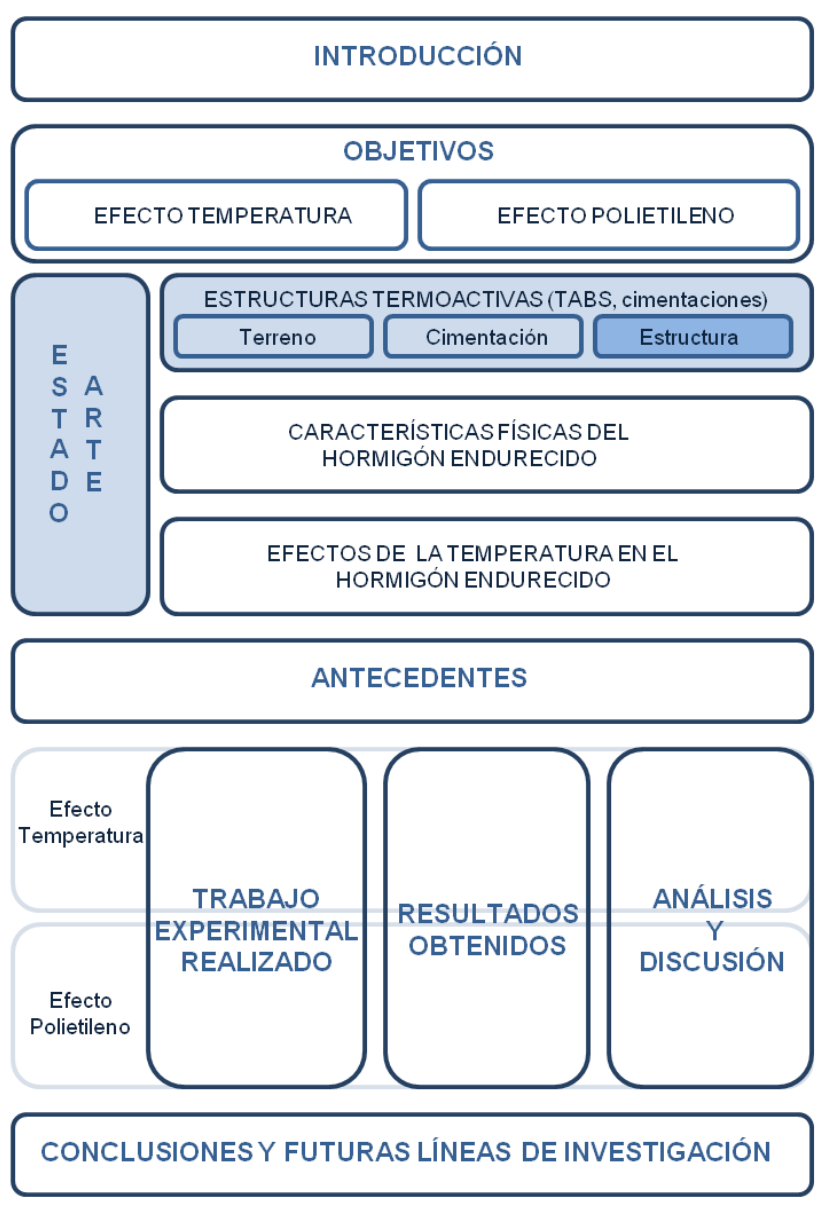

\subsubsection{Efecto de las estructuras de hormigón armado, utilizadas como elementos termoactivos, sobre la estructura del edificio.}

En la revisión bibliográfica efectuada no se han encontrado estudios acerca del efecto de la activación térmica de los forjados de los edificios sobre su comportamiento mecánico.

Sí existe una cantidad importante de estudios sobre los métodos para resolver el proceso de transferencia térmica en los forjados y losas y evaluar térmicamente el edificio que utiliza forjados termoactivos.

Algunas investigaciones se basan en soluciones analíticas para resolver el proceso de transferencia térmica, como los efectuados por Koschenz M., et al [73]. Otras utilizan simulaciones numéricas para resolverlo, como los métodos desarorollados por Koschenz M., et al. [72]. 
Y en tercer lugar se analizan utilizando herramientas de simulación energética de los edificios, como TRNSYS y EnergyPlus, para simular el proceso dinámico de transferencia de calor. (Rijksen D.O., et al.) [115]

Además se han realizado otros estudios de monitorización y simulación para estimar y analizar el confort térmico y el consumo de energía de las estructuras termoactivas del interior del edifico o TABS como los de Park, S.H., et al., [110] y Lim J.H., et al. [83]. 


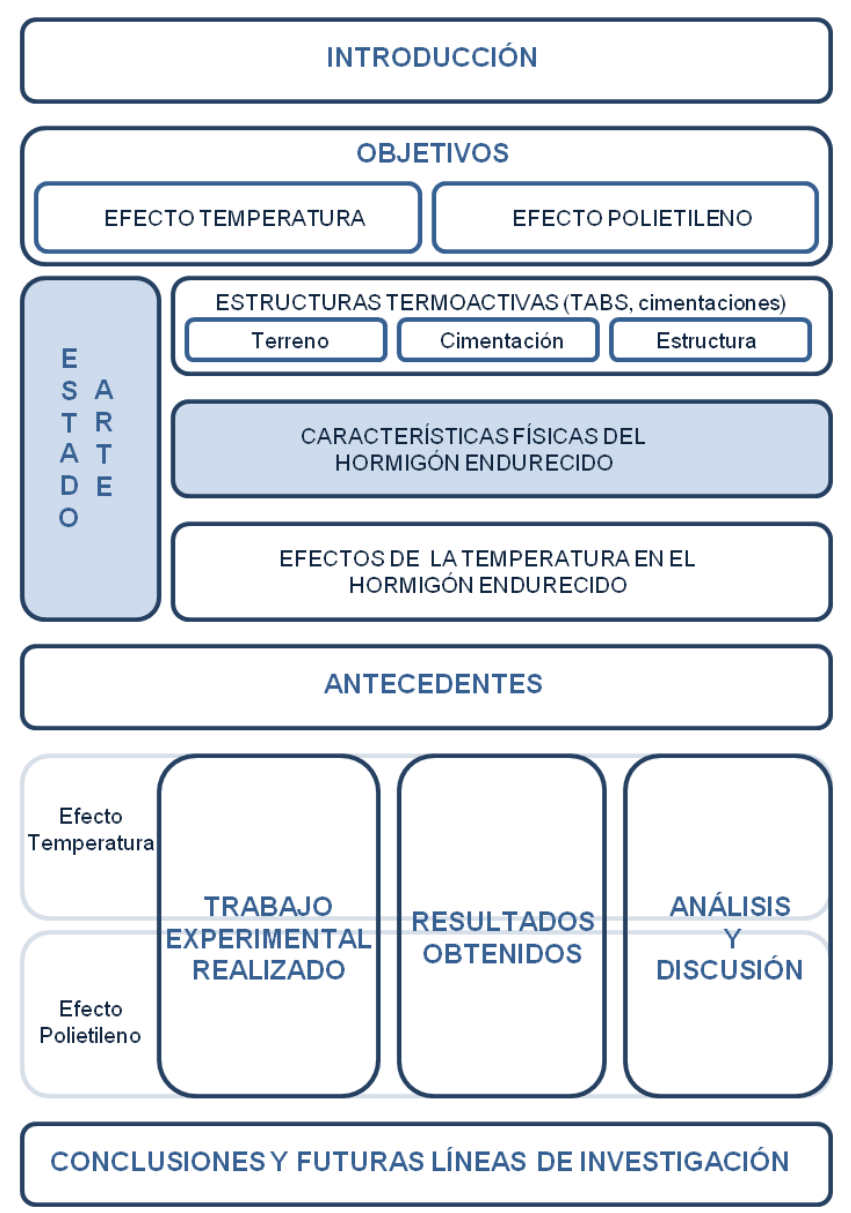

\subsection{Características físicas del hormigón endurecido.}

Existe una serie de factores externos que condicionan las características físicas del hormigón, independientemente de la naturaleza de su composición, como su edad y las condiciones de humedad y temperatura a las que haya estado sometido.

Aunque la característica mecánica que se mide con más frecuencia en los hormigones es la resistencia a compresión, hay casos en los que los elementos estructurales trabajan a flexión y se hace indispensable conocer su resistencia a flexotracción.

Entre los factores más determinantes que condicionan las características físicas del hormigón se encuentran: su densidad, impermeabilidad, compacidad, porosidad y elasticidad. 
Conociendo la densidad de un hormigón se puede averiguar cuál va a ser su comportamiento físico y químico, y su impermeabilidad nos indicará la durabilidad que va a tener el hormigón frente a agresiones físicas y químicas.

Si se lleva a cabo una buena dosificación del hormigón y una adecuada puesta en obra y curado de éste, se puede obtener una compacidad elevada, factor que favorece que la densidad sea superior, indicando que el hormigón posee unas buenas resistencias mecánicas y buena durabilidad.

La densidad, por lo tanto, se verá favorecida por la utilización de áridos muy densos y con granulometrías que aumenten la compacidad del hormigón, por el aumento del grado de compactación o vibrado de éste, y en cambio, se verá desfavorecida por una alta relación agua/cemento y por la utilización de aditivos aireantes, ya que éstos potencian la porosidad y la formación de burbujas de aire en el interior del hormigón.

Se puede utilizar dos vías complementarias para mejorar la impermeabilidad de un hormigón: en primer lugar se puede llevar a cabo procesos de curado húmedo prolongado para que tenga lugar la formación de geles en la matriz del hormigón, y por otro lado se puede reducir la relación agua/cemento, con el fin de reducir su porosidad.

Otra característica que determina la forma de trabajar de las estructuras de hormigón es la elasticidad. Los factores fundamentales para estudiar la elasticidad son: la fluencia del hormigón o deformación que sufre al estar sometido a una carga constante; sus variaciones dimensionales provocados por cambios de temperatura, en relación con sus propiedades térmicas; las retracciones sufridas durante su fraguado $o$ en edades tempranas; 0 el entumecimiento como consecuencia de la absorción de agua.

\subsubsection{Factores que afectan a la resistencia del hormigón.}

La resistencia de un material se define como la capacidad de resistir una tensión determinada sin llegar al fallo mecánico, que en algunas ocasiones se identifica con la aparición de fisuras.

Independientemente, investigaciones realizadas por Calavera, J. et al [22] sobre la microestructura del hormigón muestran que, al contrario que la mayoría de 
los materiales estructurales, el hormigón contiene numerosas pequeñas fisuras incluso antes de ser sometido a tensiones externas.

Por lo tanto, cuando nos referimos al hormigón, la resistencia es la tensión necesaria para causar el fallo mecánico, es decir la máxima tensión que el elemento de hormigón puede resistir.

Cuando se realiza un ensayo de tracción la fractura de la probeta se relaciona normalmente con su colapso; en cambio, en un ensayo a compresión la pieza de hormigón puede haber llegado al colapso sin mostrar signos visuales externos de fisuración, aunque los daños internos ya muestran la imposibilidad de la muestra de ser sometida a más carga.

A la hora de definir un hormigón o de ensayarlo se suele utilizar la resistencia, ya que, comparada con otras propiedades del hormigón, el ensayo de la resistencia es relativamente simple. Es más, muchas otras propiedades del hormigón, como los módulos de elasticidad, estanqueidad al agua 0 impermeabilidad, o la resistencia a los agentes atmosféricos, incluyendo las aguas agresivas, se considera que dependen directamente de la resistencia del hormigón, y pueden deducirse sus valores teniendo los de resistencia.

Es importante conocer la microestructura física del hormigón para poder entender cómo factores externos, entre ellos la temperatura, pueden afectar sobre sus distintos elementos produciendo una degradación del hormigón que tiene como una de sus manifestaciones la pérdida de resistencia mecánica.

El hormigón es un material multifásico constituido de una mezcla de áridos con un conglomerante, la pasta de cemento, que representa del 25 al $40 \%$ del volumen total del hormigón y está a su vez constituida a partir del cemento y el agua. Tanto el cemento como el agua, juegan un papel bien definido, el de ligante hidráulico para la pasta de cemento, y de elemento de relleno que atenúa las variaciones voluminosas y fuente de resistencias para los áridos.

Los áridos ocupan entre el 60 y el $75 \%$ del volumen del hormigón. Se distinguen dos tipos de áridos: la arena o árido fino, cuyas partículas son inferiores a $4 \mathrm{~mm}$, y la grava o árido grueso, que son mayores de $4 \mathrm{~mm}$ de diámetro.

El cemento Portland es un conglomerante hidráulico, es decir, que su endurecimiento resulta de su combinación con el agua. Las cualidades del 
aglomerante son pues dadas a la reacción química entre el cemento y el agua y que es conocida como hidratación.

El agua es un constituyente del hormigón que se encuentra presente física y químicamente. Se pueden distinguir tres tipos de agua: el agua cristalizada, el agua absorbida, estando adherida a los granos del árido y pasta, y el agua capilar o libre que ocupa los macroporos.

La zona de adherencia árido-pasta está constituida de fibras de silicato cálcico hidratado, agujas de etringita, y de plaqueta de hidróxido de calcio orientadas perpendicularmente a la superficie del árido.

Si pasamos a analizar los factores más influyentes que condicionan las características físicas del hormigón, es importante señalar que, en los sólidos existe una relación inversa entre su porosidad, entendida como el volumen de huecos, y su resistencia. Por ese motivo, en materiales compuestos como el hormigón la porosidad de cada uno de los componentes de su microestructura puede limitar su resistencia.

Los áridos que componen el hormigón tienen la dureza y densidad suficiente como para que sea la porosidad de la pasta, así como la de la zona de adherencia entre el árido y la pasta de cemento, las que normalmente determinan la resistencia característica de hormigones de peso normal.

En general, existe una relación inversamente proporcional entre la porosidad y la resistencia de los sólidos, relación que no se limita únicamente a productos cementosos, sino que es aplicable de forma general a una amplia variedad de materiales.

Aunque en el caso de los morteros de cemento endurecido existe una relación directa entre la porosidad del material y su resistencia, con el hormigón dicha afirmación no es tan simple, ya que la presencia de microfisuras en la zona de adherencia entre el árido y la pasta hace que resulte muy complejo tratar de predecir de forma precisa la resistencia del hormigón partiendo de las relaciones resistencia/porosidad.

En el caso de utilizar un hormigón convencional, que suele tener una porosidad baja y la grava utilizada suele ser de alta dureza, la resistencia del 
material en conjunto dependerá directamente tanto de la resistencia de la pasta como de la resistencia de la zona de adherencia con el árido.

Por lo tanto, la relación agua cemento utilizada es un factor determinante en la resistencia del hormigón, al influir en la porosidad tanto de la pasta como la de la zona de adherencia pasta/árido. No obstante, existen otros factores como las condiciones de compactación y curado (de los que depende el grado de hidratación del hormigón), la mineralogía y tamaño de los áridos, los tipos de aditivos utilizados, las condiciones geométricas y de humedad de los elementos estructurales, el tipo de tensión a que estén sometidas y el incremento de carga aplicado, que pueden tener también una influencia muy importante en la resistencia del hormigón.

La determinación directa de la porosidad de cada uno de los elementos individuales que componen el hormigón, la pasta de cemento y la zona de adherencia pasta/árido, es poco práctica, por lo que resulta imposible desarrollar modelos de predicción de resistencia del hormigón basados en esos datos.

No obstante, en los últimos años se han desarrollado varias relaciones empíricas de uso práctico, que proporcionan numerosa información indirecta sobre la influencia de muchos factores que afectan a la resistencia a compresión del hormigón, y una vez conocido el valor de su resistencia a compresión, se correlaciona con los otros tipos de resistencia.

Aunque la respuesta del hormigón cuando está sometido a un esfuerzo es el resultado de una compleja interacción entre varios factores, pueden examinarse estos por separado, con el fin de ver cómo le afecta cada uno, y en este sentido estos factores pueden unificarse en tres áreas: los factores relacionados con las propiedades de los materiales que componen el hormigón, los relacionados con las condiciones de curado, y los que dependen de las características del ensayo a realizar. 


\subsubsection{Características y proporciones de los materiales que componen el hormigón}

En primer lugar existen unos factores relacionados con las características y las proporciones de los materiales, que se utilizan para realizar la amasada, que conviene conocer ya que afectarán directamente a la resistencia del hormigón. Siempre, partiendo de la base de que los materiales elegidos, tipo de cemento, áridos, aditivos y adiciones, son acordes con las características mecánicas que debe tener el hormigón, en función de las acciones que tenga que soportar el elemento estructural y del medio en el que se vaya a ejercer su función.

- Relación agua/cemento

La resistencia a compresión del hormigón depende de la relación agua/cemento y del grado de hidratación del cemento. A una temperatura de hidratación determinada, el grado de hidratación aumentará con el tiempo y del mismo modo lo hará la resistencia.

A medida que se aumenta la relación agua-cemento se disminuye progresivamente la resistencia de la pasta, debido al incremento de porosidad, en cambio, cuando se aumenta el contenido de cemento la cantidad de pasta es superior, elevando la docilidad del hormigón, parámetro que facilita su compactación y da lugar a menos huecos, y por lo tanto a una mayor resistencia relativa.

Cuando nos referimos a hormigones de baja o media resistencia realizados con áridos convencionales, existe una correlación directa entre la relación agua/cemento y la resistencia, ya que la porosidad de la pasta y de la zona de adherencia pasta/árido son determinantes.

No obstante, tal y como recoge en sus investigaciones De Larrad et al [35], para hormigones de alta resistencia con relaciones agua/cemento por debajo de 0,3 , se puede conseguir elevados aumentos de resistencia con reducciones muy pequeñas en la relación agua-cemento. Este fenómeno se debe a que, cuando las relaciones agua/cemento son muy bajas, con pequeños cambios se producen mejoras muy significativas de resistencia en la zona de adherencia pasta/árido, ya que el tamaño de los cristales de los productos de hidratación son mucho más pequeños y por lo tanto su superficie mucho mayor. 
- Árido

Normalmente, la resistencia del árido no se suele considerar un parámetro determinante en la resistencia del hormigón, ya que, a excepción de los áridos ligeros, para los áridos convencionales el fallo del hormigón estará determinado por la resistencia de la pasta o de la zona de adherencia pasta/árido, debido a que la resistencia del árido siempre será superior.

El tamaño, la forma, la textura superficial y la mineralogía de los áridos, pueden influir en las características de la zona de adherencia pasta/árido, independientemente de la relación agua/cemento utilizada, variando la resistencia del hormigón.

Por otro lado, dependiendo de la relación agua/cemento, existe una influencia más o menos negativa del tamaño del árido, en el sentido de que cuanto mayor sea éste necesitará menos agua de amasada pero menor será la resistencia del hormigón, debido a que a mayor tamaño de árido existirá menor superficie adherente entre la pasta y él. Además, a que la pasta poseerá menos libertad para deformarse sin sufrir microfisuraciones. (Meddah, M.S. et al) [89]

Esta situación puede variar dependiendo de la relación agua/cemento del hormigón y del tipo de esfuerzo aplicado, tal y como apuntan Sengui, O. et al [122]. El efecto del aumento del tamaño máximo del árido a la edad de 28 días es más pronunciado con resistencias medias y altas que con bajas resistencias y, por otro lado, al tener la zona de adherencia pasta/árido más efecto sobre las resistencias a tracción que sobre las resistencias a compresión cualquier cambio que se produce en las características del árido puede influir en la relación resistencia a compresión/tracción del hormigón. Para una misma relación agua/cemento si se aumenta el tamaño del árido utilizado se aumenta la relación resistencia tracción/compresión.

La cantidad de aportación del árido afecta a la consistencia de la pasta, siendo determinantes no sólo en la resistencia del hormigón sino en su coste. Por otro lado, la elección de áridos con textura rugosa puede garantizar unas resistencias iniciales mayores, al favorecer la resistencia de adherencia superficial árido/pasta. No obstante, como a mayores edades del hormigón, cuando ya han tenido lugar las reacciones químicas de hidratación entre la pasta de cemento y el árido, esta resistencia disminuye, por una pequeña mejora en la resistencia inicial el uso de 
este tipo de áridos puede comprometer la resistencia final del hormigón, al requerir una mayor cantidad de agua de amasada para mejorar su trabajabilidad.

\section{- Aire ocluido}

Tanto la existencia de huecos en el interior de la pasta de cemento del hormigón, debido a una inadecuada compactación, como la existencia de aire ocluido afectan directamente a la porosidad del material y, por lo tanto, a su resistencia. Las pérdidas de resistencia, como consecuencia de la existencia de aire ocluido, dependen no sólo de la relación agua/cemento de la mezcla sino también del contenido de cemento.

Según los datos de Cordon, W.A. [29], y contrastado por los estudios efectuados por Kumar, P. et al [74], el hecho de que sea un hormigón de alta resistencia, con altos contenidos de cemento, hace que la existencia de aire ocluido influya considerablemente en la disminución de su resistencia y, en cambio, en el caso de los hormigones de baja resistencia con contenidos bajos de cemento su influencia es muy inferior.

Esto se debe a dos factores opuestos: el aire ocluido por un lado perjudica la resistencia por la porosidad que produce pero, cuando se trata de hormigones con muy baja relación agua/cemento y bajo contenido de cemento, al intentar mejorar su compactación y trabajabilidad, las partículas de aire ocluido tienden a mejorar la resistencia de la zona de adherencia pasta/árido.

- Tipo de cemento

El grado de hidratación del cemento tiene un efecto directo sobre la porosidad del hormigón y por lo tanto sobre su resistencia. Un cemento portland del tipo III, a una temperatura convencional, según la norma americana ASTM (American Society for Testing and Materials), hidrata más rápidamente que otro tipo de cemento, de modo que, en edades tempranas y para una relación agua/cemento determinada tiene una menor porosidad $y$, en consecuencia, una resistencia mayor.

Por otro lado la relación entre la hidratación y la resistencia de los cementos portland tipo IV y V, con adición de escorias y puzolanas, es menor en comparación con la relación hidratación/resistencia de los cementos portland tipos I, II y III, según ASTM. (Kumar, P. et al )[74] 
Los cementos normalizados en Estados Unidos son de uso general en muchos otros países. Los tipos mencionados anteriormente se refieren a las siguientes características: Tipo I: uso general cuando no se precisan otras propiedades específicas, Tipo II: uso general cuando se precisa resistencia a sulfatos o moderado calor de hidratación, Tipo III: cuando se precisan altas resistencias iniciales, Tipo IV: cuando se precisa bajo calor de hidratación y Tipo IV: cuando se precisan altas resistencias iniciales.

\section{- Agua de amasada}

Como regla general, cualquier tipo de agua que es aceptable para el consumo humano, lo es también para utilizarla en el hormigón, de esa manera nos aseguramos de que las posibles impurezas que pueda contener un agua no potable no perjudiquen al hormigón desde otros puntos de vista distintos a su resistencia, como la posible formación de eflorescencias o la corrosión de sus armaduras.

Pueden ser utilizadas también aguas de reciclaje, e incluso agua marina con un contenido de sal determinado, siempre y cuando sea para realizar hormigón en masa, y en ningún caso para hormigón armado o pretensado, ya que las partículas de sal incrementan el riesgo de corrosión de las armaduras. Desde el punto de vista de la resistencia existen señales de riesgo cuando aparecen contenidos elevados de algas, aceite, sal o azúcar en las aguas utilizadas para amasar en hormigón.

\section{- Aditivos y adiciones}

Interesa que el volumen de aireantes que se introducen en el hormigón sea el menor posible, aunque sean necesarios bajo determinadas condiciones térmicas desde el punto de vista de resistencia a las heladas, ya que al sustituir un volumen de sólidos resistentes en el interior de la mezcla se obtienen, como es de esperar, resistencias mecánicas más reducidas cuanto mayor es la cantidad de aire que se incorpora.

No obstante, con la habilidad de ser capaces de reducir el contenido de agua, proporcionando una consistencia adecuada, los aditivos reductores de agua consiguen aumentar las resistencias tempranas y las de mayor edad del hormigón. 
Los aditivos aceleradores o retardadores de fraguado tienen una gran influencia en el aumento de resistencias tempranas del hormigón, y poca en la resistencia a mayor edad. No obstante, muchos investigadores, como Targan, S. et al [128], señalan la tendencia a conseguir mayores resistencias a mayor edad del hormigón, cuando la resistencia a edades tempranas se retarda.

Las adiciones minerales con puzolanas, escorias, cenizas volantes, humo de sílice, fíller calizo, etc., se utilizan de forma generalizada por motivos ecológicos y económicos. No obstante, también tienen un efecto beneficioso en la resistencia del hormigón, por un lado porque tienen un efecto retardador de la adquisición de resistencias a edad temprana en el hormigón; por otro lado, por su capacidad de reaccionar a temperatura ambiente con el hidróxido de calcio favoreciendo la porosidad de la pasta de cemento y de la zona de adherencia pasta/árido; y por último, porque son especialmente efectivas para aumentar la resistencia a tracción del hormigón.

\subsubsection{Condiciones de curado del hormigón.}

Existe una serie de condiciones relacionadas con el curado del hormigón, como: la temperatura de fraguado, el tiempo de fraguado, la hidratación del cemento, y las condiciones de humedad en el momento posterior a su vertido, que pueden influir directamente en su resistencia.

Con unas relaciones agua/cemento determinadas, la porosidad de la pasta de cemento depende del grado de hidratación de éste, y como la hidratación se produce de forma satisfactoria sólo bajo unas determinadas condiciones de saturación; el tiempo y la humedad, de los que depende la presión de vapor del agua intersticial y por lo tanto la continuación de su fraguado, serán determinantes en los procesos de hidratación, y la temperatura, como en todas reacciones químicas, tendrá un efecto acelerador en el fraguado.

- Tiempo

Con una relación agua/cemento constante, cuanto mayor sea el tiempo de curado, mayores serán las resistencias obtenidas, siempre y cuando el fraguado no se vea interrumpido, como en el caso de elementos de hormigón muy delgados, 
en los que se puede perder el agua de capilaridad por evaporación y no aumentar su resistencia en función del tiempo.

Se recomienda un curado mínimo de 7 días en hormigones realizados con cemento portland, aunque con hormigones con cementos portland mixtos o con adiciones minerales, convienen periodos superiores de curado para garantizar la contribución de la reacción del mineral a la resistencia del hormigón.

Generalmente, las resistencias más interesantes son las correspondientes a los 28 días puesto que son las especificadas para el cálculo estructural; sin embargo, a veces es conveniente conocer por razones de seguridad la capacidad de resistencia de una estructura a una edad superior.

- Humedad.

La humedad interviene de forma clara en la resistencia del hormigón, evitando que, por evaporación del agua de curado, se pueda generar microfisuración en la zona de adherencia pasta/árido, debida a la retracción cuando el elemento de hormigón es delgado y es curado al aire. Aunque, la cantidad de agua que pierde el hormigón no depende sólo de la relación superficie/volumen del elemento estructural, sino que interviene también la temperatura, la humedad relativa y la velocidad del aire del entorno.

El curado con agua, o con protección de humedad de las superficies hormigonadas, suele ser el método más utilizado para prevenir fisuras de retracción por temperatura.

Los productos industrializados de hormigón pretensado suelen curarse al vapor para acelerar el proceso de endurecimiento y agilizar el desencofrado. Autores como Toutanji, H.A. et al [58], han estudiado el efecto de distintos tipos de curado en hormigones con adiciones de humo de sílice en distintas proporciones, concluyendo que el hecho de que se realice el curado al vapor del hormigón, en comparación del curado con humedad, disminuye la permeabilidad del humo de sílice, y, en cambio, cuando el curado se produce al aire la permeabilidad aumenta proporcionalmente al aumento de adición, debido a las fisuras de retracción, siendo superiores los valores de resistencia en las probetas curadas al vapor. 


\section{- Temperatura.}

La influencia de las distintas temperaturas por las que ha pasado el hormigón, tanto en su vertido como en su curado, tiene una importancia muy relevante en su resistencia, siendo mucho más importante la temperatura de su curado que la temperatura en el momento de vertido. Es decir, hormigones convencionales que se han colocado en obra a bajas temperaturas deben mantenerse durante el tiempo de curado a cierta temperatura mínima para garantizar su resistencia.

Un mismo hormigón curado a temperaturas tropicales o en verano tendrá mayores resistencias a edades tempranas, pero inferiores resistencias a edades avanzadas que un hormigón que ha sido curado en invierno o a una temperatura ambiente más fría.

Bizzotto, M.B. [13] concluye que comparando la resistencia a compresión de un hormigón, expuesto a diferentes tipos de curado a distintas edades, la permanente exposición en laboratorio de probetas a temperaturas y humedades que oscilan entre $23^{\circ} \mathrm{C}$ y $27^{\circ} \mathrm{C}$ y entre $45 \%$ y $55 \%$, ocasiona entre el $5 \%$ y el $10 \%$ menos de resistencia respectivamente, asemejándose al curado acelerado.

En el caso de elementos de gran volumen de hormigón, según BRIFFAUT, M. et al [17], cuando no se llevan a cabo controles de la temperatura, debido a la inercia térmica, la temperatura de la masa de hormigón se mantiene más elevada que la temperatura ambiente durante bastante tiempo, de modo que, comparado con las probetas elaboradas con el mismo hormigón y curadas en condiciones normales de temperatura en laboratorio, el hormigón curado in-situ tendrá unas resistencias superiores a temprana edad e inferiores a edad avanzada.

Cuando se trata de elementos prefabricados, en los que se utiliza el aumento de temperatura o el curado al vapor para acelerar la velocidad del fraguado, no se debe superar la temperatura de $50^{\circ} \mathrm{C}$ hasta el momento en el que éste se haya iniciado, ya que cualquier tipo de hormigón fresco sometido a temperaturas inferiores a $4^{\circ} \mathrm{C}$ o superiores a $50^{\circ} \mathrm{C}$ antes de iniciarse el fraguado sufrirá descensos en su resistencia. (Carril, C.) [23]

Se han llevado a cabo investigaciones como las de Fernández-Jiménez, A. et al [53], que tienen en cuenta los problemas derivados del curado térmico del hormigón, desfavoreciendo las resistencias mecánicas a largo plazo, e incluso 
cuando las temperaturas de curado son superiores a $50^{\circ} \mathrm{C}$ o $60^{\circ} \mathrm{C}$, produciéndose un ataque interno de sulfatos que generan fisuración alrededor de los áridos; por otro lado, investigaciones que tienen en cuenta las necesidades de la industria de los prefabricados proponen, con ese fin, el uso en el hormigón de adiciones de ceniza volante activada alcalinamente para paliar estos inconvenientes.

\subsubsection{Parámetros relacionados con los ensayos}

- Influencia de la forma y dimensiones de la probeta

Existe una marcada tendencia a utilizar probetas cilíndricas de $15 \mathrm{~cm}$ de diámetro y $30 \mathrm{~cm}$ de altura, aunque en Francia se emplean las de $16 \mathrm{~cm}$ de diámetro y $32 \mathrm{~cm}$ de altura por la ventaja de tener una superficie de aplicación de la carga de, prácticamente, $200 \mathrm{~cm}^{2}$.

Se recomienda que la dimensión menor de las probetas no sea inferior a 100 $\mathrm{mm}$, y se ha podido comprobar, empleando diferentes dimensiones de probetas, que con áridos de tamaño máximo comprendido entre $20 \mathrm{~mm}$ y $40 \mathrm{~mm}$, las probetas de $15 \mathrm{~cm}$ de diámetro por $30 \mathrm{~cm}$ de alto son las que proporcionan mayores resistencias y uniformidad en los resultados, mientras que con áridos de tamaño máximo de $10 \mathrm{~mm}$ las probetas de $10 \mathrm{~cm}$ de diámetro por $29 \mathrm{~cm}$ de alto son las más idóneas.

La influencia de la forma y tamaño de la probeta de hormigón en la resistencia obtenida en su ensayo ha sido estudiada por muchos investigadores, Zabini, N. [139], Dillon, R. et al [44], estudian las diferencias en la resistencia obtenida en ensayos realizados a probetas cúbicas y probetas cilíndricas.

Desde el RILEM [117], BSI (2006) [18], BSI (2009) [19] y los estudios sobre propiedades del hormigón de Neville, A.M [99], se establece una serie de factores de conversión, con el fin de determinar la relación existente entre la resistencia obtenida en el ensayo y el hecho de que la probeta ensayada sea cilíndrica o cúbica.

Aunque esta relación depende de muchos factores distintos, como son: la forma, las dimensiones, la proporción, el curado, la edad del hormigón, etc, las investigaciones consultadas y mencionadas en el párrafo anterior establecen como factor de conversión generalmente aceptado 0,8 para probetas cilíndricas con una 
relación altura diámetro de 2, como es el caso de las probetas que se utilizan en nuestro trabajo experimental.

Estudios realizados por Del Viso, J.R. et al [40], sobre la influencia de la forma y tamaño de la probeta en la resistencia a compresión de hormigones de alta resistencia, indican que el modo de fallo y la carga máxima en el ensayo de compresión están relacionadas con los procesos de fisuración y, por lo tanto, pueden analizarse aplicando las teorías de la Mecánica de la Fractura.

De los resultados de su investigación se desprende que las curvas tensión/deformación obtenidas dependen del tamaño y de la forma de la probeta, y en cambio los mapas de fisuración sólo dependen de la forma de éstas, localizándose daños más leves en las probetas cúbicas, siendo éstas además las que obtienen resultados mayores de resistencia, superando a las de forma cilíndrica en un 10-15\%.

- Condiciones de aplicación de la carga

Debido a que, antes de que se aplique un esfuerzo determinado sobre un elemento estructural de hormigón, éste ya tiene una serie de microfisuras en la zona de adherencia pasta/árido, el comportamiento del elemento a las distintas condiciones y tipo de esfuerzo que se apliquen sobre él será determinante en el resultado de su resistencia.

\subsubsection{Factores que afectan al módulo de elasticidad del hormigón.}

En el hormigón, al ser un material compuesto, no se puede encontrar una relación directa entre su densidad y su módulo de elasticidad, ya que intervienen otros factores además de la densidad, como la fracción de volumen y las características de la zona de adherencia pasta/árido, que condiciona su comportamiento elástico.

El hormigón tiene un comportamiento de pseudo-sólido, debido a las microfisuras que aparecen en la superficie de adherencia pasta/árido al aplicar un esfuerzo sobre él. Éste hecho condiciona directamente el comportamiento de la masa de hormigón, que además está compuesta por materiales que, considerados aisladamente, tienen módulos de elasticidad muy diferentes. 
Como la densidad está inversamente relacionada con la porosidad los factores que modifican la porosidad de los áridos, la de la pasta de cemento y la de la zona de adherencia pasta/árido serán determinantes en la densidad del hormigón y, por lo tanto, en su elasticidad.

El módulo de Young E o módulo de elasticidad estático de un hormigón es un valor muy importante para determinar su forma de trabajar en el elemento estructural del que va a formar parte.

En función de las consideraciones que se tengan en cuenta en su determinación se utilizará uno de sus valores posibles a utilizar, el módulo tangente inicial, el módulo tangente en un punto determinado, o un módulo secante; siendo el último el habitualmente más empleado, pudiendo admitirse, a falta de otros valores, que el valor del módulo secante es aproximadamente el $90 \%$ del valor del módulo tangente en el origen.

El módulo de elasticidad estático se determina midiendo el módulo de elasticidad secante en dos puntos en la curva tensión-deformación a compresión, realizada en ensayo estático en laboratorio sobre probeta cilíndrica, a la que se aplican escalones de carga determinados y se van midiendo los acortamientos que experimenta.

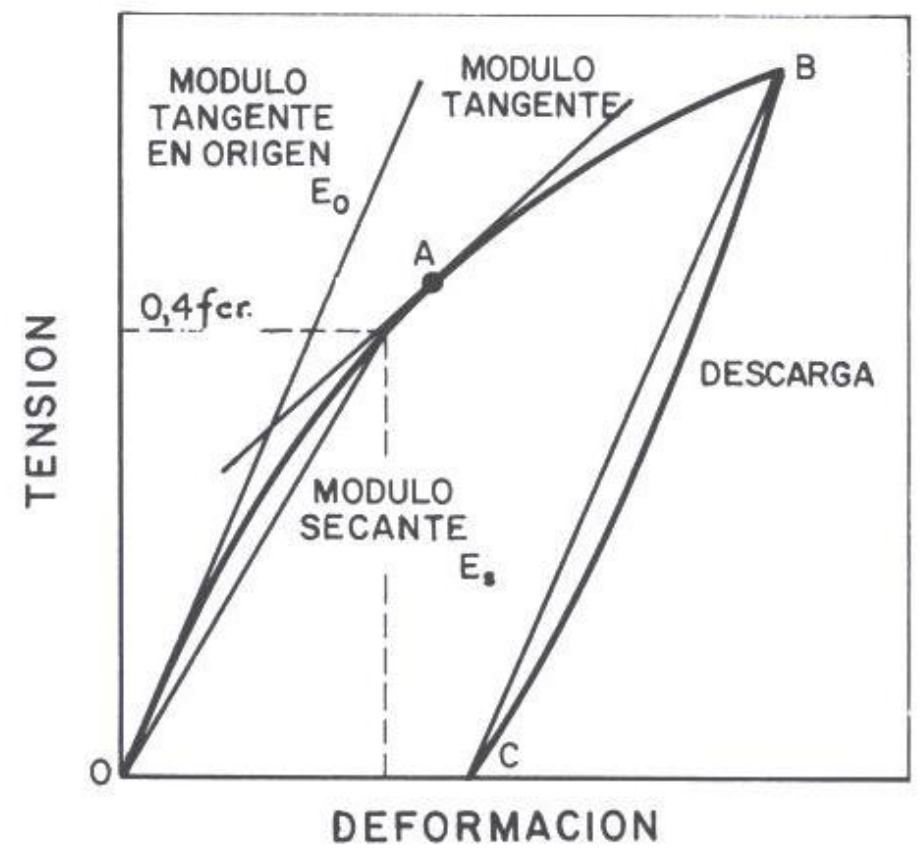

Figura 2.3- 1. Módulos de elasticidad de un hormigón. (Fernández Canovas, M. [52] 
Por otro lado el módulo de elasticidad dinámico, además de poder determinarse por medio de un ensayo no destructivo, permite observar la respuesta en el tiempo de un elemento de hormigón a acciones físicas y químicas, y poder predecir su resistencia a compresión, siempre que se haya establecido una correlación entre ambos valores. Se realiza sometiendo al elemento de hormigón a una serie de impulsos ultrasónicos y midiendo el tiempo que tardan en recorrer un espacio fijo.

Aunque puede conocerse el valor de la resistencia a compresión y el de la resistencia a flexotracción habiendo averiguado su módulo de elasticidad estático, una vez relacionados sus valores, salvo que se trate de un hormigón determinado, es muy difícil dar una relación entre velocidad de propagación de las ondas ultrasónicas y resistencia del hormigón, debido a que la relación entre éstas no es lineal a medida que el hormigón va endureciendo, sino que se aparta de la recta tendiendo a una parábola más o menos acentuada en función de factores como la relación agua/cemento, la granulometría del árido, el tipo de cemento, la utilización de aireantes, las condiciones de curado, etc.

Existen ecuaciones propuestas por investigadores como Sang-Hung, $\mathrm{H}$. et al [119], en los que se establecen relaciones entre el módulo de elasticidad estático, el módulo de elasticidad dinámico y la resistencia a compresión del hormigón, y que además han estudiado la influencia del tipo de cemento, de la edad del hormigón, y de la temperatura de curado en la relación entre ambos módulos de elasticidad, concluyendo que el único factor que de forma aislada genera diferencias en la relación entre los módulos es la temperatura de curado, cuando ésta es de $50^{\circ} \mathrm{C}$, a diferencia de cuando es de $10^{\circ} \mathrm{C}$ o $23^{\circ} \mathrm{C}$. No obstante, los propios autores no lo consideran determinante por los pocos ensayos realizados al respecto.

En el caso de los áridos, su módulo de elasticidad es más elevado que el del hormigón, variando en función de su naturaleza, debido a la influencia de la forma del árido y de su textura superficial en la formación de microfisuras en la superficie de adherencia con la pasta. En todo caso, el módulo de elasticidad del hormigón aumenta proporcionalmente con el aumento del módulo de elasticidad del árido y también con la edad del hormigón. 
La característica de los áridos que más afecta al módulo de elasticidad del hormigón que los contiene es la porosidad de éstos, ya que es el factor que determina la capacidad del árido de atenuar la deformación de la pasta de cemento. Otras propiedades de los áridos que influyen en el módulo de elasticidad del hormigón son: su forma, su tamaño, la textura de su superficie, y su composición mineralógica, ya que son valores que pueden provocar microfisuraciones en la zona de adherencia pasta/árido y modificar la curva de la gráfica tensión-deformación.

De forma general cuanto mayor sea la cantidad de árido agregado, y con el mayor módulo de elasticidad, mayor será el módulo de elasticidad del hormigón, pero no tiene porque pasar lo mismo con su resistencia, ya que en el caso de hormigones de baja o media resistencia, ésta no se ve modificada por las variaciones de porosidad en el árido.

El módulo de elasticidad de la pasta de cemento también se determina en función de su porosidad, y ésta depende a su vez de factores como: la relación agua/cemento, el contenido de aire, las adiciones minerales y el grado de hidratación del cemento.

En el caso de la zona de adherencia pasta/árido su porosidad depende, de igual manera, de la relación agua/cemento, el grado de hidratación del cemento, y de las adiciones minerales, pero también intervienen las características de los áridos agregados, el grado de consolidación, y la interacción química existente entre el árido y la pasta de cemento. Estos valores determinan la aparición de microfisuras, la existencia de cristales de hidróxido de calcio, y el aire ocluido en la zona de adherencia, influyendo de forma importante en la relación tensióndeformación del hormigón.

El hecho de que la interacción química producida entre la pasta de cemento alcalina y el árido se realice de una forma lenta beneficia la densidad de la zona de adherencia pasta/árido, mejorando las relaciones esfuerzo-deformación en mayor nivel que la propia resistencia a compresión del hormigón.

Ambos valores, módulo de elasticidad y resistencia a compresión del hormigón, están relacionados directamente y muy influenciados por los parámetros con los que se realizan los ensayos, es decir, la velocidad de carga, humedad del hormigón, el tipo de probeta utilizada, edad del hormigón, etc. No obstante, el 
módulo de elasticidad aumenta más rápidamente con la edad del hormigón que su resistencia a compresión.

Por su parte, la velocidad con la que se realice la carga es determinante, pues, al someter a un esfuerzo de forma rápida a una probeta, las deformaciones son reducidas y por lo tanto el módulo de elasticidad es muy elevado, y viceversa.

La humedad de la probeta influye también en la determinación del módulo de elasticidad el hormigón, observándose valores menores en ensayos de probetas de un mismo hormigón en estado húmedo que en estado seco.

No obstante, la resistencia a compresión de los mismos ensayos varía de forma opuesta, los resultados son superiores en estado húmedo, posiblemente porque la humedad afecta de forma distinta a la pasta de cemento y a la zona de adherencia pasta/árido, beneficiando la resistencia inicial al aumentar las fuerzas de atracción entre los productos hidratados de la pasta de cemento, y perjudicando la zona de adherencia pasta/árido al generar mayor microfisuración y afectar la relación esfuerzo/deformación.

La temperatura elevada afecta por igual y en el mismo sentido a la resistencia a compresión y al módulo de elasticidad, aunque se considera de forma generalizada que hasta una temperatura de más de $200^{\circ} \mathrm{C}$ el hormigón no sufre alteraciones. (Fernandez Cánovas, M.) [52]

\subsubsection{Factores que afectan a la adherencia hormigón-acero.}

El hecho de que exista adherencia entre el hormigón y las armaduras en las estructuras de hormigón armado es fundamental para el funcionamiento de las mismas; sin adherencia la armadura se deslizaría ante cualquier esfuerzo de tracción, y no podría garantizarse la continuidad de las armaduras por medio de solape ni, por supuesto, considerarlas ancladas.

El fenómeno de la adherencia es muy complejo, depende en distinta medida de varios mecanismos resistentes, adhesión química, rozamiento e interacción mecánica, y afecta a aspectos diversos del comportamiento estructural, no sólo para estados límites últimos, sino también en situaciones de servicio, en aspectos relacionados por ejemplo con la fisuración y la deformación. 
La fisuración debe ser controlada en cualquier estructura, ya que, su existencia puede acelerar el proceso de deterioro del elemento estructural al dejar la armadura desprotegida frente a agentes agresivos, humedad, etc. Y el principal síntoma y uno de los fallos más habituales, cuando existe falta de adherencia entre el hormigón y el acero, es la fisuración en dirección paralela a las armaduras, fenómeno denominado "splitting", que resulta muy peligroso al sufrir el recubrimiento una rotura frágil y limitar de forma comprometida el anclaje de la armadura, su exposición a la intemperie y, por lo tanto, la durabilidad del elemento estructural.

Otro de los fallos por adherencia estudiados por investigadores como es el fallo a "pull-out", que consiste en el deslizamiento de la armadura dentro del elemento de hormigón cuando éstas son lisas, y a arrancamiento en caso de ser corrugadas, aunque este tipo de fallo se produce en raras ocasiones, tal y como apunta Tepfers, R. en su tesis doctoral. [129]

Al ser muchos los factores, tanto físicos como químicos, que intervienen en el fenómeno de la adherencia entre el hormigón y el acero, hay que tener en cuenta, además de los parámetros relacionados con las características de la armadura, otros aspectos como: las propiedades del hormigón, el recubrimiento de la barra, su posición con respecto a la dirección de hormigonado, su grado de confinamiento, y la historia de la carga que se ejerce sobre el elemento estructural, ya que son parámetros que van a influir en el estado tensional del hormigón.

Molina, M. [93] realiza un estudio pormenorizado de estos factores influyentes, concluyendo, en su recopilación de investigaciones y normas al respecto, que en el caso de las propiedades del hormigón no sólo afecta a la adherencia entre éste y la armadura a su resistencia sino que otros factores, como la dosificación (que influirá a su vez en la retracción y grado de asentamiento), y cómo se ejecuta la estructura (que incidirá en su homogeneidad y grado de compactación), son también decisivos.

A medida que aumenta el diámetro de la armadura utilizada disminuye la tensión de adherencia con el hormigón, pero además otras propiedades de la armadura, como su geometría, la distribución, separación y altura de las corrugas, influyen en la transferencia de tensiones entre hormigón y acero, tendiéndose 
actualmente en el diseño de corrugas a disminuir la altura y separación entre ellas con el objeto de evitar tensiones elevadas en el hormigón.

El recubrimiento es fundamental para garantizar la durabilidad de las estructuras, pero cuando es insuficiente representa un papel decisivo en el modo de rotura por falta de adherencia, ya que facilita la formación de fisuras en la superficie.

Molina, M. et al [94] estudian cómo la relación entre el recubrimiento de la armadura y el diámetro de ésta afectan a la adherencia hormigón-acero, concluyendo que la tensión máxima de adherencia local aumenta con el recubrimiento hasta una relación recubrimiento/diámetro igual a cuatro veces el diámetro, a partir de ésta se estabiliza al garantizar el anillo de tracciones en el hormigón que equilibra las fuerzas de adherencia, y a partir de ese límite la influencia del recubrimiento es escasa.

La posición de las armaduras con respecto a la dirección del hormigonado es otro de los parámetros a estudiar para cualquier tipo de estructura de hormigón armado, ya que no se considera igual el recubrimiento de una armadura en posición vertical, en la que se produce el vertido por la parte superior, que otra en posición horizontal y además situada en la zona superior del elemento a hormigonar, ya que puede verse comprometido su recubrimiento en la parte inferior de la barra. La Instrucción de hormigón estructural EHE-08 [48], recoge este fenómeno para determinar las longitudes de anclaje y de solape de las armaduras de refuerzo en el hormigón.

El confinamiento de la armadura, la historia de la carga y otros factores como la temperatura, la degradación del hormigón, o el hecho de que la estructura se encuentre en un ambiente agresivo o con alto grado de humedad, influyen directamente en la transferencia de tensiones entre el hormigón y el acero.

Para la investigación que se está realizando el recubrimiento es uno de los parámetros determinantes, ya que el motivo por el que se estudia la adherencia entre la armadura y el hormigón en los elementos de estructuras termoactivas se debe a la incorporación de los tubos de polietileno, que en obra se atan habitualmente con alambre a las armaduras de refuerzo, y en función de si su posición es paralela o perpendicular a la barra pueden interferir en el 
recubrimiento, y por lo tanto en la superficie de adherencia de la armadura con el hormigón, en toda su longitud.

Además, en el caso de forjados termoactivos, los tubos de polietileno suelen disponerse en la zona superior atados a las armaduras de negativos y al mallazo superior de la capa de compresión, que justamente son las armaduras que se consideran en posición de adherencia deficiente.

También la temperatura es uno de los factores que más interés tiene en la investigación, pues el fluido caloportador que circula por el interior de los tubos de polietileno embebidos en los elementos estructurales alcanza una temperatura de alrededor de $40^{\circ} \mathrm{C}$. Existen varios estudios en los que se investiga el efecto producido por las bajas y altas temperaturas en la adherencia del hormigón-acero y se aportan en el siguiente apartado en el que se aborda el efecto de la temperatura en el hormigón. 


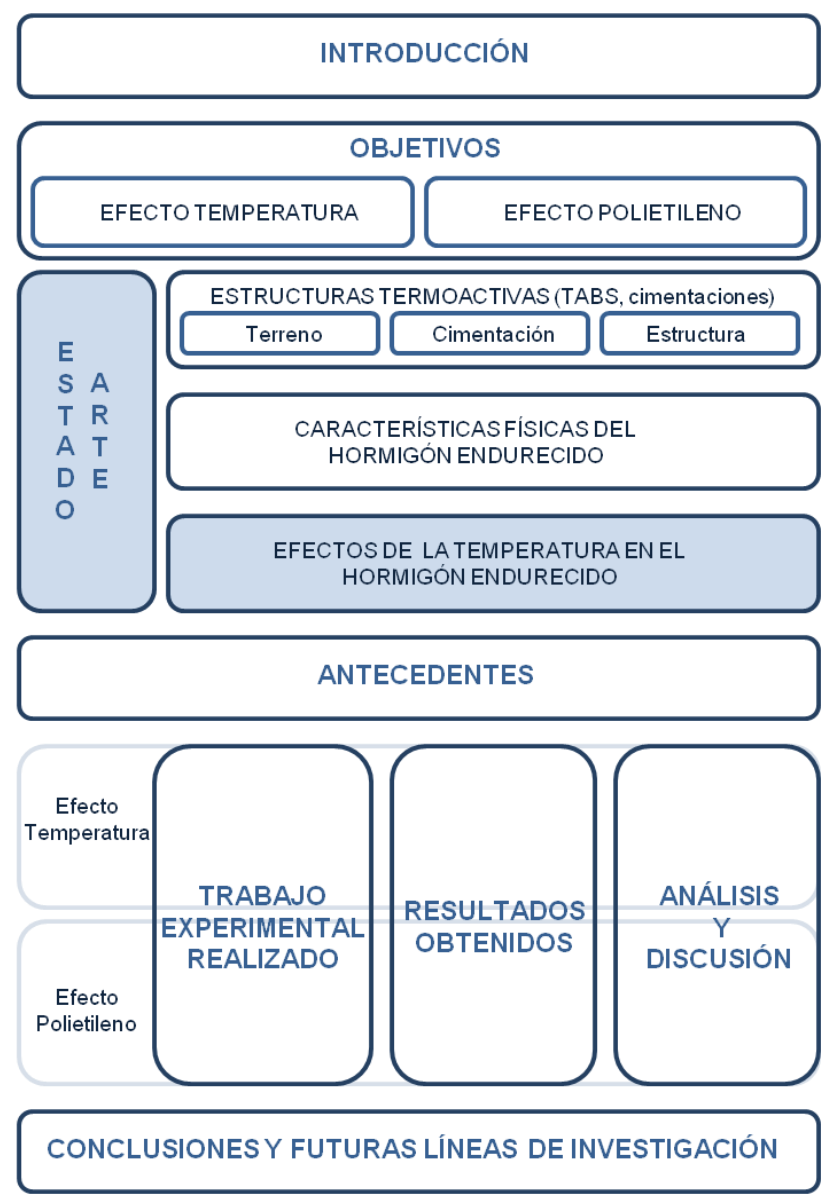

\subsection{Cómo afecta la temperatura al hormigón endurecido.}

El efecto que tiene la temperatura sobre el hormigón, cuando esté está en estado fresco, durante su vertido, o inmediatamente después de comenzar su fraguado, se ha estudiado ampliamente con el fin de determinar cuáles son las mejores condiciones de curado del mismo en relación con su resistencia tanto inicial como a edad avanzada (Wang, X., et al.) [132]; también para determinar la posibilidad de mejorar las resistencias del hormigón a edades tempranas, acelerando su fraguado para permitir aligerar los procesos industriales de prefabricación; y, por otro lado, con el fin de garantizar que las características mecánicas del hormigón no se vean comprometidas cuando el hormigonado se realiza en tiempo caluroso o con materiales a los que se ha elevado su temperatura en tiempo frío.

Al referirnos a cómo afecta la temperatura al hormigón endurecido, las investigaciones que se han encontrado se dirigen fundamentalmente a dos 
conceptos principales: cómo afectan las altas temperaturas (superiores a $200^{\circ} \mathrm{C}$ ) del fuego a las estructuras de hormigón armado en los incendios, y, en segundo lugar, como afecta la temperatura al hormigón destinado a formar parte de estructuras cuya función es contener combustibles nucleares.

El estudio del comportamiento del hormigón sometido a elevadas temperaturas comenzó a realizarse en la década de 1950. Los resultados de los estudios iniciales han constituido la base técnica para las recomendaciones y guías de diseño relativas al hormigón sometido a elevadas temperaturas. (Malhotra, V. et al. [86], Abrams, M.S. [1], Schneider, U. [121])

De todos los estudios realizados, la mayor recopilación de documentación en referencia al estudio del hormigón sometido a incrementos de temperatura lo ha realizado la Comisión Reguladora de la Energía Nuclear en Estados Unidos (Naus, D.) $[98]$

En cualquier caso, aunque todos los estudios de investigación aportan datos sobre las diferencias en el comportamiento del hormigón sometido a temperaturas altas, en relación con los hormigones a temperatura ambiente o sometidos a temperaturas inferiores a $100-200^{\circ} \mathrm{C}$, no se ha podido encontrar información que demuestre experimentalmente y de forma específica cómo se ven afectadas las estructuras de hormigón sometidas a las temperaturas moderadas de $30-45^{\circ} \mathrm{C}$, que son las utilizadas en el fluido caloportador, que circula por los tubos de polietileno, dentro de las estructuras de hormigón armado en los sistemas termoactivos.

La exposición del hormigón a una temperatura elevada provoca una degradación química progresiva del hormigón que modifica su microestructura. (Sreenivasulu, A., et al.) [124]

Para poder cuantificar la degradación que experimenta el hormigón debida al incremento de temperatura conviene conocer cómo se modifican las características térmicas, hídricas, y mecánicas del hormigón con su incremento.

Ya que, cuando un hormigón convencional se expone a temperaturas elevadas, se inician reacciones de deshidratación en la pasta hidratada de cemento, pudiendo aparecer incompatibilidades térmicas entre la pasta y los agregados debido a sus diferentes coeficientes de dilatación lineal y, 
eventualmente, pueden producirse deterioros físico-químicos de los agregados tal y como indican Kassir M.K., et al. [67] en sus investigaciones.

Las distintas investigaciones encontradas estudian, por un lado, los efectos físico-químicos de la temperatura sobre los elementos que constituyen el hormigón, la pasta de cemento y los áridos, y, por otro lado, el efecto que producen las altas temperaturas en el hormigón como material compuesto.

Las altas temperaturas afectan de manera distinta a la pasta de cemento y al árido:

El comportamiento de la pasta de cemento depende del grado de hidratación; a medida que aumenta la temperatura el agua que contiene comienza a evaporarse. La temperatura necesaria para provocar el cambio del agua intersticial de estado líquido a vapor es considerable, y el hormigón no comienza a aumentar su temperatura hasta que toda el agua se ha evaporado.

Aunque pueda parecer lo contrario, la presencia de grandes cantidades de agua evaporable puede ser un problema cuando la temperatura sube con rapidez y la permeabilidad de la pasta de cemento es baja, ya que se pueden producir daños en el hormigón microfisurándose su superficie.

Fu, $\mathrm{Y}$ et al. [55] propone un modelo numérico para cuantificar en qué medida, las distintas características del hormigón afectan a que las altas temperaturas lo dañen, concluyendo que los dos factores que intervienen principalmente en el cuarteamiento superficial de las superficies de hormigón sometidas a altas temperaturas son: las tensiones de colapso térmico, y la presión del poro que determina la permeabilidad del hormigón.

La porosidad, mineralogía, y grado de humedad de los áridos, ejercen también una influencia importante en los cambios térmicos del hormigón. Áridos con baja porosidad no suelen tener problemas relacionados con los cambios de humedad interior; la porosidad elevada, al contrario, hace a los áridos susceptibles de sufrir y generar en el hormigón roturas de expansión como las producidas por las bajas temperaturas.

Trabajos realizados por Harmathy, T. [60] y por Bazant, Z.P, et al. [11], aseguran que la deshidratación de la pasta de cemento comienza a observarse a partir de los $180^{\circ} \mathrm{C}$ de temperatura, percibiéndose también en otros trabajos 
realizados por Bazant, Z.P [10] un aumento de la porosidad de la pasta de cemento, en función del incremento de temperatura, debido a la ruptura interna de la estructura del gel de silicato cálcico hidratado en el momento del proceso de deshidratación.

De los estudios realizados por Harada, T. et al. [59], se desprende que aunque a altas temperaturas los áridos del hormigón se descomponen modificando las características microestructurales del hormigón, los áridos calizos y silíceos son relativamente estables hasta los $500^{\circ} \mathrm{C}$ de temperatura.

Otros estudios experimentales realizados en nuestro país, como el de Fargueta, F. et al. [51], analizan el efecto de la temperatura en la resistencia del hormigón. Del estudio se desprende que cuando se utilizan hormigones de resistencia normal el tipo de árido utilizado interviene en el aporte de resistencia de forma más relevante, aunque de forma generalizada esto ocurre tanto para hormigones de resistencia normal como para hormigones de alta resistencia.

En los ensayos realizados por Fargueta, F. et al., la utilización de árido calizo contribuyó en la obtención de resultados en las resistencias superiores a los obtenidos con árido silíceo.

Se estima en el estudio que estos resultados obtenidos pueden ser debidos a que, por un lado, el árido silíceo tiene mayor conductividad y mayor dilatación que el calizo y, por lo tanto, provoca fracturas y caídas de resistencia más severas, y por otro lado, porque el árido calizo es más consistente e íntegro.

Estos datos también se observan en las investigaciones llevadas a cabo por Savva, A. et al. [120], en los que se estudia el hormigón sometido a temperaturas de entre $100^{\circ} \mathrm{C}$ y $300^{\circ} \mathrm{C}$ y se nota que para todos los tipos de hormigón estudiados, sometidos al rango de temperaturas mencionado, la resistencia inicial de los hormigones experimenta aumentos, y en el caso de hormigones con árido silíceo estas resistencias iniciales son superiores que las de los hormigones elaborados con árido calizo. La reducción experimentada en su módulo de elasticidad es significativa a cualquier temperatura, pero es superior en el caso de utilizar áridos calizos.

Estos resultados están respaldados por las conclusiones sobre los estudios realizados por Arioz, O. [6], de los que se desprende que no se observan efectos 
visibles superficiales en las muestras sometidas a distintas temperaturas hasta que ésta no supera los $400^{\circ} \mathrm{C}$, su color comienza a variar con temperaturas superiores a $200^{\circ} \mathrm{C}$; las pérdidas de masa son del $5 \%$ cuando las temperaturas alcanzan los $200^{\circ} \mathrm{C}$, siendo inferiores dichas pérdidas de peso cuando el árido utilizado en la amasada de hormigón era silíceo.

Se observa mayor repercusión de la temperatura en la resistencia de hormigones con árido silíceo, provocando, en este tipo de árido, expansiones y daños mayores; las pérdidas importantes de resistencia en el hormigón se comienzan a observar cuando la temperatura supera los $400 \stackrel{\circ}{\circ}$; sobre temperaturas de $500^{\circ} \mathrm{C}$ el hecho de contener árido silíceo o calizo resulta insignificante; claramente se observa en los resultados una relación de pérdida de resistencia cuando se produce una pérdida de masa por evaporación de agua; la diferencia en la relación agua/cemento y en el tipo de árido no se considera representativa con respecto a las pérdidas de peso por evaporación, ni se considera significativa la relación agua/cemento en las variaciones de resistencia.

Por el contrario, a temperaturas muy inferiores, de $120^{\mathrm{a}} \mathrm{C}$, comienza a observarse el deterioro progresivo de la zona de adherencia pasta-árido, ya que es la parte más frágil, más porosa y más cristalizada, favoreciéndose el desarrollo de fisuras producidas por la contracción por secado que produce la evaporación del agua atrapada en los poros, tal como se desprende de investigaciones como las de De Morais, M. et al. [36]

También a partir de los $100^{\circ} \mathrm{C}$ comienza a observarse un aumento en la porosidad del hormigón, debido al aumento del volumen total de la dimensión de los poros y a la microfisuración generada por la dilatación diferencial entre la pasta y el árido, tal como apuntan estudios realizados por Kalifa, P. et al. [65].

Las altas temperaturas también interfieren en las características térmicas del hormigón, fundamentales en nuestra investigación, para garantizar que las estructuras de hormigón cumplen adecuadamente su función de elemento termoactivo requerida.

El hecho de que las altas temperaturas comiencen a degradar los áridos del hormigón, a cifras cercanas a los $600^{\circ} \mathrm{C}$, implica una reducción de la masa volumínica que se incrementa de forma importante a partir de esas temperaturas; en cambio, la conductividad térmica tiende a aumentar cuando comienzan a 
elevarse las temperaturas, hasta los $100^{\circ} \mathrm{C}$ momento en que sufre un decremento importante sin recuperación.

El parámetro de la difusividad térmica está absolutamente ligado al calor específico y a la conductividad térmica (Montanaro, M.I., et al. [95]), ambos directamente relacionados con el tipo y cantidad de árido existente en el hormigón, $y$, por lo tanto, con valor descendente a medida que aumenta la temperatura.

En las investigaciones centradas en el modo en el que afecta la temperatura al hormigón utilizado para estructuras de uso nuclear, los investigadores están más interesados en estudiar temperaturas más bajas, Dal Pont, S. [31] y Bary, B. et al. [8], presentan modelos matemáticos de su estudio en los que intervienen la velocidad y el rango de aumento de la temperatura, y en el caso de Yang, C.C. et al. [136], interesa la exposición del hormigón durante largos periodos de tiempo a temperaturas de alrededor de $95^{\circ} \mathrm{C}$ y cómo la temperatura afecta a la porosidad del hormigón, tanto desde el punto de vista de su pasta de cemento como de la zona de adherencia pasta-árido, en las propiedades mecánicas y de transporte molecular del hormigón.

En su investigación halló estudios como el de Noumowe et al. [102], en el que se ensayaban hormigones normales y de alta resistencia, realizados con el mismo árido calizo, y a los que se sometía a temperaturas distintas para estudiar sus características mecánicas y físicas.

Noumowe A.N. et al. [102], observan que los hormigones sometidos a temperaturas entre $22^{\circ} \mathrm{C}$ y $120^{\circ} \mathrm{C}$ no ven significativamente afectada su porosidad. Evidentemente cuando la finalidad del estudio es conocer las propiedades de trasporte molecular del hormigón, aunque esas diferencias de porosidad no se consideraran significativas por Noumowe A.N. et al. [102]. Los datos arrojaban unas diferencias en el diámetro de los poros entre los hormigones sometidos a $22^{\circ} \mathrm{C}$ y los sometidos a $120^{\circ} \mathrm{C}$ que sí eran determinantes para las investigaciones de Yang et al. [136]

Los datos expuestos por las investigaciones realizadas por Yang et al. [136], concluyen que no se ha hallado diferencias significativas, en los resultados de resistencias a compresión y a tracción, entre las probetas sometidas a $95^{\circ} \mathrm{C}$ de temperatura y las probetas de referencia. 
Estudios realizados por Dias, W. [42] en 1990, señalan que, en hormigones sometidos a temperaturas entre $22^{\circ} \mathrm{C}$ y $120^{\circ} \mathrm{C}$, se produce una reducción en su resistencia a compresión, que se atribuye al aumento de volumen del agua intersticial provocado por la temperatura, que causa una variación de presiones.

También se hace referencia a la diferencia de valores de temperatura medidos en la superficie y en puntos interiores de las probetas, hallándose diferencias de hasta $20^{\circ} \mathrm{C}$ entre la superficie y puntos a $2 \mathrm{~cm}$ bajo la misma; este factor puede ser determinante para generar una gran inestabilidad térmica en el hormigón, sometido a altas temperaturas, que produzca roturas inestables.

En los ensayos que se han realizado en este trabajo sobre el efecto de la temperatura moderada en las estructuras termoactivas, se ha colocado sensores térmicos en el interior de las probetas de referencia, con el fin de proceder a romper las mismas en el momento en el que el interior de las probetas se encontraba a la temperatura requerida.

Con respecto a la pérdida de peso de los hormigones, los estudios de Noumowe, A.N. et al. [102], arrojan datos en los que se refleja que hormigones sometidos hasta temperaturas de $70^{\circ} \mathrm{C}$ retienen hasta el $99 \%$ de su peso, en cambio, a partir de esa temperatura se comienza a evaporar el agua libre del hormigón a una velocidad superior en los hormigones normales que en los de alta resistencia.

La suma de los efectos de la temperatura, tanto en la pasta de cemento como en el árido, motiva las distintas variables en las que el hormigón, como compuesto, puede reaccionar ante el incremento de temperatura; no obstante, otras circunstancias, como las condiciones en las que se producen los ensayos, pueden variar el grado en el que se ve afectado el hormigón.

\subsubsection{Factores que afectan a la resistencia a compresión del hormigón.}

El motivo fundamental por el que la resistencia a compresión del hormigón se ve disminuida con el aumento de la temperatura, tal como apunta DeJong M.J, et al. [39], deriva de la degradación provocada en el hormigón como causa de la deshidratación producida. 
Respecto a las referencias relacionadas con cómo afectan las altas temperaturas derivadas de incendios a las estructuras de hormigón, en estudios como el de Castillo, C. et al. [24] y Culfic, M.S. et al. [30], se concluye que las temperaturas elevadas (superiores a $250^{\circ} \mathrm{C}$ ), tienen efectos considerables en las propiedades mecánicas de los hormigones.

De los trabajos de Culfic, M.S. et al. [30], se obtienen otros datos interesantes, como el hecho de que, cuando las estructuras de hormigón están sometidas a altas temperaturas, la reducción de la relación agua cemento y la inclusión de humo de sílice mejora la resistencia del hormigón al calor.

De los resultados de los ensayos de resistencia a tracción se desprende que las probetas en las que se había adicionado humo de sílice no sufren ningún tipo de reducción, en las resistencias, derivada por las altas temperaturas, cuando las probetas sin dicha adición sufren una pérdida del $37 \%$ con respecto a los valores iniciales.

Se estima que ese fenómeno se produce porque la adición de humo de sílice al hormigón de resistencia normal propicia la formación de más silicato de calcio hidratado con gran fuerza de cohesión, que crea una enorme y estable unión entre el árido y la pasta de cemento a temperaturas superiores a $250^{\circ} \mathrm{C}$.

En otros estudios se corrobora que el hecho de que el hormigón contenga adiciones de cenizas volantes le permite no sufrir decrementos en su resistencia a compresión hasta temperaturas de $600^{\circ} \mathrm{C}$. Y se relacionan los resultados de probetas que contienen como adición fibras de polipropileno ensayadas a temperaturas de hasta $200^{\circ} \mathrm{C}$ en comparación con probetas sin someter a altas temperaturas. Noumowe, A. [101]

Como hemos comentado anteriormente, las condiciones en las que se producen los ensayos pueden variar el grado en el que se ve afectado el hormigón.

En las investigaciones realizadas por Abrams, M.S. [2], se han llevado a cabo ensayos en los que se carga inicialmente la estructura y posteriormente se somete a alta temperatura, y los datos no reflejan efectos significativos en la reducción de su resistencia.

También se han relacionado los resultados de rotura de probetas de la misma amasada de hormigón, ensayadas justo cuando alcanzan la temperatura de 
consigna y una vez enfriadas, observándose que a temperaturas entre $100^{\circ} \mathrm{C}$ y $300^{\circ} \mathrm{C}$ los resultados de resistencia son superiores en las probetas que ya han sido enfriadas en relación con las que se rompieron a elevada temperatura.

Husem, M. [63], incorpora estudios, que pueden verse en la figura 2.4- 1, sobre las diferencias de pérdida de resistencia del hormigón cuando éste ha sido sometido a altas temperaturas y posteriormente enfriado al aire o con agua, y, en caso de ser con agua, estudia como varía esa resistencia en función del tiempo de exposición al agua.

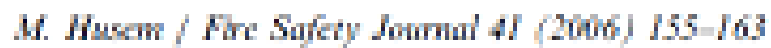

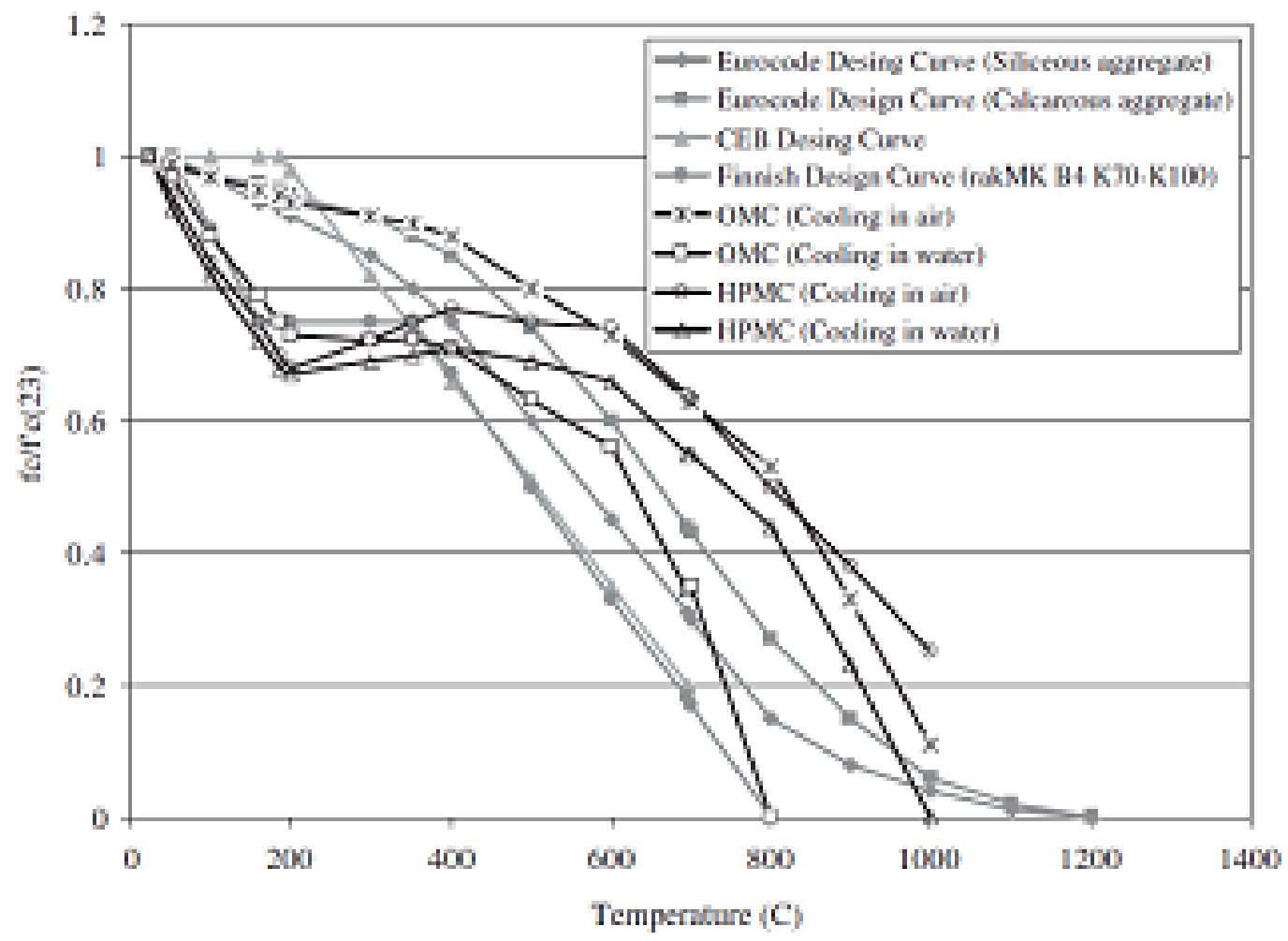

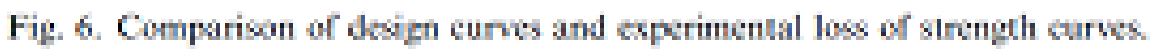

Figura 2.4- 1. Comparación de curvas de diseño y de las curvas de pérdidas experimentales de resistencia. Husem, M. [63]

Petkovski, M. [111], realiza los ensayos teniendo en cuenta que normalmente cuando las estructuras de hormigón están sometidas a un incremento de temperatura también están sometidas a un esfuerzo, pues están en pleno 
funcionamiento. En su trabajo observó que se obtienen menores resistencias en hormigones sometidos a temperatura, mientras se ejercía una tensión relativamente baja sobre ellos, que en los hormigones sobre los que no se aplica ninguna tensión al someterlos al aumento de temperatura.

En todos los ensayos puede comprobarse que el hecho de que se varíen las condiciones de ensayo, que el elemento esté sometido a esfuerzos o no, o que se haya dejado enfriar antes de realizar en el ensayo, así como el grado de humedad y temperatura de la muestra, afectan al grado de microfisuración de ésta, generando, por lo tanto, variaciones en su resistencia.

Existen otros análisis como el realizado por Phan, L.T. et al. [112], en el que se reflejan las diferencias de pérdida de resistencia cuando los hormigones están sometidos a cargas normales o a cargas elevadas, concluyéndose que los hormigones de alta resistencia tienen pérdidas de resistencia muy variables al estar sometidas a distintas temperaturas, y tienen una tendencia mayor a sufrir roturas explosivas cuando colapsan.

En general muchas de las investigaciones, aunque no realizan un estudio específico del comportamiento mecánico del hormigón utilizado como estructuras termoactivas, sí nos ilustran con datos de los ensayos realizados que nos pueden dar pistas sobre la evolución de las estructuras de hormigón sometidas a temperaturas inferiores a $100^{\circ} \mathrm{C}$.

En los ensayos realizados por Culfic, M.S. et al. [30], se observa como a $100^{\circ} \mathrm{C}$ de temperatura, tanto las probetas de hormigón de resistencia normal como las de alta resistencia pierden un $16 \%$ de su resistencia a compresión inicial, y en cuanto se aumenta algo más la temperatura las probetas de hormigón de resistencia normal aumentan su pérdida hasta un $22 \%$. En el estudio se estima que esas pérdidas iniciales, que pueden verse en la figura 2.4-2, son debidas a la pérdida de agua en el hormigón, que causa la disminución de las fuerzas de cohesión entre el silicato de calcio hidratado, formando microfisuras en el mortero y en la superficie de adherencia árido/pasta. 


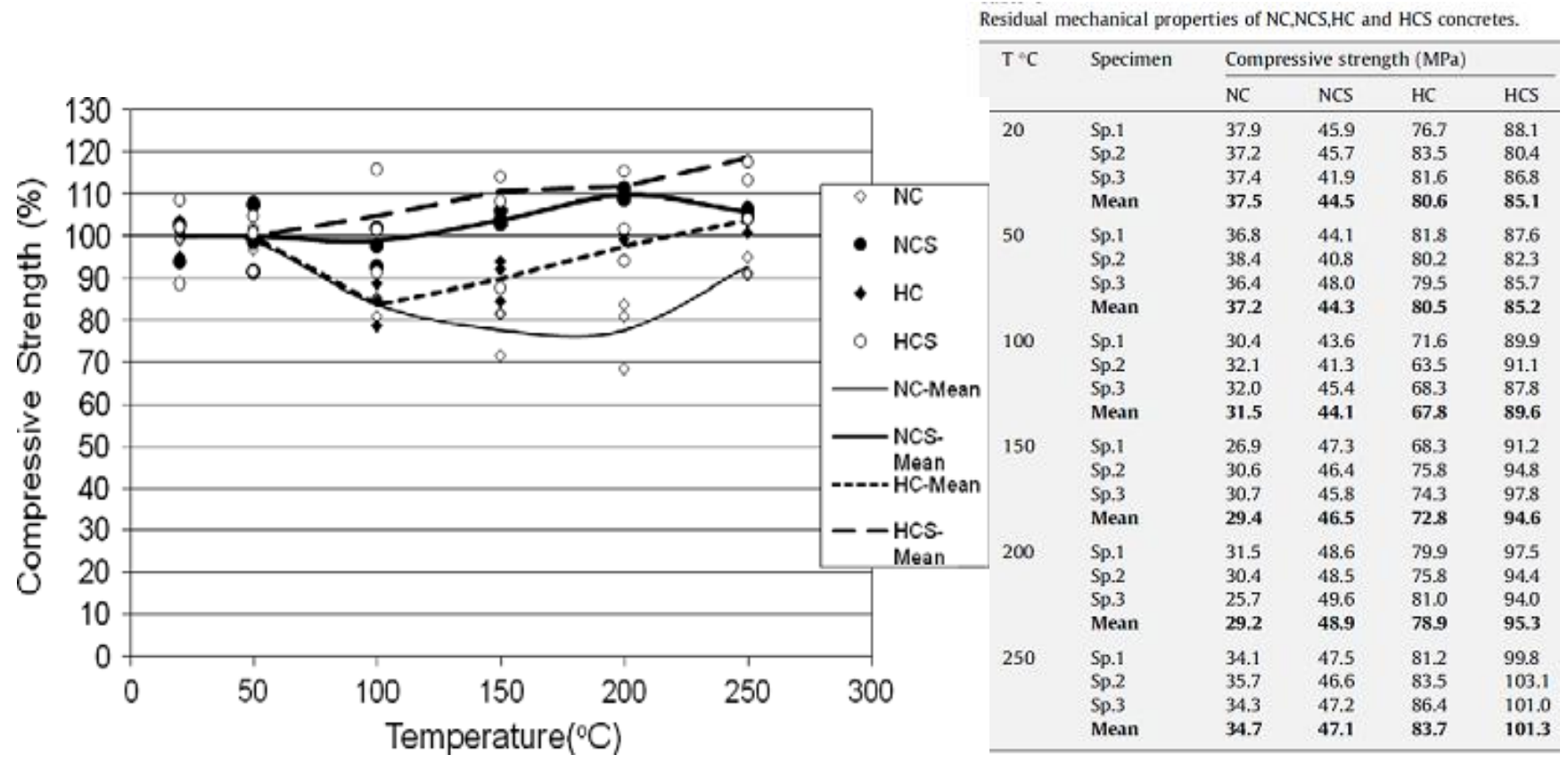

Figura 2.4- 2. Resistencia a compresión residual de hormigones normales y de alta resistencia con y sin adición de humo de sílice. Culfic, M.S. et al. [30]

La mayoría de las investigaciones realizadas, como la de Zhai, Y., et al. [140], Wu, X., et al. [134] y Kim, G., et al. [69], obtienen datos de ensayos a altas temperaturas que podrían ser extrapolables a nuestro caso, por abarcar rangos que cubren entre los $50^{\circ} \mathrm{C}$ y los $100^{\circ} \mathrm{C}$, si bien es cierto que muchas de las investigaciones como la de Sait, M., et al. [118], que muestran en sus resultados pérdidas de resistencia de alrededor del $20 \%$ para temperaturas de $100^{\circ} \mathrm{C}$, y avalarían los resultados que hemos obtenido en nuestro ensayo experimental, están realizadas con hormigones de alta resistencia.

No obstante, se puede considerar la comparación de los datos obtenidos para hormigones de alta resistencia con los obtenidos en la investigación que se relata en esta tesis doctoral, en la que se ha utilizado hormigón normal, ya que estudios realizados por [113] Potha, $M$. et al, a pesar de afirmar que los cambios en las capacidades mecánicas de hormigones normales y hormigones de alta resistencia no son iguales, confirman, coincidiendo con otros autores, que las diferencias en la reacción ante el fuego de hormigones normales y de alta resistencia, son notables 
a partir de los $200^{\circ} \mathrm{C}$ de temperatura, y las diferencias en las pérdidas de resistencia relativa ocurren desde temperaturas de $100^{\circ} \mathrm{C}$.

En la figura 2.4- 3, se ven reflejadas las conclusiones de Sait, M., et al. [118], que coinciden con los resultados que se han obtenido en los trabajos experimentales llevados a cabo en la investigación realizada en esta tesis doctoral.

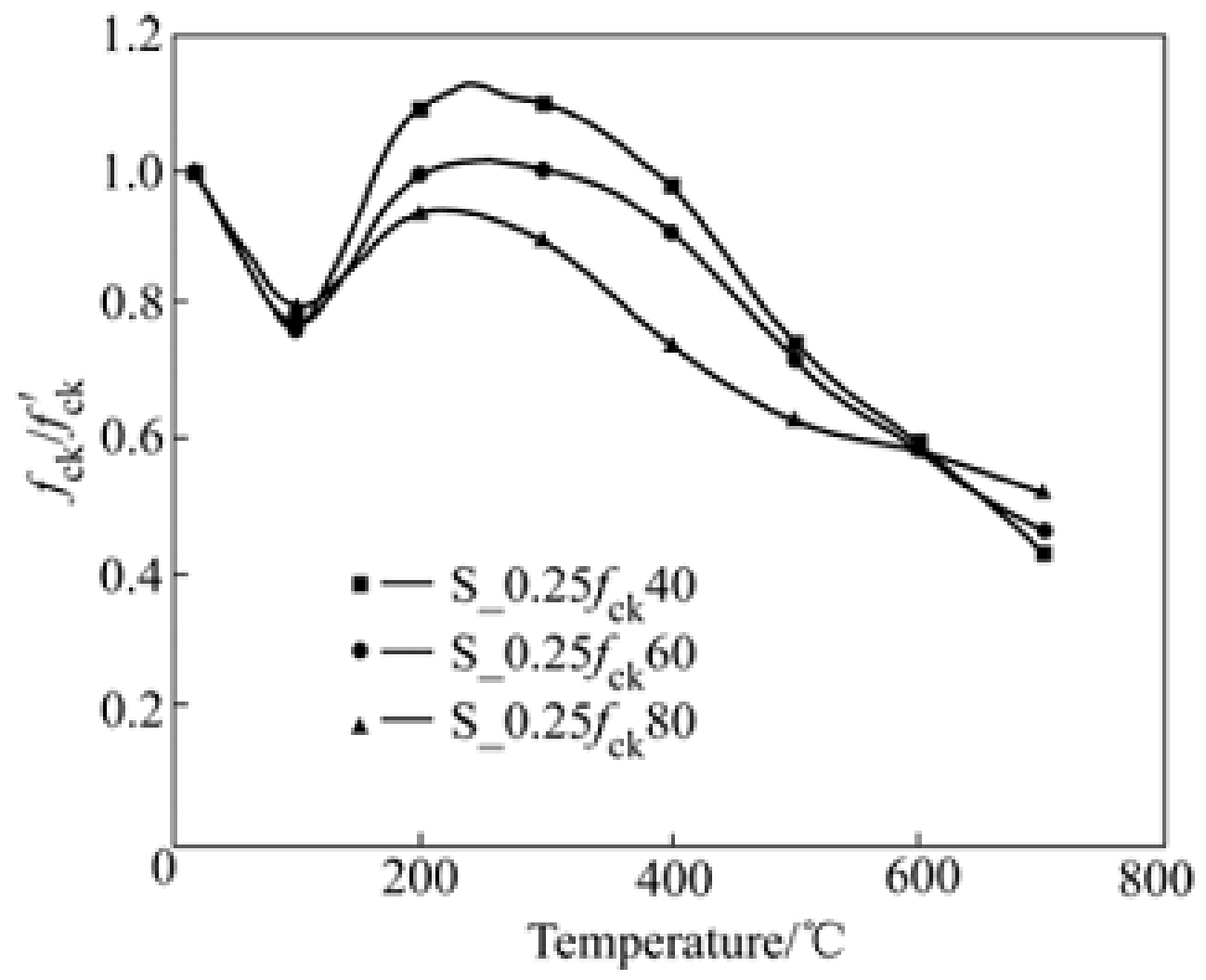

Figura 2.4- 3. Variación de la resistencia a compresión en función de la temperatura. Sait, M., et al. [118]

\subsubsection{Factores que afectan a la adherencia hormigón-acero.}

Se ha demostrado que la tensión de adherencia se ve afectada positivamente por las bajas temperaturas. (Shih, T.S. et al). [123]

En el caso de las altas temperaturas los ensayos demuestran que la pérdida de adherencia en barras corrugadas es del mismo orden de magnitud que la pérdida de resistencia a compresión del hormigón. (Katz, A. et al). [68] 


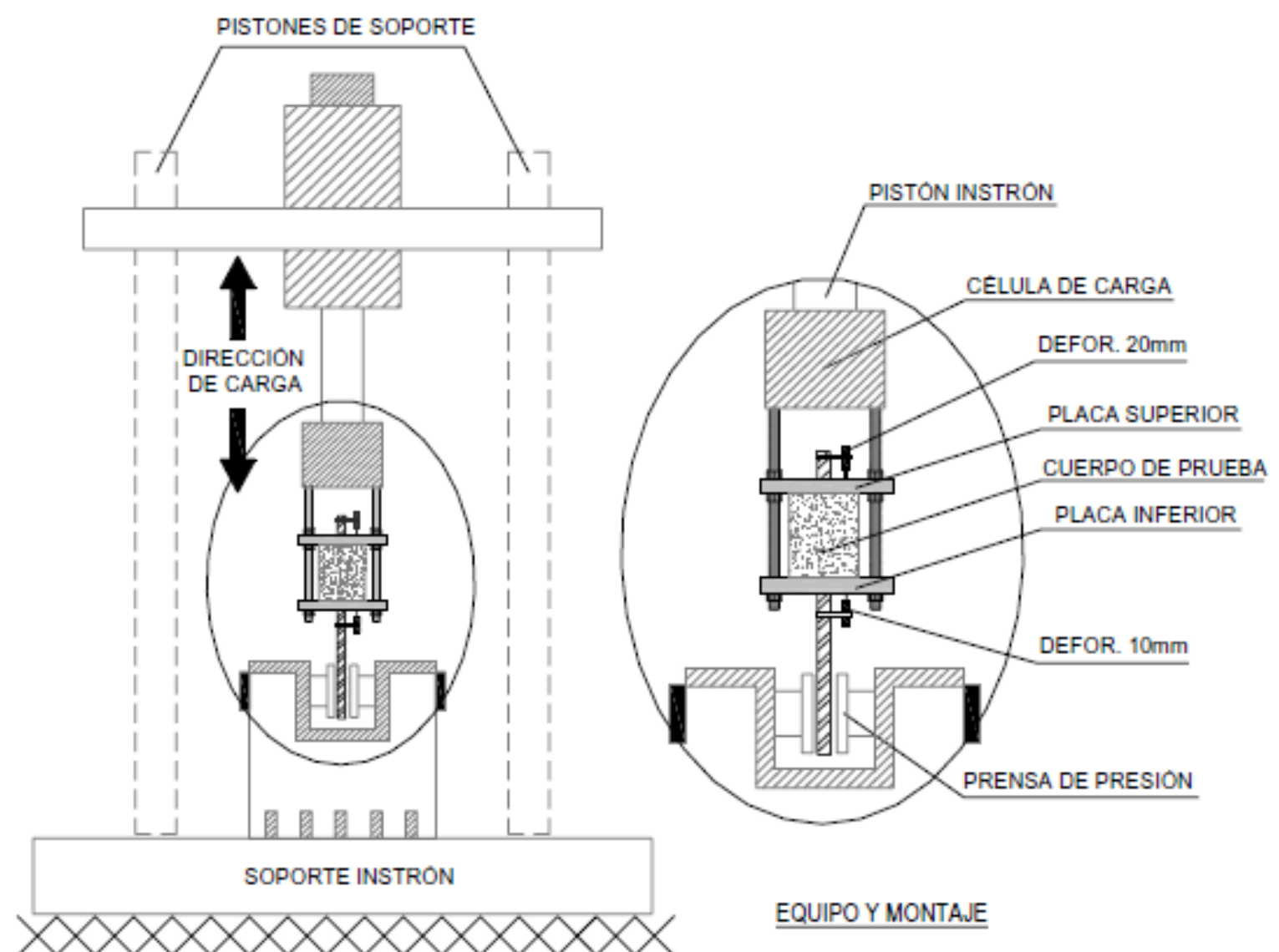

Figura 2.4- 4. Montaje e instrumentación de la máquina universal de ensayos mecánicos, servo-hidráulica. (Garzón, F.E. et al). [56]

Para una temperatura de $200^{\circ} \mathrm{C}$ la tensión de adherencia sufre una reducción severa entre el $80 \%$ y $90 \%$ respecto a una temperatura inicial de $+20^{\circ} \mathrm{C}$, además de cambios en las diferentes curvas de tensión de adherencia-deslizamiento, tal y como obtiene Diederichs, U. et al. [43], en los ensayos "pull-out" en barras de diámetro $16 \mathrm{~mm}$ y longitud adherida $5 \varphi$, para temperaturas de: $20^{\circ} \mathrm{C}, 300^{\circ} \mathrm{C}$, $370^{\circ} \mathrm{C}, 500^{\circ} \mathrm{C}, 600^{\circ} \mathrm{C}$ y $800^{\circ} \mathrm{C}$, donde se aprecia, de forma generalizada, la importante reducción de la tensión de adherencia con el aumento de la temperatura. 


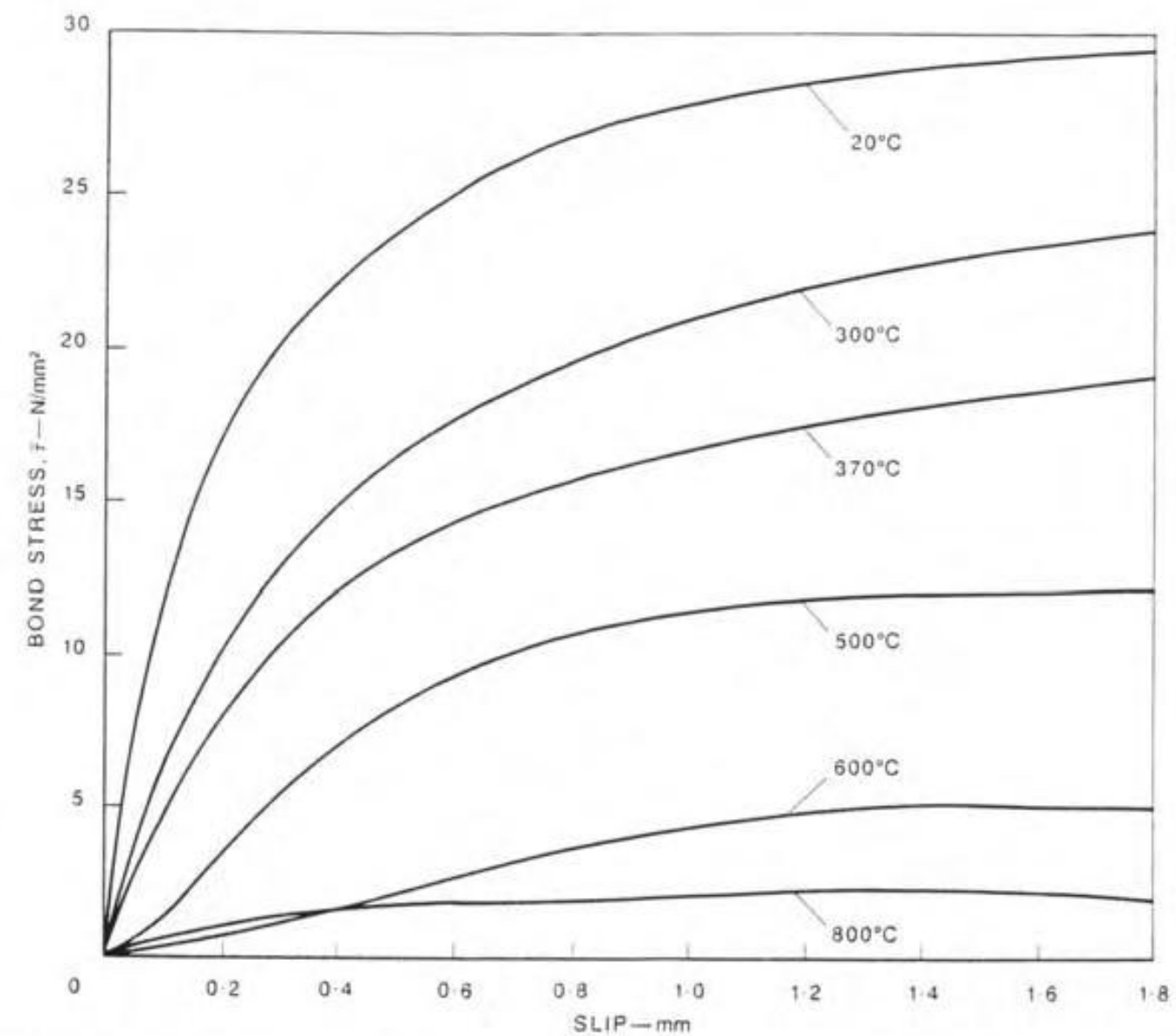

Figure 7: Bond-stress-slip relationship of cold deformed steel (Tor steel, BSt 420/500 RK) at elevated temperatures. $d_{\mathrm{e}}=16 \mathrm{~mm}, l_{\mathrm{v}}=80 \mathrm{~mm}$

Figura 2.4- 5. Relación tensión de adherencia-deslizamiento para diferentes temperaturas. (Diederichs, U. et al.) [43]

Bingol, A.F. et al. [12], calcularon el efecto de las elevadas temperaturas (ensayando probetas a 12 temperaturas distintas en un rango de $50^{\circ} \mathrm{C}$ a $700^{\circ} \mathrm{C}$ ) en la adherencia hormigón/acero, en función de si la probeta era enfriada al aire o con agua, y para distintos tipos de hormigón y de longitud de barra embebida. Como conclusión, observan que a partir de temperaturas de $150^{\circ} \mathrm{C}$ se producen reducciones de adherencia, y en cambio con temperaturas inferiores se producen aumentos en la resistencia a arrancamiento y reducciones en la resistencia a compresión del hormigón, existiendo pérdidas de adherencia y de resistencia superiores en las probetas enfriadas con agua que en las enfriadas al aire. 


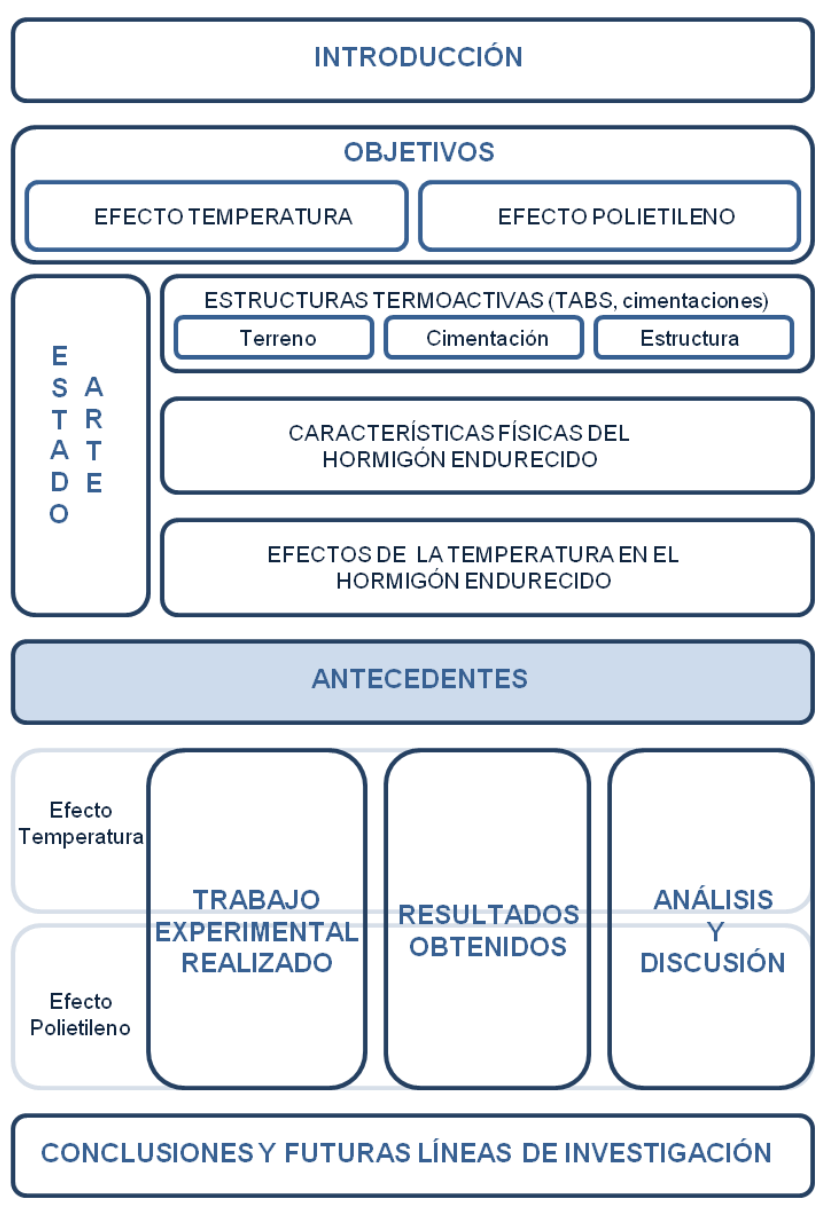

\subsection{Antecedentes que influyen en la metodología de cálculo.}

\subsubsection{Caracterización de los ensayos en probetas de hormigón endurecido.}

A continuación se aporta un estudio sobre los distintos métodos de caracterización de los tipos de ensayo que se han utilizado en el trabajo experimental de esta investigación, realizado con el fin de seleccionar los métodos más adecuados y a la vez factibles, al depender de la infraestructura existente en el laboratorio donde se han realizado los trabajos. 


\subsubsection{Métodos de caracterización de la resistencia a compresión del hormigón. Ensayo de resistencia a compresión.}

El comportamiento del hormigón a compresión se puede determinar mediante ensayos destructivos, que son los más utilizados, y no destructivos. Los primeros se realizan en laboratorio mediante la rotura de probetas cilíndricas o cúbicas dependiendo de la normativa del país en el que se realice el ensayo.

En España se realiza el ensayo siguiendo las especificaciones de la norma UNE-EN 12390-3: 2009, comprimiéndose las probetas hasta rotura en una maquina de ensayo de compresión conforme a la Norma EN 12390-4:2001, y después de que se registre la máxima carga alcanzada por la probeta, se calcula la resistencia a compresión del hormigón.

En España es usual determinar la resistencia a compresión sobre probetas cilíndricas de $15 \mathrm{~cm}$ de diámetro por $30 \mathrm{~cm}$ de altura, a la edad de 28 días y con un tamaño máximo de árido entre $20 \mathrm{~mm}$ y $40 \mathrm{~mm}$; no obstante, la norma permite su realización sobre probetas cúbicas o testigos que cumplan las especificaciones de las normas UNE correspondientes.

Se recomienda que la dimensión menor de las probetas, no sea inferior a 100 $\mathrm{mm}$, y se ha podido comprobar, empleando diferentes dimensiones de probetas, que, con áridos de tamaño máximo comprendido entre $20 \mathrm{~mm}$ y $40 \mathrm{~mm}$, las probetas de $15 \mathrm{~cm}$ de diámetro por $30 \mathrm{~cm}$ de alto, son las que proporcionan mayores resistencias y uniformidad en los resultados, mientras que con áridos de tamaño máximo de $10 \mathrm{~mm}$, las probetas de $10 \mathrm{~cm}$ de diámetro por $29 \mathrm{~cm}$ de alto son las más idóneas.

Los moldes empleados en la confección de probetas deben ser de acero y suficientemente rígidos, dado que estos proporcionan probetas más uniformes al tener dimensiones muy precisas y realizarse una buena compactación del hormigón en ellos.

Las probetas deben tener perfectamente planas y paralelas las caras que han de estar en contacto con los platos de la prensa; para ello, en el caso de las probetas cilíndricas, deben refrentarse con azufre para garantizar el paralelismo entre las caras comprimidas. 
Las probetas cúbicas no suelen tener este problema debido a que se ensayan en dirección perpendicular a la cara de moldeo, contando siempre con dos caras paralelas perfectamente planas.

La resistencia a compresión viene dada por la ecuación:

$$
f c=\frac{F}{A c}
$$

Donde:

fc es la resistencia a compresión, en Mpa (N/mm2),

$F$ es la carga máxima de rotura, en $\mathrm{N}$,

Ac es el área transversal de la probeta sobre la que actúa la fuerza de compresión, calculada a partir de las dimensiones normalizadas de la probeta.

La resistencia a compresión debe expresarse con aproximación de 0,1 Mpa $(\mathrm{N} / \mathrm{mm} 2)$.

Debido a la variación existente entre los resultados obtenidos, por roturas procedentes de la misma masa, no puede identificarse la resistencia compresión de un hormigón como la dada por la rotura de una única probeta, sino que hay que proceder a la rotura de una serie de ellas a fin de tener más certeza sobre el verdadero valor a tomar como resistencia representativa de los ensayos realizados.

En nuestra investigación de los ensayos, realizados sobre varias probetas de la misma amasada, se obtienen valores individuales para cada probeta, y se realiza la media aritmética para calcular la resistencia media a compresión del hormigón ensayado; utilizamos, por lo tanto, la resistencia media del hormigón, aunque esta no tenga en cuenta la dispersión entre los resultados individuales, para comparar los datos obtenidos de cada grupo de probetas ensayadas bajo las mismas características.

$\mathrm{Y}$, con el fin de comparar los datos entre probetas ensayadas bajo las mismas características, realizaremos el diagrama tensión-deformación partiendo de los datos que nos arroja la máquina de ensayos, dividiendo los valores de fuerza 
obtenidos por el área de la probeta a ensayar, y averiguaremos otra serie de valores que nos pueden ser de utilidad en la comparación de los resultados.

También conviene destacar que a la hora de calcular la resistencia a compresión de las probetas en las que se ha incorporado el tubo de polietileno, existe la posibilidad de realizar el cálculo teniendo en cuenta el área bruta de la probeta o el área neta al restarle el área ocupada por el tubo de polietileno y el hueco de su interior.

\subsubsection{Métodos de caracterización de la adherencia hormigón-acero.}

Los principales tipos de ensayo de adherencia que se utilizan son: arrancamiento directo de barras hormigonadas en cubos o prismas y los de adherencia en vigas mediante ensayos a flexión, que aunque parecen distintos, no constituye más que una variante del anterior, en la práctica los más utilizados son el ensayo de arrancamiento "pull-out", y el "beam-test".

Los métodos de caracterización de adherencia entre hormigón y acero, debidos a la complejidad del fenómeno de la adherencia, constituyen uno de los campos en los que más trabajo se ha invertido, los métodos normalizados "pullout", y "beam-test" fueron propuestos en Europa por la RILEM/CEB/FIP en 1970, y cada país adoptó una variante del método.

En el comité técnico del RILEM, Noghabai, K. [100] expuso las conclusiones de su trabajo, aunque todavía no han finalizado las investigaciones para obtener un método de ensayo normalizado definitivo de adherencia, ya que parece que tendría más sentido desarrollar un sistema de ensayos que se complementen entre sí, debido a la diversidad de formas en las que la adherencia puede afectar al comportamiento estructural.

\section{Ensayo de arrancamiento, "pull-out"}

El ensayo normalizado de "pull-out" contemplado por el CEB, sufrió una modificación en su versión de 1978, fruto del trabajo de la comisión VII "Reinforcement: Technology and Quality Control" del CEB, de acuerdo con el RILEM (Reunión International des Laboratories d'Essais de Matériaux), en la que se varió la dimensión de la arista de la probeta cúbica, a la cual se ancla la 
armadura, para realizar el ensayo a arrancamiento, que anteriormente debía ser 10 veces el diámetro de la barra y después de la revisión se adoptó un mínimo en la definición geométrica de la arista de la probeta de $200 \mathrm{~mm}$, condición que no afectaba prácticamente a las probetas con armaduras mayores a $16 \mathrm{~mm}$ de diámetro, pero si a las probetas en las que se utilizan armaduras inferiores a 16 mm. (Delibes, A. et al) [41]

En general se puede considerar que nunca un ensayo de adherencia es completamente satisfactorio; no obstante, los dos métodos más utilizados han permitido, gracias a las comparación de sus resultados, sentar criterios para establecer cuándo una geometría de corrugado es adecuada para su empleo con las fórmulas de adherencia, anclaje y fisuración actualmente en uso. (Calavera, J.) [21]

Pero, en concreto, este tipo de ensayos de arrancamiento está lejos de ser un método perfecto, puesto que presentan algunos inconvenientes, como la reacción de la probeta contra el plato de la prensa y coacción que el plato ejerce a la expansión transversal del hormigón, que, unidas a las reacciones de apoyo, crean una bóveda de compresiones que ejerce un cierto pinzamiento sobre la barra que hace mejorar las condiciones de adherencia.

Para reducir ese problema de pinzamiento de la armadura se coloca un protector de plástico, y para evitar el rozamiento placa probeta se coloca una plancha de goma entra la superficie de apoyo y la probeta.

Las directrices para la realización de este ensayo quedan recogidas en la norma UNE-EN 12504-3 y parte del CEB (1983) [26]. Este ensayo mide la fuerza necesaria que se aplica para romper la adherencia de una barra embebida en una probeta de hormigón.

Del ensayo se obtienen los diagramas tipo que relacionan la tensión de adherencia local y el desplazamiento de la barra en el extremo opuesto al que se aplica la carga respecto a la superficie de la probeta de hormigón, pero no es posible medir directamente la tensión de adherencia local y el deslizamiento relativo del la barra respecto al hormigón a lo largo de una longitud determinada, y el método para obtener estos valores consiste en medir la fuerza aplicada y asumir una distribución uniforme de la tensión. 


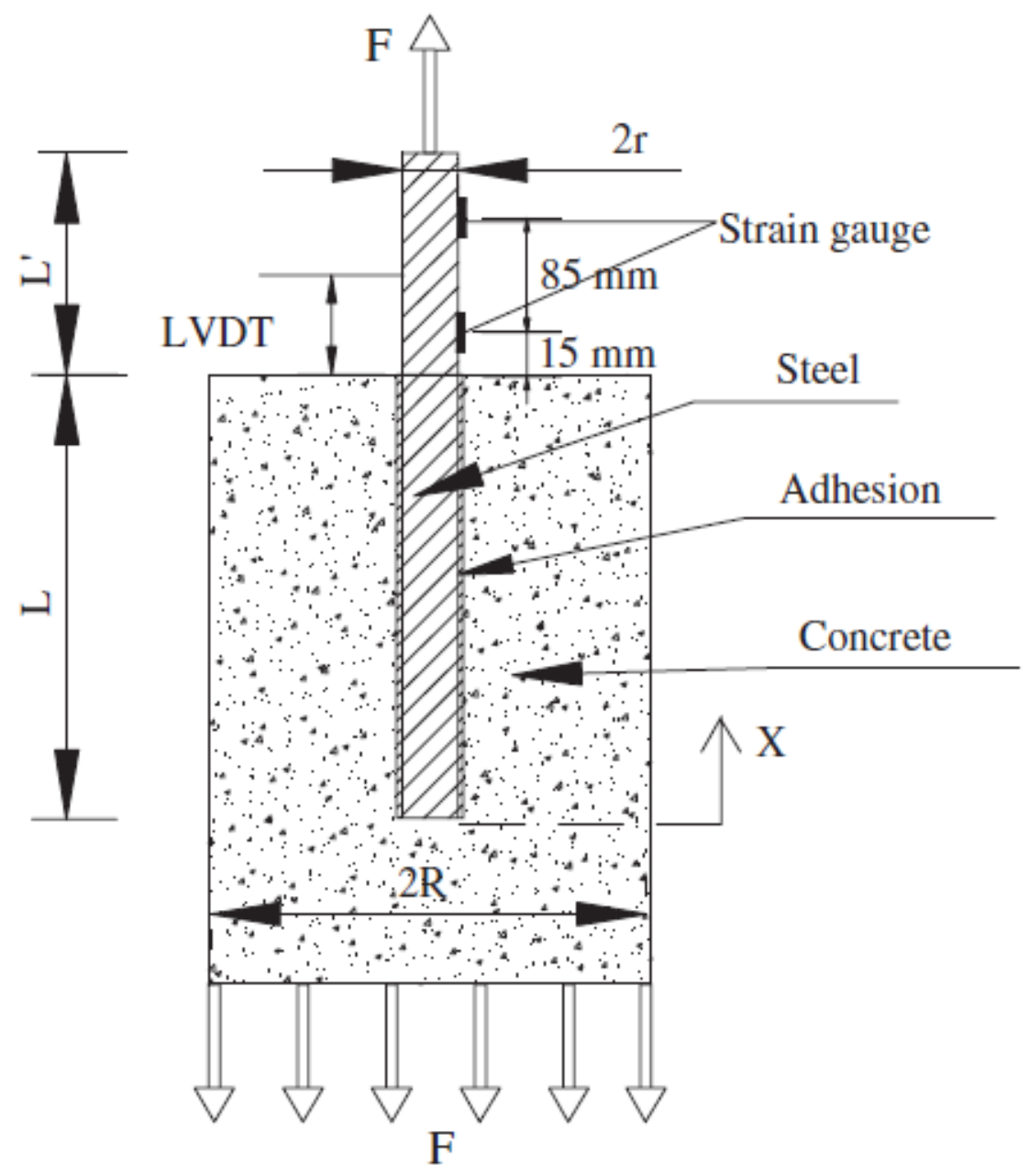

Figura 2.5- 1. Geometría del ensayo "pull-out". (Bouazaoui, L. et al) [14]

En los ensayos "pull-out" generalmente se sitúa la longitud adherente en el centro de una probeta prismática o cilíndrica de hormigón, de diferentes dimensiones, algunas veces relacionadas con el diámetro de la barra 0 simplemente un valor constante.

Existen otros ensayos basados en el "pull-out" desarrollados para analizar específicamente el fallo por splitting por ser el de mayor fragilidad y más relevante para el comportamiento estructural.

Los ensayos con "Iongitudes adherentes cortas", es decir, relación entre recubrimiento y diámetro de la barra menor que 5, pueden realizarse por 
deslizamiento de la barra, sin contar con ningún tipo de compresión transversal, o utilizando en la muestra algún tipo de confinamiento como cercos o anillos.

En ambos casos únicamente hay adherencia hormigón-acero en una zona de la barra, colocando en el resto unos protectores de plástico tipo "manguitos" que impiden la interacción entre los dos materiales.

\section{Ensayo de adherencia en vigas, "beam-test"}

Este ensayo es el adoptado por el CEB (1982) [27], por la antigua instrucción de hormigón estructural EHE, aunque la actual EHE-08 no lo menciona, y está descrito en la norma UNE 36740:98, aunque sea un ensayo a flexión; el método es muy similar al "pull-out" y tiene la ventaja de permitir hacer dos ensayos a la vez y el inconveniente de que el equipo de ensayo es bastante más complejo.

Consiste en la realización de un ensayo a flexión, mediante dos cargas puntuales simétricas, sobre una viga que está biapoyada. Del mismo modo al ensayo "pull-out", se obtienen gráficas de tensión de adherencia local y de desplazamientos, tomándose como tensión de adherencia la media entre las tensiones correspondientes a los desplazamientos de $0,01 \mathrm{~mm}, 0,1 \mathrm{~mm}$, y $1 \mathrm{~mm}$.

Al igual que en el ensayo "pull-out", se garantiza la zona no adherente mediante la colocación de manguitos de plástico alrededor de la barra.

Además de estos ensayos existen un gran número de modelos, Miguel, J. R. et al [107], y Humbert, J. et al [62], que simulan la transferencia de tensiones entre el hormigón y el acero, en los que la relación entre la tensión de adherencia y el deslizamiento no se debe a una característica específica de la barra, sino que es el resultado de haber tenido en cuenta la geometría, las propiedades del material y las condiciones de carga de la estructura.

Los mismos autores Miguel, J.R. et al [108] estudiaron uno de los nuevos procedimientos destinados a estudiar la capacidad adherente de las armaduras pretesas, denominado ECADA, que permite reproducir de manera secuencial, sobre una misma pieza de hormigón, las operaciones de transmisión del pretensado y de puesta en servicio, y permite no sólo averiguar la longitud de transmisión, como ocurre con los ensayos "pull-out" y "beam-test", sino también, determinar la longitud de anclaje de la armadura. 
a)
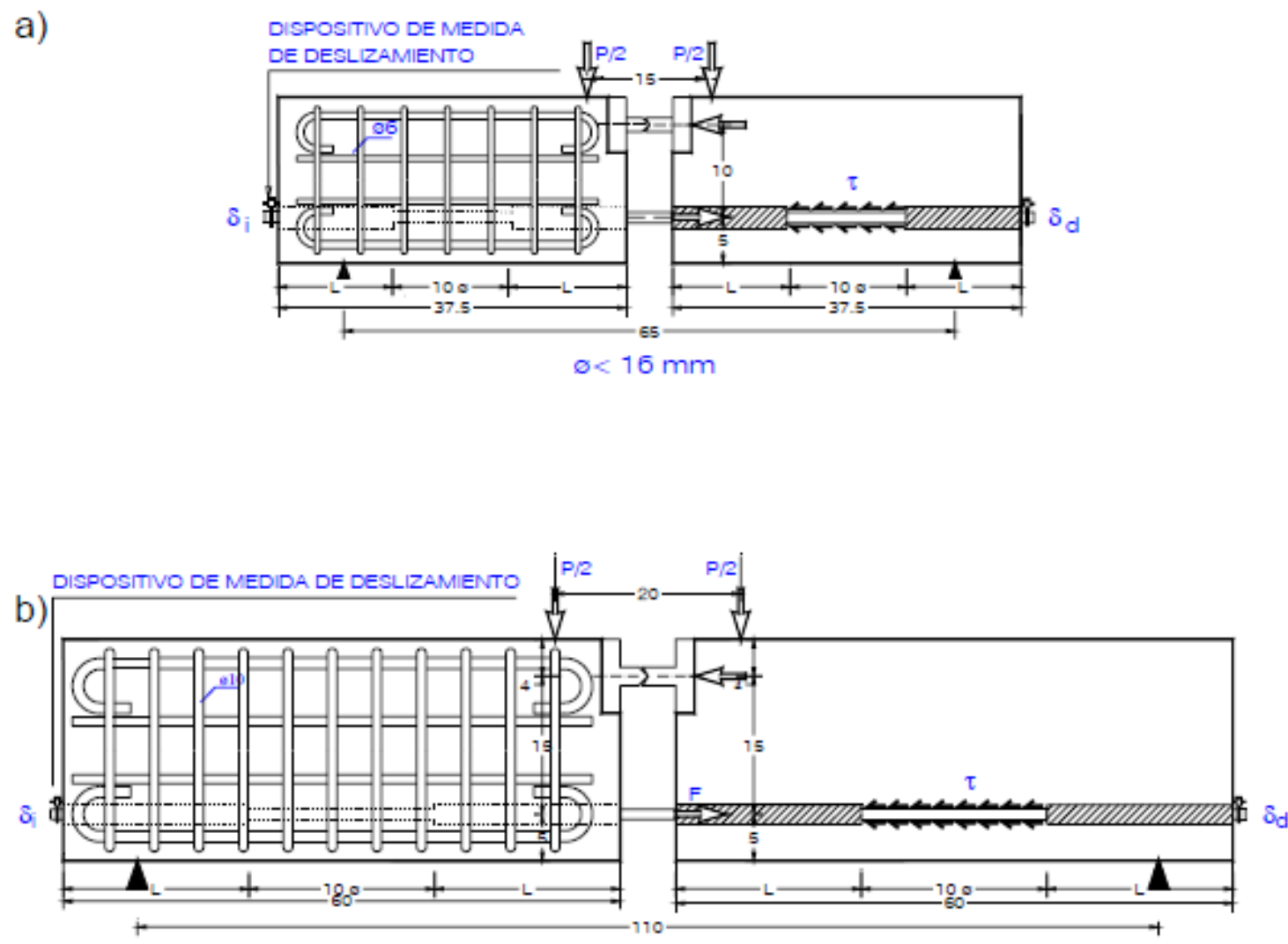

ø> $16 \mathrm{~mm}, \mathrm{BT} 2+\mathrm{BT} 3$

UNE $36740: 98$

Figura 2.5- 2. Ensayo tipo "beam-test" para la homologación de la adherencia en barras corrugadas: a) geometría de vigas para $\varnothing<16 \mathrm{~mm}$, y b) geometría de vigas para $\varnothing \geq 16 \mathrm{~mm}$, (cotas en cm). (Molina. M) [93] 


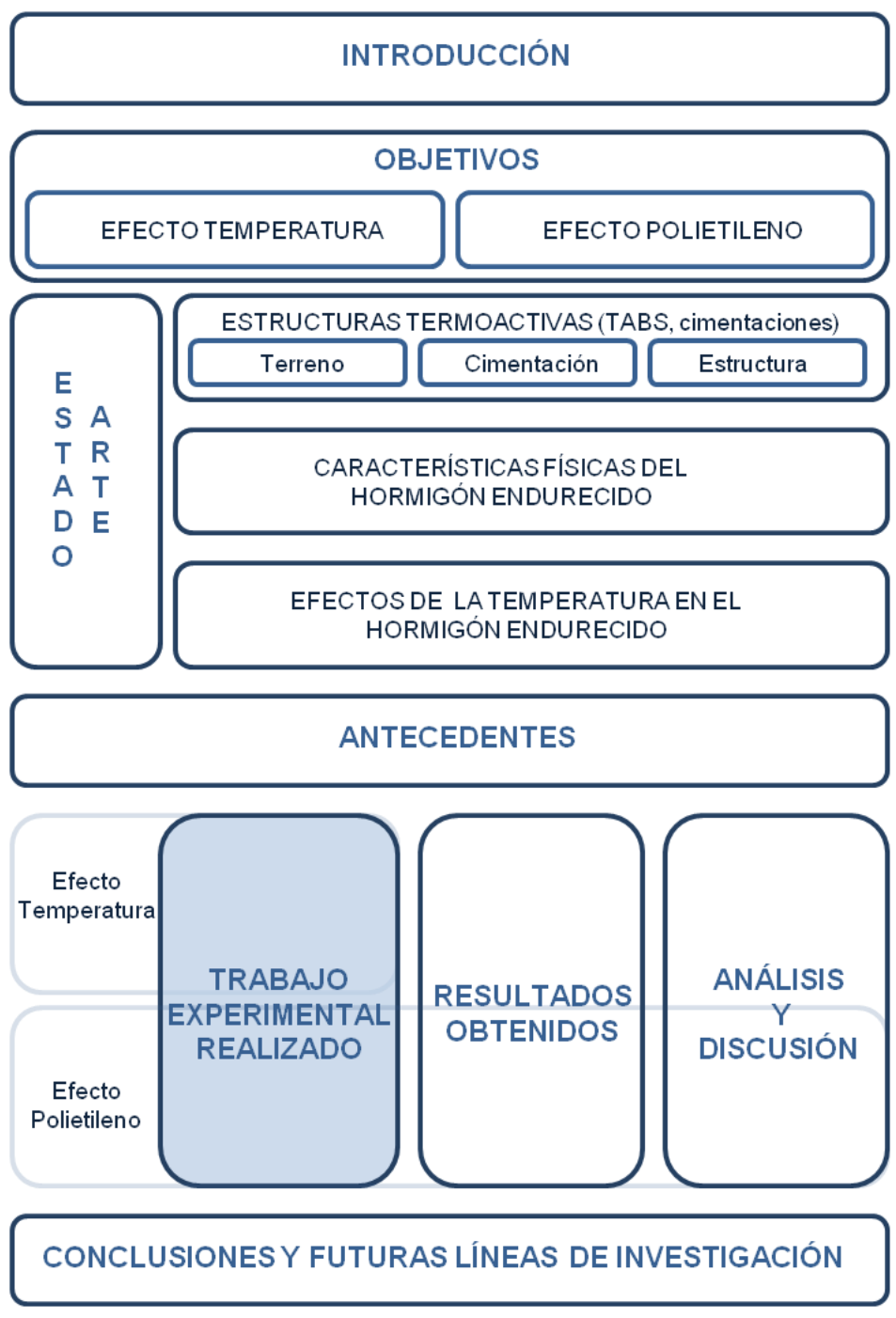

CAPÍTULO 3

TRABAJO

EXPERIMENTAL

REALIZADO 


\subsection{Introducción}

Se realizó una campaña experimental de probetas de hormigón, estudiando por separado los dos efectos que se producen en las estructuras de hormigón al ser activadas térmicamente:

- Para evaluar el efecto de la temperatura, se elaboraron 52 probetas con dos tipos de hormigones, tipo $\mathrm{H}-25$ y tipo $\mathrm{H}-30$, y fueron sometidas a cuatro temperaturas diferentes: $20^{\circ} \mathrm{C}, 40^{\circ} \mathrm{C}, 70^{\circ} \mathrm{C}$ y $100^{\circ} \mathrm{C}$, ejecutándose la mitad de ellas con molde cilíndrico para realizar ensayos de resistencia a compresión y la otra mitad con molde de probeta cúbica a la que se incorporó una armadura de acero corrugado de $10 \mathrm{~mm}$ de diámetro para determinar su adherencia mediante ensayo de arrancamiento "pull-out".

Con este fin se realizaron 2 amasadas, una con hormigón $\mathrm{H}-25$ y probetas cilíndricas para ensayar a compresión, y cúbicas con armadura embebida para ensayar a arrancamiento (amasada 1), y otra con hormigón H-30 y probetas cilíndricas para ensayar a compresión, y cúbicas con armadura embebida para ensayar a arrancamiento (amasada 2).

- Para analizar el efecto de la incorporación de los tubos, se realizaron 54 probetas, 24 elaboradas con molde cilíndrico y 30 con molde cúbico, la mitad de cada tipo con hormigón, $\mathrm{H}-25$ y la otra mitad con hormigón $\mathrm{H}-30$, y se colocaron tubos de polietileno en su interior en distintas posiciones, para posteriormente efectuar ensayos de su resistencia a compresión.

Se realizaron 2 amasadas, una con hormigón H-25 y probetas cilíndricas, cúbicas y tubos de polietileno dispuestos en distintas posiciones, para ensayar a compresión (amasada 1), y otra con hormigón H-30 y probetas cilíndricas, cúbicas y tubos de polietileno dispuestos en distintas posiciones, para ensayar a compresión (amasada 2). 


\subsection{Materiales utilizados y proceso de elaboración}

Para el desarrollo de la parte experimental de este trabajo se contó con los siguientes medios pertenecientes al laboratorio de materiales de las Escuela Técnica Superior de Edificación de Madrid (ETSEM) de la Universidad Politécnica de Madrid.

- Amasadora de hormigón planetaria de eje vertical con una capacidad máxima de 100 litros y capacidad de trabajo de 75 litros IBETERTEST modelo CIB-701 actualizado a IB32-040V0.

- Báscula Balanco con esfera graduada de 0 a $100 \mathrm{Kg}$

- Tamices metálicos UNE 7050

- Equipos de ensayo de consistencia del hormigón fresco (Cono de Abrams).

- Moldes cúbicos de 100×100 mm de fundición.

- Moldes cilíndricos 100x200 mm de acero.

- Sensor térmico para mediar la temperatura interna de la probeta.

- Tubos de polietileno reticulado de $24 \mathrm{~mm}$ de diámetro exterior, fabricados por la empresa Uponor, utilizados para estudiar el efecto de su incorporación en el interior de las probetas.

- Cámara de curado.

- $\quad$ Dispositivo de refrentado de $100 \mathrm{~mm}$ de diámetro y equipo para fundir azufre

- $\quad$ Estufa de secado P/Selecta de 150 litros. Modelo 2210 de $2 \mathrm{Kw}$ con selector de temperatura de $0^{\circ}$ a $250^{\circ} \mathrm{C}$

- Prensa universal IBERTEST MIB-60/AM para ensayos de rotura a compresión y a tracción. Con actualización de software Wintest 32 instalado en el ordenador para la obtención de los resultados.

- $\quad$ Mordazas de agarre prensa universal (0-5) y (5-16) planas.

- Armadura corrugada de diámetro $10 \mathrm{~mm}$ 


\section{Materiales empleados}

\section{- Áridos (Arenas y grava)}

Los áridos empleados provienen de la gravera Sotopajares que pertenece a la empresa Aricemex S.A., situada en la ctra. Arganda-Chinchón Km 4,2, 28330 San Martín de la Vega, Madrid.

La arena utilizada para elaborar el hormigón es un árido fino de fracción granulométrica $0 \mathrm{~mm}-4 \mathrm{~mm}$ de naturaleza silícea lavada.

La grava utilizada es un árido grueso de fracción granulométrica 4 mm-20 mm también de naturaleza silícea lavada. El tamaño máximo de árido grueso se ha fijado en $12 \mathrm{~mm}$.

\section{- Cemento}

Aunque todos los cementos utilizados cumplen con la Instrucción RC-08, se utilizaron 4 tipos distintos de cemento para cada una de las cuatro amasadas realizadas, ya que no se iba a establecer ninguna relación entre los parámetros ensayados en las probetas de cada amasada.

Los cuatro cementos empleados pertenecen a la empresa Portland Valderrivas, S.A. elaborados en la fábrica "El Alto" situada en la carretera M-311, Km. 4,5, 28530 Morata de Tajuña, Madrid, conforme a la norma UNE-EN 1971:2000/A3:2008

Amasada 1: CEM II/BL 32,5

Amasada 2: CEM II/AL 42,5

Amasada 3: CEM IV/B (V) $32,5 \mathrm{~N}$

Amasada 4: CEM II/AL 42,5 R

\section{- Adiciones}

No se utilizó ningún tipo de adición. 


\section{- Agua}

El agua que se utilizó procedía del sistema de suministro del Canal de Isabel II, ya que cumple con las prescripciones que se establecen para el hormigón estructural.

\section{- Aditivo}

No se utilizó ningún tipo de aditivo.

\section{Dosificaciones de cada amasada}

En la tabla 3- 1 se muestra la dosificación que se utilizó para elaborar las cuatro amasadas, los contenidos de cada material y los conos obtenidos.

\begin{tabular}{|c|c|c|c|c|c|}
\hline AMASADAS & 1 & 32 & 3 & {$\left[\begin{array}{lll}4 & \square\end{array}\right.$} & \\
\hline $\begin{array}{l}\text { TIPO DE } \\
\text { HORMIGÓN }\end{array}$ & $\mathrm{H}-25$ & $\mathrm{H}-30$ & H-25 & $\mathrm{H}-30$ & \\
\hline $\begin{array}{l}\text { TIPO DE } \\
\text { CEMENTO }\end{array}$ & $\begin{array}{c}\text { CEM II/BL } \\
32,5\end{array}$ & $\begin{array}{c}\text { CEM II/AL } \\
42,5\end{array}$ & $\begin{array}{l}\text { CEM IV/B } \\
\text { (V) } 32,5 \mathrm{~N}\end{array}$ & $\begin{array}{c}\text { CEM II/AL } \\
\text { 42,5 R }\end{array}$ & DOSIFICACIÓN \\
\hline CEMENTO kg & 21,00 & 15,50 & 15,50 & 15,50 & 1,00 \\
\hline ARENA kg & 56,28 & 41,54 & 41,54 & 41,54 & 2,68 \\
\hline GRAVA kg & 53,76 & 39,68 & 39,68 & 39,68 & 2,56 \\
\hline AGUA kg & 10,71 & 7,90 & 6,26 & 7,90 & 0,51 \\
\hline CONO & 8,5 & 9,5 & 13 & 10 & \\
\hline
\end{tabular}

Tabla 3- 1. Dosificación de las amasadas, contenidos de cada material y resultados de cono de Abrams obtenidos. Elaboración propia.

* Las variaciones en la cantidad de agua incorporada se deben a las diferencias de humedad en las arenas utilizadas en cada amasada. 


\section{Proceso de fabricación del hormigón}

El proceso de elaboración del hormigón fresco que describe a continuación se repitió para cada una de las 4 amasadas elaboradas:

En primer lugar, y previamente al inicio de la fabricación del hormigón, los materiales se mantienen 24 horas en condiciones de laboratorios.

Se tamiza la grava para garantizar que no hubiese áridos de tamaño superior a $12 \mathrm{~mm}$.

Se procede al pesado por separado de cada uno de los materiales a utilizar cemento, arena, grava y agua, con una báscula industrial tipo dial.

El amasado se realiza en una amasadora planetaria de eje vertical con una capacidad máxima de 100 litros y capacidad de trabajo de 75 litros, previa humectación del tambor, donde se introducen los materiales en el siguiente orden: grava, cemento, y, por último, la arena.

Una vez incorporados todos los materiales, excepto el agua en la amasadora, se inicia el proceso de amasado con la ayuda de las paletas rotatorias de la hormigonera, con una duración de aproximadamente 2 minutos con el objetivo de homogenizar bien la mezcla en seco. Posteriormente se mide la cantidad de agua, corrigiendo el aporte de la arena húmeda. Pasado este tiempo, sin parar la hormigonera, se añade el agua corrigiendo su factor por el agua aportada por la arena. La duración del proceso de amasado fue de alrededor de 5 minutos (contabilizando los 2 minutos previos de amasado en seco).
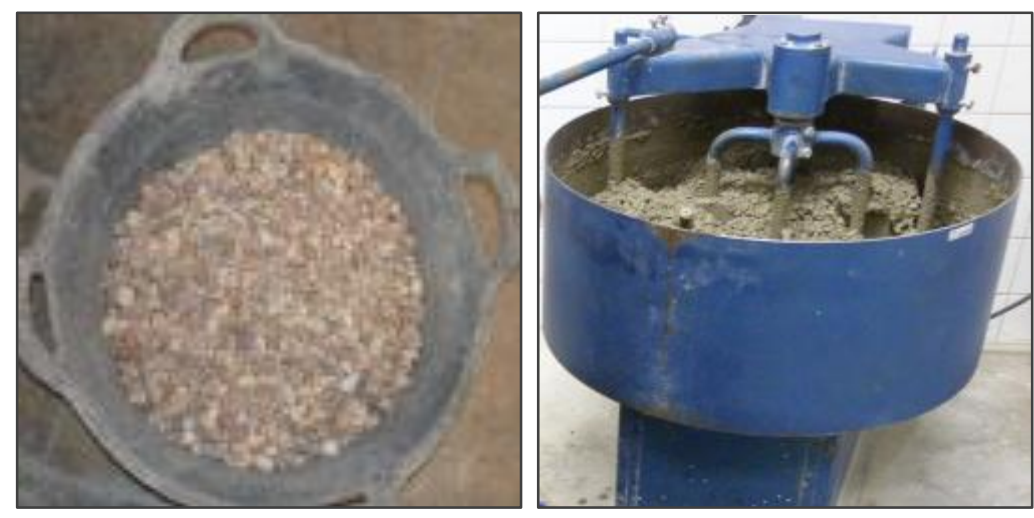

Figura 3- 1. Proceso de fabricación del hormigón, grava pesada antes de ser incorporada, amasado en la amasadora. 
Tras el proceso de amasado, se procede en cada amasada a analizar la consistencia del hormigón, por medio de ensayo de asentamiento según norma UNE-EN 12350-2, 2009, utilizando el cono de Abrams y una placa de acero plana metálica de 850 × $850 \mathrm{~mm}$.

El ensayo se efectúa en las cuatro amasadas de la siguiente manera. Primero, se coloca el cono en el centro de la bandeja. Se llena el molde en tres tongadas compactando el hormigón con una barra compactadora de acero, picando 25 veces cada capa. Se enrasa y se levanta el molde, midiéndose el asentamiento tal y como se observa en la figura 3-2. De modo que el diferencial obtenido entre la regla dispuesta horizontalmente a la altura del cono y la masa del hormigón constituye el asentamiento producido por el mismo.

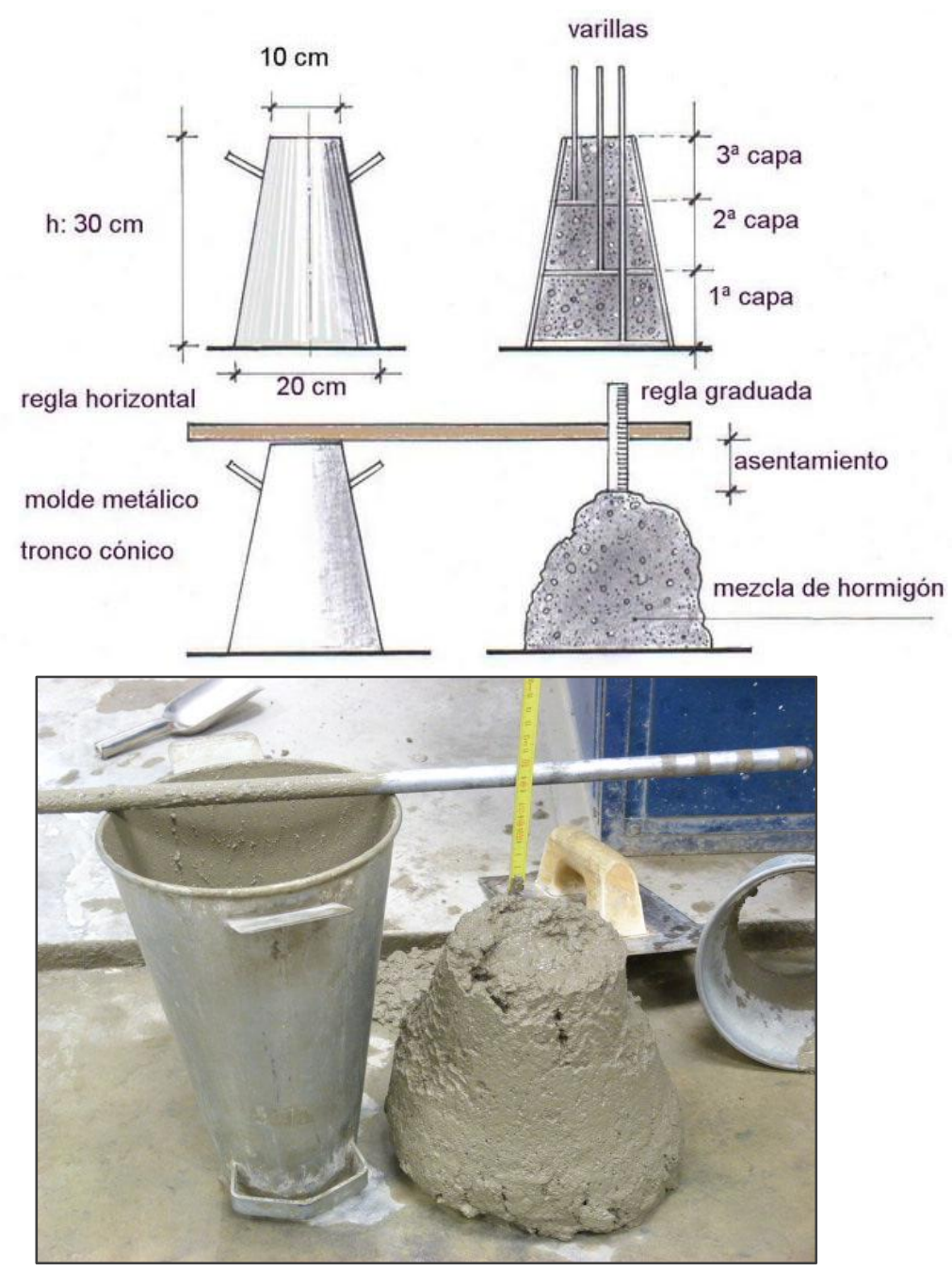

Figura 3- 2. Ensayo de asentamiento para analizar la consistencia del hormigón. 


\section{Proceso de elaboración de las probetas de hormigón fresco}

Una vez elaborado el hormigón fresco de cada una de las cuatro amasadas, se procede al llenado de los moldes, cuyas características geométricas cumplen, en todo caso, la norma UNE-EN 12390-1:2001

En cada amasada se procede a realizar el llenado de las probetas de un modo distinto en función de la forma de la probeta, y de si debe llevar anclada una armadura corrugada para el posterior ensayo a arrancamiento, o si debe llevar embebido un tubo de polietileno. Las características específicas del llenado de las probetas mencionadas se relatan en el siguiente apartado de ensayos.

Se fabrican cuatro tipos de probetas, y en número suficiente de cada tipo, de modo que siempre existan 3 probetas idénticas de hormigón de la misma amasada y con las mismas características de estudio, y así poder utilizar como valor de resistencia la media aritmética de los tres valores, tanto en el caso de los ensayos a compresión como el de los ensayos a arrancamiento.

- Cilíndricas de $100 \varnothing \times 200$ mm. Empleadas para realizar los ensayos de rotura a compresión a distintas temperaturas. (2 amasadas, una con hormigón $\mathrm{H}-25$, amasada 1, y otra con hormigón $\mathrm{H}-30$, amasada 2)

- Cúbicas de 100 × 100 mm, con armadura de 10 mm de diámetro anclada en su interior. Empleadas para realizar los ensayos a arrancamiento o "pull-out" a distintas temperaturas. (2 amasadas, una con hormigón $\mathrm{H}-25$, amasada 1, y otra con hormigón H-30, amasada 2)

- Cilíndricas de $100 \varnothing \times 200 \mathrm{~mm}$. Colocando tubos de polietileno de $24 \mathrm{~mm}$ en su interior en distintas posiciones. Empleadas para los ensayos de rotura a compresión. (2 amasadas, una con hormigón H-25, amasada 3, y otra con hormigón $\mathrm{H}-30$, amasada 4)

- Cúbicas de 100 x $100 \mathrm{~mm}$. Colocando tubos de polietileno de $24 \mathrm{~mm}$ en su interior en distintas posiciones. Empleadas para los ensayos de rotura a compresión. (2 amasadas, una con hormigón H-25, amasada 3, y otra con hormigón H-30, amasada 4)

Una vez confeccionado el hormigón, se llenan los moldes de los diferentes tipos de probetas, según la norma UNE-EN12390-2:2001. Posteriormente se 
enrasan y se mantienen durante 24 horas a temperatura ambiente de laboratorio a $22^{\circ} \mathrm{C} \pm 3^{\circ} \mathrm{C}$ y humedad relativa aproximada del $60 \%$, antes de proceder a su desencofrado.

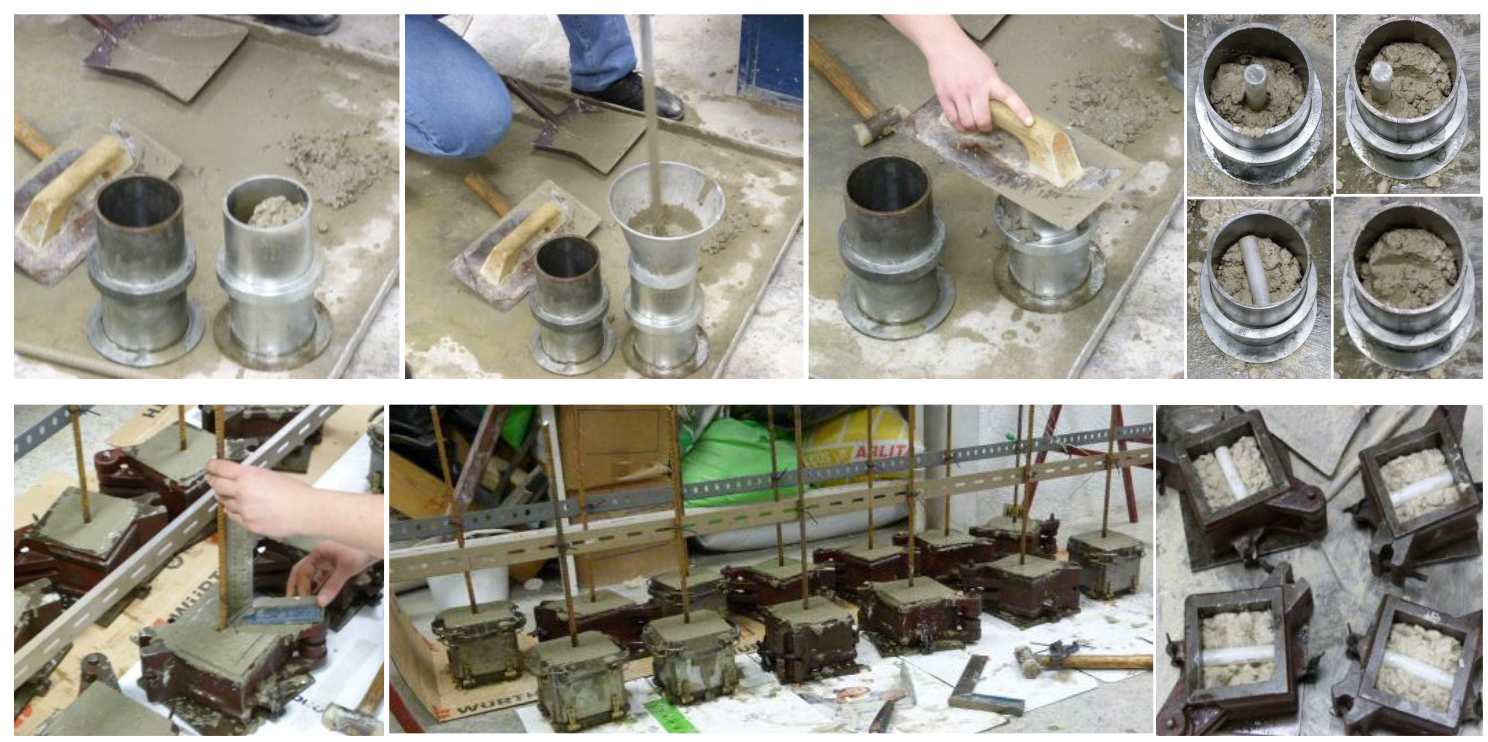

Figura 3- 3. Proceso de elaboración de los cuatro tipos de probetas. Arriba 3 imágenes izquierda: elaboración de probetas cilíndricas para analizar efecto temperatura y ensayar a compresión; arriba imagen derecha: probetas cilíndricas para analizar efecto incorporación tubo polietileno y ensayar a compresión; abajo izquierda: probetas cúbicas con armadura corrugada embebida para analizar efecto temperatura y ensayar a "pull-out"; abajo derecha: probetas cúbicas para analizar efecto incorporación tubo de polietileno y ensayar a compresión.

Transcurrido este tiempo, se desmoldan y se guardan en una cámara de curado a temperatura de $20^{\circ} \mathrm{C} \pm 2{ }^{\circ} \mathrm{C}$ y humedad relativa $\geq 95 \%$ durante 28 días.

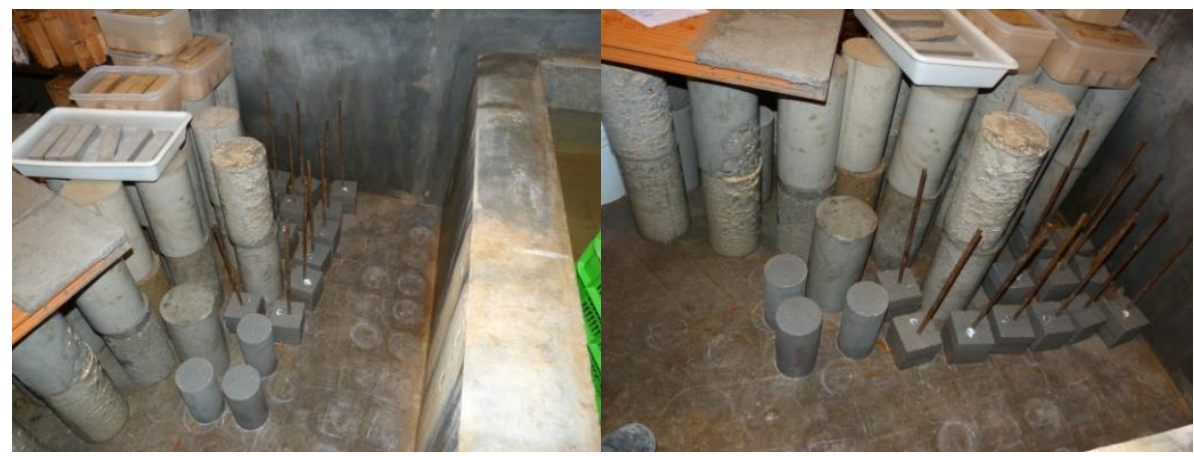

Figura 3- 4. Proceso de curado de las probetas en cámara. 


\section{Planificación de los procesos de fabricación del hormigón}

En la tabla 3- 2 se muestran las fechas en las que se procedió a la elaboración del hormigón fresco, desencofrado de las probetas, introducción y permanencia en cámara de curado, extracción de la cámara y rotura de las probetas.

\begin{tabular}{|c|c|c|c|c|}
\hline AMASADAS & 1 & 2 & 3 & 4 \\
\hline TIPO DE HORMIGÓN & $\mathrm{H}-25$ & H-30 & H-25 & $H-30$ \\
\hline FECHA ELABORACIÓN & 1 Marzo 2011 & 9 Marzo 2011 & 30 Marzo 2011 & 6 Abril 2011 \\
\hline $\begin{array}{c}\text { FECHA INTRODUCCIÓN } \\
\text { EN CÁMARA }\end{array}$ & 2 Marzo 2011 & 10 Marzo 2011 & 31 Marzo2011 & 7 Abril 2011 \\
\hline $\begin{array}{c}\text { FECHA EXTRACCIÓN } \\
\text { DE CÁMARA }\end{array}$ & 30 Marzo 2011 & 7 Abril 2011 & 29 Abril 2011 & $\begin{array}{l}6 \text { Mayo } \\
2011\end{array}$ \\
\hline $\begin{array}{l}\text { FECHA ROTURA } \\
\text { PROBETAS }\end{array}$ & $\begin{array}{c}6 \text { Y } 7 \text { Abril } \\
2011\end{array}$ & $\begin{array}{c}13 \text { Y } 14 \text { Abril } \\
2011\end{array}$ & $\begin{array}{c}4 \text { Y } 5 \text { Mayo } \\
2011\end{array}$ & $\begin{array}{c}11 \text { Y } 12 \\
\text { Mayo } 2011\end{array}$ \\
\hline
\end{tabular}

Tabla 3- 2. Fechas de los procesos de elaboración, curado y ensayo de las probetas realizadas con las 4 amasadas de hormigón fresco ejecutadas. Elaboración propia.

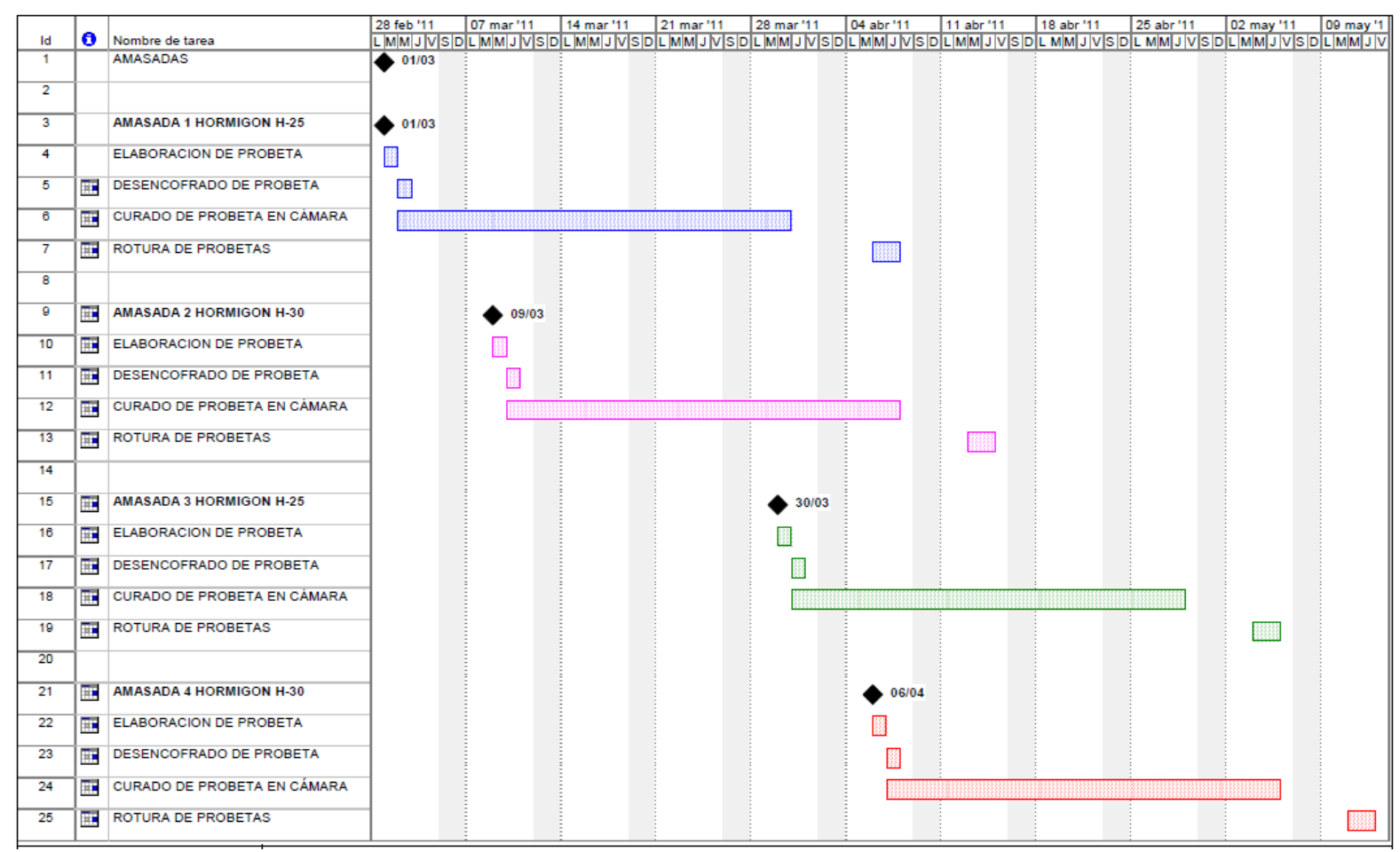

Figura 3- 5. Diagrama de Gantt con la planificación de los trabajos. Elaboración propia.

Se utilizó el software Microsoft Project para elaborar el diagrama que se presenta en la figura 3- 5, con el fin de mostrar la planificación de los trabajos realizados de un modo más gráfico. 


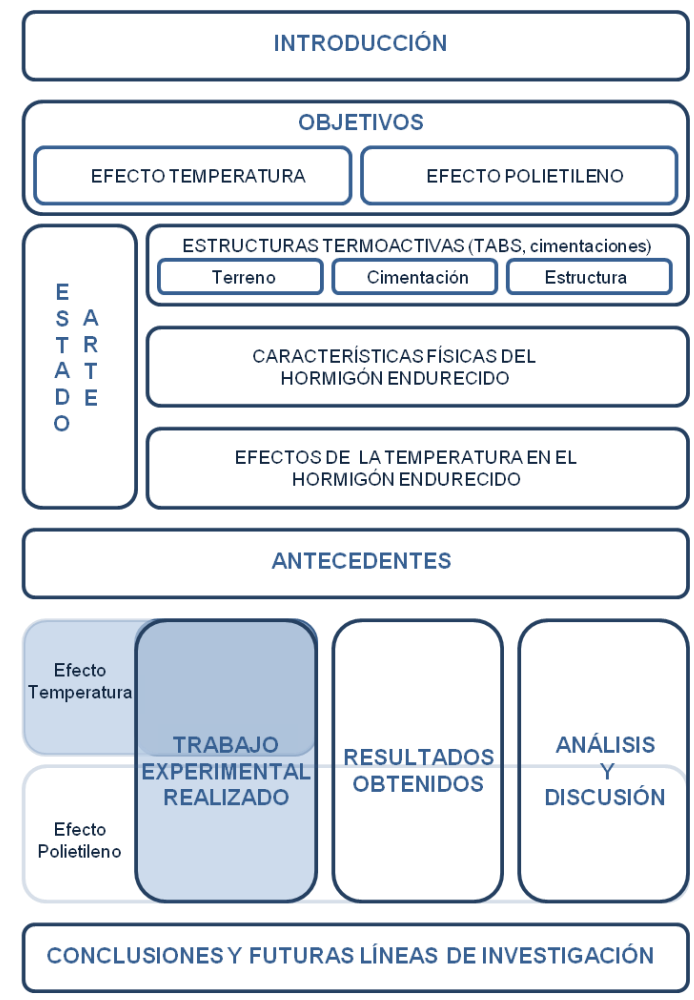

\subsection{Estudio del efecto del incremento de temperatura}

Con el fin de conocer el efecto producido por el ascenso de temperatura de $20^{\circ} \mathrm{C}, 40^{\circ} \mathrm{C}, 70^{\circ} \mathrm{C}$ y $100^{\circ} \mathrm{C}$, se procedió a la elaboración de probetas cilíndricas para ensayar a compresión, elaboradas con hormigón H-25 (amasada 1) y con hormigón H-30 (amasada 2), y a la elaboración de probetas cúbicas con armadura corrugada embebida para ensayar a "pull-out", elaboradas con hormigón H-25 (amasada 1) y con hormigón H-30 (amasada 2).

\subsubsection{Probetas cilíndricas para estudiar el efecto del incremento de temperatura analizando su resistencia a compresión}

Se elaboraron 26 probetas cilíndricas con los dos tipos de hormigones fabricados, $\mathrm{H}-25$ de la amasada 1 y H-30 de la amasada 2, tal y como se muestra en la tabla 3- 3.

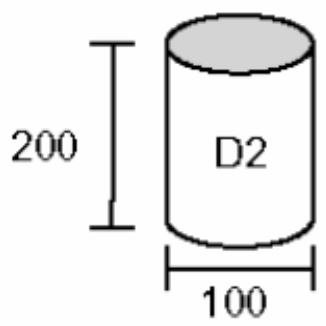

Figura 3- 6. Probetas cilíndricas de $100 \emptyset$ x 200 mm 


\section{Probetas de la amasada 1:}

Se realizaron 13 probetas cilíndricas de $100 \varnothing \times 200 \mathrm{~mm}$ para ser ensayadas a compresión a distintas temperaturas, con hormigón H-25.

\section{Probetas de la amasada 2:}

Se realizaron 13 probetas cilíndricas de $100 \varnothing \times 200 \mathrm{~mm}$ para ser ensayadas a compresión a distintas temperaturas, con hormigón H-30.

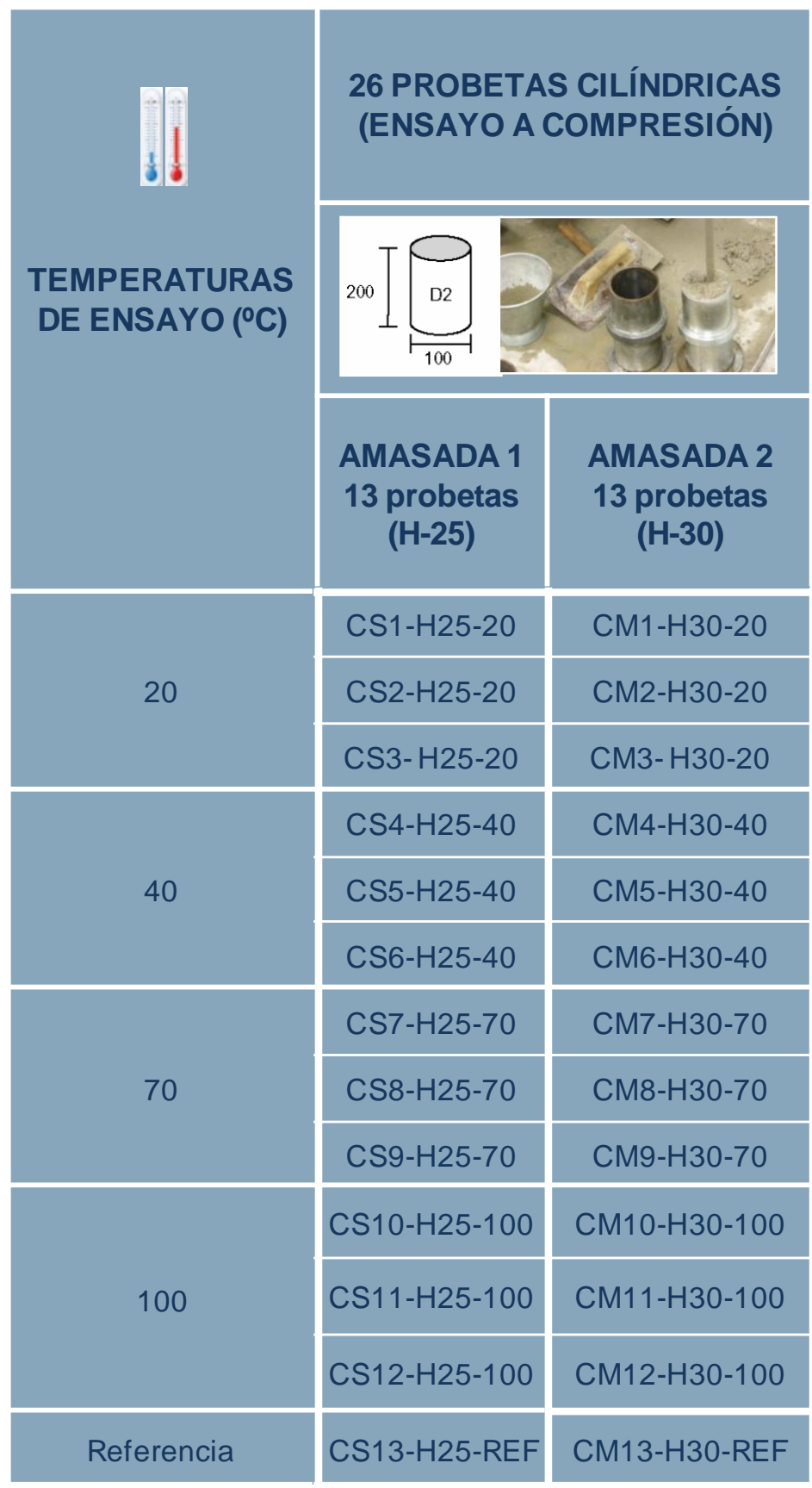

Tabla 3- 3. Nomenclatura y característica de las probetas cilíndricas para ensayar a compresión a distintas temperaturas y ${ }^{\circ} \mathrm{C}$ a los que se sometió a cada grupo de tres probetas. 
El proceso a realizar es idéntico para las dos series de probetas elaboradas con los dos tipos de hormigón: se numeran las probetas y se coloca en el interior de las probetas número 13, en el centro de su sección circular y a mitad de altura de la probeta, un sensor térmico con el fin de utilizar dichas probetas como referencia de la temperatura interior que va a ir alcanzando el hormigón en la estufa, y saber con certeza cuándo las probetas alcanzan la temperatura de consigna, para proceder a su ensayo a compresión.

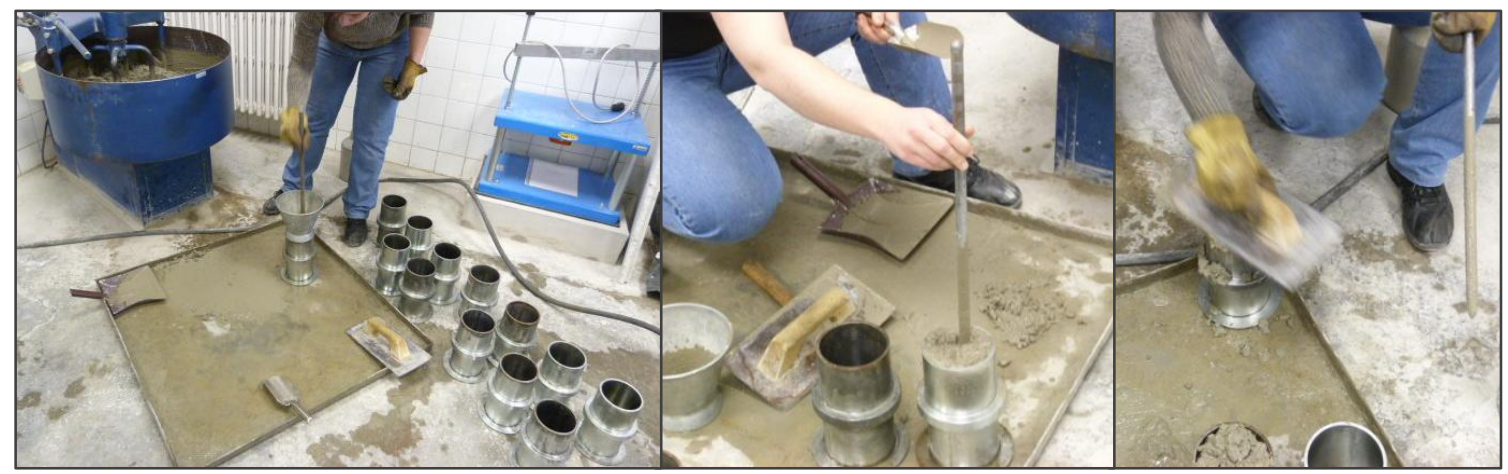

Figura 3- 7. Proceso de llenado de probetas cilíndricas según UNE-EN12390-2:2001.

Una vez transcurridos los 28 días en cámara de curado, se dejan una semana a temperatura ambiente en el laboratorio para que tenga lugar su secado al aire, con el fin de no ensayar las probetas de $20^{\circ} \mathrm{C}$ con una humedad muy distinta a la de las probetas a las que se va a someter a mayores temperaturas, ya que estas últimas, para adquirirla, van a estar varias horas en la estufa.

Se colocan dentro de la estufa de secado y a medida que, gracias a las probeta de referencia número 13 , se ve que van alcanzando la temperatura deseada en el centro de su masa, se procede a refrentar las probetas siguiendo las instrucciones de la norma UNE 83506:2004, y a colocarlas una a una sobre el plato inferior de la prensa Universal MIB-60 de acuerdo con la norma UNEEN12390-4:2001, donde se regulan las características que deben cumplir las máquinas para realizar el ensayo de rotura a compresión, y se realizan los ensayos según norma UNE-EN12390-3:2009. 


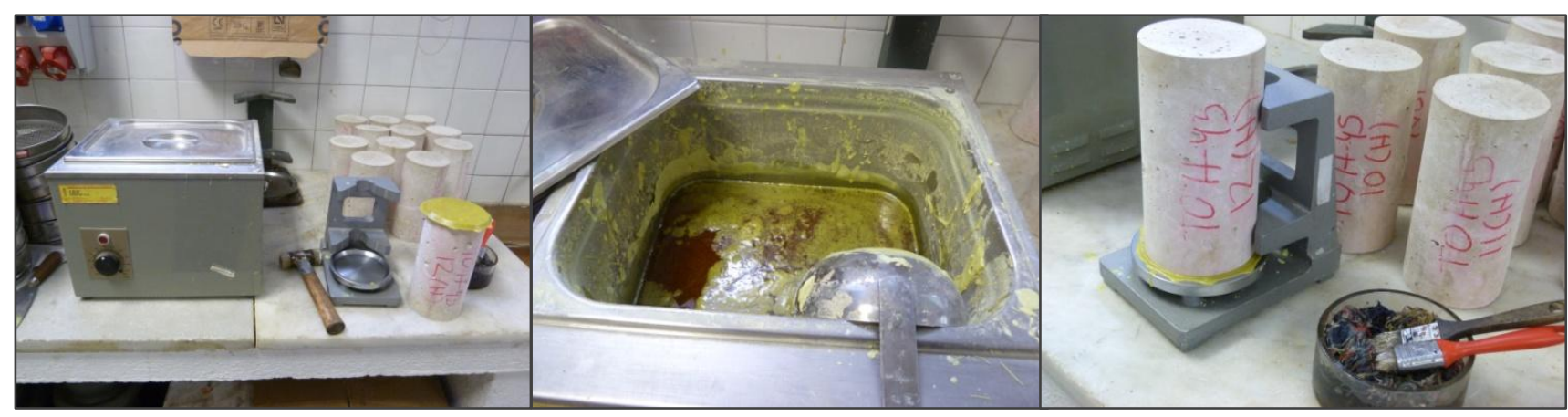

Figura 3- 8. Proceso de refrentado de las probetas según UNE 83506:2004.

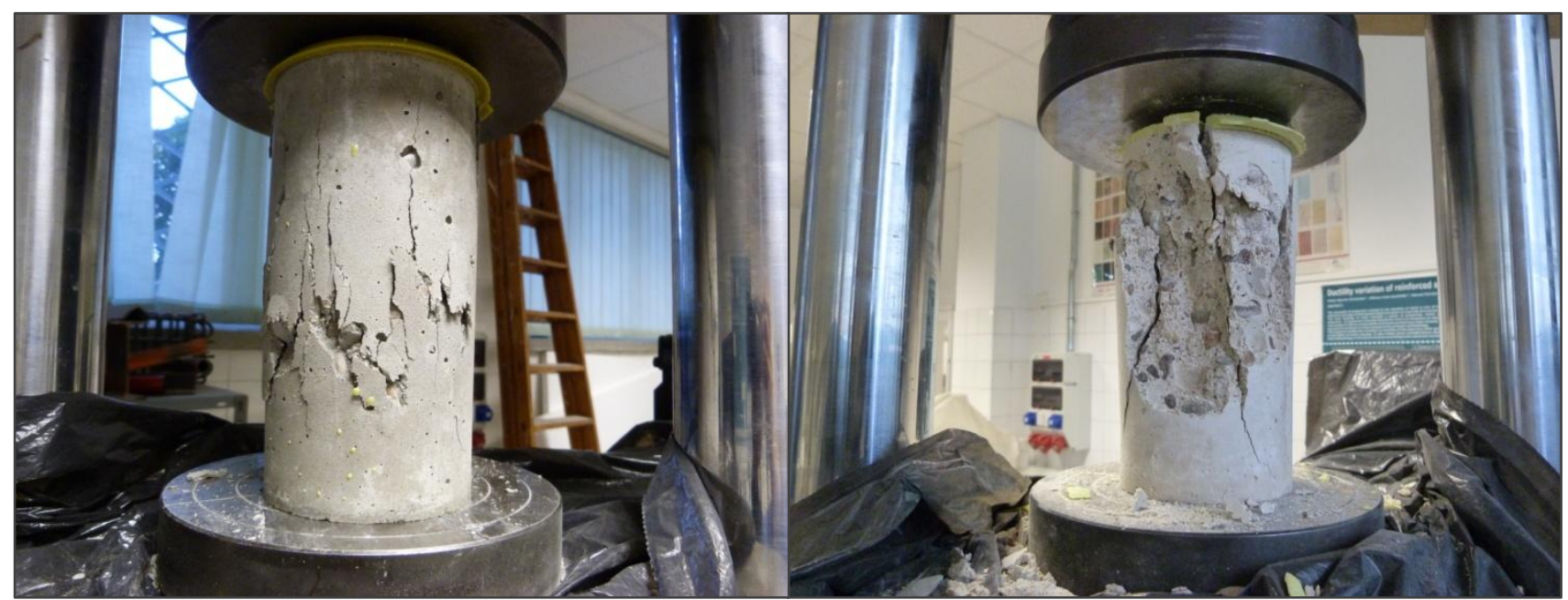

Figura 3- 9. Distintas formas de rotura de las probetas cilíndricas, sometidas a distintas temperaturas, después de haber sido ensayadas a compresión según UNE-EN12390-3:2001.

\subsubsection{Probetas cúbicas para ensayar a arrancamiento "pull-out"}

Se elaboraron 26 probetas cilíndricas con los dos tipos de hormigones fabricados, $\mathrm{H}-25$ de la amasada 1 y $\mathrm{H}-30$ de la amasada 2, tal y como se muestra en la tabla 3- 4.

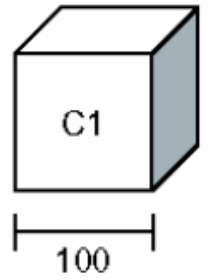

Figura 3- 10. Probetas cúbicas de 100 x 100 mm 


\section{Probetas de la amasada 1:}

Se realizaron 13 probetas cúbicas de $100 \times 100 \mathrm{~mm}$, con armadura de $10 \mathrm{~mm}$ de diámetro anclada en su interior, para ser ensayadas a arrancamiento "pull-out" a distintas temperaturas, con hormigón $\mathrm{H}-25$.

\section{Probetas de la amasada 2:}

Se realizaron 13 probetas cúbicas de $100 \times 100 \mathrm{~mm}$, con armadura de $10 \mathrm{~mm}$ de diámetro anclada en su interior, para ser ensayadas a arrancamiento o "pullout" a distintas temperaturas, con hormigón $\mathrm{H}-30$.

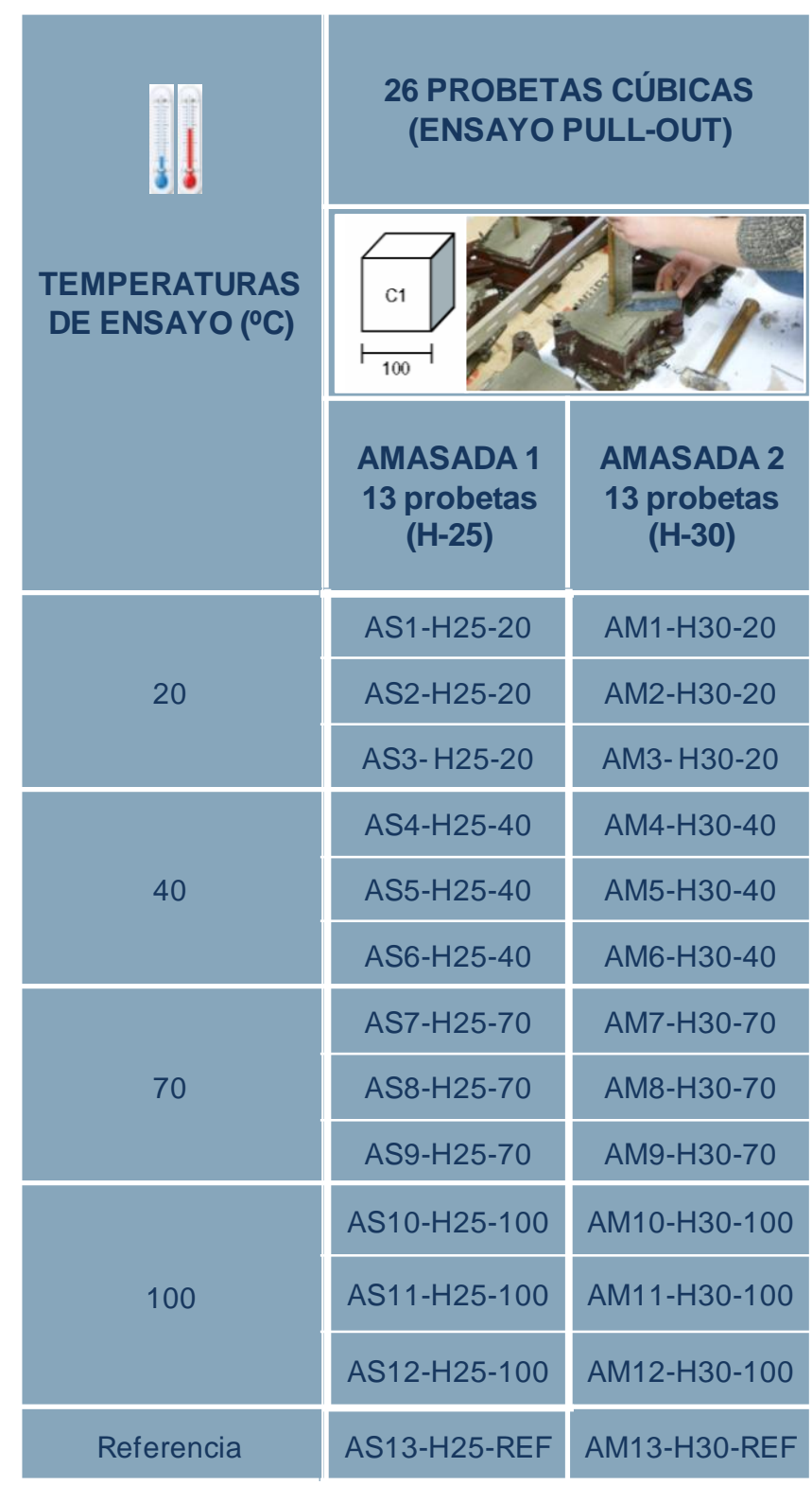

Tabla 3- 4. Nomenclatura y característica de las probetas cúbicas con armadura corrugada embebida para ensayar a arrancamiento a distintas temperaturas y ${ }^{\circ} \mathrm{C}$ a los que se sometió a cada una en grupos de tres probetas. 
El proceso a seguir se realiza de igual manera para los dos tipos de hormigones: se numeran las probetas y se coloca en el interior de las probetas número 13, a mitad de la distancia entre la armadura de acero corrugado de 10 $\mathrm{mm} \varnothing$ y una de las caras laterales de la probeta, y a mitad de altura de esta, un sensor térmico, con el fin de utilizar dichas probetas como referencia de la temperatura interior que va a ir alcanzando el hormigón en la estufa, y saber con certeza cuándo las probetas alcanzan la temperatura de consigna, para proceder a su ensayo de adherencia.

Una vez elaboradas, permanecen 28 días en la cámara de curado y a temperatura ambiente durante una semana, posteriormente se aumenta su temperatura en la estufa de secado y a medida que los valores de medición de temperatura de las probetas no 13 van alcanzando los grados establecidos, se sacan las probetas de la estufa y se procede a su ensayo.

Los ensayos de arrancamiento, "pull-out", se realizan con la misma prensa MIB-60 con la que se han hecho los ensayos a compresión, gracias a un husillo elaborado por los técnicos del laboratorio de materiales de la EUATM, consistente en dos placas metálicas unidas por sus cuatro esquinas por medio de tornillos roscados, que permiten que se adapte su separación a la altura de la probeta a ensayar, y sirven para que la mordaza inferior de la máquina pueda anclar la probeta de forma estable, para que la mordaza superior pueda ensayarla a tracción tirando de la armadura corrugada de $10 \mathrm{~mm}$ de diámetro que la probeta lleva anclada.

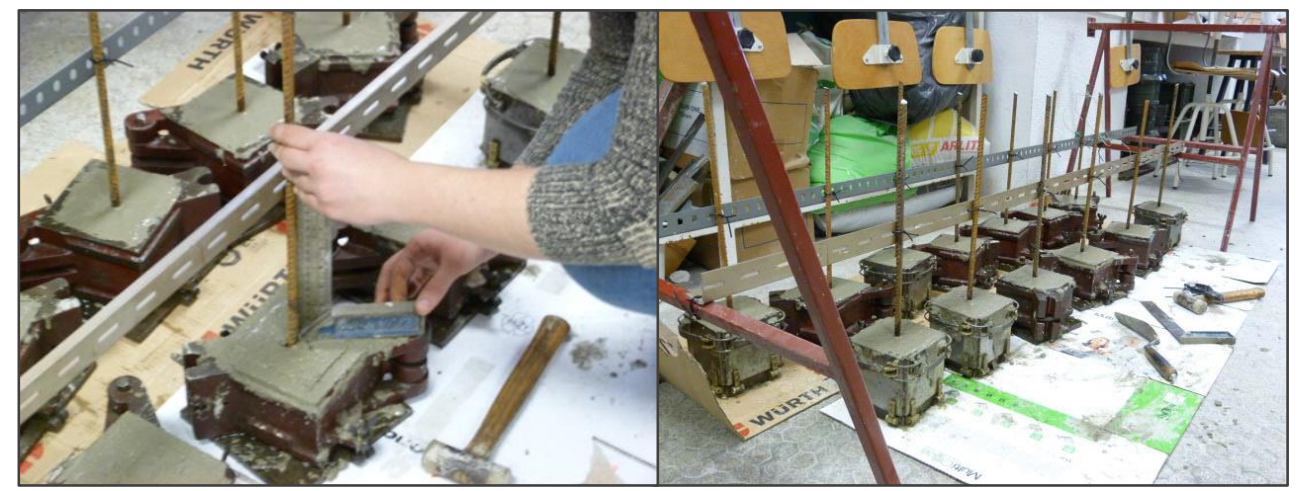

Figura 3- 11. Probetas cúbicas con armadura corrugada de $10 \mathrm{~mm} \varnothing$, para ensayo de adherencia. 


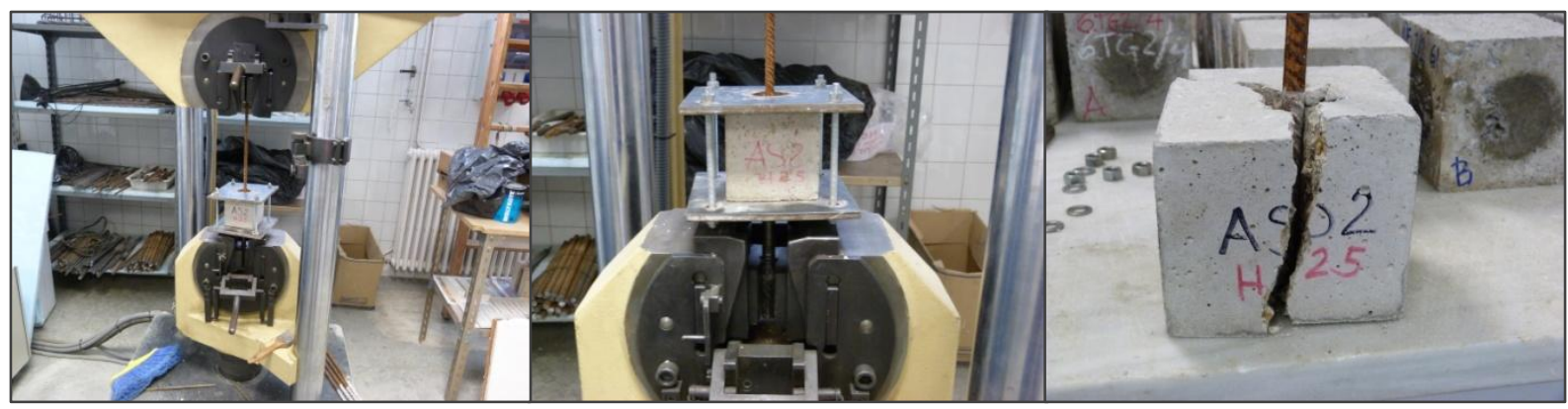

Figura 3- 12. Probetas cúbicas con armadura corrugada de $10 \mathrm{~mm}$, durante ensayo de adherencia.

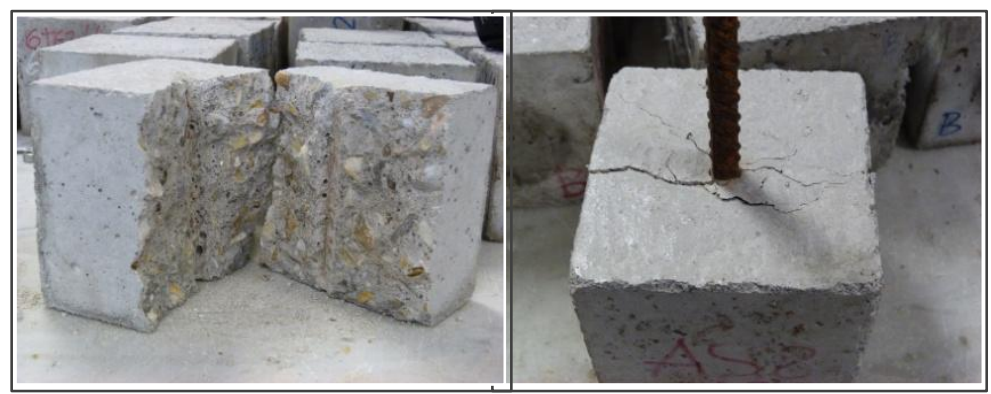

Figura 3- 13. Distintas formas de rotura de las probetas cúbicas con armadura corrugada de $10 \mathrm{~mm}$, durante ensayo de adherencia.

Conviene destacar que el hecho de la disposición de un sensor térmico en el interior de las probeta de referencia para garantizar el conocimiento exacto del momento en el que la probeta alcanza la temperatura de consigna para extraer las probetas a ensayar de la estufa y proceder a su rotura, se ha realizado con el fin de conocer el momento en el que la temperatura interna de la probeta alcanza la de consigna.

Como ya se mencionó en el capítulo 2 sobre el estado del conocimiento, investigaciones llevadas a cabo por Dias, W. et al [42] hacen referencia a la diferencia de valores de temperatura medidos en la superficie y en puntos interiores de las probetas, hallándose diferencias de hasta $20^{\circ} \mathrm{C}$ entre la superficie y puntos a $2 \mathrm{~cm}$. Bajo la misma. 


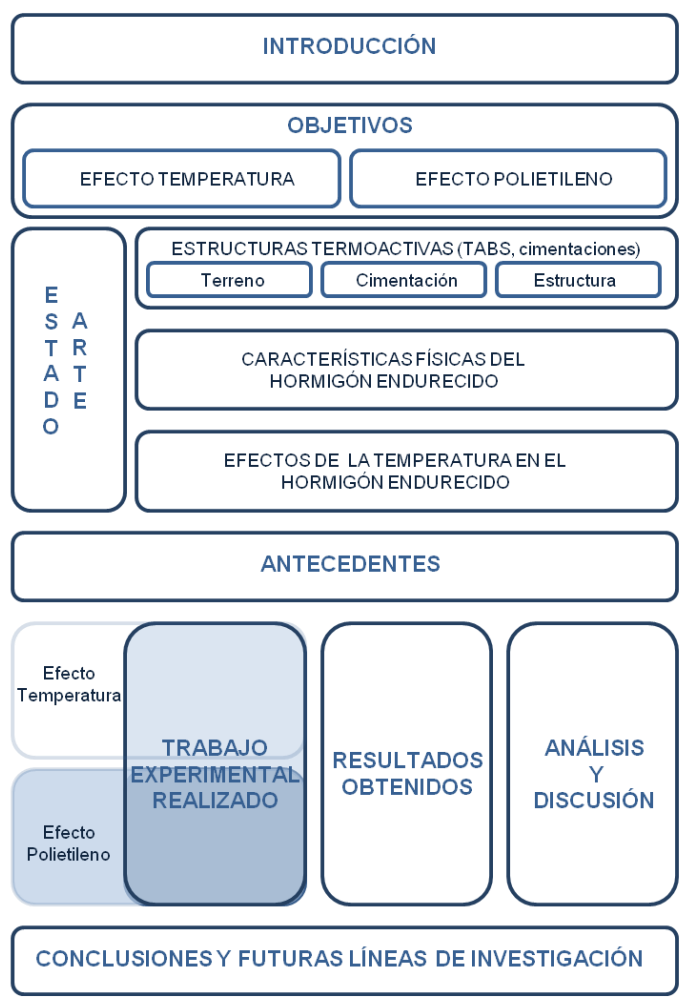

\subsection{Estudio del efecto de la incorporación de tubos de PE}

Con el fin de conocer el efecto producido por la incorporación de tubos de polietileno en el interior del hormigón, en las distintas posiciones a las que potencialmente podría encontrarse el tubo con respecto a la dirección de la carga en una losa trabajando a flexión (en posición vertical centrada, vertical descentrada y horizontal), se procedió a la elaboración de probetas cilíndricas para ensayar a compresión, elaboradas con hormigón H-25 (amasada 1) y con hormigón H-30 (amasada 2), y a la elaboración de probetas cúbicas también para ensayar a compresión, elaboradas con hormigón H-25 (amasada 1) y con hormigón H-30 (amasada 2).

\subsubsection{Probetas cilíndricas para estudiar la resistencia a compresión}

Se elaboraron 24 probetas cilíndricas con los dos tipos de hormigones fabricados, $\mathrm{H}-25$ de la amasada 3 y H-30 de la amasada 4, tal y como se muestra en la tabla 3- 5.

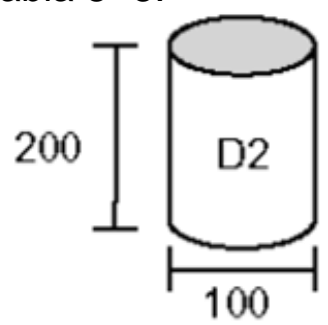

Figura 3- 14. Probetas cilíndricas de $100 \varnothing \times 200$ mm 


\section{Probetas de la amasada 3:}

Se realizaron 12 probetas cilíndricas de $100 \varnothing \times 200 \mathrm{~mm}$ para ser ensayadas a compresión, colocando tubos de polietileno en su interior en distintas posiciones, con hormigón H-25.

\section{Probetas de la amasada 4:}

Se realizaron 12 probetas cilíndricas de $100 \varnothing \times 200 \mathrm{~mm}$ para ser ensayadas a compresión, colocando tubos de polietileno en su interior en distintas posiciones, con hormigón H-30.

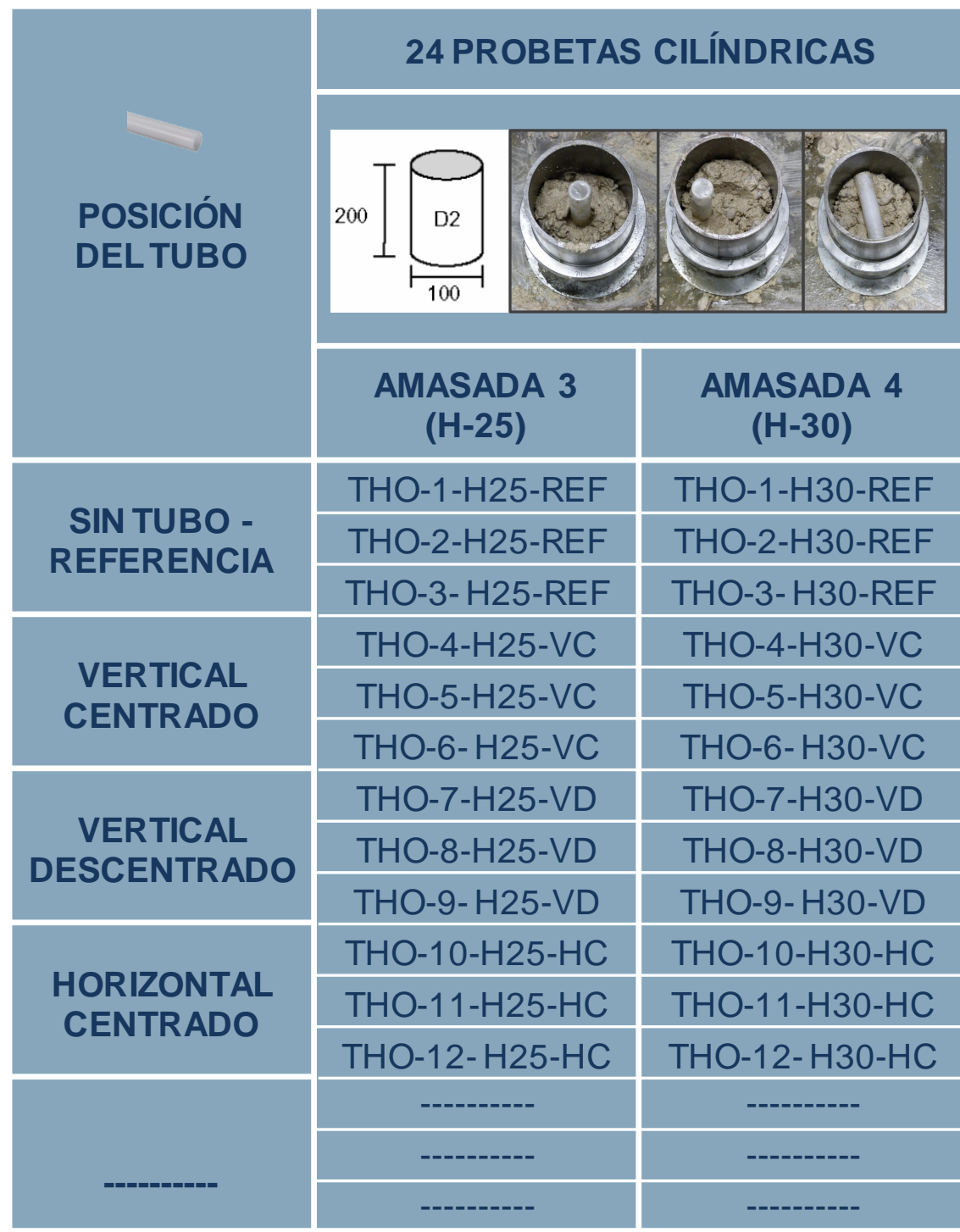

Tabla 3- 5. Nomenclatura $y$ características de las probetas cilíndricas para ensayar a compresión con las distintas posiciones en las que se embebieron los tubos de polietileno. 
El proceso a seguir fue el mismo para las probetas de los dos tipos de hormigones: se numeran las probetas y se coloca en el interior de las probetas 4 a 12 un trozo de tubo de polietileno de $24 \mathrm{~mm}$, de los que se embeben en el hormigón, para activar térmicamente las estructuras, suministrado por la empresa ENERES.

En las probetas 1, 2 y 3 no se incorpora el tubo, para poder utilizarlas como probetas de referencia y comprobar los resultados de rotura de las probetas con tubo con los resultados obtenidos en éstas.

Para las probetas 4 a 9, el tubo tiene una longitud de aproximadamente 200 $\mathrm{mm}$, igual que la altura de la probeta cilíndrica, y para las probetas 9, 10 y 11 se utiliza un tubo de longitud inferior a la del diámetro de la probeta $(100 \mathrm{~mm})$, para facilitar su posicionamiento.

En todos los casos se procede a sellar lateralmente los tubos para impedir la entrada de hormigón en ellos que pudiera falsear los resultados, si se encontraran éstos rellenos de hormigón en lugar de huecos.

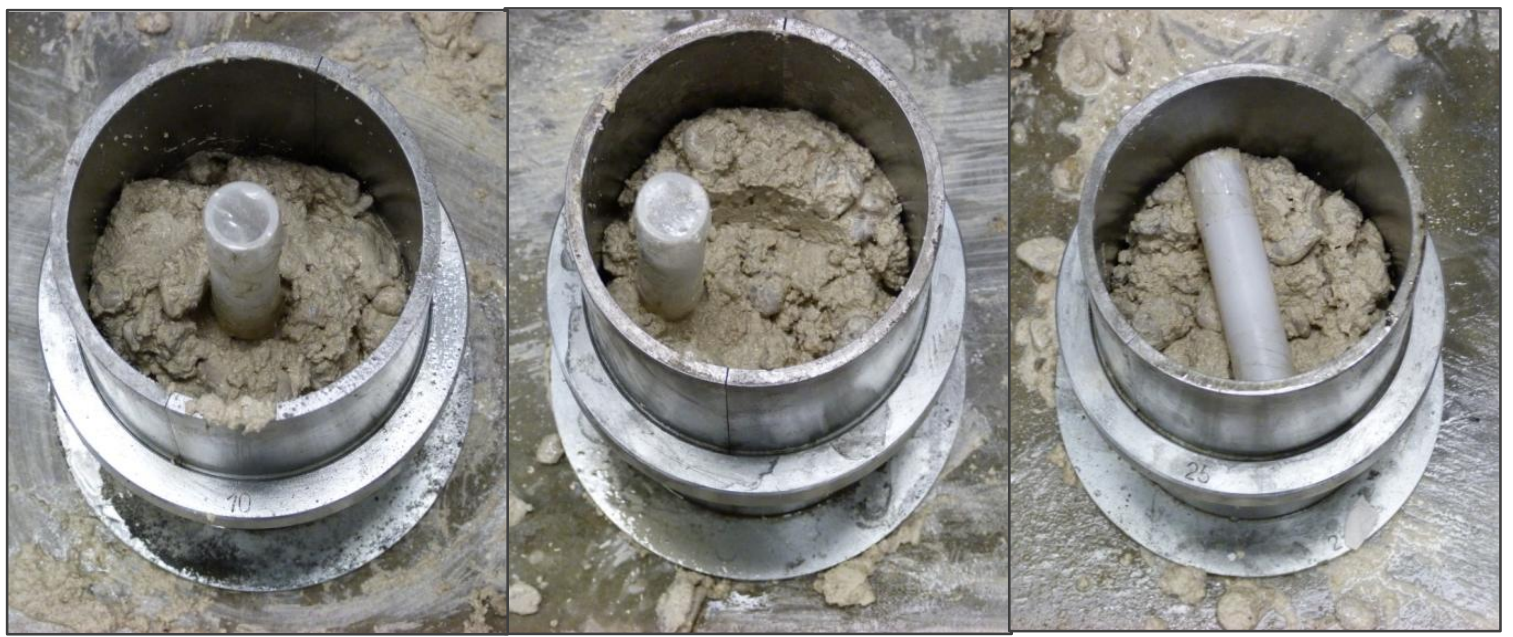

Figura 3- 15. Probetas cilíndricas para ser ensayadas a compresión con tubo de polietileno de $24 \mathrm{~mm} \varnothing$, sellado lateralmente y colocado en posiciones: vertical centrado, vertical descentrado y horizontal centrado a mitad de la altura de la probeta.

Una vez elaboradas las probetas, permanecen 28 días en la cámara de curado, y posteriormente, para la realización del ensayo de resistencia a compresión, se refrenta la cara superior de las probetas con mortero de azufre 
dejándolas en ambiente de laboratorio durante 2 horas antes de la realización del ensayo.

Transcurrido este tiempo, se coloca la probeta en la máquina de ensayos. Este equipo está compuesto por dos platos de compresión, uno inferior adosado al bastidor, y el otro, superior, que está acoplado al pistón del equipo mediante una rótula de asiento esférico engrasada. Se aplica una precarga del 10\% de la carga máxima del ensayo con la finalidad de que el plato superior quede uniformemente apoyado en la cara superior de la probeta.

Una vez que el plato de compresión está apoyado en la probeta, se realiza el ensayo de resistencia a compresión por carrera, con el fin de obtener además de los datos de tensión y tiempo, los de desplazamiento.

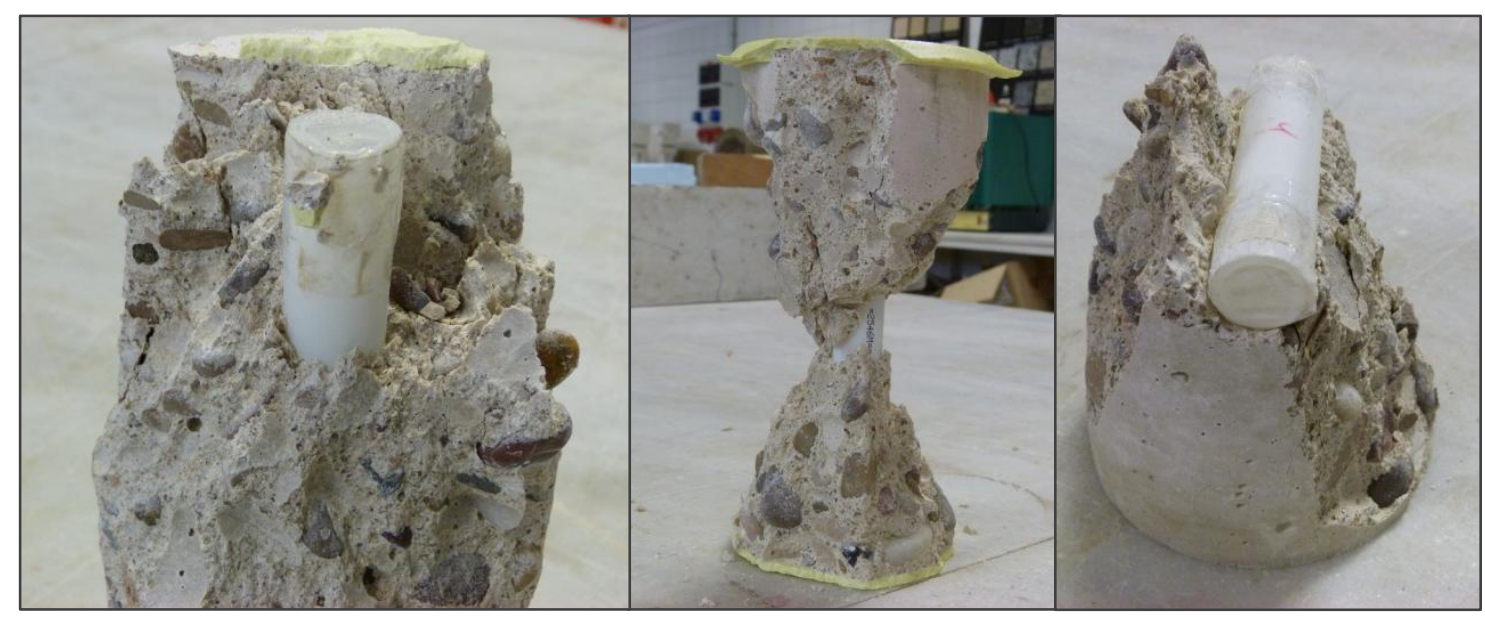

Figura 3- 16. Distintas formas de rotura de las probetas cilíndricas con tubo de polietileno, después de haber sido ensayadas a compresión.

\subsubsection{Probetas cúbicas para estudiar la resistencia a compresión}

Se elaboraron 30 probetas cúbicas con los dos tipos de hormigones fabricados, $\mathrm{H}-25$ de la amasada 3 y $\mathrm{H}-30$ de la amasada 4, tal como se muestra en la tabla 3- 6.

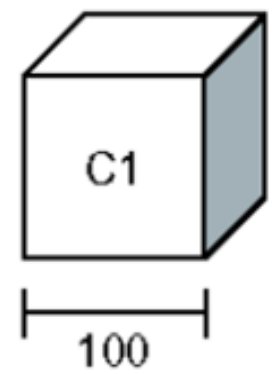

Figura 3- 17. Probetas cúbicas de 100 x 100 mm 


\section{Probetas de la amasada 3:}

Se realizaron 15 probetas cúbicas de $100 \times 100 \mathrm{~mm}$, para ser ensayadas a compresión, colocando tubos de polietileno en su interior en distintas posiciones, con hormigón H-25.

\section{Probetas de la amasada 4:}

Se realizaron 15 probetas cúbicas de $100 \times 100 \mathrm{~mm}$, para ser ensayadas a compresión, colocando tubos de polietileno en su interior, en distintas posiciones, con hormigón H-30.

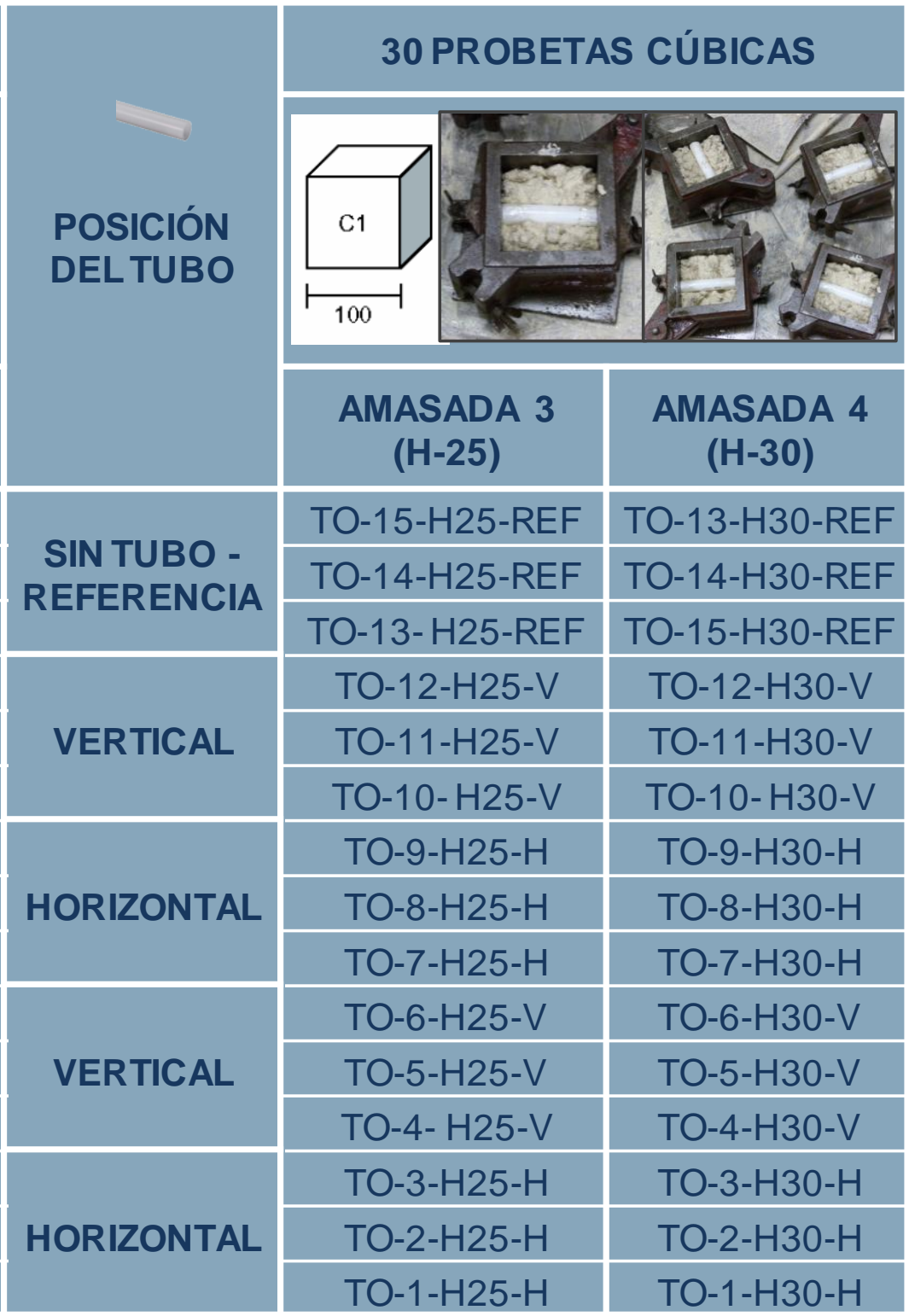

Tabla 3- 6. Nomenclatura $\quad y$ características de las probetas cúbicas para ensayar a compresión con las distintas posiciones en las que se embebieron los tubos de polietileno. 
El proceso a seguir es el mismo para las probetas de los dos tipos de hormigones: se numeran las probetas y se coloca en el interior de las probetas 1 a 12 un trozo de tubo de polietileno de $24 \mathrm{~mm}$ de diámetro y $100 \mathrm{~mm}$ de largo, de los que se embeben en el hormigón para activar térmicamente las estructuras, suministrado por la empresa ENERES.

Se disponen los tubos, en todos los casos, centrados en ancho y en altura, señalizando adecuadamente su posición, para luego poder colocar la probeta en la prensa del modo adecuado, y proceder a ensayarla considerándola como probeta con tubo en posición horizontal o vertical.

En este caso se elaboran 6 probetas de cada tipo de hormigón con el tubo posicionado en vertical y otras 6 con el tubo dispuesto en posición horizontal.

En las probetas 13, 14 y 15 no se incorpora el tubo para poder utilizarlas como probetas de referencia, y comprobar los resultados de rotura de las probetas con tubo con los resultados obtenidos en éstas.

En todos los casos se procede a sellar lateralmente los tubos para impedir la entrada de hormigón en ellos que pudiera falsear los resultados, si se encontraran éstos rellenos de hormigón en lugar de huecos.

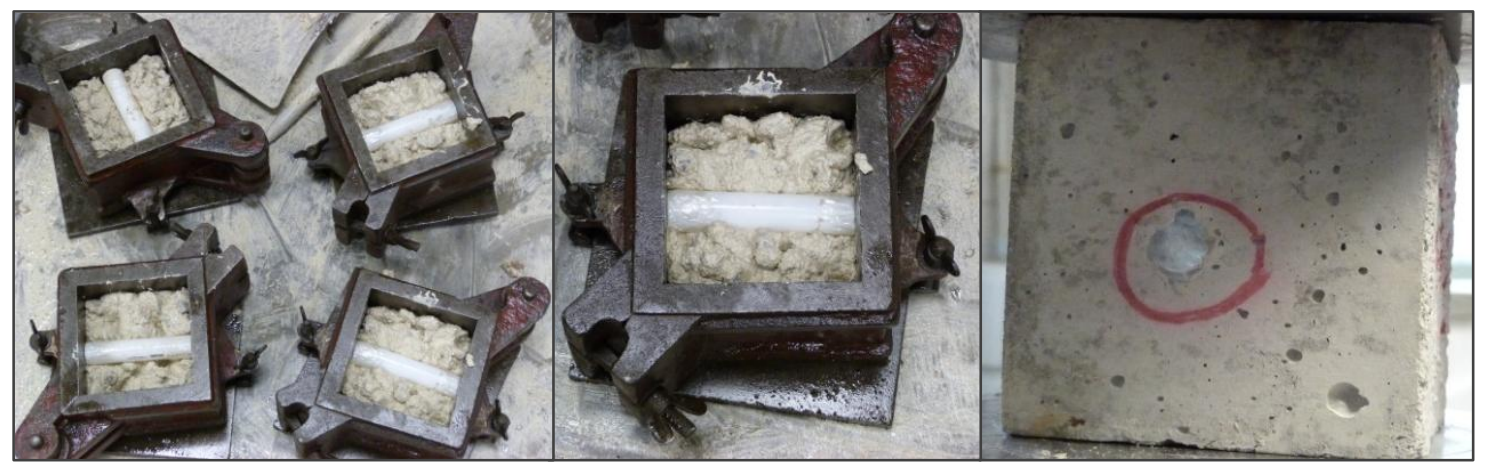

Figura 3- 18. Probetas cúbicas para ser ensayadas a compresión con tubo de polietileno de $24 \mathrm{~mm} \varnothing$, sellado lateralmente y colocado a mitad de la altura de la probeta.

Una vez elaboradas las probetas, permanecen 28 días en la cámara de curado $y$, posteriormente, se realiza el ensayo de resistencia a compresión, siempre de acuerdo a la norma UNE-EN12390-3:2009, secando la humedad de la superficie 
de la probeta, y colocando la probeta de tal manera que la carga se aplique en dirección perpendicular a la de vertido del hormigón durante su llenado.

Se aplica una precarga del $10 \%$ de la carga máxima del ensayo con la finalidad de que el plato superior quede uniformemente apoyado en la cara superior de la probeta, y se realiza en el ensayo de resistencia a compresión por carrera, con el fin de obtener además de los datos de tensión y tiempo, los de desplazamiento.

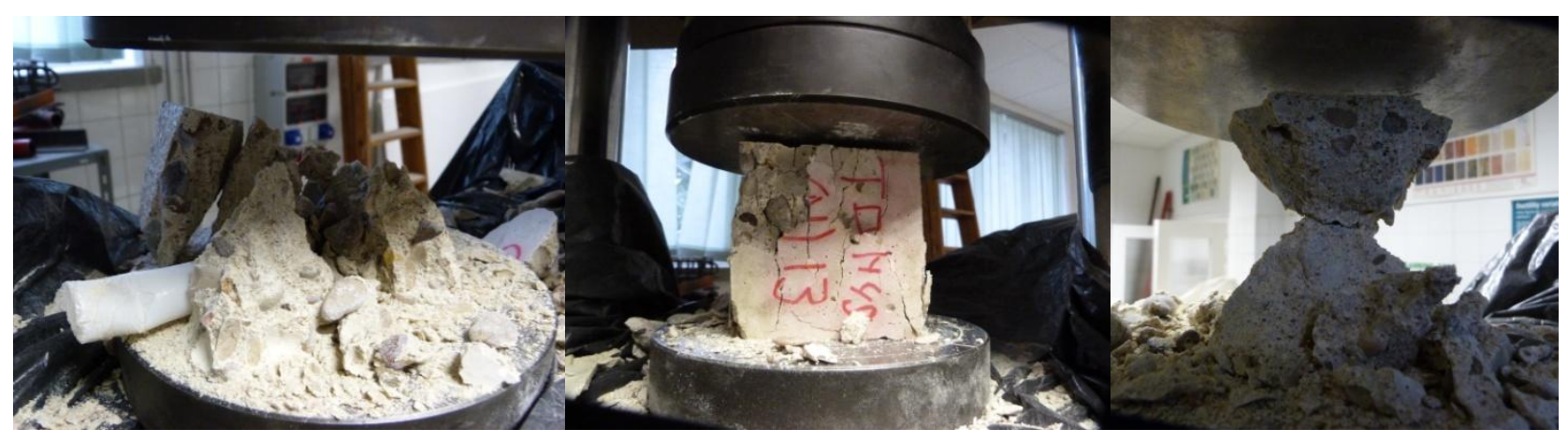

Figura 3- 19. Distintas formas de rotura de las probetas cúbicas con tubo de polietileno, después de haber sido ensayadas a compresión. 


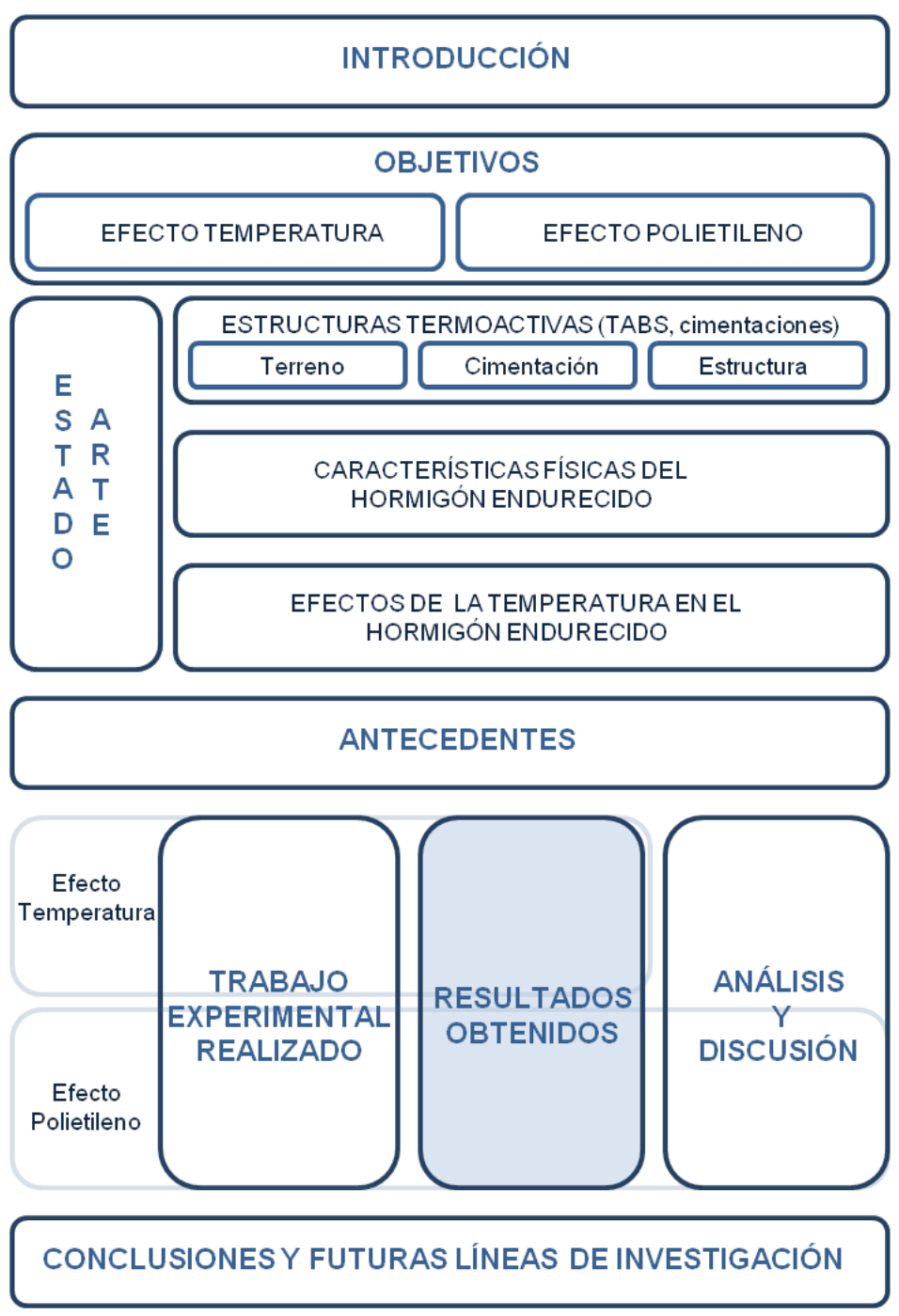

CAPÍTULO 4

RESULTADOS

OBTENIDOS 


\subsection{Introducción}

En este apartado se expone los resultados obtenidos tras el desarrollo del programa experimental descrito anteriormente. Se ha dividido el apartado en función del estudio a realizar.

Por un lado se incorpora los resultados de los ensayos efectuados para analizar el efecto producido por el incremento de temperatura, aportando los resultados de rotura a compresión de las probetas cilíndricas elaboradas con hormigón $\mathrm{H}-25$, las elaboradas con hormigón $\mathrm{H}-30$, y los resultados de ensayo a arrancamiento o pull-out de las probetas cúbicas con armadura corrugada anclada elaboradas con ambos tipos de hormigón.

En segundo lugar se incorpora los resultados de los ensayos efectuados para analizar el efecto producido por la introducción de tubos de polietileno en el interior de las probetas, aportando los resultados de rotura a compresión de las probetas cilíndricas elaboradas con hormigón $\mathrm{H}-25$ y las elaboradas con hormigón $\mathrm{H}-30$, con posiciones de tubo de polietileno en vertical centrado en el interior de la probeta, en vertical descentrado con respecto al eje vertical de la probeta y en horizontal; y los resultados de rotura a compresión de las probetas cúbicas elaboradas con hormigón $\mathrm{H}-25$ y las elaboradas con hormigón $\mathrm{H}-30$, con posiciones de tubo de polietileno en vertical centrado en el interior de la probeta y en horizontal.

\subsection{Diagramas tipo de los ensayos}

A continuación se explica cómo se procedió a tratar los datos obtenidos de los ensayos realizados a compresión y a "pull-out", y el tipo de diagramas generados y utilizados para averiguar los datos más característicos necesarios para analizar los resultados obtenidos. 


\subsubsection{Diagrama tensión-deformación tipo de ensayos de resistencia}

\section{a compresión}

En primer lugar de los aproximadamente 4000 datos obtenidos de la prensa universal MIB 60/AM en el ensayo a compresión en carrera, se obtiene una gráfica fuerza $\mathrm{F}$ en $\mathrm{KN} /$ desplazamiento $\delta$ en $\mathrm{mm}$, con todos los resultados.

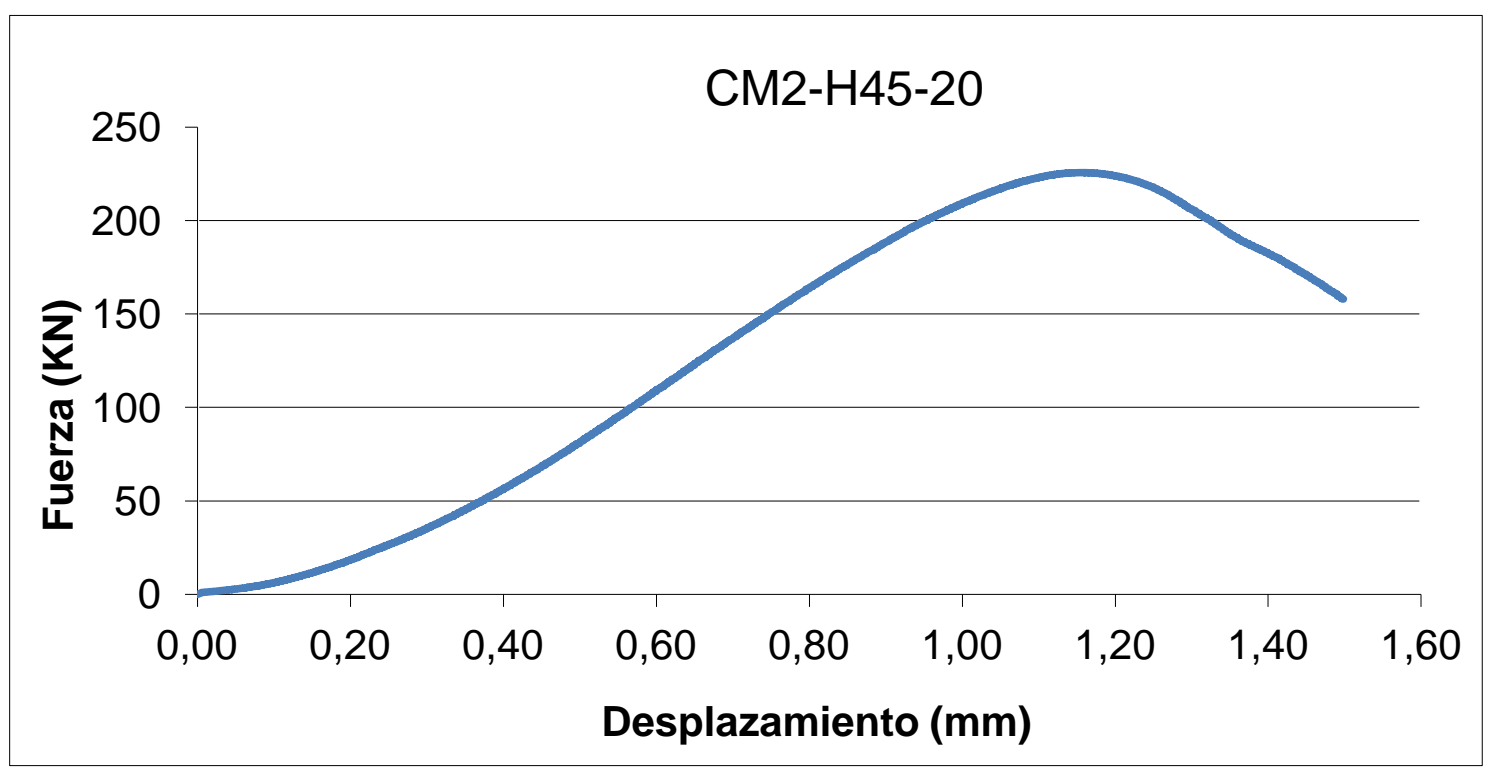

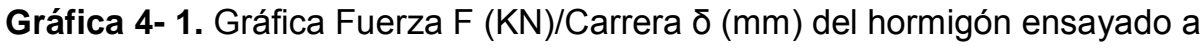
compresión.

Como lo que nos interesa realmente es el valor de resistencia del hormigón de la probeta, con los datos de fuerza $\mathrm{F}$ en $\mathrm{KN}$, los de área de la sección, cilíndrica o cúbica $A c$ en $\mathrm{mm}^{2}$, se obtienen los alrededor de 4000 datos de $\sigma c$ tensión de resistencia a compresión del hormigón en $\mathrm{N} / \mathrm{mm} 2$ y los de $\varepsilon c$ deformación del hormigón, sin unidades. 
Con estos datos ya podemos proceder a realizar la gráfica tensióndeformación y averiguar los datos más representativos de esta.

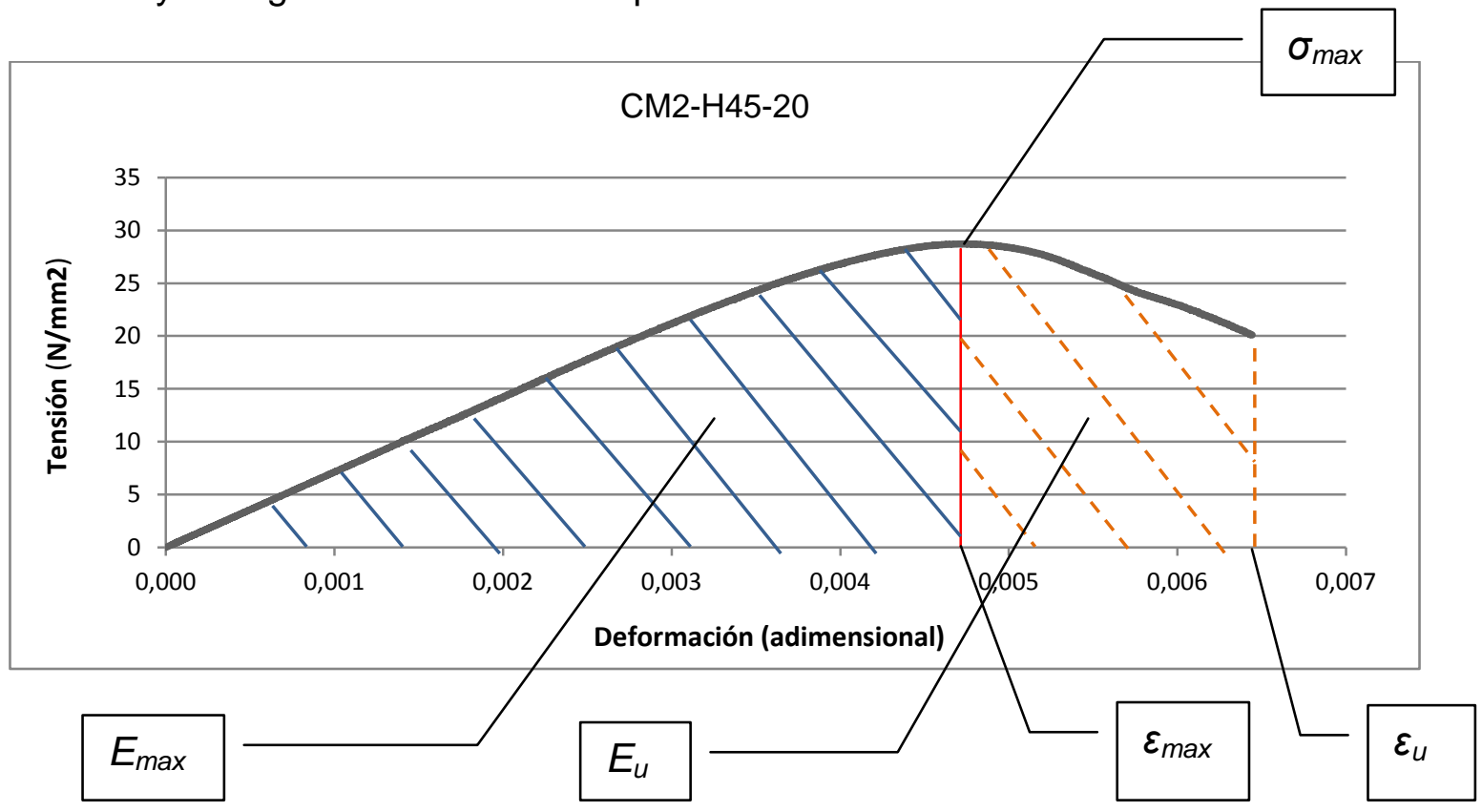

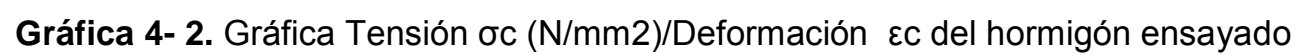
a compresión.

A continuación se seleccionan los valores $\sigma_{\max }, \varepsilon_{\max }, \varepsilon_{u}, E_{\max }$ y $E_{u}$ más característicos del ensayo, tal como se representa en la gráfica 4- 2.

Donde:

$\begin{array}{ll}F & \text { fuerza }(\mathrm{KN}) \\ \delta & \text { desplazamientos obtenidos en el ensayo en carrera }(\mathrm{mm}) \\ A_{c} & \text { sección de hormigón }\left(\mathrm{mm}^{2}\right) \\ \sigma_{c} & \text { tensión de resistencia a compresión del hormigón }\left(\mathrm{N} / \mathrm{mm}^{2}\right) \\ \sigma_{\max } & \text { tensión máxima del hormigón }\left(\mathrm{N} / \mathrm{mm}^{2}\right) \\ \varepsilon_{c} & \text { deformación del hormigón } \\ \varepsilon_{\max } & \text { deformación máxima del hormigón } \\ \varepsilon_{u} & \text { deformación última del hormigón } \\ E_{\max } & \text { energía máxima generada durante el ensayo }\left(\mathrm{N} / \mathrm{mm}^{2}\right) \\ E u & \text { energía última generada durante el ensayo }\left(\mathrm{N} / \mathrm{mm}^{2}\right)\end{array}$

Como se indicó en el apartado de antecedentes que influyen en la metodología de los ensayos, a la hora de calcular los valores de tensión/deformación con los 
resultados obtenidos de la rotura a compresión de las probetas en las que se ha introducido un tubo de polietileno para estudiar el efecto que tiene su incorporación sobre las propiedades del hormigón, estos se han realizado teniendo en cuenta el área bruta, es decir, sin descontar el área de hormigón inexistente debida a la introducción del tubo de polietileno en posición paralela a la dirección de la carga que se va a efectuar en el ensayo.

Esta decisión fue corroborada al comprobar, después de la obtención de todos los resultados, como las diferencias en el cálculo por utilizar el área neta o el área bruta eran inferiores a las diferencias obtenidas en los resultados de las distintas probetas semejantes ensayadas bajo las mismas características, e incluso en determinados ensayos las diferencias de resistencia en los resultados de probetas sin tubo y otras con tubo, eran muy similares.

\subsubsection{Diagrama fuerza - desplazamiento tipo de ensayos de} adherencia a arrancamiento "pull-out"

Con los aproximadamente 1000 datos que arroja la prensa universal MIB $60 / \mathrm{AM}$ al realizar el ensayo en carrera, $F$ fuerza en $\mathrm{KN}$ y $\delta$ desplazamientos en $\mathrm{mm}$, se obtiene la gráfica fuerza/desplazamiento.

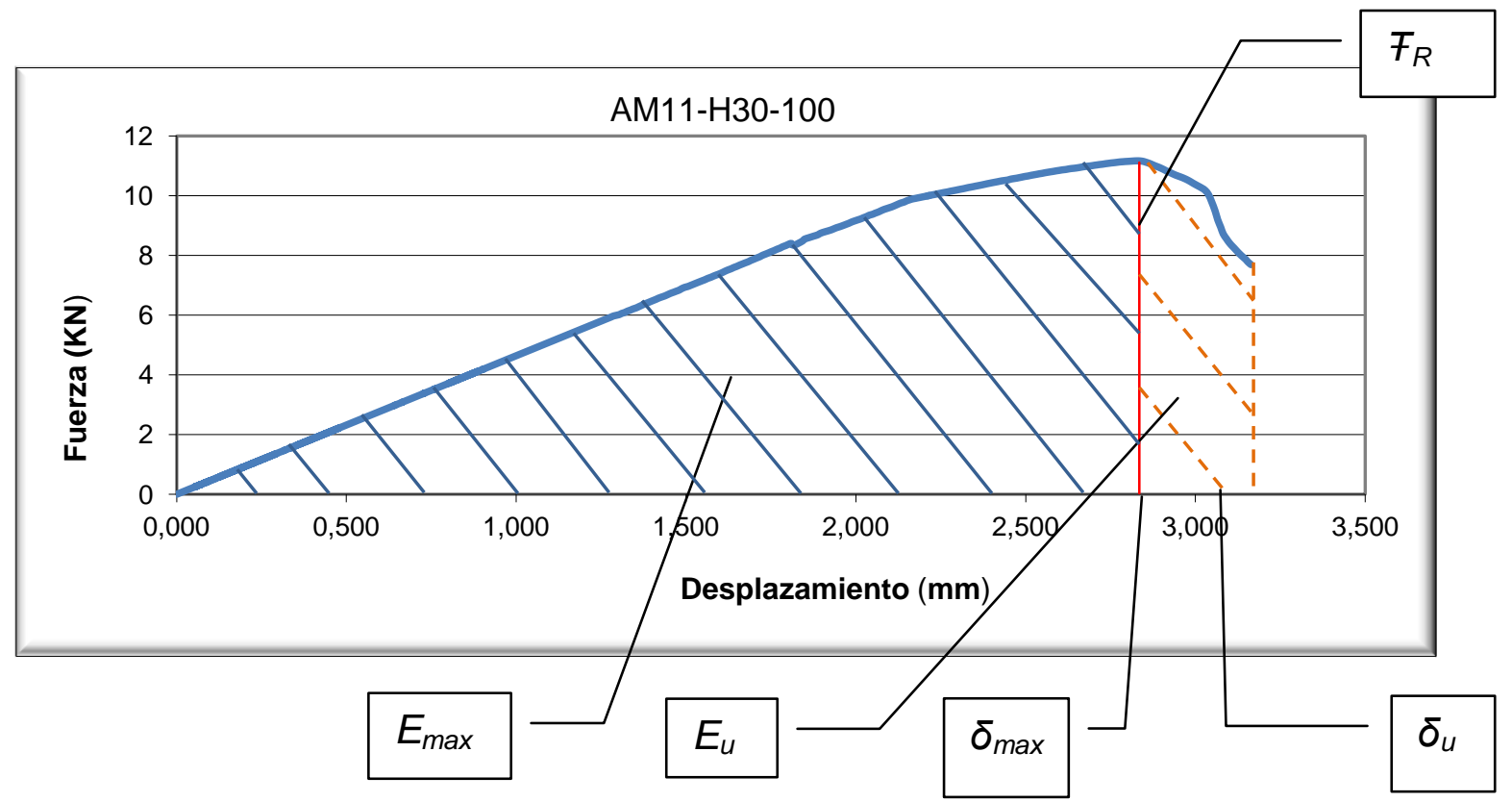

Gráfica 4- 3. Gráfica Fuerza $F(\mathrm{KN}) /$ Desplazamiento $\delta(\mathrm{mm})$ del hormigón ensayado a arrancamiento "pull-out". 
A continuación se obtiene los valores $\mp_{R}, \delta_{\max }, \delta_{u}, E_{\max }$ y $E_{u}$ más característicos del ensayo, tal como se representa en la gráfica 4- 3.

Donde:

$$
\begin{array}{ll}
F & \text { fuerza }(\mathrm{KN}) \\
F_{R} & \text { fuerza de rotura ensayo de arrancamiento "pull-out" (KN) } \\
\delta & \text { desplazamientos obtenidos en el ensayo en carrera }(\mathrm{mm}) \\
\delta_{\max } & \text { desplazamiento máximo }(\mathrm{mm}) \\
\delta_{u} & \text { desplazamiento último }(\mathrm{mm}) \\
E_{\max } & \text { energía máxima generada durante el ensayo }(\mathrm{KN} / \mathrm{mm}) \\
E u & \text { energía última generada durante el ensayo }(\mathrm{KN} / \mathrm{mm})
\end{array}
$$

Es importante señalar que el ensayo de adherencia realizado a arrancamiento o "pull-out" no es el ensayo normalizado, situación que carece de importancia dado que la metodología de estudio de los resultados consiste en la comparación de unos valores con otros. 


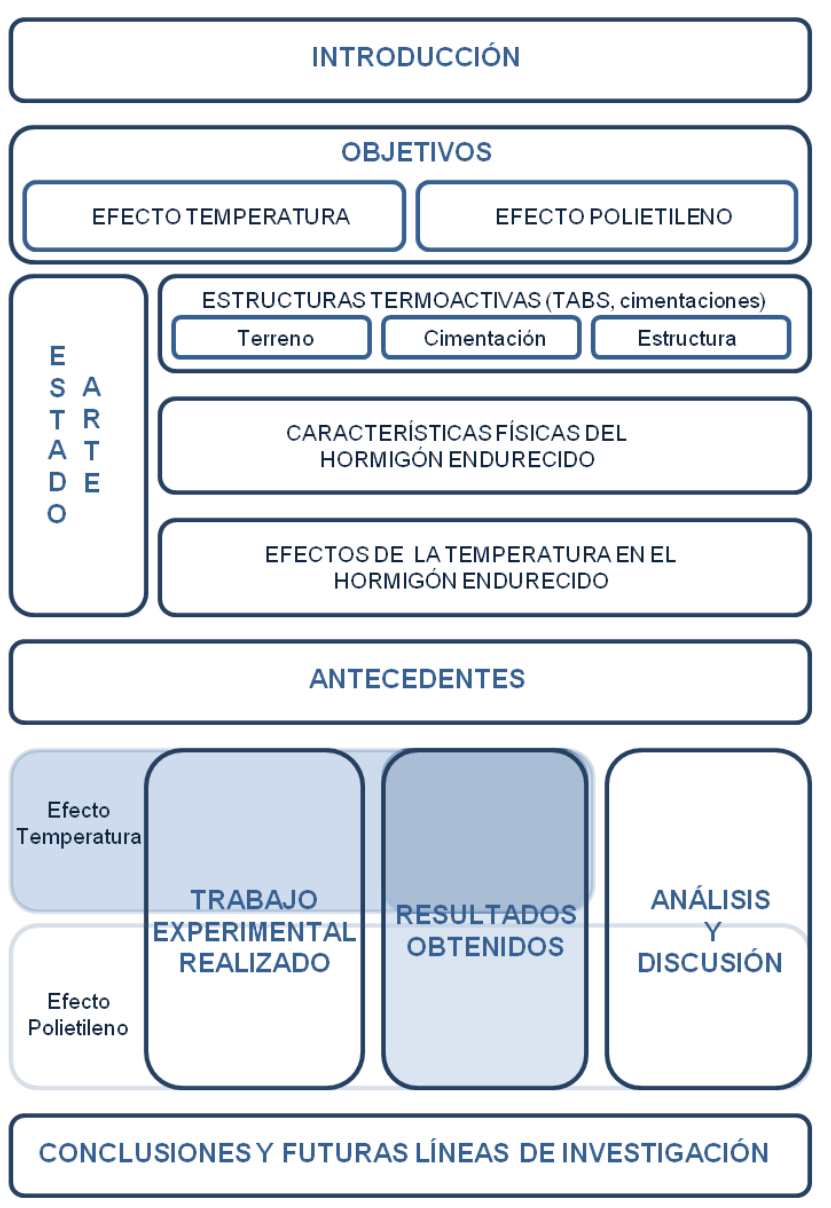

\subsection{Estudio del efecto del incremento de temperatura}

Una vez realizados los ensayos de rotura a compresión de la probetas cilíndricas fabricadas con hormigones $\mathrm{H}-25$ y H-30, sometidas en grupos de tres probetas a temperaturas de $20^{\circ} \mathrm{C}, 40^{\circ} \mathrm{C}, 70^{\circ} \mathrm{C}$ y $100^{\circ} \mathrm{C}$, y los ensayos a arrancamiento o "pull-out" de las probetas cúbicas fabricadas con hormigones $\mathrm{H}-25$ y H-30, sometidas en grupos de tres probetas a temperaturas de $20^{\circ} \mathrm{C}$, $40^{\circ} \mathrm{C}, 70^{\circ} \mathrm{C}$ y $100{ }^{\circ} \mathrm{C}$, se procede a elaborar una gráfica tensión/deformación para los resultados de ensayo a compresión, y fuerza/desplazamiento para los resultados de ensayo a arrancamiento, para cada una de las probetas ensayadas.

Los gráficos del resultado de rotura de cada probeta pueden encontrarse en el capítulo 9, anexo 2.1, de este documento. 


\subsubsection{Resultados de los ensayos a compresión}

Las tablas en las que se recoge los resultados de los valores más característicos $\left(\sigma_{\max }, \varepsilon_{\max }, \varepsilon_{u}, E_{\max }\right.$ y $\left.E_{u}\right)$, hallados con los datos obtenidos en el ensayo de rotura a compresión de todas y cada una de las probetas cilíndricas elaboradas con hormigones $\mathrm{H}-25$ y $\mathrm{H}-30$, y sometidas en grupos de tres a temperaturas de $20^{\circ} \mathrm{C}, 40^{\circ} \mathrm{C}, 70^{\circ} \mathrm{C}$ y $100^{\circ} \mathrm{C}$, pueden encontrarse en el capítulo 9, anexo 1 , de este documento.

No obstante, en la tabla 4- 1 pueden consultarse los valores de media más característicos $\left(\sigma_{\max }, \varepsilon_{\max }, \varepsilon_{u}, E_{\max } \mathrm{y} E_{u}\right)$ de cada tres probetas sometidas a la misma temperatura, obtenidos de los ensayos de rotura a compresión de probetas cilíndricas.

\begin{tabular}{|c|c|c|c|c|c|c|}
\hline \multirow{2}{*}{$\begin{array}{l}\text { TEMPE } \\
\text { RATURA } \\
\text { (ํ) }\end{array}$} & \multirow{2}{*}{$\begin{array}{c}\text { TIPO } \\
\text { DE } \\
\text { HOR } \\
\text { MIGÓN }\end{array}$} & \multicolumn{4}{|c|}{$\begin{array}{l}\text { ENSAYOS A COMPRESIÓN } \\
\text { PROBETA CILÍNDRICA }\end{array}$} & [1 \\
\hline & & $\begin{array}{c}\sigma \max \\
(\mathrm{N} / \mathrm{mm} 2)\end{array}$ & $\varepsilon \max$ & $\varepsilon u$ & $\begin{array}{c}\text { Emax } \\
(\mathrm{N} / \mathrm{mm} 2)\end{array}$ & $\begin{array}{c}\mathrm{Eu} \\
(\mathrm{N} / \mathrm{mm} 2)\end{array}$ \\
\hline \multirow{2}{*}{20} & $\mathrm{H}-25$ & 24.10 & 0.0049 & 0.0066 & 0.0671 & 0.1016 \\
\hline & $\mathrm{H}-30$ & 27.70 & 0.0052 & 0.0069 & 0.0827 & 0.1225 \\
\hline \multirow{2}{*}{40} & H-25 & 22.81 & 0.0052 & 0.0069 & 0.0621 & 0.0996 \\
\hline & H-30 & 26.12 & 0.0052 & 0.0069 & 0.0777 & 0.1169 \\
\hline \multirow{2}{*}{70} & H-25 & 19.51 & 0.0051 & 0.0073 & 0.0566 & 0.0941 \\
\hline & H-30 & 24.61 & 0.0048 & 0.0061 & 0.0669 & 0.0967 \\
\hline \multirow{2}{*}{100} & H-25 & 18.22 & 0.0051 & 0.0075 & 0.0525 & 0.0908 \\
\hline & H-30 & 21.40 & 0.0046 & 0.0066 & 0.0560 & 0.0932 \\
\hline
\end{tabular}

Tabla 4- 1. Valores medios de las tres probetas cilíndricas sometidas a cada temperatura, con hormigones $\mathrm{H}-25$ y H-30, en los ensayos a compresión. 
En el capítulo 9, anexo 2.2, se recoge las gráficas tensión/deformación elaboradas como comparativa de los resultados de rotura a compresión de cada grupo de tres probetas cilíndricas, sometidas a las misma temperatura, tanto para las probetas elaboradas con hormigón H-25 como con hormigón H-30.

Como muestra de estas gráficas realizadas se aporta la gráfica 4- 4, correspondiente a las probetas cilíndricas elaboradas con hormigón $\mathrm{H}-25$, sometidas a $40^{\circ} \mathrm{C}$ de temperatura y ensayadas a compresión, y la gráfica 4- 5, perteneciente a las probetas cilíndricas elaboradas con hormigón $\mathrm{H}-30$, sometidas a $100^{\circ} \mathrm{C}$ de temperaturas y ensayadas a compresión.

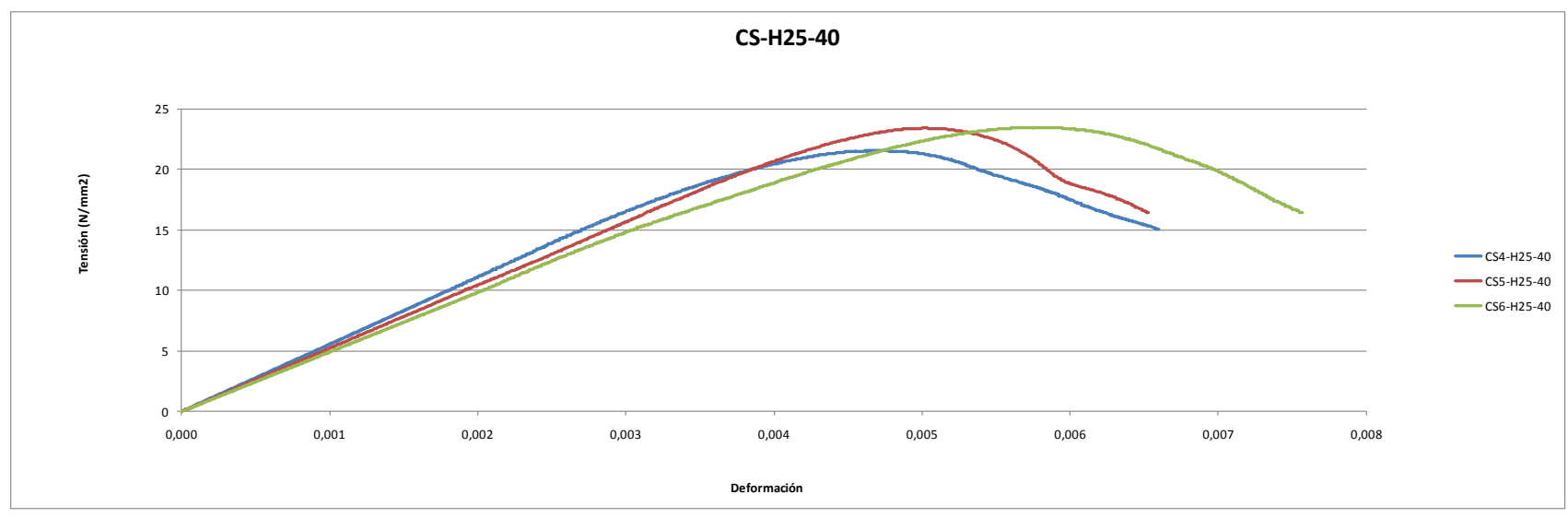

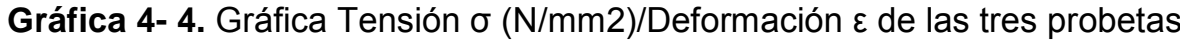
cilíndricas sometidas a $40^{\circ} \mathrm{C}$, de hormigón H-25 ensayado a compresión. Esta gráfica se presenta como ejemplo, el resto de gráficas de este apartado se encuentran en el

Anexo 2.2. Gráficas y tablas de medias de resultados de probetas semejantes.

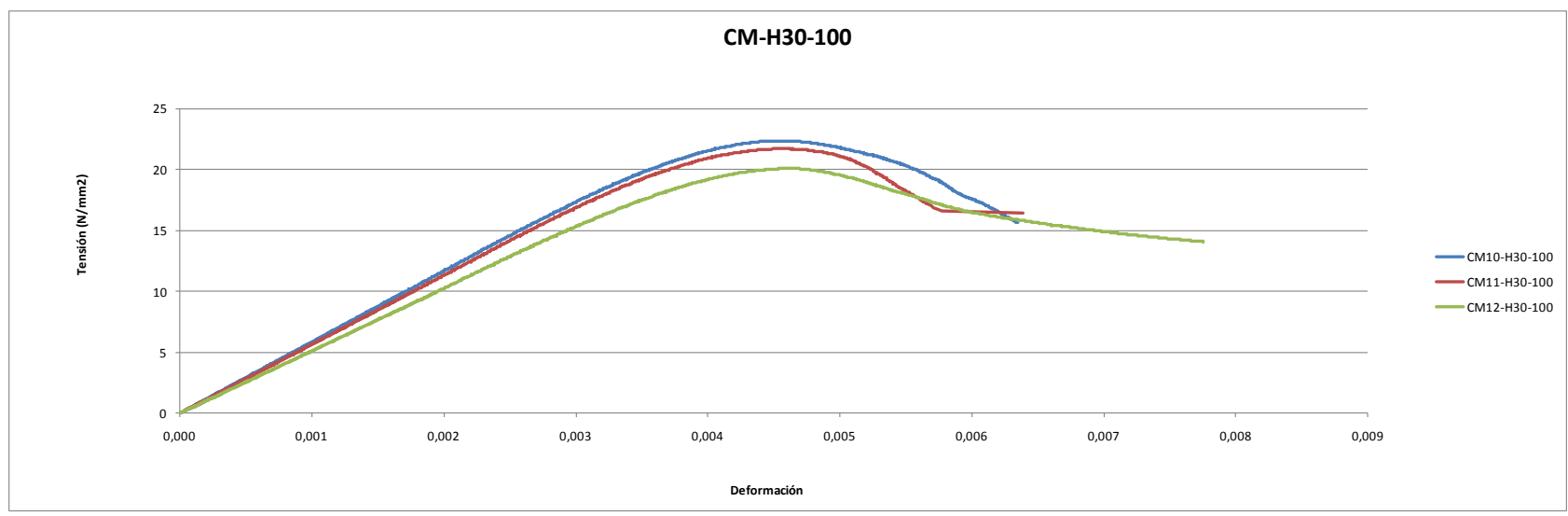

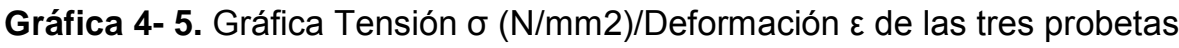
cilíndricas sometidas a $100^{\circ} \mathrm{C}$, de hormigón H-30 ensayado a compresión. Esta gráfica se presenta como ejemplo, el resto de gráficas de este apartado se encuentran en el

Anexo 2.2. Gráficas y tablas de medias de resultados de probetas semejantes. 


\subsubsection{Resultados de los ensayos a arrancamiento "pull-out"}

Las tablas en las que se recoge los resultados de los valores más característicos $\left(F_{R}, \delta_{\max }, \delta_{u}, E_{\max }\right.$ y $\left.E_{u}\right)$, hallados con los datos obtenidos en el ensayo de rotura a arrancamiento de todas y cada una de las probetas cúbicas con armadura corrugada anclada, elaboradas con hormigones $\mathrm{H}-25$ y $\mathrm{H}-30$, y sometidas en grupos de tres a temperaturas de $20^{\circ} \mathrm{C}, 40^{\circ} \mathrm{C}, 70^{\circ} \mathrm{C}$ y $100^{\circ} \mathrm{C}$, pueden encontrarse en el capítulo 9, anexo 1, de este documento.

No obstante, en la tabla 4- 2 pueden consultarse los valores de media más característicos $\left(F_{R}, \delta_{\max }, \delta_{u}, E_{\max }\right.$ y $\left.E_{u}\right)$ de cada tres probetas sometidas a la misma temperatura, obtenidos de los ensayos de adherencia realizados a las probetas cúbicas.

\begin{tabular}{|c|c|c|c|c|c|c|}
\hline \multirow{2}{*}{$\begin{array}{l}\text { TEMPE } \\
\text { RATURA } \\
\quad\left({ }^{\circ} \mathrm{C}\right)\end{array}$} & \multirow{2}{*}{$\begin{array}{c}\text { TIPO } \\
\text { DE } \\
\text { HOR } \\
\text { MIGÓN }\end{array}$} & \multicolumn{5}{|c|}{$\begin{array}{l}\text { ENSAYOS A ARRANCAMIENTO } \\
\text { "PULL OUT" PROBETA CÚBICA }\end{array}$} \\
\hline & & $\begin{array}{c}\text { FR } \\
(\mathrm{kN})\end{array}$ & $\begin{array}{l}\delta \max \\
(\mathrm{mm})\end{array}$ & $\begin{array}{c}\delta \mathrm{u} \\
(\mathrm{mm})\end{array}$ & $\begin{array}{c}\text { Emax } \\
(\mathrm{N} / \mathrm{mm} 2)\end{array}$ & $\begin{array}{c}\text { Eu } \\
(\mathrm{N} / \mathrm{mm} 2)\end{array}$ \\
\hline \multirow{2}{*}{20} & H-25 & 24.22 & 5.63 & 5.78 & 69.92 & 73.52 \\
\hline & $\mathrm{H}-30$ & 27.42 & 5.49 & 5.64 & 80.35 & 85.06 \\
\hline \multirow{2}{*}{40} & $\mathrm{H}-25$ & 21.31 & 6.74 & 6.94 & 72.85 & 77.07 \\
\hline & $\mathrm{H}-30$ & 22.51 & 5.21 & 6.35 & 62.33 & 73.95 \\
\hline \multirow{2}{*}{70} & H-25 & 18.37 & 6.21 & 6.32 & 57.58 & 59.60 \\
\hline & $\mathrm{H}-30$ & 18.92 & 5.95 & 6.08 & 53.83 & 56.22 \\
\hline \multirow{2}{*}{100} & H-25 & 15.17 & 4.77 & 4.89 & 36.75 & 38.73 \\
\hline & H-30 & 14.52 & 3.61 & 3.80 & 28.50 & 30.71 \\
\hline
\end{tabular}

Tabla 4- 2. Valores medios de las tres probetas cúbicas sometidas a cada temperatura, con hormigones $\mathrm{H}-25$ y H-30, en los ensayos a arrancamiento. 
En el capítulo 9, anexo 2.2, se recoge las gráficas fuerza/desplazamiento, elaboradas como comparativa de los resultados de rotura a compresión de cada grupo de tres probetas cúbicas con armadura corrugada anclada, sometidas a las misma temperatura, tanto para las probetas elaboradas con hormigón $\mathrm{H}-25$ como para las elaboradas con hormigón H-30.

Como muestra de estas gráficas realizadas se aporta la gráfica 4- 6, correspondiente a las probetas cúbicas con armadura corrugada anclada elaboradas con hormigón $\mathrm{H}-25$, sometidas a $20^{\circ} \mathrm{C}$ de temperatura y ensayadas a arrancamiento o "pull-out", y la gráfica 4- 7, perteneciente a las probetas cúbicas con armadura corrugada anclada, elaboradas con hormigón $\mathrm{H}-30$, sometidas a $70^{\circ} \mathrm{C}$ de temperaturas y ensayadas a "pull-out".

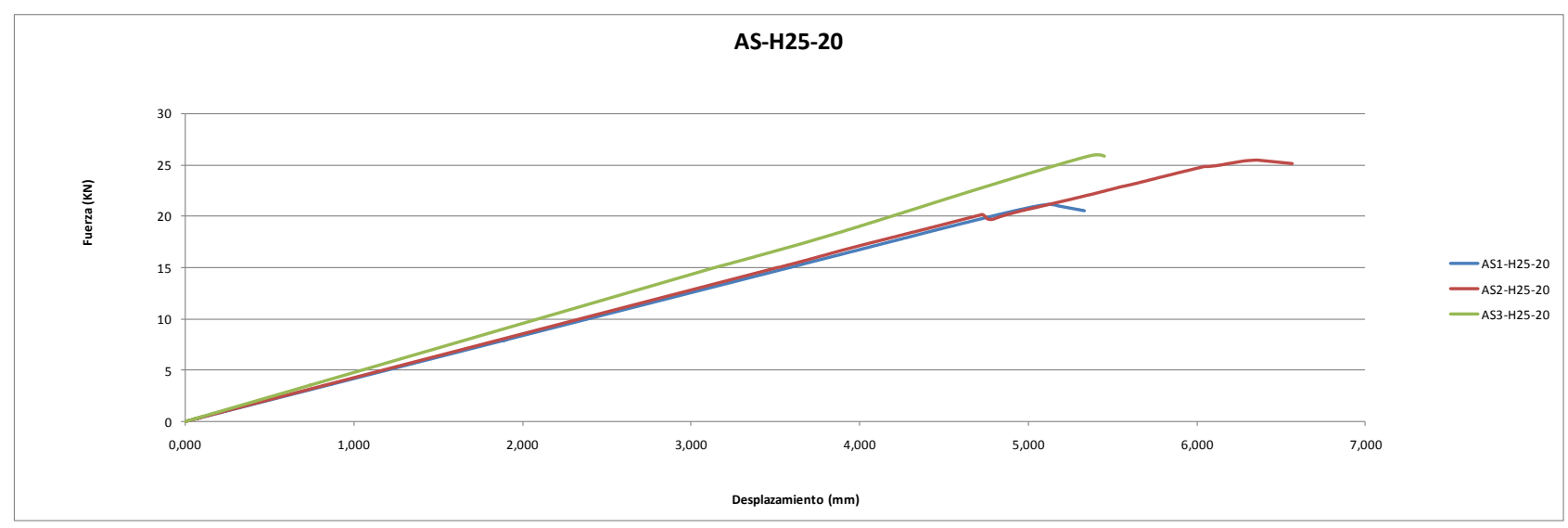

Gráfica 4- 6. Gráfica Fuerza $F(\mathrm{KN}) /$ Desplazamiento $\delta(\mathrm{mm})$ de las tres probetas cúbicas sometidas a $20^{\circ} \mathrm{C}$, de hormigón $\mathrm{H}-25$ ensayado a arrancamiento "pull-out". Esta gráfica se presenta como ejemplo, el resto de gráficas de este apartado se encuentran en el Anexo 2.2. Gráficas y tablas de medias de resultados de probetas semejantes.

Se aporta también la gráfica 4- 7, perteneciente a las probetas cúbicas con armadura corrugada anclada, elaboradas con hormigón $\mathrm{H}-30$, sometidas a $70^{\circ} \mathrm{C}$ de temperatura y ensayadas a "pull-out". 


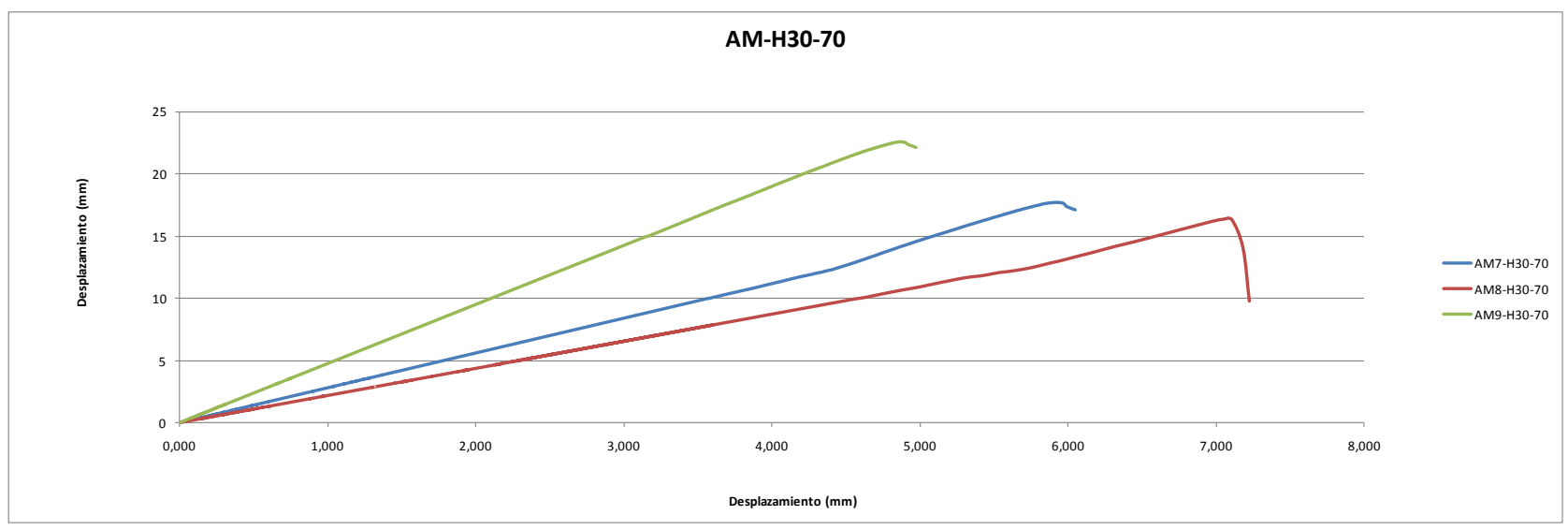

Gráfica 4- 7. Gráfica Fuerza $F(\mathrm{KN})$ /Desplazamiento $\delta(\mathrm{mm})$ de las tres probetas cúbicas sometidas a $70^{\circ} \mathrm{C}$ de hormigón H-30 ensayado a arrancamiento "pull-out". Esta gráfica se presenta como ejemplo, el resto de gráficas de este apartado se encuentran en el Anexo 2.2. Gráficas y tablas de medias de resultados de probetas semejantes. 


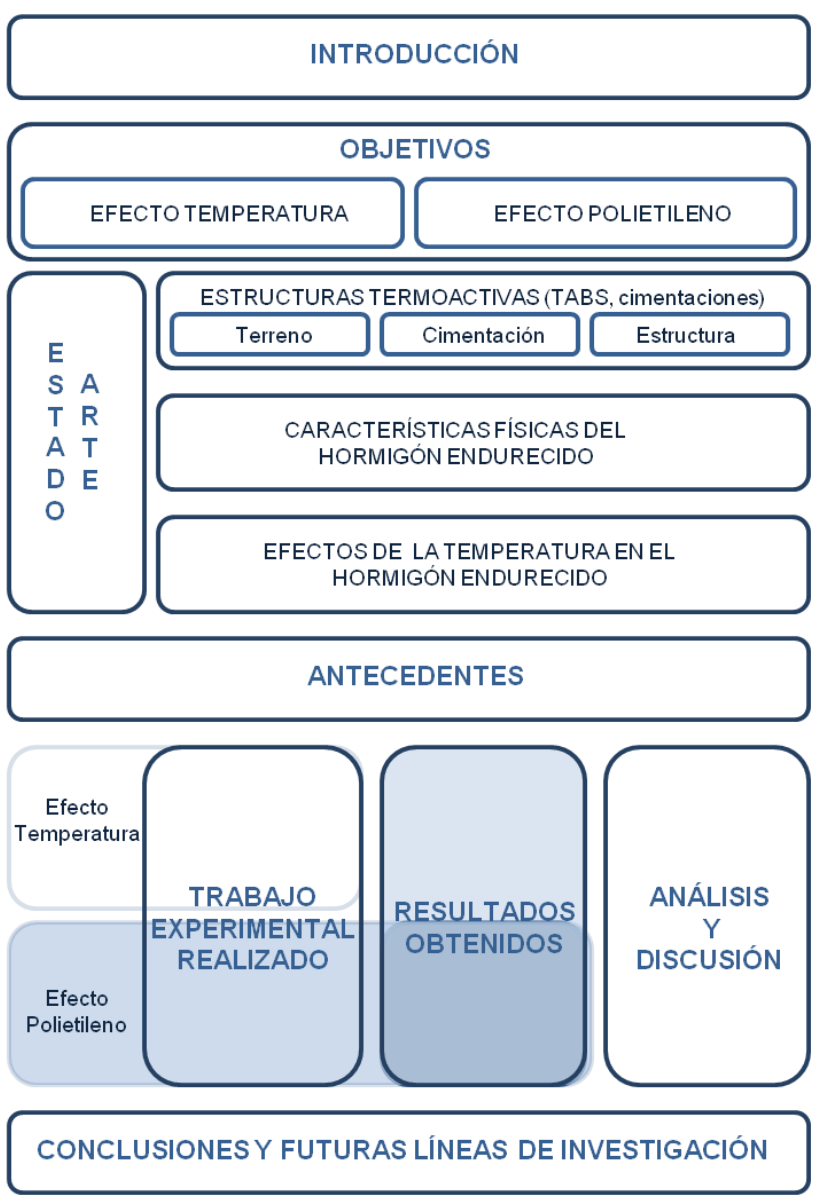

\subsection{Estudio del efecto de la incorporación de tubos de polietileno}

Una vez realizados los ensayos de rotura a compresión de la probetas cilíndricas, fabricadas con hormigones $\mathrm{H}-25$ y H-30, en las que se ha dispuesto tubos de polietileno en posición vertical, vertical descentrada, horizontal y sin tubo, y de las probetas cúbicas fabricadas con hormigones $\mathrm{H}-25$ y H-30, en las que se ha dispuesto tubos de polietileno en posición vertical, horizontal y sin tubo, se procede a elaborar una gráfica tensión/deformación para los resultados de ensayo a compresión, para cada una de las probetas ensayadas.

Los gráficos del resultado de rotura de cada probeta pueden localizarse en el capítulo 9, anexo 2.1, de este documento. 


\subsubsection{Resultados de los ensayos a compresión probeta cilíndrica}

Las tablas en las que se recoge los resultados de los valores más característicos $\left(\sigma_{\max }, \varepsilon_{\max }, \varepsilon_{u}, E_{\max }\right.$ y $\left.E_{u}\right)$, hallados con los datos obtenidos en el ensayo de rotura a compresión de todas y cada una de las probetas cilíndricas elaboradas con hormigones $\mathrm{H}-25$ y $\mathrm{H}-30$, en las que se ha incorporado de manera semejante en grupos de tres tubería de polietileno en posición vertical, vertical descentrada, horizontal y sin tubo, pueden encontrarse en el capítulo 9, anexo 1 , de este documento.

No obstante, en la tabla 4- 3 pueden consultarse los valores de media más característicos $\left(\sigma_{\max }, \varepsilon_{\max }, \varepsilon_{u}, E_{\max }\right.$ y $\left.E_{u}\right)$ de cada tres probetas cilíndricas fabricadas con el tubo de polietileno en su interior, dispuesto de manera semejante, obtenidos de los ensayos de rotura a compresión.

\begin{tabular}{|c|c|c|c|c|c|c|}
\hline \multirow{2}{*}{$\begin{array}{l}\text { POSICIÓN } \\
\text { DEL TUBO }\end{array}$} & \multirow{2}{*}{$\begin{array}{l}\text { TIPO } \\
\text { DE } \\
\text { HOR } \\
\text { MIGÓ } \\
\text { N }\end{array}$} & \multicolumn{5}{|c|}{$\begin{array}{l}\text { ENSAYOS A COMPRESIÓN } \\
\text { PROBETA CILÍNDRICA }\end{array}$} \\
\hline & & $\begin{array}{c}\sigma \mathrm{max} \\
(\mathrm{N} / \mathrm{mm} 2)\end{array}$ & $\varepsilon \max$ & $\varepsilon u$ & $\begin{array}{c}\text { Emax } \\
(\mathrm{N} / \mathrm{mm} 2)\end{array}$ & $\underset{(\mathrm{N} / \mathrm{mm} 2)}{\mathrm{Eu}}$ \\
\hline \multirow{2}{*}{ SIN TUBO } & $\mathrm{H}-25$ & 23.22 & 0.0038 & 0.0047 & 0.0472 & 0.0434 \\
\hline & H-30 & 29.91 & 0.0048 & 0.0056 & 0.0806 & 0.0867 \\
\hline \multirow{2}{*}{$\begin{array}{l}\text { VERTICAL } \\
\text { CENTRADO }\end{array}$} & H-25 & 22.02 & 0.0041 & 0.0051 & 0.0505 & 0.0701 \\
\hline & H-30 & 27.09 & 0.0046 & 0.0053 & 0.0694 & 0.0546 \\
\hline \multirow{2}{*}{$\begin{array}{l}\text { VERTICAL } \\
\text { DESCENTR }\end{array}$} & H-25 & 22.42 & 0.0042 & 0.0055 & 0.0534 & 0.0718 \\
\hline & H-30 & 26.77 & 0.0046 & 0.0058 & 0.0702 & 0.0624 \\
\hline \multirow{2}{*}{$\begin{array}{l}\text { HORIZONT } \\
\text { CENTRADO }\end{array}$} & H-25 & 18.28 & 0.0034 & 0.0046 & 0.0343 & 0.0531 \\
\hline & H-30 & 21.58 & 0.0044 & 0.0053 & 0.0531 & 0.0597 \\
\hline
\end{tabular}

Tabla 4- 3. Valores medios de las tres probetas cilíndricas con igual posición de tubo de polietileno, con hormigones $\mathrm{H}-25$ y H-30, en los ensayos a compresión. 
En el capítulo 9, anexo 2.2, se recoge las gráficas tensión/deformación elaboradas como comparativa de los resultados de rotura a compresión de cada grupo de tres probetas cilíndricas, con igual posición de tubo de polietileno, tanto para las probetas elaboradas con hormigón $\mathrm{H}-25$ como con hormigón H-30.

Como muestra de estas gráficas realizadas se aporta la gráfica 4- 8, correspondiente a las probetas cilíndricas elaboradas con hormigón $\mathrm{H}-25$, con tubo de polietileno dispuesto en posición vertical centrado y ensayadas a compresión.

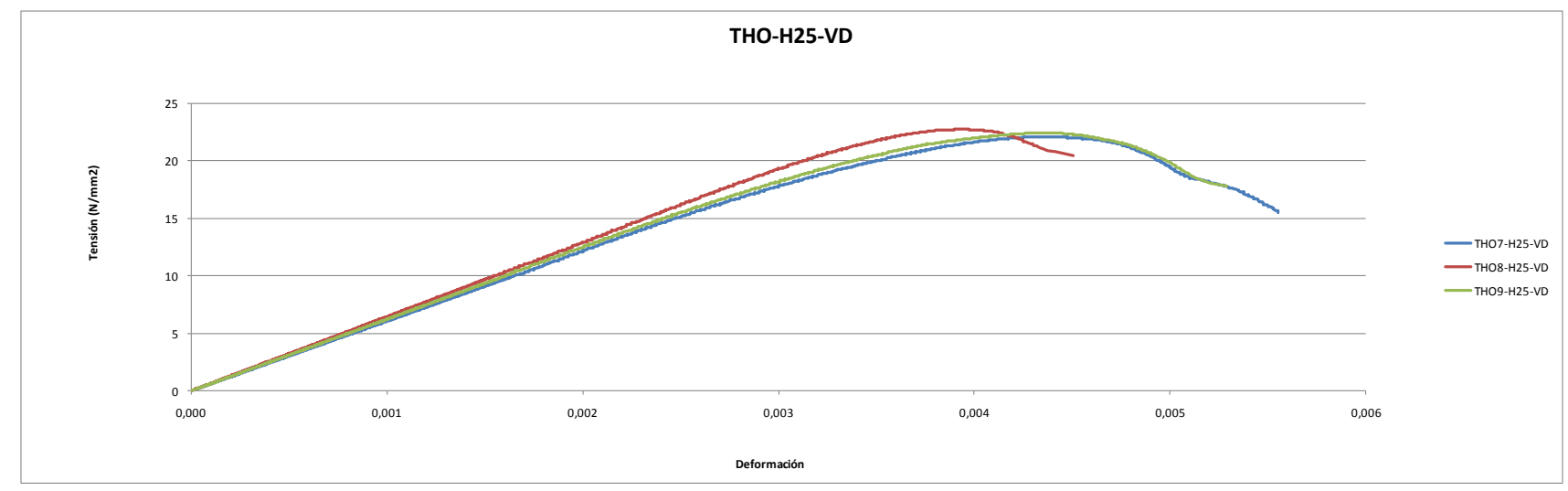

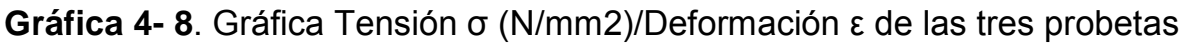
cilíndricas con tubo PE en posición vertical centrado, de hormigón H-25 ensayado a compresión. Esta gráfica se presenta como ejemplo, el resto de gráficas de este apartado se encuentran en el Anexo 2.2. Gráficas y tablas de medias de resultados de probetas semejantes.

También se aporta la gráfica 4- 9, perteneciente a las probetas cilíndricas elaboradas con hormigón $\mathrm{H}-30$, con tubo de polietileno situado en posición horizontal y ensayadas a compresión. 


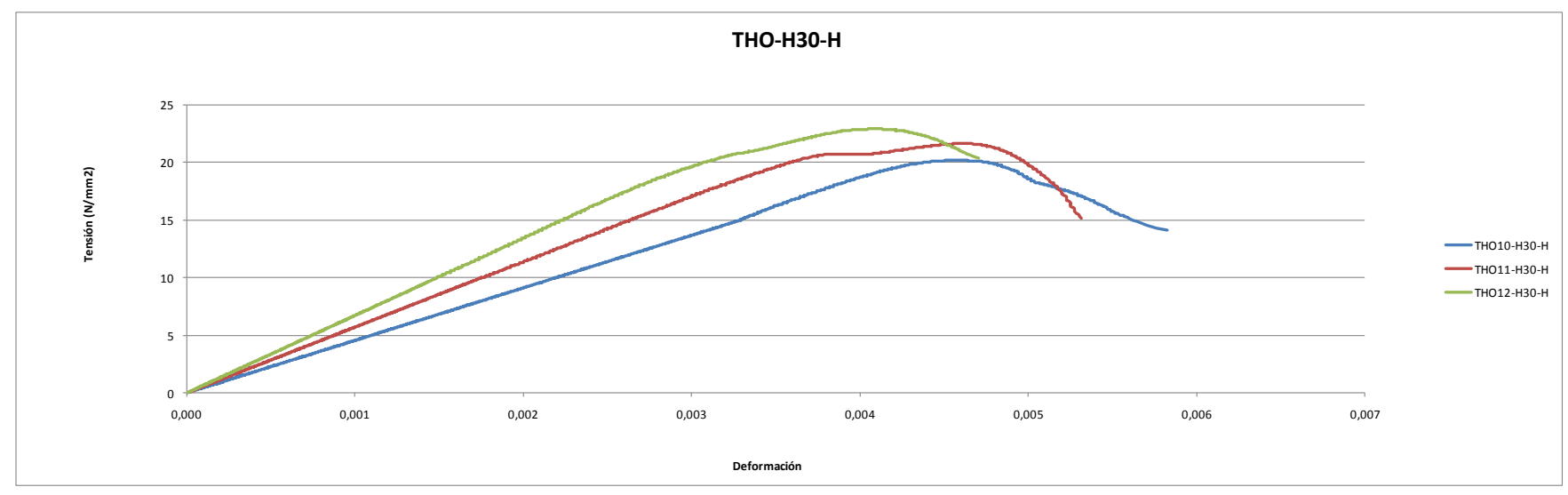

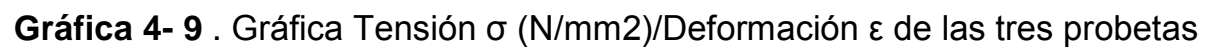
cilíndricas con tubo PE en posición horizontal, de hormigón H-30 ensayado a compresión. Esta gráfica se presenta como ejemplo, el resto de gráficas de este apartado se encuentran en el Anexo 2.2. Gráficas y tablas de medias de resultados de probetas semejantes. 


\subsubsection{Resultados de los ensayos a compresión probeta cúbica}

Las tablas en las que se recoge los resultados de los valores más característicos $\left(\sigma_{\max }, \varepsilon_{\max }, \varepsilon_{u}, E_{\max }\right.$ y $\left.E_{u}\right)$, hallados con los datos obtenidos en el ensayo de rotura a compresión de todas y cada una de las probetas cúbicas elaboradas con hormigones $\mathrm{H}-25$ y $\mathrm{H}-30$, en las que se ha incorporado de manera semejante en grupos de tres tubería de polietileno en posición vertical, horizontal y $\sin$ tubo, pueden encontrarse en el capítulo 9, anexo 1, de este documento.

No obstante, en la tabla 4- 4 pueden consultarse los valores de media más característicos $\left(\sigma_{\max }, \varepsilon_{\max }, \varepsilon_{u}, E_{\max }\right.$ y $\left.E_{u}\right)$ de cada tres probetas cúbicas fabricadas con el tubo de polietileno en su interior, dispuesto de manera semejante, obtenidos de los ensayos de rotura a compresión.

\begin{tabular}{|c|c|c|c|c|c|}
\hline \multirow{2}{*}{$\begin{array}{l}\text { POSICIÓN } \\
\text { DEL TUBO }\end{array}$} & \multirow{2}{*}{$\begin{array}{c}\text { TIPO } \\
\text { DE } \\
\text { HOR } \\
\text { MIGÓ } \\
\text { N }\end{array}$} & \multicolumn{3}{|c|}{$\begin{array}{l}\text { ENSAYOS A COMPRESIÓN } \\
\text { PROBETA CÚBICA }\end{array}$} & Q: \\
\hline & & $\varepsilon \max$ & $\varepsilon \mathrm{u}$ & $\underset{(\mathrm{N} / \mathrm{mm} 2)}{\operatorname{Emax}}$ & $\underset{(\mathrm{N} / \mathrm{mm} 2)}{\mathrm{Eu}}$ \\
\hline \multirow{2}{*}{ SIN TUBO } & H-25 & 0.0049 & 0.0101 & 0.0878 & 0.2097 \\
\hline & H-30 & 0.0064 & 0.0094 & 0.1156 & 0.1929 \\
\hline \multirow{2}{*}{$\begin{array}{l}\text { VERTICAL } \\
\text { CENTRADO }\end{array}$} & H-25 & 0.0047 & 0.0091 & 0.0720 & 0.1626 \\
\hline & H-30 & 0.0053 & 0.0079 & 0.1018 & 0.1330 \\
\hline \multirow{2}{*}{$\begin{array}{l}\text { VERTICAL } \\
\text { DESCENTR }\end{array}$} & H-25 & ----- & ----- & ----- & ---- \\
\hline & H-30 & ----- & ----- & ----- & ----- \\
\hline \multirow{2}{*}{$\begin{array}{l}\text { HORIZONT } \\
\text { CENTRADO }\end{array}$} & H-25 & 0.0042 & 0.0085 & 0.0587 & 0.1369 \\
\hline & H-30 & 0.0045 & 0.0085 & 0.0717 & 0.1282 \\
\hline
\end{tabular}

Tabla 4- 4. Valores medios de las tres probetas cúbicas con igual posición de tubo de polietileno, con hormigones $\mathrm{H}-25$ y H-30, en los ensayos a compresión. 
En el capítulo 9, anexo 2.2, se recoge las gráficas tensión/deformación elaboradas como comparativa de los resultados de rotura a compresión de cada grupo de tres probetas cúbicas con igual posición de tubo de polietileno, tanto para las probetas elaboradas con hormigón $\mathrm{H}-25$ como con hormigón $\mathrm{H}-30$.

Como muestra de estas gráficas realizadas se aporta la gráfica 4- 10, correspondiente a las probetas cúbicas elaboradas con hormigón $\mathrm{H}-25$, con tubo de polietileno dispuesto en posición vertical y ensayadas a compresión.

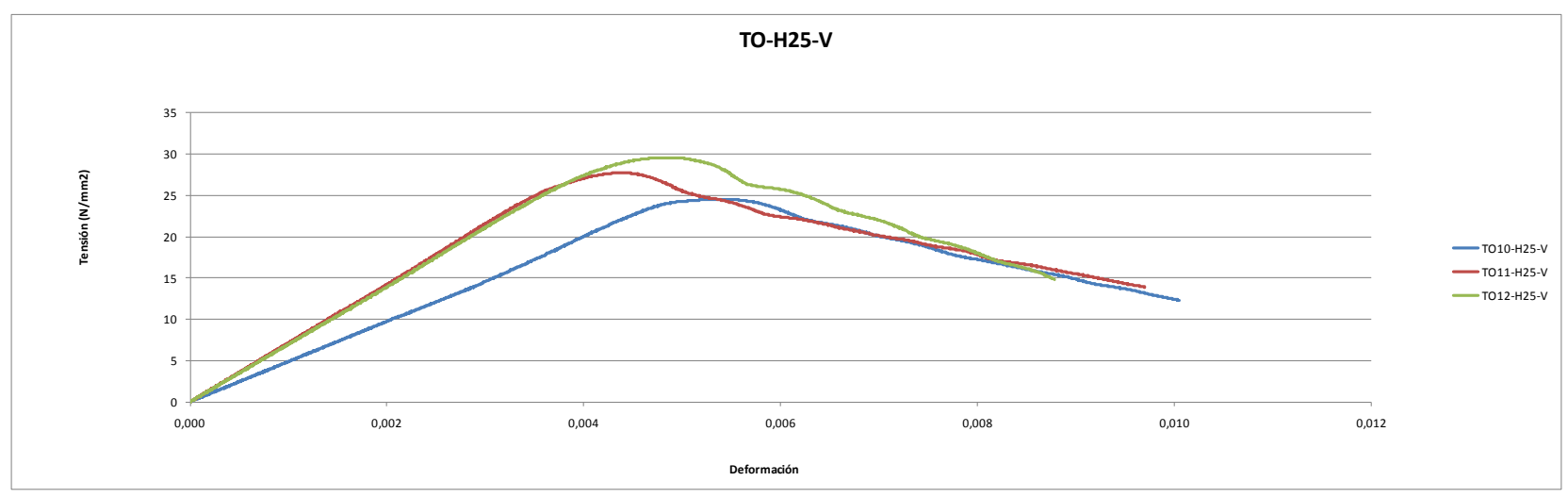

Gráfica 4- 10. Gráfica Tensión $\sigma(\mathrm{N} / \mathrm{mm} 2) /$ Deformación $\varepsilon$ de tres de las probetas cúbicas, con tubo PE en posición vertical, de hormigón H-25 ensayado a compresión.

Esta gráfica se presenta como ejemplo, el resto de gráficas de este apartado se encuentran en el Anexo 2.2. Gráficas y tablas de medias de resultados de probetas semejantes.

Del mismo modo, se aporta la gráfica 4- 11, perteneciente a las probetas cúbicas elaboradas con hormigón $\mathrm{H}-30$, con tubo de polietileno situado en posición horizontal y ensayadas a compresión. 


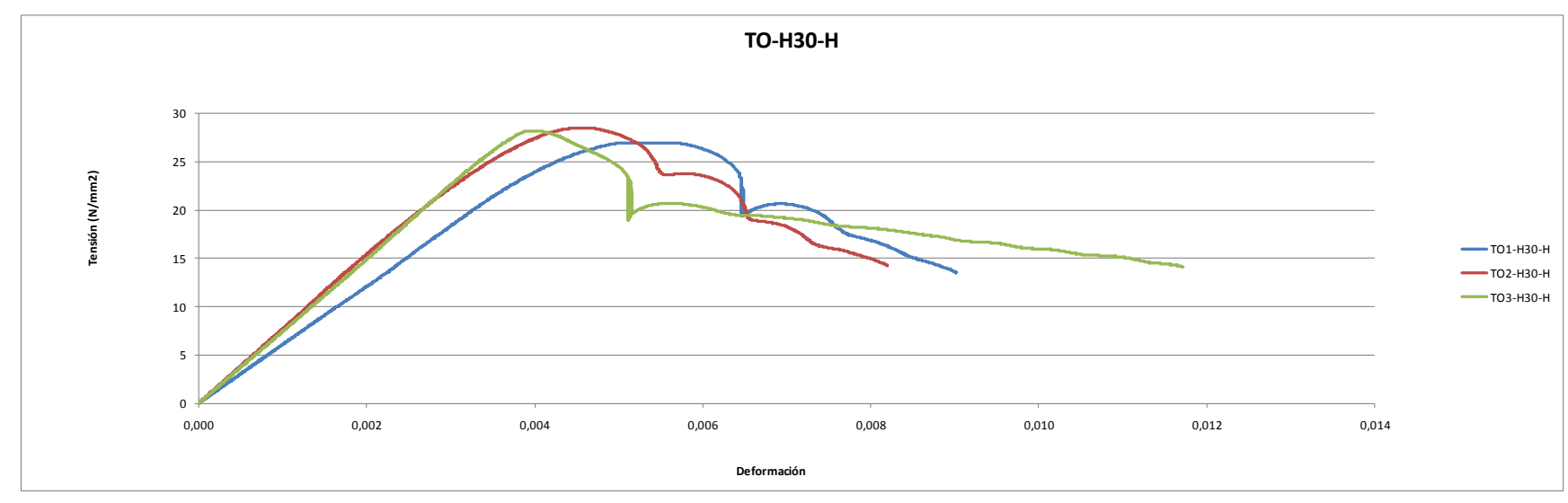

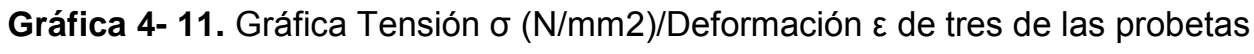
cúbicas, con tubo $\mathrm{PE}$ en posición horizontal, de hormigón $\mathrm{H}-30$ ensayado a compresión. Esta gráfica se presenta como ejemplo, el resto de gráficas de este apartado se encuentran en el Anexo 2.2. Gráficas y tablas de medias de resultados de probetas semejantes. 


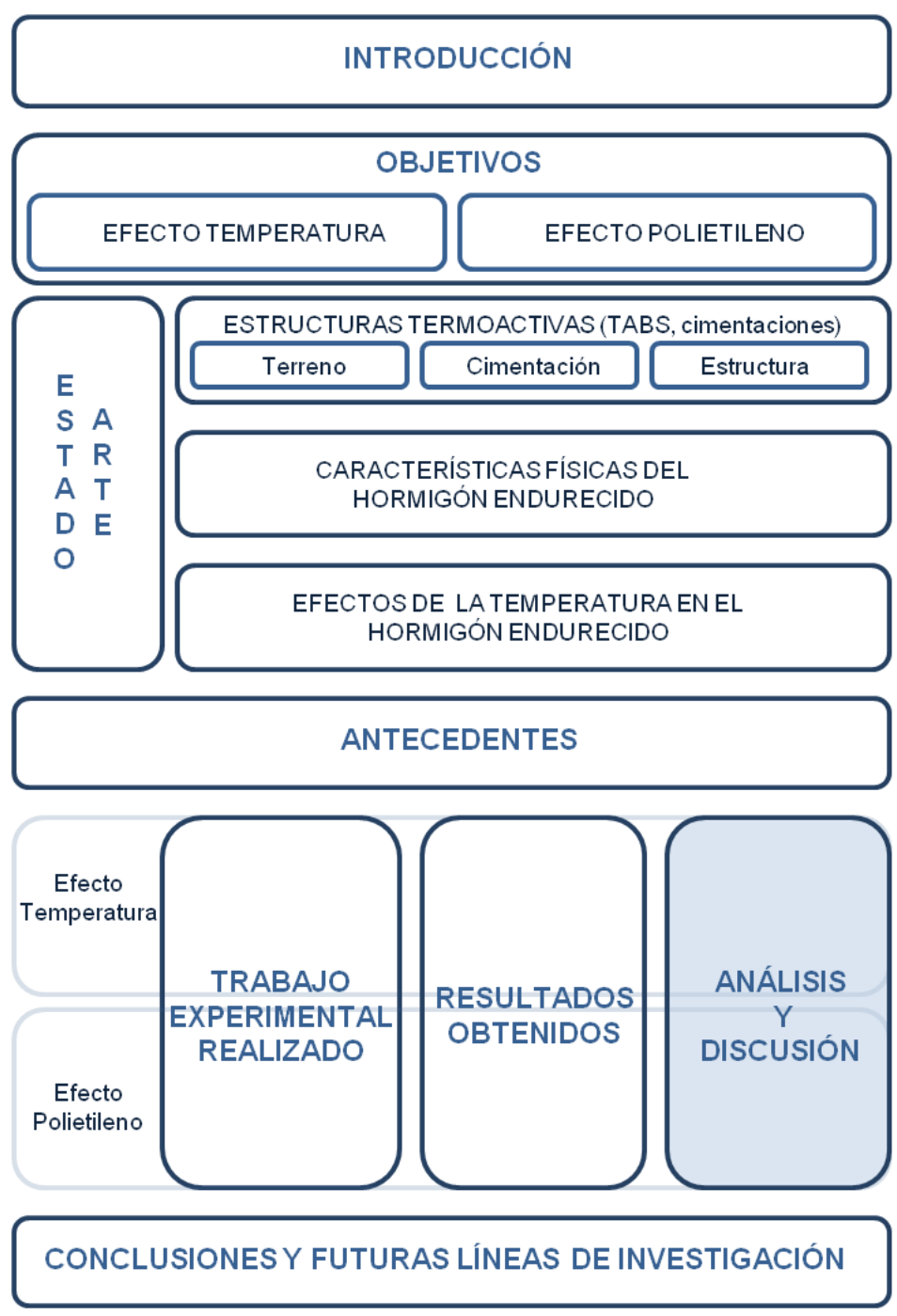

CAPÍTULO 5

\section{ANÁLISIS Y DISCUSIÓN}

DE LOS RESULTADOS

OBTENIDOS 


\section{$5.1 \quad$ Introducción}

En este capítulo se procede a analizar los datos obtenidos en el análisis realizado para estudiar por separado el efecto producido por la temperatura moderada en el hormigón endurecido y el efecto producido por la incorporación de tubos de polietileno en su interior.

Para realizar este análisis se ha elaborado una serie de gráficos que ayudan a la interpretación de los resultados.

Además se ha realizado un estudio de análisis estadístico de la varianza multifactorial, que puede encontrarse en el capítulo 9, anexo 3, en el que se estudia la interacción de los tres factores estudiados en esta investigación, los dos tipos de hormigón (H-25 y H-30), los dos tipos de probeta (cilíndrica y cúbica) y los tres tipos de posicionamiento de tubo de polietileno (vertical, horizontal y sin tubo).

Del estudio se desprende la influencia de los tres factores en el valor de la variable aleatoria Resistencia a compresión del hormigón, a un 95\% de confianza.

Como era de esperar el factor tipo de hormigón influye en la resistencia a compresión de las probetas ensayadas, siendo superiores las resistencias de las probetas en las que se utiliza hormigón H-30.

La forma de la probeta también influye directamente en los resultados de rotura a compresión, confirmándose tal y como ya habían hecho otros investigadores, que el hecho de que la probeta tenga forma cúbica favorece que los resultados de rotura sean superiores que los resultados de probetas con forma cilíndrica.

Y por último el factor de la posición en la que se coloca el tubo de polietileno influye también directamente en la resistencia a compresión del hormigón, obteniéndose resultados más desfavorables cuando existe el tubo de polietileno en el interior de la probeta y mucho más desfavorable cuando su posición es perpendicular a la dirección en la que se aplica la carga. 


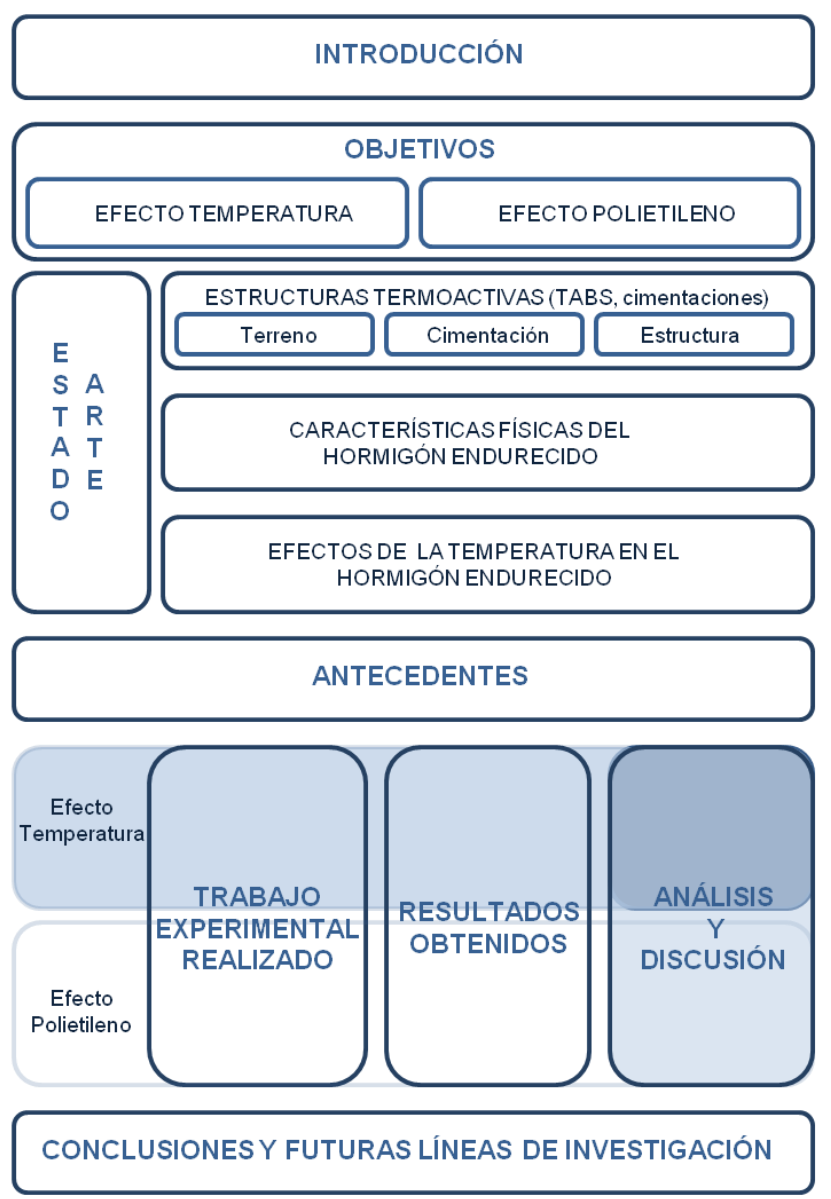

\subsection{Estudio del efecto del incremento de temperatura}

Los resultados obtenidos de los ensayos efectuados para analizar el efecto del aumento de temperatura en el hormigón endurecido permiten establecer comparativas de los valores más característicos averiguados en cada caso.

En ese sentido se realizan cuatro análisis diferentes: un primer análisis, que permite analizar gráficamente cuál es la evolución del hormigón provocada por el efecto de la temperatura $\left(20^{\circ} \mathrm{C}, 40^{\circ} \mathrm{C}, 70^{\circ} \mathrm{C}\right.$ y $\left.100^{\circ} \mathrm{C}\right)$, utilizando los resultados de tensión o fuerza de arrancamiento (en su caso) de las probetas más representativas para cada uno de los dos tipos de hormigón $(\mathrm{H}-25$ y H-30) por separado.

Un segundo análisis comparativo de las probetas de los dos hormigones $(\mathrm{H}-25$ y $\mathrm{H}$-30), que nos permite analizar la evolución de las distintos resultados más característicos $\left(\sigma_{\max }, \varepsilon_{\max }, \varepsilon_{u}, E_{\max }\right.$ y $\left.E_{u}\right)$ y $\left(\mp_{R}, \delta_{\max }, \delta_{u}, E_{\max }\right.$ y $\left.E_{u}\right)$ obtenidos de 
los ensayos a compresión y arrancamiento, y su evolución en función del aumento de temperatura $\left(20^{\circ} \mathrm{C}, 40^{\circ} \mathrm{C}, 70^{\circ} \mathrm{C}\right.$ y $\left.100^{\circ} \mathrm{C}\right)$.

Un tercer análisis comparativo, que permite analizar la evolución con respecto al aumento de temperatura $\left(20^{\circ} \mathrm{C}, 40^{\circ} \mathrm{C}, 70^{\circ} \mathrm{C}\right.$ y $\left.100^{\circ} \mathrm{C}\right)$, de los valores máximos más característicos $\left(\sigma_{\max }, \varepsilon_{\max }, E_{\max }\right)$ y $\left(\delta_{\max }, \delta_{u}, E_{\max }\right)$ obtenidos de las medias de los resultados de rotura a compresión o a arrancamiento, en su caso, de las probetas elaboradas con hormigón H-25 y de las elaboradas con hormigón H-30.

Y un último análisis porcentual, que nos permite establecer la temperatura de consigna a partir de la cual las pérdidas de resistencia de las probetas de hormigón endurecido $\mathrm{H}-25$ y H-30 sobrepasan el $20 \%$.

\subsubsection{Estudio de los resultados de rotura a compresión (efecto temperatura)}

En este primer apartado se presentan los cuatro estudios comparativos realizados con los resultados de probetas cilíndricas ensayadas a compresión para analizar el efecto producido por el aumento de temperatura $\left(20^{\circ} \mathrm{C}, 40^{\circ} \mathrm{C}, 70^{\circ} \mathrm{C}\right.$ y 100ํㅡ), para hormigón H-25 y hormigón H-30.

\subsubsection{Estudio comparativo de los resultados de tensión/deformación más significativos en función del aumento de temperatura.}

Se ha procedido a elaborar unas gráficas con los resultados más significativos que permitan apreciar visualmente cual es el comportamiento de cada tipo de probeta cilíndrica de hormigón endurecido sometidas a las distintitas temperaturas $\left(20^{\circ} \mathrm{C}, 40^{\circ} \mathrm{C}, 70^{\circ} \mathrm{C}\right.$ y $\left.100^{\circ} \mathrm{C}\right)$, ensayadas a compresión y para los dos hormigones utilizados $\mathrm{H}-25$ y $\mathrm{H}-30$.

Los resultados obtenidos en el ensayo a compresión de las probetas cilíndricas se detallan en las gráficas 5 - 1 y 5 - 2, donde se muestra la evolución de la tensión respecto a la deformación, para las diferentes temperaturas de ensayo y para los dos tipos de hormigón empleados. Como se puede observar, independientemente del tipo de hormigón empleado, la tensión máxima disminuye al aumentar la temperatura, reduciéndose de manera más acusada cuando las probetas se encuentran sometidas a temperaturas iguales o superiores a $70^{\circ} \mathrm{C}$. 


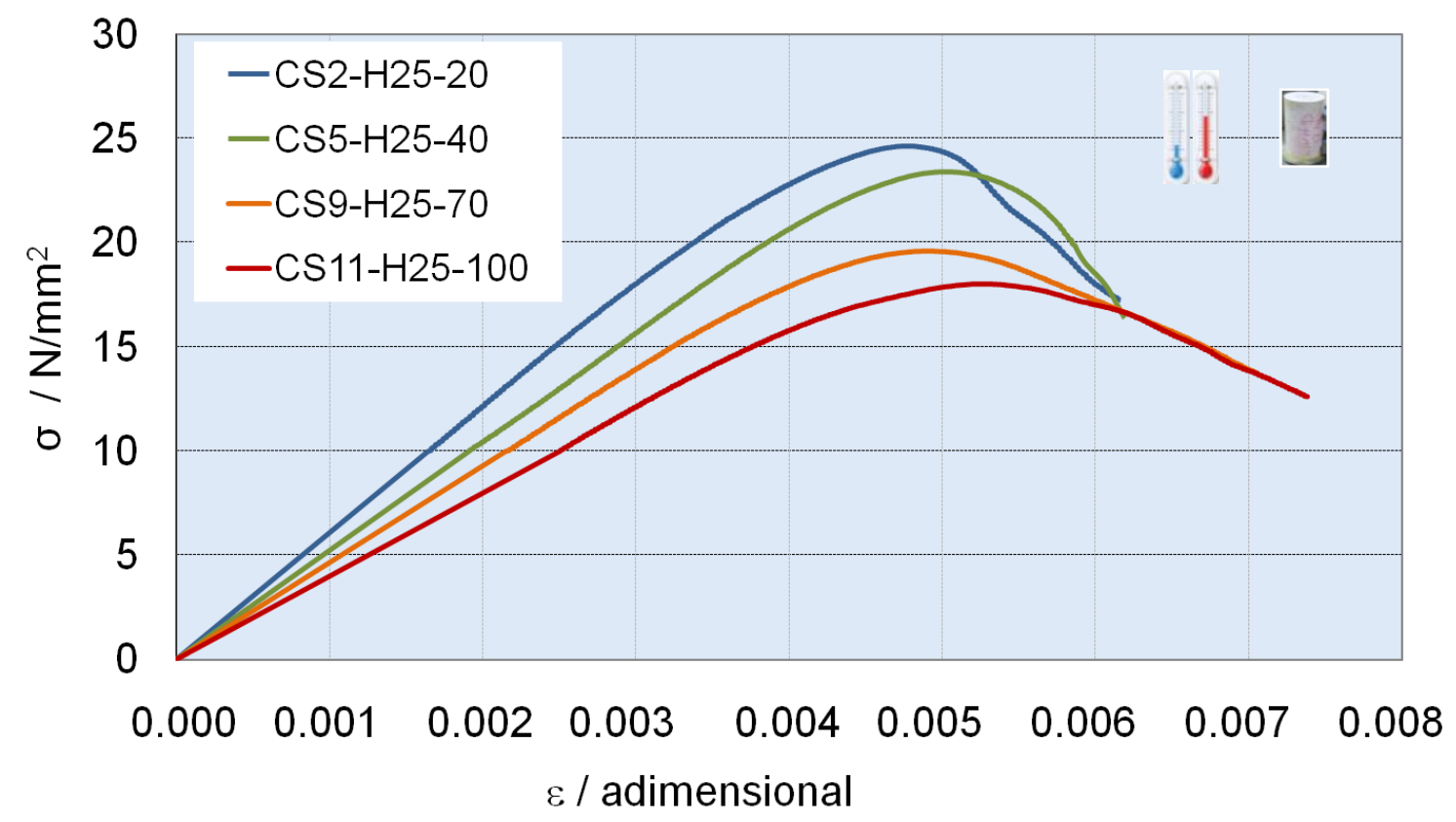

Gráfica 5- 1. Gráfica de evolución de la Tensión $\sigma(\mathrm{N} / \mathrm{mm} 2)$ respecto a la deformación $\varepsilon$ (adimensional) en probetas cilíndricas más representativas, para temperaturas de $20^{\circ} \mathrm{C}, 40^{\circ} \mathrm{C}, 70^{\circ} \mathrm{C}$ y $100^{\circ} \mathrm{C}$, realizadas con hormigón $\mathrm{H}-25$, ensayadas a compresión.

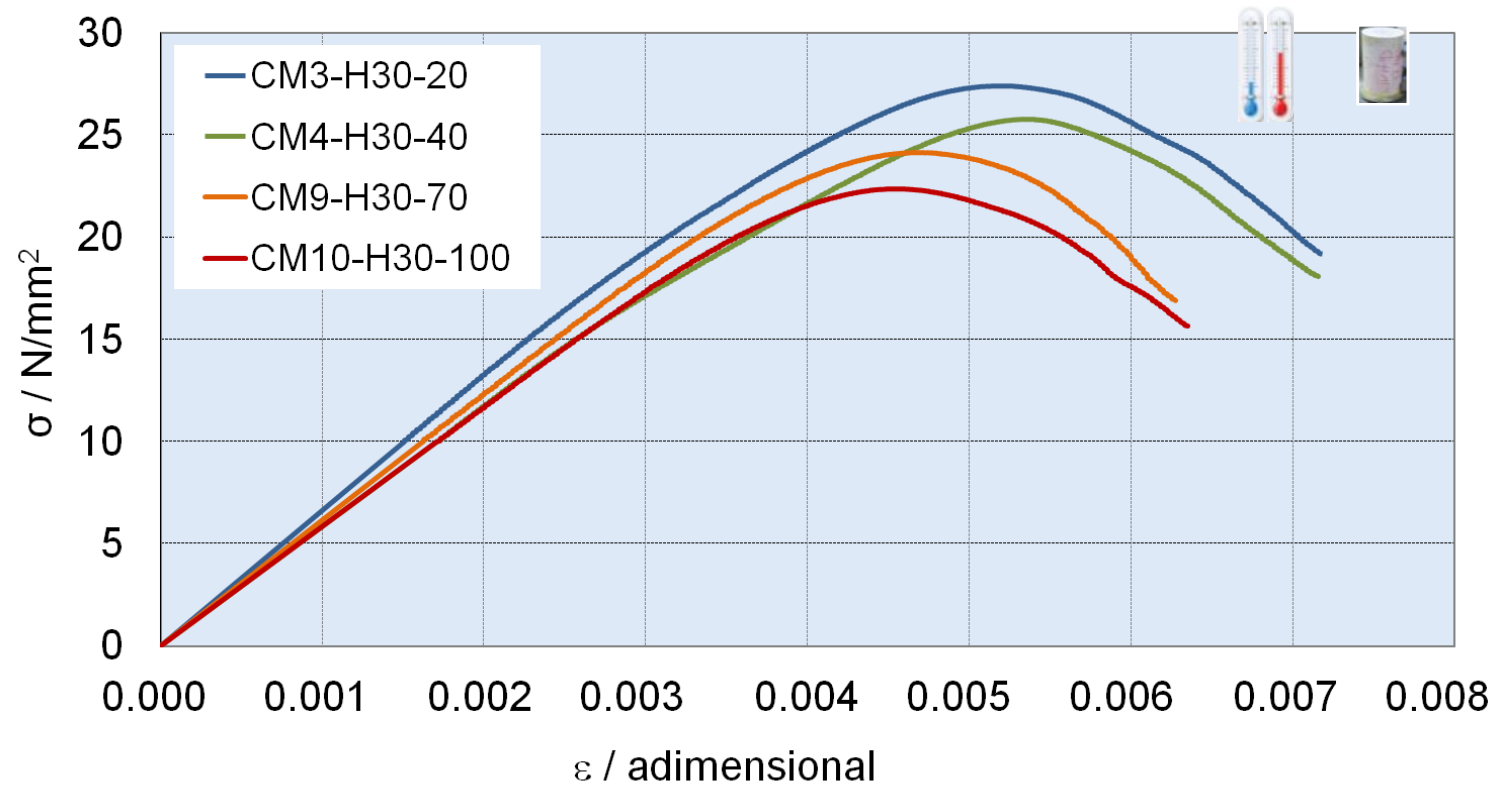

Gráfica 5- 2. Gráfica de evolución de la Tensión $\sigma(\mathrm{N} / \mathrm{mm} 2)$ respecto a la deformación $\varepsilon$ (adimensional) en probetas cilíndricas más representativas, para temperaturas de $20^{\circ} \mathrm{C}, 40^{\circ} \mathrm{C}, 70^{\circ} \mathrm{C}$ y $100^{\circ} \mathrm{C}$, realizadas con hormigón $\mathrm{H}-30$, ensayadas a compresión. 


\subsubsection{Estudio comparativo de los resultados $\sigma_{\max }, \varepsilon_{\max }, \varepsilon_{u}, E_{\max }$ y $E_{u}$ de rotura a compresión de las probetas cilíndricas sometidas a temperatura.}

A continuación se presenta las gráficas comparativas de los valores que se han obtenido como resultado del ensayo de resistencia a compresión de probetas cilíndricas sometidas a distintas temperaturas $\left(20^{\circ} \mathrm{C}, 40^{\circ} \mathrm{C}, 70^{\circ} \mathrm{C}\right.$ y $\left.100^{\circ} \mathrm{C}\right)$, de los dos hormigones utilizados $\mathrm{H}-25$ y H-30.

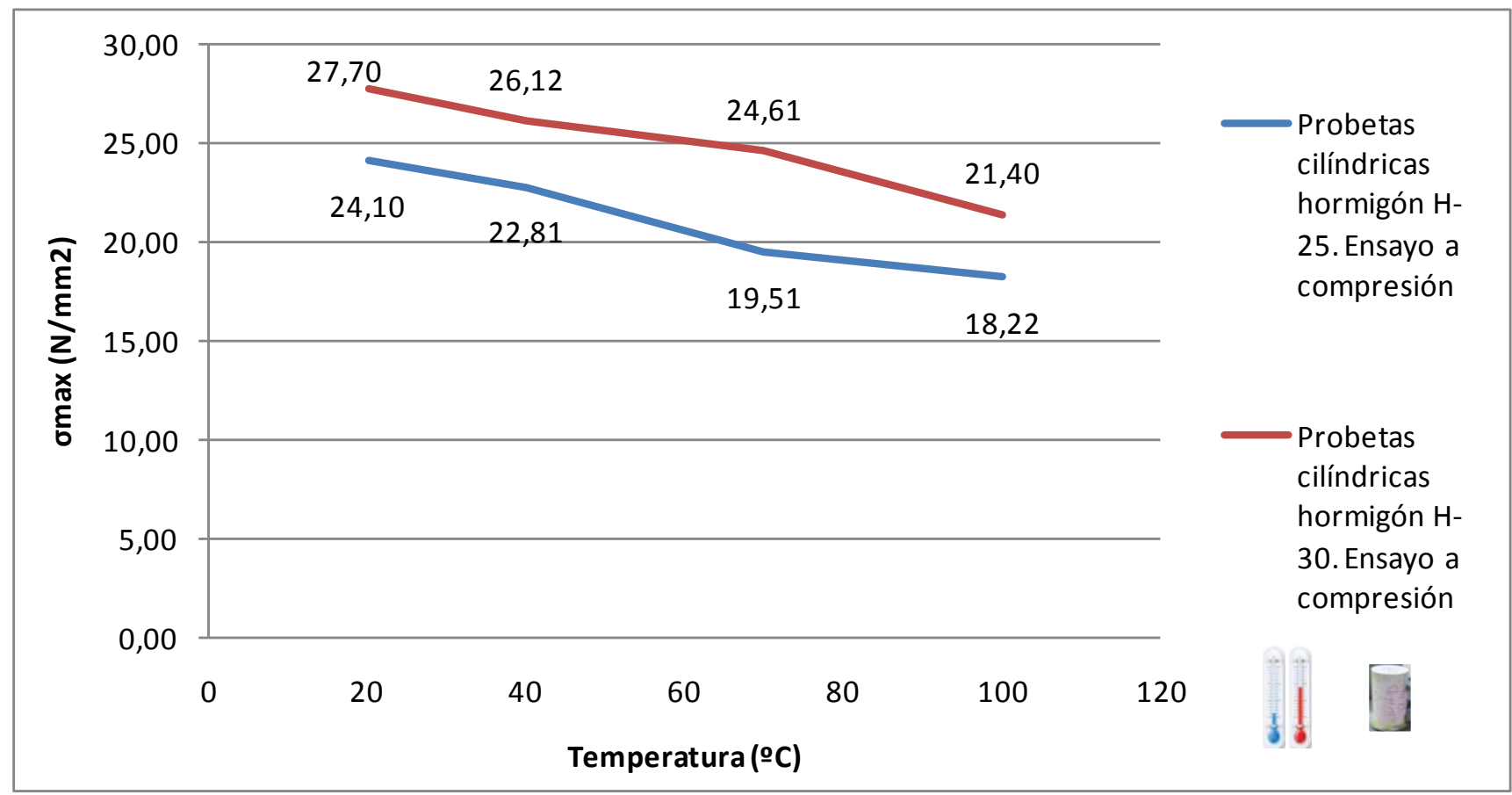

Gráfica 5- 3. Gráfica Tensión $\sigma_{\max }(\mathrm{N} / \mathrm{mm} 2) /$ Temperatura ${ }^{\circ} \mathrm{C}$ de de las medias aritméticas de los resultados de resistencia a compresión de las probetas cilíndricas sometidas a $20^{\circ} \mathrm{C}, 40^{\circ} \mathrm{C}, 70^{\circ} \mathrm{C}$, y $100^{\circ} \mathrm{C}$, comparando los resultados de hormigón $\mathrm{H}$ 25 y del hormigón $\mathrm{H}-30$, ensayados a compresión.

Como se puede observar en la gráfica a medida que se produce el incremento de temperatura, tiene lugar una disminución en la resistencia a compresión del hormigón ya sea este $\mathrm{H}-25$ o H-30, siendo los porcentajes de disminución muy similares para los dos hormigones. 


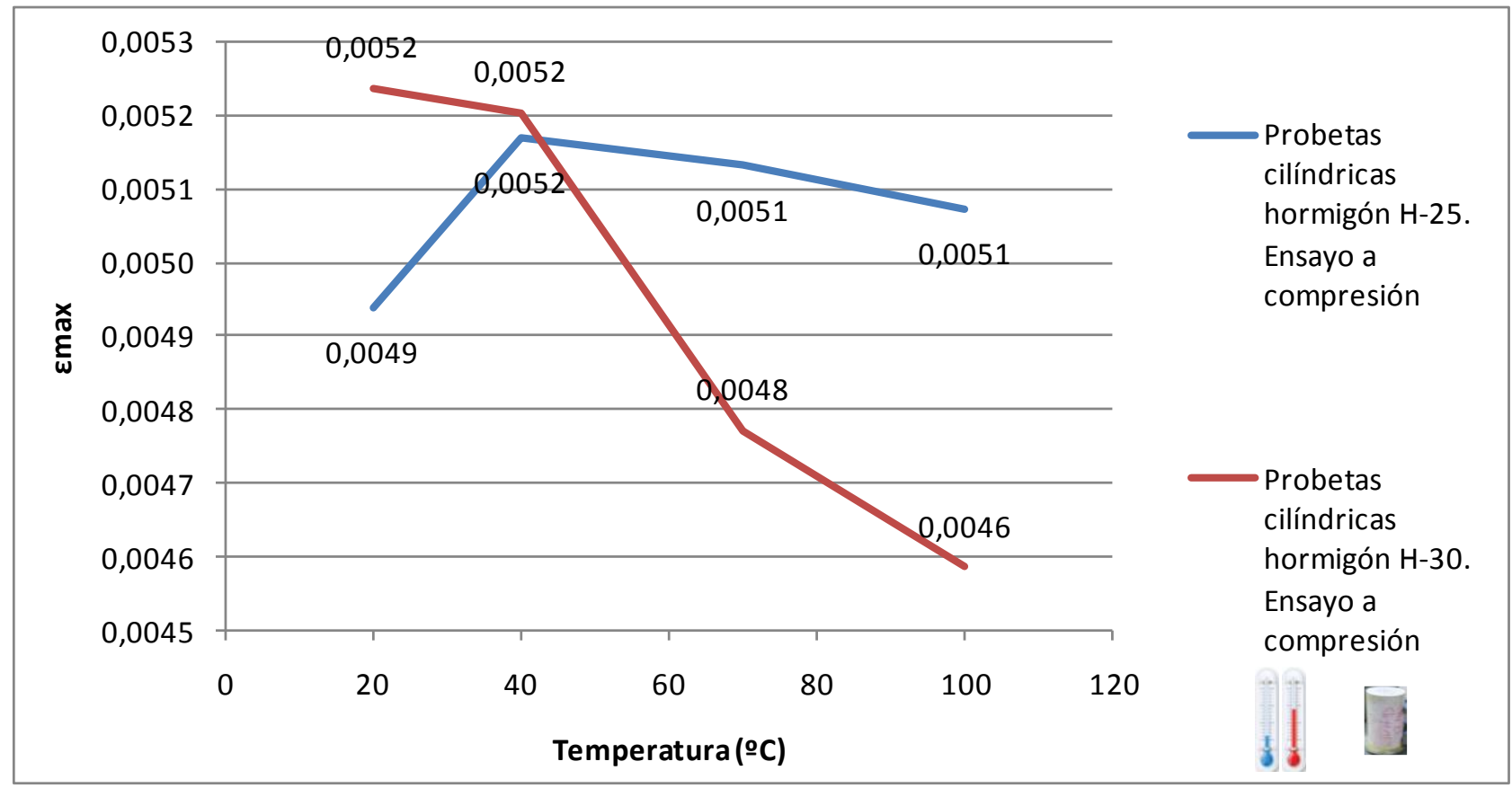

Gráfica 5- 4. Gráfica Deformación máxima $\varepsilon_{\max }$ / Temperatura ${ }^{\circ} \mathrm{C}$ de de las medias aritméticas de los resultados de deformación correspondiente a la tensión máxima de las probetas cilíndricas sometidas a $20^{\circ} \mathrm{C}, 40^{\circ} \mathrm{C}, 70^{\circ} \mathrm{C}$, y $100^{\circ} \mathrm{C}$, comparando los resultados de hormigón $\mathrm{H}-25$ y del hormigón $\mathrm{H}-30$, ensayados a compresión.

Se puede observar en la figura que, aunque de los $40^{\circ} \mathrm{C}$ de temperatura a los $100^{\circ} \mathrm{C}$ parece que la deformación aumenta al aumentar la temperatura para los dos hormigones, $\mathrm{H}-25$ y $\mathrm{H}-30$, el cambio que se produce al pasar los dos hormigones de $20^{\circ} \mathrm{C}$ a $40^{\circ} \mathrm{C}$ tiene un efecto contrario en su deformación correspondiente a la tensión máxima. En el caso del hormigón H-25, al aumentar la temperatura esos $20^{\circ} \mathrm{C}$ la deformación aumenta también y, por el contrario, en el caso del hormigón H-30, para ese mismo incremento, la deformación disminuye. 


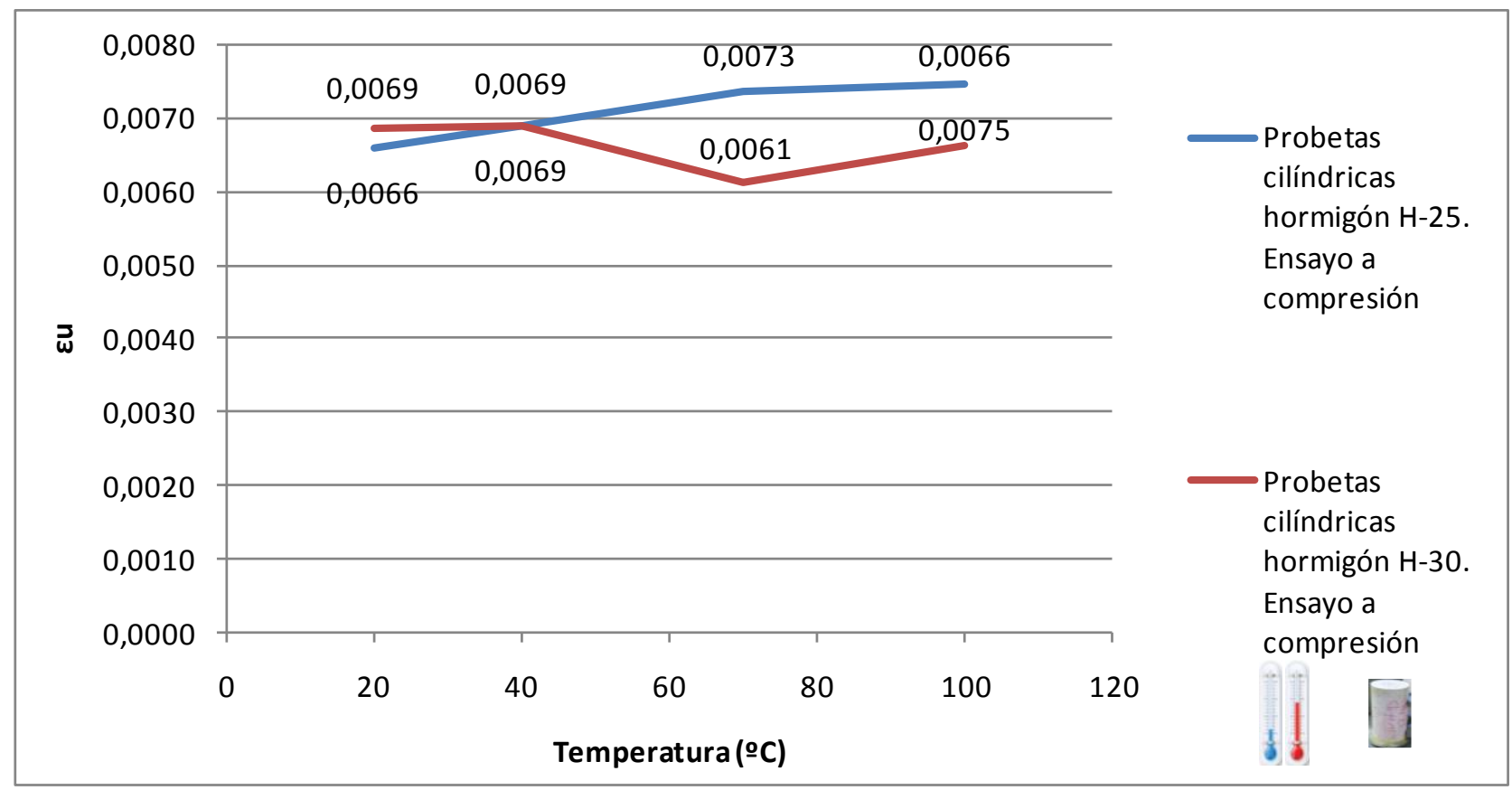

Gráfica 5- 5. Gráfica Deformación última $\varepsilon_{u} /$ Temperatura ${ }^{\circ} \mathrm{C}$ de de las medias aritméticas de los resultados de deformación última de las probetas cilíndricas sometidas a $20^{\circ} \mathrm{C}, 40^{\circ} \mathrm{C}, 70^{\circ} \mathrm{C}$, y $100^{\circ} \mathrm{C}$, comparando los resultados de hormigón $\mathrm{H}-25$ y del hormigón $\mathrm{H}-30$, ensayados a compresión.

Se podría decir que el comportamiento que sufre la línea de deformación última de los dos hormigones sigue las líneas de la deformación máxima que observamos en la gráfica anterior a efectos comparativos de los dos hormigones pero mucho más suavizadas.

Entre los $20^{\circ} \mathrm{C}$ y los $40^{\circ} \mathrm{C}$ sigue habiendo una inclinación inversa en la deformación de los dos tipos de hormigones, el hormigón $\mathrm{H}-25$ con el aumento de $20^{\circ} \mathrm{C}$ aumenta su deformación, y en cambio el hormigón $\mathrm{H}-30$ la disminuye. 
Con respecto a la gráfica correspondiente a deformación en tensión máxima existe una diferencia fundamental en la gráfica de deformación máxima, al aumentar la temperatura el hormigón $\mathrm{H}-25$ sufría un aumento entre los $20^{\circ} \mathrm{C}$ y los $40^{\circ} \mathrm{C}$, y a partir de esa temperatura descendía; en cambio en la gráfica de deformación última la tendencia a aumentar la deformación es continua para cualquier valor de temperatura, y el hormigón $\mathrm{H}-30$, que tendía a disminuir su deformación máxima entre $70^{\circ} \mathrm{C}$ y $100^{\circ} \mathrm{C}$, tiende a aumentar por el contrario su deformación última para el mismo rango de temperaturas.

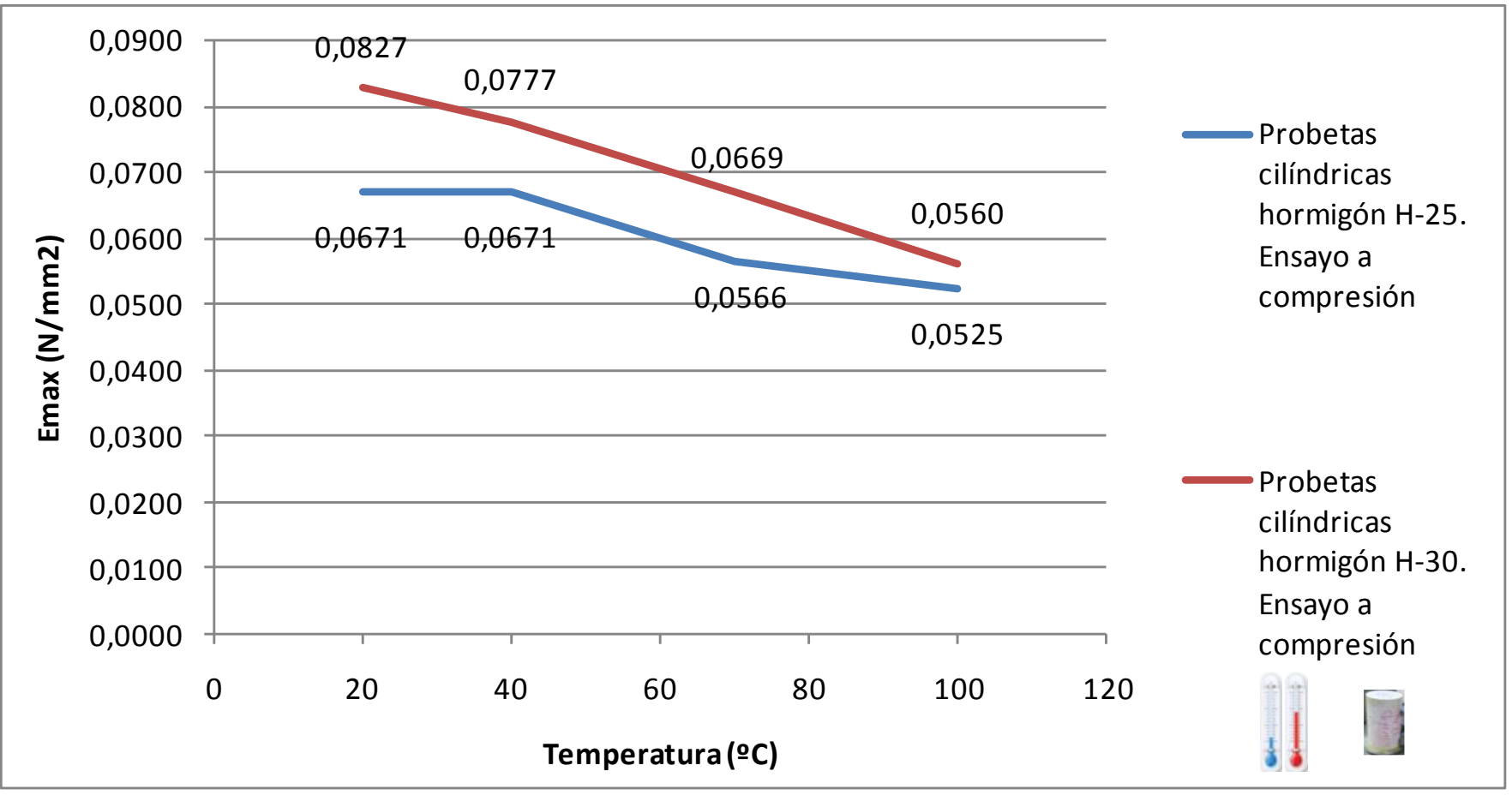

Gráfica 5- 6. Gráfica Energía máxima $E_{\max }\left(\mathrm{N} / \mathrm{mm}^{2}\right)$ / Temperatura ${ }^{\circ} \mathrm{C}$ de las medias aritméticas de los resultados de deformación última de las probetas cilíndricas sometidas a $20^{\circ} \mathrm{C}, 40^{\circ} \mathrm{C}, 70^{\circ} \mathrm{C}$, y $100^{\circ} \mathrm{C}$, comparando los resultados de hormigón $\mathrm{H}-25$ y del hormigón $\mathrm{H}-30$, ensayados a compresión.

La gráfica muestra cómo la tendencia a disminuir la energía generada hasta el valor de tensión máxima se produce a medida que aumenta la temperatura, y de una forma proporcional para los dos hormigones ensayados, igual que como ocurría con los valores de tensión máxima. 


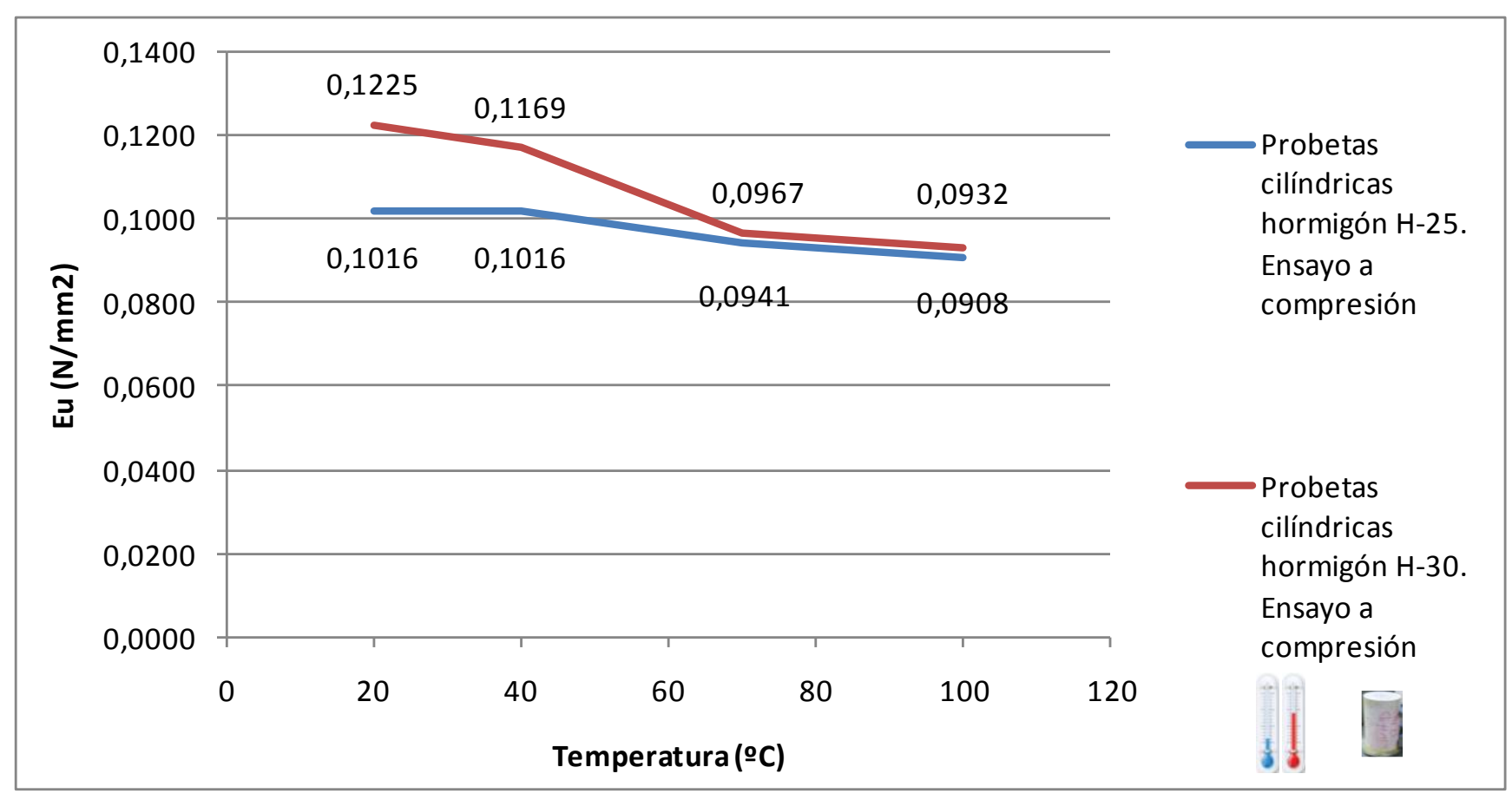

Gráfica 5- 7. Gráfica Energía última $E_{u}\left(\mathrm{~N} / \mathrm{mm}^{2}\right)$ / Temperatura ${ }^{\circ} \mathrm{C}$ de de las medias aritméticas de los resultados de deformación última de las probetas cilíndricas sometidas a $20^{\circ} \mathrm{C}, 40^{\circ} \mathrm{C}, 70^{\circ} \mathrm{C}$, y $100^{\circ} \mathrm{C}$, comparando los resultados de hormigón $\mathrm{H}-25$ y del hormigón $\mathrm{H}-30$, ensayados a compresión.

Del mismo modo, la gráfica energía última / temperatura muestra un descenso de valores de energía a medida que aumenta la temperatura, aunque para valores de temperatura más elevados el descenso que se produce es menos acusado que el que se producía para los valores de energía de máxima tensión.

\subsubsection{Estudio comparativo de los dos tipos de hormigón de la} evolución de los resultados máximos $\sigma_{\max }, \varepsilon_{\max }$ y $E_{\max }$ medios de rotura a compresión de las probetas cilíndricas sometidas a temperatura.

La gráfica 5- 8 permite comparar la evolución de los valores máximos característicos calculados a partir del ensayo a compresión, en función de la temperatura, en los dos tipos de hormigones estudiados. Como se puede observar, las resistencias a compresión son mayores en el hormigón $\mathrm{H}-30$ que en el hormigón $\mathrm{H}-25$, aunque a una temperaturas de $100^{\circ} \mathrm{C}$ las tensiones se aproximan, 
pero en ambos casos disminuyen al aumentar la temperatura. La deformación máxima aumenta al aumentar la temperatura en el hormigón $\mathrm{H}-25$ y disminuye en el hormigón H-30. La energía máxima de deformación disminuye en ambos tipos de hormigones cuando aumenta la temperatura, siendo la pendiente bastante constante en el hormigón $\mathrm{H}-30$, mientras que el hormigón $\mathrm{H}-25$ acusa mucho el aumento de temperatura entre $40^{\circ} \mathrm{C}$ y $70^{\circ} \mathrm{C}$.

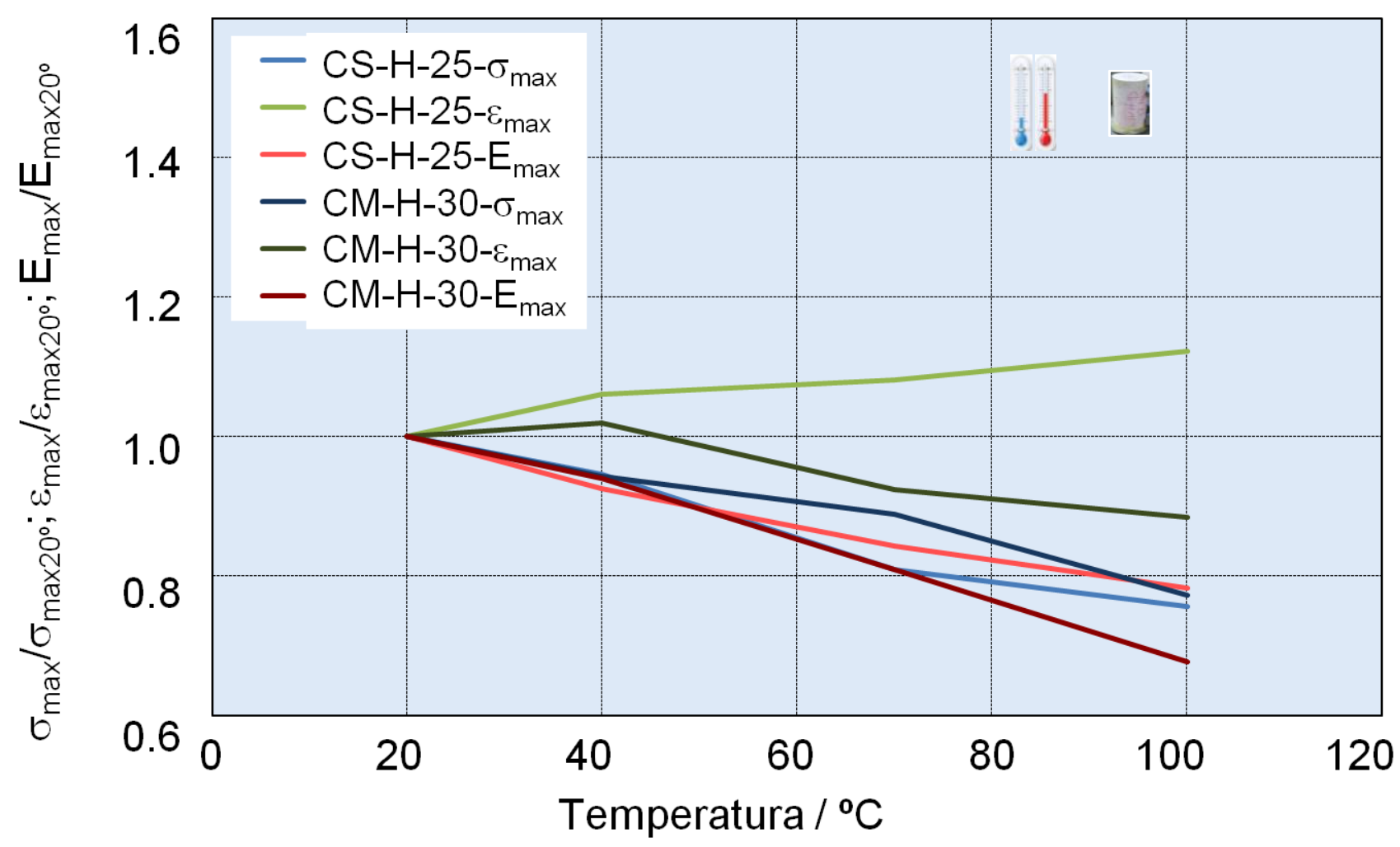

Gráfica 5- 8. Evolución en función del incremento de temperatura $\left(20^{\circ} \mathrm{C}, 40^{\circ} \mathrm{C}\right.$, $70^{\circ} \mathrm{C}$, y $\left.100^{\circ} \mathrm{C}\right)$ de los valores medios máximos $\left(\sigma_{\max }, \varepsilon_{\max }, E_{\max }\right)$ obtenidos del ensayo a compresión de cada grupo de tres probetas cilíndricas, sometidas a la misma temperatura, con hormigones $\mathrm{H}-25$ y H-30.

\subsubsection{Análisis porcentual de las pérdidas de resistencia observadas en} los ensayos a compresión de las probetas cilíndricas de hormigón H-25 y $\mathrm{H}-30$ sometidas a las distintas temperaturas $\left(20^{\circ} \mathrm{C}, 40^{\circ} \mathrm{C}, 70^{\circ} \mathrm{C}\right.$, y $\left.100^{\circ} \mathrm{C}\right)$.

En la tabla 5- 1 y la gráfica 5- 9 se muestra la relación entre la pérdida de resistencia y la temperatura, para los hormigones $\mathrm{H}-25$ y H-30. $\mathrm{Y}$ se representa gráficamente el momento en el que las pérdidas de resistencia superan el $20 \%$. 


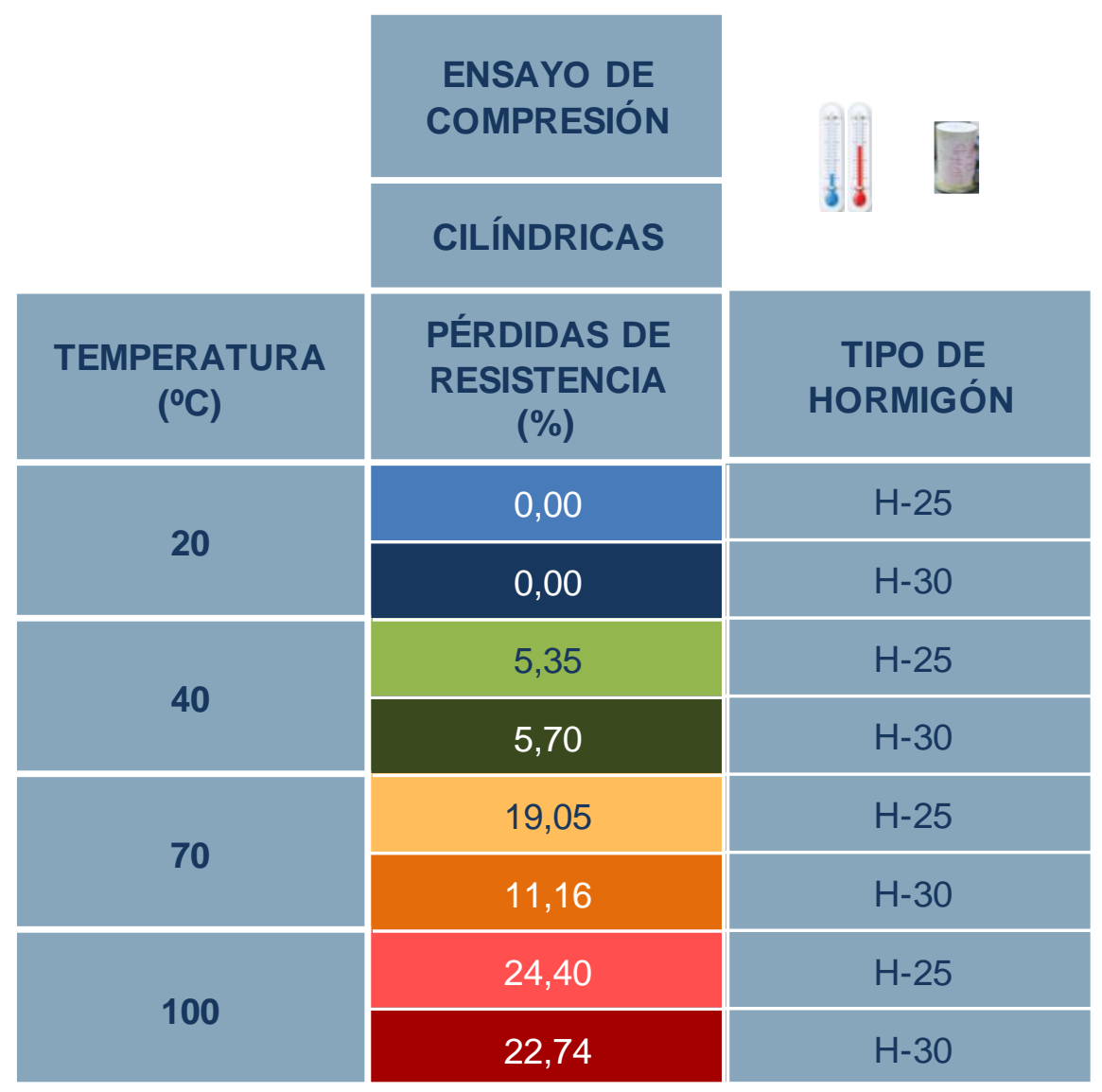

Tabla 5- 1. Pérdidas de resistencia en tanto por ciento en hormigones $\mathrm{H}-25$ y H30 , ensayados a compresión, en función de la temperatura.

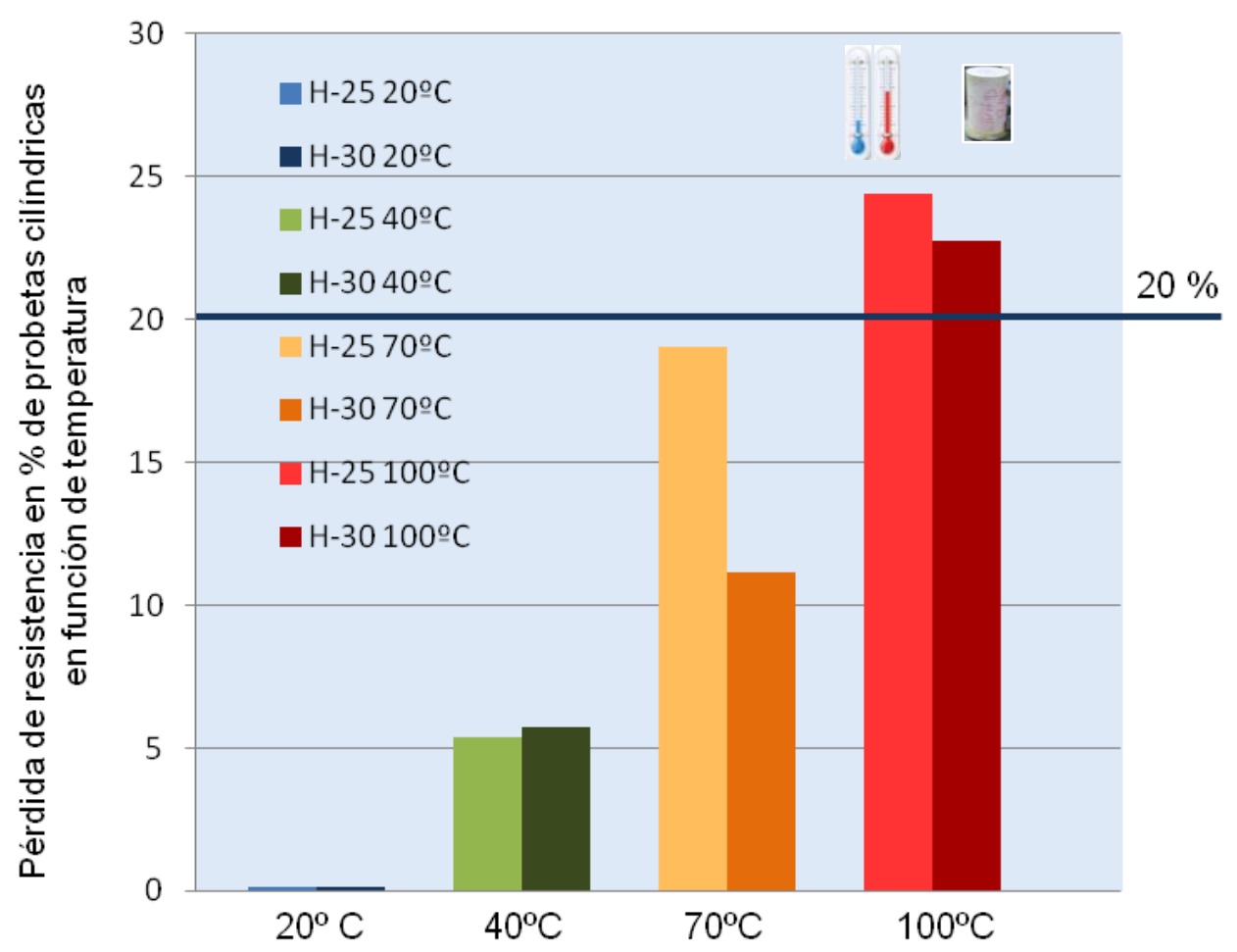


Gráfica 5- 9. Gráfica de análisis porcentual de pérdidas de resistencia en función de la temperatura de las probetas cilíndricas en el momento de la rotura a compresión para hormigones $\mathrm{H}-25$ y $\mathrm{H}-30$.

Como se puede observar, las pérdidas de resistencia aumentan a medida que aumenta la temperatura, produciéndose pérdidas de tensión alrededor del $20 \%$ cuando el hormigón H-25 alcanza los $70^{\circ} \mathrm{C}$ y el hormigón $\mathrm{H}-30$ los $100^{\circ} \mathrm{C}$.

\subsubsection{Estudio comparativo de los resultados de rotura a arrancamiento (temperatura)}

En este segundo apartado se presentan los cuatro estudios comparativos realizados con los resultados de probetas cúbicas con armadura corrugada anclada, ensayadas a arrancamiento o "pull-out", para analizar el efecto producido por el aumento de temperatura $\left(20^{\circ} \mathrm{C}, 40^{\circ} \mathrm{C}, 70^{\circ} \mathrm{C}\right.$ y $\left.100^{\circ} \mathrm{C}\right)$, para hormigón $\mathrm{H}-25$ y hormigón $\mathrm{H}-30$.

\subsubsection{Estudio comparativo de los resultados de fuerza de arrancamiento/desplazamiento más significativos en función del aumento de temperatura.}

Se ha procedido a elaborar unas gráficas con los resultados más significativos que permitan apreciar visualmente cuál es el comportamiento de cada tipo de probeta cúbica de hormigón endurecido con armadura corrugada anclada, sometidas a las distintitas temperaturas $\left(20^{\circ} \mathrm{C}, 40^{\circ} \mathrm{C}, 70^{\circ} \mathrm{C}\right.$ y $\left.100^{\circ} \mathrm{C}\right)$, ensayadas a arrancamiento y para los dos hormigones utilizados $\mathrm{H}-25$ y H-30.

Los resultados obtenidos en el ensayo de adherencia de las probetas cúbicas con armadura corrugada anclada se pueden observar en las gráficas 5 - 10 y 5- 11, donde se muestra la evolución de la fuerza de arrancamiento respecto al desplazamiento, para las diferentes temperaturas de ensayo y para los dos tipos de hormigón empleados.

Como se puede comprobar, independientemente del tipo de hormigón empleado, la fuerza de arrancamiento disminuye al aumentar la temperatura, y de modo bastante similar para los dos tipos de hormigones empleados. 


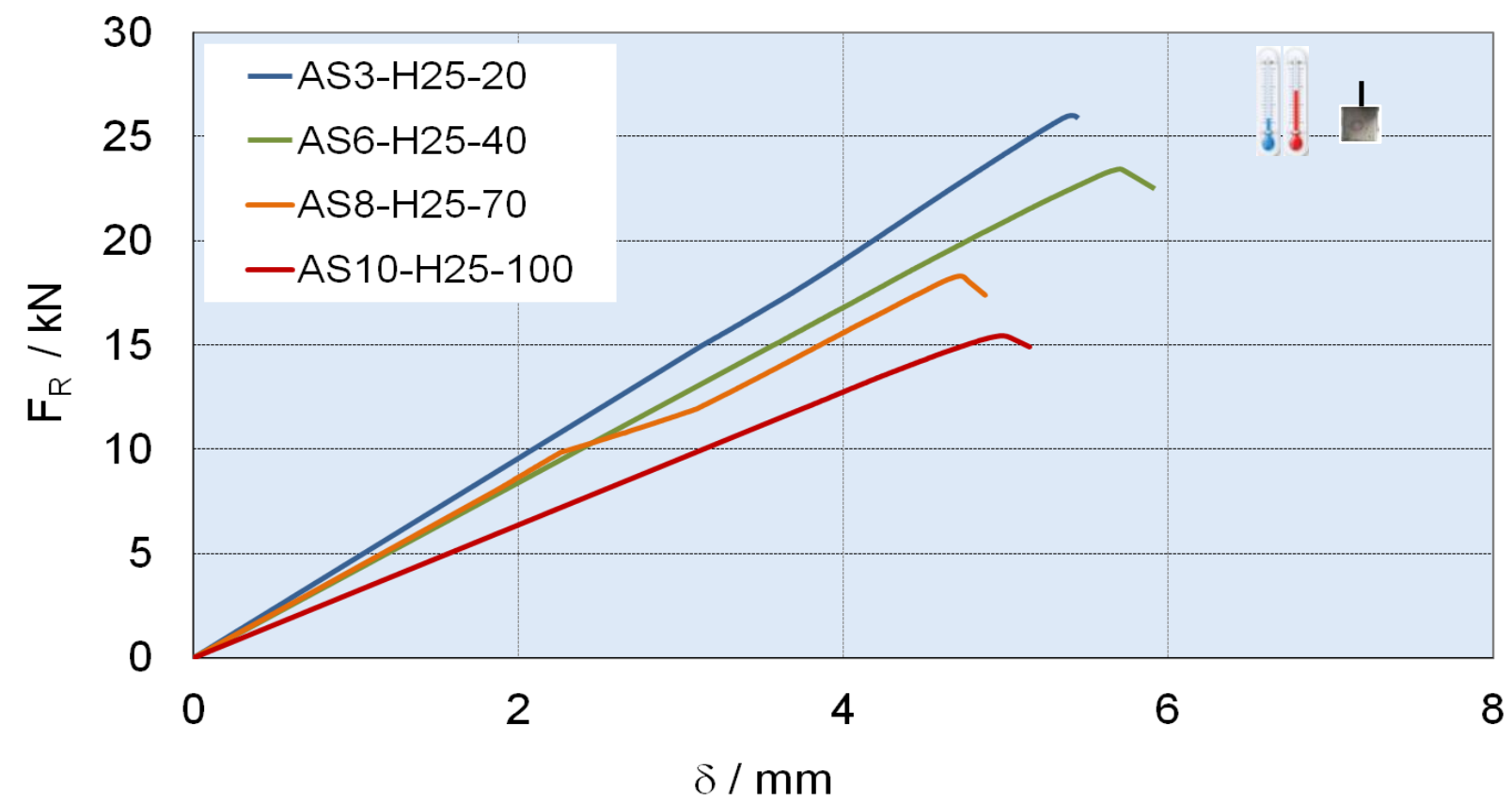

Gráfica 5- 10. Gráfica de evolución de la Fuerza de arrancamiento $F(K N)$ respecto al desplazamiento $\delta(\mathrm{mm})$ en probetas cúbicas con armadura corrugada anclada, más representativas, para temperaturas de $20^{\circ} \mathrm{C}, 40^{\circ} \mathrm{C}, 70^{\circ} \mathrm{C}$ y $100^{\circ} \mathrm{C}$, realizadas con hormigón $\mathrm{H}-25$, ensayadas a arrancamiento o "pull-out".

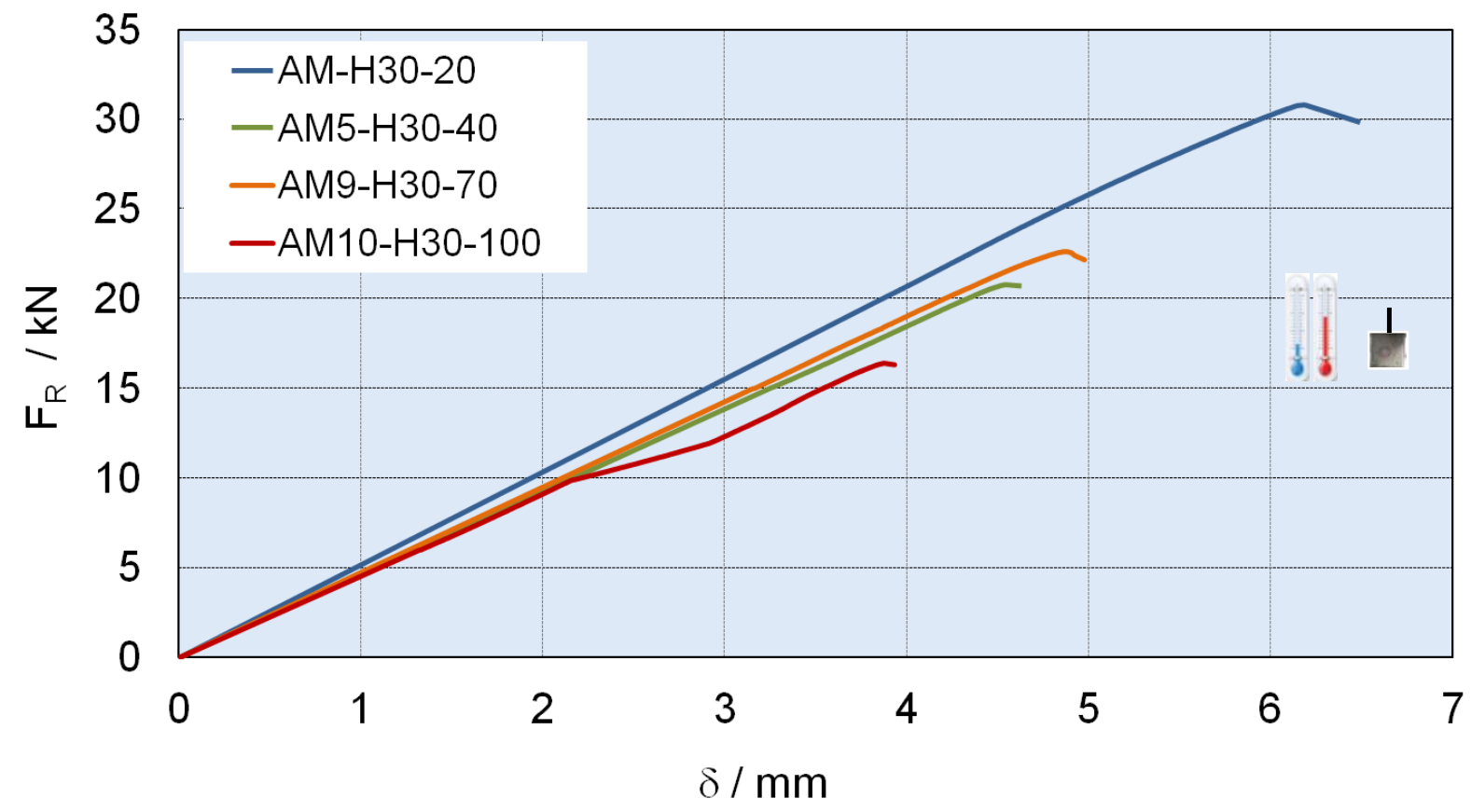

Gráfica 5- 11. Gráfica de evolución de la Fuerza de arrancamiento $F(K N)$ respecto al desplazamiento $\delta(\mathrm{mm})$ en probetas cúbicas con armadura corrugada anclada, más representativas, para temperaturas de $20^{\circ} \mathrm{C}, 40^{\circ} \mathrm{C}, 70^{\circ} \mathrm{C}$ y $100^{\circ} \mathrm{C}$, realizadas con hormigón $\mathrm{H}-30$, ensayadas a arrancamiento o "pull-out". 
5.2.2.2. Estudio comparativo de los resultados $\mp_{R}, \delta_{\max }, \delta_{u}, E_{\max }$ y $E_{u}$ de rotura a arrancamiento o "pull-out" de las probetas cúbicas con armadura corrugada anclada, sometidas a distintas temperaturas.

A continuación se presenta las gráficas comparativas de los valores que se han obtenido como resultado de adherencia del ensayo de arrancamiento "pull-out" de probetas cúbicas con armadura de acero corrugado, de diámetro $10 \mathrm{~mm}$ anclado a ellas, y sometidas a distintas temperaturas $\left(20^{\circ} \mathrm{C}, 40^{\circ} \mathrm{C}, 70^{\circ} \mathrm{C}\right.$ y $\left.100^{\circ} \mathrm{C}\right)$, de los dos hormigones utilizados $\mathrm{H}-25$ y $\mathrm{H}-30$.

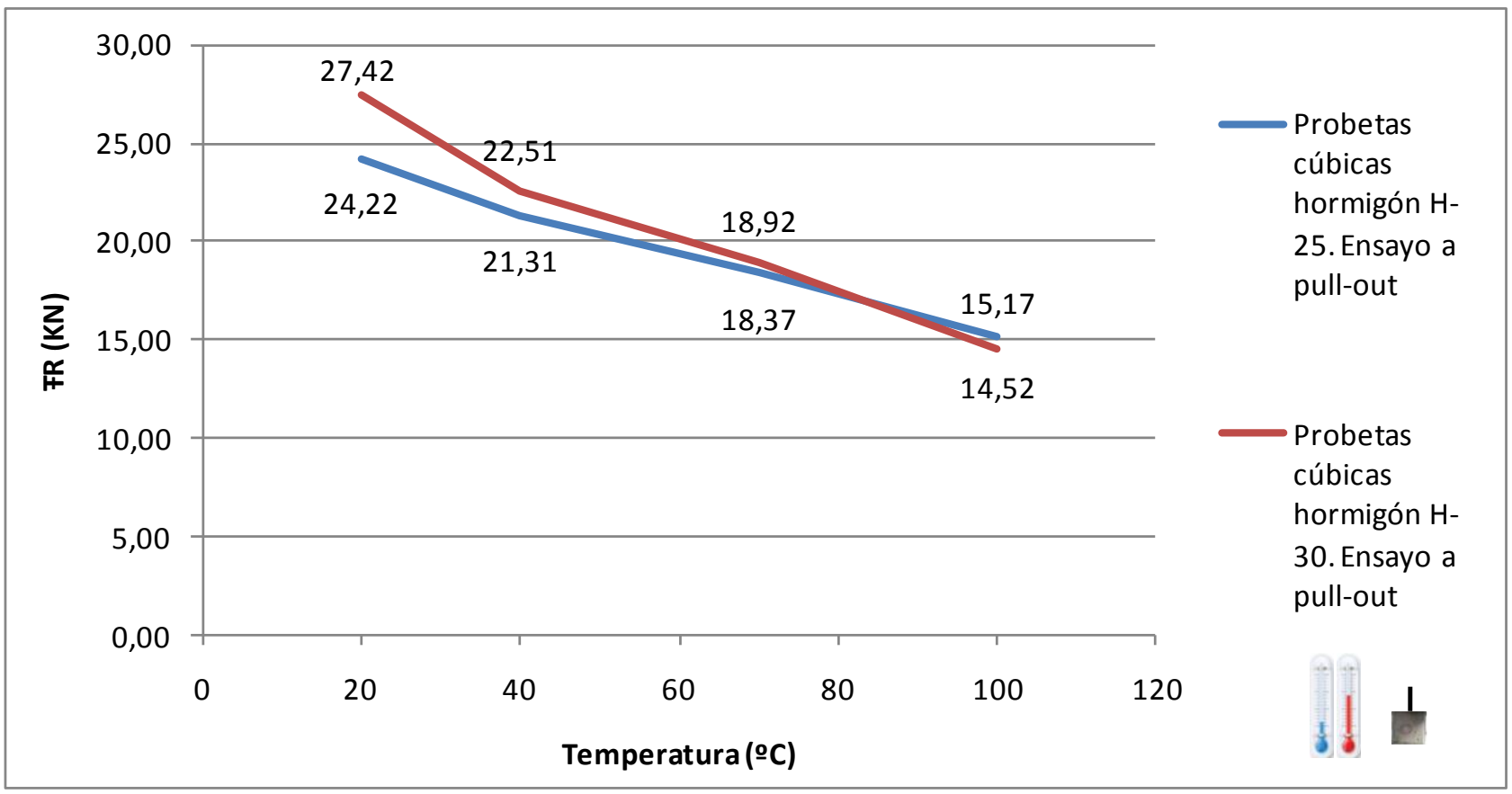

Gráfica 5- 12. Gráfica Tensión $\mp_{R}(\mathrm{KN})$ / Temperatura ${ }^{\circ} \mathrm{C}$ de de las medias aritméticas de los resultados de tensión de las probetas cúbicas sometidas a $20^{\circ} \mathrm{C}$, $40^{\circ} \mathrm{C}, 70^{\circ} \mathrm{C}$, y $100^{\circ} \mathrm{C}$, comparando los resultados de hormigón $\mathrm{H}-25$ y del hormigón $\mathrm{H}-$ 30 ensayados a arrancamiento.

Como se puede observar en la gráfica, a medida que la temperatura a la que se somete a las probetas cúbicas es mayor, la tensión de rotura a arrancamiento va disminuyendo, debido a una menor adherencia entre la armadura corrugada y el hormigón. 
Los resultados de las probetas realizadas con hormigón $\mathrm{H}-30$ son superiores a los resultados obtenidos de las probetas realizadas con hormigón H-25.

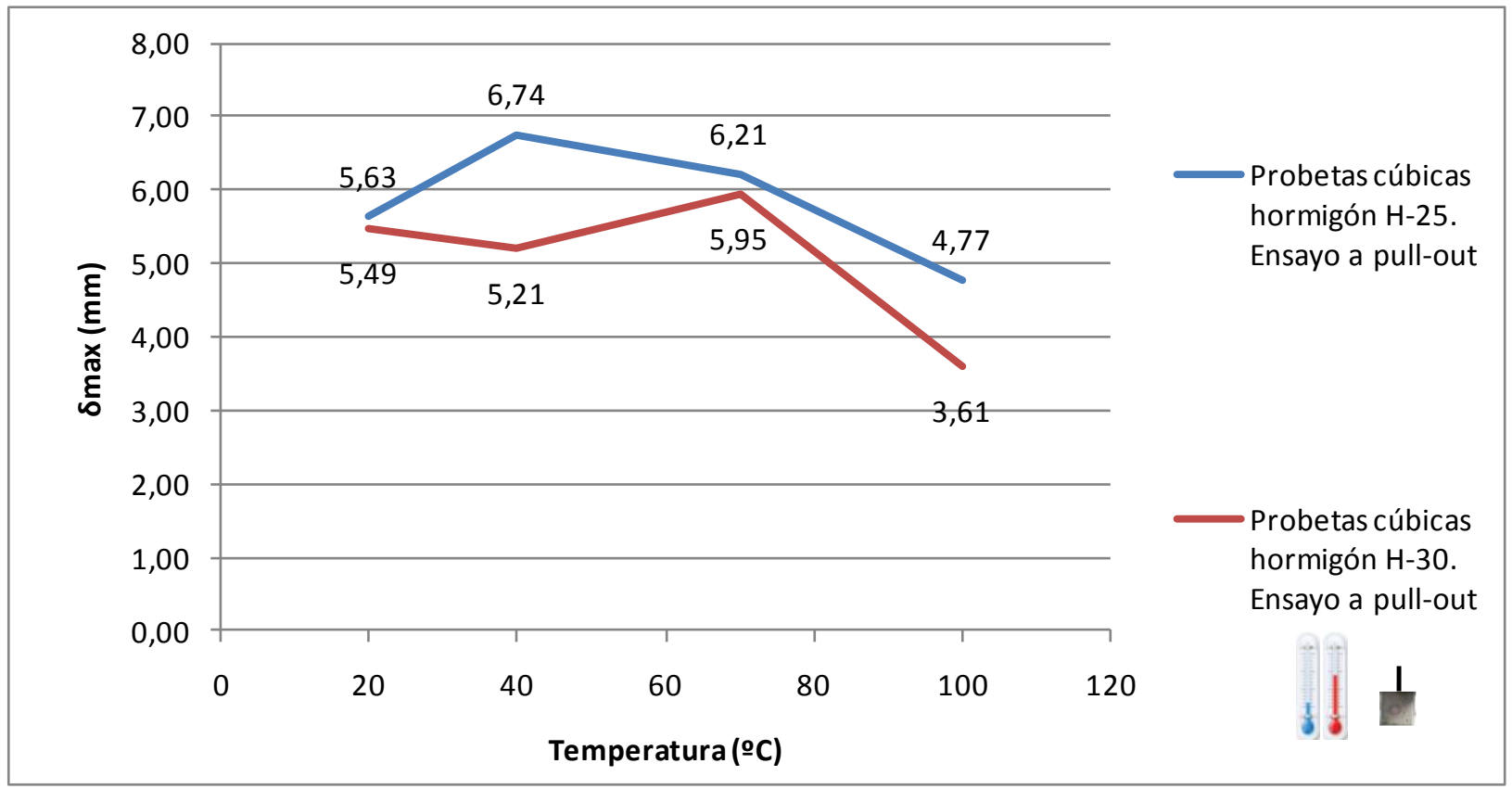

Gráfica 5- 13. Gráfica Desplazamiento máximo $\delta_{\max } \mathrm{mm} /$ Temperatura $\stackrel{\circ}{ } \mathrm{C}$ de de las medias aritméticas de los resultados de desplazamiento correspondiente a la tensión de rotura de las probetas cúbicas sometidas a $20^{\circ} \mathrm{C}, 40^{\circ} \mathrm{C}, 70^{\circ} \mathrm{C}$, y $100^{\circ} \mathrm{C}$, comparando los resultados de hormigón $\mathrm{H}-25$ y del hormigón $\mathrm{H}-30$ ensayados a arrancamiento.

La gráfica desplazamiento/temperatura, por su parte, para las primeras temperaturas del ensayo, no muestra una tendencia clara en ninguno de los dos tipos de hormigones, $\mathrm{H}-25$ y $\mathrm{H}-30$; en cambio parece que cuando las probetas se someten a las temperaturas de 100 grados, en ambos casos se percibe un descenso más acusado en los valores de desplazamiento.

Sin embargo, los resultados de las probetas realizadas con hormigón $\mathrm{H}-25$ son superiores a los resultados obtenidos de las probetas realizadas con hormigón $\mathrm{H}-30$. 


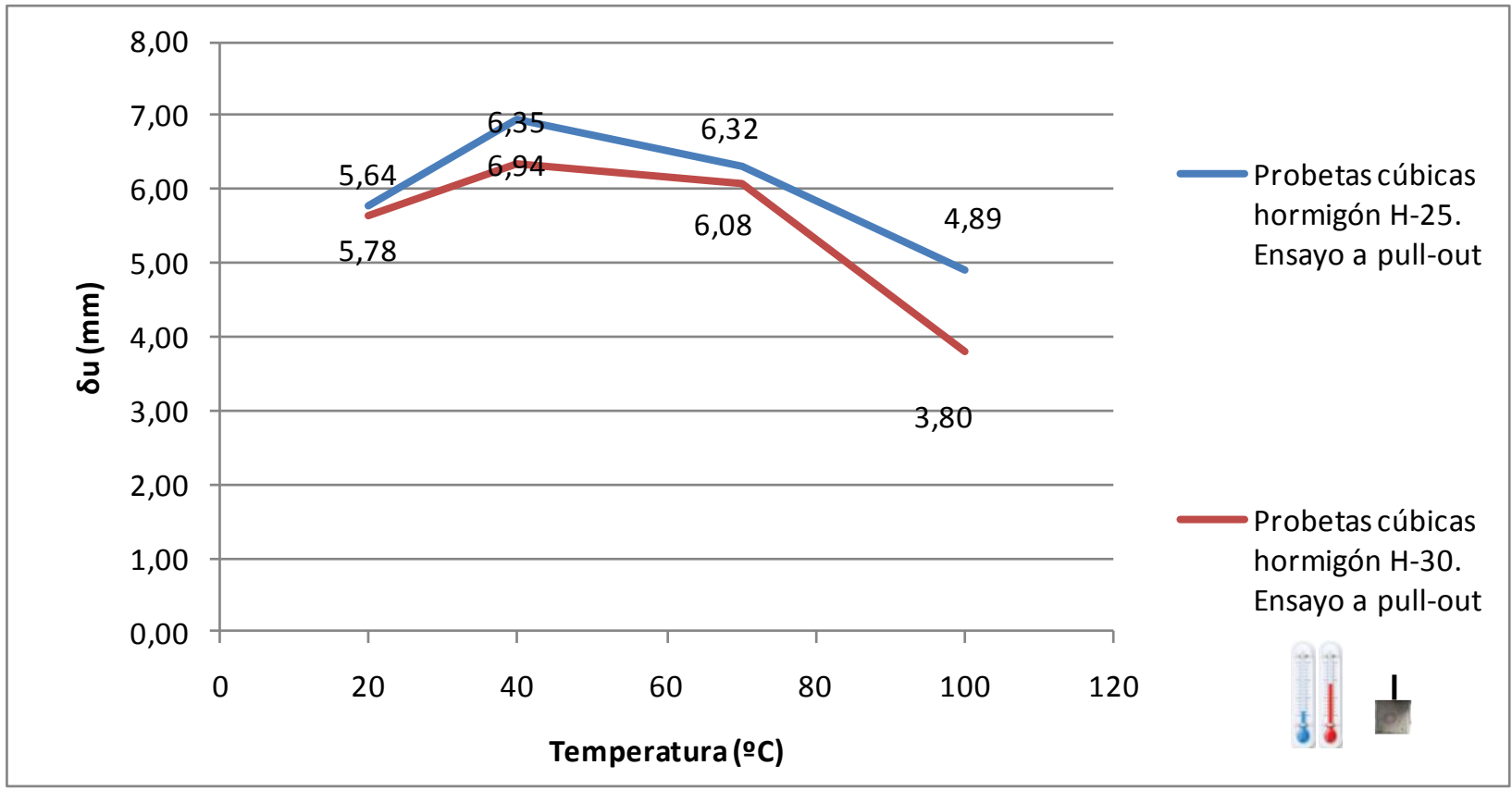

Gráfica 5- 14. Gráfica Desplazamiento último $\delta_{u} \mathrm{~mm} /$ Temperatura ${ }^{\circ} \mathrm{C}$ de de las medias aritméticas de los resultados de desplazamiento último de las probetas cúbicas sometidas a $20^{\circ} \mathrm{C}, 40^{\circ} \mathrm{C}, 70^{\circ} \mathrm{C}$, y $100^{\circ} \mathrm{C}$, comparando los resultados de hormigón $\mathrm{H}-25$ y del hormigón $\mathrm{H}-30$ ensayados a arrancamiento.

En el caso de la gráfica desplazamiento último/temperatura la tendencia de los resultados del hormigón $\mathrm{H}-25$ es prácticamente idéntica a la de los resultados de desplazamiento máximo.

Para el hormigón H-30 la tendencia se iguala en dirección y proporción a la del otro hormigón, salvando las diferencias halladas entre ambos hormigones en la gráfica deformación máxima temperatura.

Al igual que en la gráfica 5- 13, los resultados de las probetas realizadas con hormigón $\mathrm{H}-25$ son superiores a los resultados obtenidos de las probetas realizadas con hormigón $\mathrm{H}-30$. 


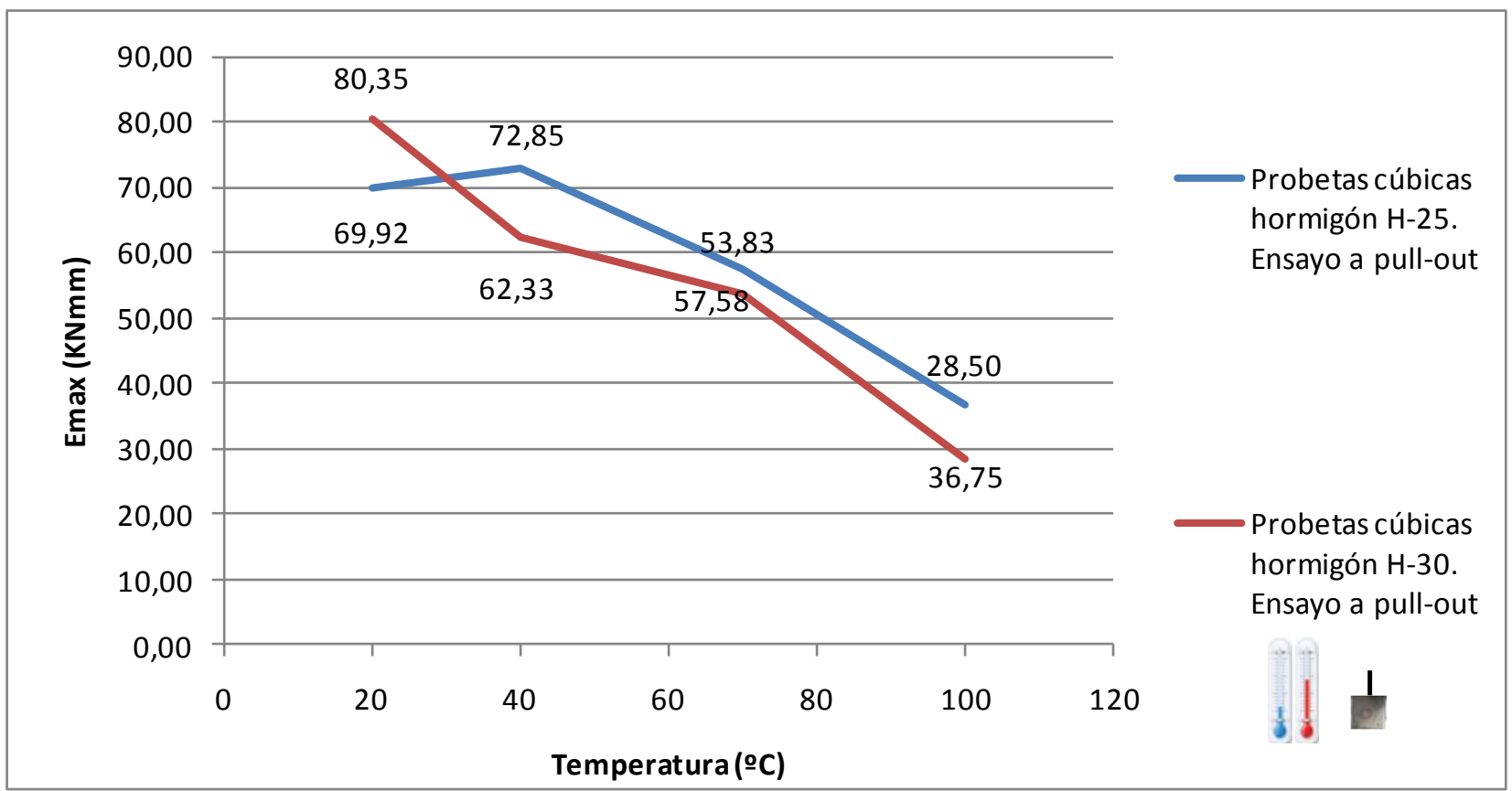

Gráfica 5- 15. Gráfica Energía máxima $E_{\max } \mathrm{KN} / \mathrm{mm}$ / Temperatura ${ }^{\circ} \mathrm{C}$ de de las medias aritméticas de los resultados de energía máxima de las probetas cúbicas sometidas a $20^{\circ} \mathrm{C}, 40^{\circ} \mathrm{C}, 70^{\circ} \mathrm{C}$, y $100^{\circ} \mathrm{C}$, comparando los resultados de hormigón $\mathrm{H}-25$ y del hormigón H-30 ensayados a arrancamiento.

Los valores de energía para tensión máxima de rotura sufren un descenso a medida que las probetas se someten a temperaturas mayores. Las tendencias son similares en proporción a las mostradas en la gráfica fuerza/desplazamiento.

Se observa cómo los valores obtenidos para el hormigón $\mathrm{H}-25$ son superiores a los del hormigón H-30 ensayado. 


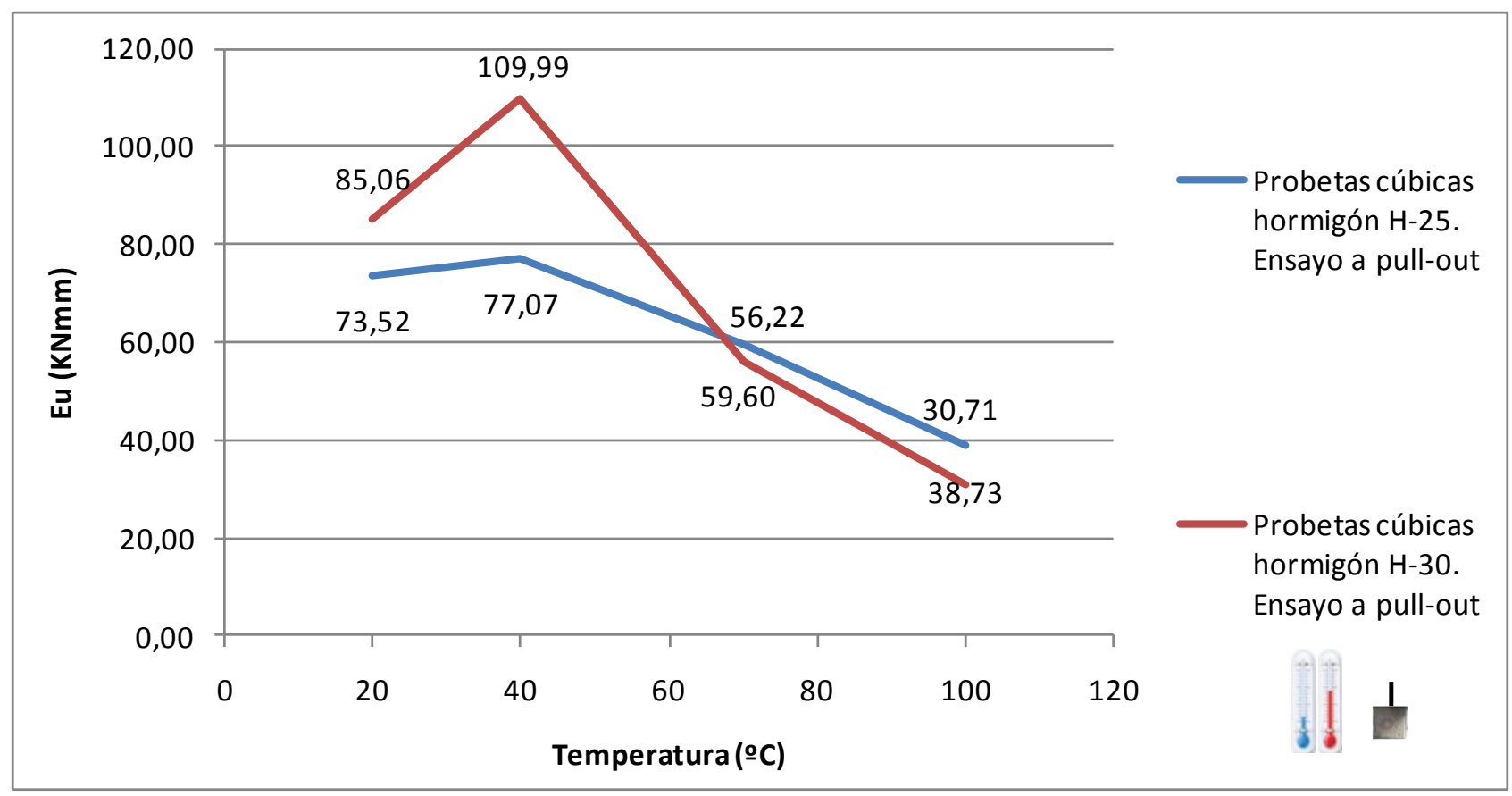

Gráfica 5- 16. Gráfica Energía máxima $E_{u} \mathrm{KN} / \mathrm{mm} /$ Temperatura ${ }^{\circ} \mathrm{C}$ de de las medias aritméticas de los resultados de energía última de las probetas cúbicas sometidas a $20^{\circ} \mathrm{C}, 40^{\circ} \mathrm{C}, 70^{\circ} \mathrm{C}$, y $100^{\circ} \mathrm{C}$, comparando los resultados de hormigón $\mathrm{H}-25$ y del hormigón $\mathrm{H}-30$ ensayados a arrancamiento.

Los valores de la gráfica energía última/desplazamiento indican un aumento en valor para el primer incremento de temperatura (de $20^{\circ} \mathrm{C}$ a $40^{\circ} \mathrm{C}$ ) y un descenso para los siguientes incrementos de temperatura.

En este caso, en el comparativo de energía última para los dos tipos de hormigones, los resultados de hormigón $\mathrm{H}-30$ para las temperaturas $20^{\circ} \mathrm{C}$ y $40^{\circ} \mathrm{C}$ son superiores a las del hormigón $\mathrm{H}-25$, y para temperaturas $70^{\circ} \mathrm{C}$ y $100^{\circ} \mathrm{C}$ ocurre a la inversa. 


\subsubsection{Estudio comparativo de los dos tipos de hormigón de la} evolución de los resultados máximos $\delta_{\max }, \delta_{u}, \mathbf{y} E_{\max }$ medios de rotura a arrancamiento de las probetas cúbicas con armadura corrugada anclada sometidas a temperatura.

La gráfica 5- 17 permite comparar la evolución de los valores máximos característicos calculados a partir del ensayo a arrancamiento, en función de la temperatura, en los dos tipos de hormigones estudiados.

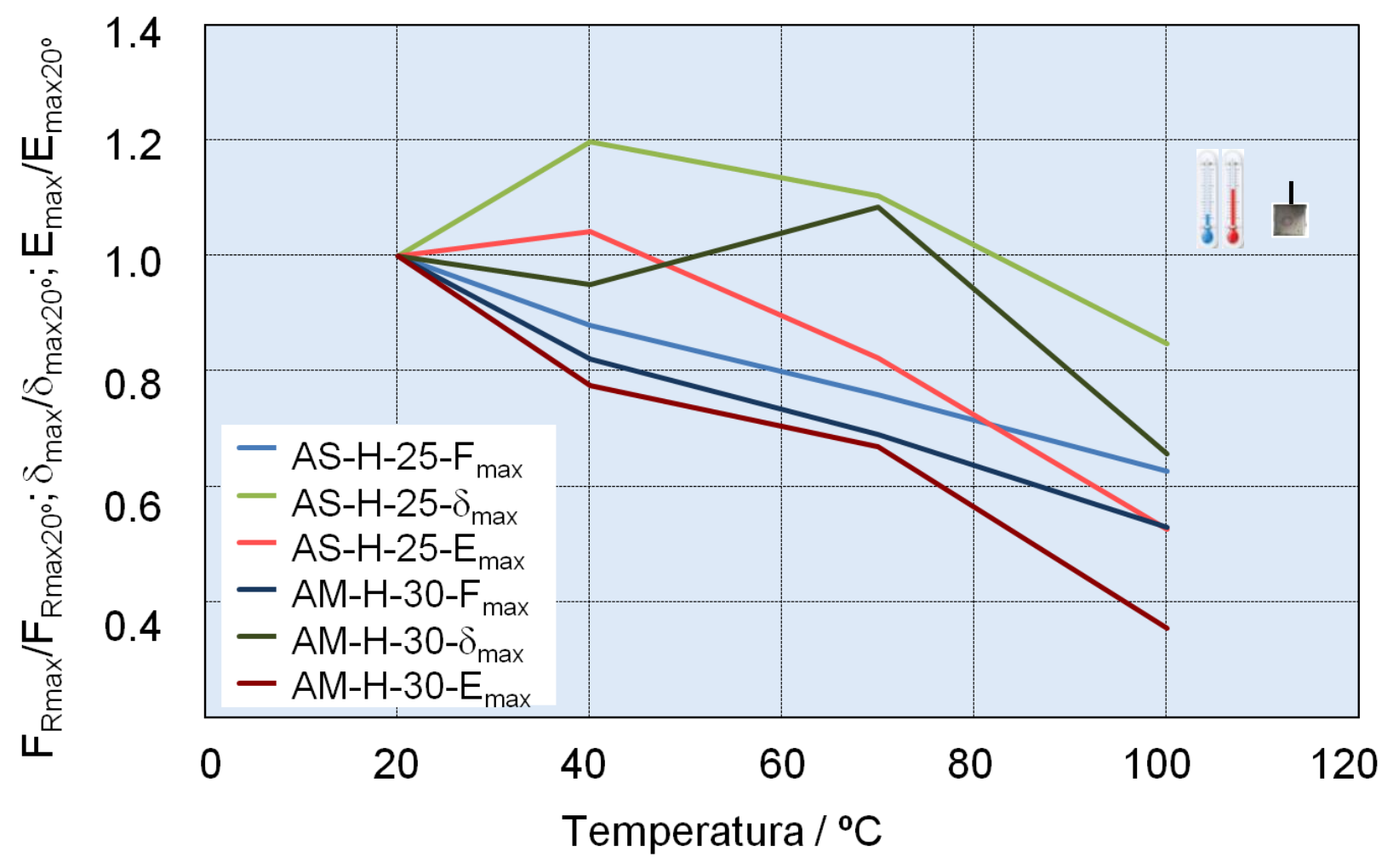

Gráfica 5- 17. Evolución en función del incremento de temperatura $\left(20^{\circ} \mathrm{C}, 40^{\circ} \mathrm{C}\right.$, $70^{\circ} \mathrm{C}$, y $\left.100^{\circ} \mathrm{C}\right)$ de los valores medios máximos $\left(\delta_{\max }, \delta_{u}, y E_{\max }\right)$, obtenidos del ensayo a arrancamiento de cada grupo de tres probetas cúbicas con armadura corrugada anclada, sometidas a la misma temperatura, con hormigones $\mathrm{H}-25$ y $\mathrm{H}-30$.

Como se puede observar, la fuerza máxima de arrancamiento, aún siendo mayor en el hormigón $\mathrm{H}-30$, experimenta un descenso proporcionalmente mayor que en el hormigón $\mathrm{H}-25$, sobre todo en al pasar de $20^{\circ} \mathrm{C}$ a $40^{\circ} \mathrm{C}$. El desplazamiento máximo aumenta para una temperatura de $40^{\circ} \mathrm{C}$ y va disminuyendo al seguir aumentando la temperatura, mientras que el hormigón $\mathrm{H}$ 30 tiende a comportamientos semejantes para temperaturas de $70^{\circ}$. La energía 
máxima de deformación disminuye de manera más importante en el hormigón $\mathrm{H}$ 30. Comparando las gráficas correspondientes a los valores relativos más representativos, se puede observar que las mayores pendientes en todos los gráficos se encuentran para el intervalo de temperaturas de $70^{\circ} \mathrm{C}$ a $100^{\circ} \mathrm{C}$, es decir, cuando se hace más acusado el descenso en las características del hormigón.

\subsubsection{Análisis porcentual de las pérdidas de resistencia observadas en} los ensayos a arrancamiento de las probetas cúbicas con armadura corrugada anclada, de hormigón H-25 y H-30, sometidas a las distintas temperaturas $\left(20^{\circ} \mathrm{C}, 40^{\circ} \mathrm{C}, 70^{\circ} \mathrm{C}\right.$, y $\left.100^{\circ} \mathrm{C}\right)$.

En la tabla 5- 2 y la gráfica 5- 18 se muestra la relación entre la pérdida de resistencia y la temperatura, para los hormigones $\mathrm{H}-25$ y $\mathrm{H}-30$. Y se representa gráficamente el momento en el que las pérdidas de resistencia superan el $20 \%$.

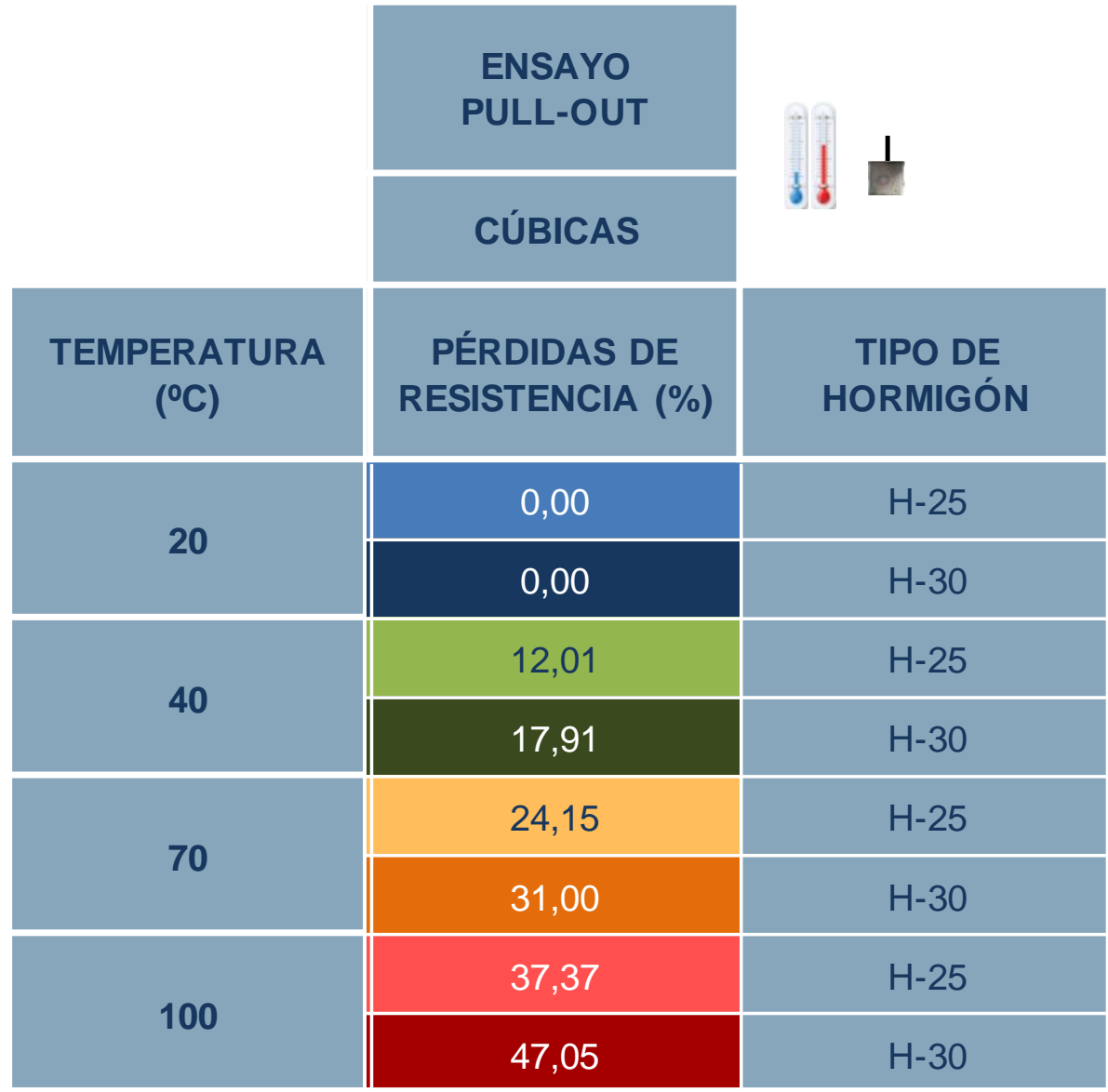

Tabla 5- 2. Pérdidas de resistencia en tanto por ciento en hormigones $\mathrm{H}-25$ y H-30 ensayados a "pull-out", en función de la temperatura. 


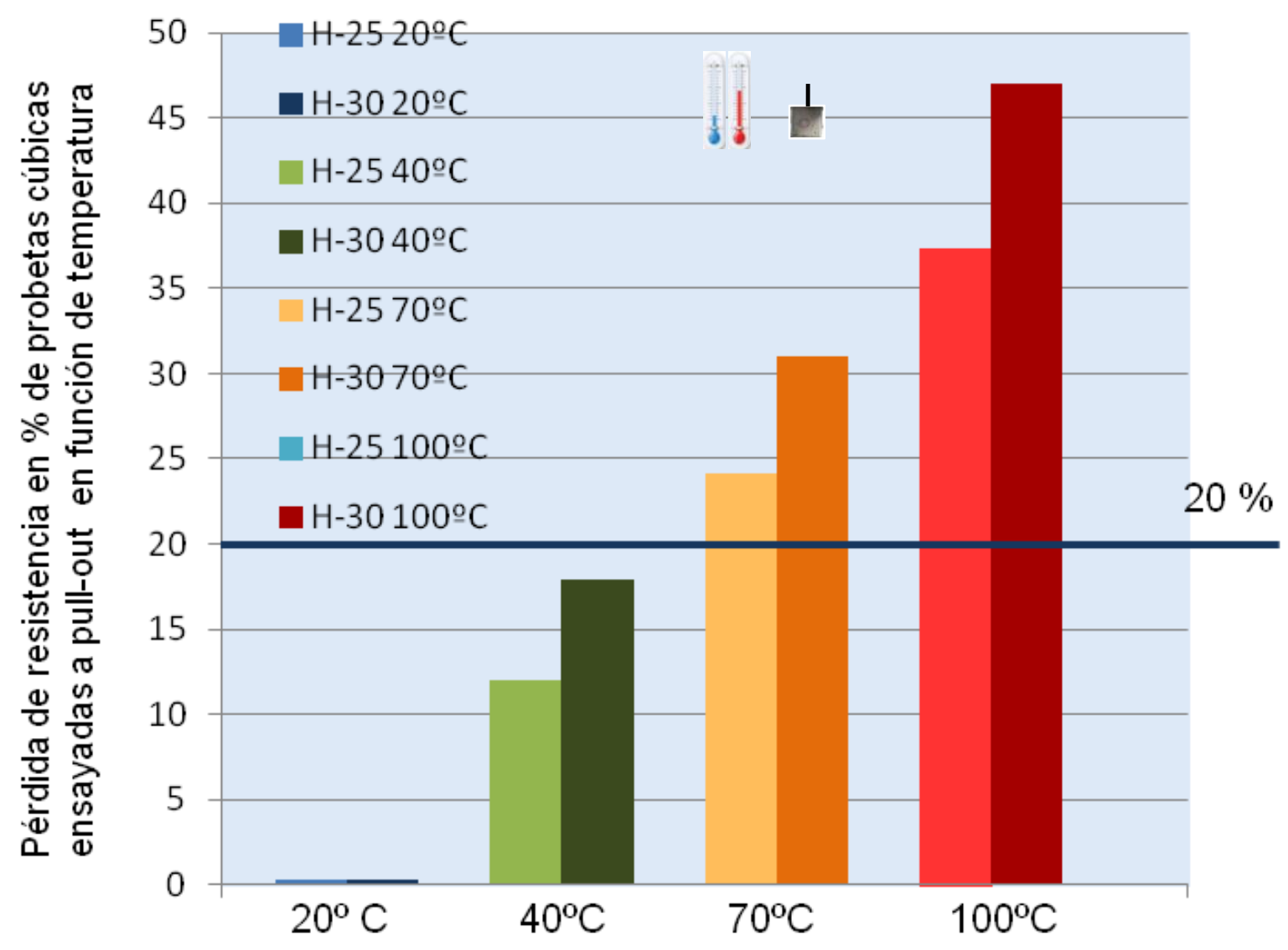

Gráfica 5- 18. Gráfica de análisis porcentual de pérdidas de resistencia en función de la temperatura de las probetas cúbicas con armadura corrugada anclada, en el momento de la rotura a arrancamiento, para hormigones $\mathrm{H}-25$ y H-30.

Como se puede observar, las pérdidas de resistencia aumentan a medida que aumenta la temperatura, produciéndose pérdidas de tensión alrededor del 20\% cuando el hormigón $\mathrm{H}-25$ alcanza los $70^{\circ} \mathrm{C}$.

En comparación con la gráfica 20 de análisis porcentual de pérdidas de resistencia en las probetas cilíndricas ensayadas a compresión, se observa que en los resultados de ensayo de arrancamiento "pull-out" los valores de pérdida de resistencia son mayores a menor temperatura, alcanzándose valores superiores al $20 \%$ en los dos tipos de hormigones para temperaturas de $70^{\circ} \mathrm{C}$. 


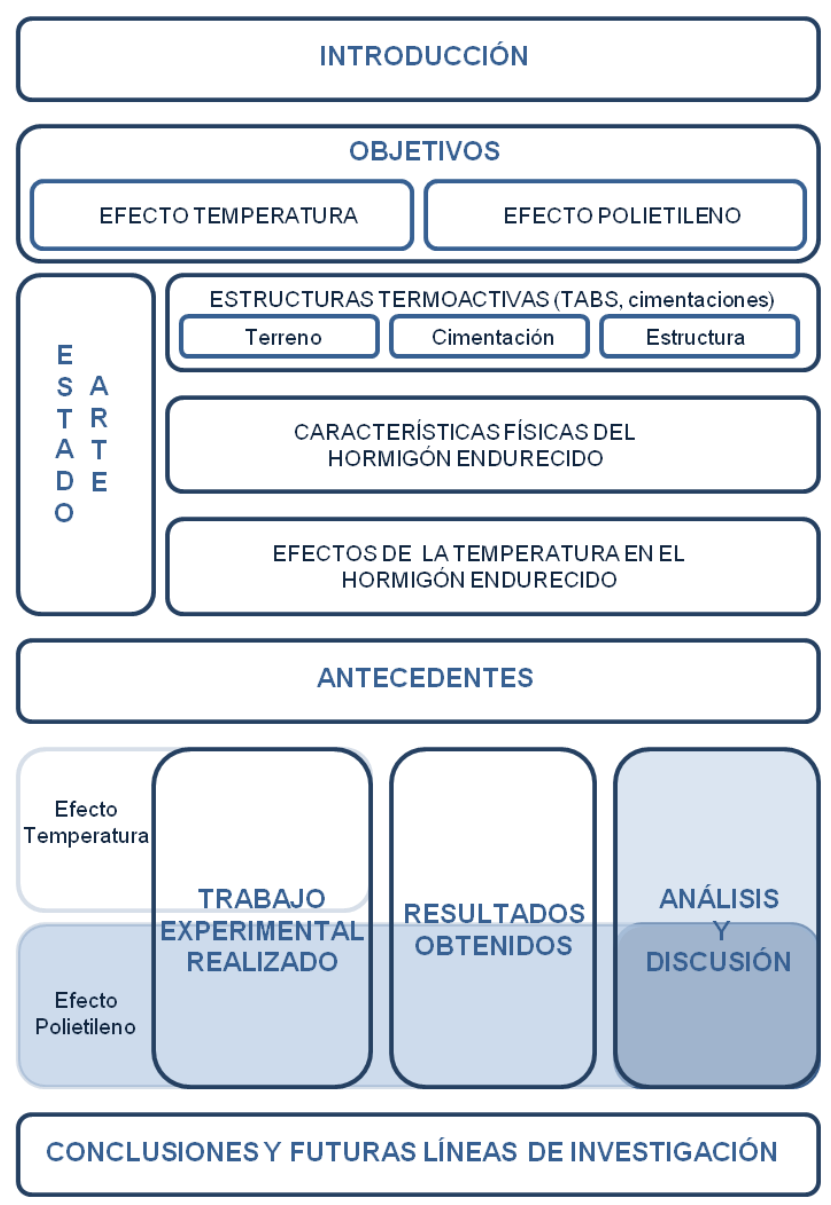

\subsection{Estudio del efecto de la incorporación de tubos de polietileno}

Los resultados obtenidos de los ensayos efectuados para analizar el efecto de la incorporación de tubos de polietileno en el interior de las probetas de hormigón endurecido permiten establecer comparativas de los valores más característicos averiguados en cada caso.

En ese sentido se realizaron cinco análisis diferentes: un primer análisis, que permite analizar gráficamente cuál es la evolución del hormigón provocada por las distintas disposiciones de tubo de polietileno en su interior (vertical centrada, vertical descentrada, horizontal o sin tubo), utilizando los resultados de tensión de las probetas más representativas para cada uno de los dos tipos de hormigón $(\mathrm{H}$ 25 y H-30) por separado. 
Un segundo análisis comparativo de las probetas de los dos hormigones $(\mathrm{H}-25$ y H-30), que nos permite analizar la evolución de las distintos resultados más característicos ( $\sigma_{\max }, \varepsilon_{\max }, \varepsilon_{u}, E_{\max }$ y $E_{u}$ ) obtenidos de los ensayos a compresión, y su evolución en función de las distintas disposiciones de tubo de polietileno en su interior (vertical centrada, vertical descentrada, horizontal o sin tubo).

Un tercer análisis comparativo, que permite analizar la evolución con respecto al las distintas disposiciones de tubo de polietileno en su interior (vertical centrada, vertical descentrada, horizontal o sin tubo) de los valores máximos más característicos $\left(\sigma_{\max }, \varepsilon_{\max }, E_{\max }\right.$ ), obtenidos de las medias de los resultados de rotura a compresión de las probetas elaboradas con hormigón H-25 y de las elaboradas con hormigón H-30.

Un cuarto análisis porcentual, que nos permite establecer la temperatura de consigna a partir de la cual las pérdidas de resistencia de las probetas de hormigón endurecido $\mathrm{H}-25$ y H-30 sobrepasan el $20 \%$.

Y un último análisis gráfico comparativo, para comprobar la evolución con respecto a las distintas disposiciones de tubo de polietileno en su interior (vertical centrada, vertical descentrada, horizontal o sin tubo) de los valores de energía última $E_{u}$, que nos permite establecer de modo no comparativo entre las distintas probetas (ya que su diferencia de esbeltez y tamaño generan unas diferencias absolutas en los resultados obtenidos), cuál es la evolución de dicha energía para cada tipo de probeta en las distintas disposiciones de tubo.

\subsubsection{Estudio de los resultados de rotura a compresión de probetas cilíndricas (efecto tubo polietileno)}

En este primer apartado se presentan los cuatro estudios comparativos realizados con los resultados de probetas cilíndricas ensayadas a compresión, para analizar el efecto producido por la disposición de tubos de polietileno en su interior en distintas posiciones (vertical centrada, vertical descentrada, horizontal o sin tubo), para hormigón H-25 y hormigón H-30. 


\subsubsection{Estudio comparativo de los resultados de tensión/deformación más significativos en función de la distinta disposición de tubos de polietileno.}

Se ha procedido a elaborar unas gráficas con los resultados más significativos que permitan apreciar visualmente cual es el comportamiento de cada tipo de probeta cilíndrica de hormigón endurecido con tubo de polietileno incorporado en las distintas posiciones (vertical centrada, vertical descentrada, horizontal o sin tubo), ensayadas a compresión, para los dos hormigones utilizados $\mathrm{H}-25$ y H-30.

Los resultados obtenidos en el ensayo a compresión de las probetas cilíndricas se pueden observar en las gráficas 5 - 19 y 5-20, donde se muestra la evolución de la tensión respecto a la deformación longitudinal unitaria, para las diferentes disposiciones de tubo de polietileno y para los dos tipos de hormigón empleados.

Como se puede observar, en ambos tipo de hormigón, los valores de la tensión máxima son parecidos en las probetas de referencia y cuando el tubo se encuentra en posición vertical, disminuyendo drásticamente cuando el tubo se encuentra en posición horizontal.

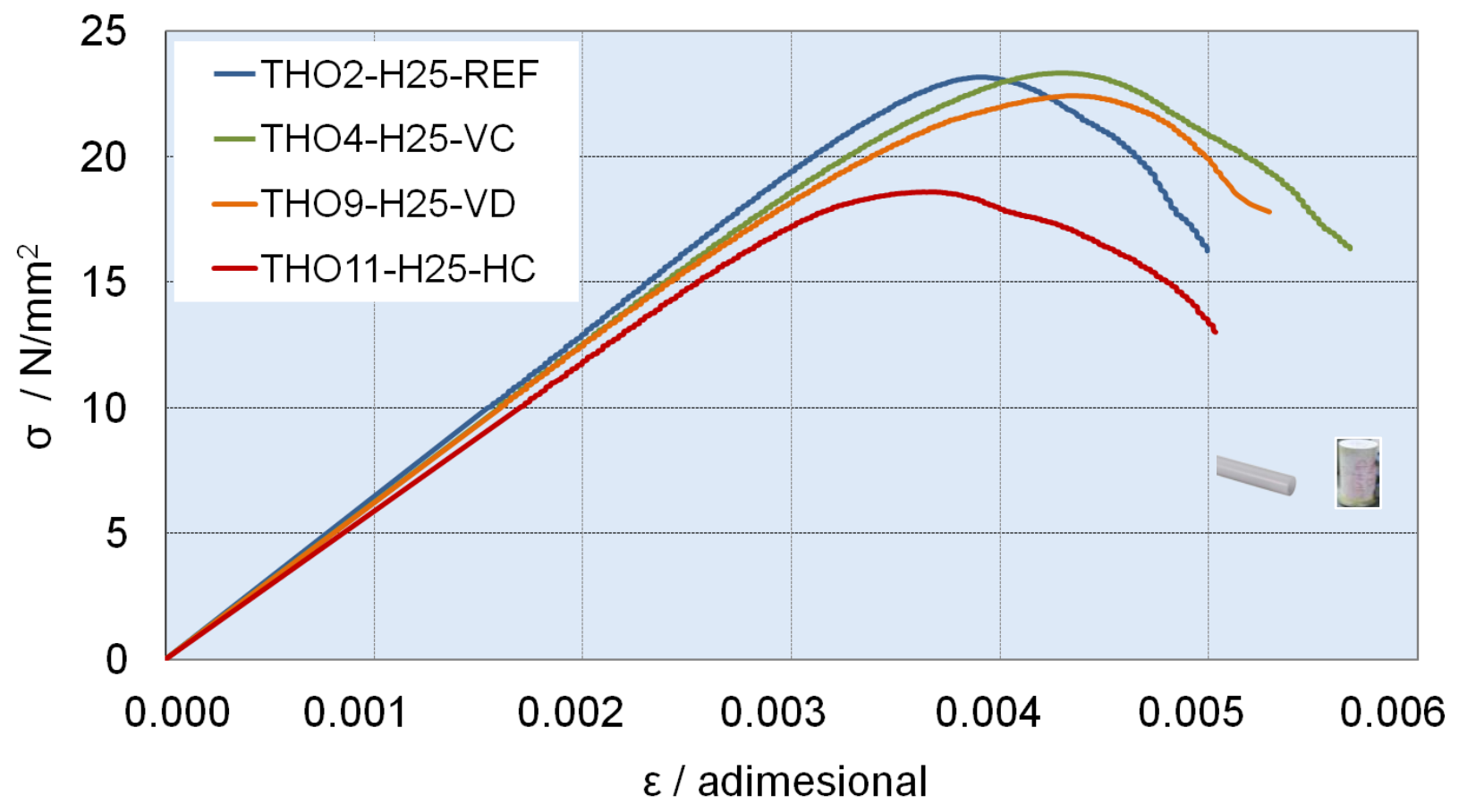


Gráfica 5- 19. Gráfica de evolución de la Tensión $\sigma(\mathrm{N} / \mathrm{mm} 2)$ respecto a la deformación $\varepsilon$ (adimensional) en probetas cilíndricas más representativas, para las distintas disposiciones de tubo (vertical centrada, vertical descentrada, horizontal o sin tubo), realizadas con hormigón $\mathrm{H}-25$, ensayadas a compresión.

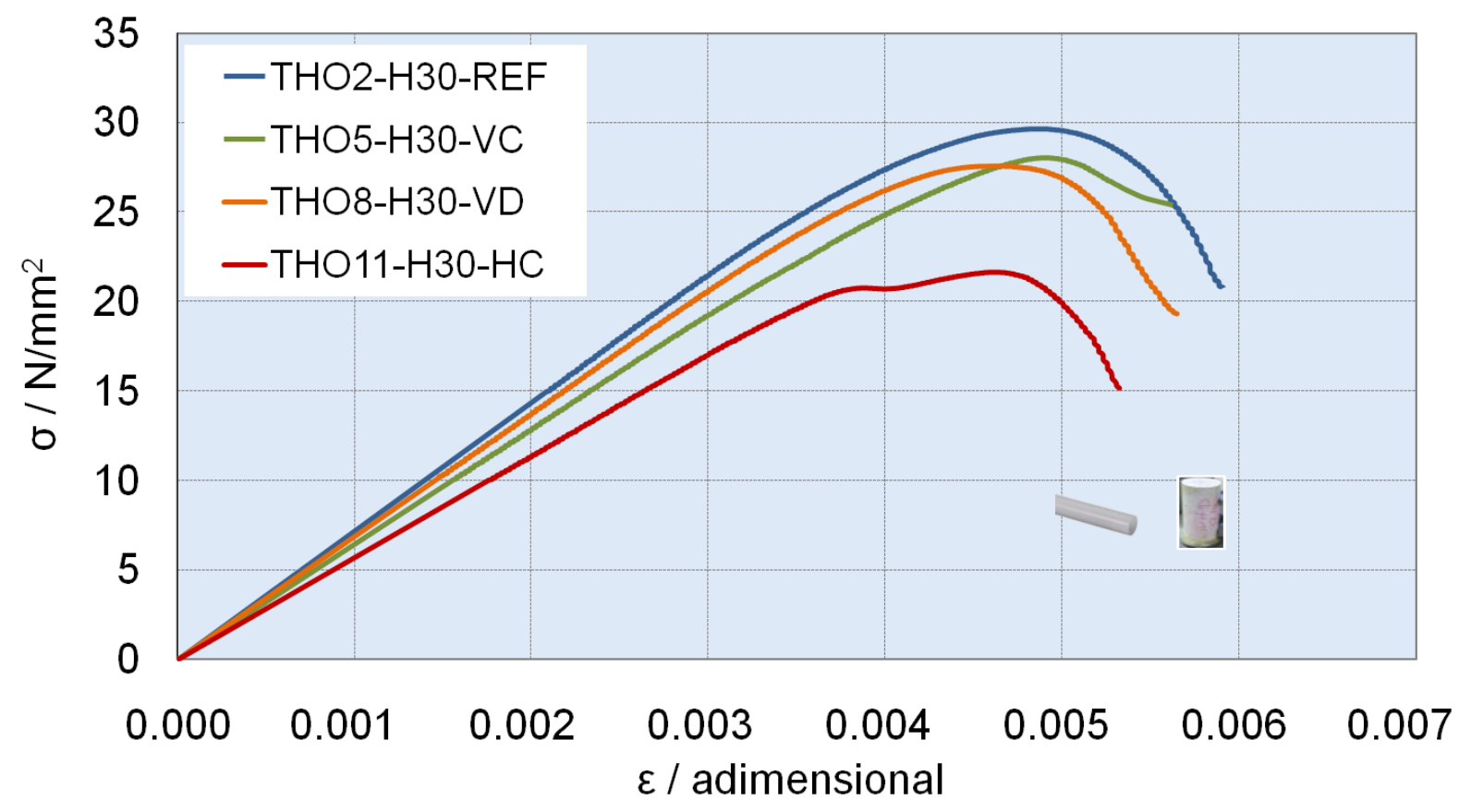

Gráfica 5- 20. Gráfica de evolución de la Tensión $\sigma(\mathrm{N} / \mathrm{mm} 2)$ respecto a la deformación $\varepsilon$ (adimensional), en probetas cilíndricas más representativas, para las distintas disposiciones de tubo (vertical centrada, vertical descentrada, horizontal o sin tubo), realizadas con hormigón $\mathrm{H}-30$, ensayadas a compresión.

\subsubsection{Estudio comparativo de los resultados $\sigma_{\max }, \varepsilon_{\max }, \varepsilon_{u}, E_{\max }$ y $E_{u}$ obtenidos de la rotura a compresión de las probetas cilíndricas con distintas disposiciones de tubo de polietileno.}

A continuación se presentan las gráficas comparativas de los valores que se han obtenido como resultado del ensayo de resistencia a compresión de probetas cilíndricas elaboradas con dos hormigones distintos, $\mathrm{H}-25$ y H-30, en los que se ha 
incorporado tubos de PE en tres posiciones distintas: vertical centrado, vertical descentrado y horizontal centrado, y además se ha ensayado probetas sin tubo para servir como probetas de referencia.

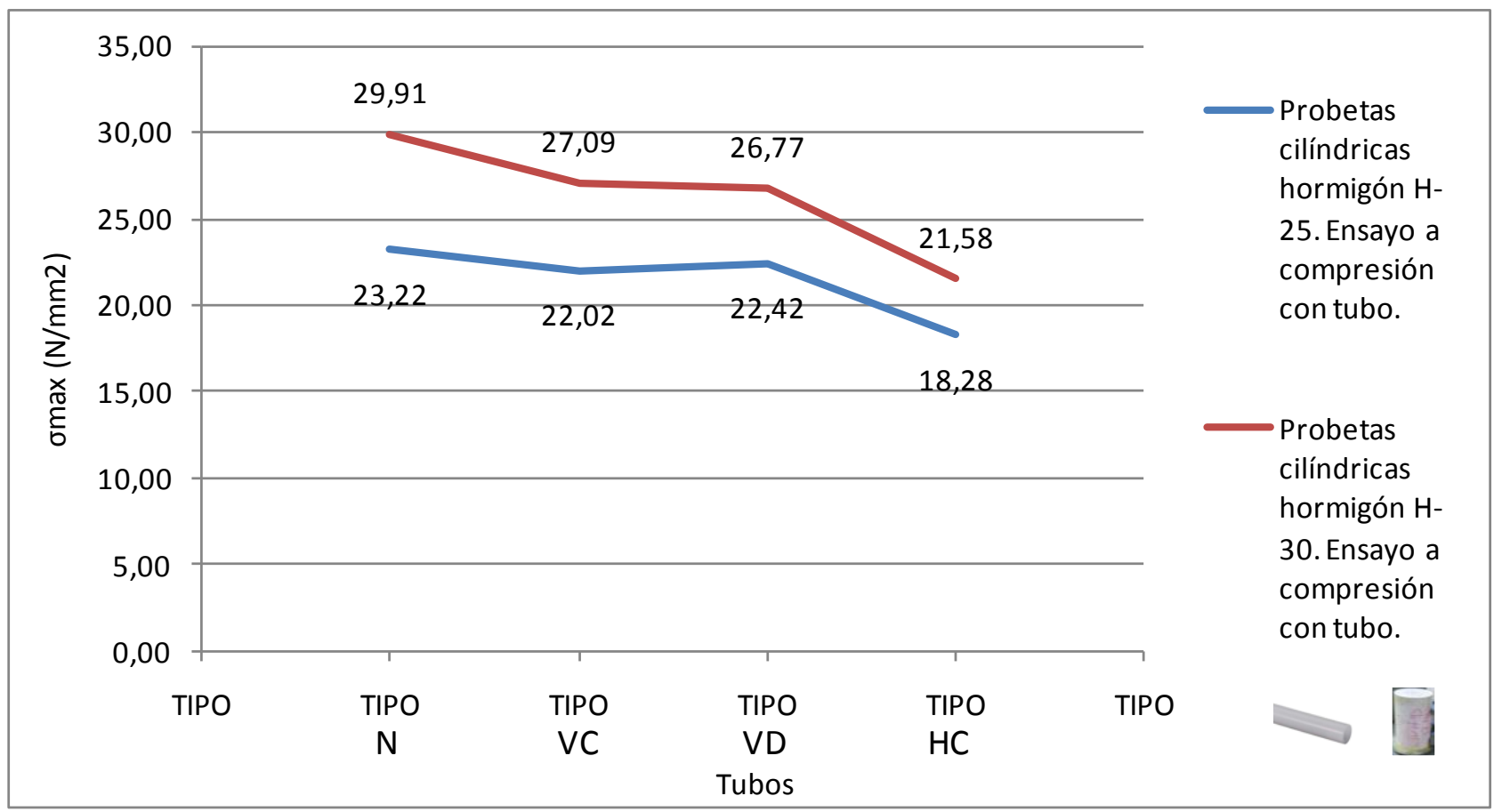

Gráfica 5- 21. Gráfica Tensión $\sigma_{\max }(\mathrm{N} / \mathrm{mm} 2)$ / Tubo PE, de de las medias aritméticas de los resultados de resistencia a compresión de las probetas cilíndricas en las que se han colocado los tubos de polietileno con cuatro variantes distintas, comparando los resultados de hormigón $\mathrm{H}-25$ y del hormigón H-30 ensayados a compresión.

El gráfico tensión/tubo de la gráfica muestra una tendencia general a decrecer de los resultados de tensión para cada una de las posiciones de los tubos a medida que estos se disponen en la probeta en la posición que se considera más desfavorable, a priori. Los valores obtenidos son proporcionales para los dos tipos de hormigones $\mathrm{H}-25$ y H-30, aunque superiores para hormigón H-30. 


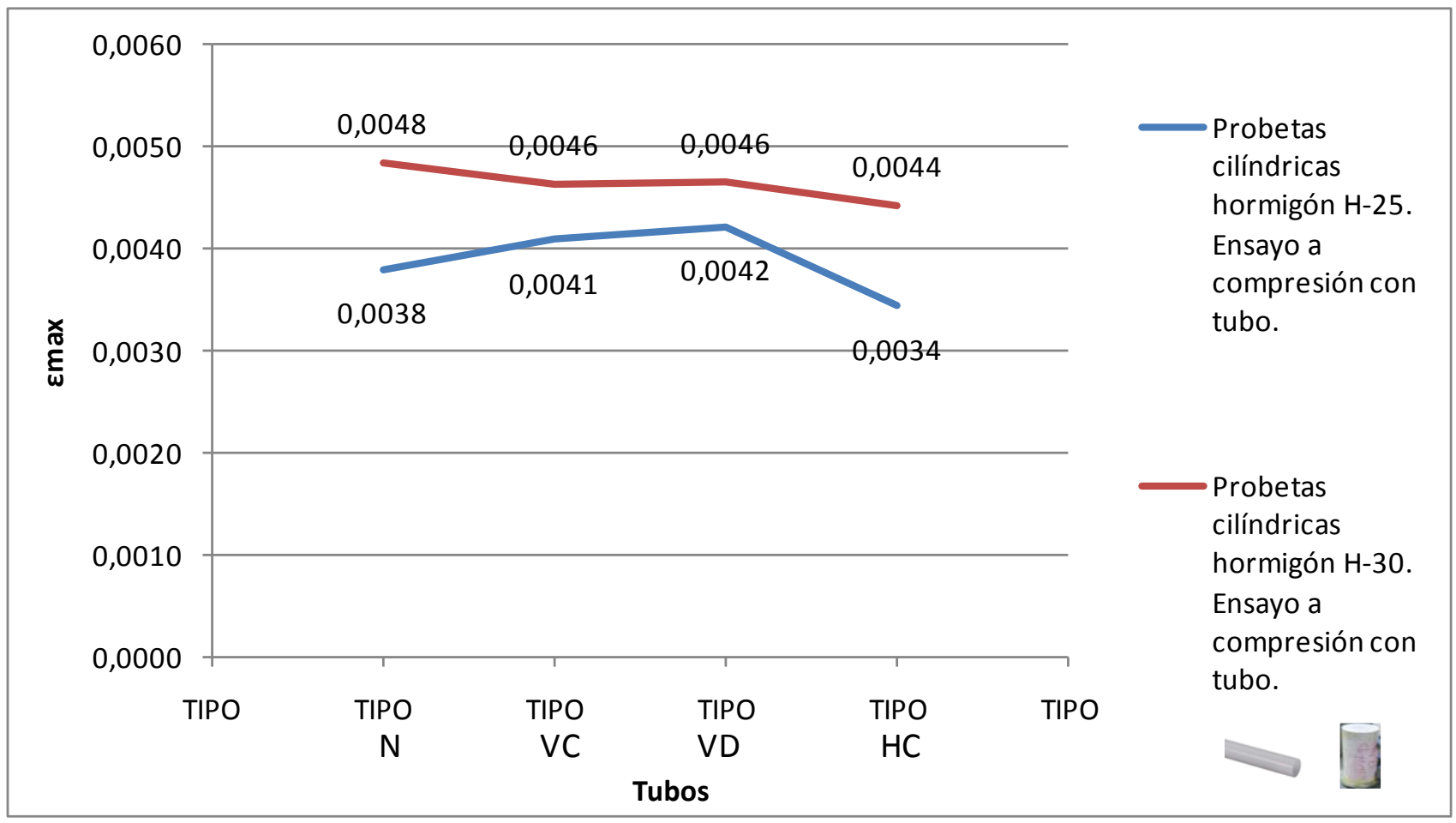

Gráfica 5- 22. Gráfica Deformación máxima $\boldsymbol{\varepsilon}_{\max } /$ Tubo PE, de de las medias aritméticas de los resultados de deformación correspondiente a la máxima tensión de las probetas cilíndricas en las que se han colocado los tubos de polietileno con cuatro variantes distintas, comparando los resultados de hormigón H-25 y del hormigón H-30 ensayados a compresión.

Los datos observados en la gráfica 5- 22, no permiten establecer una relación clara en los resultados de deformación observados para las distintas posiciones de los tubos, aunque en valor absoluto el decremento existente para los dos tipos de hormigones $(\mathrm{H}-25$ y H-30) en la deformación correspondiente a la tensión máxima de rotura de las probetas sin tubo en comparación con la deformación de las probetas que tienen el tubo colocado en posición horizontal, es el mismo.

Los valores obtenidos para hormigón $\mathrm{H}-30$ son superiores a los obtenidos para hormigón H-25. 


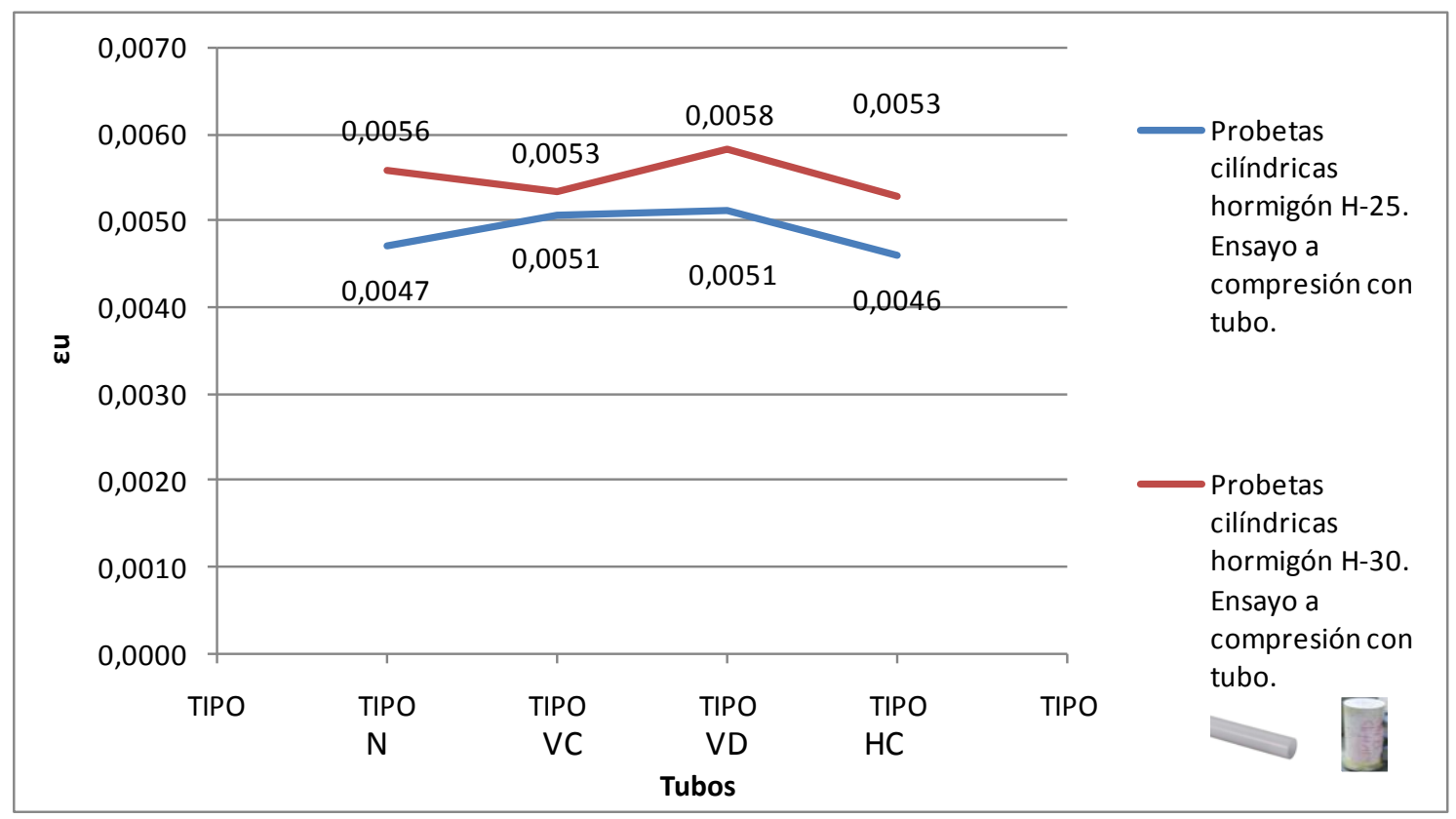

Gráfica 5- 23. Gráfica Deformación última $\varepsilon_{u} /$ Tubo PE, de de las medias aritméticas de los resultados de deformación última de las probetas cilíndricas en las que se han colocado los tubos de polietileno con cuatro variantes distintas, comparando los resultados de hormigón H-25 y del hormigón H-30 ensayados a compresión.

Para la gráfica deformación última/tubo las tendencias son similares a las de la grafica 5- 24, no pudiendo establecerse una relación clara entre los valores correspondientes a los dos tipos de hormigón (H-25 y H-30).

Se observa que al igual que ocurre en las gráficas de tensión máxima y de deformación correspondiente a la tensión máxima, los valores de deformación última son superiores para las probetas elaboradas con hormigón H-30 en relación con los de las probetas elaboradas con hormigón H-25. 


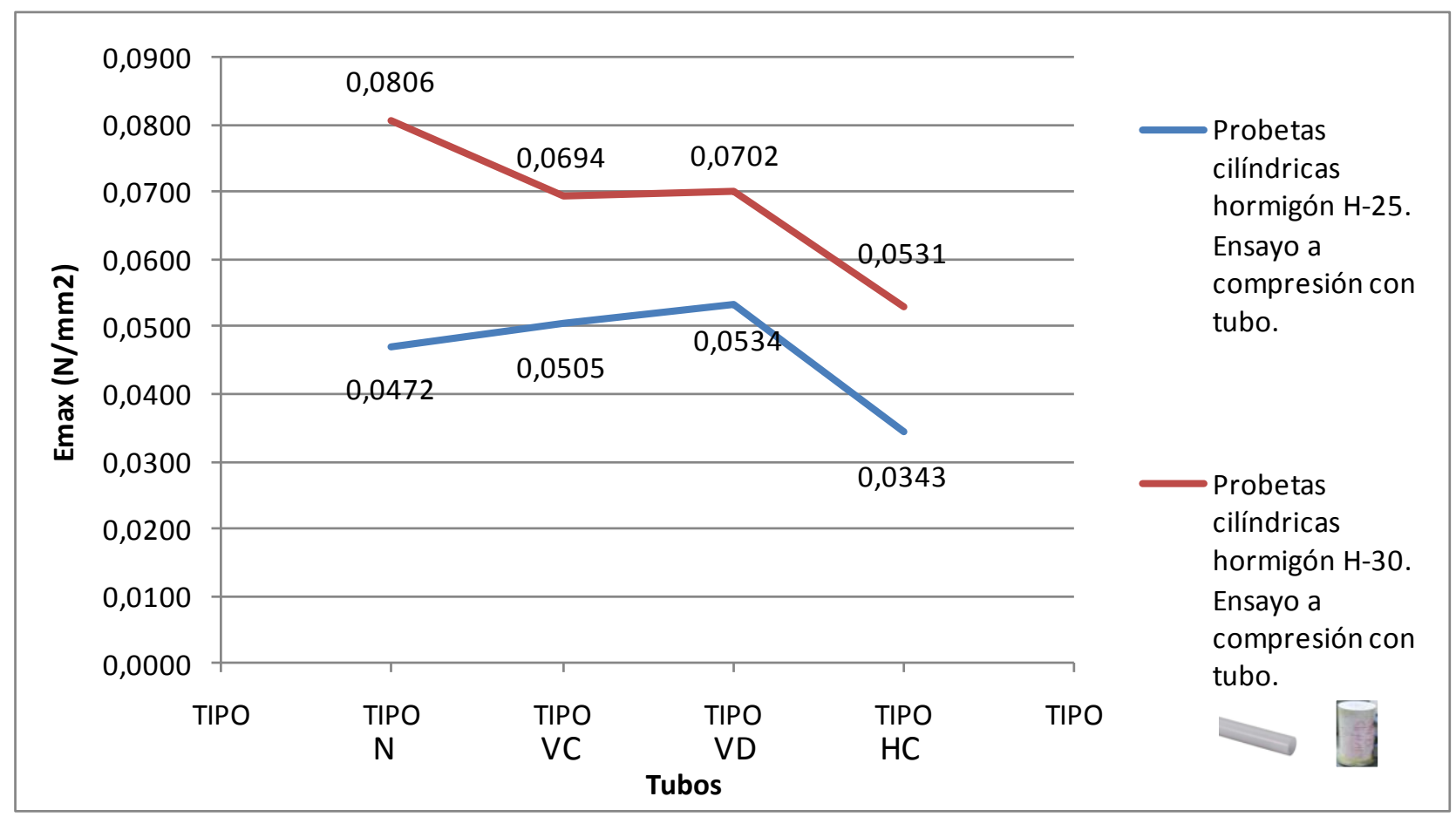

Gráfica 5- 24. Gráfica Energía máxima $E_{\max }\left(\mathrm{N} / \mathrm{mm}^{2}\right)$ / Tubo PE, de de las medias aritméticas de los resultados de energía máxima de las probetas cilíndricas en las que se han colocado los tubos de polietileno con cuatro variantes distintas, comparando los resultados de hormigón H-25 y del hormigón H-30 ensayados a compresión.

La tendencia de los resultados de energía correspondientes a la tensión máxima de las probetas realizadas con los dos hormigones es exactamente la misma, pero los valores de hormigón $\mathrm{H}-30$ son superiores a los de hormigón $\mathrm{H}-25$.

En el caso del hormigón $\mathrm{H}-25$ la tendencia en los resultados de deformación para tensión última y máxima también en similar, aunque analizando la variación entre los valores de probetas sin tubo y los que tienen el tubo en posición vertical, para la gráfica de tensión máxima se observa un leve decremento, y en cambio en la gráfica de energía máxima se observa un ligero incremento. 


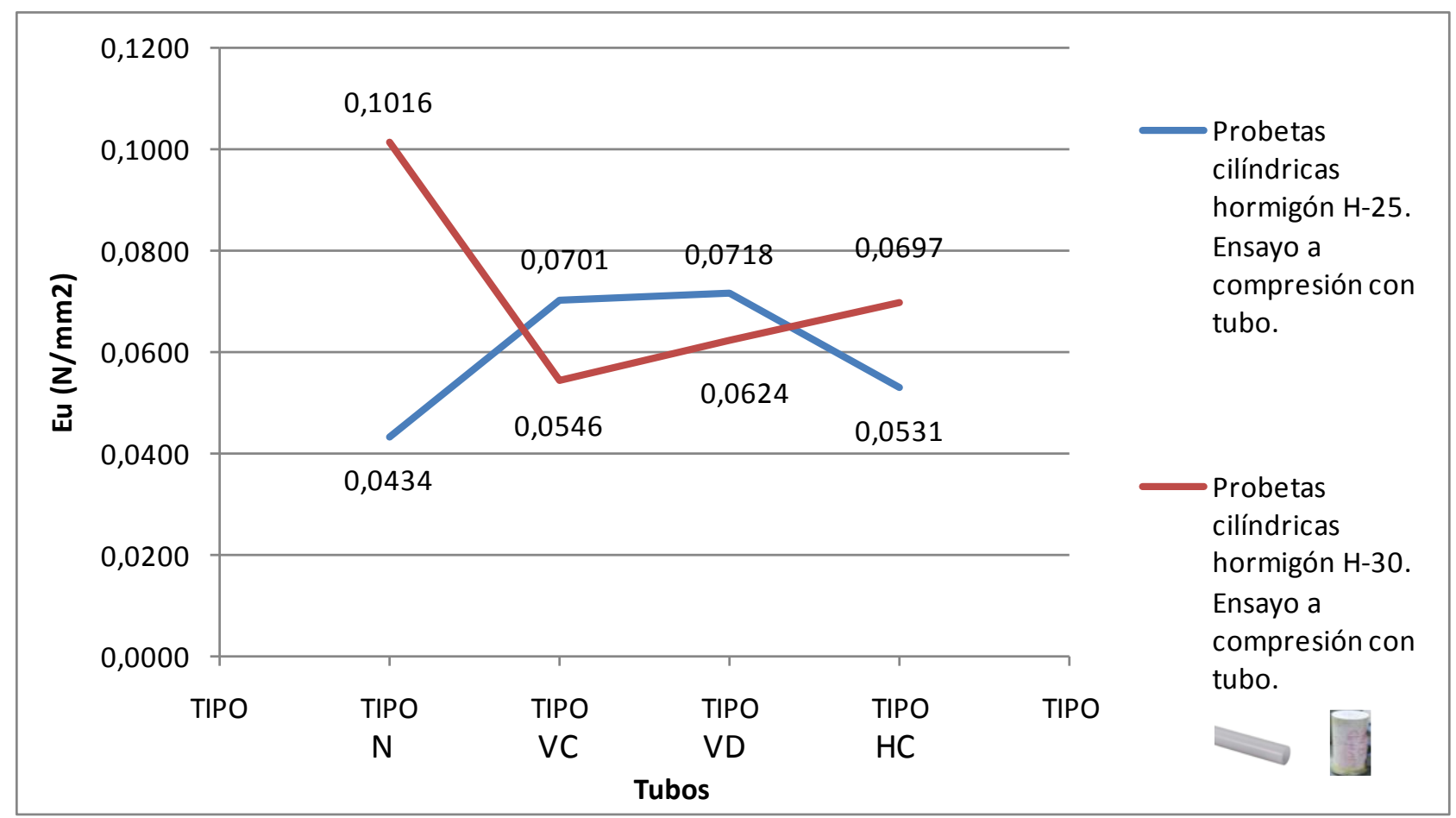

Gráfica 5- 25. Gráfica Energía última $E_{u}\left(\mathrm{~N} / \mathrm{mm}^{2}\right) /$ Tubo PE, de de las medias aritméticas de los resultados de energía última de las probetas cilíndricas en las que se han colocado los tubos de polietileno con cuatro variantes distintas, comparando los resultados de hormigón H-25 y del hormigón H-30 ensayados a compresión.

Aunque las tendencias generales de los hormigones $\mathrm{H}-25$ y H-30 de la gráfica 5- 24 son similares a las tendencias de la gráfica 5- 25, los incrementos y decrementos sufridos por los valores de energía última son mucho más acusados, hasta el punto de que en la comparación de valores entre los dos hormigones, en esta gráfica existen valores de energía de las probetas de hormigón H-30 inferiores a los valores de energía última de las probetas de hormigón H-25.

No se puede extraer de la grafica una conclusión acerca de si los valores son mayores para hormigón $\mathrm{H}-25$ o para hormigón $\mathrm{H}-30$, ya que de los cuatro resultados existentes para cada hormigón, dos de ellos son mayores para uno de los hormigones y otros dos para el otro. 


\subsubsection{Estudio comparativo de los dos tipos de hormigón de la} evolución de los resultados máximos $\sigma_{\max }, \varepsilon_{\max }$ y $E_{\max }$ medios de rotura a compresión de las probetas cilíndricas con distintas disposiciones de tubo de polietileno.

La gráfica 5- 26 permite comparar la evolución de los valores máximos característicos calculados a partir del ensayo a compresión, en función de la disposición de los tubos, en los dos tipos de hormigones estudiados.

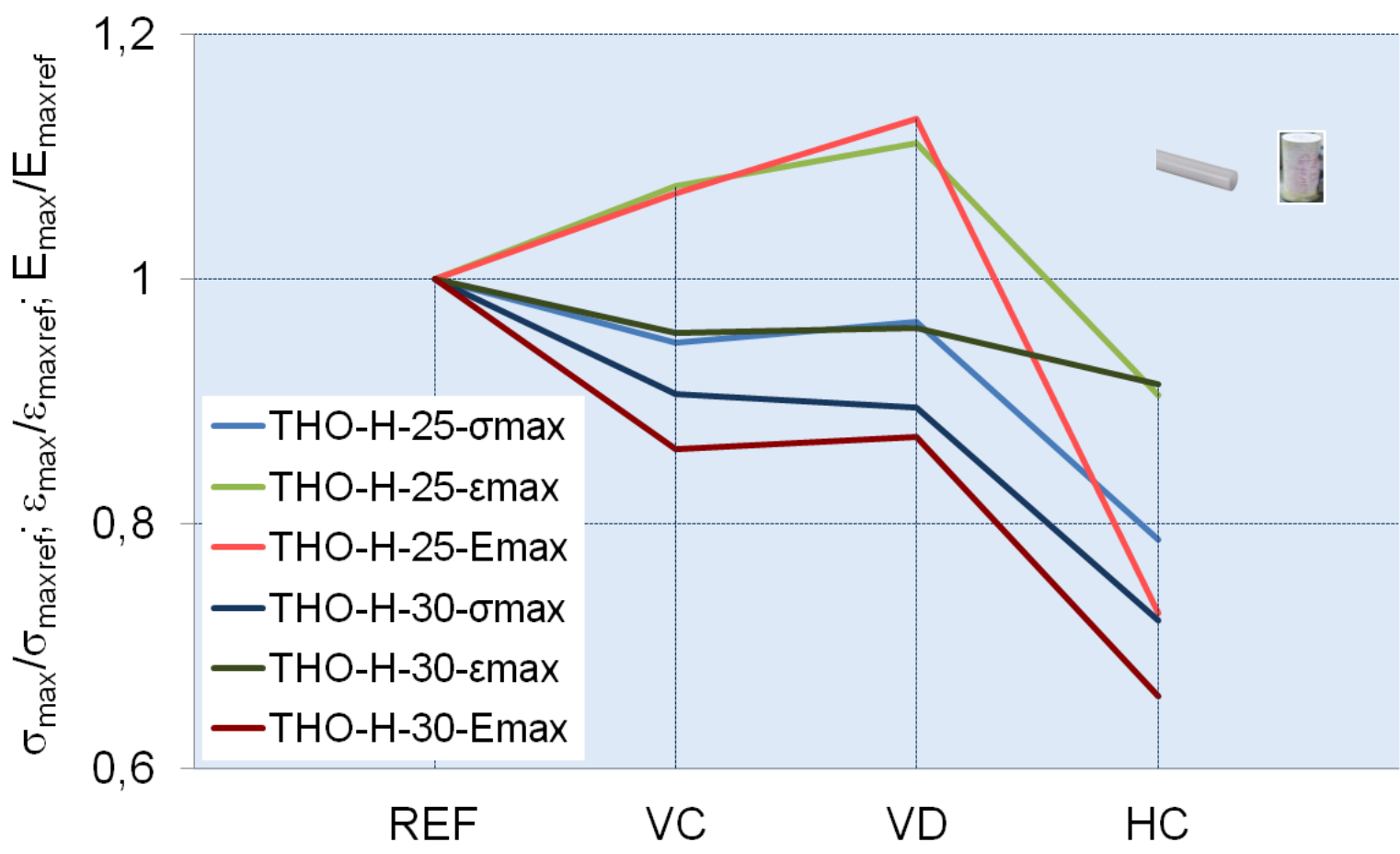

Gráfica 5- 26. Evolución, en función de la disposición del tubo de polietileno (vertical centrada, vertical descentrada, horizontal o sin tubo) de los valores medios máximos

$\left(\sigma_{\max }, \varepsilon_{\max }, E_{\max }\right.$ ) obtenidos del ensayo a compresión de cada grupo de tres probetas cilíndricas con semejante disposición de tubo, con hormigones H-25 y H-30.

Como se puede observar, la pérdida de resistencia es más acusada cuando el tubo está dispuesto en posición horizontal y con hormigón H-25. Cuando el tubo se encuentra en posición vertical, la pérdida de resistencia porcentual es semejante en ambos tipos de hormigones. La deformación máxima es menor cuando el tubo está en posición horizontal independientemente de la posición del tubo. Las mayores resistencias se obtienen en las probetas sin tubo y las menores, cuando el tubo se encuentra en posición perpendicular a la carga. La disposición centrada 
o descentrada del tubo, colocado paralelamente a la dirección de la carga, no influye en la resistencia.

\subsubsection{Análisis porcentual de las pérdidas de resistencia observadas en} los ensayos a compresión de las probetas cilíndricas de hormigón H-25 y H-30 con distintas disposiciones de tubo de polietileno (vertical centrada, vertical descentrada, horizontal o sin tubo).

En la tabla 5- 3 y la gráfica 5- 27 se muestra la relación entre la pérdida de resistencia y la disposición del tubo de polietileno, para los hormigones $\mathrm{H}-25$ y H30. Y se representa gráficamente el momento en el que las pérdidas de resistencia superan el $20 \%$.

\begin{tabular}{|c|c|c|}
\hline & $\begin{array}{l}\text { ENSAYO DE } \\
\text { COMPRESIÓN }\end{array}$ & \\
\hline & CILÍNDRICAS & \\
\hline TIPO DE HORMIGÓN & $\begin{array}{c}\text { PÉRDIDAS DE } \\
\text { RESISTENCIA (\%) }\end{array}$ & POSICIÓN DEL TUBO \\
\hline H-25 & 0,00 & \multirow{2}{*}{ SIN TUBO } \\
\hline H-30 & 0,00 & \\
\hline $\mathrm{H}-25$ & 5,17 & \multirow{2}{*}{$\begin{array}{l}\text { VERTICAL } \\
\text { CENTRADO }\end{array}$} \\
\hline $\mathrm{H}-30$ & 9,43 & \\
\hline $\mathrm{H}-25$ & 13,45 & \multirow{2}{*}{$\begin{array}{c}\text { VERTICAL } \\
\text { DESCENTRADO }\end{array}$} \\
\hline H-30 & 10,50 & \\
\hline $\mathrm{H}-25$ & 21,27 & \multirow{2}{*}{$\begin{array}{l}\text { HORIZONTAL } \\
\text { CENTRADO }\end{array}$} \\
\hline $\mathrm{H}-30$ & 27,85 & \\
\hline
\end{tabular}

Tabla 5- 3. Pérdidas de resistencia en tanto por ciento en hormigones $\mathrm{H}-25$ y H30, ensayados a compresión, en función de la disposición de tubo. 


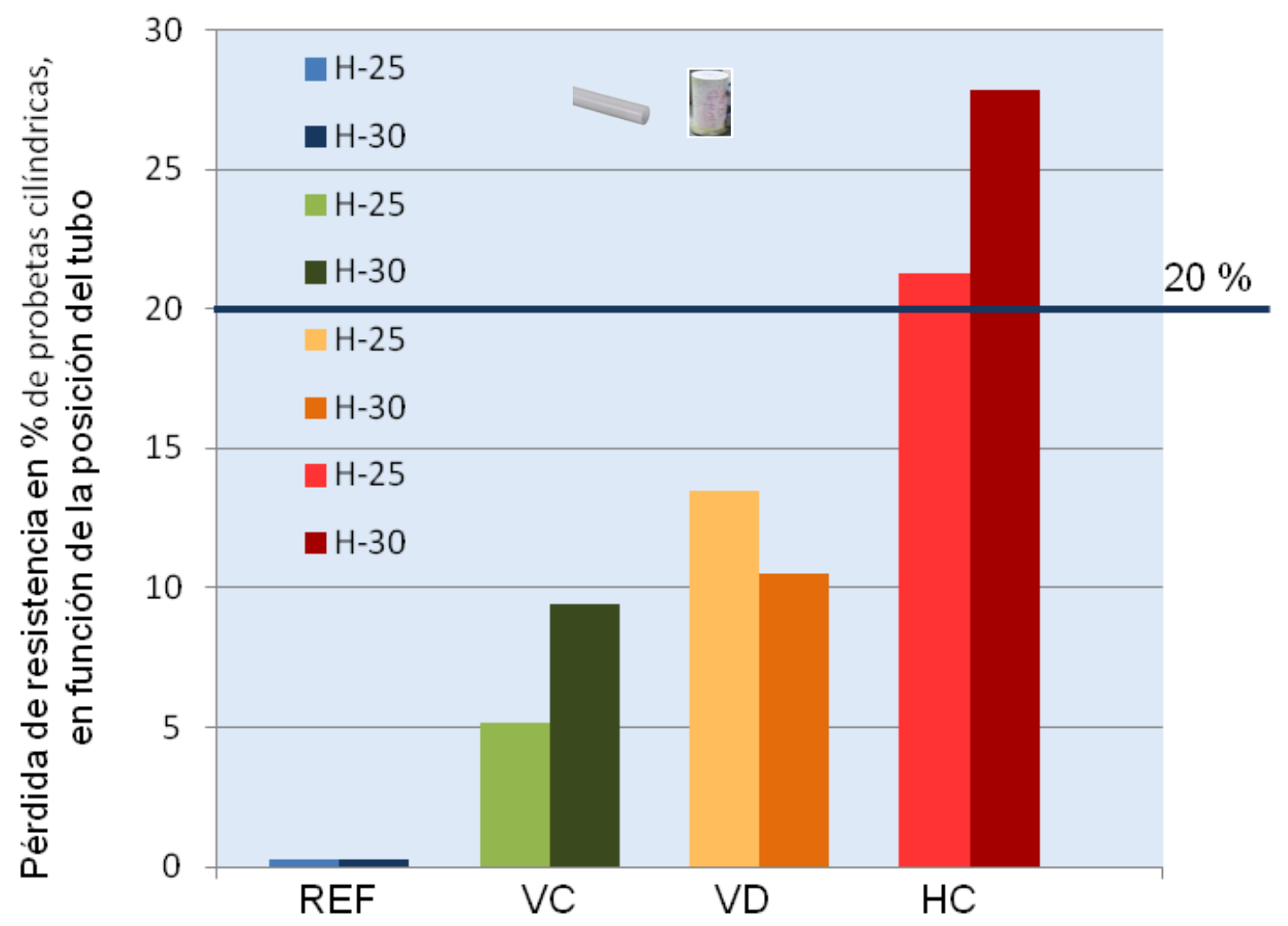

Gráfica 5- 27. Gráfica de análisis porcentual de pérdidas de resistencia en función de la disposición de tubo de polietileno en el interior de las probetas cilíndricas ensayadas a compresión, para hormigones $\mathrm{H}-25$ y H-30.

Del análisis se desprende cómo la introducción de tubos poliuretano en el hormigón disminuye su resistencia en las probetas cilíndricas, produciéndose las mayores pérdidas cuando el tubo se encuentra en posición horizontal, es decir, perpendicular a la carga, alcanzado pérdidas de resistencia superiores al 20\% tanto para hormigón H-25 como para el hormigón H-30.

5.3.1.5. Análisis gráfico comparativo de la evolución de la energía última obtenido en los ensayos de resistencia a compresión de las probetas cilíndricas de hormigón $\mathrm{H}-25$ y H-30 con distintas disposiciones de tubo de polietileno (vertical centrada, vertical descentrada, horizontal o sin tubo). 
La gráfica 5- 28 muestra los valores de la energía última $(\mathrm{Eu})$ en función del tipo de hormigón y de la disposición de los tubos de las probetas cilíndricas ensayadas a compresión.

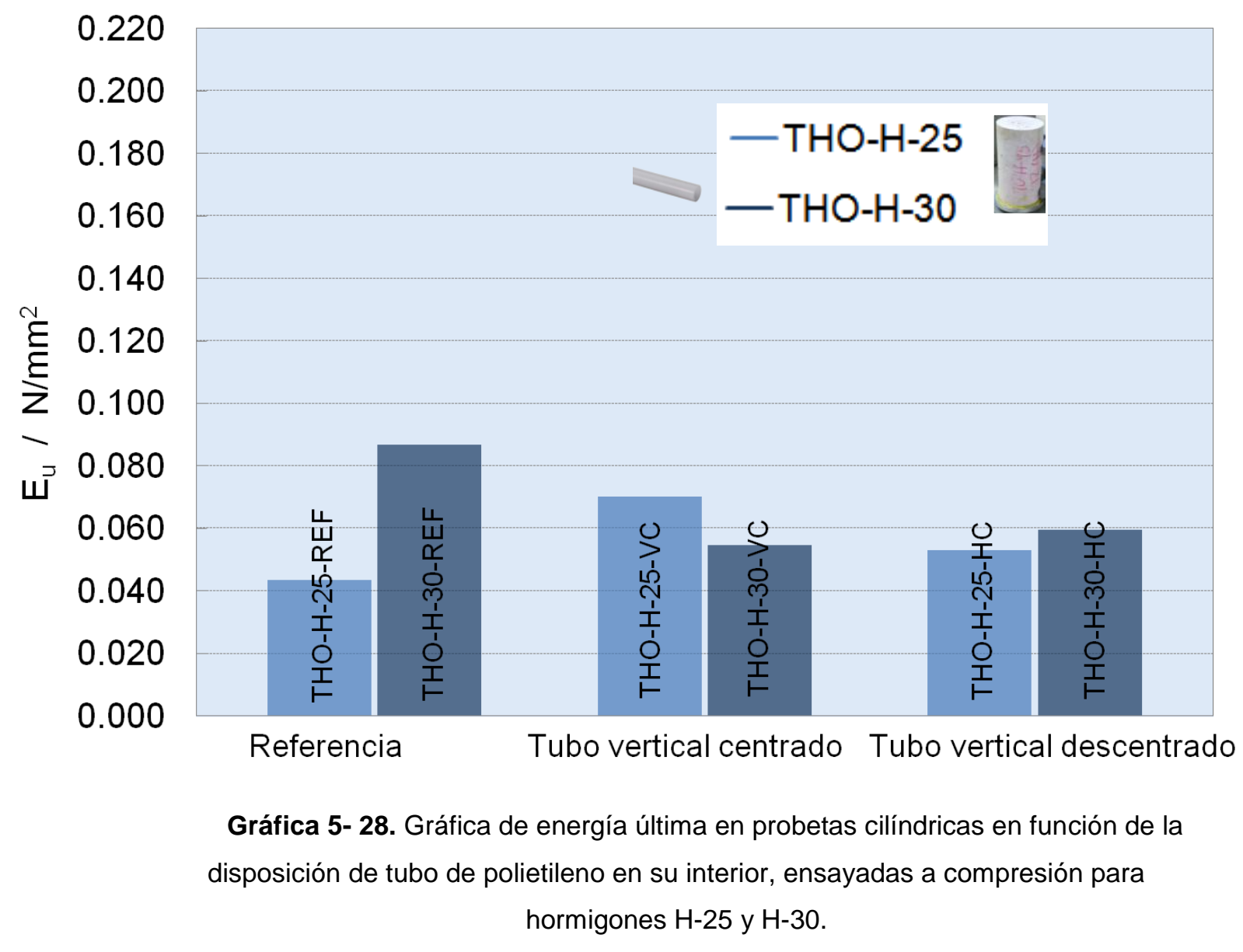

Como se puede observar el comportamiento de los resultados de energía última en función de las disposición de los tubos de polietileno no es lineal, siendo mayor la energía última en el hormigón $\mathrm{H}-30$ en las probetas sin tubo o con el tubo en horizontal, mientras que la energía última es mayor en las probetas realizadas con hormigón H-25, cuando el tubo se encuentra en posición vertical.

\subsubsection{Estudio de los resultados de rotura a compresión de probetas cúbicas (efecto tubo polietileno)}

En este segundo apartado se presentan los cinco estudios comparativos realizados con los resultados de probetas cúbicas ensayadas a compresión para analizar el efecto producido por la disposición de tubos de polietileno en su interior, 
en distintas posiciones (vertical, horizontal o sin tubo), y para hormigón $\mathrm{H}-25$ y hormigón H-30.

\subsubsection{Estudio comparativo de los resultados de tensión/deformación} más significativos en función de la distinta disposición de tubos de polietileno.

Se ha procedido a elaborar unas gráficas con los resultados más significativos que permitan apreciar visualmente cuál es el comportamiento de cada tipo de probeta cúbica de hormigón endurecido con tubo de polietileno incorporado en las distintas posiciones (vertical, horizontal o sin tubo), ensayadas a compresión y para los dos hormigones utilizados $\mathrm{H}-25$ y H-30.

Los resultados obtenidos en el ensayo a compresión de las probetas cúbicas se pueden observar en las gráficas 5- 29 y 5- 30, donde se muestra la evolución de la tensión respecto a la deformación longitudinal unitaria para las diferentes disposiciones de tubo de polietileno y para los dos tipos de hormigón empleados.

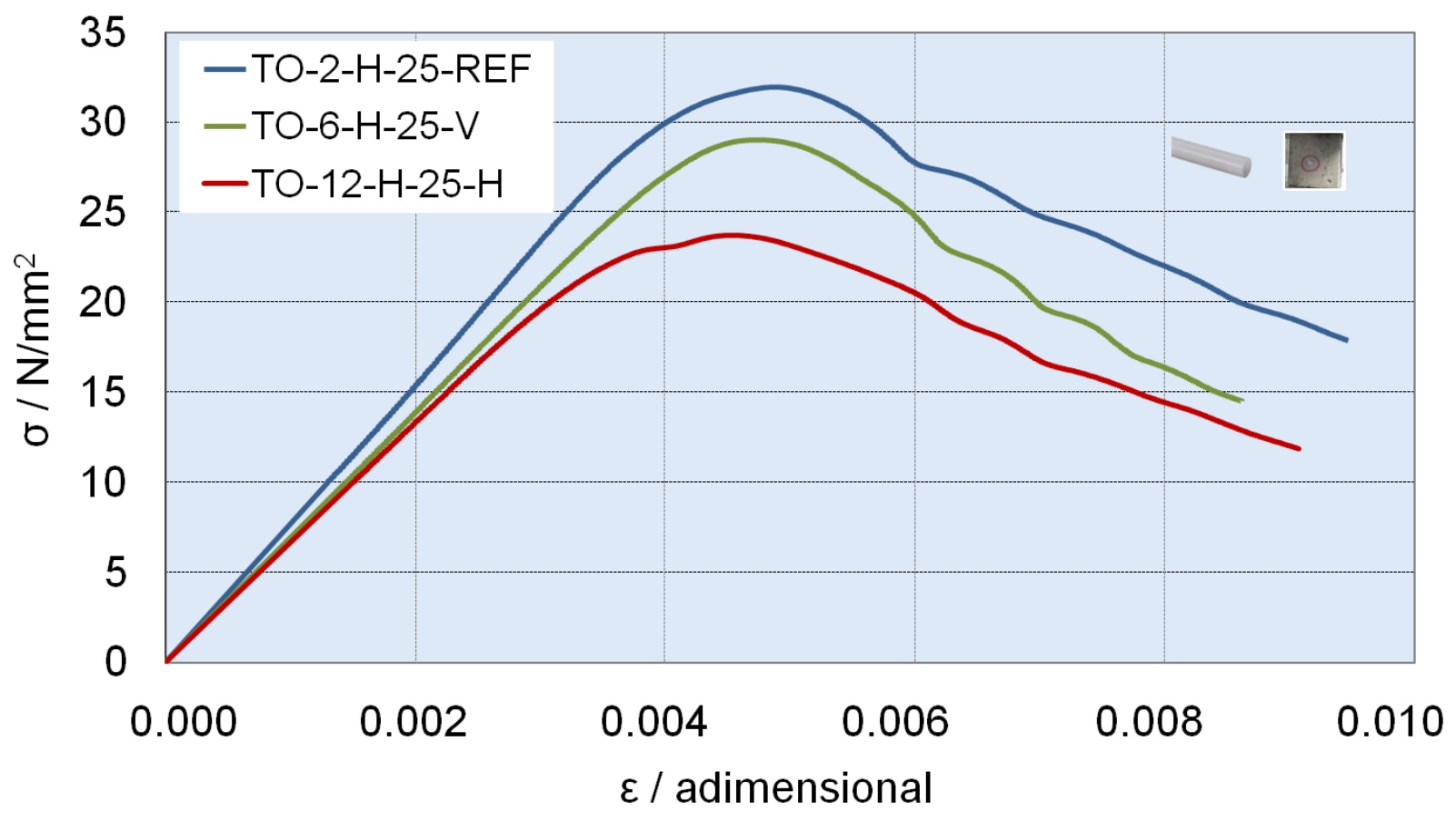

Gráfica 5- 29. Gráfica de evolución de la Tensión $\sigma(\mathrm{N} / \mathrm{mm} 2)$ respecto a la deformación $\varepsilon$ (adimensional) en probetas cúbicas más representativas, para las distintas disposiciones de tubo (vertical, horizontal o sin tubo), realizadas con hormigón $H-25$, ensayadas a compresión. 


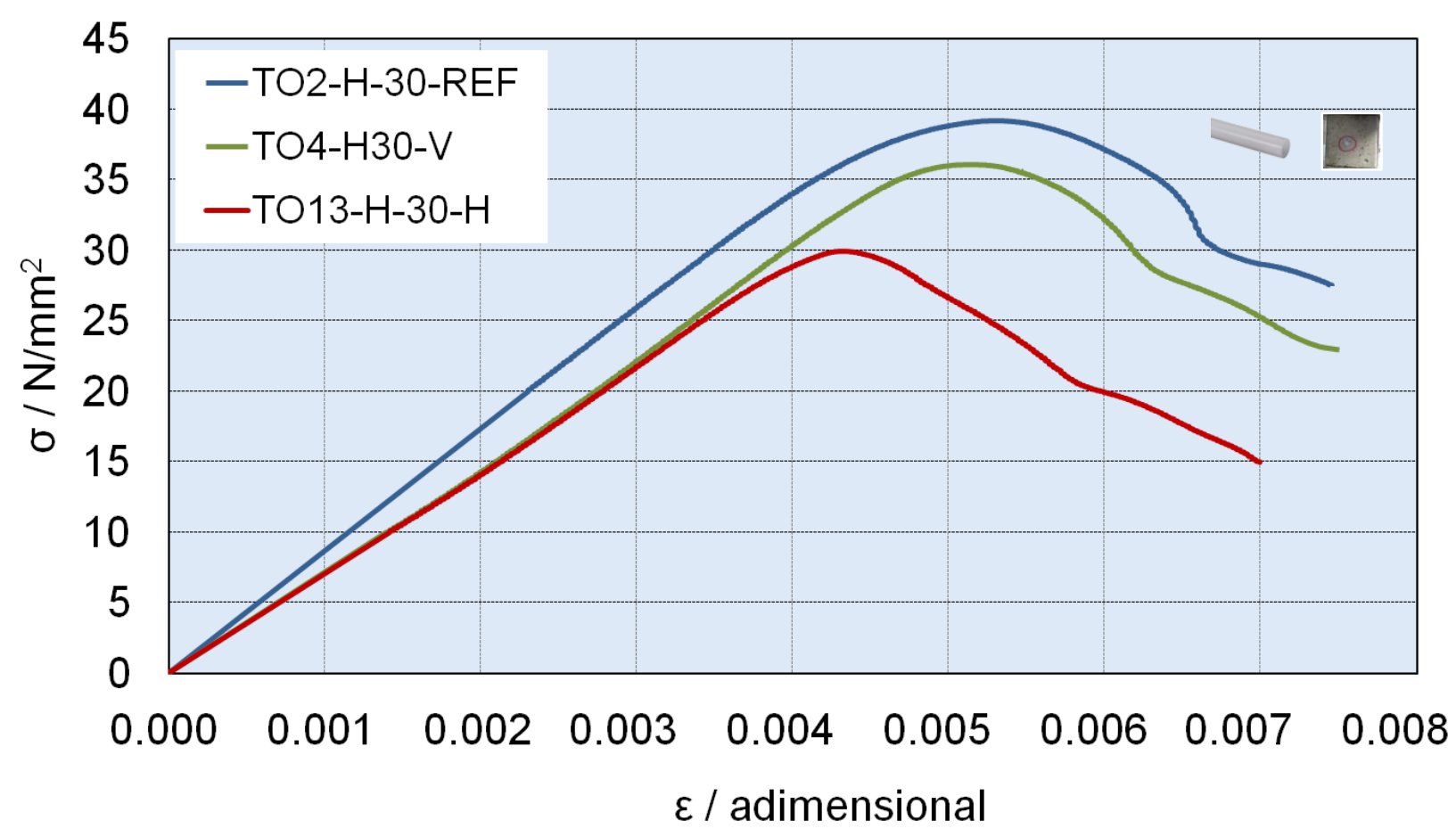

Gráfica 5- 30. Gráfica de evolución de la Tensión $\sigma(\mathrm{N} / \mathrm{mm} 2)$ respecto a la deformación $\varepsilon$ (adimensional) en probetas cúbicas más representativas, para las distintas disposiciones de tubo (vertical, horizontal o sin tubo), realizadas con hormigón H-30, ensayadas a compresión.

Los resultados obtenidos en el ensayo a compresión de las probetas cúbicas, con tubos de polietileno en diferentes posiciones, muestran que cuando el tubo se encuentra dispuesto en posición vertical la tensión máxima es inferior a cuando las probetas no poseen tubo, pero la pérdida de resistencia es mucho menos significativa que cuando el tubo se encuentra en posición horizontal.

5.3.2.2. Estudio comparativo de los resultados $\sigma_{\max }, \varepsilon_{\max }, \varepsilon_{u}, E_{\max }$ y $E_{u}$ obtenidos de la rotura a compresión de las probetas cúbicas con distintas disposiciones de tubo de polietileno. 
A continuación se presentan las gráficas comparativas de los valores que se han obtenido como resultado del ensayo de resistencia a compresión de probetas cúbicas elaboradas con dos hormigones distintos, $\mathrm{H}-25$ y H-30, en los que se han incorporado tubos de PE en dos posiciones distintas; se analiza la relación entre los valores de las probetas sin tubo, las que tienen tubo colocado en posición vertical y las que tienen tubo en posición horizontal.

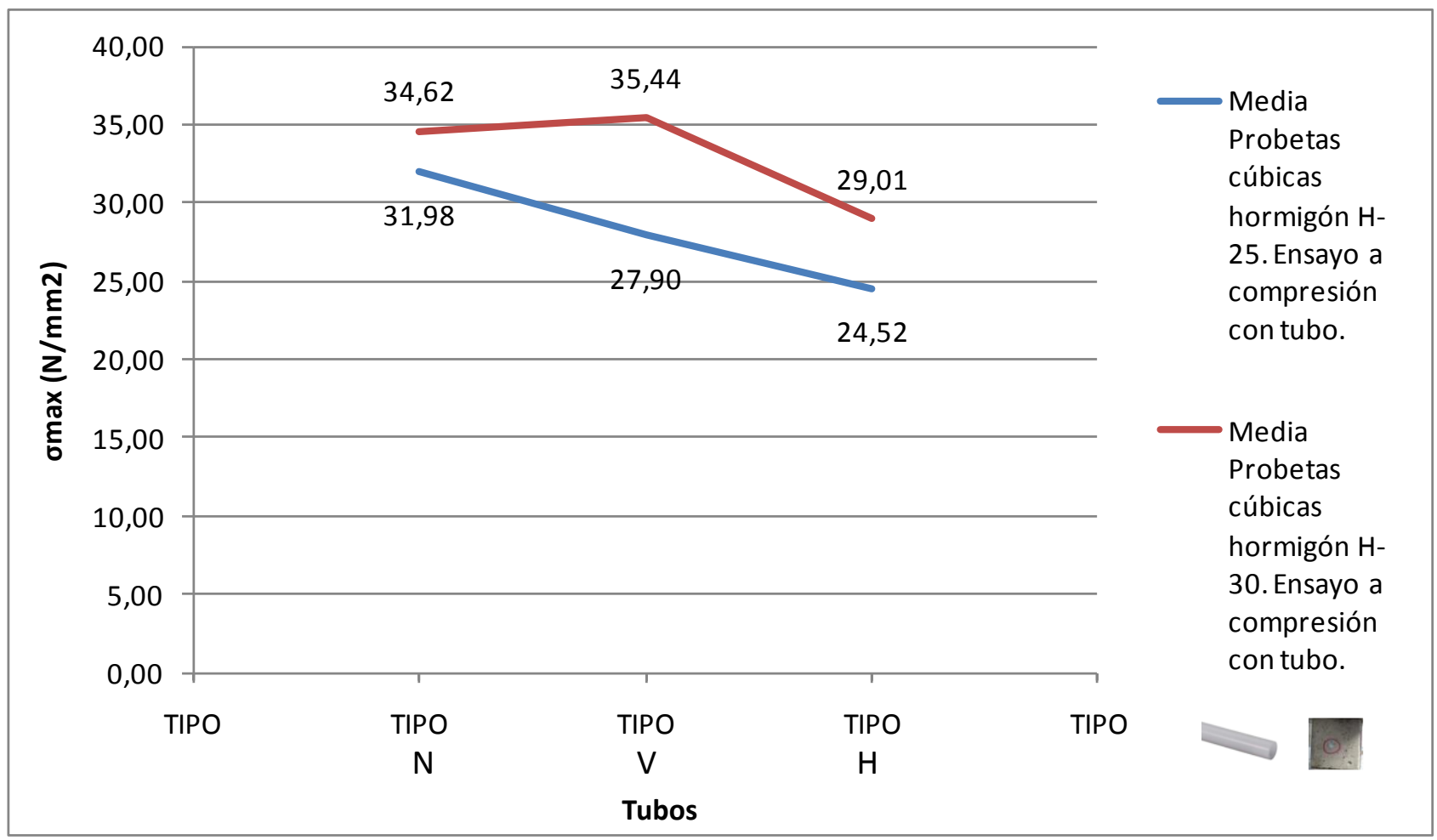

Gráfica 5- 31. Gráfica Tensión $\sigma_{\max }(\mathrm{N} / \mathrm{mm} 2)$ / Tubo PE, de de las medias aritméticas de los resultados de resistencia a compresión de las probetas cúbicas en las que se han colocado los tubos de polietileno con tres variantes distintas, comparando los resultados de hormigón $\mathrm{H}-25$ y del hormigón $\mathrm{H}-30$ ensayados a compresión.

Se observa de una forma generalizada cómo los resultados de tensión máxima para los dos hormigones $(\mathrm{H}-25$ y $\mathrm{H}-30)$ decrecen a medida que los tubos se colocan en las posiciones que se han considerado a priori más desfavorables. En el caso del hormigón H-25 el descenso observado en los valores se realiza de forma proporcional al relacionar los ensayos realizados sin tubo y con tubo vertical, y los de con tubo vertical y con tubo horizontal. 
Los resultados de las probetas realizadas con hormigón $\mathrm{H}-30$ son superiores a los de las probetas realizadas con hormigón H-25.

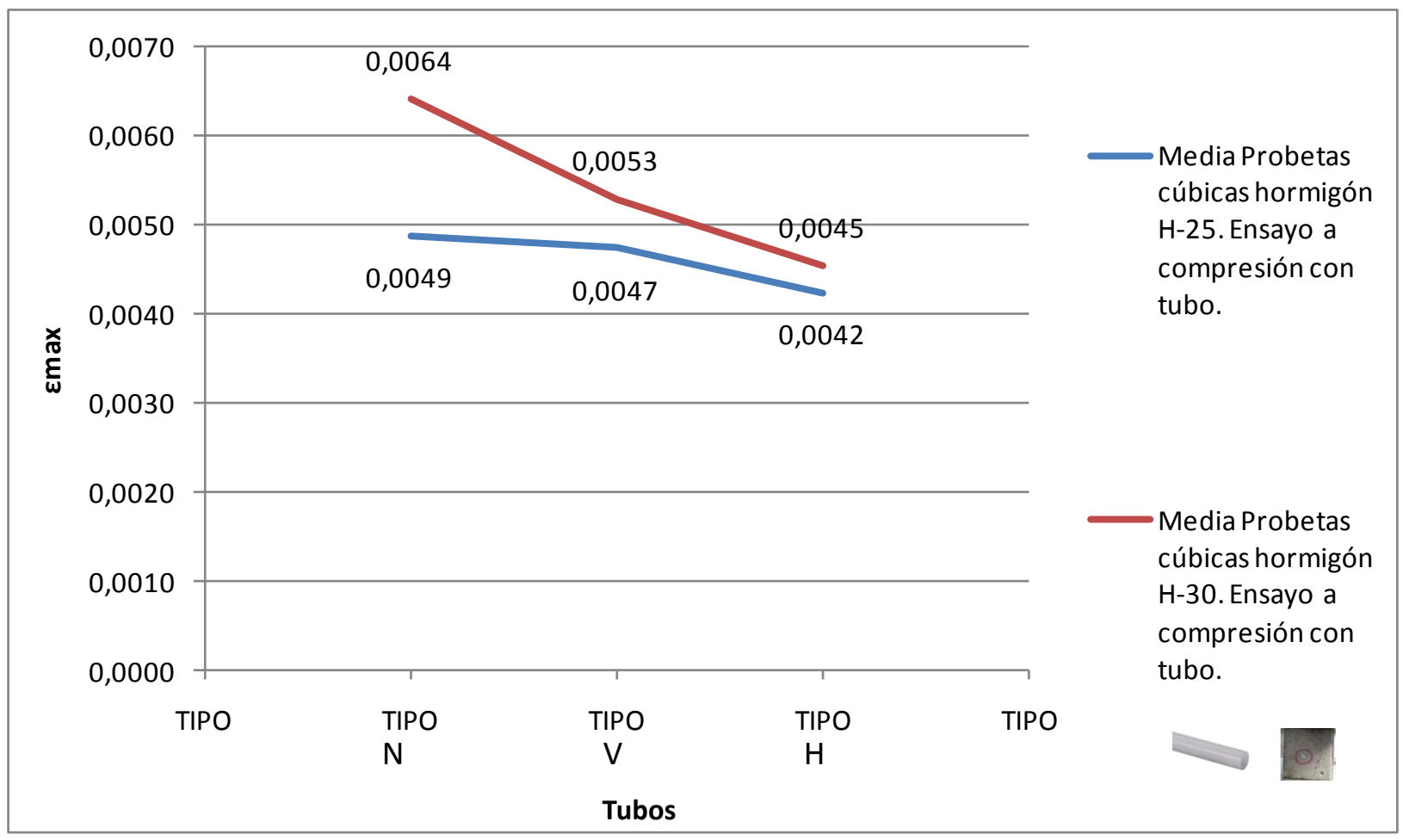

Gráfica 5- 32. Gráfica Deformación máxima $\boldsymbol{\varepsilon}_{\max }$ / Tubo PE, de de las medias aritméticas de los resultados de deformación correspondiente a la máxima tensión de las probetas cúbicas en las que se han colocado los tubos de polietileno con tres variantes distintas, comparando los resultados de hormigón H-25 y del hormigón H-30 ensayados a compresión.

Los resultados de deformación correspondiente a la tensión máxima, son similares a los de tensión para los dos hormigones $(\mathrm{H}-25$ y H-30). Se observa una tendencia a sufrir decremento a medida que la existencia de tubo en el interior de las probetas tiene lugar de forma más desfavorable, es decir, los valores son menores para las probetas con tubo colocado en posición horizontal, mayores para los tubos colocados en posición vertical y superiores a los anteriores en las probetas que no tienen tubo embebido en su interior. 
También en esta grafica los resultados de las probetas realizadas con hormigón H-30 son superiores a los de las probetas realizadas con hormigón $\mathrm{H}-25$.

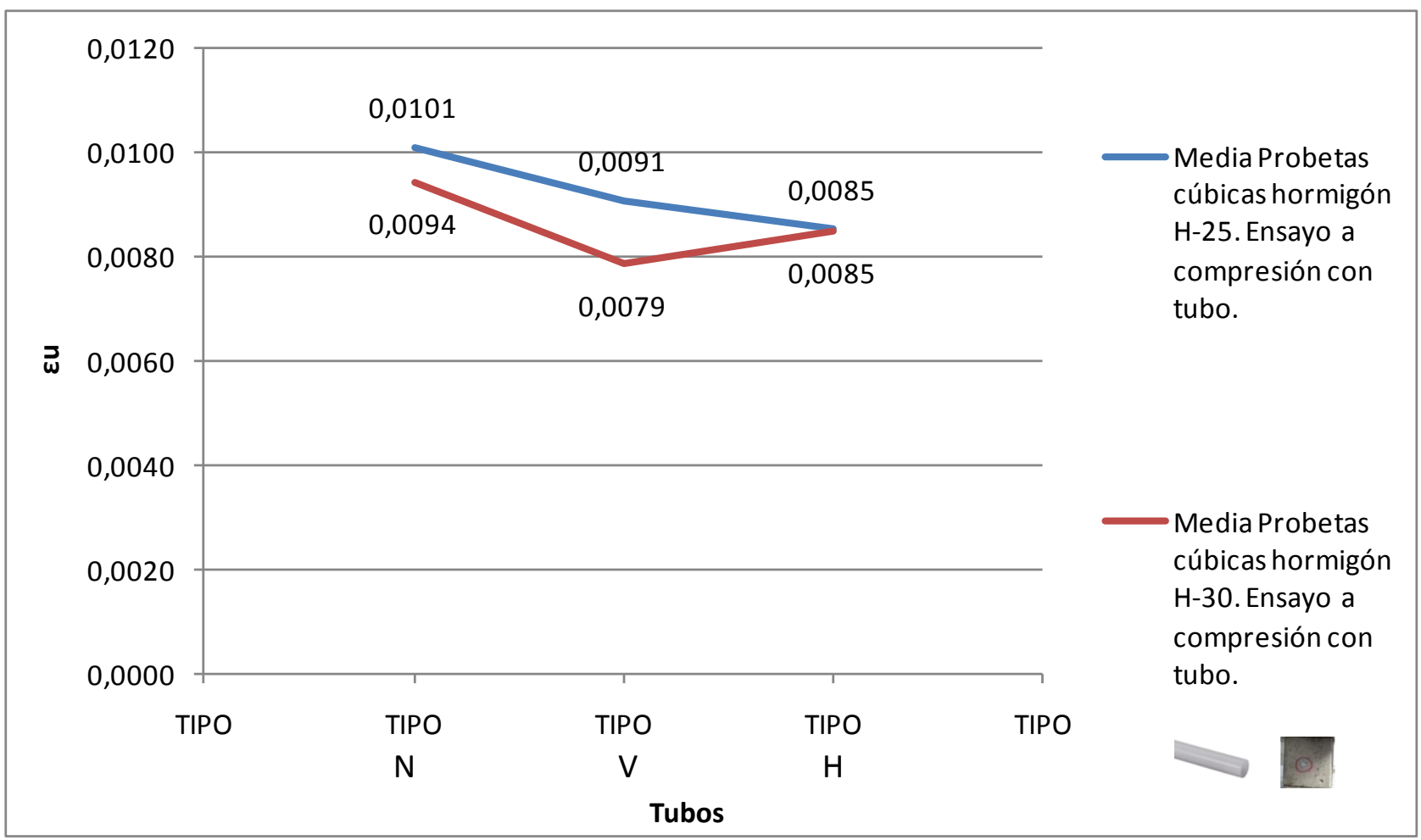

Gráfica 5- 33. Gráfica Deformación última $\varepsilon_{u} /$ Tubo PE, de de las medias aritméticas de los resultados de deformación última de las probetas cúbicas en las que se han colocado los tubos de polietileno con tres variantes distintas, comparando los resultados de hormigón H-25 y del hormigón H-30 ensayados a compresión.

La tendencia de la grafica deformación última es de decrecer en valores a medida que se colocan los tubos en posición vertical y posición horizontal con respecto a las probetas sin tubo.

En la gráfica 5- 33, se observa cómo los resultados de deformación última son superiores para las probetas preparadas con hormigón H-25 en comparación con los de las probetas preparadas con hormigón $\mathrm{H}-30$, cuando en el caso de las deformaciones correspondientes a tensión máxima los valores para hormigón H-30 eran superiores a los correspondientes al hormigón H-25. 


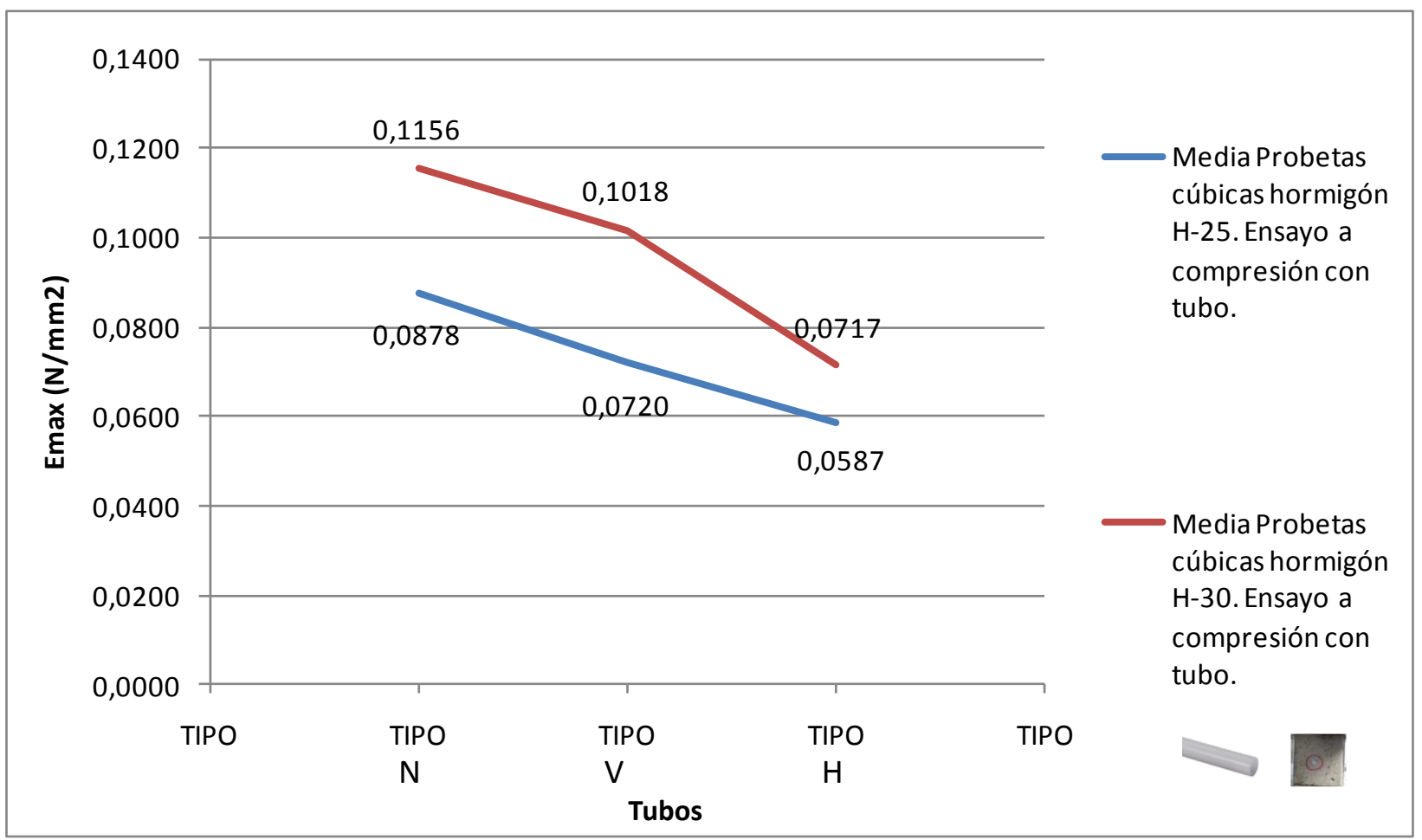

Gráfica 5- 34. Gráfica Energía máxima $E_{\max }\left(\mathrm{N} / \mathrm{mm}^{2}\right) /$ Tubo PE, de de las medias aritméticas de los resultados de energía máxima de las probetas cúbicas en las que se han colocado los tubos de polietileno con tres variantes distintas, comparando los resultados de hormigón H-25 y del hormigón H-30 ensayados a compresión.

Se observa un decremento generalizado en los resultados de energía correspondiente a la zona de gráfica tensión/deformación hasta tensión máxima, para los dos tipos de hormigones utilizados $(\mathrm{H}-25$ y H-30), entre los resultados de probetas sin tubo y los de probetas con tubo colocado en posición vertical y horizontal en este orden.

Además dichos decrementos son proporcionales para los dos hormigones, siendo los resultados superiores para las probetas de hormigón $\mathrm{H}-30$ que para las probetas de hormigón $\mathrm{H}-25$. 


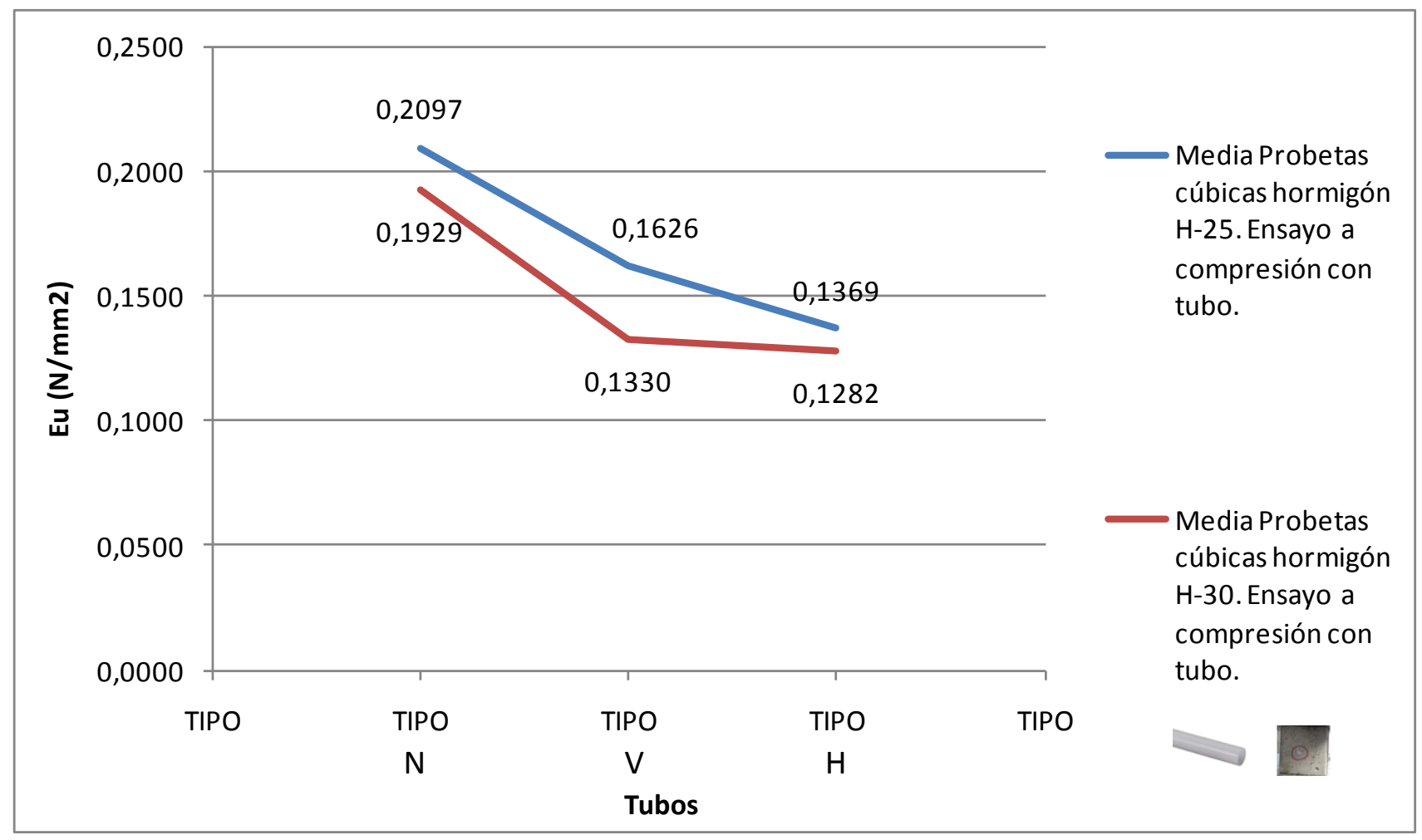

Gráfica 5- 35. Gráfica Energía última $E_{u}\left(\mathrm{~N} / \mathrm{mm}^{2}\right) /$ Tubo PE, de de las medias aritméticas de los resultados de energía última de las probetas cúbicas en las que se han colocado los tubos de polietileno con tres variantes distintas, comparando los resultados de hormigón H-25 y del hormigón H-30 ensayados a compresión.

Los valores de energía correspondientes al área bajo la curva de la gráfica tensión deformación decrecen al colocar el tubo en posición vertical en comparación con los valores de las probetas sin tubo, y también decrecen los de las probetas con el tubo en posición horizontal en comparación con los resultados de las probetas con tubo en posición vertical.

En este caso los decrementos sufridos por los valores también son proporcionales para los dos tipos de hormigón $(\mathrm{H}-25$ y $\mathrm{H}-30)$, pero a diferencia de los observado en la gráfica 5- 34, los resultados para hormigón H-25 son superiores que los de hormigón H-30. 


\subsubsection{Análisis porcentual de las pérdidas de resistencia observadas en los ensayos a compresión de las probetas cúbicas de hormigón $\mathrm{H}-25$ y H- 30 con distintas disposiciones de tubo de polietileno (vertical, horizontal o sin tubo).}

En la tabla 5- 4 y la gráfica 5- 36 se muestra la relación entre la pérdida de resistencia y la disposición del tubo de polietileno, para los hormigones $\mathrm{H}-25$ y H30. Y se representa gráficamente el momento en el que las pérdidas de resistencia superan el $20 \%$.

\begin{tabular}{|c|c|c|}
\hline & $\begin{array}{l}\text { ENSAYO DE } \\
\text { COMPRESIÓN }\end{array}$ & \\
\hline & CÚBICAS & \\
\hline TIPO DE HORMIGÓN & $\begin{array}{c}\text { PÉRDIDAS DE } \\
\text { RESISTENCIA (\%) }\end{array}$ & POSICIÓN DEL TUBO \\
\hline H-25 & 0,00 & \multirow{2}{*}{ SIN TUBO } \\
\hline $\mathrm{H}-30$ & 0,00 & \\
\hline $\mathrm{H}-25$ & 12,76 & \multirow{2}{*}{ VERTICAL } \\
\hline $\mathrm{H}-30$ & 6,37 & \\
\hline $\mathrm{H}-25$ & 23,33 & \multirow{2}{*}{ HORIZONTAL } \\
\hline $\mathrm{H}-30$ & 16,20 & \\
\hline
\end{tabular}

Tabla 5- 4. Pérdidas de resistencia en tanto por ciento en hormigones $\mathrm{H}-25$ y $\mathrm{H}$ 30 , ensayados a compresión, en función de la disposición de tubo.

Como se puede observar, del análisis se desprende cómo la introducción de tubos poliuretano en el hormigón disminuye su resistencia en las probetas cúbicas, produciéndose las mayores pérdidas cuando el tubo se encuentra en posición horizontal, es decir, perpendicular a la carga, alcanzado pérdidas de resistencia superiores al $20 \%$ para hormigón $\mathrm{H}-25$. 


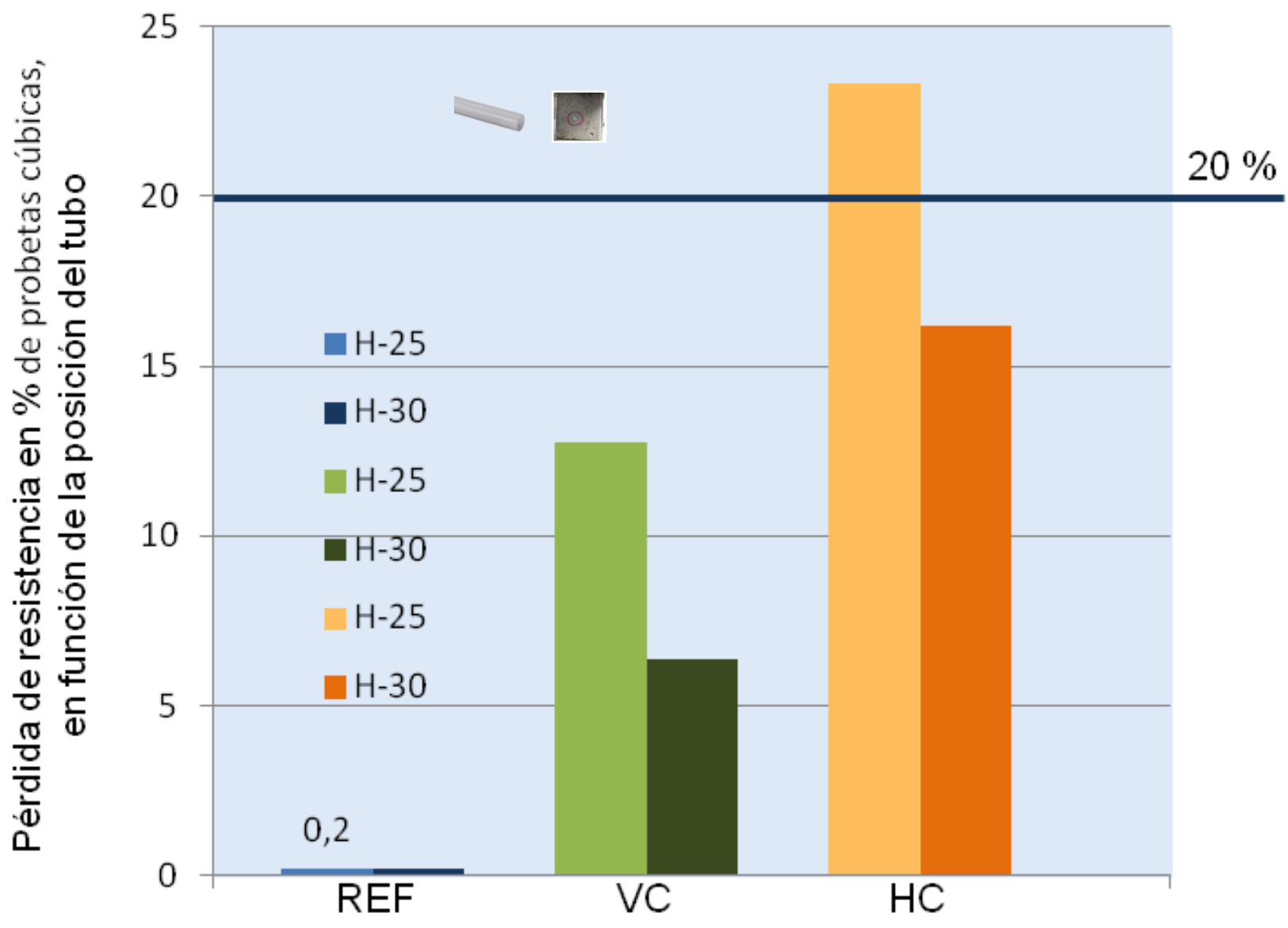

Gráfica 5- 36. Gráfica de análisis porcentual de pérdidas de resistencia en función de la disposición de tubo de polietileno en el interior de las probetas cúbicas, ensayadas a compresión, para hormigones $\mathrm{H}-25$ y H-30.

5.3.2.5. Análisis gráfico comparativo de la evolución de la energía última obtenido en los ensayos de resistencia a compresión de las probetas cúbicas de hormigón H-25 y H-30 con distintas disposiciones de tubo de polietileno (vertical, horizontal o sin tubo).

La gráfica 5- 37 muestra los valores de la energía última (Eu) en función del tipo de hormigón y de la disposición de los tubos de las probetas cúbicas ensayadas a compresión. 


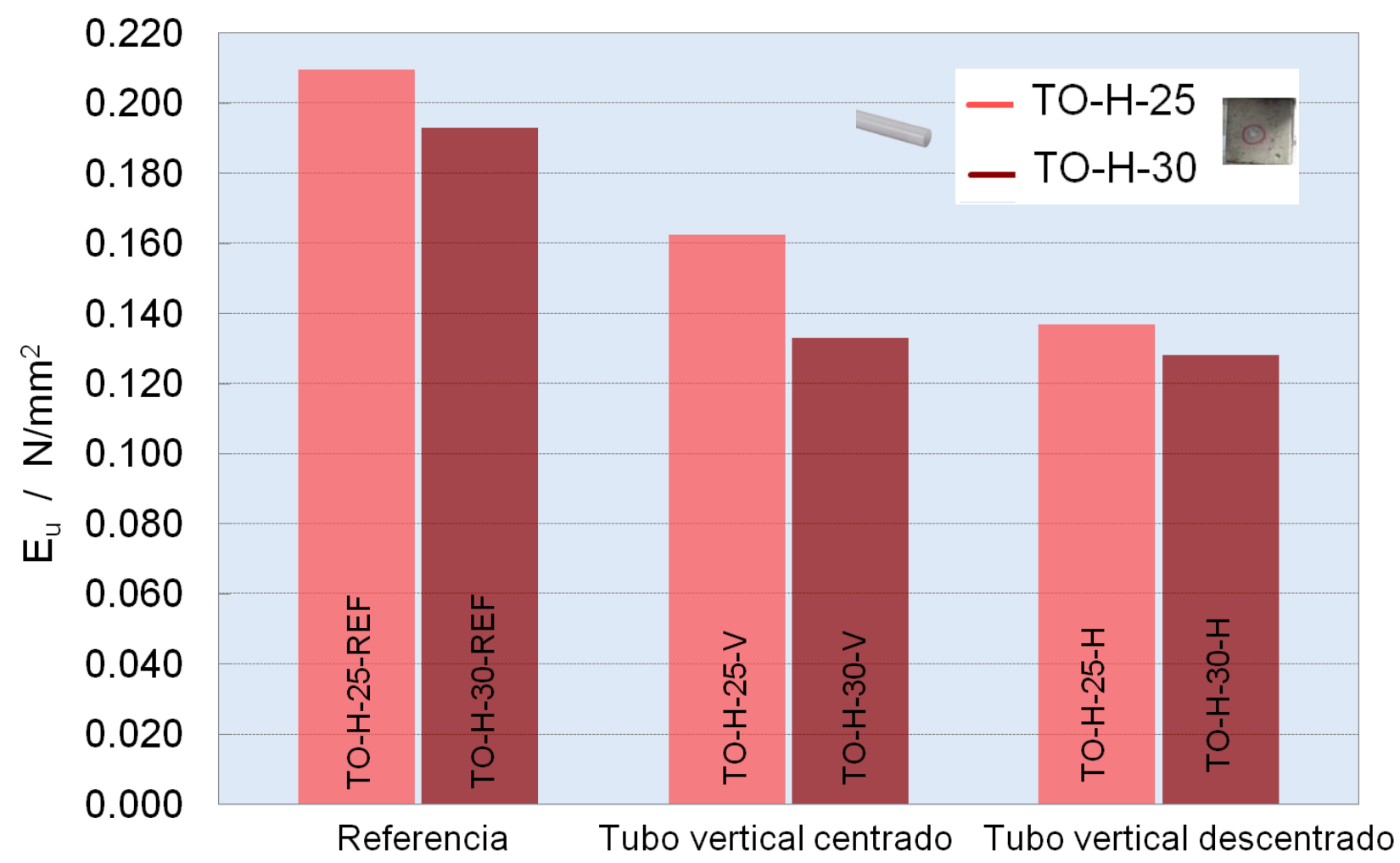

Gráfica 5- 37. Gráfica de energía última en probetas cúbicas en función de la disposición de tubo de polietileno en su interior, ensayadas a compresión, para hormigones $\mathrm{H}-25$ y $\mathrm{H}-30$.

Del gráfico se desprende le hecho de que el valor de la energía última de deformación es prácticamente lineal en las probetas cúbicas, siendo mayores en el hormigón $\mathrm{H}-30$ y en las probetas sin tubo. Disminuye la energía cuando se introduce el tubo en posición vertical, y se reduce aún más si el tubo se encuentra en posición horizontal. 


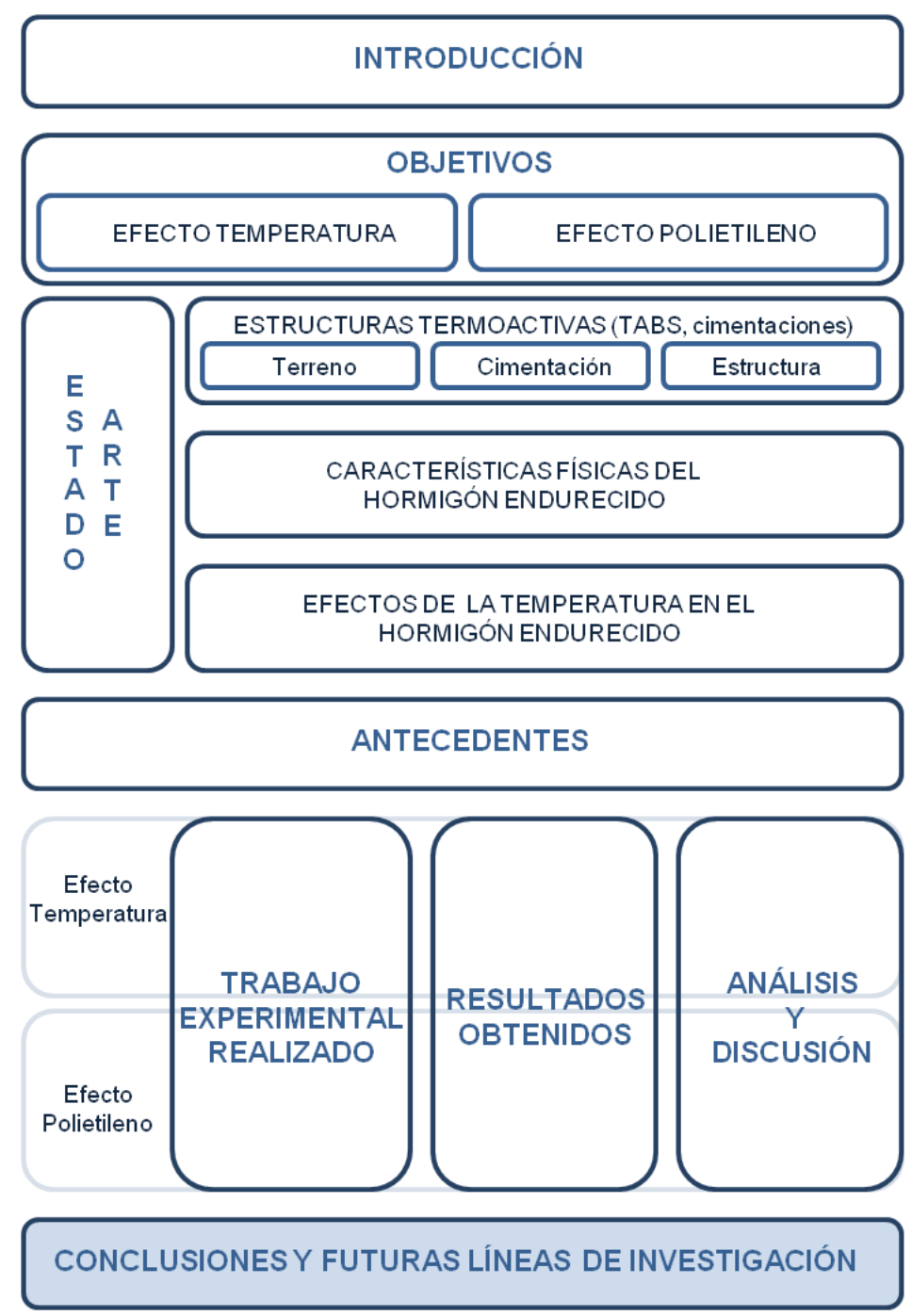

CAPÍTULO 6

CONCLUSIONES 


\subsection{Conclusiones generales}

Se puede concluir de forma general que los resultados de resistencia a compresión y adherencia obtenidos en los ensayos realizados, son de valor superior para todos especímenes elaborados con hormigón H-30, en comparación con los resultados de las probetas realizadas con hormigón H-25.

También se puede concluir que el incremento de la temperatura provoca una disminución de las propiedades mecánicas del hormigón. En los ensayos realizados, se ha apreciado que dicha disminución es más acusada en las probetas de hormigón H-30 que en las probetas de hormigón H-25.

Con respecto a los ensayos realizados en probetas en las que se han integrado tubos de polietileno, se puede observar como las resistencias a compresión obtenidas en los ensayos realizados en probeta cúbica son en todos los casos superiores a las obtenidas en probeta cilíndrica, tal y como han concluido otros investigadores.

Así mismo, la presencia del tubo de polietileno en el interior de las muestras ejerce un efecto adverso en el comportamiento mecánico de las mismas, siendo éste más acusado cuando el tubo está dispuesto en posición perpendicular a la de aplicación de la carga, que cuando está colocado en la misma dirección. 


\subsection{Conclusiones sobre el efecto de la temperatura $\left(20^{\circ}, 40^{\circ}, 70^{\circ}\right.$ y $\left.100^{\circ} \mathrm{C}\right)$} en las estructuras de hormigón armado utilizadas como elementos termoactivos.

El incremento de temperatura disminuye las propiedades mecánicas del hormigón, independientemente del tipo de hormigón empleado.

En los análisis realizados con probetas cilíndricas ensayadas a compresión y con probetas cúbicas ensayadas a arrancamiento o pull-out, las pérdidas de resistencia debidas al sometimiento de las probetas de hormigón endurecido a temperaturas de $20^{\circ}, 40^{\circ}, 70^{\circ}$ y $100^{\circ} \mathrm{C}$, sufren un incremento más acusado cuando las probetas alcanzan los $70^{\circ} \mathrm{C}$. Es a partir de esa temperatura cuando las pérdidas de resistencia alcanzan, o en algunos casos, sobrepasan el $20 \%$.

Por lo tanto, para garantizar que la resistencia del hormigón de las estructuras termoactivas no disminuya en porcentajes superiores al $20 \%$, es recomendable que la temperatura del fluido caloportador sea inferior a $70^{\circ} \mathrm{C}$.

Dado que las estructuras termoactivas están ideadas para trabajar como sistemas de acumulación térmica de baja temperatura para calefacción (16ํㅡ$\left.20^{\circ} \mathrm{C}\right)$ y alta temperatura para refrigeración $\left(25^{\circ} \mathrm{C}-30^{\circ} \mathrm{C}\right)$, en principio las temperatura del fluido caloportador no superará los $55^{\circ} \mathrm{C}$, por lo que es razonable asumir que los cambios de temperaturas producidos por esta tecnología no comprometen las propiedades mecánicas del hormigón con disminuciones de resistencia superiores al $20 \%$.

\subsection{Conclusiones sobre el efecto de la incorporación de tubos de polietileno en las estructuras de hormigón armado utilizadas como elementos termoactivos.}

La incorporación de tubos de polietileno en el interior de las probetas reduce su capacidad mecánica, siendo esta reducción más acusada cuando el tubo se encuentra en posición perpendicular a la aplicación de la carga. 
En los análisis realizados con probetas cilíndricas y cúbicas ensayadas a compresión con tubos de polietileno integrados en su interior en distintas posiciones, con el fin de estudiar todas las posibilidades de posicionamiento de tubo con respecto a la dirección de la carga que tendrían lugar en una losa trabajando a flexión, se observa que as pérdidas de resistencia sufren un incremento más acusado cuando existe incorporación de tubo con respecto a las probetas sin tubo, y este es mucho más desfavorable, sobrepasando el $20 \%$ de pérdidas, cuando el tubo está ubicado en posición horizontal.

Por lo tanto, para garantizar que la resistencia del hormigón de las estructuras termoactivas no disminuya en porcentajes superiores al $20 \%$, es recomendable que en la medida de lo posible, se dispongan los tubos de polietileno en la dirección paralela a la carga. 


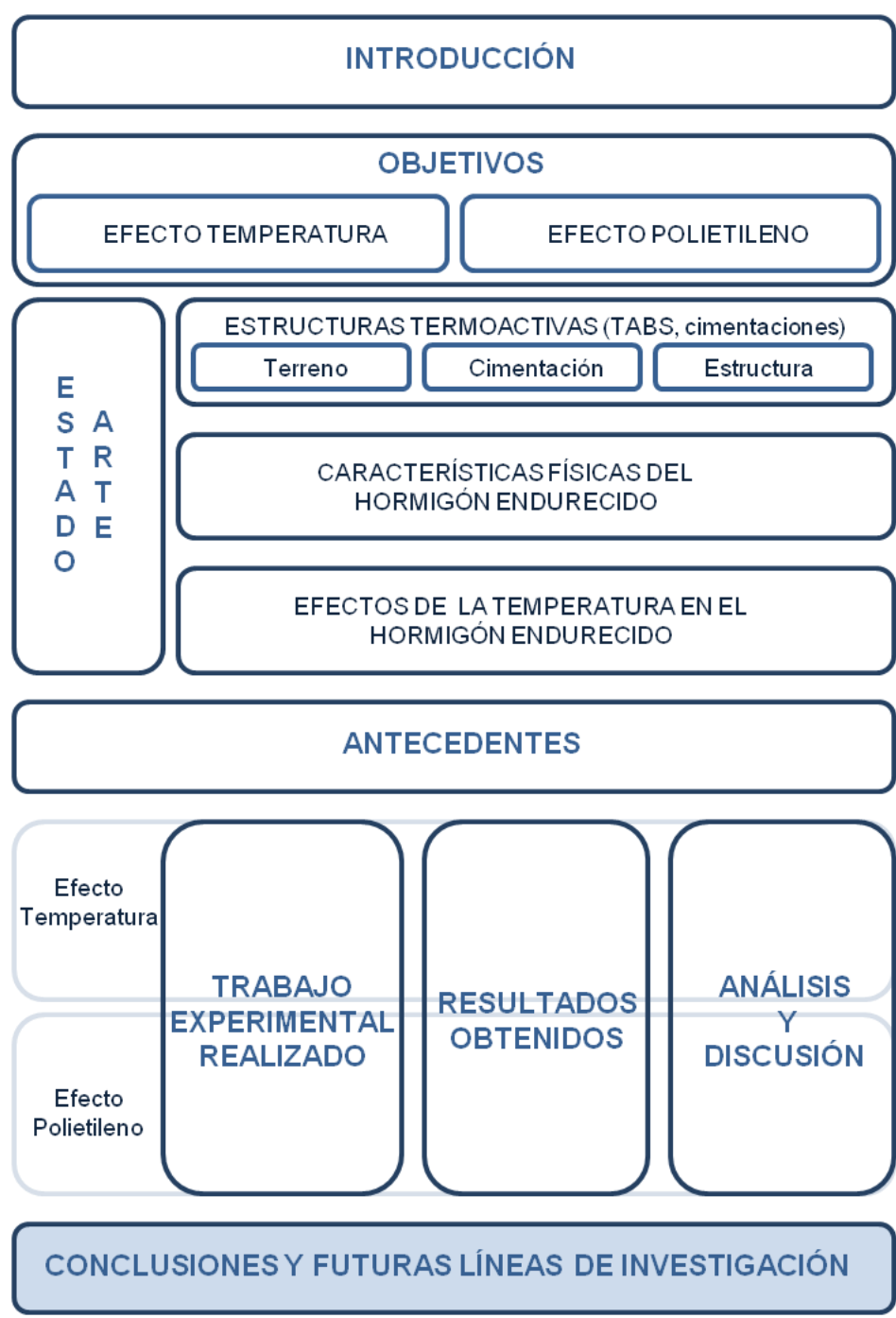

CAPÍTULO 7

FUTURAS

LINEAS DE

INVESTIGACIÓN 


\subsection{Introducción}

Habida cuenta de las incógnitas que aún quedan por despejar, y teniendo en cuenta que los resultados obtenidos en éste trabajo proceden de un limitado número de ensayos, sería conveniente ampliar la campaña experimental.

7.2 Futuras líneas de investigación sobre el efecto de la temperatura y la incorporación de tubos de polietileno en las estructuras de hormigón armado utilizadas como elementos termoactivos.

7.2.1 Futuras líneas de investigación sobre el efecto de la temperaturas en las estructuras de hormigón armado utilizadas como elementos termoactivos, utilizando probetas cilíndricas para analizar su resistencia a compresión en función de la temperatura.

Repetir la campaña experimental realizando probetas iguales a las de las amasadas 1, 2, 3 y 4 para hormigón $\mathrm{H}-25$ y H-30 utilizando en su elaboración árido 
calizo, como árido grueso, en lugar de árido silíceo, con el fin de determinar cómo afecta a la resistencia a compresión y a la adherencia la diferencia de árido.

Aunque se utilicen los mismos condicionantes de este estudio, convendría que se realizaran 3 probetas más de cada tipo, en el caso de las que deben ser ensayadas a distintas temperaturas, con el fin de añadir como temperatura de ensayo la de $0^{\circ} \mathrm{C}$, ya que existen muchas posibilidades de que el fluido caloportador que circula por los tubos de polietileno llegue a tener la temperatura mencionada.

Se propone también, realizar los ensayos una vez haya transcurrido un periodo superior a 5 meses, en las primeras amasadas, para averiguar si la edad del hormigón influye en los resultados obtenidos en el trabajo realizado hasta la fecha y determinar la edad a la que se deben realizar los ensayos en las probetas del resto de amasadas.

Por lo tanto, se realizarán las probetas teniendo en cuenta las variables: distintos tipos de probeta (cilíndrica y cúbica), distintos tipos de hormigón (H-25 y $\mathrm{H}-30$ ), distintos tipos de árido (calizo o silíceo), distintas posiciones de tubo y distintas temperaturas $\left(0^{\circ}, 20^{\circ}, 40^{\circ}, 70^{\circ}\right.$ y $\left.100^{\circ} \mathrm{C}\right)$.

\subsubsection{Futuras líneas de investigación sobre el efecto conjunto de la} temperatura y de la incorporación de tubo de polietileno en las estructuras de hormigón armado utilizadas como elementos termoactivos, utilizando probetas cúbicas con armadura corrugada anclada y tubo de polietileno, para analizar su adherencia por medio de ensayos a arrancamiento o pull-out en función de la temperatura.

Continuar la campaña experimental de probetas para realizar ensayos de rotura a arrancamiento "pull-out", con el fin de determinar cuál es la adherencia existente entre la armadura corrugada anclada a la probeta y el hormigón de la misma (para hormigón H-25 y hormigón H-30 y para árido calizo y árido silíceo), y como se ve influenciada dicha adherencia por la colocación de los tubos de polietileno dispuestos en las posiciones vertical y horizontal, pegada a la barra de acero y separada de la barra de acero realizando, con las misma amasadas, probetas cilíndricas para romper en ensayo a compresión y servir como resistencia de referencia. 
7.2.3 Futuras líneas de investigación sobre el efecto conjunto de la temperatura y de la incorporación de tubo de polietileno en las estructuras de hormigón armado utilizadas como elementos termoactivos, utilizando probetas cilíndricas con tubo de polietileno incorporado, para analizar su resistencia a compresión en función de la temperatura.

Continuar la campaña experimental de probetas para realizar ensayos de rotura a compresión, incorporando tubos de polietileno en posición vertical centrada, vertical descentrada, horizontal y sin tubo, (para hormigón $\mathrm{H}-25$ y hormigón $\mathrm{H}-30$ y para árido calizo y árido silíceo), y someter a las probetas al aumento de temperatura de $0^{\circ}, 20^{\circ}, 40^{\circ}, 70^{\circ}$ y $100^{\circ} \mathrm{C}$, con el fin de poder establecer como su resistencia se ve influenciada por los dos factores a la vez, temperatura y posición del tubo.

7.2.4 Futuras líneas de investigación sobre el efecto por separado de la temperatura y de la incorporación de tubo de polietileno en las estructuras de hormigón armado utilizadas como elementos termoactivos, utilizando vigas armadas con tubo de polietileno incorporado, para analizar su resistencia a flexión en función de la temperatura como estudio independiente.

Comenzar una campaña experimental de vigas armadas en las que se pueda analizar de forma independiente la influencia del aumento de temperatura y de la disposición de los tubos en su interior ensayándolas a flexión, para distintos tamaños de viga, distintas cuantías de armado (baja, media y alta), distintos tipos de hormigón (H-25 y H-30), distintos tipos de árido (calizo o silíceo), distintas posiciones de tubo y distintas temperaturas $\left(0^{\circ}, 20^{\circ}, 40^{\circ}, 70^{\circ}\right.$ y $\left.100^{\circ} \mathrm{C}\right)$.

7.2.5 Futuras líneas de investigación sobre el efecto conjunto de la temperatura y de la incorporación de tubo de polietileno en las estructuras de hormigón armado utilizadas como elementos termoactivos, utilizando vigas armadas con tubo de polietileno incorporado, para analizar su resistencia a flexión en función de la temperatura como estudio en conjunto. 
Analizar el comportamiento de las estructuras de hormigón termoactivas, utilizando una serie de vigas armadas elaboradas en el laboratorio, en las que previamente se hayan introducido los tubos de polietileno, y se realice su ensayo a flexión mientras se hace circular un fluido caloportador por el interior de los tubos a temperaturas de $0^{\circ}, 2^{\circ}, 40^{\circ}, 70^{\circ}$ y $100^{\circ} \mathrm{C}$, considerando las variables: distintos tamaños de viga, distintas cuantías de armado (baja, media y alta), distintos tipos de hormigón ( $\mathrm{H}-25$ y H-30), distintos tipos de árido (calizo o silíceo) y distintas posiciones de tubo. 


\section{CAPÍTULO 8}

FUENTES

BIBLIOGRÁFICAS 


\subsection{Bibliografía, normativa y legislación consultada}

- ACI 318-08. (2008) American Concrete Institute. 2008 Building code requirements for structural concrete and commentary.

- AENOR (Asociación Española de Normalización y Certificación) UNEEN 12390-1: 2001. Ensayos de hormigón endurecido. Parte 1: Forma, medidas y otras características de las probetas y moldes. AEN/CTN 83 - Hormigón. Madrid-España.

- AENOR (Asociación Española de Normalización y Certificación) UNEEN 12390-1: 2001 / AC: 2005. Erratum. Ensayos de hormigón endurecido. Parte 1: Forma, medidas y otras características de las probetas y moldes. AEN/CTN 83 - Hormigón. Madrid-España.

- AENOR (Asociación Española de Normalización y Certificación) UNEEN 197-1:2000/A3:2008 Cemento. Parte 1: Composición, especificaciones y criterios de conformidad de los cementos comunes. AEN/CTN 83 - Hormigón. Madrid-España.

- AENOR (Asociación Española de Normalización y Certificación) UNEEN 12390-2: 2009 Ensayos de hormigón endurecido, Parte 2: Fabricación y curado de probetas para ensayos de resistencia. AEN/CTN 83 - Hormigón. Madrid-España.

- AENOR (Asociación Española de Normalización y Certificación) UNE 83506: 2004 Hormigones con fibras. Refrentado de probetas con mortero de azufre. AEN/CTN 83 - Hormigón. Madrid-España.

- AENOR (Asociación Española de Normalización y Certificación) UNEEN 12390-3: 2009 Ensayos de hormigón endurecido, Parte 3: Determinación de la resistencia a compresión de probetas. MadridEspaña.

- AENOR (Asociación Española de Normalización y Certificación) UNEEN 12390-4: 2001 Ensayos de hormigón endurecido, Parte 4: Resistencia a compresión. Características de las máquinas de ensayo. AEN/CTN 83 - Hormigón. Madrid-España.

- AENOR (Asociación Española de Normalización y Certificación) UNE 83316, 1996 Ensayos de hormigón. Determinación del modulo de elasticidad en compresión. AEN/CTN 83 - Hormigón. Madrid-España. 
- AENOR (Asociación Española de Normalización y Certificación) UNEEN 12350-2, 2009 Ensayos de hormigón fresco: Ensayo de asentamiento. AEN/CTN 83 - Hormigón. Madrid-España.

- AENOR (Asociación Española de Normalización y Certificación) UNEEN 12504-3: 2006 Ensayos de hormigón en estructuras. Parte 3: Determinación de la fuerza de arrancamiento. AEN/CTN 83 Hormigón. Madrid-España.

- AENOR (Asociación Española de Normalización y Certificación) UNEEN 36740: 1998 Determinación de la adherencia de las barras y alambres de acero para armaduras de hormigón armado. Ensayo de la viga. AEN/CTN 83 - Hormigón. Madrid-España.

- AENOR (Asociación Española de Normalización y Certificación) UNEEN 1264-5:2009 Sistemas de calefacción y refrigeración de circulación de agua integrados en superficies. Parte 5: Suelos, techos y paredes radiantes. Determinación de la emisión térmica. AEN/CTN $83-$ Hormigón. Madrid-España.

- AENOR (Asociación Española de Normalización y Certificación) UNEEN 1264-4:2010 Sistemas de calefacción y refrigeración de circulación de agua integrados en superficies. Parte 4: Instalación. AEN/CTN 83 Hormigón. Madrid-España.

- ASTM C39, (1988) Test method for compressive strength of cylindrical concrete specimens, Annual Book of ASTM Standards, volume 04.02, p. 19.

- Bailey and Toh (2007a) A Study of Breakdown in Concrete. American Concrete Institute, Farmington Hills, MI, USA, Report STP 67, pp. 1-10.

- Comisión Europea. The 2020 climate and energy package. http://ec.europa.eu/clima/policies/package/index en.htm. Consultado por última vez 13/09/2014

- Código Técnico de la Edificación, CTE (2006).

- Conde, E., Ramos, A., Reina, P., y Vega, A., (2009), Guía técnica de bombas de calor geotérmicas. CM y Fenercom. ISBN: 978-84-6129142-7 España.

- Conde, E., Ramos, A., Reina, P., y Vega, A., (2009), Guía técnica de bombas de calor geotérmicas. CM y Fenercom. ISBN: 978-84-6129142-7 España. 
- De Isabel, J.A.(2009). Guía Técnica sobre Pilotes Geotérmicos. CM y Fenercom. ISBN: 978-84-612-9137-3. España.

- De Pereda, L., Widerin, B., Hendriks, M., Fernandez, J., Catalán, E., Stuki, B., Cubillo, J.M., y Cuesta, M.A., (2011), Guía sobre aprovechamiento energético de las infraestructuras subterráneas. CM y Fenercom. ISBN: 978-84-614-1418-5 España.

- Directiva 2010/31/UE del Parlamento Europeo y del Consejo de 19 de mayo de 2010 relativa a la eficiencia energética de edificios

- Directiva 2012/27/UE del Parlamento Europeo y el Consejo de 25 de octubre de 2012, relativa a la eficiencia energética

- EHE (2008). Instrucción de hormigón estructural. Comisión permanente del hormigón. Ministerio de Fomento. España.

- EN ISO 7730. CEN (European committee for standardization) (2005) Ergonomics of the thermal environment - Analytical determination and interpretation of thermal-comfort using calculation of the PMV and PPD indices and local thermal-comfort criteria.

- Eurocódigo 2 (1992). Estructuras de hormigón. AENOR. España.

- Instrucción para la recepción de cementos. RC-08 (2008). España.

- Llopis. G. y López, C., (2009), Guía técnica de sondeos geotérmicos superficiales. CM y Fenercom. ISBN: 978-84-612-9136-6 España.

- Naciones Unidas. Protocolo de Kyoto de la Convención Marco de las Naciones Unidas sobre el cambio climático. 1998.

- Naciones Unidas. Convención Marco de las Naciones Unidas sobre el cambio climático. 1992.

- Naciones Unidas. La Puerta Climática de Doha. http://unfccc.int/portal espanol/informacion basica/la puerta climatica de doha/items/7477.php. Consultado por última vez 25/08/2014.

- Reglamento de Instalaciones Térmicas de los Edificios, RITE (2007).

- Ruiz, E., Hendriks, M., Toimil, D., (2010), Guía técnica de los sistemas geotérmicos abiertos. CM y Fenercom. ISBN: 978-84-614-1418-5 España.

- SIA 384/6 Societe suisse des ingenieurs et des architectes (2010) 546 384/6 SN , Sondes géothermiques. Suiza. 
- SIA D0190 Societe suisse des ingenieurs et des architectes (2005), Utilisation de la chaleur du sol par des ouvrages de fondation et de soutenement en beton. ISBN: 3-908483-59X

- VDI 4640. Verein Deutscher Ingenieure (Diciembre 2000). Parte 1: Thermal use of the underground. Fundamentals, approvals, environmental aspects. ICS 27.080. Alemania.

- VDI 4640. Verein Deutscher Ingenieure (Septiembre 2001). Parte 2: Thermal use of the underground Ground source heat pump systems. ICS 27.080. Alemania.

- VDI 4640. Verein Deutscher Ingenieure (Junio 2001). Parte 3: Utilization of the subsurface for thermal purposes Underground thermal energy storage. ICS 27.080. Alemania.

- VDI 4640. Verein Deutscher Ingenieure (Septiembre 2004). Parte 4: Thermal use of the underground direct uses. ICS 27.080. Alemania.

\subsection{Bibliografía citada}

[1] Abrams MS (1971) Compressive strength of concrete at temperatures to 1600F. ACI SP 25, temperature and Concrete. American Concrete Institute, Detroit Michigan, USA.

[2] Abrams, M.S., (1973), Temperature and concrete. ACI SP-25 33-50

[3] Abuel-Naga D.T., Bergado A. and Bouazz A. (2007) Thermally induced volume change and excess pore water pressure of soft Bangkok clay. Engineering Geology 89: 144-154.

[4] Alonso E., Vaunat J., and Gens A., (1999). Modeling the mechanical behaviour of expansive clays. Engineering Geology 54: 173-183.

[5] Amatya B.L.,, Soga K and Bourne-Webb PJ (2012) Thermo-mechanical behaviour of energy piles. Géotechnique 62(6): 50-519.

[6] Arioz, O., (2007), Effects of elevated temperaturas on properties of concrete. Fire Safety Journal 42 516-522. 
[7] Artmann, N., Manz, H., Heiselberg, P. (2007) Climatic potential for passive cooling of buildings by night-time ventilation in Europe. Applied Energy 84 Issue 2: 187-201.

[8] Bary, B., Ranc, G., Durand, S. and Capentier, O., (2008) A coupled thermohydro-mechanical-damage model for concrete subjected to moderate temperatures. International Journal of Heat and Mass Transfer 51: 2847-2862.

[9] Basecq V., Michaux G., Inard C., and Blondeau P., (2013) Short-term storage systems of thermal energy for buildings: a review. Advances in Building Energy Research 7(1): 66-119.

[10] Bazant ZP, T. W. (1985). Practical prediction of cyclic humidity effect in creep and shrinkage of concrete. Materials and Structures, 18(4), 247-252. doi:10.1007/BF02472911

[11] Bazant, Z. P., \& Kaplan, M. F. (1996). Concrete at high temperatures: Material properties and mathematical models Longman Group Limited.

[12] Bingol, A.F:, and Gül, Rüstem, (2009), Residual bond strength between steel bars and concrete after elevated temperatures. Fire Safety Journal 44: 854859.

[13] Bizzotto, M.B., Astori, R.E., Sanguinetti, B.M., (2005), Influencia del curado en el desarrollo de la resistencia compresiva de hormigones de alto desempeño. Universidad Nacional del Nordeste. Comunicaciones Científicas y Tecnológicas.

[14] Bouazaoui, L. and Li, A. (2007), Analysis of steel/concrete interfacial shear stress by means of pull out test. International Journal of Adhesion and Adhesives 28: 101-108.

[15] Bourne-Webb P.J., Amatya B., and Soga K., (2009). Energy pile test at Lambeth College, London: geotechnical and thermodynamics aspects of pile response to heat cycles. Géotechnique 59(3): 237-248.

[16] Brandl, H., (2006), Energy foundations and other thermo-active ground structures. Geotechnique 56: 3-44. 
[17] Briffaut, M., Benboudjema, F., Torrenti, J.M, and Nahas, G., (2011), Numerical analysis of the thermal active restrained shrinkage ring test to study the early age behavior of massive concrete structures. Engineering Structures 33: 1390-1401.

[18] BSI (2006) BS 8500-1: Concrete - complementary British Standard to BS EN 206-1. Part 1: Method of specifying and guidance for the specifier. BSI, London, UK.

[19] BSI (2009) BS EN 12504-1 (including UK National Annex): Testing concrete in structures. Cored specimens - taking, examining and testing in compression. BSI, London, UK.

[20] Burghignoli A., Desideri A., and Milizaino S., (2000). A laboratory study on the thermomechanical behaviour of clayey soils. Canadian Geotechnical Journal 37: 764-780.

[21] Calavera, J., (1997) Armaduras pasivas para hormigón estructural. Recomendaciones sobre el proyecto, detalle, elaboración y montaje. Cuadernos técnicos de INTEMAC. Calidad siderúrgica S.R.L. 29.

[22] Calavera, J., González Valle, E., Delibes, A., Izquierdo, J.M., Fernández, J.M., (1977). Influencia de las compresiones previas en el hormigón sobre su microfisuración y resistencia a compresión. A.S.I.C., INTEMAC, I.S.B.N.: 84-5002280-0.

[23] Carril, C. (1951) El curado a vapor del hormigón. CICCP, Revista de obras públicas. (Diciembre 1951) Tomo I 621-626.

[24] Castillo, C. and Durrani, A.J., (1990), Effect of transient high temperature on high-strength concrete. ACI Mater. J. 87, p. 47)

[25] Causone, F., Baldin, F., Olesen, B.W., (2010), Floor heating and cooling combined with displacement ventilation: Possibilities and limitations. Energy and Buildings 42 Issue 12: 2338-2352.

[26] CEB Bulletin d'Information 13 (1983), Recommendations on reinforcement steel for reinforced concrete. Revised Edition of RC-6: Bond test for reinforcement steel: (2) Pull-out test, 5 pp. 
[27] CEB Bulletin d'Information 61 (1982), Recommendations on reinforcement steel for reinforced concrete. Revised Edition of RC-2: Tensile test on reinforcement bars for reinforced concrete, RC-4: rebend test for reinforcement steel, RC-5: bond test for reinforcement steel: (1) Beam Test, 7 pp.

[28] Cekerevac C., and Laloui L., (2004). Experimental study of termal effects on the mechanical behaviour of a clay. International Journal of Numerical and Analytical Method in Geomechanics 28(3): 209-228.

[29] Cordon, W.A., (1979) Properties, evaluation and Control of engineering materials, McGraw-Hill, New York.

[30] Culfic, M.S.; Ozturan, T., (2010), Mechanical properties of normal and high strength concretes subject to high temperatures and using image analysis to detect bond deteriorations. Construction and building materials Vol. 24, Issue 8:14861493.

[31] Dal Pont, S.Meftah, F. and Schrefler, B.A.,, (2011), Modeling concrete under severe conditions as a multiphase material. Nuclear engineering and Design 241: 562-572.

[32] De Isabel, J.A. (2008). Cimentación termoactiva: Una aplicación de la geotermia de muy baja entalpía. Diciembre de 2008. Geotermia. Obras Urbanas. Diciembre 2008: 14-19.

[33] De Isabel, J.A. (2009). Guía Técnica sobre Pilotes Geotérmicos. CM y Fenercom. ISBN: 978-84-612-9137-3. España.

[34] De Isabel, J.A. (2009). Guía Técnica sobre Pilotes Geotérmicos. CM y Fenercom. ISBN: 978-84-612-9137-3. España.

[35] De Larrard, F. and Belloc, A., (1997). The influence of aggregate on the compressive strength of normal and high-strength concrete, ACI Mater J 94 (5): 417-426.

[36] De Morais, M., Bary, B., Ranc, G., Dal Pont, S., and Durand, S. (2009) Comparative analysis of coupled thermo-hydro-mechanical models for concrete exposed to moderate temperatures. Numerical Heat Transfer, Part A, 55: 654-682, 2009. 
[37] De Pereda, L. (2010). Rehabilitación para la eficiencia energética en la climatización de edificios. Geotermia 177: 44-47.

[38] De Pereda, L., Widerin, B., Hendriks, M., Fernandez, J., Catalán, E., Stuki, B., Cubillo, J.M., y Cuesta, M.A., (2011), Guía sobre aprovechamiento energético de las infraestructuras subterráneas. CM y Fenercom. ISBN: 978-84-614-1418-5 Madrid.

[39] DeJong, M. J., \& Ulm, F. (2007). The nanogranular behavior of C-S-H at elevated temperatures (up to $700{ }^{\circ} \mathrm{C}$ ). Cement and Concrete Research, 37(1), 112.

[40] Del Viso, J.R, Carmona, J.R. y Ruiz, G., (2007), Influencia de la forma y del tamaño de la probeta en la resistencia a compresión de hormigones de alta resistencia. Anales de la Mecánica de Fractura, Vol2: 527-532.

[41] Delibes. A., Gonzalez, G., Determinación de la adherencia de armaduras de pequeño diámetro. Nuevo método RILEM de Ensayo de Arrancamiento: Pull Out Test. Documentación interna INTEMAC.

[42] Dias, W., Khoury, G., \& Sullivan, P. (1990). Mechanical properties of hardened cement paste exposed to temperatures up to $700 \mathrm{C}$ (1292 F). ACl Materials Journal, 87(2) Página 17 ensayos experimentales

[43] Diederichs, U., Schneider, U. (1981), Bond strength at high temperatures. Magazine of Concrete Research, Vol. 33, n115: 75-84.

[44] Dillon R and Rankin GIB (2013) Cube, cylinder, core and pull-off strength relationships. Structures and Buildings 166(10): 521-536.

[45] Directiva 2010/31/UE del Parlamento Europeo y del Consejo de 19 de mayo de 2010 relativa a la eficiencia energética de edificios.

[46] Directiva 2012/27/UE del Parlamento Europeo y el Consejo de 25 de octubre de 2012, relativa a la eficiencia energética.

[47] Edenhofer, O., Seyboth, K. (2013): Intergovernmental panel on climate change, In: Shogren JF (ed) Encyclopedia of energy, Natural resource and environmental economics, Volumne 1: ENERGY, 48-56. 
[48] EHE (2008). Instrucción de hormigón estructural. Comisión permanente del hormigón. Ministerio de Fomento. España.

[49] EN ISO 7730. CEN (European committee for standardization) (2005) Ergonomics of the thermal environment - Analytical determination and interpretation of thermal-comfort using calculation of the PMV and PPD indices and local thermal-comfort criteria.

[50] Escuer. J., (2008). Estructuras termoactivas: aprovechamiento de la energía geotérmica en las infraestructuras. Diciembre de 2008. Geotermia. Obras Urbanas. Diciembre de 2008: 26-30.

[51] Fargueta, F.; Benavent, J., (2010), Estudio experimental de los efectos de la temperatura sobre la Resistencia del hormigón. II Congreso Nacional de Investigación en Edificación. UPM. Madrid. España.

[52] Fernández Cánovas, M. (1999), Hormigón. Colegio de Ingenieros de Caminos, Canales y Puertos. Madrid, España. I.S.B.N.: 84-7493-125-8.

[53] Fernández-Jiménez, A., Palomo, A., (2006) Factores que afectan al desarrollo inicial de resistencias a compresión en hormigones de ceniza volante activados alcalinamente (sin OPC), Materiales de Construcción. Vol. 57, 287, 7-22. J/S 2007) I.S.S.N: 0465-2746.

[54] Fonseca, N., (2011). Modeling of a hydronic ceiling system and its environment as energetic auditing tool. Appl Energy 2011;88:636-49.

[55] Fu, Y., and Li, L., (2010), Study on mechanism of thermal spalling in concrete exposed to elevated temperatures. Materials and Structures 44: 361-376.

[56] Garzón, F:E., De Almeida, F.M., Khalil, M and El Debs, A:L, (2008), Bond between steel bars and self-compacting and ordinary concretes submitted to cyclic and monotonic loadin. Science and Engineering Journal. 17 (1/2): 1-10.

[57] Gens A., and Alonso E.E., (1998). Constitutive models for unsaturated soils: thermodynamic approach. Proceedings of the 2nd International Conference on Unsaturated Soils. International Academic Publishers, Beijing, vol 1, pp. 455460. 
[58] H.A. Toutanji and Z. Bayasi, (1999), Effect of curing procedures on properties of silica fume concrete. Cement and Concrete Reearch. 29: 497-501.

[59] Harada, T., Takeda, J., Yamane, S., \& Furumura, F. (1972). Strength, elasticity and thermal properties of concrete subjected to elevated temperatures. ACI Special Publication, 34

[60] Harmathy, T. (1970). Thermal properties of concrete at elevated temperatures. Journal of Materials, 5(1), 47-\&.

[61] Hong P.Y., Pereira J.M., and Tang A.M., (2013). On some advanced thermomechanical models for saturated clays. International Journal of Numerical and Analytical methods in Geomechanics 37(17): 2952-2971.

[62] Humbert, J, Baroth,, and J.,Daudeville, L., (2009), Probabilistic analysis of a "pull-out" test. Materials and Structures 43: 345-355.

[63] Husem, M. (2006).The effects of high temperature on compressive and flexural strengths of ordinary and high-performance concrete. Fire Safety Journal March 2006, Pages 155-163.

[64] Kalantidou A., Tang AM and Pereira JM (2012). Preliminary study on the mechanical behaviour of heat exchanger pile in physical model. Géotechnique 62(11): 1047 - 1051.

[65] Kalifa, P., \& Tsimbrovska, M. (1998). Comportement des BHP a hautes temperatures: Etat de la question et resultats experimentaux CSTB.

[66] Kalz D, Pfafferott $J$ and Koenigsdorff $R$ (2012) Operating experience with Thermo-Active Building Systems (TABS). Bauphysik / Building Physics 34(2): 6675.

[67] Kassir MK, Bandyopadhyay KK and Reich M (1996) Thermal degradation of concrete in the temperature range from ambient to $315^{\circ} \mathrm{C}\left(600^{\circ} \mathrm{F}\right)$. Associated Universities, INC. Upton, New York.

[68] Katz, A., Berman, N. (2000), Modeling the effect of high temperature on the bond of FRP reinforcing bars to concrete. Cement and Concrete Composites, Vol. 22: 433-443. 
[69] Kim, G., Kim, Y., Lee, T. (2009) Mechanical properties of high-strength concrete subjected to high temperature by stressed test. Trans. Nonferrous Met. Soc. China 19 S128-s133.

[70] Kolarik,J. Thermal Mass Activation. State of the art and perspectives. http://annex44.civil.aau.dk/Annex\%2044\%20Forum/meetings/4th\%20Annex\%2044 \%20Forum/17 Jakub TMA.pdf Consultado por última vez 12/06/2014

[71] Koschenz M, Lehmann B (2000). Thermoaktive Bauteilsysteme Tabs. EMPA Energiesysteme/Haustechnik, Zurich. (in German)

[72] Koschenz M., Dorer V. (1999). Interaction of an air system with concrete core conditioning. Energy and Buildings, 30: 139-145.

[73] Koschenz M., Lehmann B. (2000). Thermoaktive Bauteilsysteme Tabs. EMPA Energiesysteme/Haustechnik, Zurich.

[74] Kumar, P. and Monteiro, P.J.M., (2006), Concrete. Microestructure, Properties and materials. McGraw-Hill, New York I.S.B.N. 0-07-146289-9.

[75] Kwag, B.C., and Krarti, M., (2013) Performance of thermoactive foundations for commercial buildings. Journal of solar energy engineeringtransactions of the ASME, ISSN 0199-6231, V135, N 4, p. 10

[76] Laloui L and Di Donna A (2013) Energy geostructures. Innovation in underground engineering. ISTE Ltd, Great Britain.

[77] Laloui L, Nuth M and Vulliet L (2006) Experimental and numerical investigations of the behaviour of a heat exchanger pile. International Journal for Numerical and Analytical Methods in Geomechanics 30(8): 763-781.

[78] Laloui, L., \& Di Donna, A. (2011). Understanding the behaviour of energy geo-structures. Proceedings of the ICE-Civil Engineering, , 164(4) 184-191.

[79] Lehmann B., Dorer V., Renggli M.G., Werdre F and Tödtli, J., (2011). Thermally activated building systems (TABS): energy efficiency as a function of control strategy,hydronic circuit topology and (cold) genergation system. Apply Energy 2011;99:180-91. 
[80] Lehmann B., Dorer, V., Koschenz, M. (2007), Application range of thermally activated building systems tabs. Energy and Buildings 39 Issue 5: 593598.

[81] Lehmann, B., Dorer, V., Gwerder, M., Renggli, F., (2008) Control of thermally-activated building systems (TABS). Applied Energy 85: 565-581

[82] Lehmann, B., Dorer, V., Gwerder, M., Renggli, F., Tödtli, J. (2011) Thermally activated building systems (TABS): Energy efficiency as a function of control strategy, hydronic circuit topology and (cold) generation system. Applied Energy. 88 Issue 1: 180-191

[83] Lim J.H., Song J.H., Song S.Y., (2014). Development of operational guidelines for thermally activated building system according to heating and cooling load characteristics. Applied Energy, ISSN 0306-2619, Volumen 126, pp. 123 135.

[84] M. Gwerder, M.; Tödtli, J.; Lehmann, B.; Dorer, V.; Güntensperger, W.; Renggli, F. (2009) Control of thermally activated building systems (TABS) in intermittent operation with pulse width modulation. Applied Energy 86 Issue 9: 1606-1616

[85] Magraner, T., y Mazariegos, A., (2008). Pilotes Termoactivos. Proceso constructivo y caracterización térmica. Diciembre de 2008. Geotermia. Obras urbanas. Diciembre 2008: 44-48.

[86] Malhotra, V., Wilson, H., \& Painter, K. (1989). Performance of gravelstone concrete incorporating silica fume at elevated temperatures. Third International Conference Proceedings. Fly Ash, Silica Fume, Slag, and Natural Pozzolans in Concrete, (SP 114-51)

[87] McCartney J.S., and Murphy K., (2012). Strain distributions in full-scale energy foundations. DFI Journal 6(2): $28-36$.

[88] McCartney J.S., and Rosenberg J.E., (2011). Impact of heat exchange on the axial capacity of thermo-active foundations. ASCE Geotechnical Special Publication 211, ASCE: 488 - 498.

[89] Meddah, M.S., Zitouni, S. and Belaabes, S. (2010), Effect of content and particle size distribution of coarse aggregate on the compressive strength of 
concrete. Construction and building materials. Volume 24, Issue 4, April 2010: 505512.

[90] Meierhans, R.A. (1996) Room air conditioning by means of overnight cooling of the concrete ceiling. ASHRAE Transactions,. V. 102, Pt. 2: 693-697.

[91] Meierhans, RA. (1993) Slab cooling and earth coupling, ASHRAE Transactions, V. 99, Pt 2: 511-518.

[92] Minarova, M. (2006) Boundary value problems in building physics-thermal engineering of buildings. Czech-Japanese Seminar http://geraldine.fjfi.cvut.cz/cjs2006/proc/minarova.pdf Consultado por última vez 19/08/2014.

[93] Molina, M. (2005) Comportamiento de estructuras de hormigón armado con una deficiente transferencia de tensiones hormigón-acero, análisis experimental y propuesta de un modelo de evaluación estructural. 250 pp. Tesis doctoral. Universidad Politécnica de Madrid. España.

[94] Molina, M., Gutiérrezm J.P., García, M.D., (2004), Influencia del diámetro de la barra y del recubrimiento en las características adherentes del hormigón armado. Boletín de la sociedad española de Cerámica y Vidrio., 43 (2): 560-564.

[95] Montanaro, M.I., Peralta, M.H. y Di Maio, A. (2003). Distribución de temperaturas en probetas de hormigón sometidas a acciones térmicas. Mecánica Computacional Vol. XXII.

http://www.cimec.org.ar/ojs/index.php/mc/article/viewFile/796/798. Consultado por última vez 21/09/2014

[96] Muñoz, D., Mayoral G.R.; Cuesta, M.A. (2008) Energía geotérmica de baja entalpía en grandes proyectos (Termoterra). Geotermia.

[97] Naciones Unidas. Convención Marco de las Naciones Unidas sobre el cambio climático. 1992.

[98] Naus, D. (2010). In Research.,U.S.Nuclear Regulatory Commission.Office of Nuclear Regulatory, Laboratory. O. R. N. (Eds.), A compilation of elevated temperature concrete material property data and information for use in assessments of nuclear power plant reinforced concrete structures. Washington, 
D.C.: U.S. Nuclear Regulatory Commission, Office of Nuclear Regulatory Research.

[99] Neville AM (1996) Properties of Concrete, 4th edn. Wiley, London, UK.

[100] Noghabai, K. (2001) Surnmary of Results of RILEM TC 147-FMB Round Robin Investigation on Bond in Lulei. Rep Tension of Reinforced Concrete Prisms Round Robin Analysis and tests on Bond - Report 034 of RILEM TC 147-FMB: Fracture mechanics applications to anchorage and bond.

[101] Noumowe, A. (2005) Mechanical properties and microstructure of high strength concrete containing polypropylene fibres exposed to temperatures up to 200 -C. Cement and Concrete Research 35 (2005) 2192 - 2198.

[102] Noumowe, A.N., Clastres, P., Debicki, G., and Costaz, J.L., (1996), Transient heating effect on high strength concrete. Nuclear Engineering and Design. Volume 166, Issue 1. 99-108.

[103] Olesen B.W., (2012) Thermo Active Building Systems Using Building Mass To Heat and Cool. ASHRAE Journal 54(2): 44.

[104] Olesen BW (2008). Radiant floor cooling systems. ASHRAE Journal, 50(9): 16-20.

[105] Olesen, B.W. (2008) Radiant heating and cooling by embedded waterbased systems. ASHRAE Journal,50(9): 16-20.

[106] Olivella S., Gens A. and Carrera J (1996) Numerical formulation for a simulator (CODE-BRIGHT) for the coupled analysis of saline media. Engineering Computations 13(3): 87-112.

[107] P. Miguel, J.R. Martí, P. Serna, M.Á. Fernández, (2002), La adherencia en elementos prefabricados pretensados de hormigón. Problemática y tendencias actuales. VIII Congreso Nacional de Propiedades Mecánicas de Sólidos. Gandía. España.

[108] P. Miguel, J.R. Martí, P. Serna, M.Á. Fernández, (2002), Procedimiento de ensayo "ECADA" para la caracterización de la capacidad adherente de la armadura pretesas al hormigón. VIII Congreso Nacional de Propiedades Mecánicas de Sólidos. Gandía. España. 
[109] Pahud, D., \& Hubbuch, M. (2007). Mesures et optimisation de l'installation avec pieux énergétiques du dock midfield de l'aéroport de zürich. Rapport Final, Office Fédéral De L'énergie, Berne, Suisse.

[110] Park, S.H., Chung, W.J., Yeo, M.S., Kim, K.W., (2014). Evaluation of the thermal performance of a Thermally Activated Building System (TABS) according to the thermal load in a residential building. Energy and buildings, ISSN 0378-7788, Volume 73, pp. $69-82$.

[111] Petkovski, M., (2010), Effects of stress during heating on strength and stiffness of concrete at elevated temperature. Cement and Concrete Research 40: 1744-1755.

[112] Phan, L.T., and Carion, J.N., (1998), Review of mechanical properties of $\mathrm{HSC}$ at elevated temperature. Journal of Materials in Civil Engineering. American Society of Civil Engineerts, Vol. 10, 1, 58-64.

[113] Potha, M., Raju, K., Srinivasa R. and Raju, P. (2007) Compressive strength of heated high-strength. Concrete Magazine of Concrete Research, 2007, 59, No. 2, March, 79-85.

[114] Raftery, P., Lee, K., Webster, T. and Bauman, F. (2012). Performance analysis of and integrated UFAD and radiant hydronic slab system. Appl Energy 2012;90:250-7.

[115] Rijksen D.O., Wisse C.J., Schijndel A.W.M.V. (2010). Reducing peak requirements for cooling by using thermally activated building systems. Energy and Buildings, 42: 298-304.

[116] Rijksen, D.O., Wisse, CJ; van Schijndel, AWM., (2010) Reducing peak requirements for cooling by using thermally activated building systems. Energy and Buildings 42 Issue 3: 298-304.

[117] RILEM (1957) Correction factors between the strengths of different specimens. Bibliographical study. RILEM Bulletin 39: 81-105.

[118] Sait, M., Ozturan, T. (2010) Mechanical properties of normal and high strength concretes subjected to high temperatures and using image analysis to detect bond deteriorations. Construction and Building Materials 24 (2010) 14861493. 
[119] Sang-Hung, H., Jin-Keun, K., (2004), Effect of temperature and age on the relationship between dynamic and static elastic modulus of concrete. Cement and Concrete Research 34: 1219-1227.

[120] Savva, A., Manita, P., and Sideris, K.K., (2005), Influence of elevated temperatures on the mechanical properties of blended cement concretes prepared with limestone and siliceous aggregates. Cement and Concrete Composites 27:239-248.

[121] Schneider U (1983) Behavior of concrete at high temperatures. RILEMCommittee 44-PTH.

[122] Sengul, O., Tasdemir ,C. and Tasdemir, M.A. (2002), Influence of aggregate type on mechanical behaviour of normal and high-strength concretes, ACI Mater J 99 (6): 528-533.

[123] Shih, T.S., Lee, G.C., Chang, K.C. (1988): High strength concrete-steel bond behavior at low temperature, ASCE, Journal of Cold Regions engineering, Vol.2, n4: 157-168.

[124] Sreenivasulu, A., and Srinivasa, K. (2013). The Effect of Temperature on Mechanical Properties of M100 Concrete. American Journal of Engineering Research (AJER) e-ISSN: 2320-0847 p-ISSN : 2320-0936 Volume-2, Issue-4, pp152-157.

[125] Standard EN 15377-1. (2008). Heating systems in buildings - design of embedded water based surface heating and cooling systems - part 1: determination of the design heating and cooling capacity.

[126] Stewart M., and McCartney J.S., (2011). Strain distribution in centrifuge model energy foundations. ASCE Geotechnical Special Publication 211, ASCE: $4376-4385$.

[127] Suryatriyastuti M.E., Mroueh H., Burlon S., (2013). A load transfer approach for studying the cyclic behavior of thermo-active piles. Computers and Geotechnics 55 (2014) 378-391

[128] Targan, S., Olgun, Erdogan, Y. and Sevinc, V., (2002), Effects of supplementary cementing material son the properties of cement and concrete. Cement and Concrete Research. Volume 32, Issue 10, October 2002:1551-1558. 
[129] Tepfers, R. (1973) A theory of bond applied to overlapped tensile reinforcement splices for deformed bars. 328 pp. Doctoral Thesis. Ed. Chalmers University of Technology. Division of Concrete Structures, Goteborg (Sweden). Publication 73:2.

[130] Varming, N., Molholm, C., Rammer, T., Weitzmann, P., Svendsen, S. (2005). Simplified calculation of hourly temperatures, heating demands and cooling demands in buildings with thermo-active constructions. http://web.byv.kth.se/bphys/reykjavik/pdf/art 133.pdf Consultado por última vez 23/09/2014.

[131] Wang B., Bouazza A., and Barry-Macaulay D., (2011). Field and laboratory investigation of a heat exchanger pile. ASCE Geotechnical Special Publication 211, ASCE: 4395-4405.

[132] Wang, X., and Lee, S.(2012). Evaluation of the mechanical properties of concrete considering the effects of temperature and aging. Construction and Building Materials 29 (2012) 581-590.

[133] Weber, T., Johannesson, G., Koschenz, M., Lehmann, B., Baumgartner, T. (2005). Validation of a FEM-program (frecuency-domain) and a simplified RCmodel (time-domain) for thermally activated building component systems (TABS) using measurement data. Energy and Buildings 37 Issue 7: 707-724.

[134] Wu, X., Wu, Z., Zheng, J., Ueda, T. and Yi, S. (2013) An experimental study on the performance of self-compacting lightweight concrete exposed to elevated temperature. Magazine of concrete research. V. 65 I 13.

[135] Xu, X., Yu, J., Wang, S. and Wang, J. (2014). Reserch and application of active hollow core slabs in building systems for utilizing low energy sources. Appl Energy 2014;116:424-35.

[136] Yang, C.C: and Liang, C.H., (2009), The influence of medium-high temperature on the transport properties of concrete by using accelerated chloride migration test. Materials Chemistry and Physics. 114 670-675.

[137] Yavari N, Tang AM, Pereira JM and Hassen G (2014) Experimental study on the mechanical behaviour of a heat exchanger pile using physical modelling. Acta Geotechnica 9: 385-398. 
[138] Yu, T., Heiselberg, P., Lei, B., Pomianowski, M. (2014) Validation and modification of modeling thermally activated building systems (TABS) using EnergyPlus. BUILD SIMUL (2014) 7: 615-627 DOI 10.1007/s12273-014-0183-6.

[139] Zabihi N (2012) Effect of Specimen Size and Shape on Strength of Concrete. Thesis for the degree of Master of Science in Civil Engineering. Eastern Mediterranean University, Gazimağusa, North Cyprus.

[140] Zhai, Y., Deng, Z., Li, N. and Xu, R. (2014) Study on compressive mechanical capabilities of concrete after high temperature exposure and thermodamage constitutive model. Construction and Building Materials 68 (2014) 777782.

[141] Zhuang, Z., Li, Y., Chen, B., \& Guo, J. (2009). Chinese Kang as a domestic heating system in rural northern. China-A review. Energy and Buildings, 41(1), 111-119. 


\section{CAPÍTULO 9}

ANEXOS 
ANEXO 1

TABLAS DE

RESULTADOS 
Tabla 9.1. 1 ( $\sigma \max , \varepsilon \max , \varepsilon u$, Emax y Eu) de las tres probetas cilíndricas sometidas a $20^{\circ} \mathrm{C}$, de hormigón $\mathrm{H}-25$ ensayado a compresión.

\begin{tabular}{|c|c|c|c|c|c|c|}
\hline & Temperatura (oC) & $\sigma \max (\mathrm{N} / \mathrm{mm} 2)$ & $\varepsilon \max$ & $\varepsilon u$ & $\operatorname{Emax}(\mathrm{N} / \mathrm{mm} 2)$ & $\mathrm{Eu}(\mathrm{N} / \mathrm{mm} 2)$ \\
\hline MEDIA & 20 & 24,10 & 0,0049 & 0,0066 & 0,0671 & 0,1016 \\
\hline CS1-H25-20 & 20 & 25,70 & 0,0053 & 0,0068 & 0,0789 & 0,1126 \\
\hline CS2-H25-20 & 20 & 24,66 & 0,0048 & 0,0062 & 0,0668 & 0,0963 \\
\hline CS3-H25-20 & 20 & 21,93 & 0,0047 & 0,0068 & 0,0557 & 0,0960 \\
\hline
\end{tabular}

Tabla 9.1. 2 ( $\sigma \max , \varepsilon \max , \varepsilon u$, Emax y Eu) de las tres probetas cilíndricas sometidas a $40^{\circ} \mathrm{C}$, de hormigón $\mathrm{H}-25$ ensayado a compresión.

\begin{tabular}{|c|c|c|c|c|c|c|}
\hline & Temperatura (oC) & $\sigma m a x(\mathrm{~N} / \mathrm{mm} 2)$ & $\varepsilon \max$ & $\varepsilon u$ & $\operatorname{Emax}(\mathrm{N} / \mathrm{mm} 2)$ & $\mathrm{Eu}(\mathrm{N} / \mathrm{mm} 2)$ \\
\hline MEDIA & 40 & 22,81 & 0,0052 & 0,0069 & 0,0671 & 0,1016 \\
\hline CS4-H25-40 & 40 & 21,54 & 0,0047 & 0,0066 & 0,0584 & 0,0942 \\
\hline CS5-H25-40 & 40 & 23,41 & 0,0050 & 0,0065 & 0,0650 & 0,0955 \\
\hline CS6-H25-40 & 40 & 23,49 & 0,0058 & 0,0076 & 0,0777 & 0,1152 \\
\hline
\end{tabular}

Tabla 9.1. 3 ( $\sigma \max , \varepsilon \max , \varepsilon u$, Emax y Eu) de las tres probetas cilíndricas sometidas a $70^{\circ} \mathrm{C}$, de hormigón H-25 ensayado a compresión.

\begin{tabular}{|c||c|c|c|c|c|c|}
\hline & Temperatura (oC) & $\boldsymbol{\sigma m a x}$ (N/mm2) & $\boldsymbol{\varepsilon m a x}$ & $\boldsymbol{\varepsilon u}$ & Emax (N/mm2) & Eu (N/mm2) \\
\hline \hline MEDIA & 70 & 19,51 & 0,0051 & 0,0073 & 0,0566 & 0,0941 \\
\hline \hline CS7-H25-70 & 70 & 21,06 & 0,0058 & 0,0078 & 0,0696 & 0,1061 \\
\hline \hline CS8-H25-70 & 70 & 18,69 & 0,0045 & 0,0065 & 0,0460 & 0,0796 \\
\hline \hline CS9-H25-70 & 70 & 19,62 & 0,0049 & 0,0070 & 0,0545 & 0,0910 \\
\hline \hline CS10-H25-70 & 70 & 18,65 & 0,0053 & 0,0080 & 0,0563 & 0,0995 \\
\hline
\end{tabular}

Tabla 9.1. 4 ( $\sigma \max , \varepsilon \max , \varepsilon u$, Emax y Eu) de las tres probetas cilíndricas sometidas a 100 드, de hormigón H-25 ensayado a compresión.

\begin{tabular}{|c||c|c|c|c|c|c|}
\hline \multicolumn{1}{|c|}{} & Temperatura (ㅇ) & $\boldsymbol{\sigma m a x}$ (N/mm2) & $\boldsymbol{\varepsilon m a x}$ & $\boldsymbol{\varepsilon u}$ & $\operatorname{Emax}(\mathbf{N} / \mathbf{m m 2})$ & Eu (N/mm2) \\
\hline \hline MEDIA & 100 & 18,22 & 0,0051 & 0,0075 & 0,0525 & 0,0908 \\
\hline \hline CS10-H25-100 & 100 & 18,65 & 0,0053 & 0,0080 & 0,0563 & 0,0995 \\
\hline \hline CS11-H25-100 & 100 & 18,02 & 0,0053 & 0,0074 & 0,0544 & 0,0873 \\
\hline \hline CS12-H25-100 & 100 & 17,98 & 0,0046 & 0,0070 & 0,0467 & 0,0856 \\
\hline
\end{tabular}

Tabla 9.1. 5 ( $\sigma \max , \varepsilon \max , \varepsilon u$, Emax y Eu) de las tres probetas cilíndricas sometidas a 20ํㅡ, de hormigón H-30 ensayado a compresión.

\begin{tabular}{|c||c|c|c|c|c|c|}
\hline \multicolumn{1}{|c|}{} & Temperatura (-C) & $\boldsymbol{\sigma m a x}$ (N/mm2) & $\boldsymbol{\varepsilon m a x}$ & $\boldsymbol{\varepsilon u}$ & Emax (N/mm2) & Eu (N/mm2) \\
\hline \hline MEDIA & 20 & 27,70 & 0,0052 & 0,0069 & 0,0827 & 0,1225 \\
\hline \hline CM1-H30-20 & 20 & 26,97 & 0,0057 & 0,0069 & 0,0873 & 0,1162 \\
\hline \hline CM2-H30-20 & 20 & 28,72 & 0,0047 & 0,0064 & 0,0770 & 0,1198 \\
\hline \hline CM3-H30-20 & 20 & 27,42 & 0,0052 & 0,0072 & 0,0837 & 0,1314 \\
\hline \hline
\end{tabular}


Tabla 9.1. 6 ( $\sigma \max , \varepsilon \max , \varepsilon u$, Emax y Eu) de las tres probetas cilíndricas sometidas a $40^{\circ} \mathrm{C}$, de hormigón H-30 ensayado a compresión.

\begin{tabular}{|c||c|c|c|c|c|c|}
\hline & Temperatura (-C) & $\boldsymbol{\sigma m a x}$ (N/mm2) & $\boldsymbol{\varepsilon m a x}$ & $\boldsymbol{\varepsilon u}$ & Emax (N/mm2) & Eu (N/mm2) \\
\hline \hline MEDIA & 40 & 26,12 & 0,0052 & 0,0069 & 0,0777 & 0,1169 \\
\hline \hline CM4-H30-40 & 40 & 25,77 & 0,0053 & 0,0072 & 0,0783 & 0,1194 \\
\hline \hline CM5-H30-40 & 40 & 25,95 & 0,0054 & 0,0073 & 0,0807 & 0,1226 \\
\hline \hline CM6-H30-40 & 40 & 26,65 & 0,0049 & 0,0063 & 0,0742 & 0,1087 \\
\hline
\end{tabular}

Tabla 9.1. 7 ( $\sigma \max , \varepsilon \max , \varepsilon u$, Emax y Eu) de las tres probetas cilíndricas sometidas a 70드, de hormigón H-30 ensayado a compresión.

\begin{tabular}{|c||c|c|c|c|c|c|}
\hline & Temperatura (oC) & бmax (N/mm2) & $\boldsymbol{\varepsilon m a x}$ & $\boldsymbol{\varepsilon u}$ & $\operatorname{Emax~(N/mm2)~}$ & Eu (N/mm2) \\
\hline \hline MEDIA & 70 & 24,61 & 0,0048 & 0,0061 & 0,0669 & 0,0967 \\
\hline \hline CM7-H30-70 & 70 & 25,33 & 0,0049 & 0,0059 & 0,0695 & 0,0927 \\
\hline \hline CM8-H30-70 & 70 & 24,36 & 0,0048 & 0,0062 & 0,0663 & 0,0980 \\
\hline \hline CM9-H30-70 & 70 & 24,16 & 0,0047 & 0,0063 & 0,0650 & 0,0993 \\
\hline
\end{tabular}

Tabla 9.1. 8 ( $\sigma \max , \varepsilon \max , \varepsilon u$, Emax y Eu) de las tres probetas cilíndricas sometidas a 100 C , de hormigón $\mathrm{H}-30$ ensayado a compresión.

\begin{tabular}{|c||c|c|c|c|c|c|}
\hline \multicolumn{1}{|c|}{} & Temperatura (ㄷ) & $\boldsymbol{\sigma m a x}$ (N/mm2) & $\boldsymbol{\varepsilon m a x}$ & $\boldsymbol{\varepsilon u}$ & $\operatorname{Emax}(\mathbf{N} / \mathbf{m m} 2)$ & Eu (N/mm2) \\
\hline \hline MEDIA & 100 & 21,40 & 0,0046 & 0,0066 & 0,0560 & 0,0932 \\
\hline \hline CM10-H30-100 & 100 & 22,37 & 0,0045 & 0,0063 & 0,0580 & 0,0940 \\
\hline \hline CM11-H30-100 & 100 & 21,72 & 0,0046 & 0,0058 & 0,0568 & 0,0808 \\
\hline \hline CM12-H30-100 & 100 & 20,11 & 0,0046 & 0,0078 & 0,0532 & 0,1049 \\
\hline \hline
\end{tabular}

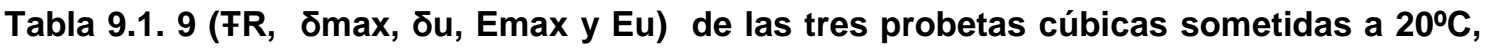
de hormigón H-25 ensayado a "pull-out".

\begin{tabular}{|c|c|c|c|c|c|c|}
\hline & Temperatura (ㅇ) & FR (KN) & $\delta \max (\mathrm{mm})$ & $\delta u(\mathrm{~mm})$ & Emax (KNmm) & Eu (KNmm) \\
\hline MEDIA & 20 & 24,22 & 5,6280 & 5,7823 & 69,9166 & 73,5220 \\
\hline AS1-H25-20 & 20 & 21,20 & 5,1198 & 5,3298 & 54,9708 & 59,3600 \\
\hline AS2-H25-20 & 20 & 25,43 & 6,3613 & 6,5674 & 84,8021 & 90,0064 \\
\hline AS3-H25-20 & 20 & 26,02 & 5,4028 & 5,4498 & 69,9769 & 71,1996 \\
\hline
\end{tabular}

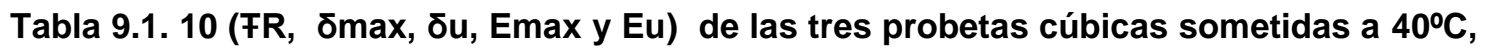
de hormigón H-25 ensayado a "pull-out".

\begin{tabular}{|c||c|c|c|c|c|c|}
\hline & Temperatura (-C) & FR (KN) & $\delta \max (\mathbf{m m})$ & $\mathbf{\delta u}(\mathbf{m m})$ & Emax (KNmm) & Eu (KNmm) \\
\hline \hline MEDIA & 40 & 21,31 & 6,7432 & 6,9431 & 72,8501 & 77,0683 \\
\hline \hline AS4-H25-40 & 40 & ERROR & & & & \\
\hline \hline AS5-H25-40 & 40 & 19,19 & 7,7848 & 7,9653 & 77,6114 & 81,0044 \\
\hline \hline AS6-H25-40 & 40 & 23,43 & 5,7016 & 5,9210 & 68,0889 & 73,1323 \\
\hline
\end{tabular}




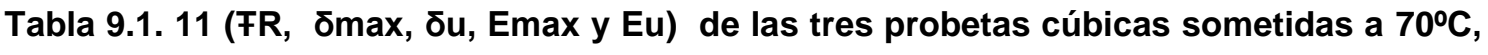
de hormigón H-25 ensayado a "pull-out".

\begin{tabular}{|c|c|c|c|c|c|c|}
\hline & \begin{tabular}{|l|} 
Temperatura (ㅇ) \\
\end{tabular} & FR (KN) & $\delta \max (\mathrm{mm})$ & $\delta u(\mathrm{~mm})$ & Emax (KNmm) & Eu (KNmm) \\
\hline MEDIA & 70 & 18,37 & 6,2075 & 6,3234 & 57,5821 & 59,6034 \\
\hline AS7-H25-70 & 70 & 19,42 & 7,0428 & 7,0561 & 69,6210 & 69,8787 \\
\hline AS8-H25-70 & 70 & 18,34 & 4,7233 & 4,8740 & 44,9303 & 47,6289 \\
\hline AS9-H25-70 & 70 & 17,34 & 6,8564 & 7,0402 & 58,1949 & 61,3027 \\
\hline
\end{tabular}

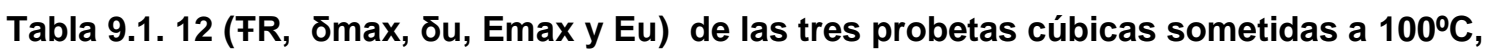
de hormigón H-25 ensayado a "pull-out".

\begin{tabular}{|c||c|c|c|c|c|c|}
\hline & Temperatura (oC) & FR (KN) & $\delta \max (\mathbf{m m})$ & $\mathbf{\delta u}(\mathbf{m m})$ & Emax (KNmm) & Eu (KNmm) \\
\hline \hline MEDIA & 100 & 15,17 & 4,7675 & 4,8899 & 36,7491 & 38,7307 \\
\hline \hline AS10-H25-100 & 100 & 15,48 & 4,9749 & 5,1456 & 39,4639 & 42,0680 \\
\hline \hline AS11a-H25-100 & 100 & 18,75 & 4,8827 & 5,0383 & 46,0623 & 48,9440 \\
\hline \hline AS12-H25-100 & 100 & 11,29 & 4,4451 & 4,4858 & 24,7211 & 25,1802 \\
\hline
\end{tabular}

Tabla 9.1. 13 (FR, סmax, סu, Emax y Eu) de las tres probetas cúbicas sometidas a $20^{\circ} \mathrm{C}$, de hormigón H-30 ensayado a "pull-out".

\begin{tabular}{|c||c|c|c|c|c|c|}
\hline & Temperatura (-C) & FR (KN) & $\delta \max (\mathbf{m m})$ & $\mathbf{\delta u}(\mathbf{m m})$ & Emax (KNmm) & Eu (KNmm) \\
\hline \hline MEDIA & 20 & 27,42 & 5,4856 & 5,6408 & 80,3519 & 85,0607 \\
\hline \hline AM1-H30-20 & 20 & ERROR & & & & \\
\hline \hline AM2-H30-20 & 20 & 30,82 & 6,1812 & 6,4916 & 98,3961 & 107,8135 \\
\hline \hline AM3-H30-20 & 20 & 24,01 & 4,7900 & 4,7900 & 62,3078 & 62,3078 \\
\hline \hline
\end{tabular}

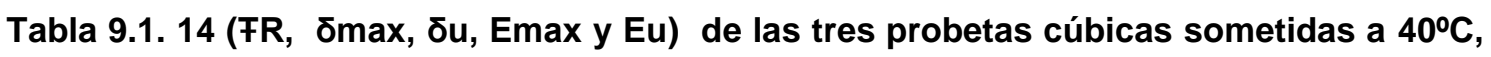
de hormigón H-30 ensayado a "pull-out".

\begin{tabular}{|c||c|c|c|c|c|c|}
\hline & Temperatura (ㅇ) & FR (KN) & $\delta \operatorname{max~(mm)~}$ & $\mathbf{\delta u}(\mathbf{m m})$ & Emax (KNmm) & Eu (KNmm) \\
\hline \hline MEDIA & 40 & 22,51 & 5,2079 & 6,3516 & 62,3340 & 109,9946 \\
\hline \hline AM4-H30-40 & 40 & 24,36 & 5,3570 & 8,5195 & 73,7697 & 130,1791 \\
\hline \hline AM5-H30-40 & 40 & 20,76 & 4,5445 & 4,6300 & 47,6270 & 130,1791 \\
\hline \hline AM6-H30-40 & 40 & 22,41 & 5,7220 & 5,9053 & 65,6055 & 69,6257 \\
\hline
\end{tabular}

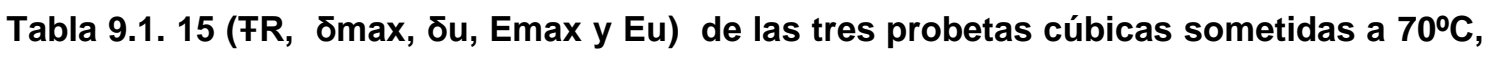
de hormigón H-30 ensayado a "pull-out".

\begin{tabular}{|c||c|c|c|c|c|c|}
\hline \multicolumn{1}{|c|}{} & Temperatura (oC) & $\mathbf{F R}(\mathbf{K N})$ & $\boldsymbol{\delta} \max (\mathbf{m m})$ & $\mathbf{\delta u} \mathbf{( m m})$ & $\mathbf{E m a x}(\mathbf{K N m m})$ & Eu (KNmm) \\
\hline \hline MEDIA & 70 & 18,92 & 5,9475 & 6,0833 & 53,8261 & 56,2202 \\
\hline \hline AM7-H30-70 & 70 & 17,75 & 5,9294 & 6,0518 & 50,4200 & 52,5601 \\
\hline \hline AM8-H30-70 & 70 & 16,38 & 7,0481 & 7,2249 & 54,8617 & 57,4783 \\
\hline \hline AM9-H30-70 & 70 & 22,62 & 4,8649 & 4,9731 & 56,1968 & 58,6222 \\
\hline \hline
\end{tabular}




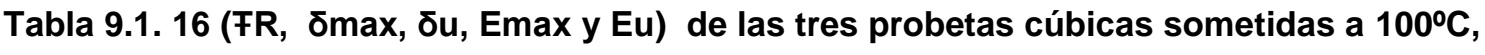
de hormigón H-30 ensayado a "pull-out".

\begin{tabular}{|c||c|c|c|c|c|c|}
\hline & Temperatura (oC) & $\mathbf{F R}(\mathbf{K N})$ & $\boldsymbol{\delta} \max (\mathbf{m m})$ & $\mathbf{\delta u}(\mathbf{m m})$ & $\mathbf{E m a x}$ (KNmm) & Eu (KNmm) \\
\hline \hline MEDIA & 100 & 14,52 & 3,6135 & 3,7960 & 28,5045 & 30,7051 \\
\hline \hline AM10-H30-100 & 100 & 16,40 & 3,8772 & 3,9318 & 32,5296 & 33,4225 \\
\hline \hline AM11-H30-100 & 100 & 11,16 & 2,8277 & 3,1631 & 17,8484 & 21,1753 \\
\hline \hline AM12-H30-100 & 100 & 16,01 & 4,1357 & 4,2931 & 35,1355 & 37,5173 \\
\hline
\end{tabular}

Tabla 9.1. 17 ( $\sigma \max , \varepsilon m a x, \varepsilon u$, Emax y Eu) de las tres probetas cilíndricas sin tubo, de hormigón H-25 ensayado a compresión.

\begin{tabular}{|c||c|c|c|c|c|c|}
\hline & Temperatura (ㅇ) & $\boldsymbol{\sigma m a x}(\mathbf{N} / \mathbf{m m}$ ) & $\boldsymbol{\varepsilon m a x}$ & $\boldsymbol{\varepsilon u}$ & Emax (N/mm2) & Eu (N/mm2) \\
\hline \hline MEDIA & & 23,22 & 0,0038 & 0,0047 & 0,0472 & 0,0434 \\
\hline \hline THO1-H25-REF & & 24,44 & 0,0040 & 0,0046 & 0,0522 & 0,0000 \\
\hline \hline THO2-H25-REF & & 23,18 & 0,0039 & 0,0050 & 0,0489 & 0,0714 \\
\hline \hline THO3-H25-REF & & 22,04 & 0,0035 & 0,0045 & 0,0404 & 0,0587 \\
\hline
\end{tabular}

Tabla 9.1. 18 ( $\sigma \max , \varepsilon \max , \varepsilon u, E \max$ y Eu) de las tres probetas cilíndricas con tubo vertical centrado, de hormigón H-25 ensayado a compresión.

\begin{tabular}{|c||c|c|c|c|c|c|}
\hline \multicolumn{1}{|c|}{} & Temperatura (-C) & $\boldsymbol{\sigma m a x}$ (N/mm2) & $\boldsymbol{\varepsilon m a x}$ & $\boldsymbol{\varepsilon u}$ & $\operatorname{Emax}(\mathbf{N} / \mathbf{m m 2})$ & $\mathrm{Eu}(\mathbf{N} / \mathbf{m m 2})$ \\
\hline \hline MEDIA & & 22,02 & 0,0041 & 0,0051 & 0,0505 & 0,0701 \\
\hline \hline THO4-H25-VC & & 23,33 & 0,0043 & 0,0057 & 0,0561 & 0,0845 \\
\hline \hline THO5-H25-VC & & 19,00 & 0,0034 & 0,0043 & 0,0355 & 0,0507 \\
\hline \hline THO6-H25-VC & & 23,71 & 0,0046 & 0,0052 & 0,0599 & 0,0750 \\
\hline
\end{tabular}

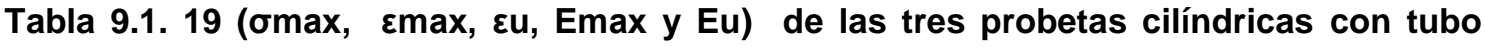
vertical descentrado, de hormigón H-25 ensayado a compresión.

\begin{tabular}{|c||c|c|c|c|c|c|}
\hline & Temperatura (ㅇ) & бmax (N/mm2) & $\boldsymbol{\varepsilon m a x}$ & $\boldsymbol{\varepsilon u}$ & Emax (N/mm2) & Eu (N/mm2) \\
\hline \hline MEDIA & & 22,42 & 0,0042 & 0,0051 & 0,0534 & 0,0718 \\
\hline \hline THO7-H25-VD & & 22,09 & 0,0043 & 0,0056 & 0,0548 & 0,0784 \\
\hline \hline THO8-H25-VD & & 22,74 & 0,0039 & 0,0045 & 0,0492 & 0,0616 \\
\hline \hline THO9-H25-VD & & 22,43 & 0,0044 & 0,0053 & 0,0562 & 0,0755 \\
\hline
\end{tabular}

Tabla 9.1. 20 ( $\sigma \max , \varepsilon \max , \varepsilon u, E \max$ y Eu) de las tres probetas cilíndricas con tubo horizontal, de hormigón H-25 ensayado a compresión.

\begin{tabular}{|c||c|c|c|c|c|c|}
\hline \multicolumn{1}{|c|}{} & Temperatura (oC) & $\boldsymbol{\sigma m a x}(\mathbf{N} / \mathbf{m m 2})$ & $\boldsymbol{\varepsilon m a x}$ & $\boldsymbol{\varepsilon u}$ & $\operatorname{Emax}(\mathbf{N} / \mathbf{m m} 2)$ & $\mathrm{Eu}(\mathbf{N} / \mathbf{m m}$ ) \\
\hline \hline MEDIA & & 18,28 & 0,0034 & 0,0046 & 0,0343 & 0,0531 \\
\hline \hline THO10-H25-H & & 17,78 & 0,0033 & 0,0045 & 0,0313 & 0,0500 \\
\hline \hline THO11-H25-H & & 18,59 & 0,0037 & 0,0050 & 0,0390 & 0,0613 \\
\hline \hline THO12-H25-H & & 18,47 & 0,0033 & 0,0043 & 0,0327 & 0,0481 \\
\hline
\end{tabular}


Tabla 9.1. 21 ( $\sigma \max , \varepsilon m a x, \varepsilon u$, Emax y Eu) de las tres probetas cilíndricas sin tubo, de hormigón H-30 ensayado a compresión.

\begin{tabular}{|c||c|c|c|c|c|c|}
\hline & Temperatura (ㅇ) & бmax (N/mm2) & $\boldsymbol{\varepsilon m a x}$ & $\boldsymbol{\varepsilon u}$ & Emax (N/mm2) & Eu (N/mm2) \\
\hline \hline MEDIA & & 29,91 & 0,0048 & 0,0056 & 0,0806 & 0,1016 \\
\hline \hline THO1-H30-Ref & & 28,98 & 0,0047 & 0,0055 & 0,0786 & 0,1010 \\
\hline \hline THO2-H30-Ref & & 29,67 & 0,0049 & 0,0059 & 0,0822 & 0,1101 \\
\hline \hline THO3-H30-Ref & & 31,08 & 0,0049 & 0,0053 & 0,0811 & 0,0938 \\
\hline
\end{tabular}

Tabla 9.1. 22 ( $\sigma \max , \varepsilon \max , \varepsilon u$, Emax y Eu) de las tres probetas cilíndricas con tubo vertical centrado, de hormigón H-30 ensayado a compresión.

\begin{tabular}{|c||c|c|c|c|c|c|}
\hline & Temperatura (oC) & $\boldsymbol{\sigma m a x}$ (N/mm2) & $\boldsymbol{\varepsilon m a x}$ & $\boldsymbol{\varepsilon u}$ & $\operatorname{Emax~(N/mm2)}$ & Eu (N/mm2) \\
\hline \hline MEDIA & & 27,09 & 0,0046 & 0,0053 & 0,0694 & 0,0546 \\
\hline \hline THO4-H30-VC & & 26,37 & 0,0042 & 0,0046 & 0,0609 & 0,0709 \\
\hline \hline THO5-H30-VC & & 28,02 & 0,0049 & 0,0056 & 0,0751 & 0,0415 \\
\hline \hline THO6-H30-VC & & 26,89 & 0,0048 & 0,0058 & 0,0722 & 0,0513 \\
\hline
\end{tabular}

Tabla 9.1. 23 ( $\sigma \max , \varepsilon \max , \varepsilon u$, Emax y Eu) de las tres probetas cilíndricas con tubo vertical descentrado, de hormigón H-30 ensayado a compresión.

\begin{tabular}{|c|c|c|c|c|c|c|}
\hline & Temperatura (으) & $\sigma m a x(\mathrm{~N} / \mathrm{mm} 2)$ & $\varepsilon \max$ & $\varepsilon \mathrm{su}$ & $\operatorname{Emax}(\mathrm{N} / \mathrm{mm} 2)$ & Eu (N/mm2) \\
\hline MEDIA & & \begin{tabular}{|l|}
26,77 \\
\end{tabular} & 0,0046 & 0,0058 & 0,0702 & 0,0624 \\
\hline TH07-H30-VD & & 24,33 & 0,0040 & 0,0053 & 0,0541 & 0,0649 \\
\hline THO8-H30-VD & & 27,61 & 0,0046 & 0,0056 & 0,0714 & 0,0624 \\
\hline THO9-H30-VD & & 28,36 & 0,0053 & 0,0065 & 0,0851 & 0,0598 \\
\hline
\end{tabular}

Tabla 9.1. 24 ( $\sigma \max , \varepsilon \max , \varepsilon u$, Emax y Eu) de las tres probetas cilíndricas con tubo horizontal, de hormigón H-30 ensayado a compresión.

\begin{tabular}{|c||c|c|c|c|c|c|}
\hline & Temperatura (oC) & $\boldsymbol{\sigma m a x}$ (N/mm2) & $\boldsymbol{\varepsilon m a x}$ & $\boldsymbol{\varepsilon u}$ & $\operatorname{Emax}(\mathbf{N} / \mathbf{m m 2})$ & $\mathrm{Eu}(\mathbf{N} / \mathbf{m m}$ ) \\
\hline \hline MEDIA & & 21,58 & 0,0044 & 0,0053 & 0,0531 & 0,0697 \\
\hline \hline THO10-H30-H & & 20,19 & 0,0046 & 0,0058 & 0,0477 & 0,0699 \\
\hline \hline THO11-H30-H & & 21,64 & 0,0046 & 0,0053 & 0,0581 & 0,0718 \\
\hline \hline THO12-H30-H & & 22,91 & 0,0041 & 0,0047 & 0,0535 & 0,0673 \\
\hline
\end{tabular}

Tabla 9.1. 25 ( $\sigma \max , \varepsilon \max , \varepsilon u$, Emax y Eu) de las tres probetas cúbicas con tubo horizontal, de hormigón H-25 ensayado a compresión.

\begin{tabular}{|c||c|c|c|c|c|c|}
\hline & Temperatura (-C) & $\boldsymbol{\sigma m a x}(\mathbf{N} / \mathbf{m m 2})$ & $\boldsymbol{\varepsilon m a x}$ & $\boldsymbol{\varepsilon u}$ & Emax (N/mm2) & Eu (N/mm2) \\
\hline \hline MEDIA H & & 24,22 & 0,0045 & 0,0085 & 0,0629 & 0,1339 \\
\hline \hline TO1-H25-H & & 25,83 & 0,0048 & 0,0082 & 0,0680 & 0,1335 \\
\hline \hline TO2-H25-H & & 23,10 & 0,0043 & 0,0081 & 0,0564 & 0,1226 \\
\hline \hline TO3-H25-H & & 23,75 & 0,0045 & 0,0091 & 0,0643 & 0,1454 \\
\hline
\end{tabular}


Tabla 9.1. 26 ( $\sigma \max , \varepsilon \max , \varepsilon u$, Emax y Eu) de las tres probetas cúbicas con tubo vertical, de hormigón H-25 ensayado a compresión.

\begin{tabular}{|c||c|c|c|c|c|c|}
\hline \multicolumn{1}{|c|}{} & Temperatura (ㅇ) & бmax (N/mm2) & $\boldsymbol{\varepsilon m a x}$ & $\boldsymbol{\varepsilon u}$ & Emax (N/mm2) & Eu (N/mm2) \\
\hline \hline MEDIA & & 28,53 & 0,0046 & 0,0087 & 0,0709 & 0,1584 \\
\hline \hline TO4-H25-V & & 27,97 & 0,0047 & 0,0094 & 0,0689 & 0,1694 \\
\hline \hline TO5-H25-V & & 28,59 & 0,0043 & 0,0080 & 0,0667 & 0,1447 \\
\hline \hline TO6-H25-V & & 29,04 & 0,0048 & 0,0086 & 0,0770 & 0,1609 \\
\hline
\end{tabular}

Tabla 9.1. 27 ( $\sigma \max , \varepsilon \max , \varepsilon u$, Emax y Eu) de las tres probetas cúbicas con tubo horizontal, de hormigón H-25 ensayado a compresión.

\begin{tabular}{|c||c|c|c|c|c|c|}
\hline & Temperatura (ㅇ) & $\boldsymbol{\sigma m a x}$ (N/mm2) & $\boldsymbol{\varepsilon m a x}$ & $\boldsymbol{\varepsilon u}$ & Emax (N/mm2) & Eu (N/mm2) \\
\hline \hline MEDIA H & & 24,81 & 0,0039 & 0,0086 & 0,0545 & 0,1400 \\
\hline \hline TO7-H25-H & & 25,06 & 0,0037 & 0,0080 & 0,0498 & 0,1295 \\
\hline \hline TO8-H25-H & & 25,55 & 0,0040 & 0,0085 & 0,0568 & 0,1446 \\
\hline \hline TO9-H25-H & & 23,82 & 0,0042 & 0,0093 & 0,0568 & 0,1460 \\
\hline
\end{tabular}

Tabla 9.1. 28 ( $\sigma \max , \varepsilon \max , \varepsilon u$, Emax y Eu) de las tres probetas cúbicas con tubo vertical, de hormigón H-25 ensayado a compresión.

\begin{tabular}{|c||c|c|c|c|c|c|}
\hline \multicolumn{1}{|c|}{} & Temperatura (ㅇ) & $\boldsymbol{\sigma m a x}(\mathbf{N} / \mathbf{m m 2})$ & $\boldsymbol{\varepsilon m a x}$ & $\boldsymbol{\varepsilon u}$ & $\operatorname{Emax}(\mathbf{N} / \mathbf{m m} 2)$ & $\mathrm{Eu}(\mathbf{N} / \mathbf{m m} \mathbf{2})$ \\
\hline \hline MEDIA V & & 27,28 & 0,0049 & 0,0095 & 0,0731 & 0,1668 \\
\hline \hline TO10-H25-V & & 24,53 & 0,0054 & 0,0101 & 0,0713 & 0,1563 \\
\hline \hline TO11-H25-V & & 27,72 & 0,0044 & 0,0097 & 0,0677 & 0,1752 \\
\hline \hline TO12-H25-V & & 29,58 & 0,0048 & 0,0088 & 0,0803 & 0,1688 \\
\hline \hline
\end{tabular}

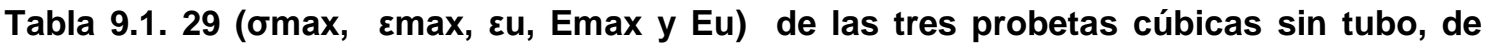
hormigón H-25 ensayado a compresión.

\begin{tabular}{|c||c|c|c|c|c|c|}
\hline & Temperatura (ㅇ) & $\boldsymbol{\sigma m a x}(\mathbf{N} / \mathbf{m m 2})$ & $\boldsymbol{\varepsilon m a x}$ & $\boldsymbol{\varepsilon u}$ & Emax (N/mm2) & Eu (N/mm2) \\
\hline \hline MEDIA Ref & & 31,98 & 0,0049 & 0,0101 & 0,0878 & 0,2097 \\
\hline \hline TO13-H25-Ref & & 31,64 & 0,0046 & 0,0097 & 0,0786 & 0,1936 \\
\hline \hline TO14-H25-Ref & & 31,96 & 0,0049 & 0,0103 & 0,0889 & 0,2164 \\
\hline \hline T015-H25-Ref & & 32,33 & 0,0052 & 0,0104 & 0,0959 & 0,2190 \\
\hline
\end{tabular}

Tabla 9.1. 30 ( $\sigma \max , \varepsilon \max , \varepsilon u$, Emax y Eu) de las tres probetas cúbicas con tubo horizontal, de hormigón H-30 ensayado a compresión.

\begin{tabular}{|c||c|c|c|c|c|c|}
\hline & Temperatura (-C) & $\boldsymbol{\sigma m a x}(\mathbf{N} / \mathbf{m m 2})$ & $\boldsymbol{\varepsilon m a x}$ & $\boldsymbol{\varepsilon u}$ & Emax (N/mm2) & Eu (N/mm2) \\
\hline \hline MEDIA H & & 27,92 & 0,0046 & 0,0096 & 0,0716 & 0,1212 \\
\hline \hline TO1-H30-H & & 26,99 & 0,0052 & 0,0090 & 0,0801 & 0,1582 \\
\hline \hline TO2-H30-H & & 28,53 & 0,0046 & 0,0082 & 0,0758 & 0,0000 \\
\hline \hline TO3-H30-H & & 28,23 & 0,0040 & 0,0117 & 0,0588 & 0,2054 \\
\hline
\end{tabular}


Tabla 9.1. 31 ( $\sigma \max , \varepsilon \max , \varepsilon u$, Emax y Eu) de las tres probetas cúbicas con tubo vertical, de hormigón H-30 ensayado a compresión.

\begin{tabular}{|c||c|c|c|c|c|c|}
\hline & Temperatura (ㅇ) & бmax (N/mm2) & $\boldsymbol{\varepsilon m a x}$ & $\boldsymbol{\varepsilon u}$ & Emax (N/mm2) & Eu (N/mm2) \\
\hline \hline MEDIA V & & 35,68 & 0,0050 & 0,0080 & 0,0923 & 0,1733 \\
\hline \hline TO4-H30-V & & 36,09 & 0,0051 & 0,0075 & 0,0974 & 0,1674 \\
\hline \hline TO5-H30-V & & 35,96 & 0,0048 & 0,0081 & 0,0915 & 0,1796 \\
\hline \hline TO6-H30-V & & 34,99 & 0,0051 & 0,0084 & 0,0878 & 0,1728 \\
\hline
\end{tabular}

Tabla 9.1. 32 ( $\sigma \max , \varepsilon \max , \varepsilon u$, Emax y Eu) de las tres probetas cúbicas con tubo horizontal, de hormigón H-30 ensayado a compresión.

\begin{tabular}{|c||c|c|c|c|c|c|}
\hline \multicolumn{1}{|c|}{} & Temperatura (oC) & $\boldsymbol{\sigma m a x}(\mathbf{N} / \mathbf{m m 2})$ & $\boldsymbol{\varepsilon m a x}$ & $\boldsymbol{\varepsilon u}$ & $\operatorname{Emax}(\mathbf{N} / \mathbf{m m} 2)$ & $\mathrm{Eu}(\mathbf{N} / \mathbf{m m}$ ) \\
\hline \hline MEDIA H & & 30,11 & 0,0045 & 0,0074 & 0,0718 & 0,1352 \\
\hline \hline TO7-H30-H & & 29,94 & 0,0043 & 0,0070 & 0,0668 & 0,1270 \\
\hline \hline TO8-H30-H & & 30,05 & 0,0050 & 0,0077 & 0,0826 & 0,1405 \\
\hline \hline TO9-H30-H & & 30,34 & 0,0042 & 0,0074 & 0,0660 & 0,1382 \\
\hline
\end{tabular}

Tabla 9.1. 33 ( $\sigma \max , \varepsilon \max , \varepsilon u$, Emax y Eu) de las tres probetas cúbicas con tubo vertical, de hormigón $\mathrm{H}-30$ ensayado a compresión.

\begin{tabular}{|c||c|c|c|c|c|c|}
\hline \multicolumn{1}{|c|}{} & Temperatura (ㅇ) & $\boldsymbol{\sigma m a x}(\mathbf{N} / \mathbf{m m 2})$ & $\boldsymbol{\varepsilon m a x}$ & $\boldsymbol{\varepsilon u}$ & $\operatorname{Emax}(\mathbf{N} / \mathbf{m m} 2)$ & $\mathrm{Eu}(\mathbf{N} / \mathbf{m m} \mathbf{2})$ \\
\hline \hline MEDIA V & & 35,20 & 0,0056 & 0,0077 & 0,1114 & 0,0927 \\
\hline \hline TO10-H30-V & & 37,05 & 0,0050 & 0,0062 & 0,1022 & 0,1429 \\
\hline \hline TO11-H30-V & & 33,96 & 0,0055 & 0,0086 & 0,1033 & 0,0556 \\
\hline \hline TO12-H30-V & & 34,59 & 0,0062 & 0,0084 & 0,1287 & 0,0797 \\
\hline \hline
\end{tabular}

Tabla 9.1. 34 ( $\sigma \max , \varepsilon m a x, \varepsilon u$, Emax y Eu) de las tres probetas cúbicas sin tubo, de hormigón H-30 ensayado a compresión.

\begin{tabular}{|c||c|c|c|c|c|c|}
\hline & Temperatura (ㅇ) & бmax (N/mm2) & हmax & $\boldsymbol{\varepsilon u}$ & Emax (N/mm2) & Eu (N/mm2) \\
\hline \hline MEDIA Ref & & 34,62 & 0,0064 & 0,0094 & 0,1156 & 0,1929 \\
\hline \hline TO13-H30-Ref & & 25,53 & 0,0087 & 0,0124 & 0,1149 & 0,1859 \\
\hline \hline TO14-H30-Ref & & 39,24 & 0,0053 & 0,0096 & 0,1179 & 0,2385 \\
\hline \hline TO15-H30-Ref & & 39,09 & 0,0053 & 0,0064 & 0,1139 & 0,1543 \\
\hline
\end{tabular}




\section{ANEXO 2}

\section{GRAFICAS DE}

RESULTADOS 


\section{ANEXO 2.1}

\section{GRAFICAS DE}

RESULTADOS

INDIVIDUALES 
9.2.1.1 Gráfica Tensión $\sigma(\mathrm{N} / \mathrm{mm} 2) /$ Deformación $\varepsilon$ (adimensional) de las probetas cilíndricas elaboradas con hormigón $\mathrm{H}-25$, sometidas a temperaturas de $20^{\circ}, 40^{\circ}, 70^{\circ}$ y $100^{\circ}$ C y ensayadas a compresión.
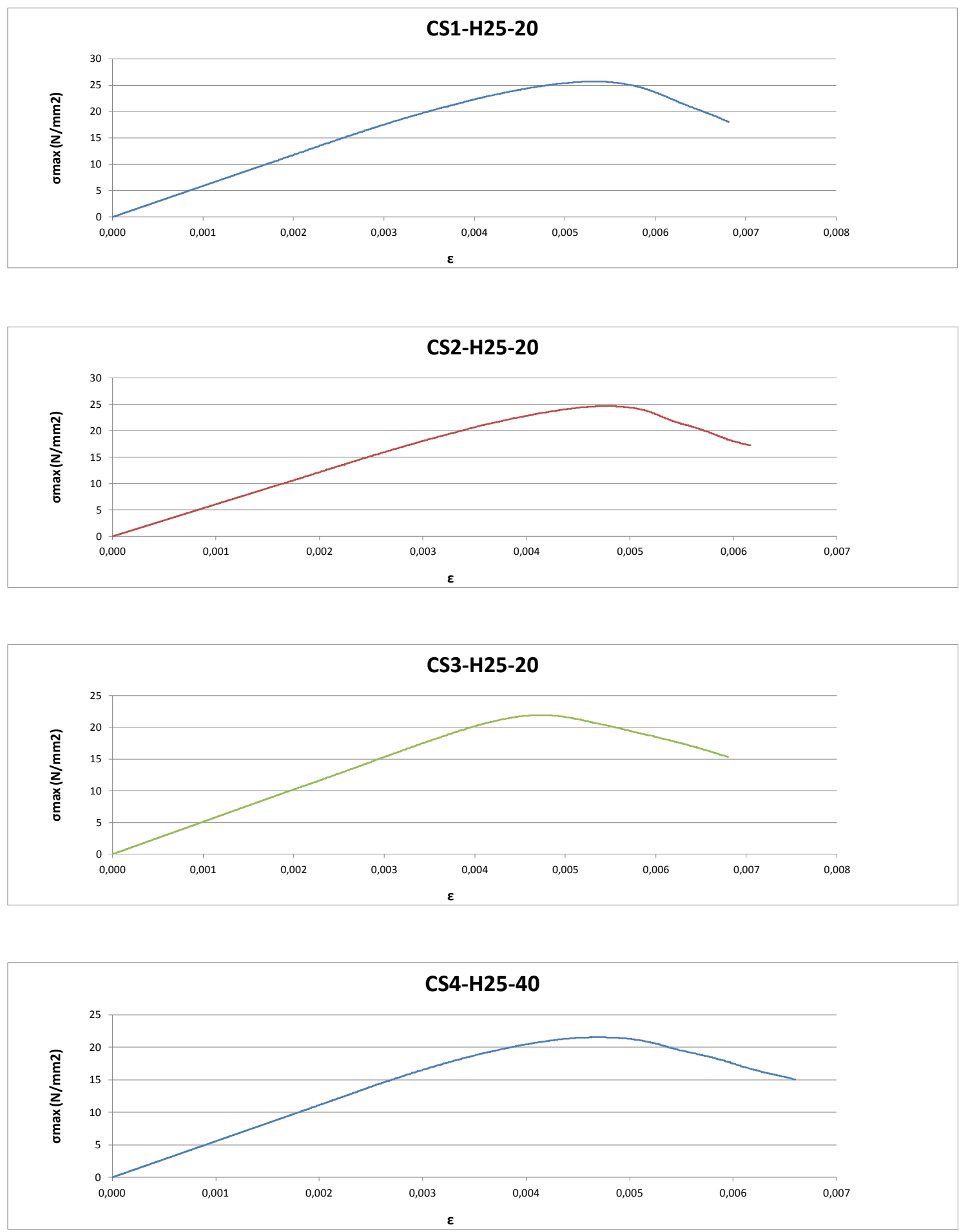

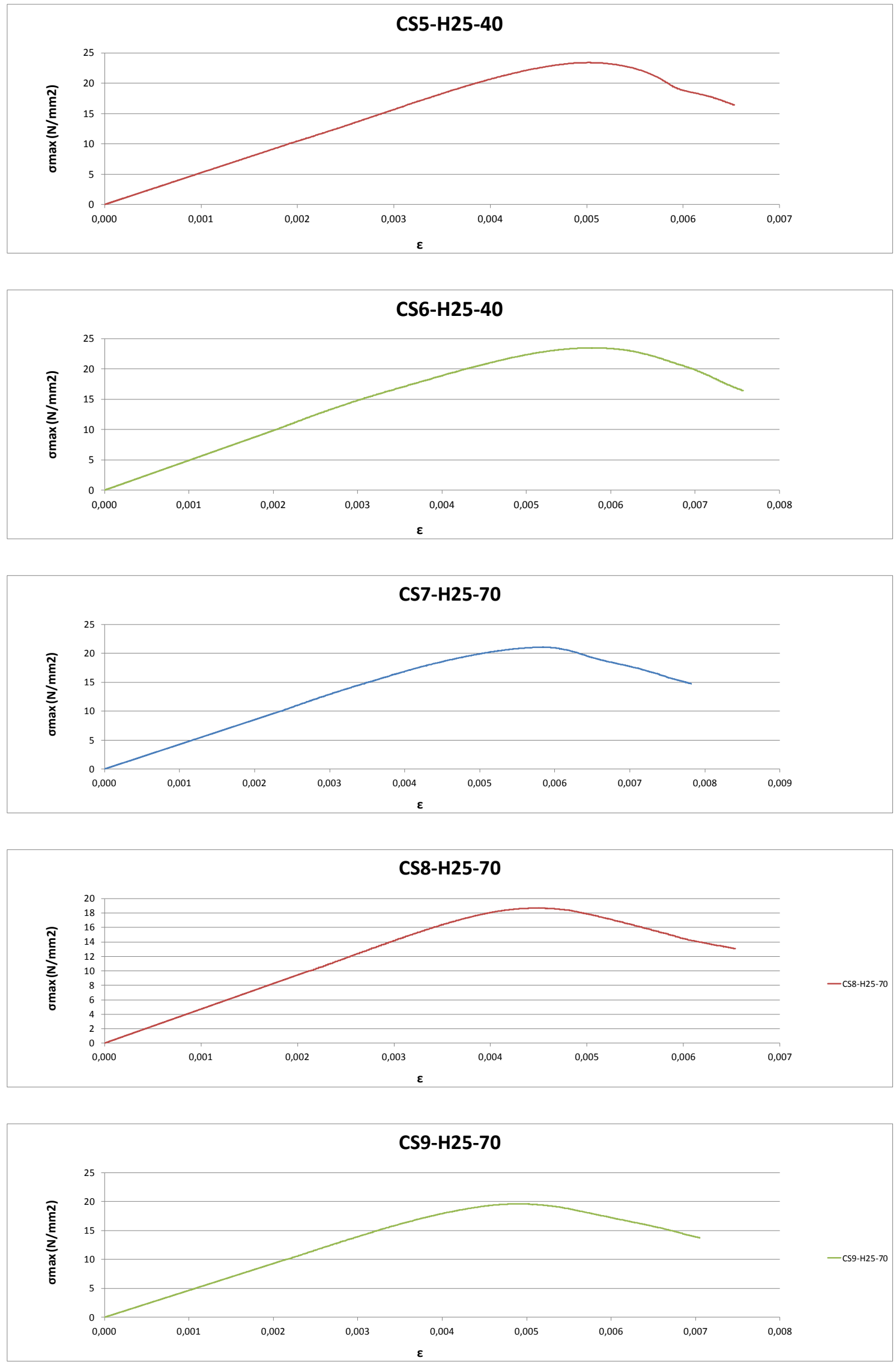

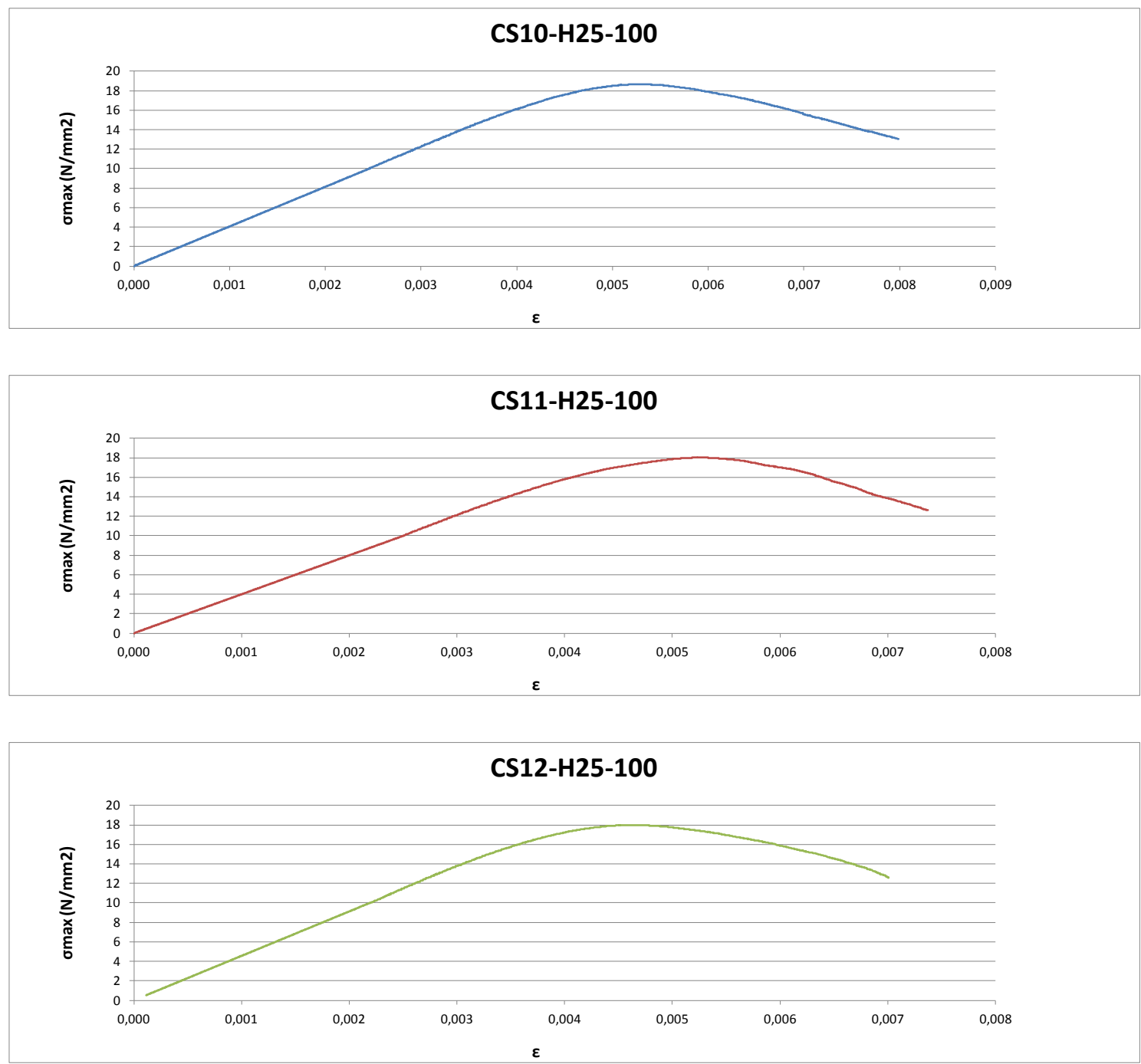
9.2.1.2 Gráfica Tensión $\sigma(\mathrm{N} / \mathrm{mm} 2) /$ Deformación $\varepsilon$ (adimensional) de las probetas cilíndricas elaboradas con hormigón $\mathrm{H}-30$, sometidas a temperaturas de $20^{\circ}, 40^{\circ}, 70^{\circ}$ y $100^{\circ} \mathrm{C}$ y ensayadas a compresión.
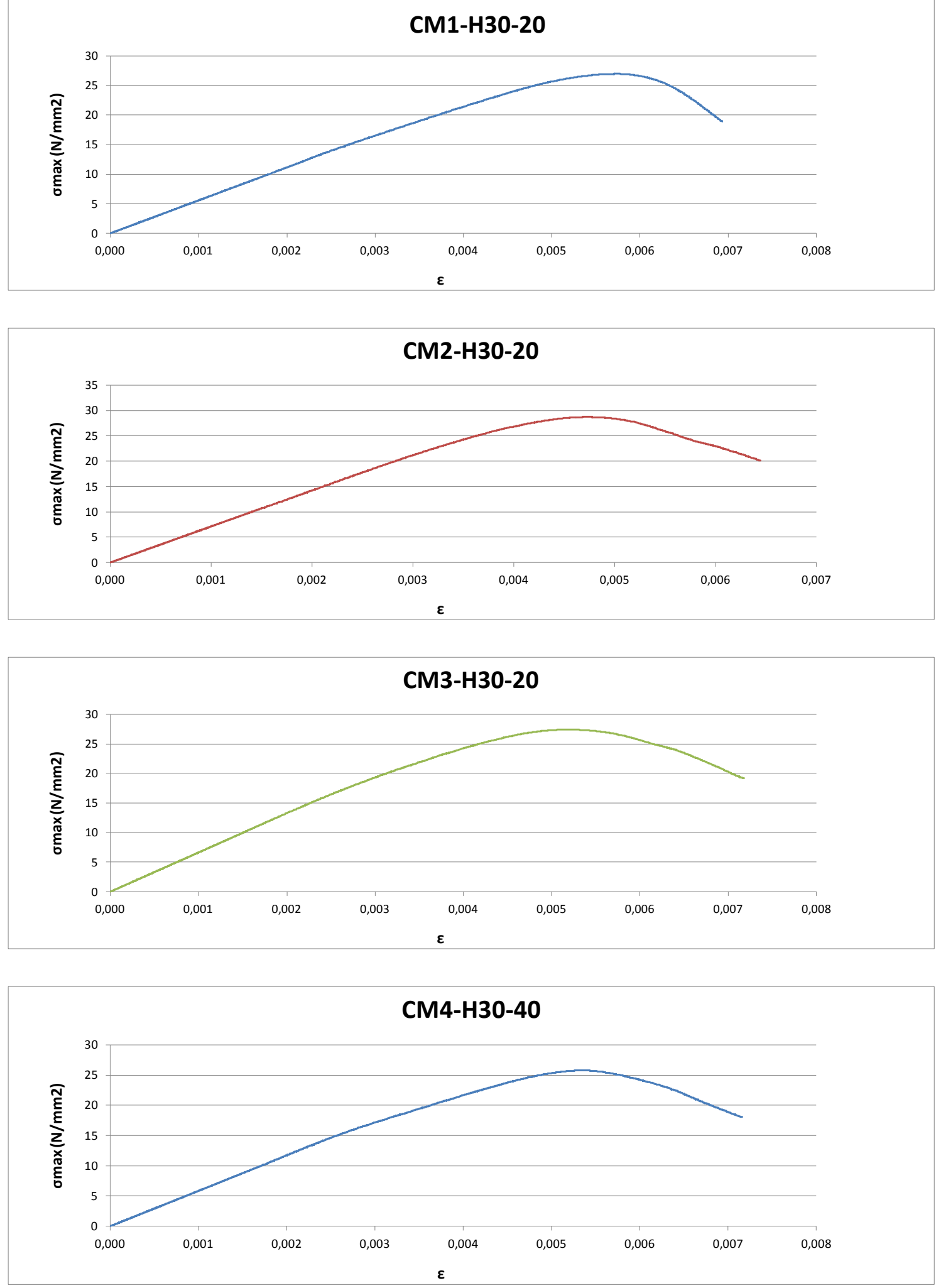

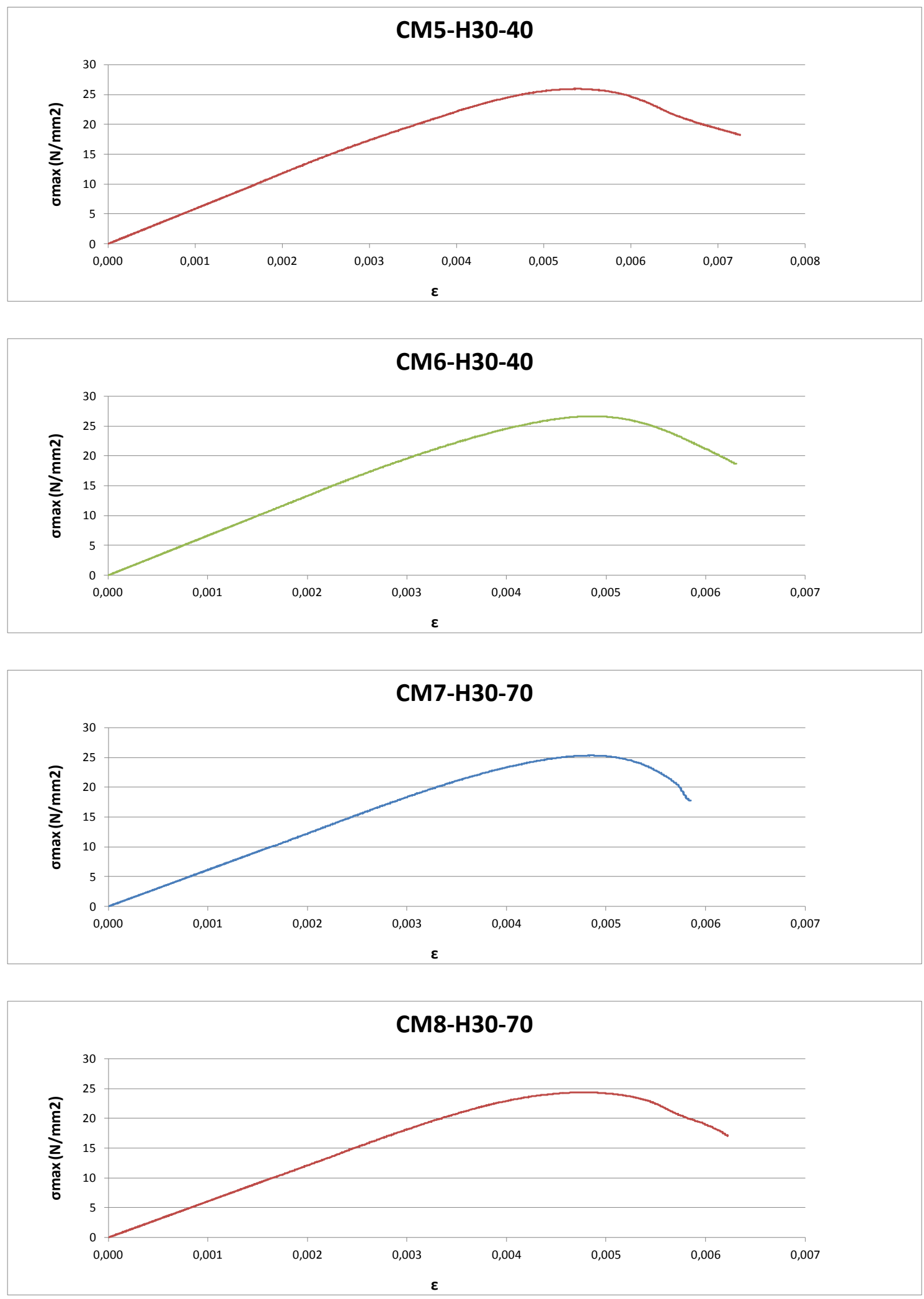

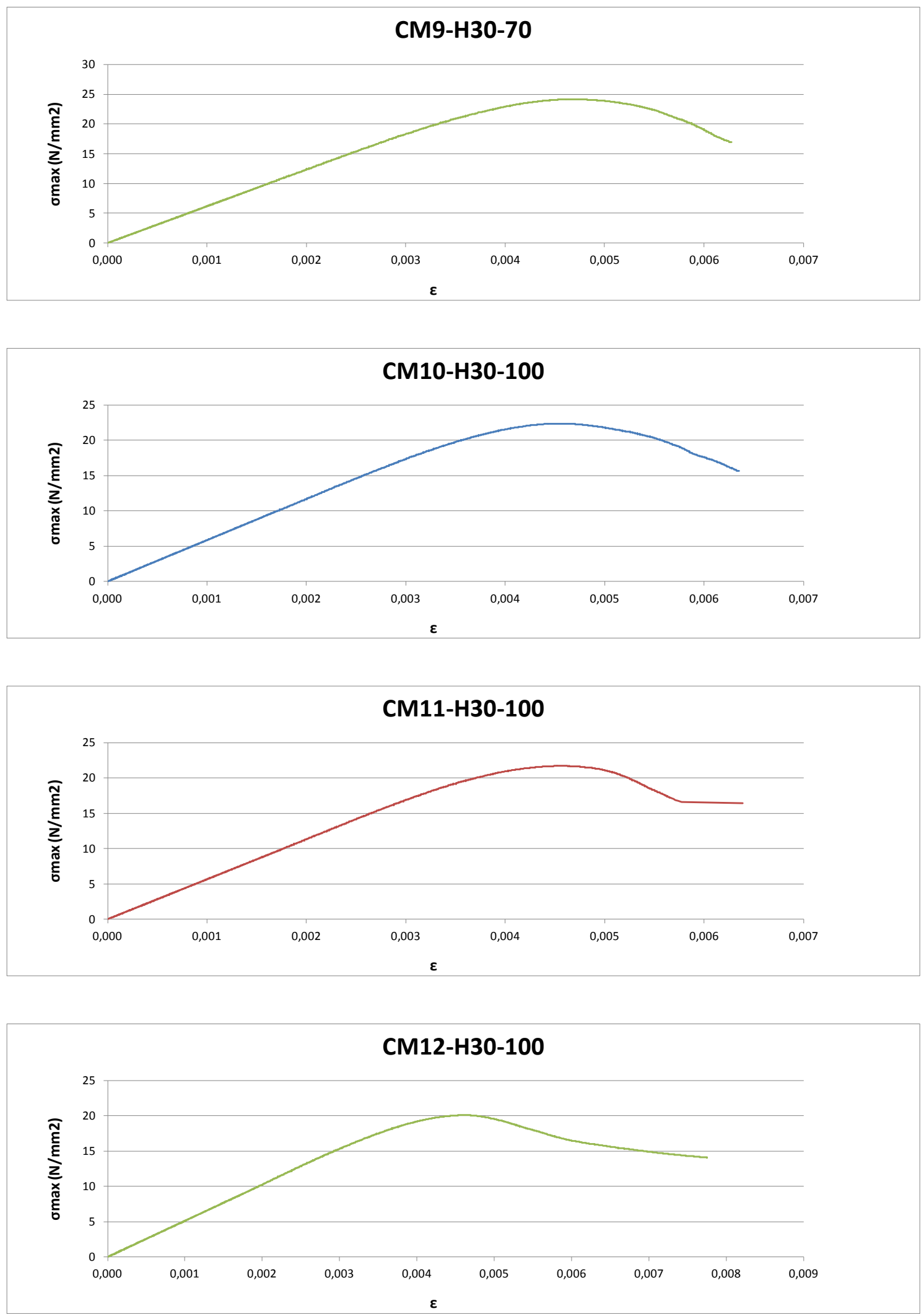
9.2.1.3 Gráfica Fuerza F (KN) / Desplazamiento $\delta(\mathrm{mm})$ de las probetas cúbicas elaboradas con hormigón $\mathrm{H}-25$, sometidas a temperaturas de $20^{\circ}$, $40^{\circ}, 70^{\circ}$ y $100^{\circ} \mathrm{C}$ y ensayadas a arrancamiento o pull-out.
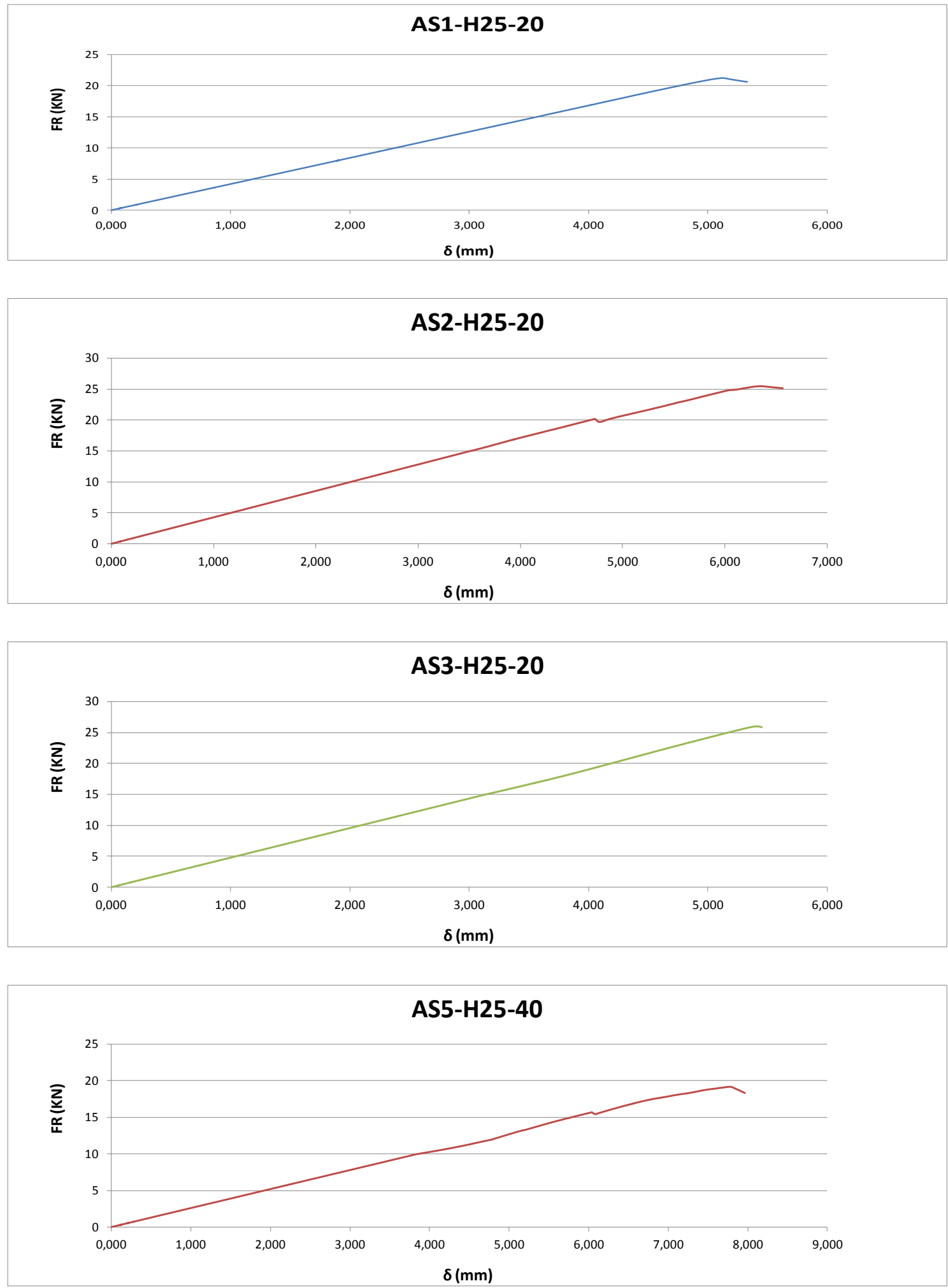

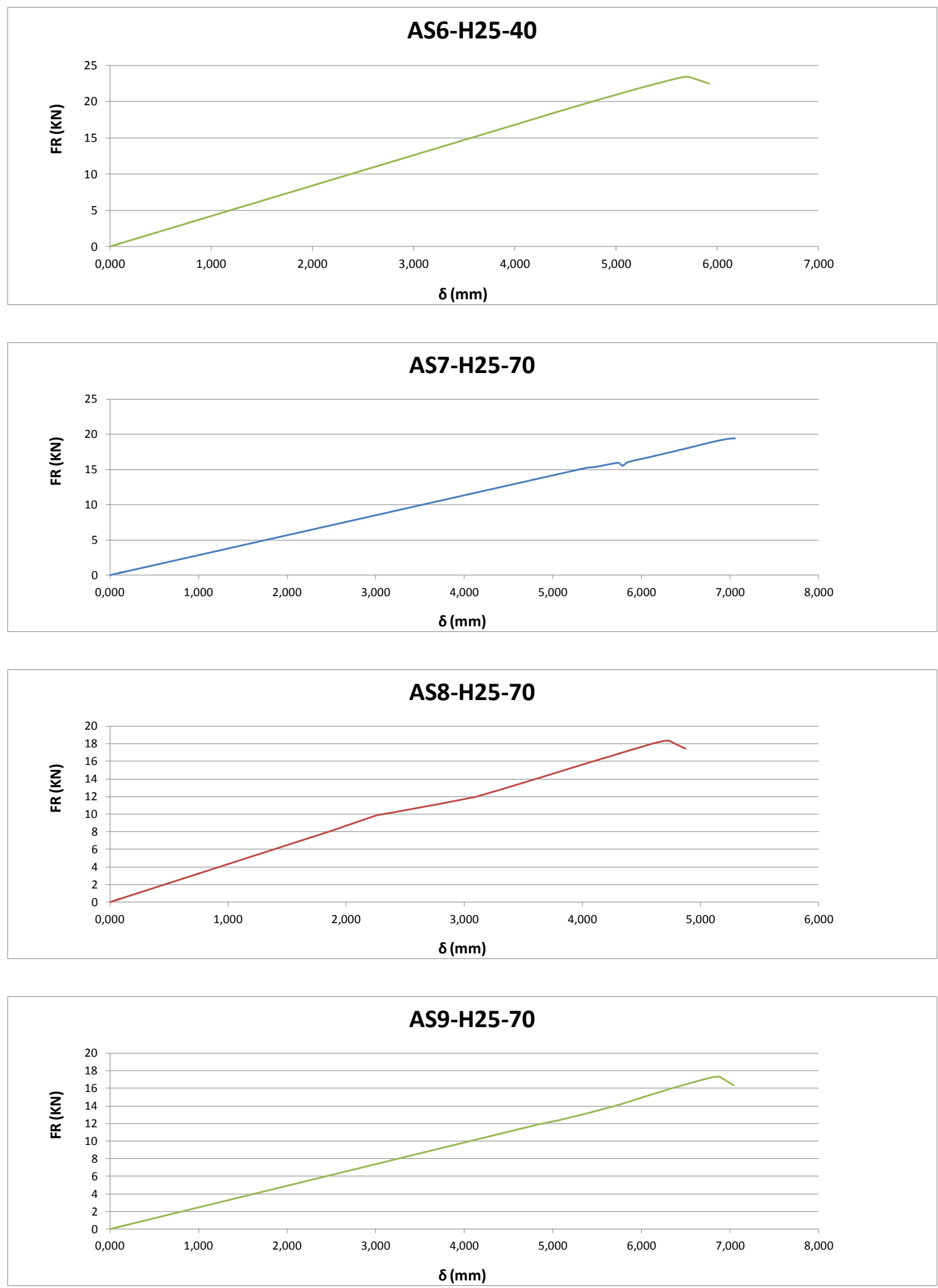

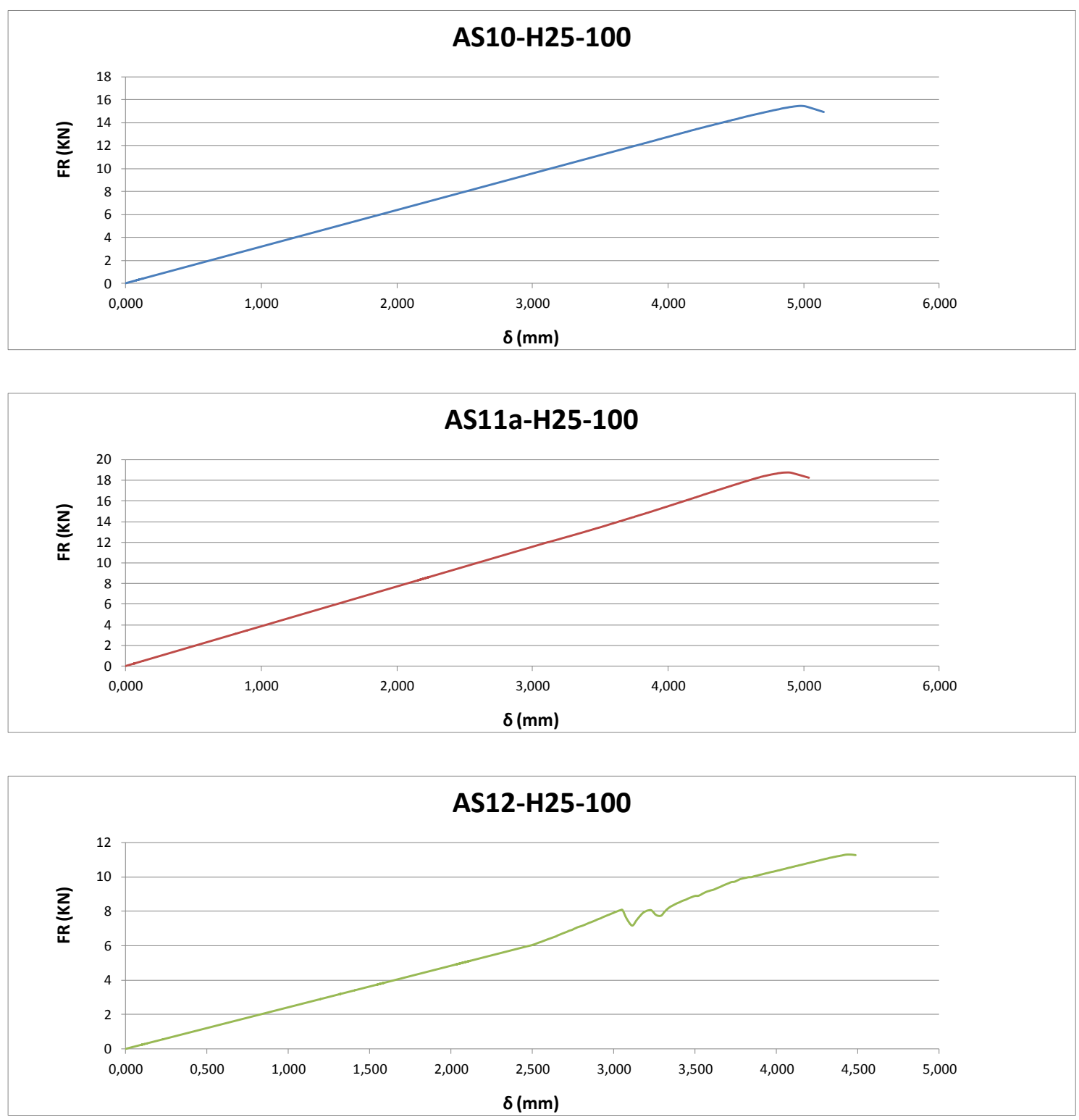
9.2.1.4 Gráfica Fuerza $F(\mathrm{KN})$ / Desplazamiento $\delta(\mathrm{mm})$ de las probetas cúbicas elaboradas con hormigón $\mathrm{H}-30$, sometidas a temperaturas de $20^{\circ}$, $40^{\circ}, 70^{\circ}$ y $100^{\circ} \mathrm{C}$ y ensayadas a arrancamiento o pull-out.
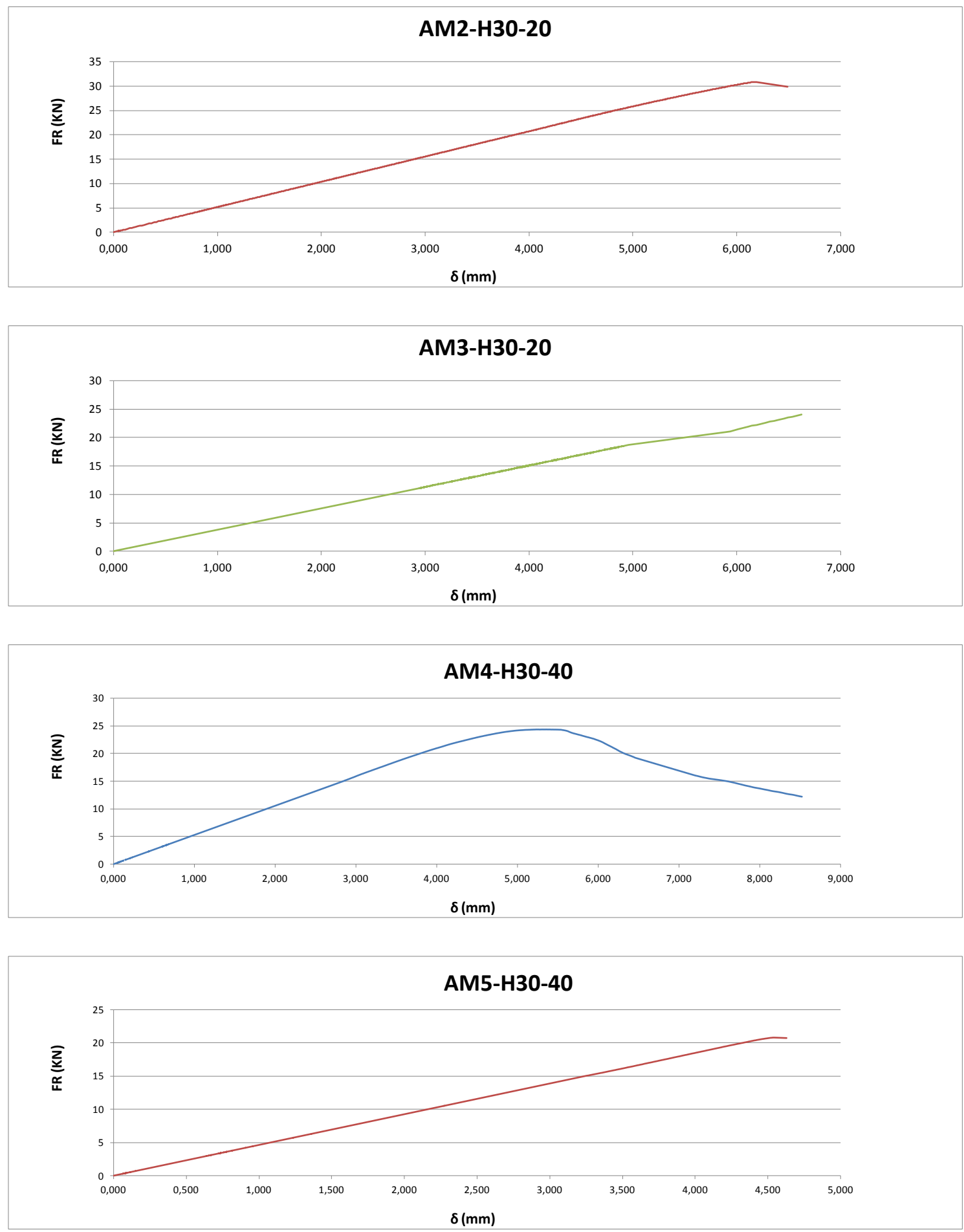

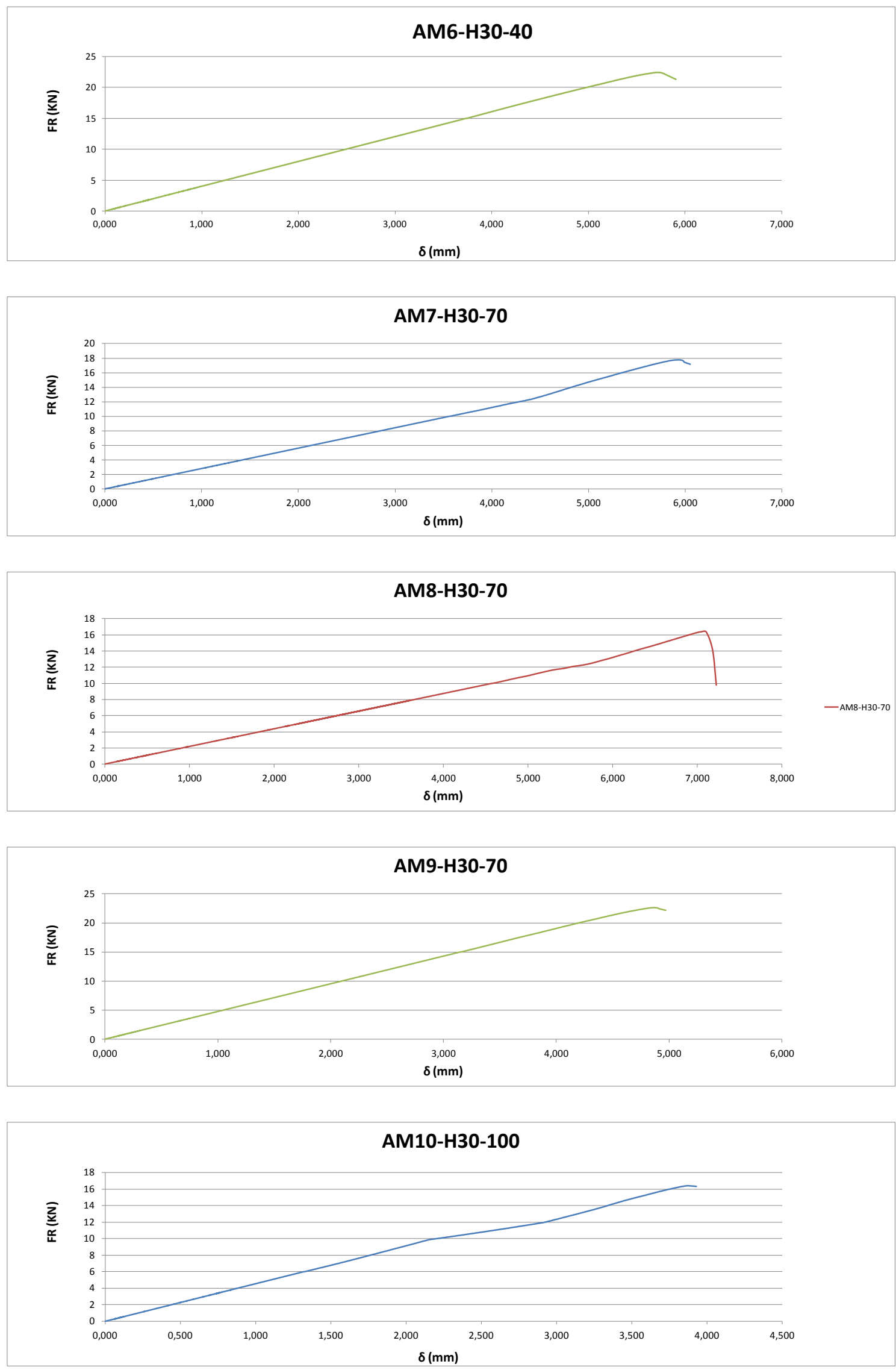

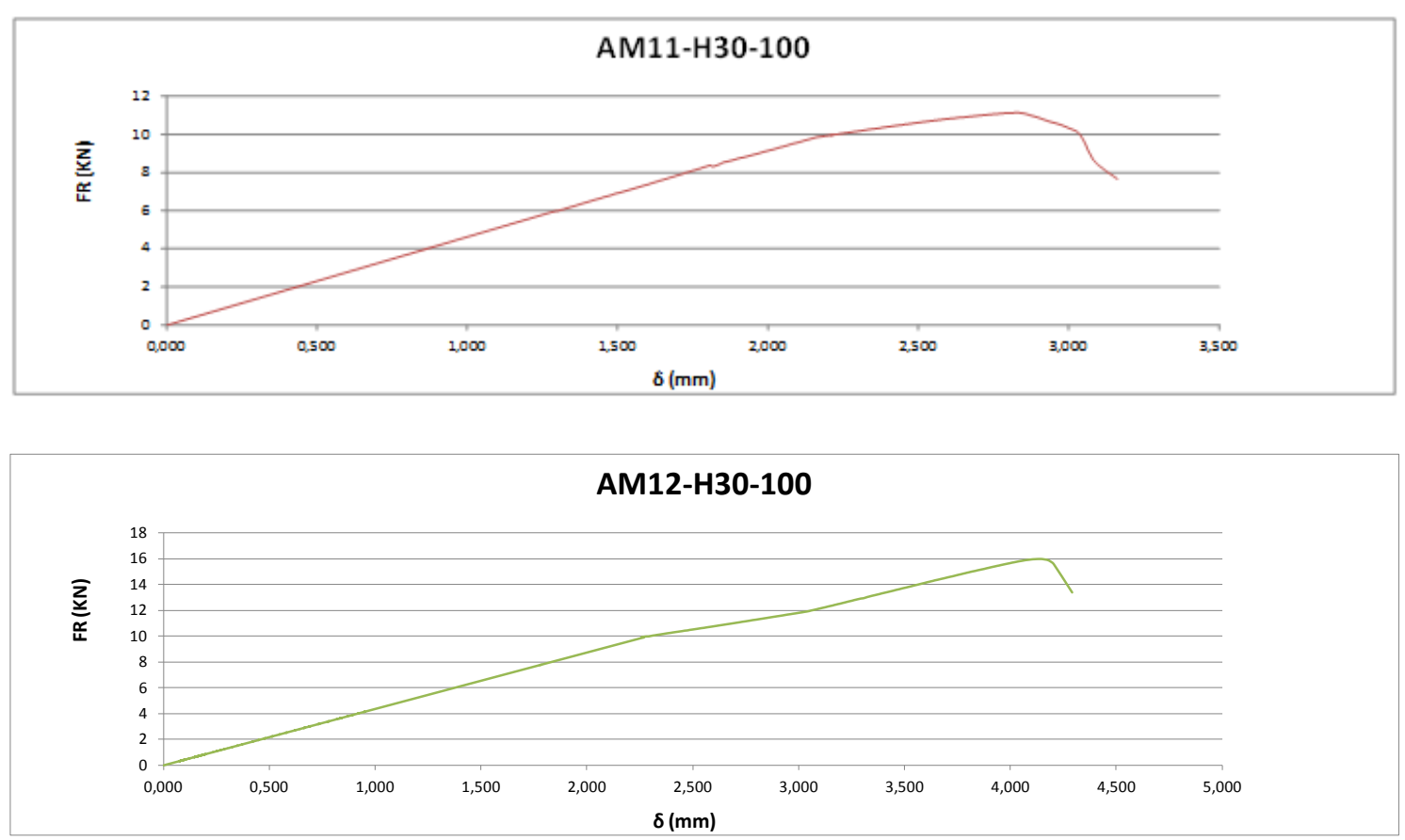
9.2.1.5 Gráfica Tensión $\sigma(\mathrm{N} / \mathrm{mm} 2) /$ Deformación $\varepsilon$ (adimensional) de las probetas cilíndricas elaboradas con hormigón $\mathrm{H}-25$, con tubo de polietileno dispuesto en su interior en distintas posiciones (vertical centrado, vertical descentrado, horizontal y sin tubo) ), ensayadas a compresión.
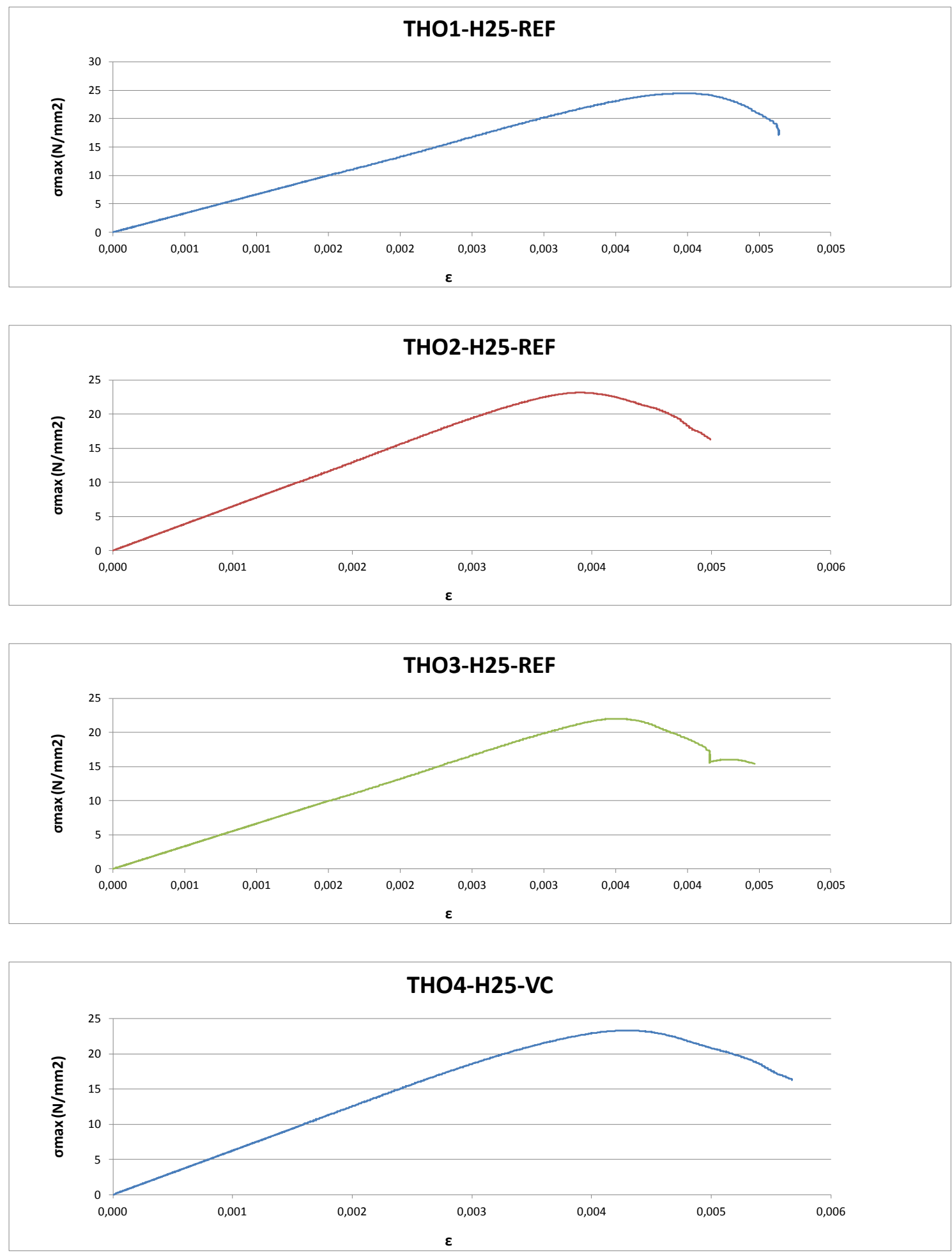

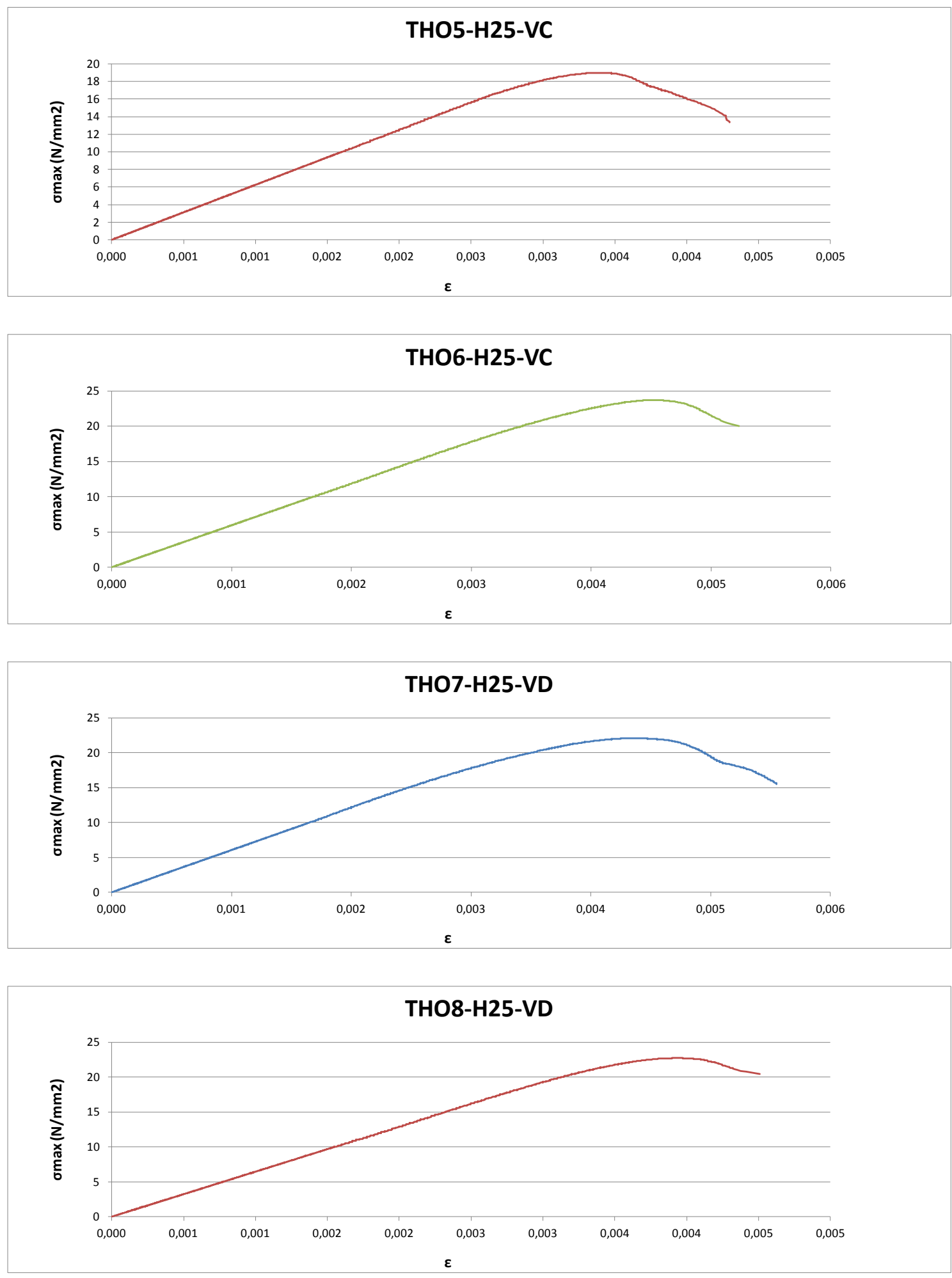

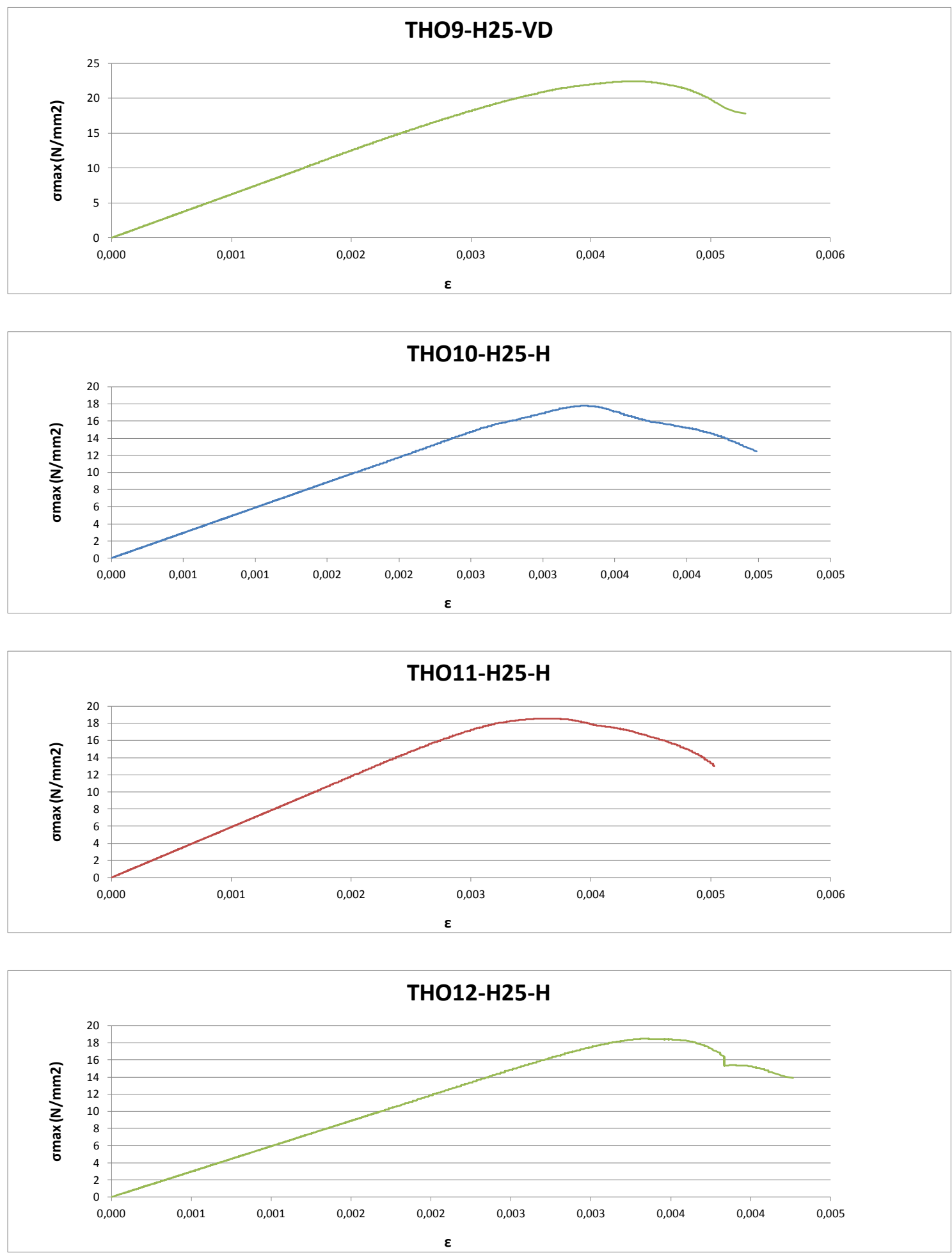
9.2.1.6 Gráfica Tensión $\sigma(\mathrm{N} / \mathrm{mm} 2) /$ Deformación $\varepsilon$ (adimensional) de las probetas cilíndricas elaboradas con hormigón $\mathrm{H}-30$, con tubo de polietileno dispuesto en su interior en distintas posiciones (vertical centrado, vertical descentrado, horizontal y sin tubo) ), ensayadas a compresión.
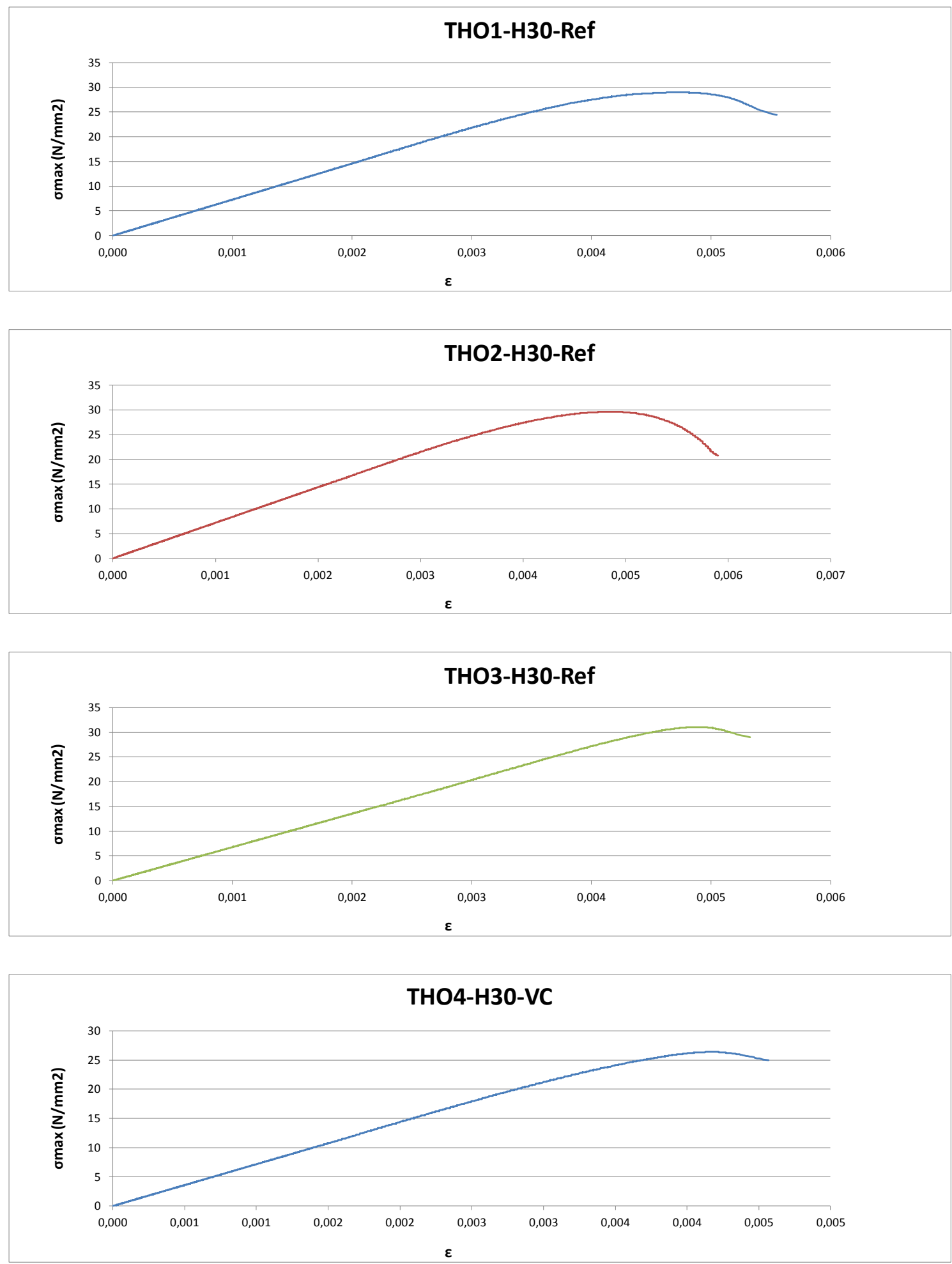

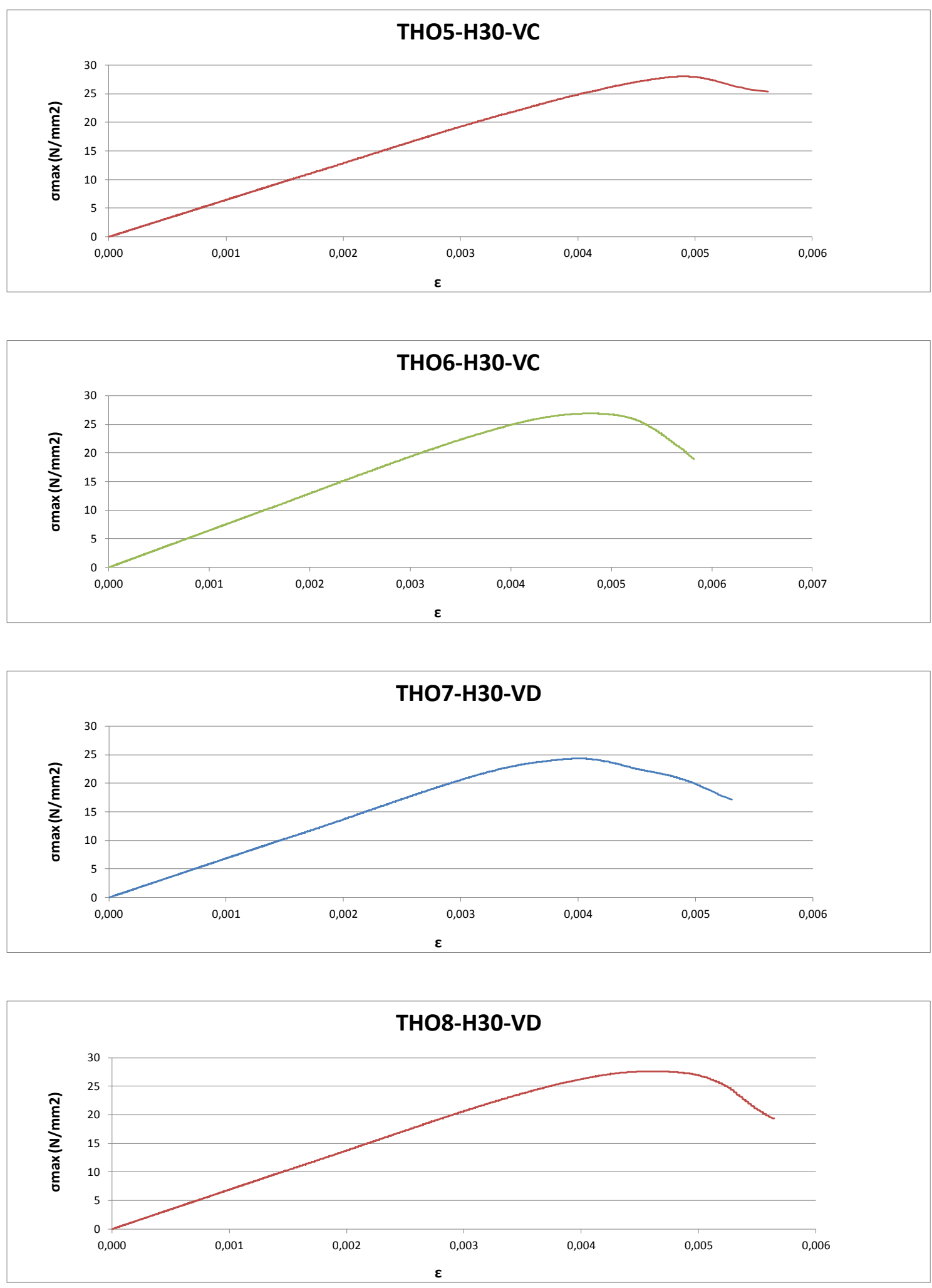

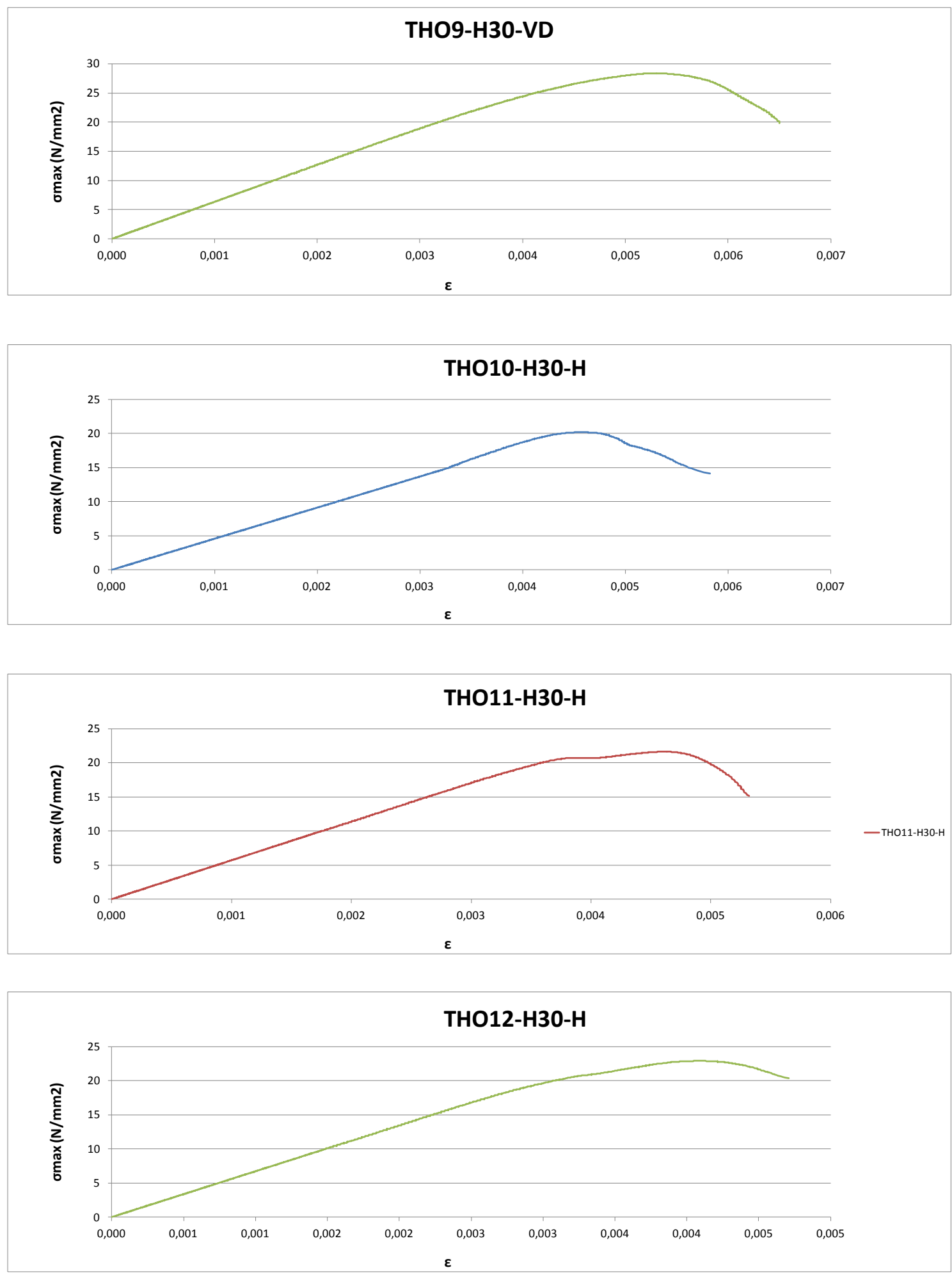
9.2.1.7 Gráfica Tensión $\sigma$ (N/mm2) / Deformación $\varepsilon$ (adimensional) de las probetas cúbicas elaboradas con hormigón $\mathrm{H}-25$, con tubo de polietileno dispuesto en su interior en distintas posiciones (vertical, horizontal y sin tubo), ensayadas a compresión.
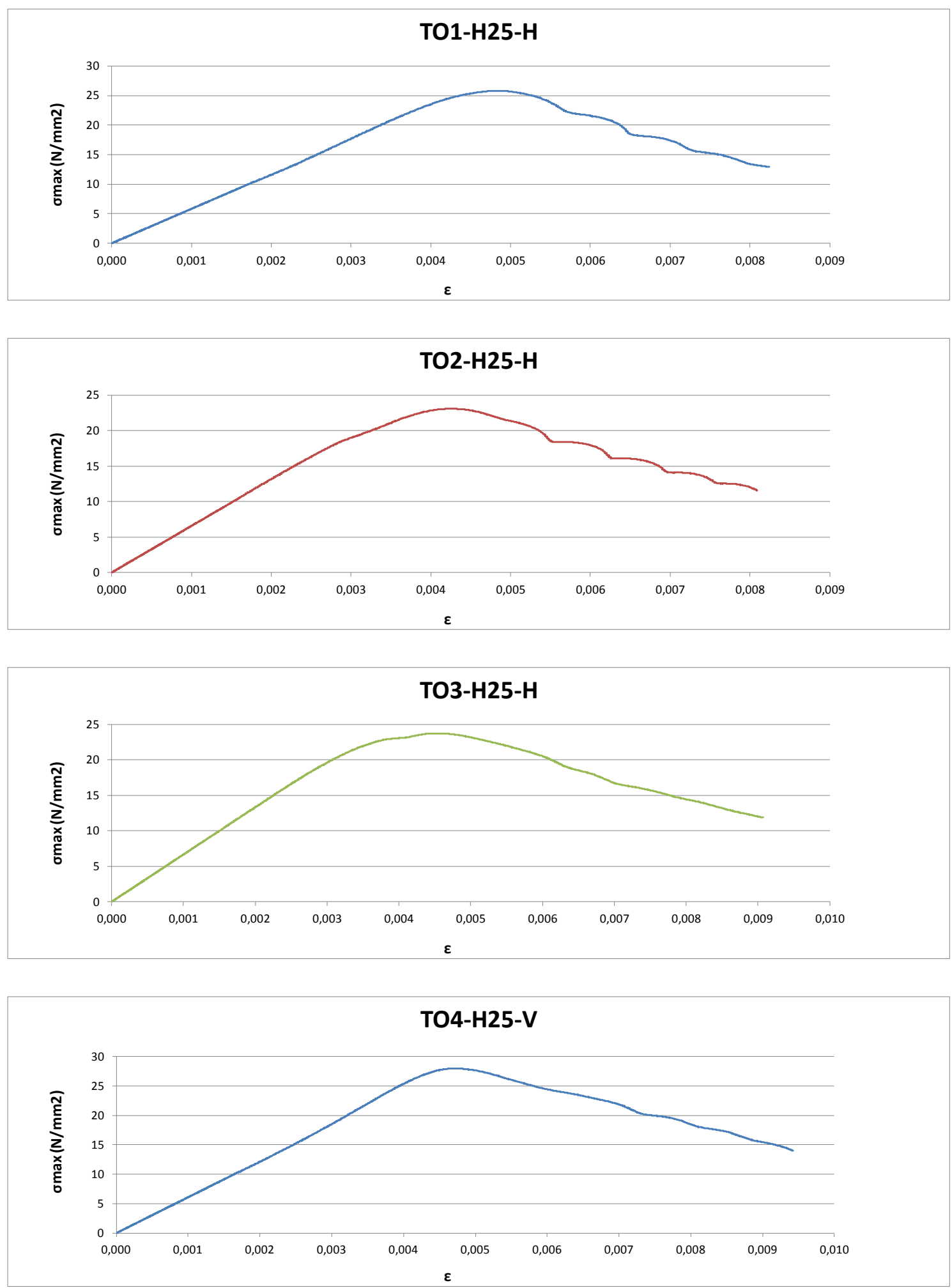

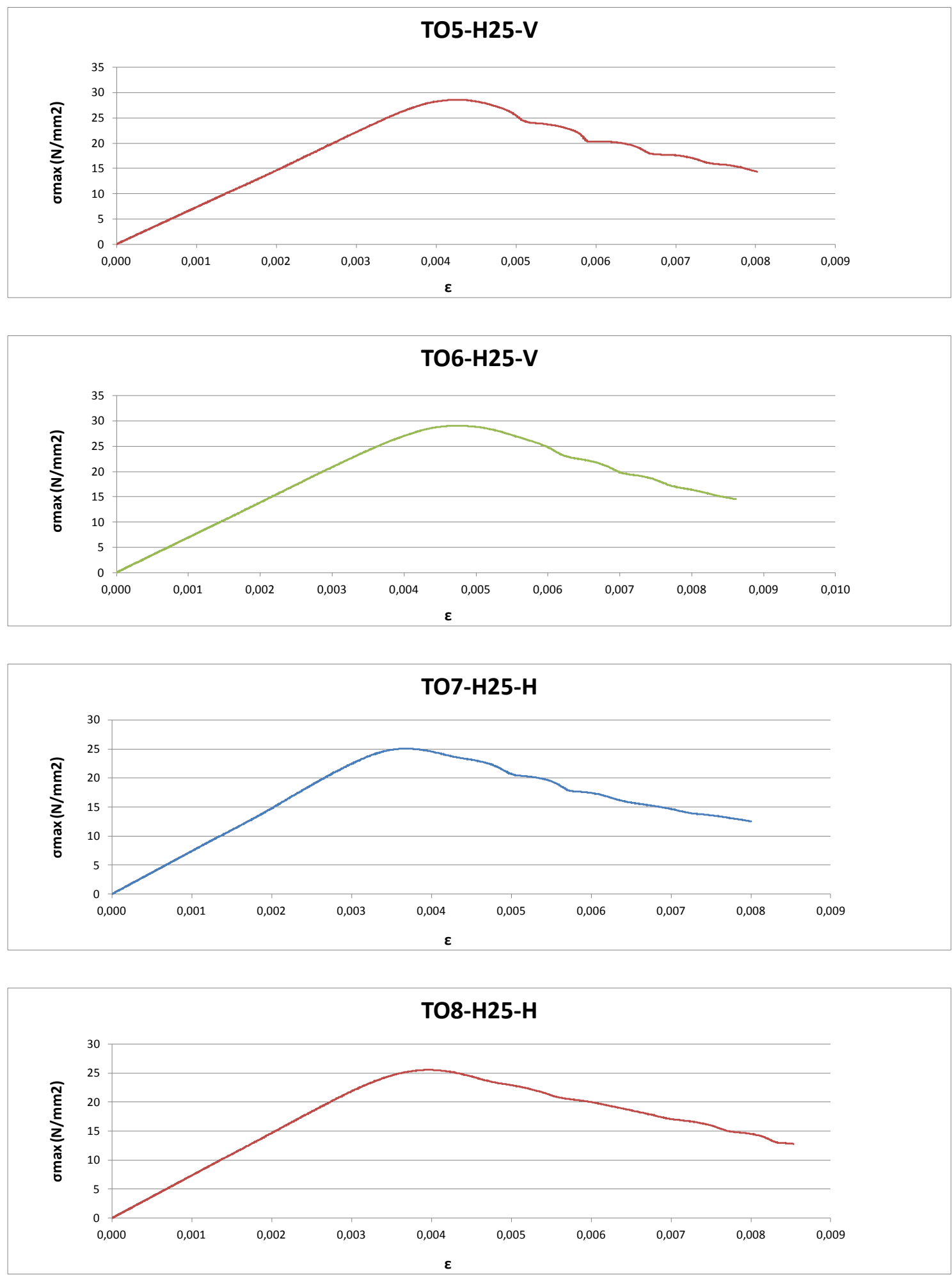

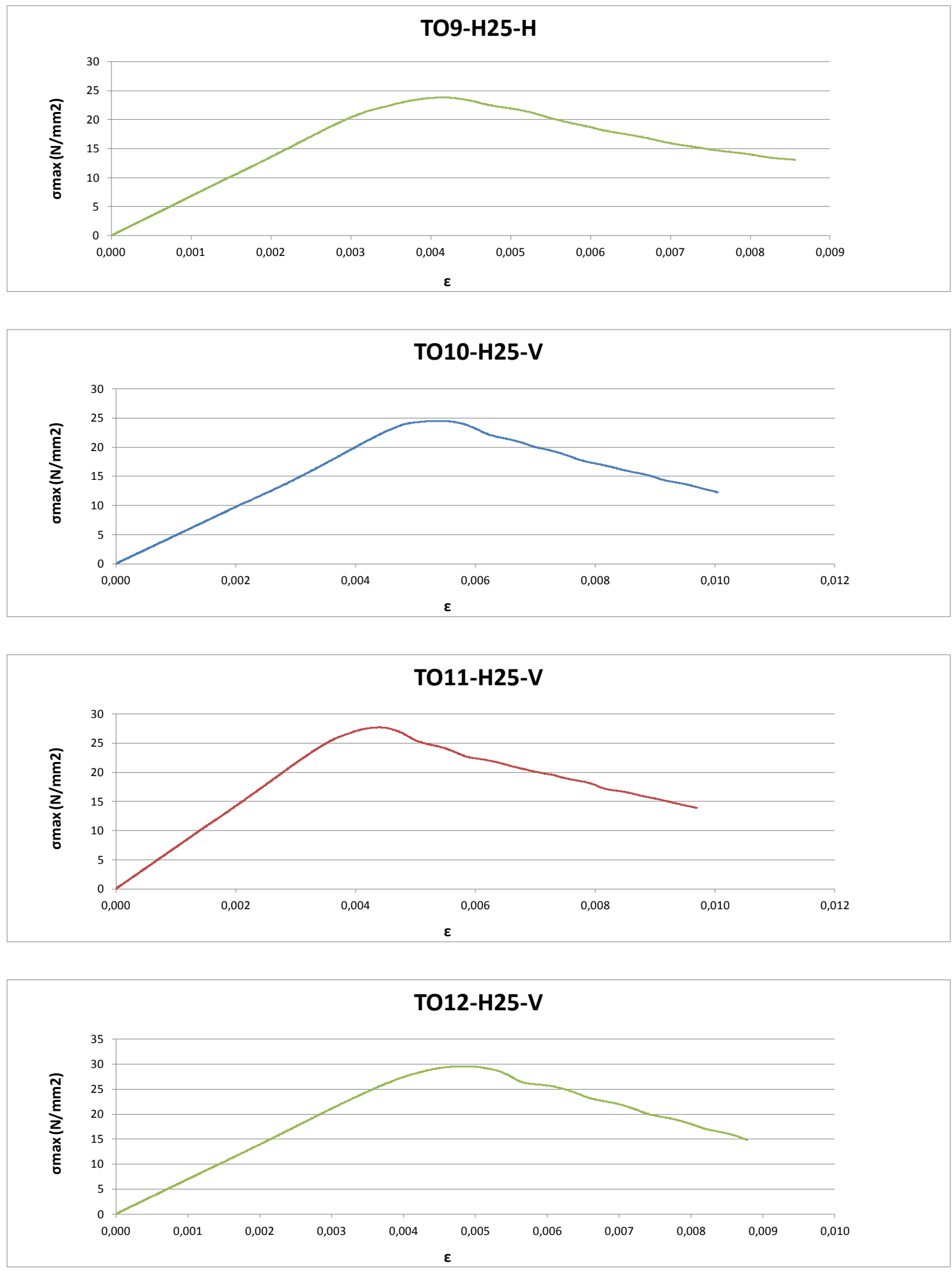

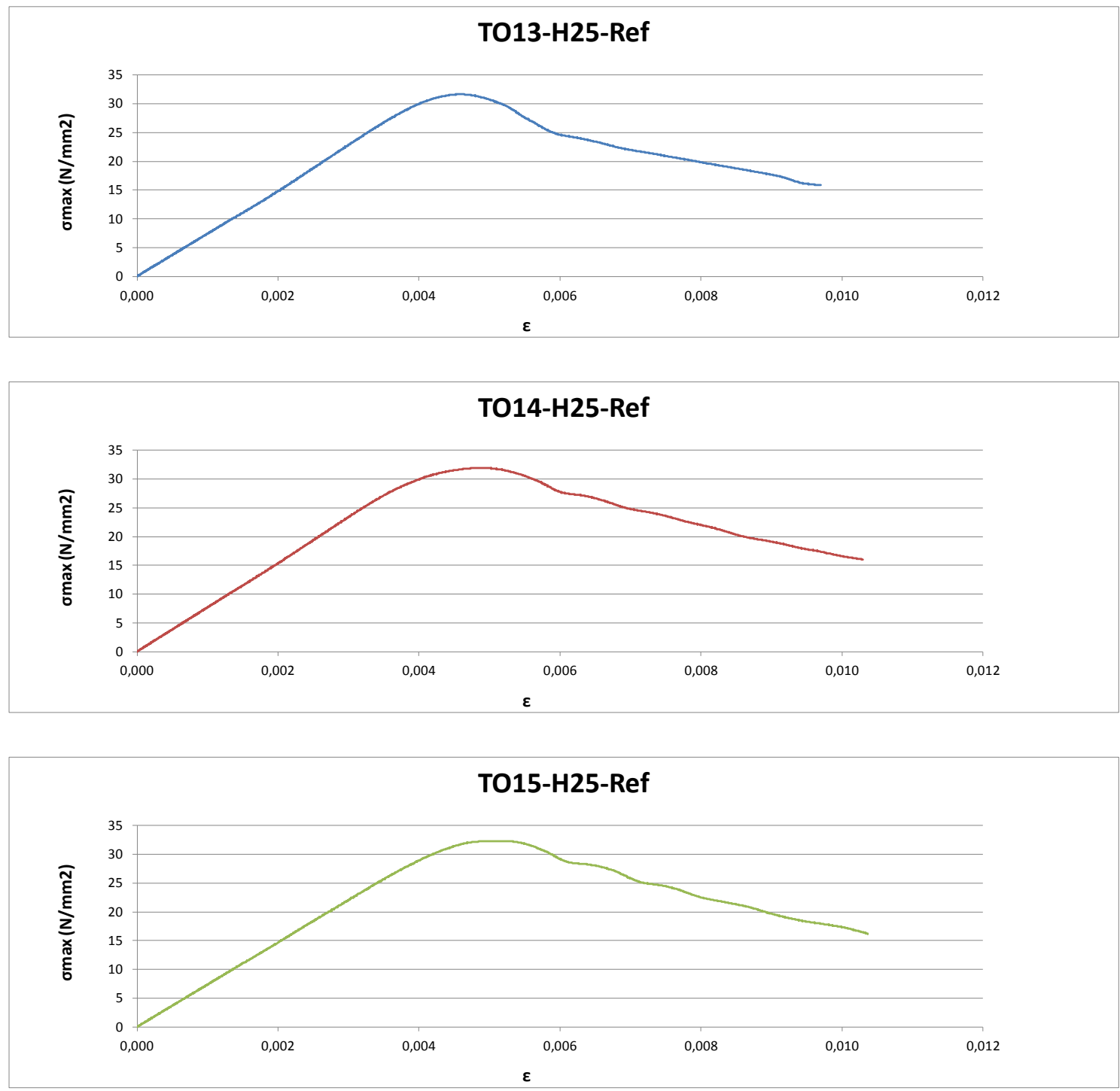
9.2.1.7 Gráfica Tensión $\sigma(\mathrm{N} / \mathrm{mm} 2) /$ Deformación $\varepsilon$ (adimensional) de las probetas cúbicas elaboradas con hormigón $\mathrm{H}-30$, con tubo de polietileno dispuesto en su interior en distintas posiciones (vertical, horizontal y sin tubo), ensayadas a compresión.
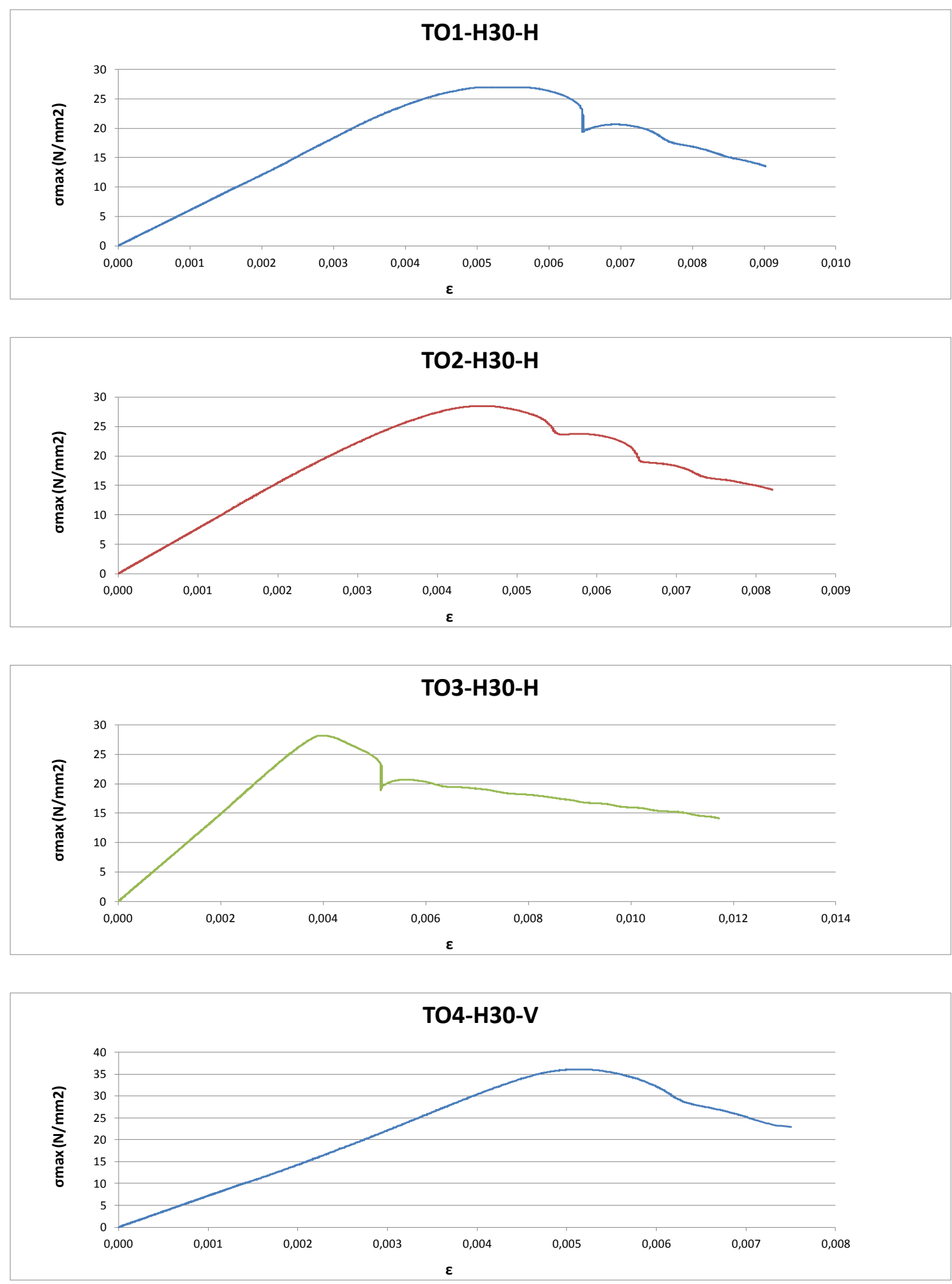

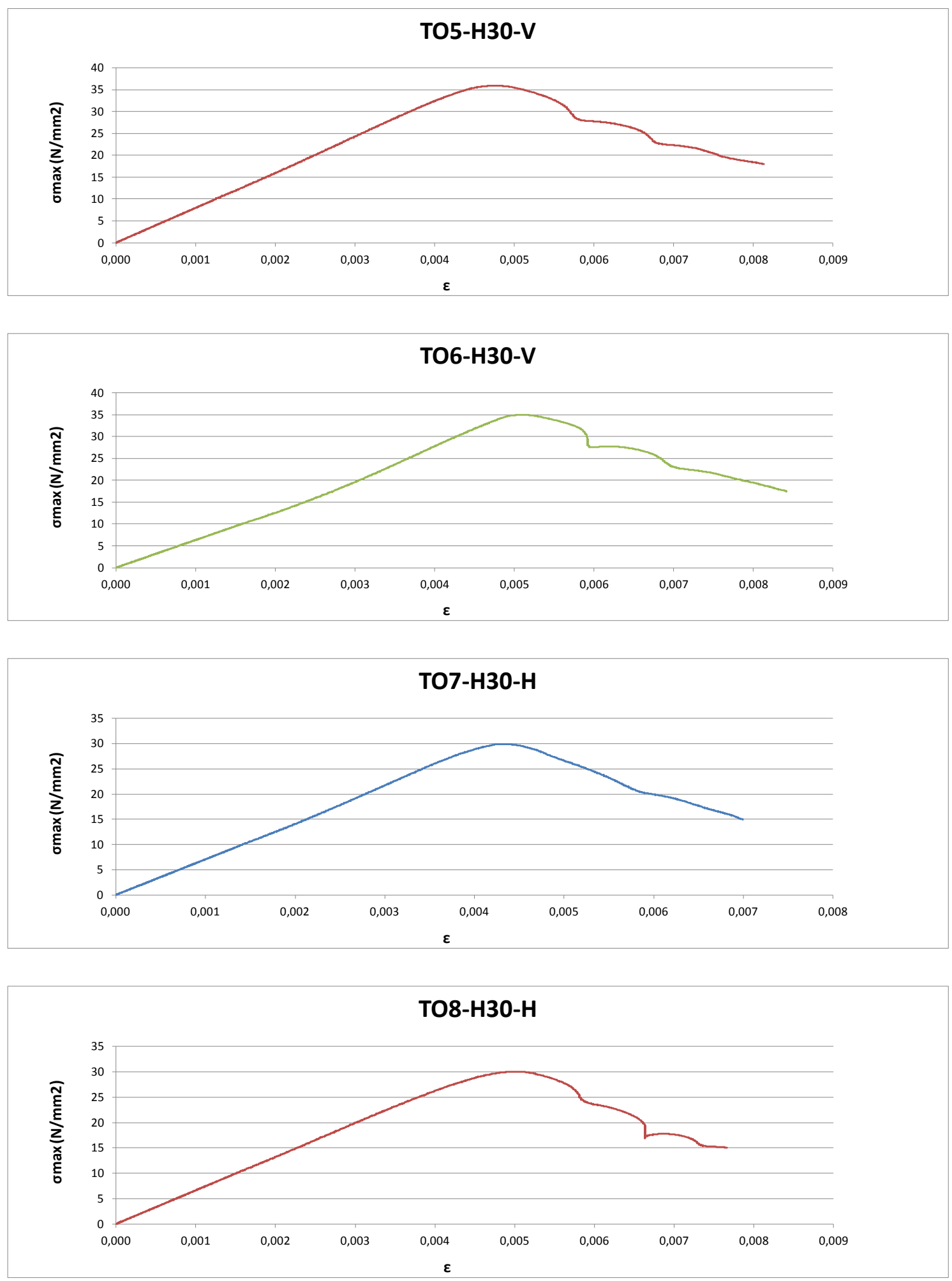

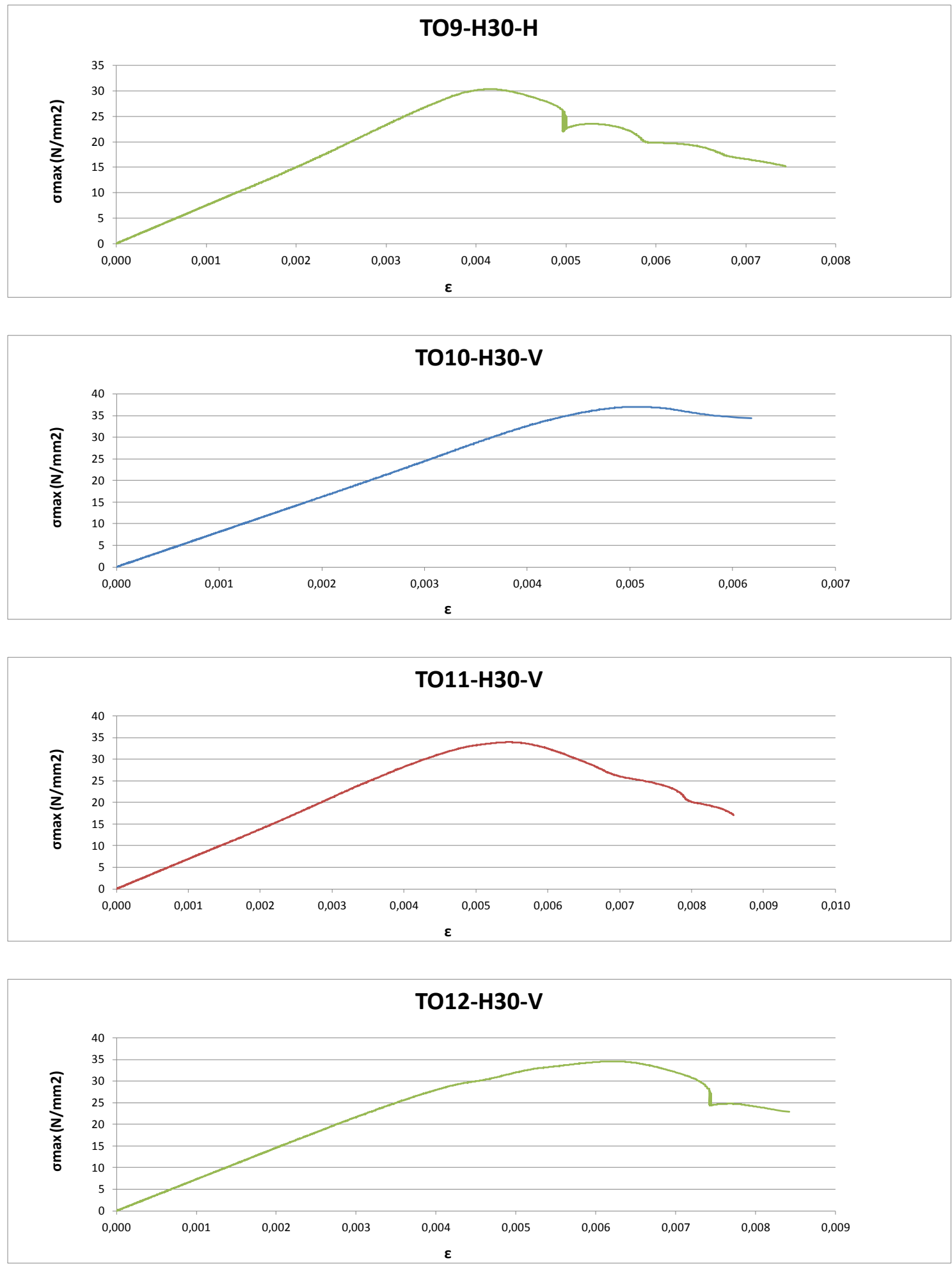

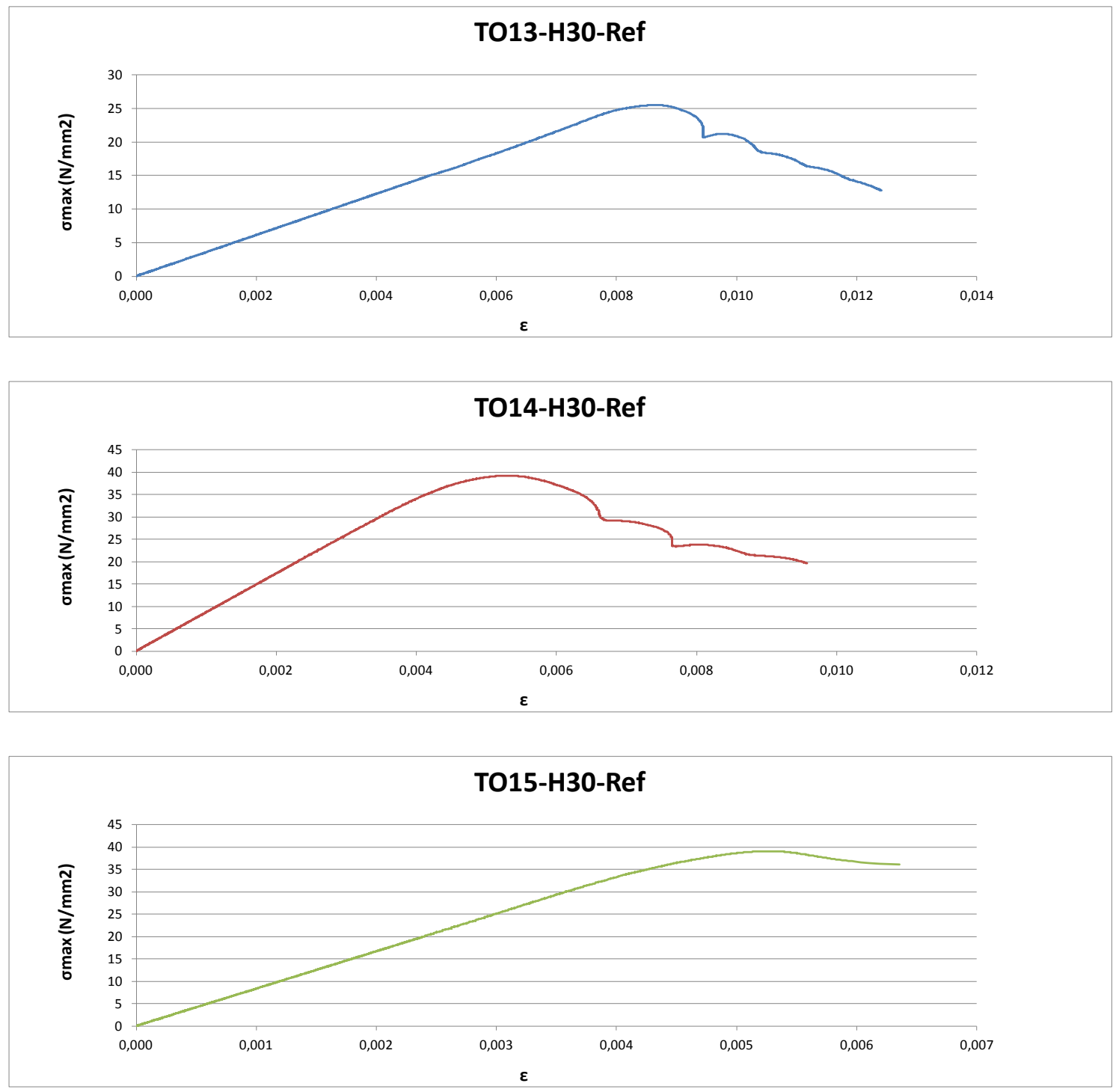
ANEXO 2.2

GRAFICAS DE

RESULTADOS

COMPARADAS 


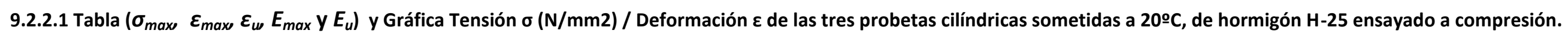

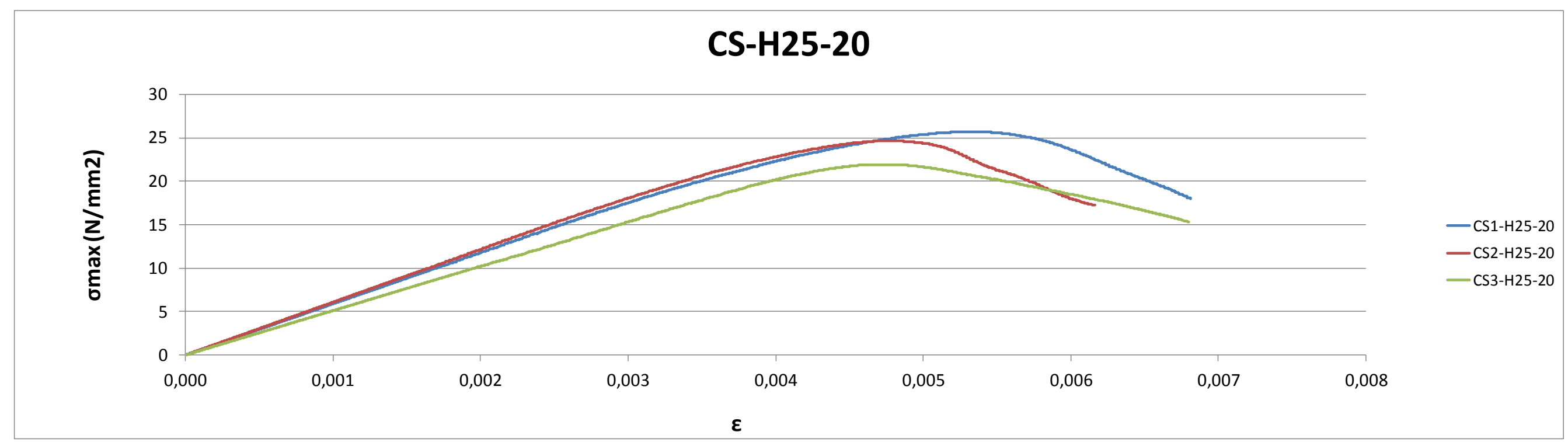

\begin{tabular}{|c|c|c|c|c|c|c|}
\hline & Temperatura (ㅇ) & $\sigma \max (\mathrm{N} / \mathrm{mm} 2)$ & $\varepsilon \max$ & $\varepsilon u$ & Emax (N/mm2) & Eu (N/mm2) \\
\hline \hline MEDIA & 20 & 24,10 & 0,0049 & 0,0066 & 0,0671 & 0,1016 \\
\hline \hline CS1-H25-20 & 20 & 25,70 & 0,0053 & 0,0068 & 0,0789 & 0,1126 \\
\hline \hline CS2-H25-20 & 20 & 24,66 & 0,0048 & 0,0062 & 0,0668 & 0,0963 \\
\hline \hline CS3-H25-20 & 20 & 21,93 & 0,0047 & 0,0068 & 0,0557 & 0,0960 \\
\hline
\end{tabular}




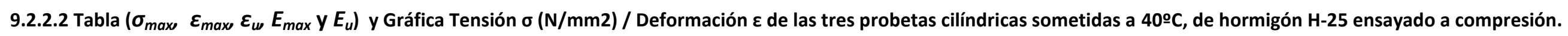

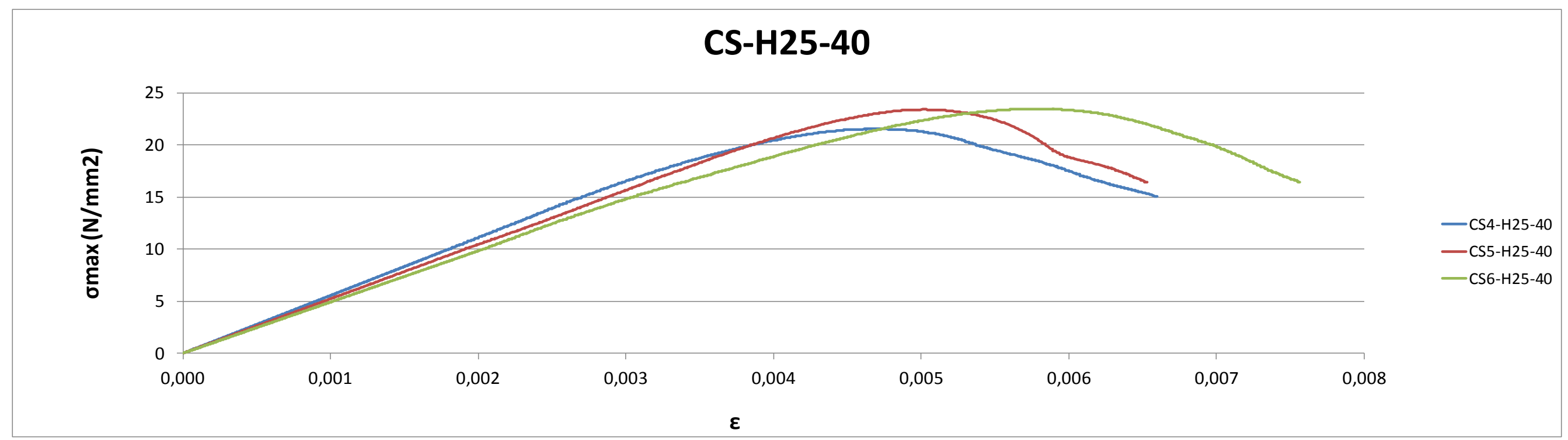

\begin{tabular}{|c||c|c|c|c|c|c|}
\hline & Temperatura (C) & $\sigma \max (\mathrm{N} / \mathrm{mm} 2)$ & $\varepsilon \max$ & $\varepsilon u$ & $\mathrm{Emax}(\mathrm{N} / \mathrm{mm} 2)$ & $\mathrm{Eu}(\mathrm{N} / \mathrm{mm} 2)$ \\
\hline \hline MEDIA & 40 & 22,81 & 0,0052 & 0,0069 & 0,0671 & 0,1016 \\
\hline \hline CS4-H25-40 & 40 & 21,54 & 0,0047 & 0,0066 & 0,0584 & 0,0942 \\
\hline \hline CS5-H25-40 & 40 & 23,41 & 0,0050 & 0,0065 & 0,0650 & 0,0955 \\
\hline \hline CS6-H25-40 & 40 & 23,49 & 0,0058 & 0,0076 & 0,0777 & 0,1152 \\
\hline
\end{tabular}




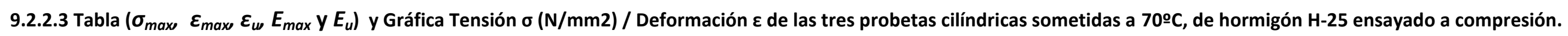

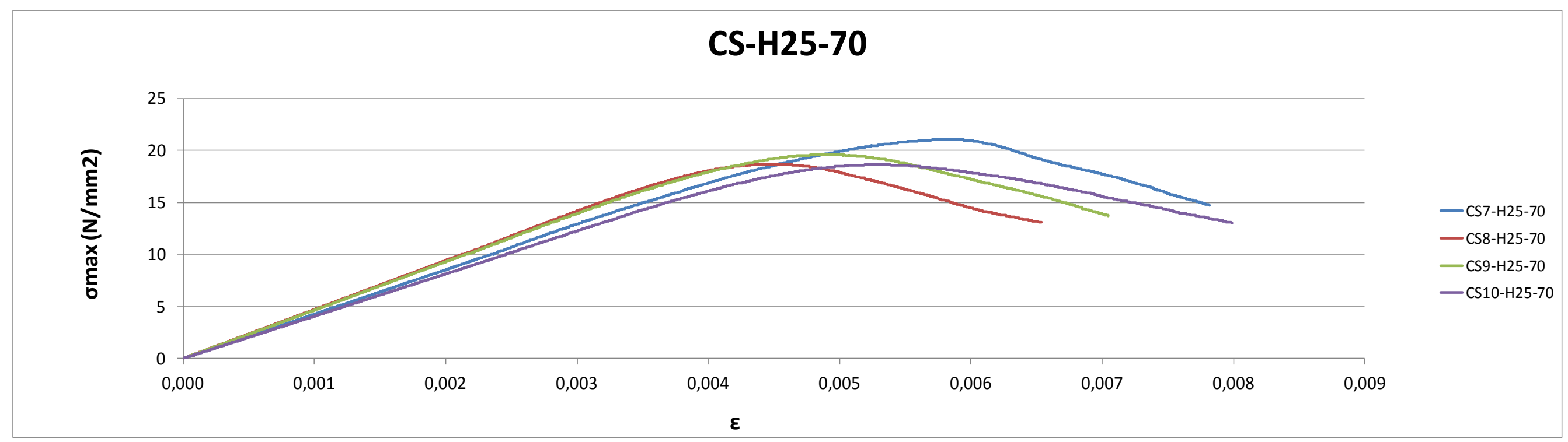

\begin{tabular}{|c||c|c|c|c|c|c|}
\hline & Temperatura (ㄷ) & $\sigma \operatorname{\sigma max}(\mathrm{N} / \mathrm{mm} 2)$ & $\varepsilon m a x$ & $\varepsilon u$ & Emax (N/mm2) & Eu (N/mm2) \\
\hline \hline MEDIA & 70 & 19,51 & 0,0051 & 0,0073 & 0,0566 & 0,0941 \\
\hline \hline CS7-H25-70 & 70 & 21,06 & 0,0058 & 0,0078 & 0,0696 & 0,1061 \\
\hline \hline CS8-H25-70 & 70 & 18,69 & 0,0045 & 0,0065 & 0,0460 & 0,0796 \\
\hline \hline CS9-H25-70 & 70 & 19,62 & 0,0049 & 0,0070 & 0,0545 & 0,0910 \\
\hline \hline CS10-H25-70 & 70 & 18,65 & 0,0053 & 0,0080 & 0,0563 & 0,0995 \\
\hline
\end{tabular}




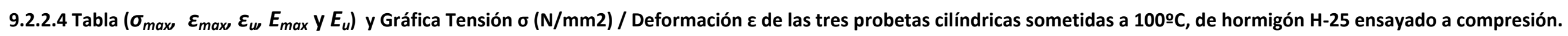

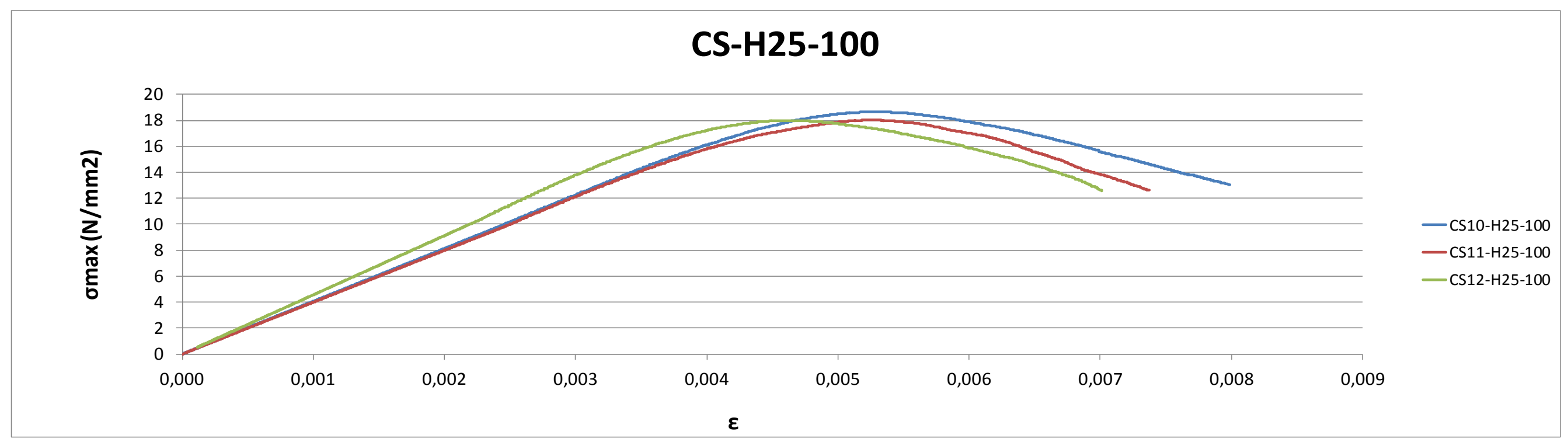

\begin{tabular}{|c||c|c|c|c|c|c|}
\hline & Temperatura (으) & $\sigma \max (\mathrm{N} / \mathrm{mm} 2)$ & $\varepsilon \max$ & $\varepsilon u$ & Emax (N/mm2) & Eu (N/mm2) \\
\hline \hline MEDIA & 100 & 18,22 & 0,0051 & 0,0075 & 0,0525 & 0,0908 \\
\hline \hline CS10-H25-100 & 100 & 18,65 & 0,0053 & 0,0080 & 0,0563 & 0,0995 \\
\hline \hline CS11-H25-100 & 100 & 18,02 & 0,0053 & 0,0074 & 0,0544 & 0,0873 \\
\hline \hline CS12-H25-100 & 100 & 17,98 & 0,0046 & 0,0070 & 0,0467 & 0,0856 \\
\hline
\end{tabular}




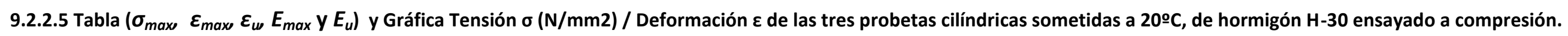

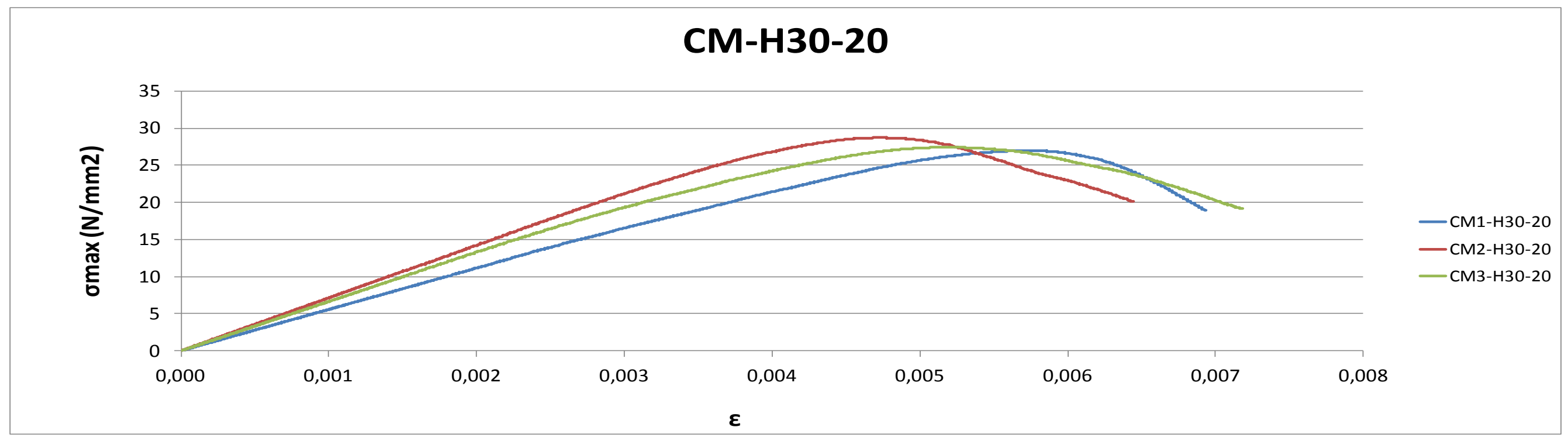

\begin{tabular}{|c||c|c|c|c|c|c|}
\hline & Temperatura (ㅇ) & $\sigma \max (\mathbf{N} / \mathbf{m m} 2)$ & $\boldsymbol{\varepsilon m a x}$ & $\varepsilon u$ & Emax (N/mm2) & Eu (N/mm2) \\
\hline \hline MEDIA & 20 & 27,70 & 0,0052 & 0,0069 & 0,0827 & 0,1225 \\
\hline \hline CM1-H30-20 & 20 & 26,97 & 0,0057 & 0,0069 & 0,0873 & 0,1162 \\
\hline \hline CM2-H30-20 & 20 & 28,72 & 0,0047 & 0,0064 & 0,0770 & 0,1198 \\
\hline \hline CM3-H30-20 & 20 & 27,42 & 0,0052 & 0,0072 & 0,0837 & 0,1314 \\
\hline
\end{tabular}




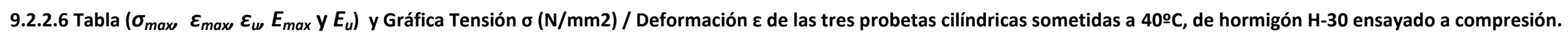

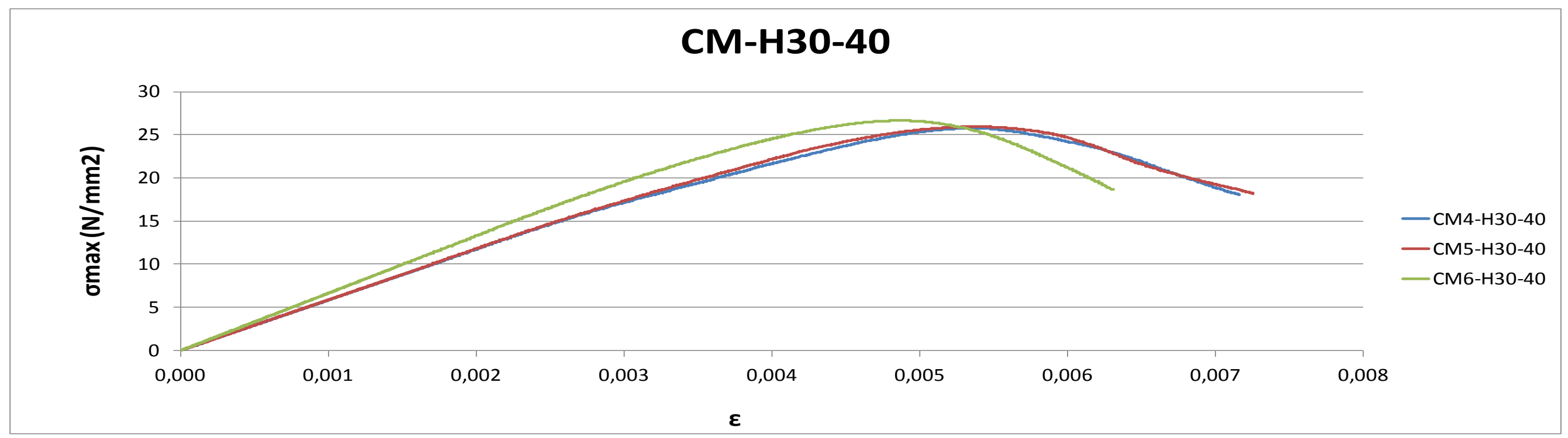

\begin{tabular}{|c||c|c|c|c|c|c|}
\cline { 2 - 7 } & Temperatura (oC) & $\sigma \max (\mathbf{N} / \mathbf{m m} \mathbf{2})$ & $\boldsymbol{\varepsilon m a x}$ & $\boldsymbol{\varepsilon u}$ & Emax (N/mm2) & Eu (N/mm2) \\
\hline \hline MEDIA & 40 & 26,12 & 0,0052 & 0,0069 & 0,0777 & 0,1169 \\
\hline \hline CM4-H30-40 & 40 & 25,77 & 0,0053 & 0,0072 & 0,0783 & 0,1194 \\
\hline \hline CM5-H30-40 & 40 & 25,95 & 0,0054 & 0,0073 & 0,0807 & 0,1226 \\
\hline \hline CM6-H30-40 & 40 & 26,65 & 0,0049 & 0,0063 & 0,0742 & 0,1087 \\
\hline
\end{tabular}




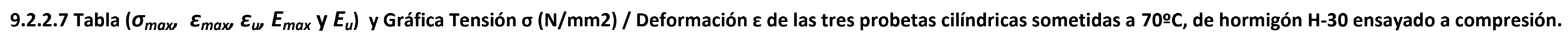

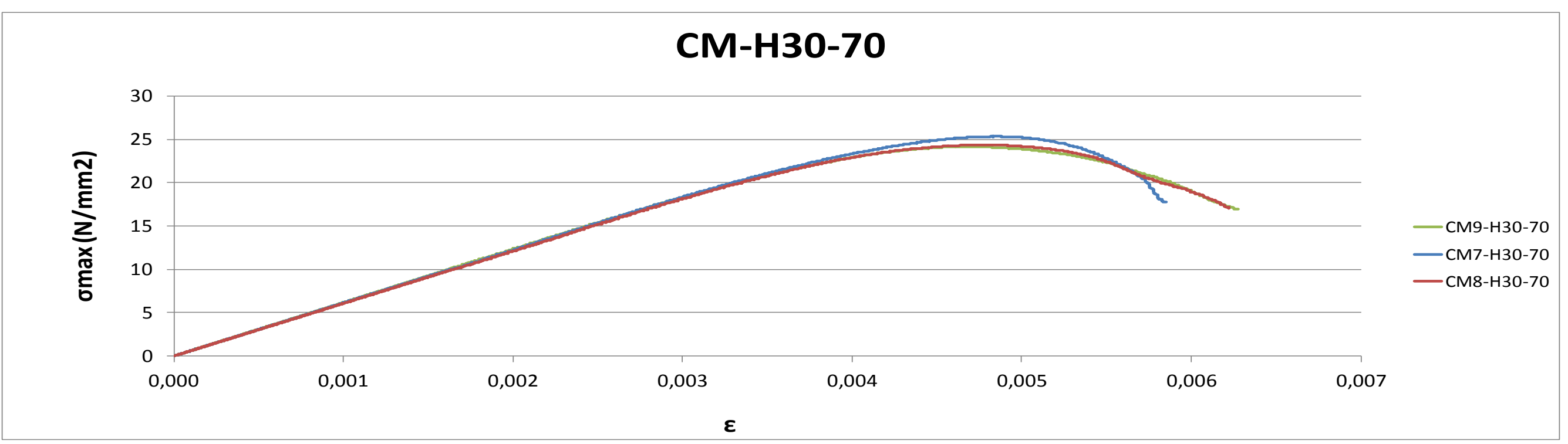

\begin{tabular}{|c||c|c|c|c|c|c|}
\hline & Temperatura (-C) & $\sigma \max (\mathbf{N} / \mathbf{m m} 2)$ & $\boldsymbol{\varepsilon m a x}$ & $\boldsymbol{\varepsilon u}$ & Emax (N/mm2) & Eu (N/mm2) \\
\hline \hline MEDIA & 70 & 24,61 & 0,0048 & 0,0061 & 0,0669 & 0,0967 \\
\hline \hline CM7-H30-70 & 70 & 25,33 & 0,0049 & 0,0059 & 0,0695 & 0,0927 \\
\hline \hline CM8-H30-70 & 70 & 24,36 & 0,0048 & 0,0062 & 0,0663 & 0,0980 \\
\hline \hline CM9-H30-70 & 70 & 24,16 & 0,0047 & 0,0063 & 0,0650 & 0,0993 \\
\hline
\end{tabular}


9.2.2.8 Tabla $\left(\sigma_{\max } \varepsilon_{\max } \varepsilon_{u} E_{\max }\right.$ y $\left.E_{u}\right)$ y Gráfica Tensión $\sigma(\mathrm{N} / \mathrm{mm} 2)$ / Deformación $\varepsilon$ de las tres probetas cilíndricas sometidas a 100둥, de hormigón $\mathrm{H}-30$ ensayado a compresión.

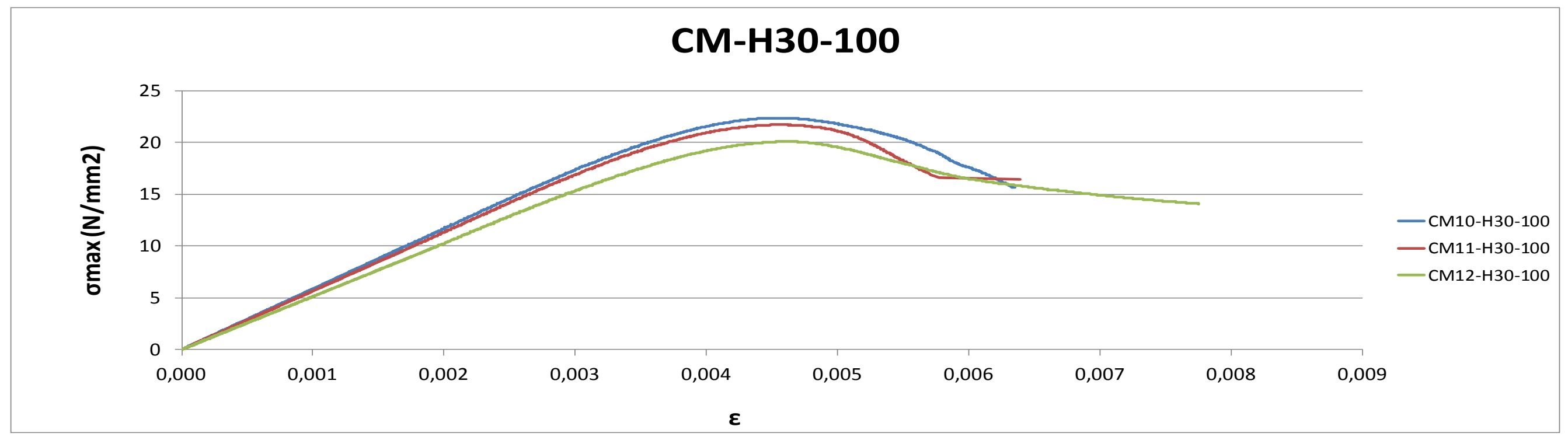

\begin{tabular}{|c||c|c|c|c|c|c|}
\hline & Temperatura (-C) & $\operatorname{\sigma max}(\mathbf{N} / \mathbf{m m 2})$ & $\boldsymbol{\varepsilon m a x}$ & $\varepsilon u$ & Emax (N/mm2) & Eu (N/mm2) \\
\hline \hline MEDIA & 100 & 21,40 & 0,0046 & 0,0066 & 0,0560 & 0,0932 \\
\hline \hline CM10-H30-100 & 100 & 22,37 & 0,0045 & 0,0063 & 0,0580 & 0,0940 \\
\hline \hline CM11-H30-100 & 100 & 21,72 & 0,0046 & 0,0058 & 0,0568 & 0,0808 \\
\hline \hline CM12-H30-100 & 100 & 20,11 & 0,0046 & 0,0078 & 0,0532 & 0,1049 \\
\hline
\end{tabular}


9.2.2.9 Tabla $\left(\mp_{R}, \delta_{\max } \delta_{u} E_{\max }\right.$ y $\left.E_{u}\right)$ y Gráfica Fuerza $\mathrm{F}(\mathrm{KN})$ / Desplazamiento $\delta(\mathrm{mm})$ de las tres probetas cúbicas sometidas a 20ㄷ, de hormigón H-25 ensayado a "pull-out".

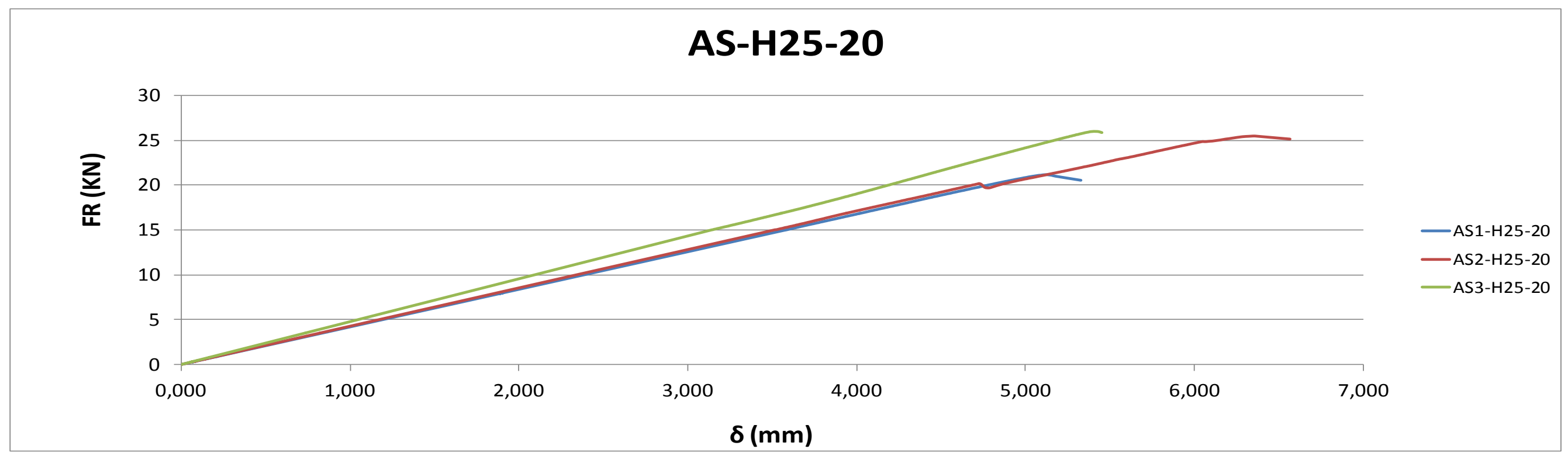

\begin{tabular}{|c||c|c|c|c|c|c|}
\hline & Temperatura (oC) & FR (KN) & $\boldsymbol{\delta m a x}(\mathbf{m m})$ & $\mathbf{\delta u}(\mathbf{m m})$ & Emax (KNmm) & Eu (KNmm) \\
\hline \hline MEDIA & 20 & 24,22 & 5,6280 & 5,7823 & 69,9166 & 73,5220 \\
\hline \hline AS1-H25-20 & 20 & 21,20 & 5,1198 & 5,3298 & 54,9708 & 59,3600 \\
\hline \hline AS2-H25-20 & 20 & 25,43 & 6,3613 & 6,5674 & 84,8021 & 90,0064 \\
\hline \hline AS3-H25-20 & 20 & 26,02 & 5,4028 & 5,4498 & 69,9769 & 71,1996 \\
\hline
\end{tabular}


9.2.2.10 Tabla $\left(\mp_{R}, \delta_{\max } \delta_{u}, E_{\max }\right.$ Y $\left.E_{u}\right)$ y Gráfica Fuerza $\mathrm{F}(\mathrm{KN}) /$ Desplazamiento $\delta(\mathrm{mm})$ de las tres probetas cúbicas sometidas a 40드, de hormigón $\mathrm{H}-25$ ensayado a "pull-out".

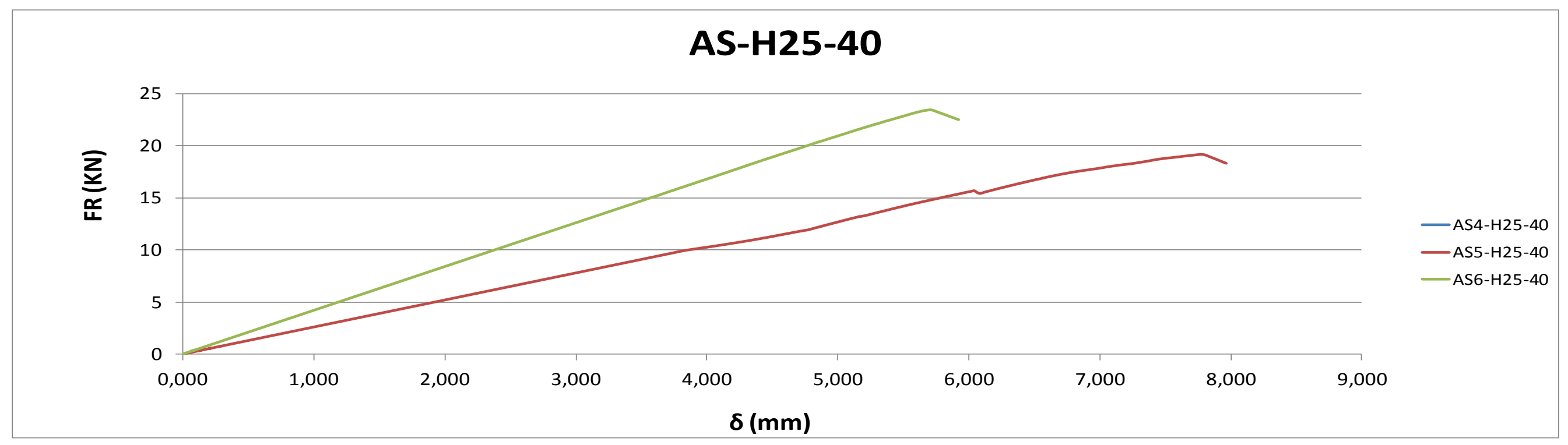

\begin{tabular}{|c||c|c|c|c|c|c|}
\hline & Temperatura (oC) & FR (KN) & $\boldsymbol{\delta m a x}(\mathbf{m m})$ & $\mathbf{\delta u}(\mathbf{m m})$ & Emax (KNmm) & Eu (KNmm) \\
\hline \hline MEDIA & 40 & 21,31 & 6,7432 & 6,9431 & 72,8501 & 77,0683 \\
\hline \hline AS4-H25-40 & 40 & ERROR & & & & \\
\hline \hline AS5-H25-40 & 40 & 19,19 & 7,7848 & 7,9653 & 77,6114 & 81,0044 \\
\hline \hline AS6-H25-40 & 40 & 23,43 & 5,7016 & 5,9210 & 68,0889 & 73,1323 \\
\hline
\end{tabular}


9.2.2117 Tabla $\left(\mp_{R}, \delta_{\max } \delta_{u} E_{\max }\right.$ y $\left.E_{u}\right)$ y Gráfica Fuerza $\mathrm{F}(\mathrm{KN}) /$ Desplazamiento $\delta(\mathrm{mm})$ de las tres probetas cúbicas sometidas a 70ㄷ, de hormigón $\mathrm{H}-25$ ensayado a “pull-out".

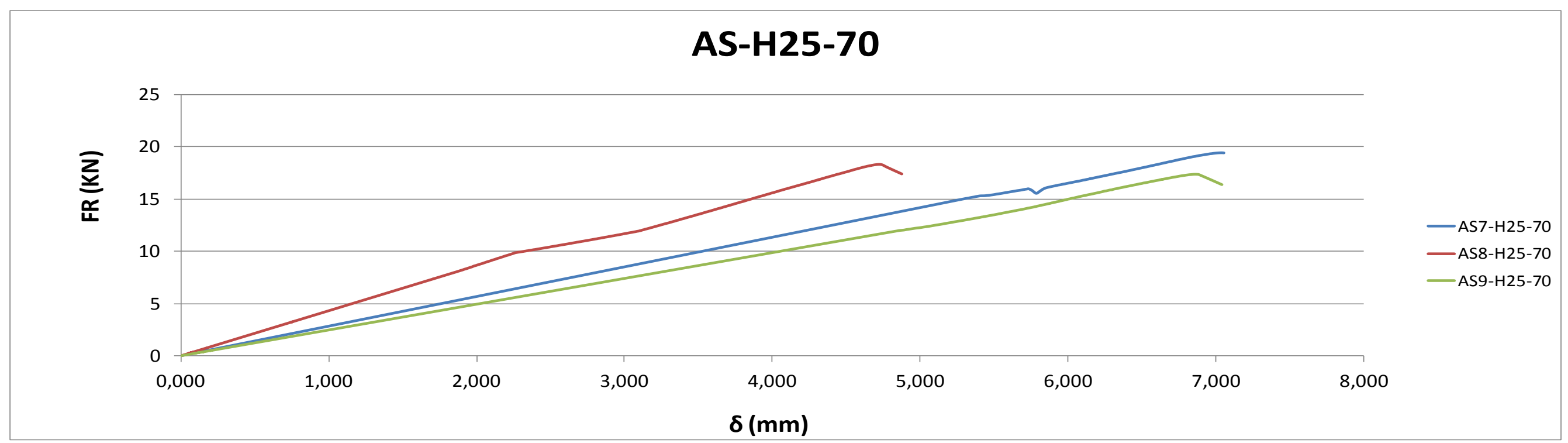

\begin{tabular}{|c||c|c|c|c|c|c|}
\hline & Temperatura (oC) & FR (KN) & $\boldsymbol{\delta m a x}(\mathbf{m m})$ & $\mathbf{\delta u}(\mathbf{m m})$ & Emax (KNmm) & Eu (KNmm) \\
\hline \hline MEDIA & 70 & 18,37 & 6,2075 & 6,3234 & 57,5821 & 59,6034 \\
\hline \hline AS7-H25-70 & 70 & 19,42 & 7,0428 & 7,0561 & 69,6210 & 69,8787 \\
\hline \hline AS8-H25-70 & 70 & 18,34 & 4,7233 & 4,8740 & 44,9303 & 47,6289 \\
\hline \hline AS9-H25-70 & 70 & 17,34 & 6,8564 & 7,0402 & 58,1949 & 61,3027 \\
\hline
\end{tabular}




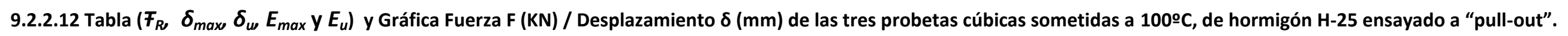

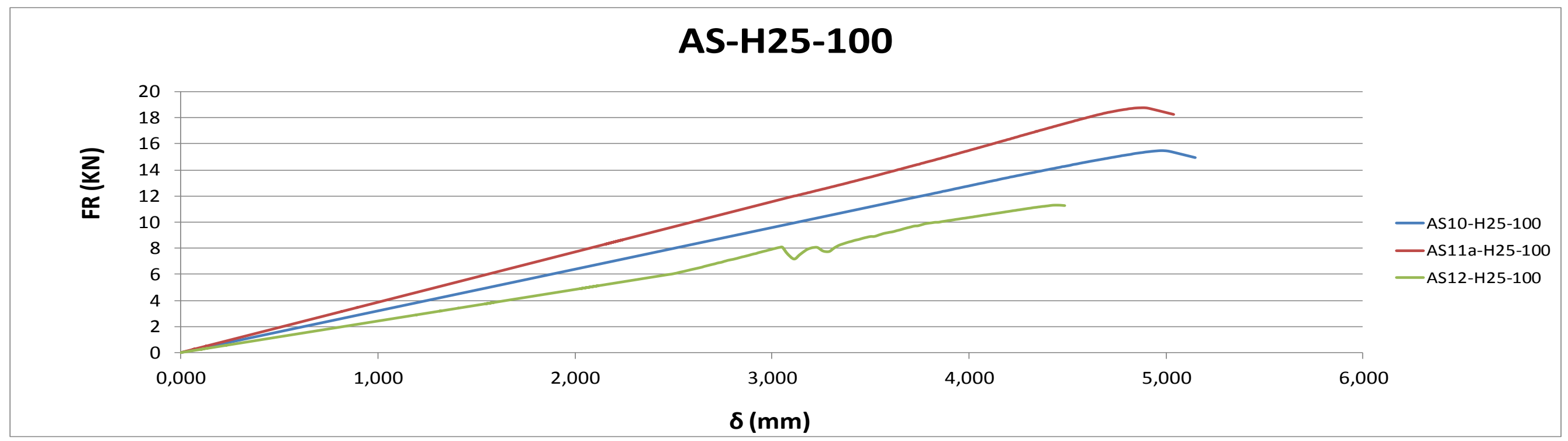

\begin{tabular}{|c||c|c|c|c|c|c|}
\hline & Temperatura (oC) & FR (KN) & $\boldsymbol{\delta m a x}(\mathbf{m m})$ & $\boldsymbol{\delta u}(\mathbf{m m})$ & Emax (KNmm) & Eu (KNmm) \\
\hline \hline MEDIA & 100 & 15,17 & 4,7675 & 4,8899 & 36,7491 & 38,7307 \\
\hline \hline AS10-H25-100 & 100 & 15,48 & 4,9749 & 5,1456 & 39,4639 & 42,0680 \\
\hline \hline AS11a-H25-100 & 100 & 18,75 & 4,8827 & 5,0383 & 46,0623 & 48,9440 \\
\hline \hline AS12-H25-100 & 100 & 11,29 & 4,4451 & 4,4858 & 24,7211 & 25,1802 \\
\hline
\end{tabular}


9.2.2.13 Tabla $\left(\mp_{R}, \delta_{\max } \delta_{u}, E_{\max }\right.$ y $\left.E_{u}\right)$ y Gráfica Fuerza $\mathrm{F}(\mathrm{KN})$ / Desplazamiento $\delta(\mathrm{mm})$ de las tres probetas cúbicas sometidas a 20ㄷ, de hormigón $\mathrm{H}-30$ ensayado a "pull-out".

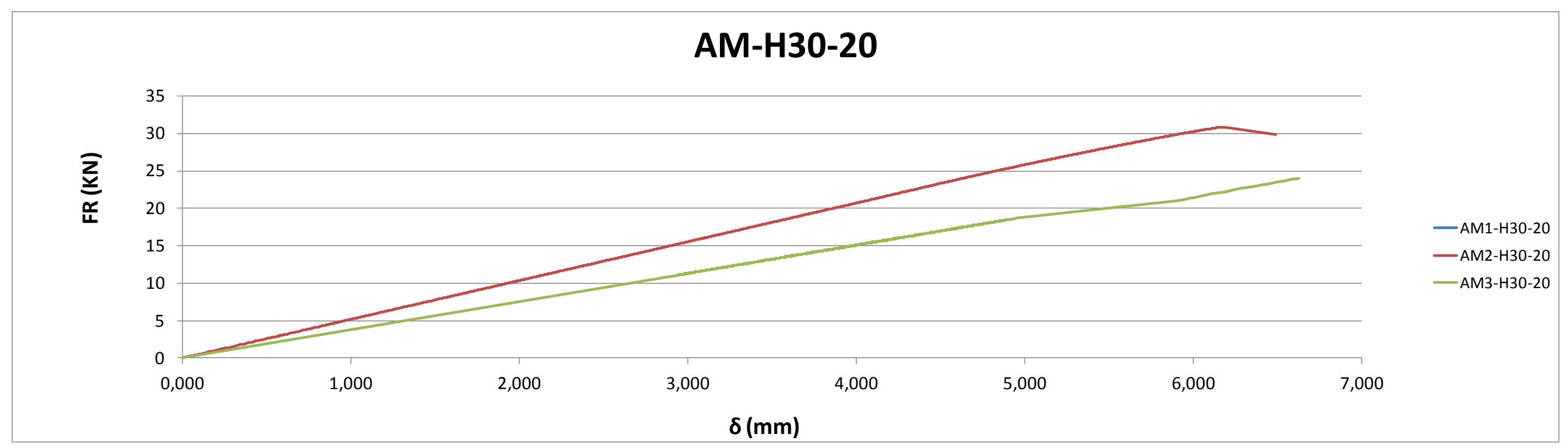

\begin{tabular}{|c||c|c|c|c|c|c|}
\hline & Temperatura (oC) & FR (KN) & $\delta \max (\mathbf{m m})$ & $\delta u(\mathbf{m m})$ & Emax (KNmm) & Eu (KNmm) \\
\hline \hline MEDIA & 20 & 27,42 & 5,4856 & 5,6408 & 80,3519 & 85,0607 \\
\hline \hline AM1-H30-20 & 20 & ERROR & & & & \\
\hline \hline AM2-H30-20 & 20 & 30,82 & 6,1812 & 6,4916 & 98,3961 & 107,8135 \\
\hline \hline AM3-H30-20 & 20 & 24,01 & 4,7900 & 4,7900 & 62,3078 & 62,3078 \\
\hline
\end{tabular}


9.2.2.14 Tabla $\left(\mp_{R}, \delta_{\max } \delta_{u} E_{\max }\right.$ Y $\left.E_{u}\right)$ y Gráfica Fuerza $\mathrm{F}(\mathrm{KN}) /$ Desplazamiento $\delta(\mathrm{mm})$ de las tres probetas cúbicas sometidas a 40드, de hormigón $\mathrm{H}-30$ ensayado a "pull-out".

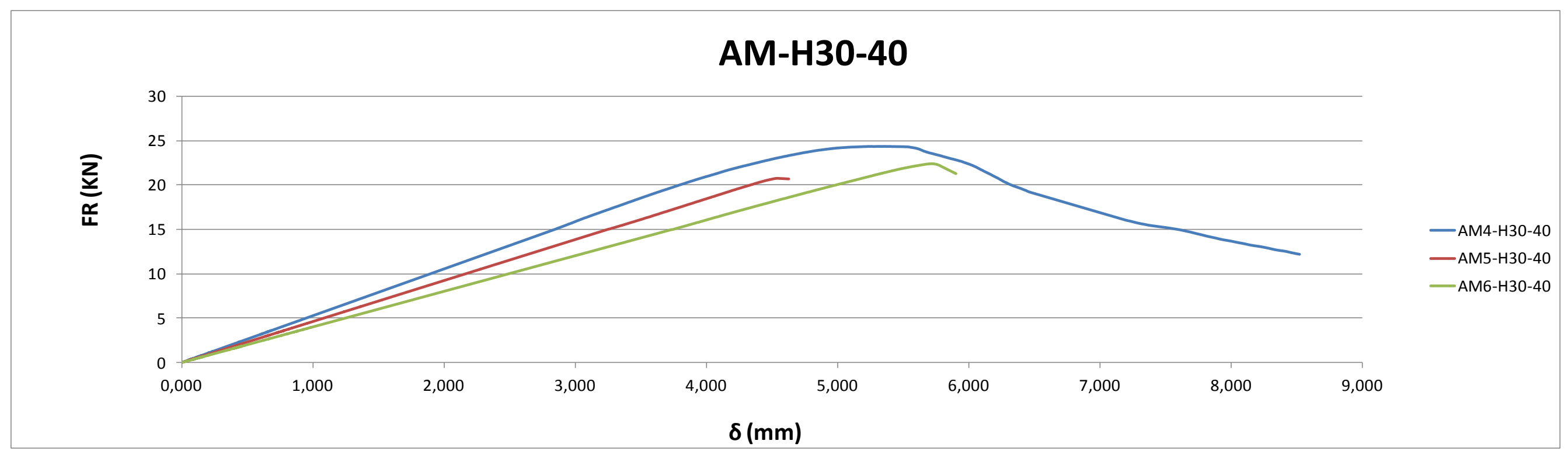

\begin{tabular}{|c||c|c|c|c|c|c|}
\hline & Temperatura (ㅇ) & FR (KN) & $\delta \max (\mathbf{m m})$ & $\delta u(\mathbf{m m})$ & Emax (KNmm) & Eu (KNmm) \\
\hline \hline MEDIA & 40 & 22,51 & 5,2079 & 6,3516 & 62,3340 & 109,9946 \\
\hline \hline AM4-H30-40 & 40 & 24,36 & 5,3570 & 8,5195 & 73,7697 & 130,1791 \\
\hline \hline AM5-H30-40 & 40 & 20,76 & 4,5445 & 4,6300 & 47,6270 & 130,1791 \\
\hline \hline AM6-H30-40 & 40 & 22,41 & 5,7220 & 5,9053 & 65,6055 & 69,6257 \\
\hline
\end{tabular}


9.2.2.15 Tabla $\left(\mp_{R}, \delta_{\max } \delta_{u} E_{\max }\right.$ Y $\left.E_{u}\right)$ y Gráfica Fuerza $\mathrm{F}(\mathrm{KN}) /$ Desplazamiento $\delta(\mathrm{mm})$ de las tres probetas cúbicas sometidas a 70드, de hormigón $\mathrm{H}-30$ ensayado a "pull-out".

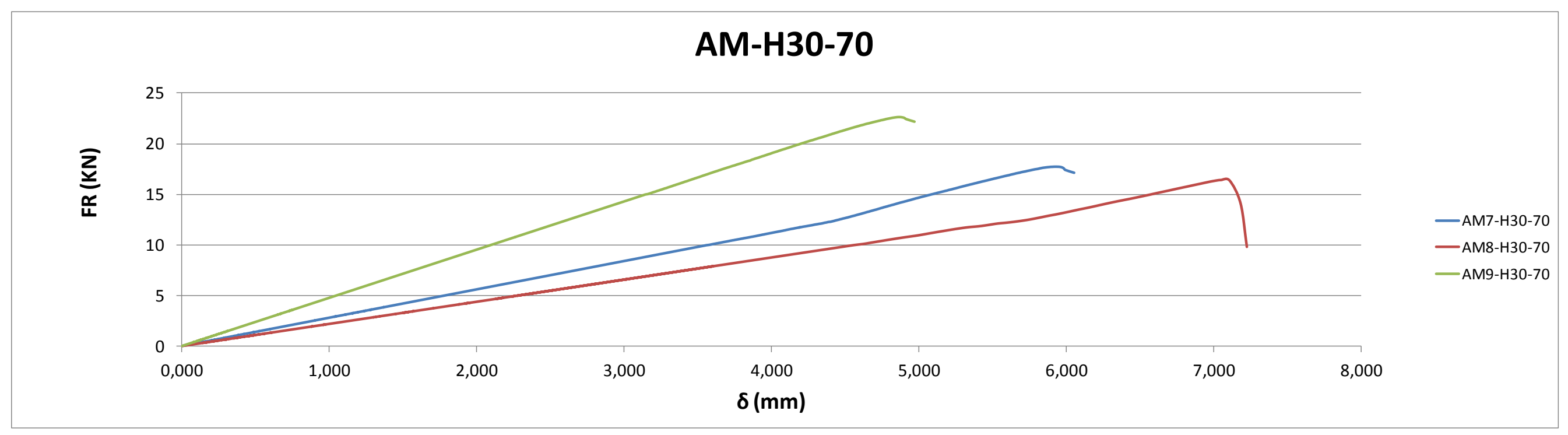

\begin{tabular}{|c||c|c|c|c|c|c|}
\hline \multicolumn{1}{c||}{} & Temperatura (OC) & FR (KN) & $\delta \max (\mathbf{m m})$ & $\delta u(m m)$ & Emax (KNmm) & Eu (KNmm) \\
\hline \hline MEDIA & 70 & 18,92 & 5,9475 & 6,0833 & 53,8261 & 56,2202 \\
\hline \hline AM7-H30-70 & 70 & 17,75 & 5,9294 & 6,0518 & 50,4200 & 52,5601 \\
\hline \hline AM8-H30-70 & 70 & 16,38 & 7,0481 & 7,2249 & 54,8617 & 57,4783 \\
\hline \hline AM9-H30-70 & 70 & 22,62 & 4,8649 & 4,9731 & 56,1968 & 58,6222 \\
\hline
\end{tabular}




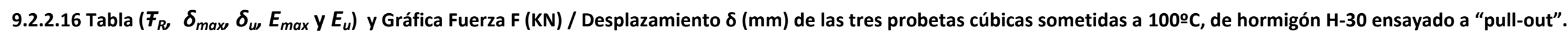

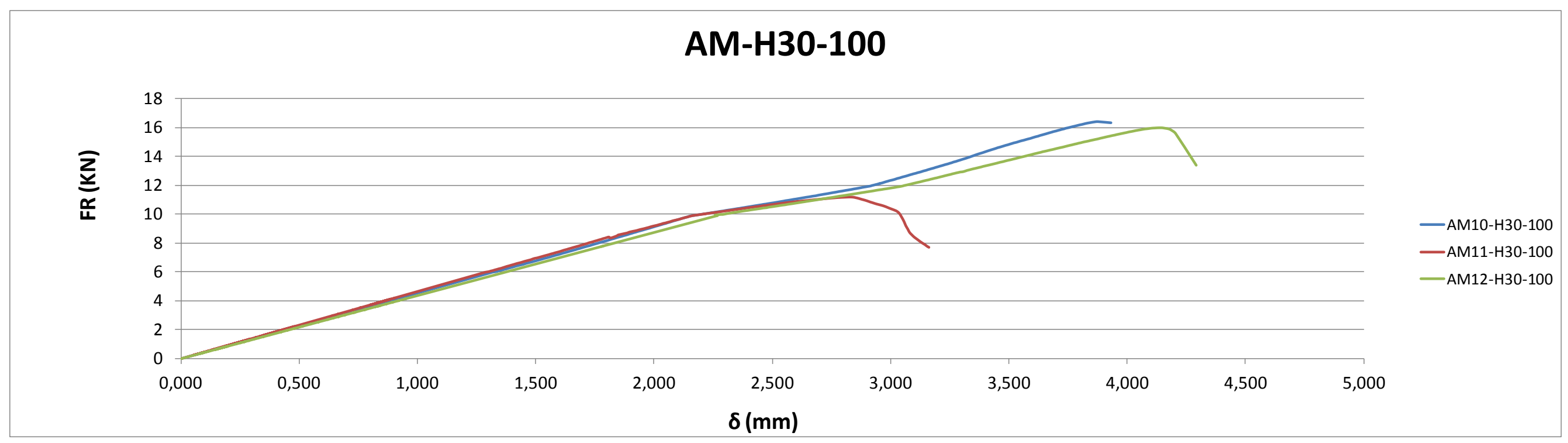

\begin{tabular}{|c||c|c|c|c|c|c|}
\hline & Temperatura (ㅇ) & FR (KN) & $\delta \max (\mathrm{mm})$ & $\delta u(m m)$ & Emax (KNmm) & Eu (KNmm) \\
\hline \hline MEDIA & 100 & 14,52 & 3,6135 & 3,7960 & 28,5045 & 30,7051 \\
\hline \hline AM10-H30-100 & 100 & 16,40 & 3,8772 & 3,9318 & 32,5296 & 33,4225 \\
\hline \hline AM11-H30-100 & 100 & 11,16 & 2,8277 & 3,1631 & 17,8484 & 21,1753 \\
\hline \hline AM12-H30-100 & 100 & 16,01 & 4,1357 & 4,2931 & 35,1355 & 37,5173 \\
\hline
\end{tabular}




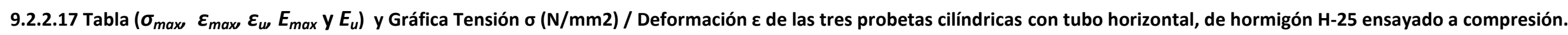

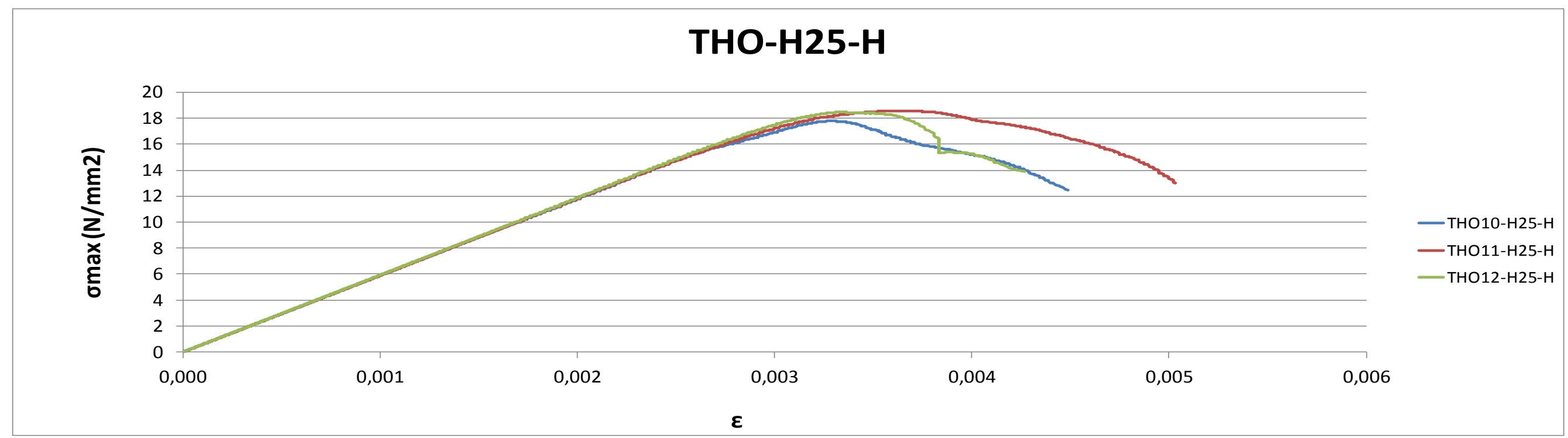

\begin{tabular}{|c||c|c|c|c|c|c|}
\hline & Temperatura (ㅇ) & $\boldsymbol{\sigma m a x}(\mathbf{N} / \mathbf{m m} 2)$ & $\boldsymbol{\varepsilon m a x}$ & $\boldsymbol{\varepsilon u}$ & Emax (N/mm2) & Eu (N/mm2) \\
\hline \hline MEDIA & & 18,28 & 0,0034 & 0,0046 & 0,0343 & 0,0531 \\
\hline \hline THO10-H25-H & & 17,78 & 0,0033 & 0,0045 & 0,0313 & 0,0500 \\
\hline \hline THO11-H25-H & 18,59 & 0,0037 & 0,0050 & 0,0390 & 0,0613 \\
\hline \hline THO12-H25-H & & 18,47 & 0,0033 & 0,0043 & 0,0327 & 0,0481 \\
\hline
\end{tabular}




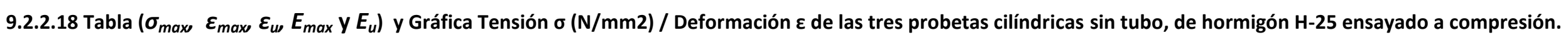

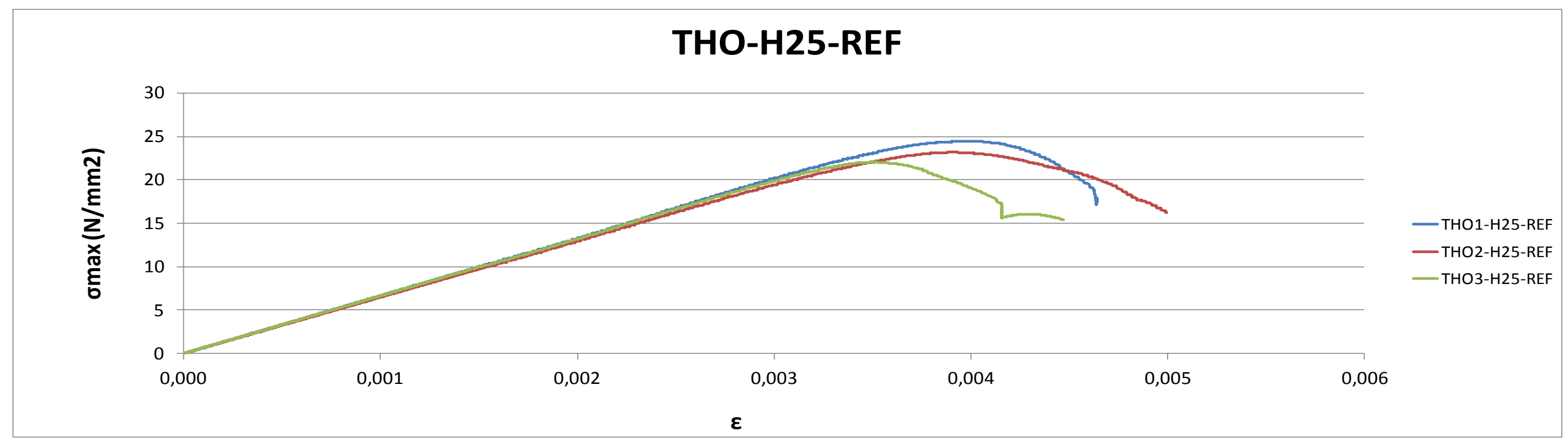

\begin{tabular}{|c||c|c|c|c|c|c|}
\hline & Temperatura (oC) & $\sigma \max (\mathbf{N} / \mathbf{m m} 2)$ & $\varepsilon m a x$ & $\varepsilon u$ & Emax (N/mm2) & Eu (N/mm2) \\
\hline \hline MEDIA & & 23,22 & 0,0038 & 0,0047 & 0,0472 & 0,0434 \\
\hline \hline THO1-H25-REF & & 24,44 & 0,0040 & 0,0046 & 0,0522 & 0,0000 \\
\hline \hline THO2-H25-REF & & 23,18 & 0,0039 & 0,0050 & 0,0489 & 0,0714 \\
\hline \hline THO3-H25-REF & & 22,04 & 0,0035 & 0,0045 & 0,0404 & 0,0587 \\
\hline
\end{tabular}


9.2.2.19 Tabla $\left(\sigma_{\max } \varepsilon_{\max } \varepsilon_{u}, E_{\max }\right.$ y $\left.E_{u}\right)$ y Gráfica Tensión $\sigma(\mathrm{N} / \mathrm{mm} 2)$ / Deformación $\varepsilon$ de las tres probetas cilíndricas con tubo vertical centrado, de hormigón $\mathrm{H}-25$ ensayado a compresión.

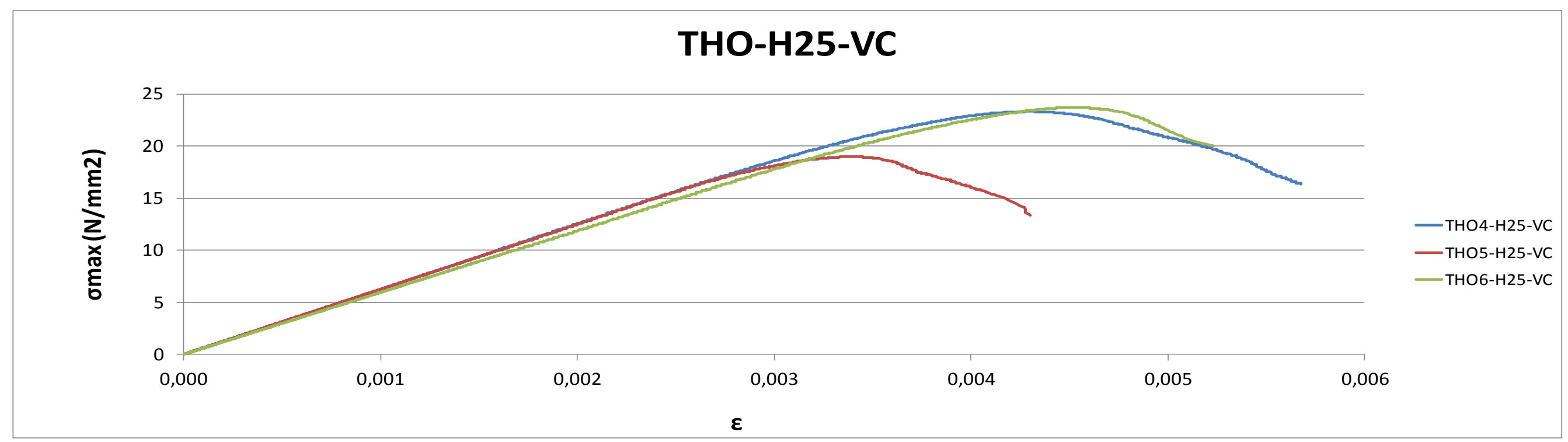

\begin{tabular}{|c||c|c|c|c|c|c|}
\hline & Temperatura (ㅇ) & $\boldsymbol{\sigma m a x}(\mathbf{N} / \mathbf{m m} 2)$ & $\boldsymbol{\varepsilon m a x}$ & $\boldsymbol{\varepsilon u}$ & Emax (N/mm2) & Eu (N/mm2) \\
\hline \hline MEDIA & & 22,02 & 0,0041 & 0,0051 & 0,0505 & 0,0701 \\
\hline \hline THO4-H25-VC & & 23,33 & 0,0043 & 0,0057 & 0,0561 & 0,0845 \\
\hline \hline THO5-H25-VC & & 19,00 & 0,0034 & 0,0043 & 0,0355 & 0,0507 \\
\hline \hline THO6-H25-VC & & 23,71 & 0,0046 & 0,0052 & 0,0599 & 0,0750 \\
\hline
\end{tabular}


9.2.2.20 Tabla $\left(\sigma_{\max } \varepsilon_{\max } \varepsilon_{u} E_{\max }\right.$ y $\left.E_{u}\right)$ y Gráfica Tensión $\sigma(\mathrm{N} / \mathrm{mm} 2)$ / Deformación $\varepsilon$ de las tres probetas cilíndricas con tubo vertical descentrado, de hormigón $\mathrm{H}-25$ ensayado a compresión.

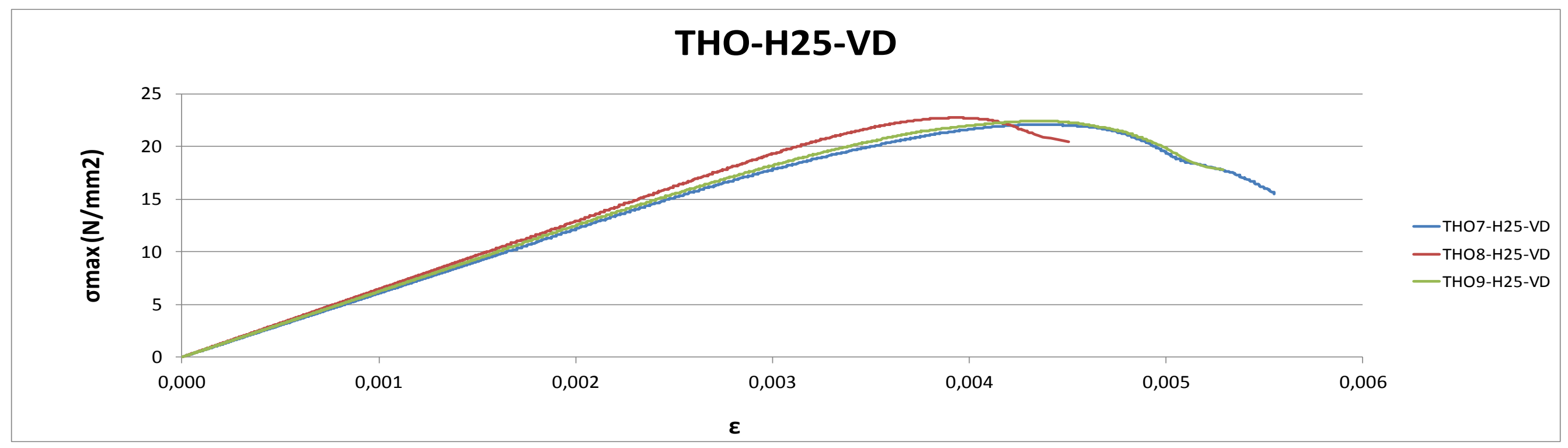

\begin{tabular}{|c||c|c|c|c|c|c|}
\hline & Temperatura (ㅇ) & $\boldsymbol{\sigma m a x}(\mathbf{N} / \mathbf{m m} 2)$ & $\boldsymbol{\varepsilon m a x}$ & $\boldsymbol{\varepsilon u}$ & Emax (N/mm2) & Eu (N/mm2) \\
\hline \hline MEDIA & & 22,42 & 0,0042 & 0,0051 & 0,0534 & 0,0718 \\
\hline \hline TH07-H25-VD & & 22,09 & 0,0043 & 0,0056 & 0,0548 & 0,0784 \\
\hline \hline TH08-H25-VD & & 22,74 & 0,0039 & 0,0045 & 0,0492 & 0,0616 \\
\hline \hline TH09-H25-VD & & 22,43 & 0,0044 & 0,0053 & 0,0562 & 0,0755 \\
\hline
\end{tabular}




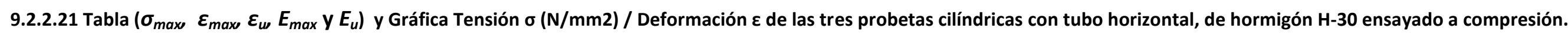

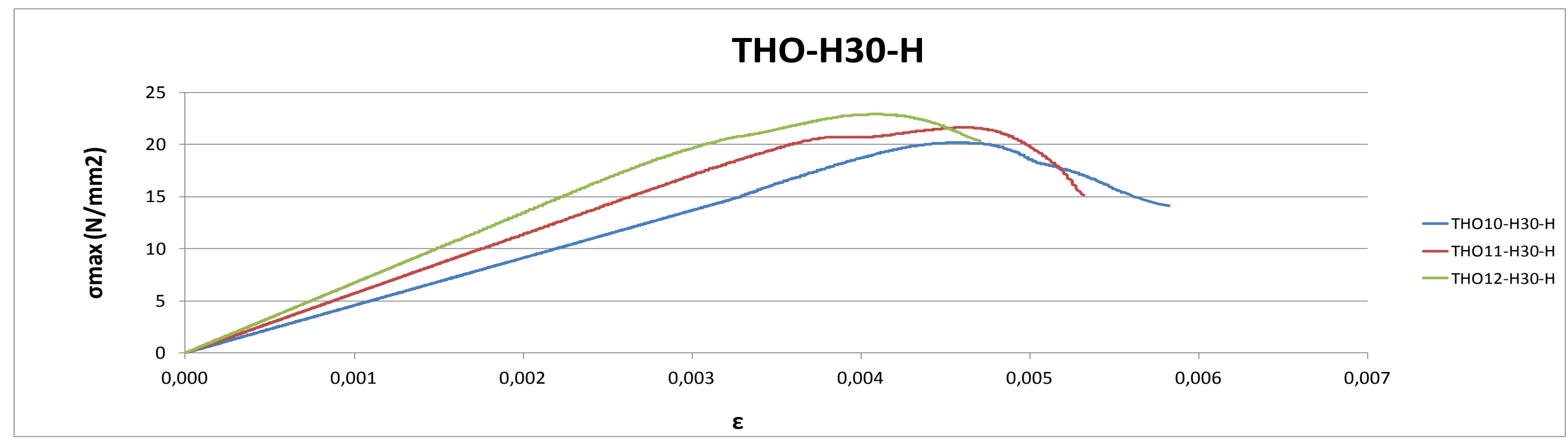

\begin{tabular}{|c||c|c|c|c|c|c|}
\hline & Temperatura (ㅇ) & $\sigma \max (\mathbf{N} / \mathbf{m m} 2)$ & $\boldsymbol{\varepsilon m a x}$ & $\varepsilon u$ & Emax (N/mm2) & Eu (N/mm2) \\
\hline \hline MEDIA & & 21,58 & 0,0044 & 0,0053 & 0,0531 & 0,0697 \\
\hline \hline THO10-H30-H & & 20,19 & 0,0046 & 0,0058 & 0,0477 & 0,0699 \\
\hline \hline THO11-H30-H & & 21,64 & 0,0046 & 0,0053 & 0,0581 & 0,0718 \\
\hline \hline THO12-H30-H & & 22,91 & 0,0041 & 0,0047 & 0,0535 & 0,0673 \\
\hline
\end{tabular}




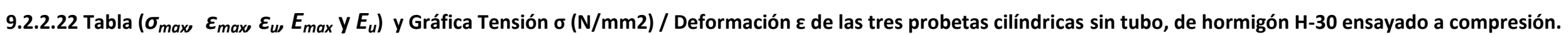

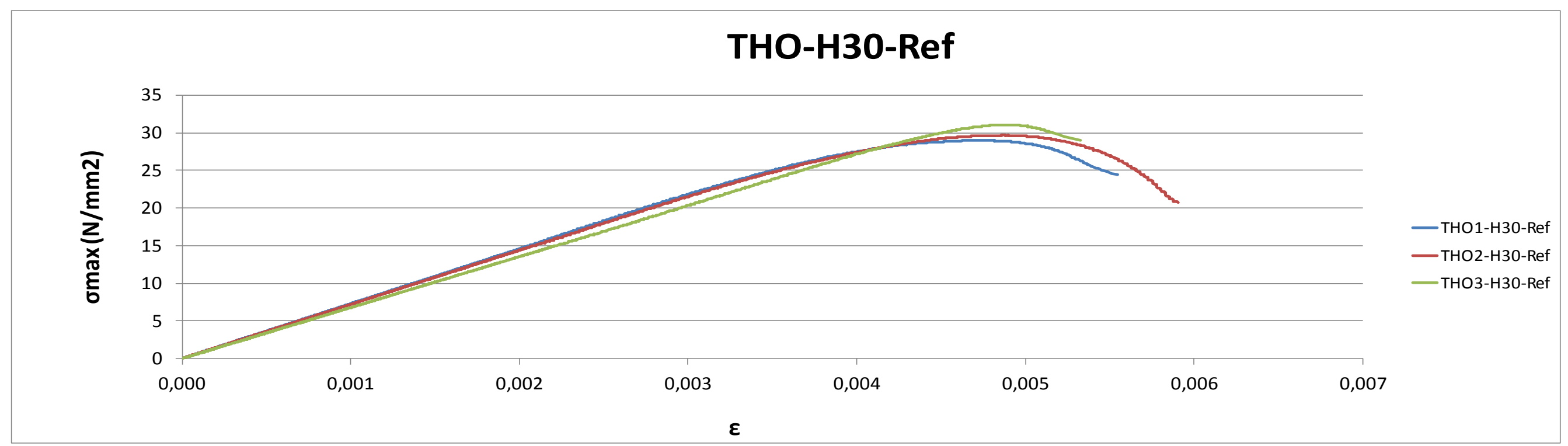

\begin{tabular}{|c||c|c|c|c|c|c|}
\hline & Temperatura (ㅇ) & $\sigma \max (\mathbf{N} / \mathbf{m m 2})$ & $\boldsymbol{\varepsilon m a x}$ & $\boldsymbol{\varepsilon u}$ & Emax (N/mm2) & Eu (N/mm2) \\
\hline \hline MEDIA & & 29,91 & 0,0048 & 0,0056 & 0,0806 & 0,1016 \\
\hline \hline THO1-H30-Ref & & 28,98 & 0,0047 & 0,0055 & 0,0786 & 0,1010 \\
\hline \hline THO2-H30-Ref & & 29,67 & 0,0049 & 0,0059 & 0,0822 & 0,1101 \\
\hline \hline THO3-H30-Ref & & 31,08 & 0,0049 & 0,0053 & 0,0811 & 0,0938 \\
\hline
\end{tabular}


9.2.2.23 Tabla $\left(\sigma_{\max } \varepsilon_{\max } \varepsilon_{u}, E_{\max }\right.$ y $\left.E_{u}\right)$ y Gráfica Tensión $\sigma(\mathrm{N} / \mathrm{mm} 2)$ / Deformación $\varepsilon$ de las tres probetas cilíndricas con tubo vertical centrado, de hormigón $\mathrm{H}-30$ ensayado a compresión.

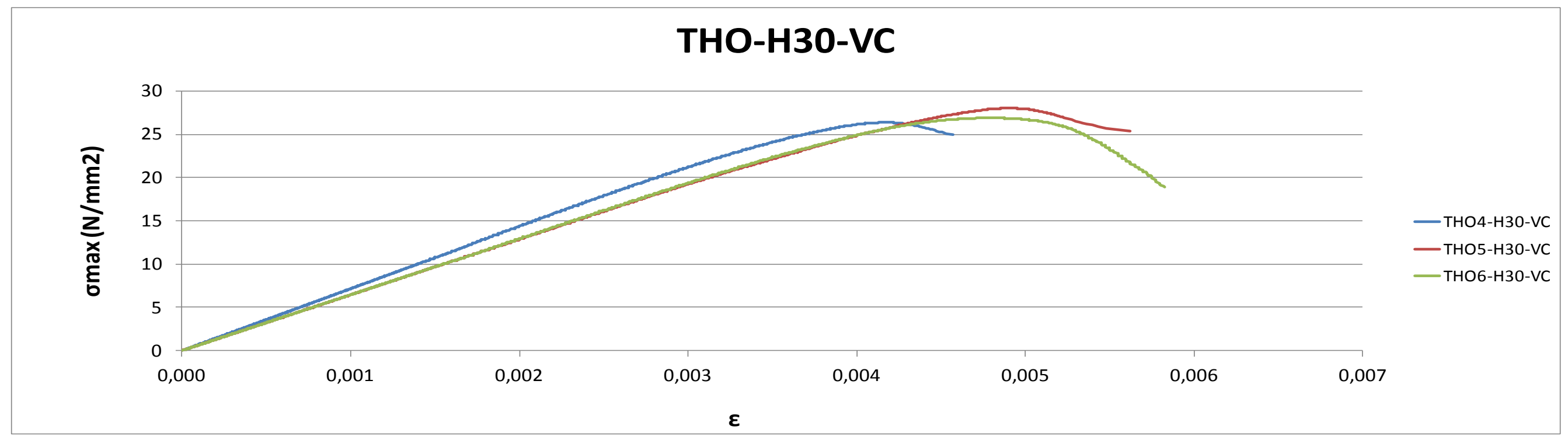

\begin{tabular}{|c||c|c|c|c|c|c|}
\hline & Temperatura (ㅇ) & $\sigma \max (\mathbf{N} / \mathbf{m m} 2)$ & $\boldsymbol{\varepsilon m a x}$ & $\varepsilon u$ & Emax (N/mm2) & Eu (N/mm2) \\
\hline \hline MEDIA & & 27,09 & 0,0046 & 0,0053 & 0,0694 & 0,0546 \\
\hline \hline TH04-H30-VC & & 26,37 & 0,0042 & 0,0046 & 0,0609 & 0,0709 \\
\hline \hline THO5-H30-VC & & 28,02 & 0,0049 & 0,0056 & 0,0751 & 0,0415 \\
\hline \hline THO6-H30-VC & 26,89 & 0,0048 & 0,0058 & 0,0722 & 0,0513 \\
\hline
\end{tabular}


9.2.2.24 Tabla $\left(\sigma_{\max } \varepsilon_{\max } \varepsilon_{u}, E_{\max }\right.$ y $\left.E_{u}\right)$ y Gráfica Tensión $\sigma(\mathrm{N} / \mathrm{mm} 2)$ / Deformación $\varepsilon$ de las tres probetas cilíndricas con tubo vertical descentrado, de hormigón $\mathrm{H}-30$ ensayado a compresión.

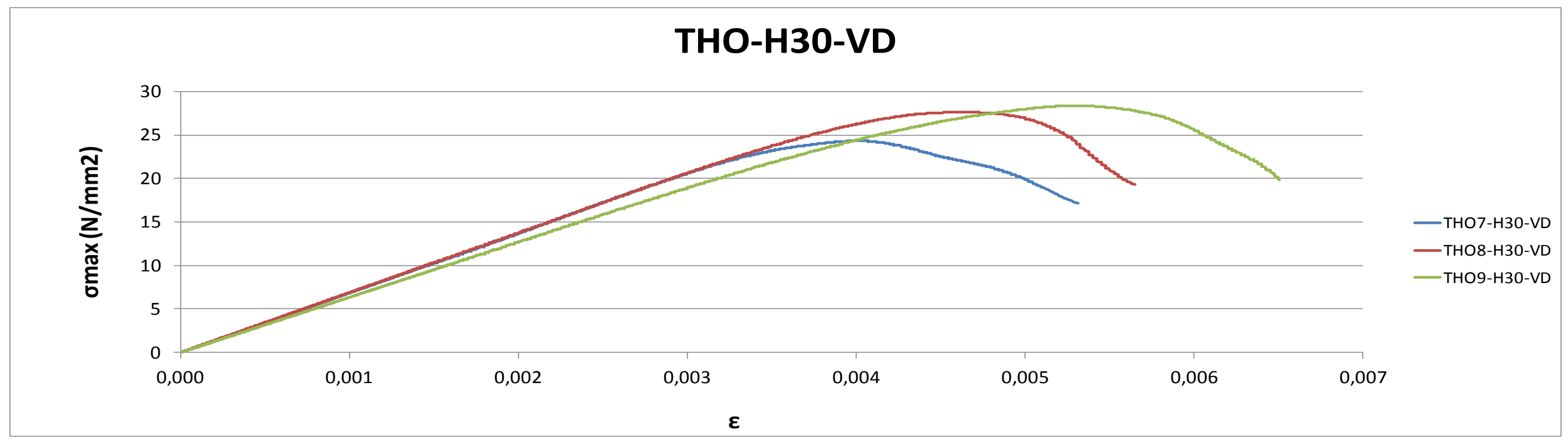

\begin{tabular}{|c|c|c|c|c|c|c|}
\hline & Temperatura (oC) & $\sigma \max (\mathrm{N} / \mathrm{mm} 2)$ & $\varepsilon \max$ & $\varepsilon u$ & $\operatorname{Emax}(\mathrm{N} / \mathrm{mm} 2)$ & $\mathrm{Eu}(\mathrm{N} / \mathrm{mm} 2)$ \\
\hline MEDIA & & 26,77 & 0,0046 & 0,0058 & 0,0702 & 0,0624 \\
\hline TH07-H30-VD & & 24,33 & 0,0040 & 0,0053 & 0,0541 & 0,0649 \\
\hline TH08-H30-VD & & 27,61 & 0,0046 & 0,0056 & 0,0714 & 0,0624 \\
\hline THO9-H30-VD & & 28,36 & 0,0053 & 0,0065 & 0,0851 & 0,0598 \\
\hline
\end{tabular}


9.2.2.25 Tabla $\left(\sigma_{\max } \varepsilon_{\max } \varepsilon_{u} E_{\max }\right.$ y $\left.E_{u}\right)$ y Gráfica Tensión $\sigma(\mathrm{N} / \mathrm{mm} 2)$ / Deformación $\varepsilon$ de las tres probetas cúbicas con tubo horizontal, de hormigón H-25 ensayado a compresión.

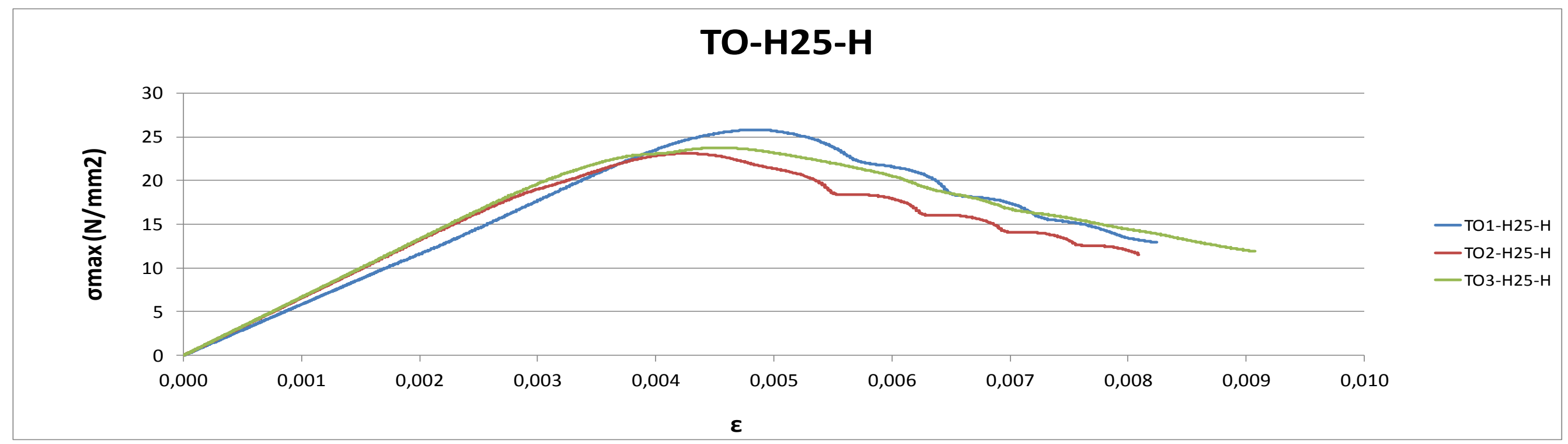

\begin{tabular}{|c||c|c|c|c|c|c|}
\hline & Temperatura (-C) & $\sigma \max (\mathbf{N} / \mathbf{m m} 2)$ & $\boldsymbol{\varepsilon m a x}$ & $\boldsymbol{\varepsilon u}$ & Emax (N/mm2) & Eu (N/mm2) \\
\hline \hline MEDIA H & & 24,22 & 0,0045 & 0,0085 & 0,0629 & 0,1339 \\
\hline \hline TO1-H25-H & & 25,83 & 0,0048 & 0,0082 & 0,0680 & 0,1335 \\
\hline \hline TO2-H25-H & & 23,10 & 0,0043 & 0,0081 & 0,0564 & 0,1226 \\
\hline \hline TO3-H25-H & 23,75 & 0,0045 & 0,0091 & 0,0643 & 0,1454 \\
\hline
\end{tabular}


9.2.2.26 Tabla $\left(\sigma_{\max } \varepsilon_{\max } \varepsilon_{u} E_{\max }\right.$ y $\left.E_{u}\right)$ y Gráfica Tensión $\sigma(\mathrm{N} / \mathrm{mm} 2)$ / Deformación $\varepsilon$ de las tres probetas cúbicas con tubo horizontal, de hormigón $\mathrm{H}-25$ ensayado a compresión.

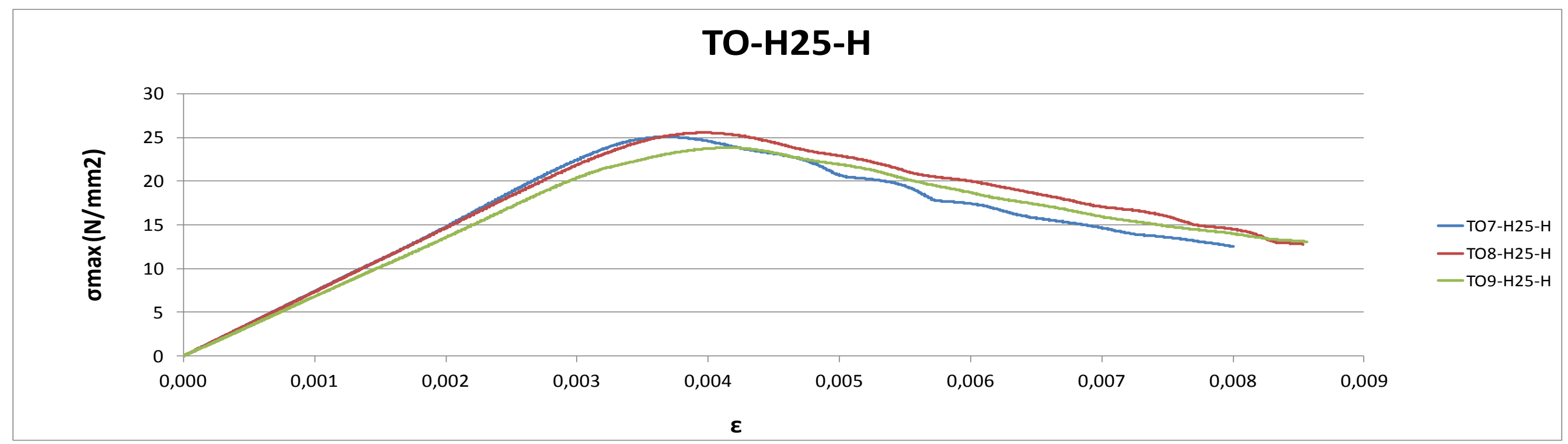

\begin{tabular}{|c||c|c|c|c|c|c|}
\cline { 2 - 7 } & Temperatura (oC) & $\sigma \max (\mathbf{N} / \mathbf{m m 2})$ & $\boldsymbol{\varepsilon m a x}$ & $\boldsymbol{\varepsilon u}$ & Emax (N/mm2) & Eu (N/mm2) \\
\hline \hline MEDIA H & & 24,81 & 0,0039 & 0,0086 & 0,0545 & 0,1400 \\
\hline \hline TO7-H25-H & & 25,06 & 0,0037 & 0,0080 & 0,0498 & 0,1295 \\
\hline \hline TO8-H25-H & & 25,55 & 0,0040 & 0,0085 & 0,0568 & 0,1446 \\
\hline \hline TO9-H25-H & & 23,82 & 0,0042 & 0,0093 & 0,0568 & 0,1460 \\
\hline
\end{tabular}


9.2.2.27 Tabla $\left(\sigma_{\max }, \varepsilon_{\max } \varepsilon_{u} E_{\max }\right.$ y $\left.E_{u}\right)$ y Gráfica Tensión $\sigma(\mathrm{N} / \mathrm{mm} 2)$ / Deformación $\varepsilon$ de las tres probetas cúbicas sin tubo, de hormigón H-25 ensayado a compresión.

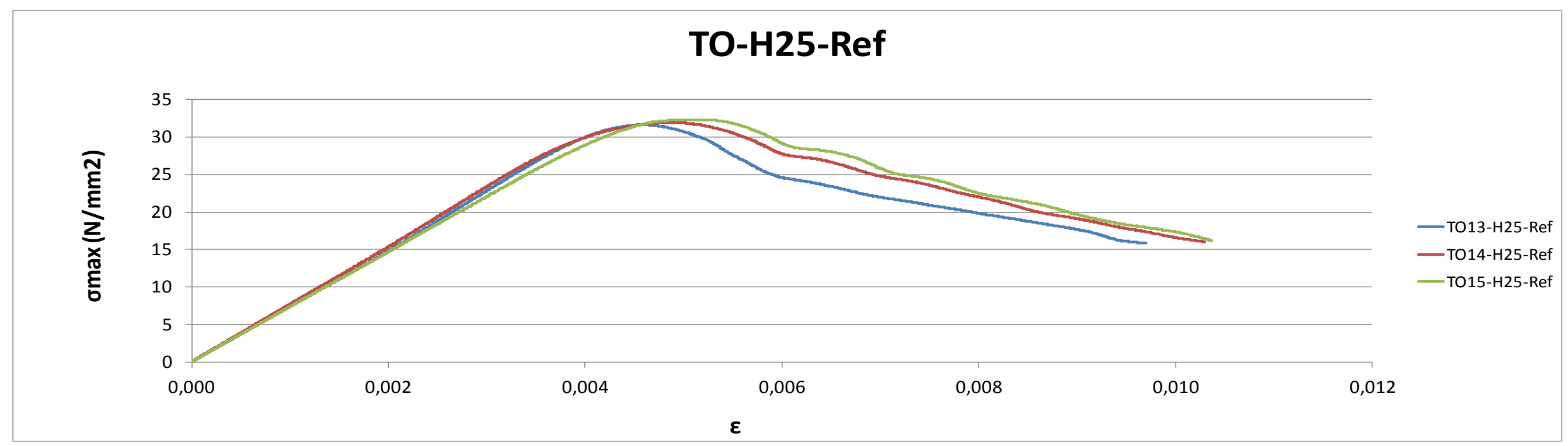

\begin{tabular}{|c||c|c|c|c|c|c|}
\hline \multicolumn{1}{|c|}{} & Temperatura (oC) & $\boldsymbol{\sigma m a x}(\mathbf{N} / \mathbf{m m 2})$ & $\boldsymbol{\varepsilon m a x}$ & $\boldsymbol{\varepsilon u}$ & Emax (N/mm2) & Eu (N/mm2) \\
\hline \hline MEDIA Ref & & 31,98 & 0,0049 & 0,0101 & 0,0878 & 0,2097 \\
\hline \hline TO13-H25-Ref & & 31,64 & 0,0046 & 0,0097 & 0,0786 & 0,1936 \\
\hline \hline TO14-H25-Ref & & 31,96 & 0,0049 & 0,0103 & 0,0889 & 0,2164 \\
\hline \hline TO15-H25-Ref & & 32,33 & 0,0052 & 0,0104 & 0,0959 & 0,2190 \\
\hline
\end{tabular}




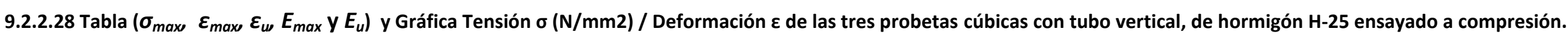

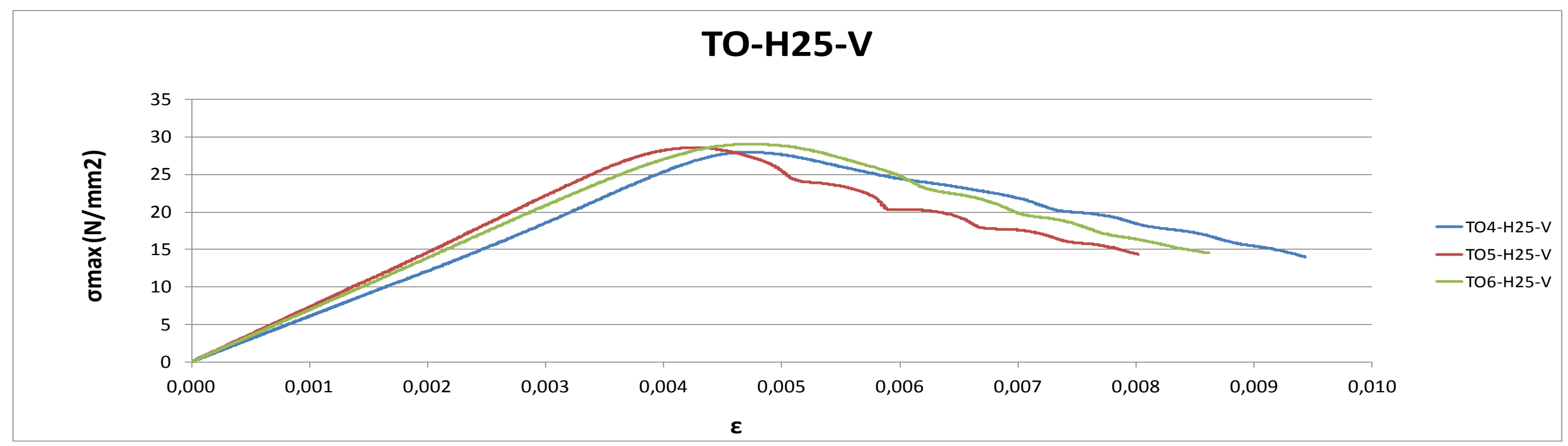

\begin{tabular}{|c||c|c|c|c|c|c|}
\hline \multicolumn{1}{|c|}{} & Temperatura (oC) & $\boldsymbol{\sigma m a x}(\mathbf{N} / \mathbf{m m 2})$ & $\boldsymbol{\varepsilon m a x}$ & $\boldsymbol{\varepsilon u}$ & Emax (N/mm2) & Eu (N/mm2) \\
\hline \hline MEDIA & & 28,53 & 0,0046 & 0,0087 & 0,0709 & 0,1584 \\
\hline \hline TO4-H25-V & & 27,97 & 0,0047 & 0,0094 & 0,0689 & 0,1694 \\
\hline \hline TO5-H25-V & & 28,59 & 0,0043 & 0,0080 & 0,0667 & 0,1447 \\
\hline \hline TO6-H25-V & & 29,04 & 0,0048 & 0,0086 & 0,0770 & 0,1609 \\
\hline
\end{tabular}




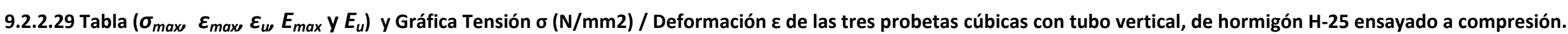

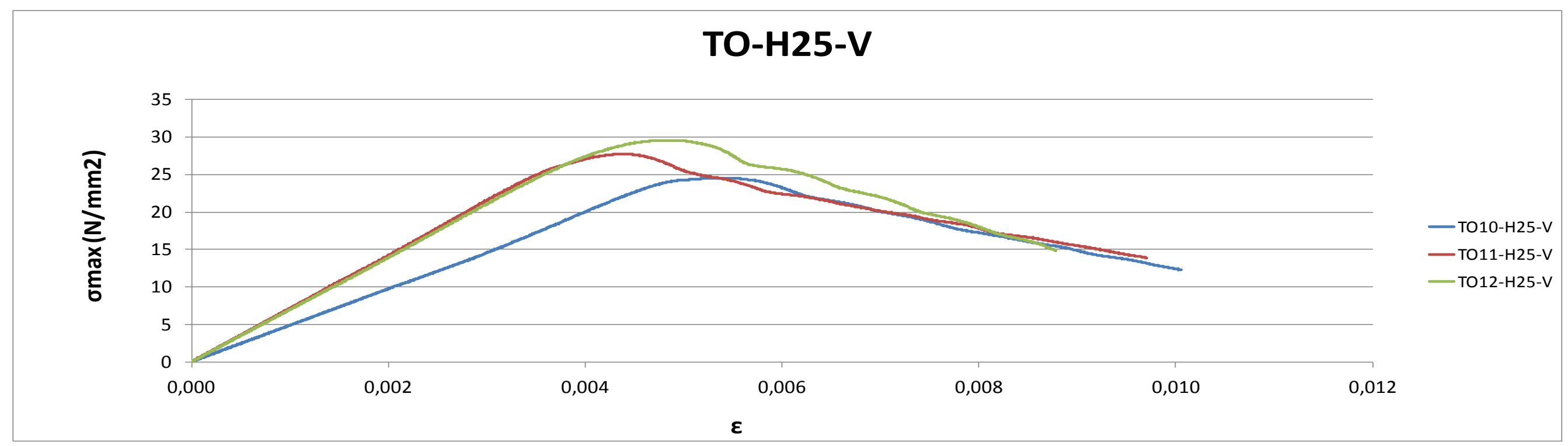

\begin{tabular}{|c||c|c|c|c|c|c|}
\hline & Temperatura (oC) & $\sigma \max (\mathbf{N} / \mathbf{m m} \mathbf{2})$ & $\boldsymbol{\varepsilon m a x}$ & $\boldsymbol{\varepsilon u}$ & Emax (N/mm2) & Eu (N/mm2) \\
\hline \hline MEDIA V & & 27,28 & 0,0049 & 0,0095 & 0,0731 & 0,1668 \\
\hline \hline TO10-H25-V & & 24,53 & 0,0054 & 0,0101 & 0,0713 & 0,1563 \\
\hline \hline TO11-H25-V & & 27,72 & 0,0044 & 0,0097 & 0,0677 & 0,1752 \\
\hline \hline TO12-H25-V & & 29,58 & 0,0048 & 0,0088 & 0,0803 & 0,1688 \\
\hline
\end{tabular}




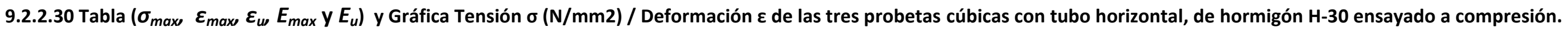

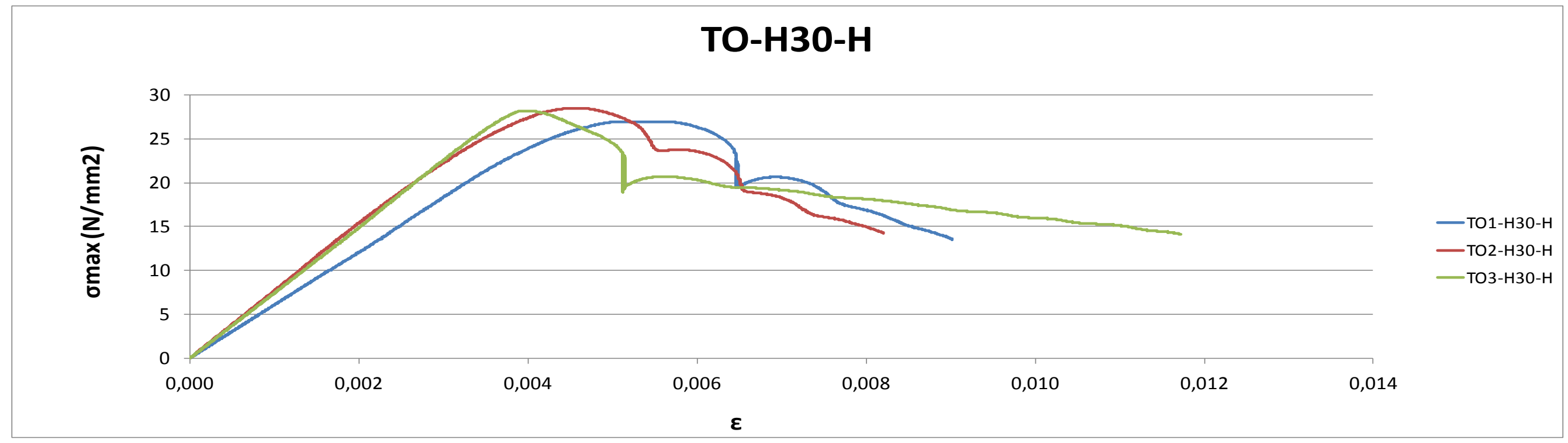

\begin{tabular}{|c||c|c|c|c|c|c|}
\hline & Temperatura (ㅇ) & $\sigma \max (\mathbf{N} / \mathbf{m m} 2)$ & $\boldsymbol{\varepsilon m a x}$ & $\boldsymbol{\varepsilon u}$ & Emax (N/mm2) & Eu (N/mm2) \\
\hline \hline MEDIA H & & 27,92 & 0,0046 & 0,0096 & 0,0716 & 0,1212 \\
\hline \hline TO1-H30-H & & 26,99 & 0,0052 & 0,0090 & 0,0801 & 0,1582 \\
\hline \hline TO2-H30-H & & 28,53 & 0,0046 & 0,0082 & 0,0758 & 0,0000 \\
\hline \hline TO3-H30-H & & 28,23 & 0,0040 & 0,0117 & 0,0588 & 0,2054 \\
\hline
\end{tabular}


9.2.2.31 Tabla $\left(\sigma_{\max } \varepsilon_{\max } \varepsilon_{u} E_{\max }\right.$ y $\left.E_{u}\right)$ y Gráfica Tensión $\sigma(\mathrm{N} / \mathrm{mm} 2)$ / Deformación $\varepsilon$ de las tres probetas cúbicas con tubo horizontal, de hormigón H-30 ensayado a compresión.

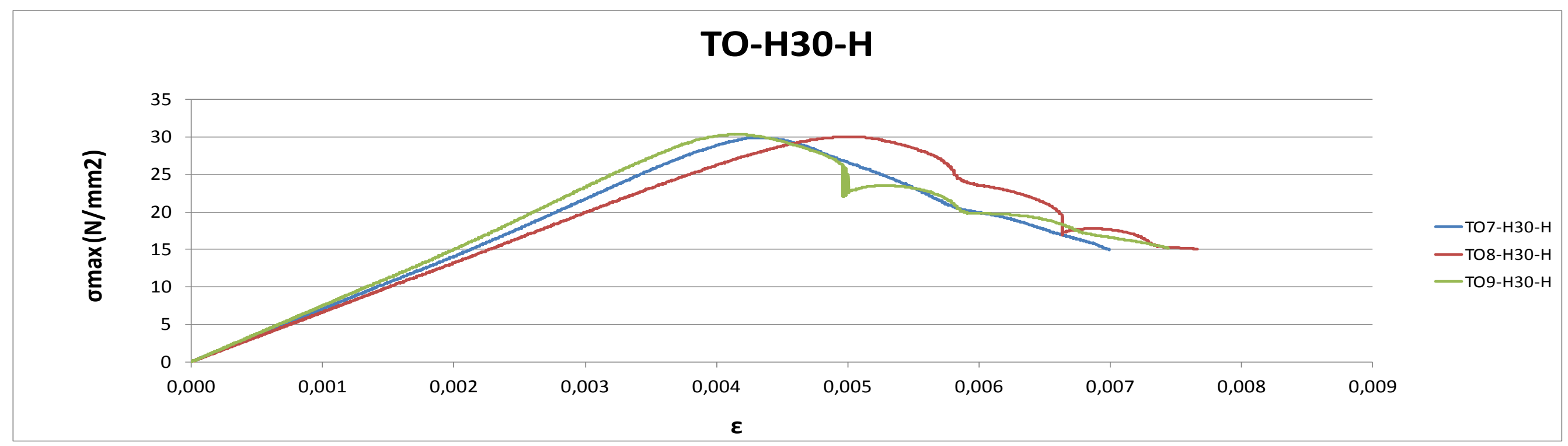

\begin{tabular}{|c||c|c|c|c|c|c|}
\hline & Temperatura (oC) & $\sigma \max (\mathbf{N} / \mathbf{m m 2})$ & $\boldsymbol{\varepsilon m a x}$ & $\boldsymbol{\varepsilon u}$ & Emax (N/mm2) & Eu (N/mm2) \\
\hline \hline MEDIA H & & 30,11 & 0,0045 & 0,0074 & 0,0718 & 0,1352 \\
\hline \hline TO7-H30-H & & 29,94 & 0,0043 & 0,0070 & 0,0668 & 0,1270 \\
\hline \hline TO8-H30-H & & 30,05 & 0,0050 & 0,0077 & 0,0826 & 0,1405 \\
\hline \hline TO9-H30-H & & 30,34 & 0,0042 & 0,0074 & 0,0660 & 0,1382 \\
\hline
\end{tabular}




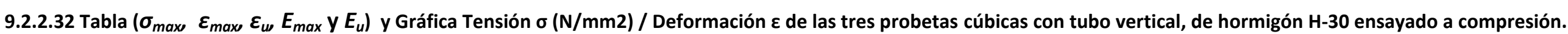

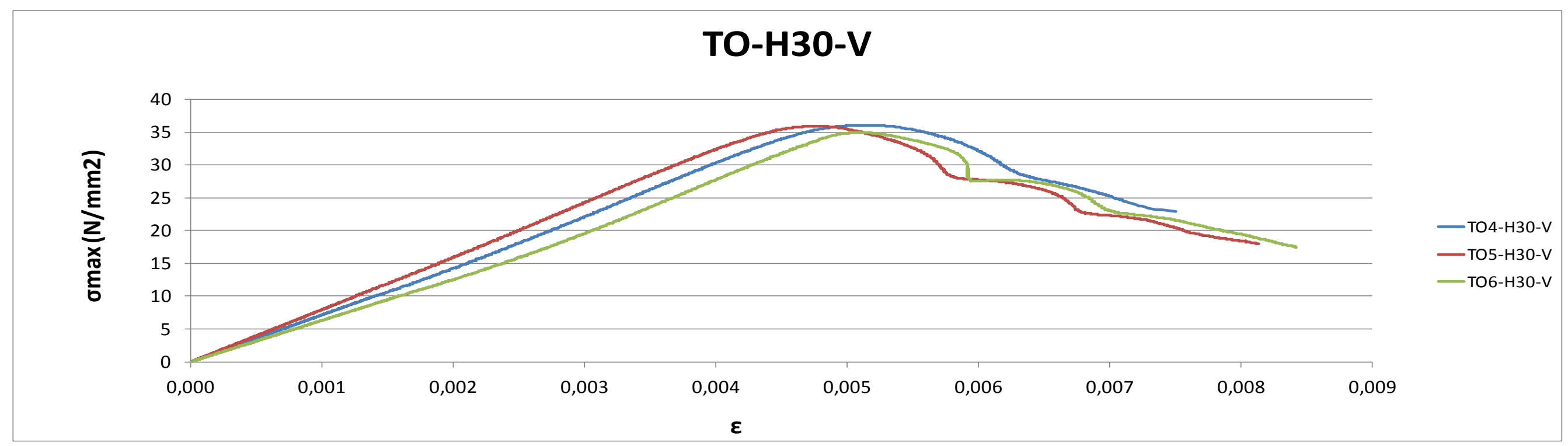

\begin{tabular}{|c||c|c|c|c|c|c|}
\hline & Temperatura (ㅇ) & $\boldsymbol{\sigma m a x}(\mathbf{N} / \mathbf{m m} 2)$ & $\boldsymbol{\varepsilon m a x}$ & $\boldsymbol{\varepsilon u}$ & Emax (N/mm2) & Eu (N/mm2) \\
\hline \hline MEDIA V & & 35,68 & 0,0050 & 0,0080 & 0,0923 & 0,1733 \\
\hline \hline TO4-H30-V & & 36,09 & 0,0051 & 0,0075 & 0,0974 & 0,1674 \\
\hline \hline TO5-H30-V & & 35,96 & 0,0048 & 0,0081 & 0,0915 & 0,1796 \\
\hline \hline TO6-H30-V & & 34,99 & 0,0051 & 0,0084 & 0,0878 & 0,1728 \\
\hline
\end{tabular}


9.2.2.33 Tabla $\left(\sigma_{\max }, \varepsilon_{\max }, \varepsilon_{u} E_{\max } y E_{u}\right)$ y Gráfica Tensión $\sigma(\mathrm{N} / \mathrm{mm} 2)$ / Deformación $\varepsilon$ de las tres probetas cúbicas sin tubo, de hormigón $\mathrm{H}-30$ ensayado a compresión.

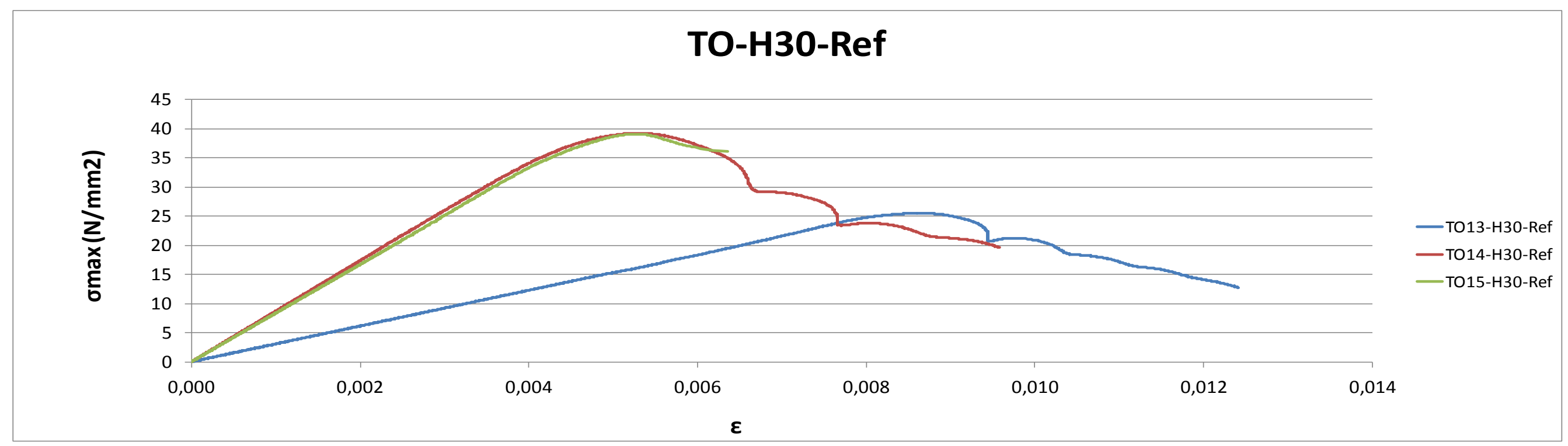

\begin{tabular}{|c||c|c|c|c|c|c|}
\hline & Temperatura (ㅇ) & $\sigma \max (\mathbf{N} / \mathbf{m m} \mathbf{2})$ & $\boldsymbol{\varepsilon m a x}$ & $\boldsymbol{\varepsilon u}$ & Emax (N/mm2) & Eu (N/mm2) \\
\hline \hline MEDIA Ref & & 34,62 & 0,0064 & 0,0094 & 0,1156 & 0,1929 \\
\hline \hline TO13-H30-Ref & & 25,53 & 0,0087 & 0,0124 & 0,1149 & 0,1859 \\
\hline \hline TO14-H30-Ref & & 39,24 & 0,0053 & 0,0096 & 0,1179 & 0,2385 \\
\hline \hline TO15-H30-Ref & & 39,09 & 0,0053 & 0,0064 & 0,1139 & 0,1543 \\
\hline
\end{tabular}




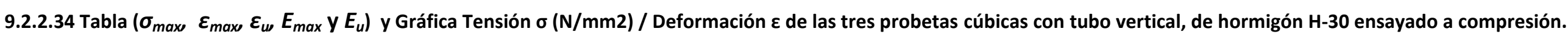

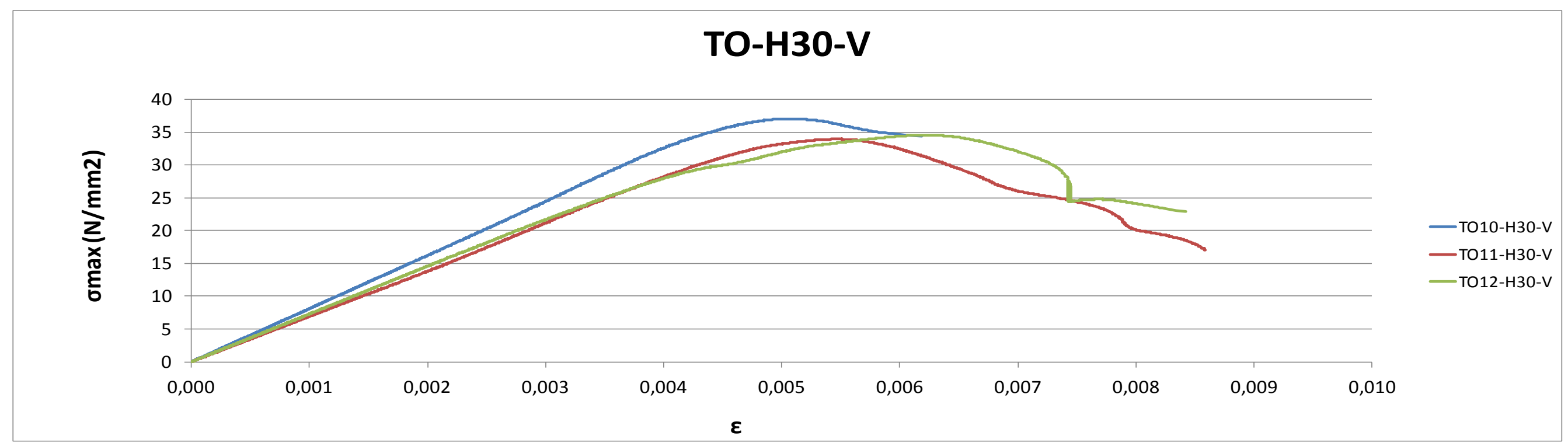

\begin{tabular}{|c||c|c|c|c|c|c|}
\hline & Temperatura (oC) & $\boldsymbol{\sigma m a x}(\mathbf{N} / \mathbf{m m} 2)$ & $\boldsymbol{\varepsilon m a x}$ & $\boldsymbol{\varepsilon u}$ & Emax (N/mm2) & Eu (N/mm2) \\
\hline \hline MEDIA V & & 35,20 & 0,0056 & 0,0077 & 0,1114 & 0,0927 \\
\hline \hline TO10-H30-V & & 37,05 & 0,0050 & 0,0062 & 0,1022 & 0,1429 \\
\hline \hline TO11-H30-V & & 33,96 & 0,0055 & 0,0086 & 0,1033 & 0,0556 \\
\hline \hline T012-H30-V & & 34,59 & 0,0062 & 0,0084 & 0,1287 & 0,0797 \\
\hline
\end{tabular}


ANEXO 3

\section{ANÁLISIS DE LA VARIANZA MULTIFACTORIAL}




\subsubsection{Estudio estadístico analisis de la varianza multifactorial}

El estudio realizado sobre el efecto del incremento de temperatura en la resistencia a compresión o a arrancamiento de las probetas, resulta fácil de estudiar con las gráficas que se han expuesto en los apartados anteriores, ya que son dos las variables que afectan al resultado, el incremento de temperatura y el tipo de hormigón utilizado.

El efecto del tipo de hormigón claramente va a influir pues, en principio, siempre tendremos mayores resultados de resistencia en los hormigones $\mathrm{H}-30$ que en los $\mathrm{H}-25$, no obstante la interacción que se produce en los valores es interesante también, es decir, si se puede establecer una relación en la que los dos factores estén vinculados.

Donde se complica algo más el estudio de la interacción entre los factores que afectan a la resistencia es en el caso de querer comparar los resultados de todas las probetas que se han ensayado para estudiar el efecto de la existencia del tubo de polietileno en su interior. Afectan tres factores distintos, el tipo de hormigón $(\mathrm{H}-$ 25, H-30), el tipo de probeta (cilíndrica, cúbica) y el posicionamiento del tubo (vertical centrado, vertical descentrado, horizontal centrado y sin tubo)

Se pretende por lo tanto utilizar el estudio estadístico de la varianza multifactorial apoyándonos en el programa informático Statgraphics, para estudiar dicha interacción.

La variable aleatoria de nuestro estudio es:

Resistencia a compresión de probetas de hormigón (N/mm2)

Tendremos 3 factores en estudio con varios niveles cada uno:

1. Tipo de hormigón: $\mathrm{H}-25(\mathrm{H} 1), \mathrm{H}-30(\mathrm{H} 2)$

2. Forma de la probeta: Cilíndrica (F1), Cúbica (F2)

2. Posición del tubo: Horizontal (P1), vertical centrado (P2) y vertical descentrado (P3) 


\begin{tabular}{|c|c|c|c|c|c|}
\hline TRATAMIENTOS & $\begin{array}{c}\text { FACTOR } 1 \\
\text { TIPO DE } \\
\text { HORMIGÓN }\end{array}$ & $\begin{array}{l}\text { FACTOR } 2 \\
\text { FORMA DE } \\
\text { PROBETA }\end{array}$ & $\begin{array}{l}\text { FACTOR } 3 \\
\text { POSICIÓN } \\
\text { DEL TUBO }\end{array}$ & $\begin{array}{c}\text { ORDEN } \\
\text { ALEATORIO DE } \\
\text { REALIZACIÓN } \\
\text { DE ENSAYOS }\end{array}$ & $\begin{array}{c}\text { RESISTENCIA A } \\
\text { COMPRESIÓN } \\
\text { N/MM }{ }^{2}\end{array}$ \\
\hline 1 & $\mathrm{H} 1$ & F1 & $\mathrm{p} 1$ & 3 & 18,28 \\
\hline 2 & H2 & $\mathrm{F} 1$ & P1 & 13 & 21,58 \\
\hline 3 & $\mathrm{H} 1$ & $\mathrm{~F} 2$ & P1 & 6 & 24,22 \\
\hline 4 & H2 & F2 & P1 & 12 & 27,92 \\
\hline 5 & $\mathrm{H} 1$ & $\mathrm{~F} 1$ & P2 & 2 & 22,02 \\
\hline 6 & H2 & $\mathrm{F} 1$ & P2 & 15 & 27,09 \\
\hline 7 & $\mathrm{H} 1$ & F2 & P2 & 5 & 28,53 \\
\hline 8 & $\mathrm{H} 2$ & F2 & P2 & 11 & 35,68 \\
\hline 9 & $\mathrm{H} 1$ & F1 & P3 & 1 & 22,42 \\
\hline 10 & H2 & F1 & P3 & 14 & 26,77 \\
\hline 11 & $\mathrm{H} 1$ & F2 & P3 & 8 & 27,28 \\
\hline 12 & H2 & $\mathrm{F} 2$ & P3 & 10 & 35,20 \\
\hline 13 & $\mathrm{H} 1$ & $\mathrm{~F} 1$ & P4 & 4 & 23,22 \\
\hline 14 & $\mathrm{H} 2$ & F1 & P4 & 16 & 29,91 \\
\hline 15 & H1 & F2 & P4 & 7 & 31,98 \\
\hline 16 & H2 & F2 & P4 & 9 & 34,62 \\
\hline
\end{tabular}

Tabla 9.3- 1. Tabla de planteamiento de estudio estadístico, 3 factores con varios niveles.

H1: Hormigón H-25

H2: Hormigón H-30 
F1: Probeta cilíndrica

F2: Probeta cúbica

P1: Tubo dispuesto en posición horizontal

P2: Tubo dispuesto en posición vertical

P3: Tubo dispuesto en posición vertical descentrado

P4: Sin tubo

\section{Formulación del problema.}

El problema consiste en contrastar las siguientes hipótesis nulas $(\mathrm{H} 0)$ :

- Ho : $\boldsymbol{\alpha}_{1}=\boldsymbol{\alpha}_{2}$ siendo $\boldsymbol{\alpha}_{1}$ la media de las poblaciones según el primer factor (Tipo de hormigón)

- Ho: $\boldsymbol{\beta}_{1}=\boldsymbol{\beta}_{2}$ siendo $\beta_{1}$ la media de las poblaciones según el segundo factor (Forma de la probeta)

- Ho: $\mathrm{y}^{1}=\mathrm{y} 2=\mathrm{y} 3=\mathrm{y} 4$ siendo $\mathrm{y} 1$ la media de las poblaciones según el tercer factor (Posición del tubo)

- Ho : $(\boldsymbol{\alpha} \boldsymbol{\beta})=\mathbf{0}$ que no exista interacción entre los factores (Hormigón / Forma)

- Ho : $(\boldsymbol{\alpha}$ y) = $\mathbf{0}$ que no exista interacción entre los factores (Hormigón / Posición)

- Ho : $(\boldsymbol{\beta} \mathbf{y})=\mathbf{0}$ que no exista interacción entre los factores (Forma / Posición)

Frente a la hipótesis alternativa $(\mathrm{H} 1)$, que se cumpla alguna de las siguientes:

- H1 : $\boldsymbol{\alpha}_{1} \neq \boldsymbol{\alpha}_{2}$ siendo $\boldsymbol{\alpha}_{1}$ la media de las poblaciones según el primer factor (Tipo de hormigón)

- $\mathbf{H 1}: \boldsymbol{\beta}_{1} \neq \boldsymbol{\beta}_{2}$ siendo $\beta_{1}$ la media de las poblaciones según el segundo factor (Forma de la probeta) 
- H1 : que exista al menos $\mathrm{i}, \mathrm{j} \mathrm{Y}_{\mathrm{i}} \neq \mathrm{Y}_{\mathrm{j}}$ siendo $\mathrm{Y}_{1}$ la media de las poblaciones según el segundo factor (Posición del tubo)

- H1 : $(\alpha \beta) \neq 0$ que exista interacción entre los factores (Hormigón / Forma)

- H1 : ( $\alpha$ y $) \neq 0$ que exista interacción entre los factores (Hormigón / Posición)

- H1 : $(\boldsymbol{\beta}$ y $) \neq 0$ que exista interacción entre los factores (Forma / Posición)

Se supone que la variable respuesta Yijk depende de los siguientes factores, según el modelo que se indica:

- $Y \mathbf{i j k}=\mu+\alpha \mathbf{i}+\beta \mathbf{j}+Y_{k}+(\alpha \beta) i j+(\alpha y) i k+(\beta Y) j k+\varepsilon i j k$

Siendo:

$\boldsymbol{\mu}$ la media global (resistencia media a compresión de las probetas)

ai el efecto sobre la resistencia media causado por primer factor (Tipo de hormigón)

$\beta \mathbf{j}$ el efecto sobre la resistencia media causado por el segundo factor (Forma de la probeta)

$\mathbf{Y}_{\mathbf{k}}$ el efecto sobre la resistencia media causado por el tercer factor (Posición del tubo)

$(\alpha \beta)$ ij el efecto sobre la resistencia media causado por la interacción entre los factores (Hormigón/Forma)

$(\alpha$ y) ik el efecto sobre la resistencia media causado por la interacción entre los factores (Hormigón / Posición)

( $\beta$ y) jk el efecto sobre la resistencia media causado por la interacción entre los factores (Forma / Posición)

$\boldsymbol{\varepsilon} \mathbf{i j k}$ el error experimental

Yijk la resistencia esperada cuando el primer factor (Tipo de hormigón) actúa a nivel "i", el segundo (Forma de la probeta) a nivel "j" y el tercero (Posición del tubo) a nivel "k". 
En primer lugar, introducimos los datos de las observaciones en una tabla de Statgraphics (Figura 9.3-1), para comprobar la influencia de la interacción.

\begin{tabular}{|c|c|c|c|c|c|}
\hline \multicolumn{6}{|c|}{ 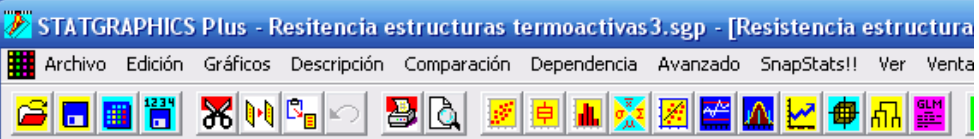 } \\
\hline & Hormigón & Forma probeta & Posición del & Resistencia & Col_5 \\
\hline 1 & 1 & 1 & 1 & 18,28 & \\
\hline 2 & 2 & 1 & 1 & 21,58 & \\
\hline 3 & 1 & 2 & 1 & 24,22 & \\
\hline 4 & 2 & 2 & 1 & 27,92 & \\
\hline 5 & 1 & 1 & 2 & 22,02 & \\
\hline 6 & 2 & 1 & 2 & 27,09 & \\
\hline 7 & 1 & 2 & 2 & 28,53 & \\
\hline 8 & 2 & 2 & 2 & 35,68 & \\
\hline 9 & 1 & 1 & 3 & 22,42 & \\
\hline 10 & 2 & 1 & 3 & 26,77 & \\
\hline 11 & 1 & 2 & 3 & 27,28 & \\
\hline 12 & 2 & 2 & 3 & 35,2 & \\
\hline 13 & 1 & 1 & 4 & 23,22 & \\
\hline 14 & 2 & 1 & 4 & 29,91 & \\
\hline 15 & 1 & 2 & 4 & 31,98 & \\
\hline 16 & 2 & 2 & 4 & 34,62 & \\
\hline 17 & & & & & \\
\hline
\end{tabular}

Figura 9.3- 1. Tabla de datos. Statgraphics.

Vamos a considerar despreciable la interacción de los tres factores, ya que si no fuera cero, no se podrían realizar los contrastes anteriores utilizando el análisis de la varianza.

Al estudiar la influencia de la interacción entre factores de orden dos, hemos comprobado que el valor del p-valor es superior a 0,05 en los tres casos (Figura 9.3- 2); lo que supone que la interacción no tiene un efecto estadísticamente significativo en la resistencia de las probetas al 95\% de confianza, por lo tanto se considerará el modelo aditivo sin interacciones. 


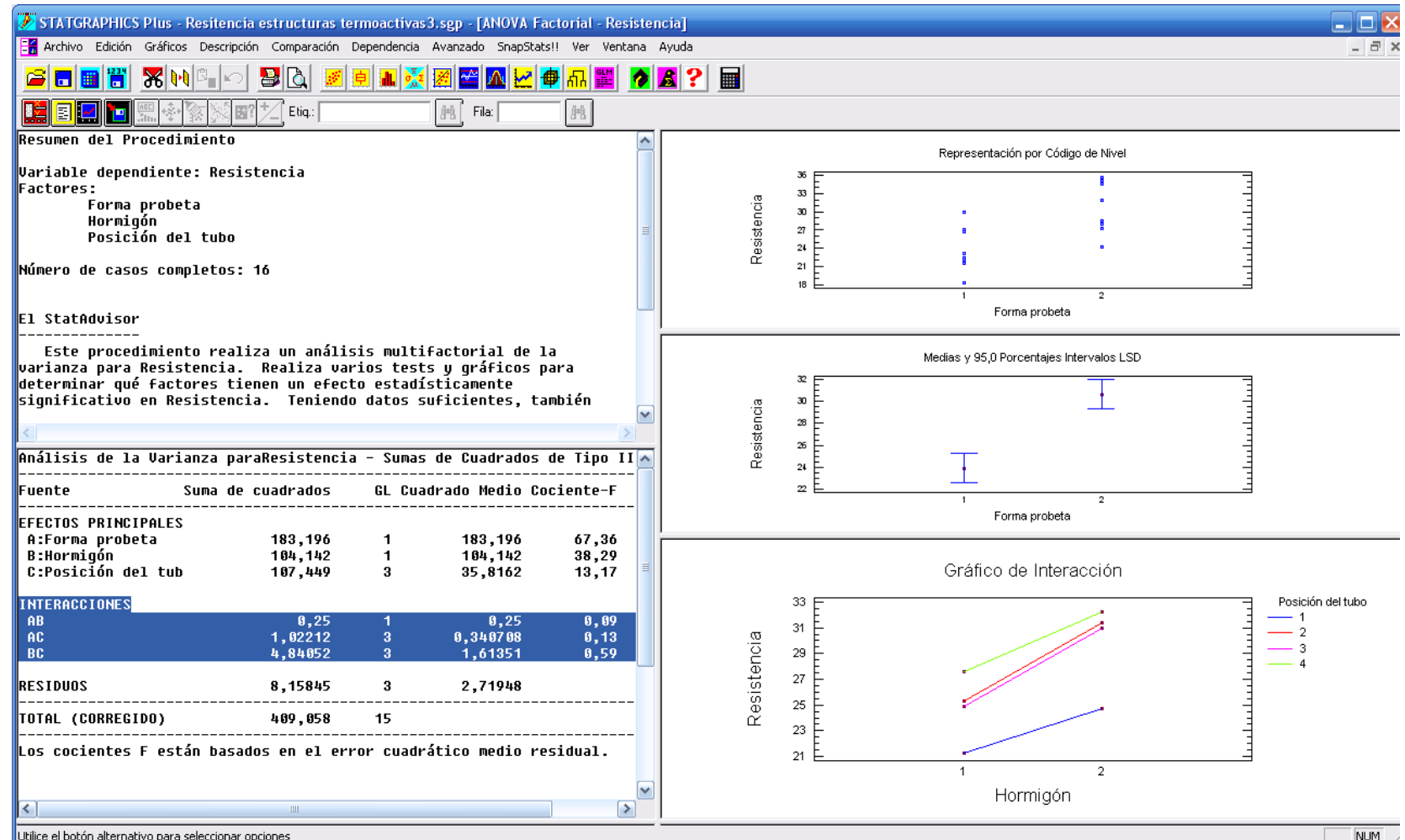

Figura 9.3- 2. Comprobación de la interacción.

Al determinar que no existe interacción $[(\alpha \beta) \mathbf{j} \mathbf{j}=\mathbf{0} ;(\alpha \mathbf{y}) \mathbf{i k}=\mathbf{0} ;(\beta \mathbf{y}) \mathbf{j k}=\mathbf{0}]$ entre los distintos factores, el modelo quedaría de la siguiente manera:

$$
\begin{aligned}
& Y i j k=\mu+\alpha i+\beta j+Y_{k}+\varepsilon i j k \\
& Y i j k=\bar{y} \bullet \bullet+a i+b j+c_{k}+e i j k
\end{aligned}
$$

Siendo

Yijk es el valor de cada observación correspondiente al nivel i $(\mathrm{H}-25 \circ \mathrm{H}-30)$ del primer factor a (Tipo de hormigón), el nivel j (Cilíndrica o cúbica) del segundo factor $b$ (Forma de la probeta) y el nivel $r$ (horizontal, vertical, vertical descentrado) del tercer factor c (Posición del tubo).

ȳ..• Es la media de todas las observaciones.

âi $=\overline{\mathbf{y}} \mathbf{i} \bullet \bullet-\bar{y} \bullet \bullet \bullet$ es la estimación del efecto del nivel i $(\mathrm{H}-25 \circ \mathrm{H}-30)$ del primer factor a (Tipo de hormigón), con ȳ i • la media de todos los datos incluidos dentro de ese nivel. 
bj $=\overline{\mathbf{y}} \cdot \mathbf{j} \bullet-\bar{y} \bullet \bullet$ es la estimación del efecto del nivel j (Cilíndrica o cúbica) del segundo factor b (Forma de la probeta), con $\bar{y} \cdot \mathbf{j} \bullet$ la media de todos los datos incluidos en ese nivel.

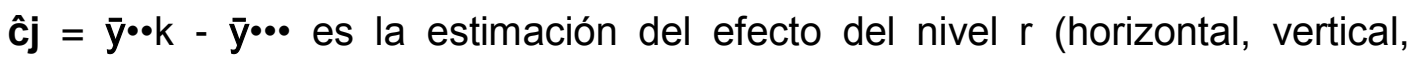
vertical descentrado) del tercer factor c (Posición del tubo), con ȳ••k la media de todos los datos incluidos en ese nivel.

eijk = Yijk - ȳ••• son los residuos o diferencias de cada observación a la media de los datos correspondientes a la combinación ijk de los factores.

Pasando al primer miembro el término ȳ•••, elevando al cuadrado y sumando, teniendo en cuenta que todos los dobles productos se anulan al sumar, queda:

$$
(\mathbf{Y i j k}-\overline{\mathbf{y}} \bullet \bullet)^{2}=(\overline{\mathbf{y}} \mathbf{i} \bullet \bullet-\overline{\mathbf{y}} \bullet \bullet)^{2}+(\overline{\mathbf{y}} \cdot \mathbf{j} \bullet-\overline{\mathbf{y}} \bullet \bullet)^{2}+(\overline{\mathbf{y}} \bullet \bullet k-\overline{\mathbf{y}} \bullet \bullet)^{2}+(\mathbf{Y i j k}-\overline{\mathbf{y}} \bullet \bullet \bullet)^{2}
$$

Que es la expresión para tres factores del teorema de Cochran cuando no existe interacción entre los factores. Los grados de libertad de cada uno de los sumandos son:

- $\mathrm{n}-1=16-1=15$, para la suma de cuadrados total (VARIABILIDAD TOTAL)

- $\mathrm{k}-1=2-1=1$ para la suma de cuadrados del primer factor Tipo de hormigón (VARIABILIDAD EXPLICADA POR EL FACTOR 1)

- $\mathrm{I}-1=2-1=1$ para la suma de cuadrados del segundo factor Forma de probeta (VARIABILIDAD EXPLICADA POR EL FACTOR 2)

- $\mathrm{m}-1=4-1=3$ para la suma de cuadrados del tercer factor Posición del tubo (VARIABILIDAD EXPLICADA POR EL FACTOR 3)

- $(n-1)-(k-1)-(l-1)-(m-1)=10$ para la suma de cuadrados del error (VARIABILIDAD NO EXPLICADA)

Siendo $\mathrm{n} \rightarrow$ el número total de observaciones, $\mathrm{k} \rightarrow$ el número de niveles del primer factor (Tipo de hormigón: $\mathrm{H}-25$ y $\mathrm{H}-30$ ), I $\rightarrow$ el número de niveles del segundo factor (Forma de la probeta: cilíndrica o cúbica) y $\mathrm{m} \rightarrow$ el número de niveles del tercer factor (Posición del tubo: horizontal, vertical, vertical centrado). 
Así, el problema se resume en saber si, en la igualdad VT = VE ( $\boldsymbol{\alpha}, \boldsymbol{\beta}$ y $\mathbf{Y})+$ VNE, el factor VE (VARIABILIDAD EXPLICADA) es grande en relación con el de VNE (VARIABILIDAD NO EXPLICADA). Esta comparación se hace dentro de una distribución de probabilidad, en este caso, una F de Snedecor con los grados de libertad respectivos: $(\mathrm{k}-1)$ ó (l-1) ó $(\mathrm{m}-1)$ y $(\mathrm{n}-1)-(\mathrm{k}-1)-(\mathrm{l}-1)-(\mathrm{m}-1)$. La comparación se hace con los valores de:

$\left(s^{2} e\right)_{\alpha}=V E \alpha / \sigma^{2}(k-1)$. En nuestro caso $\left(s^{2} e\right)_{\alpha}=\Sigma(\bar{y} i \bullet \bullet-\bar{y} \bullet \bullet)^{2} / 1=183,196$

$\left(s^{2} e\right)_{\beta}=\operatorname{VE} \beta / \sigma^{2}(I-1)$. En nuestro caso $\left(s^{2} \mathbf{e}\right)_{\beta}=\boldsymbol{\Sigma}(\overline{\mathbf{y}} \cdot \mathbf{j} \bullet-\overline{\mathbf{y}} \cdot \bullet \cdot)^{2} / \mathbf{1}=\mathbf{1 0 4 , 1 4 2}$

$\left(s^{2} e\right)_{Y}=V E Y / \sigma^{2}(I-1)$. En nuestro caso $\left(s^{2} \mathbf{e}\right)_{Y}=\boldsymbol{\Sigma}(\overline{\mathbf{y}} \cdot \bullet \mathrm{k}-\overline{\mathbf{y}} \cdot \bullet \cdot)^{2} / \mathbf{3}=\mathbf{3 5 , 8 1 6 2}$

$\left(s^{2} R\right)=V N E /(n-1)-(k-1)-(l-1)-(m-1)$. En nuestro caso $\left(\mathbf{s}^{2} \mathbf{R}\right)=(\mathbf{Y i j k}-\overline{\mathbf{y}} \cdot \bullet \bullet)^{2} / 10$ $=1,42711$

Para las distribuciones:

$F(k-1 ; n-k-I-m+1), F(l-1 ; n-k-I-m+1)$ y $F(m-1 ; n-k-I-m+1)$ Tendremos, una $F(1,9)$ para los factores 1 y 2 , y una $\mathbf{F}(3,9)$ para el factor 3 .

Esto es, para el primer factor (Tipo de hormigón): $\left(s^{2} e\right)_{\alpha} /\left(s^{2} R\right) F(1,9)$

Para el segundo (Forma de la probeta): $\left(s^{2} e\right)_{\beta} /\left(s^{2} R\right) F(1,9)$

Y para el tercero (Posición del tubo): $\left(s^{2} e\right)_{Y} /\left(s^{2} R\right) F(3,9)$

Todo se resume en la tabla ADEVA. En Statgraphics (Figura 68). 


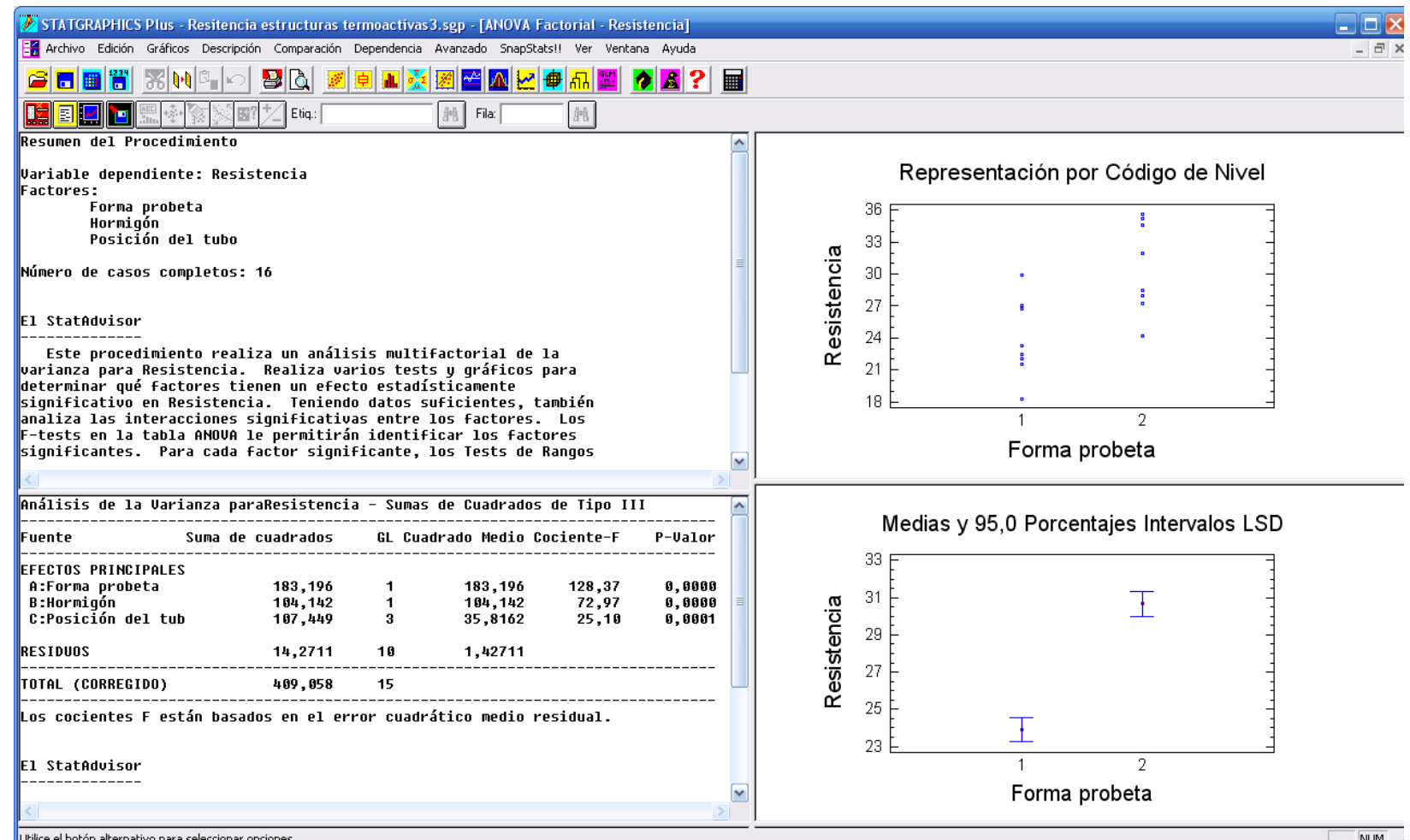

Figura 9.3- 3. Análisis de la varianza.

El Coeficiente F, para comparar en la F de Snedecor, es la relación entre el cuadrado medio de cada factor y el cuadrado medio del error:

para el primer factor (Tipo de hormigón): 183,196 / 1,42711 $=\mathbf{1 2 8 , 3 7}$

para el segundo factor (Forma de la probeta): 104,142 / 1,42711 = 72,97

para el tercer factor (Posición del tubo): 35,8162 / 1,42711 $=\mathbf{2 5 , 1 0}$

Por tanto se obtienen unos p-valores de:

0,0000 para el primer factor (Tipo de hormigón)

0,0000 para el segundo factor (Forma de la probeta)

0,0001 para el tercer (Posición del tubo)

Lo que implica que, para una confianza al $95 \%$, el $p$-valor $<0,05$ y rechazamos Ho: $\alpha_{1}=\alpha_{2} ;$ Ho $: \beta_{1}=\beta_{2} ;$ Ho $: Y_{1}=Y_{2}=Y_{3}=Y_{4} y$, por tanto, los tres factores, factor 1 (Tipo de hormigón), factor 2 (Forma de la probeta) y factor 3 (Posición del tubo) tiene un efecto significativo en la resistencia del hormigón. 
Una vez realizado el análisis de la varianza, es necesario verificar las hipótesis del modelo: normalidad y homocedasticidad de los errores. Esta verificación se lleva a cabo por medio del análisis de los residuos.

Para comprobar la normalidad, nos apoyamos nuevamente en el programa Statgraphics, observando el gráfico de probabilidad normal. En el que se comprueba que el modelo cumple la hipótesis, pues los datos se sitúan, aproximadamente, en torno a una recta (Figura 9.3-4).

Gráfico de Probabilidad Normal

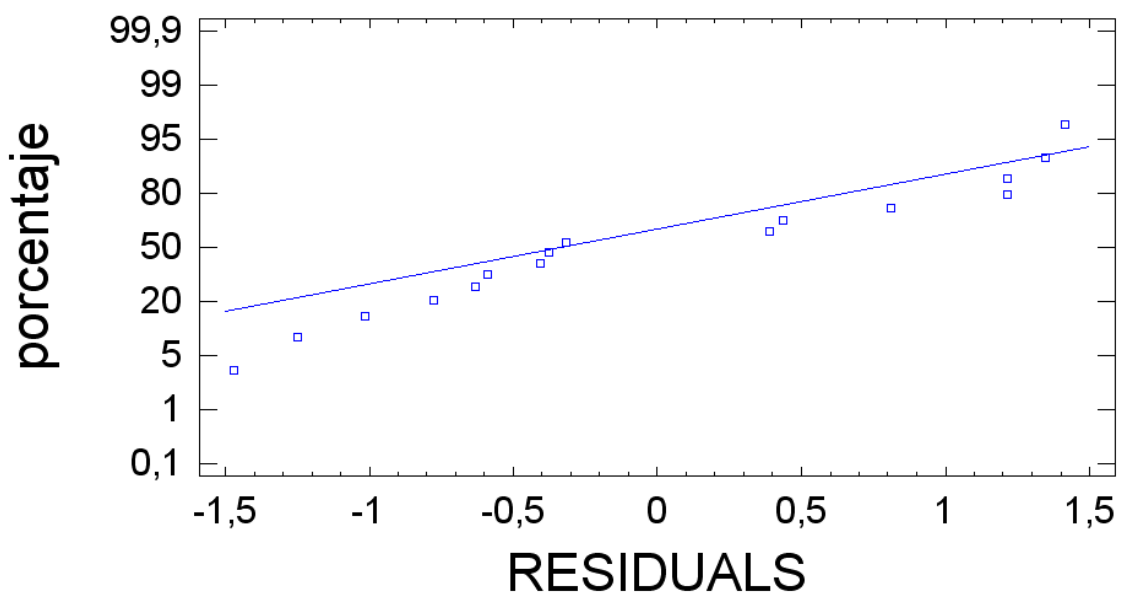

Figura 9.3- 4. Comprobación hipótesis de normalidad de los errores. 12 valores comprendidos desde $-1,47$ hasta 1,415.

Para comprobar homocedasticidad (independencia de los errores), también nos apoyamos en el programa Statgraphics, observando los gráficos de residuos frente al nivel de los factores (Tipo de hormigón, forma de las probetas y posición de los tubos).

En la figura 9.3-5, se pueden observar los gráficos de dispersión, los gráficos de medias y los residuos frente al nivel de factor para cada uno de los tres factores. 


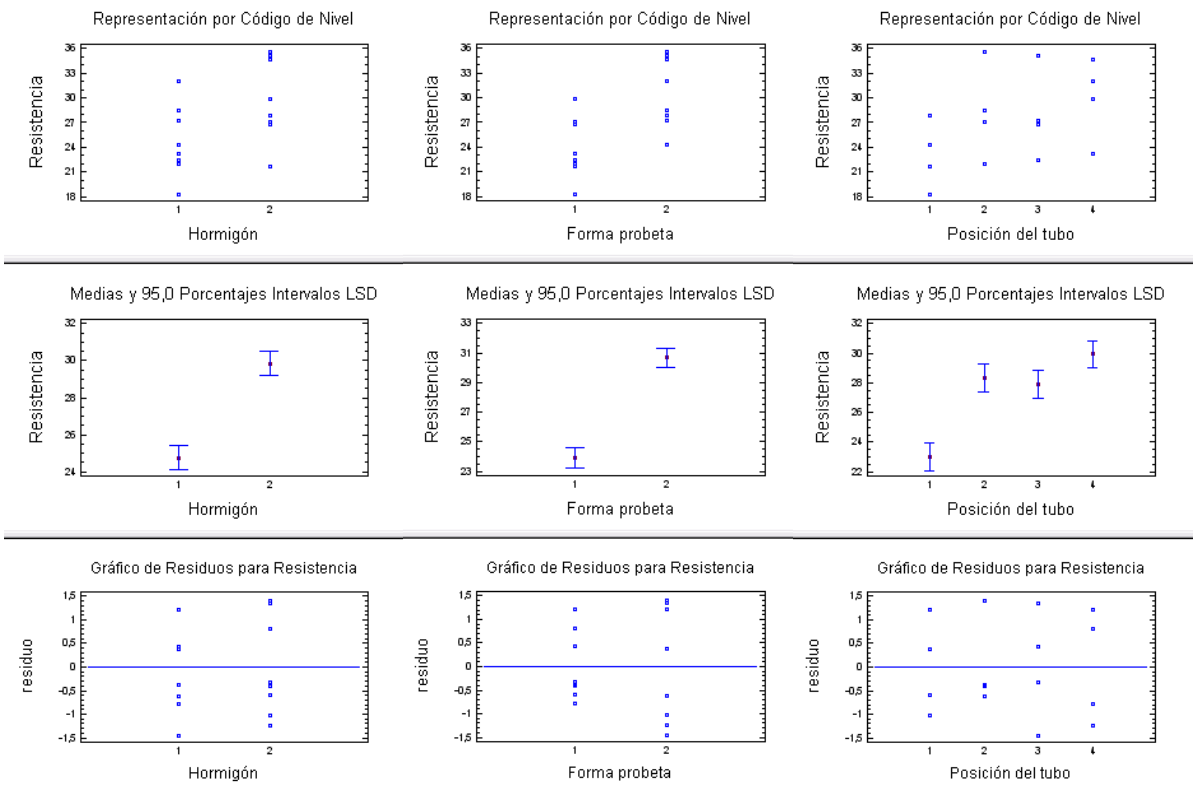

Figura 9.3- 5. Gráficos de dispersión, gráficos de medias y residuos frente a nivel de factor, para los tres factores en estudio. (Tipo de hormigón, forma de la probeta, y posición del tubo)

Si ampliamos los gráficos de residuos frente al nivel de factor para observarlos más adecuadamente, comprobamos que los tres factores: factor 1 (Tipo de hormigón), factor 2 (Forma de la probeta) y factor 3 (Posición del tubo), cumplen la hipótesis, es decir, no hay diferencia entre la dispersión de los datos entre los distintos niveles. Figuras 9.3- 6, 9.3- 7 y 9.3- 8. 


\section{Gráfico de Residuos para Resistencia}

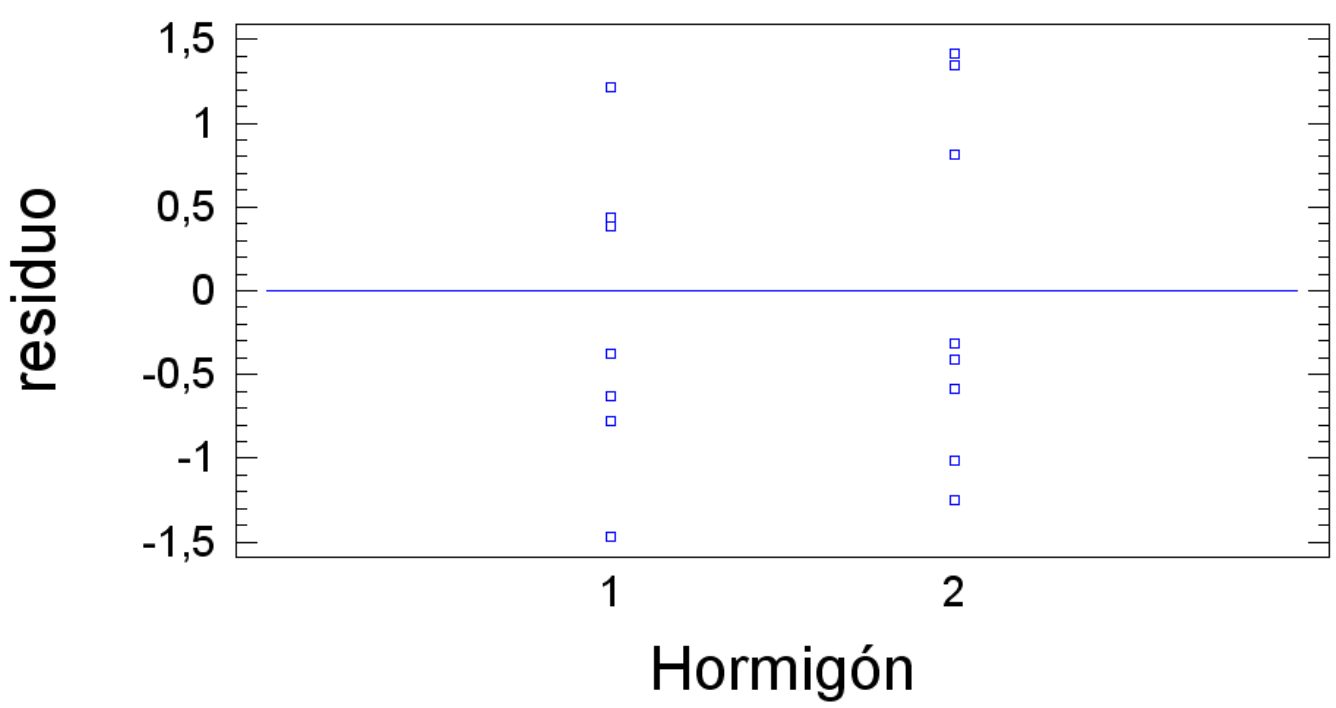

Figura 9.3- 6. Comprobación hipótesis de homocedasticidad para el factor 1 (Tipo de hormigón).

\section{Gráfico de Residuos para Resistencia}

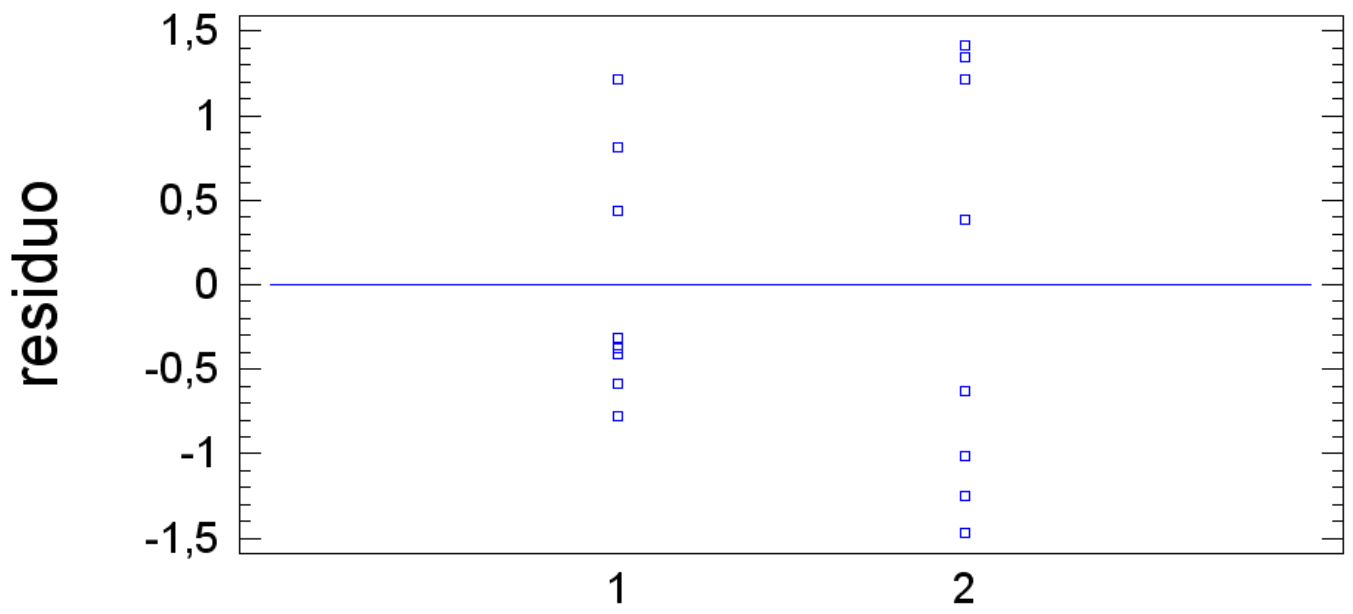

Forma probeta

Figura 9.3- 7. Comprobación hipótesis de homocedasticidad para el factor 2 (Forma de la probeta). 


\section{Gráfico de Residuos para Resistencia}

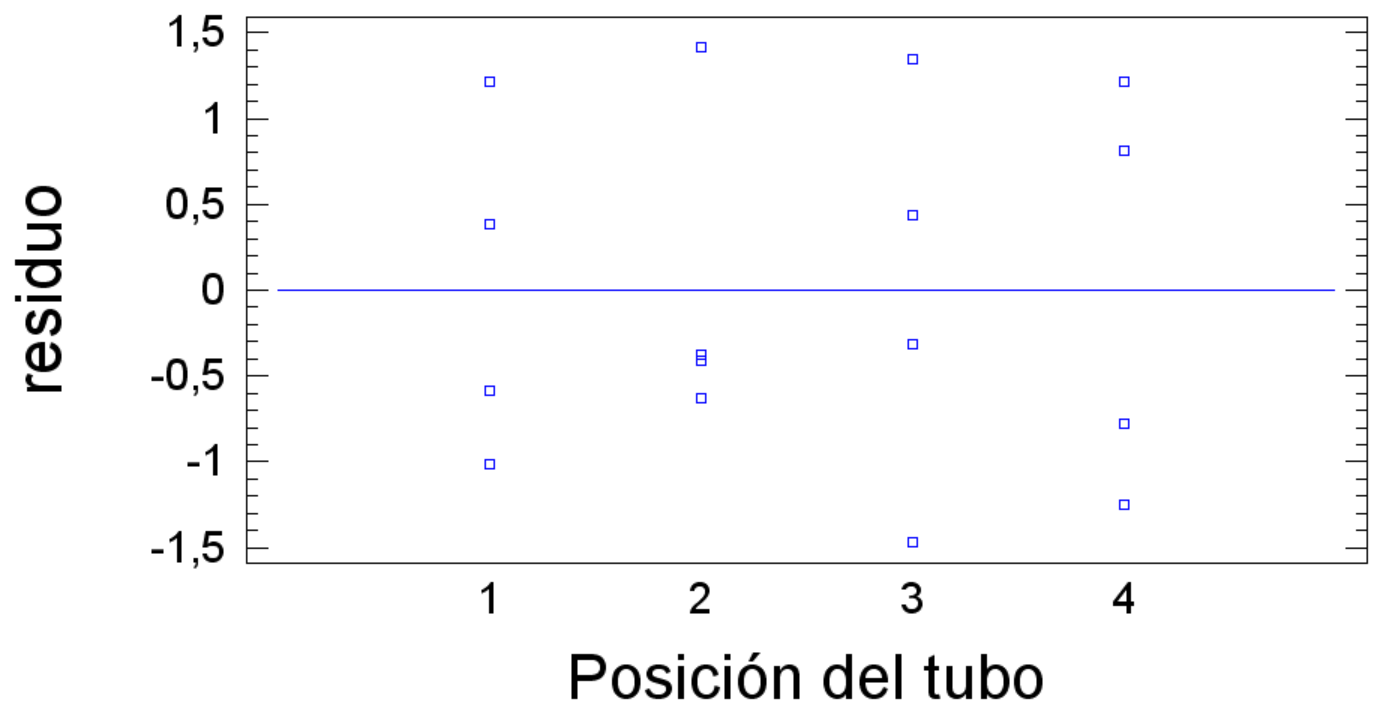

Figura 9.3- 8. Comprobación hipótesis de homocedasticidad para el factor 3 (Posición del tubo).

\section{Conclusiones del estudio estadístico}

Se puede afirmar que los tres factores: factor 1 (Tipo de hormigón), factor 2 (Forma de la probeta) y factor 3 (Posición del tubo), tienen influencia en el valor de la variable aleatoria Resistencia a compresión del hormigón, a un 95\% de confianza.

Factor 1 (Tipo de hormigón), como era de esperar el hecho de que utilicemos hormigón $\mathrm{H}-25$ u hormigón $\mathrm{H}-30$, influye en la resistencia a compresión de las probetas de hormigón ensayadas, siendo superiores las resistencias de las probetas en las que se ha utilizado el segundo tipo de hormigón.

Factor 2 (Forma de las probetas), el hecho de que la probetas tengan distinta forma, influye directamente en los resultados de rotura a compresión, observándose en los resultados que el hecho de que las probetas tengan forma cúbica favorece que los resultados de rotura sean superiores que los resultados de probetas con forma cilíndrica. 
Factor 3 (Posición del tubo), el hecho de que se disponga o no, y en la posición en la que se dispone el tubo, influye directamente en los resultados, observándose que cuando el tubo se coloca en posición vertical dentro de la probeta, ya sea centrado o descentrado, los resultados de rotura a compresión son mayores que los de las probetas que tienen los tubos dispuestos en posición horizontal, y cuando no se coloca ningún tipo de tubo dentro de la probeta los resultados son superiores que cuando se coloca tubo sea en la posición que sea.

Partiendo de la base de que despreciamos la interacción de orden 3, hemos comprobado que la interacción de orden 2 entre los distintos factores no tiene un efecto estadísticamente significativo en la resistencia a compresión de las probetas al $95 \%$ de confianza. 
ANEXO 4 INDICE

DE TABLAS 
Tabla 3- 1. Dosificación de las amasadas, contenidos de cada material y resultados de cono de Abrams obtenidos. Elaboración propia. 109

Tabla 3- 2. Fechas de los procesos de elaboración, curado y ensayo de las probetas realizadas con las 4 amasadas de hormigón fresco ejecutadas. Elaboración propia. 114

Tabla 3- 3. Nomenclatura y característica de las probetas cilíndricas para ensayar a compresión a distintas temperaturas y ${ }^{\circ} \mathrm{C}$ a los que se sometió a cada grupo de tres probetas. 116

Tabla 3- 4. Nomenclatura y característica de las probetas cúbicas con armadura corrugada embebida para ensayar a arrancamiento a distintas temperaturas $\mathrm{y}^{\circ} \mathrm{C}$ a los que se sometió a cada una en grupos de tres probetas. 119

Tabla 3- 5. Nomenclatura y características de las probetas cilíndricas para ensayar a compresión con las distintas posiciones en las que se embebieron los tubos de polietileno.

Tabla 3- 6. Nomenclatura y características de las probetas cúbicas para ensayar a compresión con las distintas posiciones en las que se embebieron los tubos de polietileno.

Tabla 4- 1. Valores medios de las tres probetas cilíndricas sometidas a cada temperatura, con hormigones $\mathrm{H}-25$ y $\mathrm{H}-30$, en los ensayos a compresión. 136

Tabla 4- 2. Valores medios de las tres probetas cúbicas sometidas a cada temperatura, con hormigones $\mathrm{H}-25$ y $\mathrm{H}-30$, en los ensayos a arrancamiento. 138

Tabla 4- 3. Valores medios de las tres probetas cilíndricas con igual posición de tubo de polietileno, con hormigones $\mathrm{H}-25$ y H-30, en los ensayos a compresión.

Tabla 4- 4. Valores medios de las tres probetas cúbicas con igual posición de tubo de polietileno, con hormigones $\mathrm{H}-25$ y H-30, en los ensayos a compresión. 145

Tabla 5- 1. Pérdidas de resistencia en tanto por ciento en hormigones $\mathrm{H}-25$ y $\mathrm{H}-30$, ensayados a compresión, en función de la temperatura.

Tabla 5- 2. Pérdidas de resistencia en tanto por ciento en hormigones $\mathrm{H}-25$ y H-30 ensayados a "pull-out", en función de la temperatura.

Tabla 5- 3. Pérdidas de resistencia en tanto por ciento en hormigones $\mathrm{H}-25$ y $\mathrm{H}-30$, ensayados a compresión, en función de la disposición de tubo.

Tabla 5- 4. Pérdidas de resistencia en tanto por ciento en hormigones $\mathrm{H}-25$ y $\mathrm{H}-30$, ensayados a compresión, en función de la disposición de tubo. 191 
Tabla 9.1. 1 ( $\sigma \max , \varepsilon \max , \varepsilon u$, Emax y Eu) de las tres probetas cilíndricas sometidas a $20^{\circ} \mathrm{C}$, de hormigón H-25 ensayado a compresión.

Tabla 9.1. 2 ( $\sigma \max , \varepsilon \max , \varepsilon u$, Emax y Eu) de las tres probetas cilíndricas sometidas a $40^{\circ} \mathrm{C}$, de hormigón $\mathrm{H}-25$ ensayado a compresión. 227

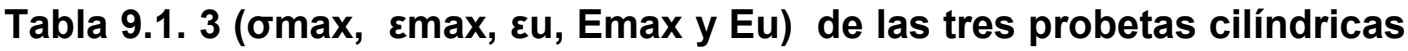
sometidas a $70^{\circ} \mathrm{C}$, de hormigón $\mathrm{H}-25$ ensayado a compresión. 227

Tabla 9.1. 4 ( $\sigma \max , \varepsilon \max , \varepsilon u$, Emax y Eu) de las tres probetas cilíndricas sometidas a $100^{\circ} \mathrm{C}$, de hormigón $\mathrm{H}-25$ ensayado a compresión. 227

Tabla 9.1. 5 ( $\sigma \max , \varepsilon \max , \varepsilon u$, Emax y Eu) de las tres probetas cilíndricas sometidas a $20^{\circ} \mathrm{C}$, de hormigón H-30 ensayado a compresión. 227

Tabla 9.1. 6 ( $\sigma \max , \varepsilon \max , \varepsilon u$, Emax y Eu) de las tres probetas cilíndricas sometidas a $40^{\circ} \mathrm{C}$, de hormigón $\mathrm{H}-30$ ensayado a compresión. 228

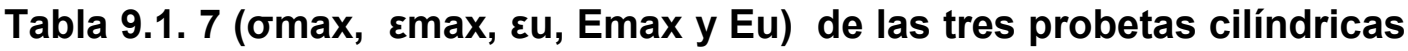
sometidas a $70^{\circ} \mathrm{C}$, de hormigón $\mathrm{H}-30$ ensayado a compresión. .228

Tabla 9.1. 8 ( $\sigma \max , \varepsilon \max , \varepsilon u$, Emax y Eu) de las tres probetas cilíndricas sometidas a $100^{\circ} \mathrm{C}$, de hormigón $\mathrm{H}-30$ ensayado a compresión. 228

Tabla 9.1. 9 ( $\mp R, \delta \max , \delta u, E \max$ y Eu) de las tres probetas cúbicas sometidas a $20^{\circ} \mathrm{C}$, de hormigón H-25 ensayado a "pull-out". 228

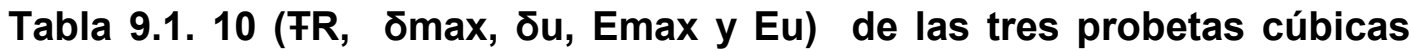
sometidas a 40C, de hormigón H-25 ensayado a "pull-out". 228

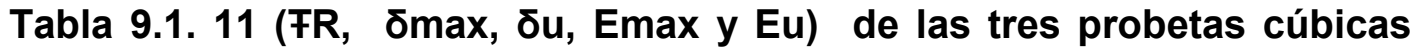
sometidas a $70^{\circ} \mathrm{C}$, de hormigón H-25 ensayado a "pull-out". 229

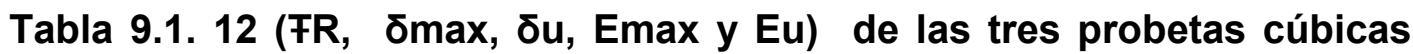
sometidas a $100^{\circ} \mathrm{C}$, de hormigón H-25 ensayado a "pull-out". .229

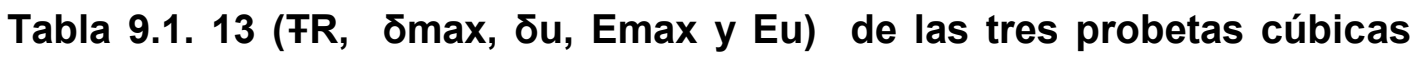
sometidas a 20C, de hormigón H-30 ensayado a "pull-out". 229

Tabla 9.1. 14 ( $\mp R, \delta \max , \delta u, E \max$ y Eu) de las tres probetas cúbicas sometidas a 40C, de hormigón H-30 ensayado a "pull-out". 229

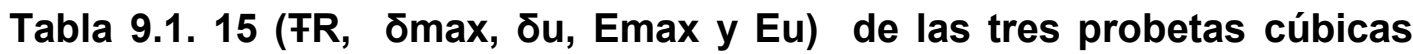
sometidas a 70ㄷ, de hormigón H-30 ensayado a "pull-out". 229

Tabla 9.1. 16 ( $\mp R$, סmax, סu, Emax y Eu) de las tres probetas cúbicas sometidas a $100^{\circ} \mathrm{C}$, de hormigón $\mathrm{H}-30$ ensayado a "pull-out". 230

Tabla 9.1. 17 (omax, $\varepsilon \max , \varepsilon u$, Emax y Eu) de las tres probetas cilíndricas sin tubo, de hormigón H-25 ensayado a compresión. 230 
Tabla 9.1. 18 (omax, $\varepsilon \max , \varepsilon u$, Emax y Eu) de las tres probetas cilíndricas con tubo vertical centrado, de hormigón H-25 ensayado a compresión.

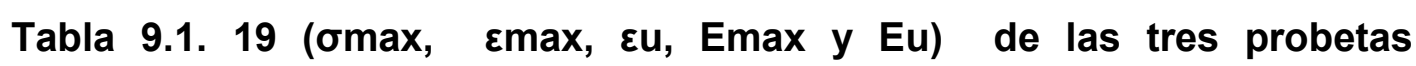
cilíndricas con tubo vertical descentrado, de hormigón H-25 ensayado a compresión.

Tabla 9.1. 20 ( $\sigma \max , \varepsilon m a x, \varepsilon u$, Emax y Eu) de las tres probetas cilíndricas con tubo horizontal, de hormigón H-25 ensayado a compresión. 230

Tabla 9.1. 21 ( $\sigma \max , \varepsilon \max , \varepsilon u$, Emax y Eu) de las tres probetas cilíndricas sin tubo, de hormigón $\mathrm{H}-30$ ensayado a compresión. 231

Tabla 9.1. 22 ( $\sigma \max , \varepsilon \max , \varepsilon u$, Emax y Eu) de las tres probetas cilíndricas con tubo vertical centrado, de hormigón H-30 ensayado a compresión.

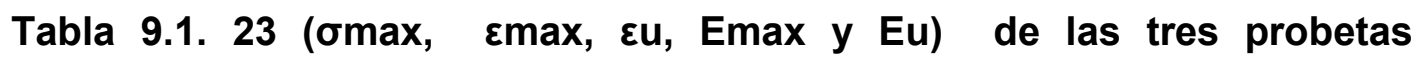
cilíndricas con tubo vertical descentrado, de hormigón H-30 ensayado a compresión.

Tabla 9.1. 24 ( $\sigma \max , \varepsilon \max , \varepsilon u$, Emax y Eu) de las tres probetas cilíndricas con tubo horizontal, de hormigón H-30 ensayado a compresión.

Tabla 9.1. 25 (бmax, عmax, عu, Emax y Eu) de las tres probetas cúbicas con tubo horizontal, de hormigón H-25 ensayado a compresión. .231

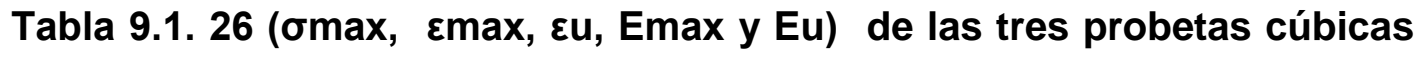
con tubo vertical, de hormigón H-25 ensayado a compresión. .232

Tabla 9.1. 27 (бmax, عmax, عu, Emax y Eu) de las tres probetas cúbicas con tubo horizontal, de hormigón H-25 ensayado a compresión. .232

Tabla 9.1. 28 (бmax, عmax, عu, Emax y Eu) de las tres probetas cúbicas con tubo vertical, de hormigón H-25 ensayado a compresión. .232

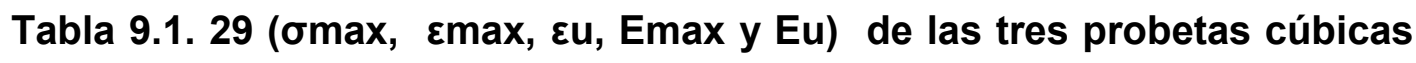
sin tubo, de hormigón H-25 ensayado a compresión.

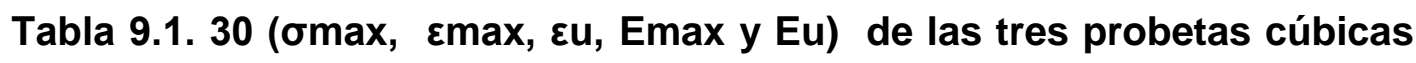
con tubo horizontal, de hormigón $\mathrm{H}-30$ ensayado a compresión. .232

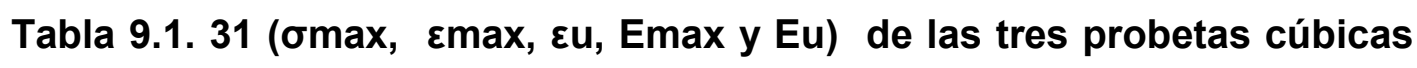
con tubo vertical, de hormigón H-30 ensayado a compresión. 233 
Tabla 9.1. 32 (бmax, عmax, عu, Emax y Eu) de las tres probetas cúbicas con tubo horizontal, de hormigón H-30 ensayado a compresión. 233

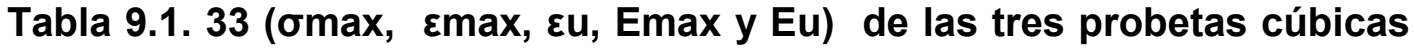
con tubo vertical, de hormigón H-30 ensayado a compresión. .233

Tabla 9.1. 34 ( $\sigma \max , \varepsilon \max , \varepsilon u$, Emax y Eu) de las tres probetas cúbicas sin tubo, de hormigón H-30 ensayado a compresión. .233 
ANEXO 5 INDICE

DE FIGURAS 
Figura 2.2- 1. Número de pilotes termoactivos instalados en Austria hasta el año 2004. (Brandl, H.,) [16] 16

Figura 2.2- 2. Cimentación termoactiva por medio de pilotes de hormigón armado. Fuente: Geothermal energy and heatstorage. Pahud, D. y SIA D 0190...18

Figura 2.2- 3. Energía geotérmica. Fuente: Geothermie-Perspectives de I'ADEMEet duBRGM. 20

Figura 2.2- 4. Distintos tipos de energía geotérmica. Variaciones en función de la profundidad y de la temperatura. Elaboración propia. .21

Figura 2.2- 5: Temperatura del subsuelo en función de la profundidad. (De Isabel, J.A.) [34]

Figura 2.2- 6. Esquema de climatización de una vivienda unifamiliar por medio de cimentación termoactiva, complementario a otros sistemas activos de captación de calor. (Brandl, H.,) [16]

Figura 2.2- 7. Componentes básicos de una bomba de calor por compresión en modo calentamiento. (Geoener 2009).

Figura 2.2- 8. La Conducción, como mecanismo de transferencia de calor entre el terreno y las cimentaciones termoactivas. Fuente: Eneres. .27

Figura 2.2- 9. Pilote termoactivo. Fuente: Eneres .29

Figura 2.2- 10. Fabricación de pilotes termoactivos. Fuente: Nagelebau/Eneres. 30

Figura 2.2- 11. Armadura de muro pantalla perimetral termoactivo con tubería de polietileno. Fuente: Enercret. 31

Figura 2.2- 12. Colocación tubos polietileno en losa de cimentación termoactiva. Fuente:Uponor. 32

Figura 2.2- 13. Ejemplos de posicionamiento de tuberías de polietileno en forjados (Olesen, B.W.) [105] y (Kolarik,J.) [70] 36

Figura 2.2- 14. Posicionamiento de los tubos de PE dentro de la losa. Fuente: Eneres. 36

Figura 2.2- 15. Ejecución forjados termoactivos. Fuente: Uponor. 38

Figura 2.2- 16. Ejecución muros termoactivos. Fuente: Rehau. 39

Figura 2.2- 17. Intercambio térmico entre el interior del edificio y el terreno a través de estructuras termoactivas. Fuente: Eneres.

Figura 2.2- 18. Curva de adecuación instantánea de la demanda energética a la generación producida por el intercambio geotérmico. Fuente: Eneres. .49 
Figura 2.2- 19. Estructura termoactiva y cimentación termoactiva. Edificio $\mathrm{C} /$ Apolonio Morales. Arquitectos Luis de Pereda y Manuel Mallo. (ENERES) 50

Figura 2.2- 20. Esquema de funcionamiento de la bomba de calor geotérmica. (Brandl, H.,) [16]

Figura 2.2- 21. Esquema de sistema geotérmico de intercambio con cimentaciones termoactivas y estructuras termoactivas con bomba de calor geotérmica. (Brandl, H.,) [16]. .52

Figura 2.2- 22. Régimen anual de temperatura de una cimentación termoactiva. (De Isabel, J.A.) [34]

Figura 2.2- 23. Gráfica tridimensional del campo de temperaturas generadas por un grupo de pilotes termoactivos sobre el terreno en el intercambio térmico con un edificio. Fuente: Eneres/Enercret

Figura 2.3- 1. Módulos de elasticidad de un hormigón. (Fernández Canovas, M. [52] .75

Figura 2.4- 1. Comparación de curvas de diseño y de las curvas de pérdidas experimentales de resistencia. Husem, M. [63]

Figura 2.4- 2. Resistencia a compresión residual de hormigones normales y de alta resistencia con y sin adición de humo de sílice. Culfic, M.S. et al. [30]......93

Figura 2.4- 3. Variación de la resistencia a compresión en función de la temperatura. Sait, M., et al. [118]

Figura 2.4- 4. Montaje e instrumentación de la máquina universal de ensayos mecánicos, servo-hidráulica. (Garzón, F.E. et al). [56] .95

Figura 2.4- 5. Relación tensión de adherencia-deslizamiento para diferentes temperaturas. (Diederichs, U. et al.) [43] .96

Figura 2.5- 1. Geometría del ensayo "pull-out". (Bouazaoui, L. et al) [14] ....102

Figura 2.5- 2. Ensayo tipo "beam-test" para la homologación de la adherencia en barras corrugadas: a) geometría de vigas para $\varnothing<16 \mathrm{~mm}$, y b) geometría de vigas para $\varnothing \geq 16 \mathrm{~mm}$, (cotas en $\mathrm{cm}$ ). (Molina. M) [93] .

Figura 3- 1. Proceso de fabricación del hormigón, grava pesada antes de ser incorporada, amasado en la amasadora.

Figura 3- 2. Ensayo de asentamiento para analizar la consistencia del hormigón.

Figura 3- 3. Proceso de elaboración de los cuatro tipos de probetas. Arriba 3 imágenes izquierda: elaboración de probetas cilíndricas para analizar efecto temperatura y ensayar a compresión; arriba imagen derecha: probetas cilíndricas 
Figura 3- 1. Proceso de fabricación del hormigón, grava pesada antes de ser incorporada, amasado en la amasadora. 110

Figura 3- 2. Ensayo de asentamiento para analizar la consistencia del hormigón

Figura 3- 3. Proceso de elaboración de los cuatro tipos de probetas. Arriba 3 imágenes izquierda: elaboración de probetas cilíndricas para analizar efecto temperatura y ensayar a compresión; arriba imagen derecha: probetas cilíndricas para analizar efecto incorporación tubo polietileno y ensayar a compresión; abajo izquierda: probetas cúbicas con armadura corrugada embebida para analizar efecto temperatura y ensayar a "pull-out"; abajo derecha: probetas cúbicas para analizar efecto incorporación tubo de polietileno y ensayar a compresión.

Figura 3- 4. Proceso de curado de las probetas en cámara. 113

Figura 3- 5. Diagrama de Gantt con la planificación de los trabajos. Elaboración propia. 114

Figura 3- 6. Probetas cilíndricas de $100 \varnothing \times 200 \mathrm{~mm}$ 115

Figura 3- 7. Proceso de llenado de probetas cilíndricas según UNE-EN123902:2001.

Figura 3- 8. Proceso de refrentado de las probetas según UNE 83506:2004.

Figura 3- 9. Distintas formas de rotura de las probetas cilíndricas, sometidas a distintas temperaturas, después de haber sido ensayadas a compresión según UNE-EN12390-3:2001.

Figura 3- 10. Probetas cúbicas de 100 × $100 \mathrm{~mm}$ 118

Figura 3- 11. Probetas cúbicas con armadura corrugada de $10 \mathrm{~mm} \varnothing$, para ensayo de adherencia 120

Figura 3- 12. Probetas cúbicas con armadura corrugada de $10 \mathrm{~mm}$, durante ensayo de adherencia.

Figura 3- 13. Distintas formas de rotura de las probetas cúbicas con armadura corrugada de $10 \mathrm{~mm}$, durante ensayo de adherencia.

Figura 3- 14. Probetas cilíndricas de $100 \varnothing \times 200$ mm 122

Figura 3- 15. Probetas cilíndricas para ser ensayadas a compresión con tubo de polietileno de $24 \mathrm{~mm} \varnothing$, sellado lateralmente y colocado en posiciones: vertical centrado, vertical descentrado y horizontal centrado a mitad de la altura de la probeta. .124 


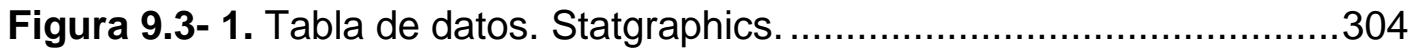

Figura 9.3- 2. Comprobación de la interacción. ...........................................305

Figura 9.3- 3. Análisis de la varianza...................................................308

Figura 9.3- 4. Comprobación hipótesis de normalidad de los errores. 12 valores comprendidos desde $-1,47$ hasta 1,415. 309

Figura 9.3- 5. Gráficos de dispersión, gráficos de medias y residuos frente a nivel de factor, para los tres factores en estudio. (Tipo de hormigón, forma de la probeta, y posición del tubo)

Figura 9.3- 6. Comprobación hipótesis de homocedasticidad para el factor 1 (Tipo de hormigón)

Figura 9.3- 7. Comprobación hipótesis de homocedasticidad para el factor 2 (Forma de la probeta)

Figura 9.3- 8. Comprobación hipótesis de homocedasticidad para el factor 3 (Posición del tubo). 


\section{ANEXO 6}

INDICE

DE GRÁFICAS 
Gráfica 4- 1. Gráfica Fuerza $F(\mathrm{KN}) /$ Carrera $\delta(\mathrm{mm})$ del hormigón ensayado a compresión. 131

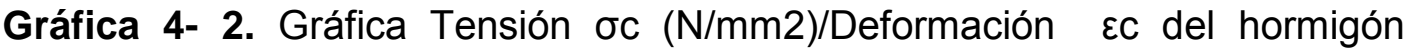
ensayado a compresión.

Gráfica 4- 3. Gráfica Fuerza $F(\mathrm{KN}) /$ Desplazamiento $\delta(\mathrm{mm})$ del hormigón ensayado a arrancamiento "pull-out".

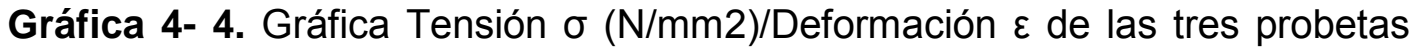
cilíndricas sometidas a $40^{\circ} \mathrm{C}$, de hormigón H-25 ensayado a compresión. Esta gráfica se presenta como ejemplo, el resto de gráficas de este apartado se encuentran en el Anexo 2.2. Gráficas y tablas de medias de resultados de probetas semejantes

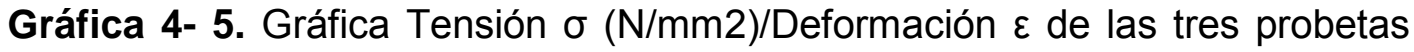
cilíndricas sometidas a $100^{\circ} \mathrm{C}$, de hormigón H-30 ensayado a compresión. Esta gráfica se presenta como ejemplo, el resto de gráficas de este apartado se encuentran en el Anexo 2.2. Gráficas y tablas de medias de resultados de probetas semejantes

Gráfica 4- 6. Gráfica Fuerza $F(\mathrm{KN}) /$ Desplazamiento $\delta(\mathrm{mm})$ de las tres probetas cúbicas sometidas a $20^{\circ} \mathrm{C}$, de hormigón $\mathrm{H}-25$ ensayado a arrancamiento "pull-out". Esta gráfica se presenta como ejemplo, el resto de gráficas de este apartado se encuentran en el Anexo 2.2. Gráficas y tablas de medias de resultados de probetas semejantes.

Gráfica 4- 7. Gráfica Fuerza $F(\mathrm{KN}) /$ Desplazamiento $\delta(\mathrm{mm})$ de las tres probetas cúbicas sometidas a $70^{\circ} \mathrm{C}$ de hormigón $\mathrm{H}-30$ ensayado a arrancamiento "pull-out". Esta gráfica se presenta como ejemplo, el resto de gráficas de este apartado se encuentran en el Anexo 2.2. Gráficas y tablas de medias de resultados de probetas semejantes.

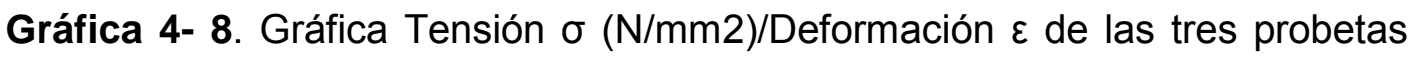
cilíndricas con tubo PE en posición vertical centrado, de hormigón $\mathrm{H}-25$ ensayado a compresión. Esta gráfica se presenta como ejemplo, el resto de gráficas de este apartado se encuentran en el Anexo 2.2. Gráficas y tablas de medias de resultados de probetas semejantes. .143 


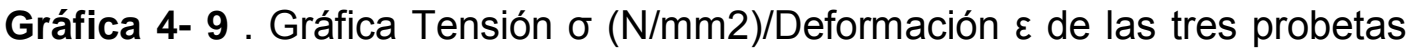
cilíndricas con tubo PE en posición horizontal, de hormigón H-30 ensayado a compresión. Esta gráfica se presenta como ejemplo, el resto de gráficas de este apartado se encuentran en el Anexo 2.2. Gráficas y tablas de medias de resultados de probetas semejantes. 144

Gráfica 4- 10. Gráfica Tensión $\sigma(\mathrm{N} / \mathrm{mm} 2) /$ Deformación $\varepsilon$ de tres de las probetas cúbicas, con tubo PE en posición vertical, de hormigón $\mathrm{H}-25$ ensayado a compresión. Esta gráfica se presenta como ejemplo, el resto de gráficas de este apartado se encuentran en el Anexo 2.2. Gráficas y tablas de medias de resultados de probetas semejantes. 146

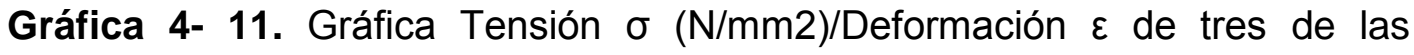
probetas cúbicas, con tubo PE en posición horizontal, de hormigón $\mathrm{H}-30$ ensayado a compresión. Esta gráfica se presenta como ejemplo, el resto de gráficas de este apartado se encuentran en el Anexo 2.2. Gráficas y tablas de medias de resultados de probetas semejantes.

Gráfica 5- 1. Gráfica de evolución de la Tensión $\sigma(\mathrm{N} / \mathrm{mm} 2)$ respecto a la deformación $\varepsilon$ (adimensional) en probetas cilíndricas más representativas, para temperaturas de $20^{\circ} \mathrm{C}, 40^{\circ} \mathrm{C}, 70^{\circ} \mathrm{C}$ y $100^{\circ} \mathrm{C}$, realizadas con hormigón $\mathrm{H}-25$, ensayadas a compresión.

Gráfica 5- 2 . Gráfica de evolución de la Tensión $\sigma(\mathrm{N} / \mathrm{mm} 2)$ respecto a la deformación $\varepsilon$ (adimensional) en probetas cilíndricas más representativas, para temperaturas de $20^{\circ} \mathrm{C}, 40^{\circ} \mathrm{C}, 70^{\circ} \mathrm{C}$ y $100^{\circ} \mathrm{C}$, realizadas con hormigón $\mathrm{H}-30$, ensayadas a compresión.

Gráfica 5- 3. Gráfica Tensión $\sigma_{\max }(\mathrm{N} / \mathrm{mm} 2)$ / Temperatura ${ }^{\circ} \mathrm{C}$ de de las medias aritméticas de los resultados de resistencia a compresión de las probetas cilíndricas sometidas a $20^{\circ} \mathrm{C}, 40^{\circ} \mathrm{C}, 70^{\circ} \mathrm{C}$, y $100^{\circ} \mathrm{C}$, comparando los resultados de hormigón H-25 y del hormigón H-30, ensayados a compresión. 154

Gráfica 5- 4. Gráfica Deformación máxima $\varepsilon_{\max } /$ Temperatura ${ }^{\circ} \mathrm{C}$ de de las medias aritméticas de los resultados de deformación correspondiente a la tensión máxima de las probetas cilíndricas sometidas a $20^{\circ} \mathrm{C}, 40^{\circ} \mathrm{C}, 70^{\circ} \mathrm{C}$, y $100^{\circ} \mathrm{C}$, comparando los resultados de hormigón $\mathrm{H}-25$ y del hormigón $\mathrm{H}-30$, ensayados a compresión. 155 
Gráfica 5- 5. Gráfica Deformación última $\varepsilon_{u} /$ Temperatura ${ }^{\circ} \mathrm{C}$ de de las medias aritméticas de los resultados de deformación última de las probetas cilíndricas sometidas a $20^{\circ} \mathrm{C}, 40^{\circ} \mathrm{C}, 70^{\circ} \mathrm{C}$, y $100^{\circ} \mathrm{C}$, comparando los resultados de hormigón $\mathrm{H}-25$ y del hormigón $\mathrm{H}-30$, ensayados a compresión. 156

Gráfica 5- 6. Gráfica Energía máxima $\boldsymbol{E}_{\max }\left(\mathrm{N} / \mathrm{mm}^{2}\right)$ / Temperatura ${ }^{\circ} \mathrm{C}$ de las medias aritméticas de los resultados de deformación última de las probetas cilíndricas sometidas a $20^{\circ} \mathrm{C}, 40^{\circ} \mathrm{C}, 70^{\circ} \mathrm{C}$, y $100^{\circ} \mathrm{C}$, comparando los resultados de hormigón $\mathrm{H}-25$ y del hormigón $\mathrm{H}-30$, ensayados a compresión. 157

Gráfica 5- 7. Gráfica Energía última $E_{u}\left(\mathrm{~N} / \mathrm{mm}^{2}\right) /$ Temperatura ${ }^{\circ} \mathrm{C}$ de de las medias aritméticas de los resultados de deformación última de las probetas cilíndricas sometidas a $20^{\circ} \mathrm{C}, 40^{\circ} \mathrm{C}, 70^{\circ} \mathrm{C}$, y $100^{\circ} \mathrm{C}$, comparando los resultados de hormigón $\mathrm{H}-25$ y del hormigón $\mathrm{H}-30$, ensayados a compresión. 158

Gráfica 5- 8. Evolución en función del incremento de temperatura $\left(20^{\circ} \mathrm{C}, 40^{\circ} \mathrm{C}\right.$, $70^{\circ} \mathrm{C}$, y $\left.100^{\circ} \mathrm{C}\right)$ de los valores medios máximos $\left(\sigma_{\max }, \varepsilon_{\max }, E_{\max }\right)$ obtenidos del ensayo a compresión de cada grupo de tres probetas cilíndricas, sometidas a la misma temperatura, con hormigones $\mathrm{H}-25$ y H-30

Gráfica 5- 9. Gráfica de análisis porcentual de pérdidas de resistencia en función de la temperatura de las probetas cilíndricas en el momento de la rotura a compresión para hormigones $\mathrm{H}-25$ y H-30.

Gráfica 5- 10. Gráfica de evolución de la Fuerza de arrancamiento $F(K N)$ respecto al desplazamiento $\delta(\mathrm{mm})$ en probetas cúbicas con armadura corrugada anclada, más representativas, para temperaturas de $20^{\circ} \mathrm{C}, 40^{\circ} \mathrm{C}, 70^{\circ} \mathrm{C}$ y $100^{\circ} \mathrm{C}$, realizadas con hormigón $\mathrm{H}-25$, ensayadas a arrancamiento o "pull-out".

Gráfica 5- 11. Gráfica de evolución de la Fuerza de arrancamiento $F(K N)$ respecto al desplazamiento $\delta(\mathrm{mm})$ en probetas cúbicas con armadura corrugada anclada, más representativas, para temperaturas de $20^{\circ} \mathrm{C}, 40^{\circ} \mathrm{C}, 70^{\circ} \mathrm{C}$ y $100^{\circ} \mathrm{C}$, realizadas con hormigón $\mathrm{H}-30$, ensayadas a arrancamiento o "pull-out". 162

Gráfica 5- 12. Gráfica Tensión $F_{R}(\mathrm{KN}) /$ Temperatura ${ }^{\circ} \mathrm{C}$ de de las medias aritméticas de los resultados de tensión de las probetas cúbicas sometidas a $20^{\circ} \mathrm{C}$, $40^{\circ} \mathrm{C}, 70^{\circ} \mathrm{C}$, y $100^{\circ} \mathrm{C}$, comparando los resultados de hormigón $\mathrm{H}-25$ y del hormigón $\mathrm{H}-30$ ensayados a arrancamiento. 163 
Gráfica 5- 13. Gráfica Desplazamiento máximo $\delta_{\max } \mathrm{mm} /$ Temperatura ${ }^{\circ} \mathrm{C}$ de de las medias aritméticas de los resultados de desplazamiento correspondiente a la tensión de rotura de las probetas cúbicas sometidas a $20^{\circ} \mathrm{C}, 40^{\circ} \mathrm{C}, 70^{\circ} \mathrm{C}$, y $100^{\circ} \mathrm{C}$, comparando los resultados de hormigón H-25 y del hormigón H-30 ensayados a arrancamiento 164

Gráfica 5- 14. Gráfica Desplazamiento último $\delta_{u} \mathrm{~mm} /$ Temperatura ${ }^{\circ} \mathrm{C}$ de de las medias aritméticas de los resultados de desplazamiento último de las probetas cúbicas sometidas a $20^{\circ} \mathrm{C}, 40^{\circ} \mathrm{C}, 70^{\circ} \mathrm{C}$, y $100^{\circ} \mathrm{C}$, comparando los resultados de hormigón $\mathrm{H}-25$ y del hormigón $\mathrm{H}-30$ ensayados a arrancamiento. 165

Gráfica 5- 15. Gráfica Energía máxima $E_{\max } \mathrm{KN} / \mathrm{mm} /$ Temperatura ${ }^{\circ} \mathrm{C}$ de de las medias aritméticas de los resultados de energía máxima de las probetas cúbicas sometidas a $20^{\circ} \mathrm{C}, 40^{\circ} \mathrm{C}, 70^{\circ} \mathrm{C}$, y $100^{\circ} \mathrm{C}$, comparando los resultados de hormigón $\mathrm{H}-25$ y del hormigón $\mathrm{H}-30$ ensayados a arrancamiento. 166

Gráfica 5- 16. Gráfica Energía máxima $E_{u} \mathrm{KN} / \mathrm{mm} /$ Temperatura ${ }^{\circ} \mathrm{C}$ de de las medias aritméticas de los resultados de energía última de las probetas cúbicas sometidas a $20^{\circ} \mathrm{C}, 40^{\circ} \mathrm{C}, 70^{\circ} \mathrm{C}$, y $100^{\circ} \mathrm{C}$, comparando los resultados de hormigón $\mathrm{H}-25$ y del hormigón $\mathrm{H}-30$ ensayados a arrancamiento.

Gráfica 5- 17. Evolución en función del incremento de temperatura $\left(20^{\circ} \mathrm{C}\right.$, $40^{\circ} \mathrm{C}, 70^{\circ} \mathrm{C}$, y $\left.100^{\circ} \mathrm{C}\right)$ de los valores medios máximos $\left(\delta_{\max }, \delta_{u}, y E_{\max }\right)$, obtenidos del ensayo a arrancamiento de cada grupo de tres probetas cúbicas con armadura corrugada anclada, sometidas a la misma temperatura, con hormigones $\mathrm{H}-25$ y H30 168

Gráfica 5- 18. Gráfica de análisis porcentual de pérdidas de resistencia en función de la temperatura de las probetas cúbicas con armadura corrugada anclada, en el momento de la rotura a arrancamiento, para hormigones $\mathrm{H}-25$ y H30.

Gráfica 5- 19. Gráfica de evolución de la Tensión $\sigma(\mathrm{N} / \mathrm{mm} 2)$ respecto a la deformación $\varepsilon$ (adimensional) en probetas cilíndricas más representativas, para las distintas disposiciones de tubo (vertical centrada, vertical descentrada, horizontal o sin tubo), realizadas con hormigón H-25, ensayadas a compresión. 
Gráfica 5- 20. Gráfica de evolución de la Tensión $\sigma(\mathrm{N} / \mathrm{mm} 2)$ respecto a la deformación $\varepsilon$ (adimensional), en probetas cilíndricas más representativas, para las distintas disposiciones de tubo (vertical centrada, vertical descentrada, horizontal o sin tubo), realizadas con hormigón H-30, ensayadas a compresión.

Gráfica 5- 21. Gráfica Tensión $\sigma_{\max }(\mathrm{N} / \mathrm{mm} 2)$ / Tubo PE, de de las medias aritméticas de los resultados de resistencia a compresión de las probetas cilíndricas en las que se han colocado los tubos de polietileno con cuatro variantes distintas, comparando los resultados de hormigón H-25 y del hormigón H-30 ensayados a compresión.

Gráfica 5- 22. Gráfica Deformación máxima $\boldsymbol{\varepsilon}_{\max }$ / Tubo PE, de de las medias aritméticas de los resultados de deformación correspondiente a la máxima tensión de las probetas cilíndricas en las que se han colocado los tubos de polietileno con cuatro variantes distintas, comparando los resultados de hormigón $\mathrm{H}-25$ y del hormigón H-30 ensayados a compresión.

Gráfica 5- 23. Gráfica Deformación última $\varepsilon_{u} /$ Tubo PE, de de las medias aritméticas de los resultados de deformación última de las probetas cilíndricas en las que se han colocado los tubos de polietileno con cuatro variantes distintas, comparando los resultados de hormigón H-25 y del hormigón $\mathrm{H}-30$ ensayados a compresión.

Gráfica 5- 24. Gráfica Energía máxima $E_{\max }\left(\mathrm{N} / \mathrm{mm}^{2}\right) /$ Tubo $\mathrm{PE}$, de de las medias aritméticas de los resultados de energía máxima de las probetas cilíndricas en las que se han colocado los tubos de polietileno con cuatro variantes distintas, comparando los resultados de hormigón H-25 y del hormigón $\mathrm{H}-30$ ensayados a compresión.

Gráfica 5- 25. Gráfica Energía última $E_{u}\left(\mathrm{~N} / \mathrm{mm}^{2}\right) /$ Tubo PE, de de las medias aritméticas de los resultados de energía última de las probetas cilíndricas en las que se han colocado los tubos de polietileno con cuatro variantes distintas, comparando los resultados de hormigón H-25 y del hormigón $\mathrm{H}-30$ ensayados a compresión.

Gráfica 5- 26. Evolución, en función de la disposición del tubo de polietileno (vertical centrada, vertical descentrada, horizontal o sin tubo) de los valores medios máximos $\left(\sigma_{\max }, \varepsilon_{\max }, E_{\max }\right)$ obtenidos del ensayo a compresión de cada grupo de tres probetas cilíndricas con semejante disposición de tubo, con hormigones $\mathrm{H}-25$ y $\mathrm{H}-30$. 
Gráfica 5- 27. Gráfica de análisis porcentual de pérdidas de resistencia en función de la disposición de tubo de polietileno en el interior de las probetas cilíndricas ensayadas a compresión, para hormigones $\mathrm{H}-25$ y H-30. 182

Gráfica 5- 28. Gráfica de energía última en probetas cilíndricas en función de la disposición de tubo de polietileno en su interior, ensayadas a compresión para hormigones $\mathrm{H}-25$ y $\mathrm{H}-30$.

Gráfica 5- 29. Gráfica de evolución de la Tensión $\sigma(\mathrm{N} / \mathrm{mm} 2)$ respecto a la deformación $\varepsilon$ (adimensional) en probetas cúbicas más representativas, para las distintas disposiciones de tubo (vertical, horizontal o sin tubo), realizadas con hormigón $\mathrm{H}-25$, ensayadas a compresión.

Gráfica 5- 30. Gráfica de evolución de la Tensión $\sigma(\mathrm{N} / \mathrm{mm} 2)$ respecto a la deformación $\varepsilon$ (adimensional) en probetas cúbicas más representativas, para las distintas disposiciones de tubo (vertical, horizontal o sin tubo), realizadas con hormigón H-30, ensayadas a compresión. 185

Gráfica 5- 31. Gráfica Tensión $\sigma_{\max }(\mathrm{N} / \mathrm{mm} 2)$ / Tubo PE, de de las medias aritméticas de los resultados de resistencia a compresión de las probetas cúbicas en las que se han colocado los tubos de polietileno con tres variantes distintas, comparando los resultados de hormigón $\mathrm{H}-25$ y del hormigón $\mathrm{H}-30$ ensayados a compresión. 186

Gráfica 5- 32. Gráfica Deformación máxima $\varepsilon_{\max } /$ Tubo PE, de de las medias aritméticas de los resultados de deformación correspondiente a la máxima tensión de las probetas cúbicas en las que se han colocado los tubos de polietileno con tres variantes distintas, comparando los resultados de hormigón $\mathrm{H}-25$ y del hormigón H-30 ensayados a compresión.

Gráfica 5- 33. Gráfica Deformación última $\varepsilon_{u} /$ Tubo PE, de de las medias aritméticas de los resultados de deformación última de las probetas cúbicas en las que se han colocado los tubos de polietileno con tres variantes distintas, comparando los resultados de hormigón $\mathrm{H}-25$ y del hormigón $\mathrm{H}-30$ ensayados a compresión.

Gráfica 5- 34. Gráfica Energía máxima $E_{\max }\left(\mathrm{N} / \mathrm{mm}^{2}\right) /$ Tubo $\mathrm{PE}$, de de las medias aritméticas de los resultados de energía máxima de las probetas cúbicas en las que se han colocado los tubos de polietileno con tres variantes distintas, comparando los resultados de hormigón $\mathrm{H}-25$ y del hormigón $\mathrm{H}-30$ ensayados a compresión. 189 
Gráfica 5- 35. Gráfica Energía última $E_{u}\left(\mathrm{~N} / \mathrm{mm}^{2}\right) /$ Tubo PE, de de las medias aritméticas de los resultados de energía última de las probetas cúbicas en las que se han colocado los tubos de polietileno con tres variantes distintas, comparando los resultados de hormigón H-25 y del hormigón H-30 ensayados a compresión. 190

Gráfica 5- 36. Gráfica de análisis porcentual de pérdidas de resistencia en función de la disposición de tubo de polietileno en el interior de las probetas cúbicas, ensayadas a compresión, para hormigones $\mathrm{H}-25$ y H-30. 192

Gráfica 5- 37. Gráfica de energía última en probetas cúbicas en función de la disposición de tubo de polietileno en su interior, ensayadas a compresión, para hormigones $\mathrm{H}-25$ y H-30 193 